Portland State University

PDXScholar

$1-1-2011$

\title{
Study of the Performance and Characteristics of U.S. Academic Research Institution Technology Commercialization (ARITC)
}

Jisun Kim

Portland State University

Follow this and additional works at: https://pdxscholar.library.pdx.edu/open_access_etds Let us know how access to this document benefits you.

Recommended Citation

Kim, Jisun, "Study of the Performance and Characteristics of U.S. Academic Research Institution Technology Commercialization (ARITC)" (2011). Dissertations and Theses. Paper 494.

https://doi.org/10.15760/etd.494

This Dissertation is brought to you for free and open access. It has been accepted for inclusion in Dissertations and Theses by an authorized administrator of PDXScholar. Please contact us if we can make this document more accessible: pdxscholar@pdx.edu. 
Study of the Performance and Characteristics of

U.S. Academic Research Institution Technology Commercialization (ARITC)

by

Jisun Kim

A dissertation submitted in partial fulfillment of the requirements for the degree of

\author{
Doctor of Philosophy \\ in \\ Technology Management
}

Dissertation Committee:

Tugrul U. Daim, Chair

Timothy R. Anderson

Dundar F. Kocaoglu

Wayne Wakeland

Charles M. Weber

Portland State University

(C) 2012 


\begin{abstract}
This dissertation aims to provide a better understanding of the technology licensing practices of academic research institutions. The study identifies time durations in licensing and incorporates these into a model to evaluate licensing performance. Performance is measured by the efficiency of an institution's technology licensing process and efficiency changes over time, using Association of University Technology Managers annual survey data from 1991 to 2007. Organizational characteristics influencing the licensing performances of 46 U.S. research institutions also are explored.
\end{abstract}

The study resulted in a new approach that integrates the identification of time lags in licensing, analysis of efficiency change, and exploration of the influence of organizational characteristics on efficiency change. A super-efficiency variable returns to scale data envelopment analysis (DEA) model was applied to the time-lag neutralized licensing data, to measure the efficiency of U.S. research institutions' licensing performance over time. The study also includes an innovative approach to resolving issues with the super-efficiency DEA model, including mathematical infeasibility and zero-data issues.

The licensing mechanisms included in the study are disclosure, patent applications, patents issued, licenses and options executed, start-ups, and licensing income. The time duration from expenditure to licensing income, including all intermediating licensing 
processes, ranged from 2 to 27 years. The study identified the organizational characteristics related to licensing practice. Academic prestige and research quality are positively related to disclosure, patents granted, and start-up. The resources of a technology licensing office influences the number of licensing agreements, whereas licensing office experience has a positive relationship with start-ups. Increased licensing resources improve the efficiency of licensing practices, and a research institution with more dedicated licensing staff has improved licensing productivity. Private institutions improved their licensing practice more than public ones during the study period. On the other hand, institutions with a medical school demonstrated low efficiency.

This dissertation fills a gap in the understanding of licensing practice and the organizational characteristics related to licensing performance. In addition, the study contributes to research methodology by providing a new approach to identifying time lags and improving the DEA method.

The results, grounded in comprehensive observations over multiple time durations, provide an insight into the licensing practices of U.S. research institutions. The dissertation presents recommendations for research institutions based on the relationships identified among academic prestige, research intensity, organizational characteristics of the technology licensing office, and licensing performance. 


\section{DEDICATION}

To my wife Jeeyoung,

who made it possible with her love and patience. 


\section{ACKNOWLEDGEMENTS}

This dissertation is a result of collaborations with many other people over several years. I would like to express my gratitude to all who made it a great success.

My deepest and sincerest gratitude is to my advisor and mentor, Dr. Tugrul Daim. I have grown as a researcher and finally a Ph.D. because of his thoughtful guidance and profound academic insight. He directed and supported my academic life and studies as an advisor, but he also became part of my family. I could not have prevailed over the many challenges and crisis situations without his heartfelt support. It is my greatest honor to be his first student that was awarded a Ph.D. degree. I pledge to continue my hard work with the goal of becoming one of his greatest academic colleagues in the future.

I am grateful to Dr. Timothy Anderson for his continuous guidance and holding my dissertation in a high standard. With his guidance I was able to overcome many methodological challenges. His keen analytical acumen is reflected throughout my dissertation.

I would like to thank Dr. Dundar Kocaoglu for encouraging my studies and inculcating a spirit of success throughout the Engineering and Technology Management Ph.D. program. 
Dr. Kocaoglu exemplifies leadership and courage. As a role model he helped me conquer many difficulties as I studied for my dissertation.

As members of my dissertation committee I would like to acknowledge Drs. Wakeland and Weber. I was able to perfect my dissertation as a result of their numerous discussions and feedback.

As well, I cannot forget Ann White for sharing an enormous amount of her time to sort out the editorial details and carefully suggesting the use of correct grammar. On behalf of those who will read my dissertation, thank you!

I am also thankful to my colleagues and friends in the Engineering and Technology Management department for their kindness and support during my studies.

I would like to give my special gratitude to Dr. Cheol-Shin Kwon for leading me to the technology management discipline and strongly encouraging my academic career for more than 15 years. My passion and energy for pursuing this study originated in the mottos he emphasized: "Lofty Ideal", "Strong Will", "Rightful Sprit", "In-depth Knowledge" and "Liberal Mind."

I would like to present my sincerest gratitude to my parents, Han-Bae Kim and Eun-Suk Yeon, for their endless support, love, and always encouraging me to continue along my 
journey. I also would like to thank my children, Wooseok and Wooyeon, for their interest, concern, and patience while I pursued my studies. They used to ask me, "By the way, when are you going to graduate?" Their questions were an incentive to keep sight of my goals! My oral defense was more meaningful by their presence.

Finally but most importantly, I could have not finished nor even started my academic journey without my wife's belief and support. Thank you, Jeeyoung Chung. Every word in my dissertation is a result of her concern, love, patience and tears. When I was discouraged I thought of her sacrifices. Her selflessness encouraged me to continue my studies. I deeply appreciate her love and support during my work, and therefore, this dissertation is dedicated to her.

Jisun Kim

Portland, Oregon

December 2011 


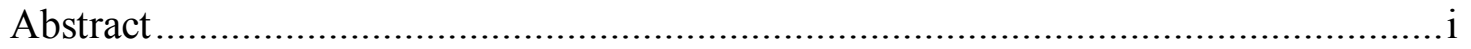

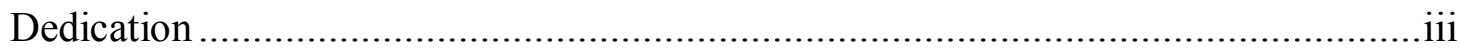

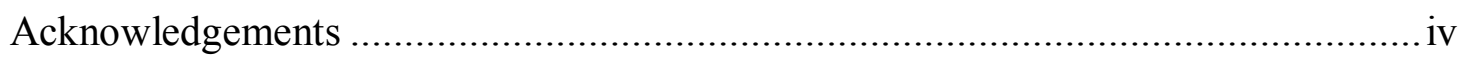

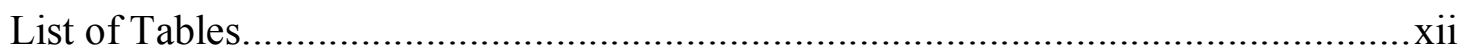

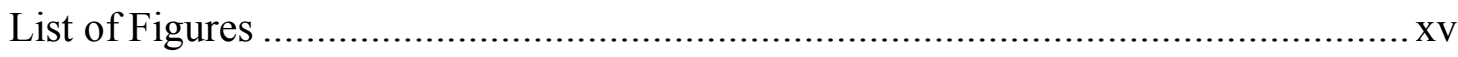

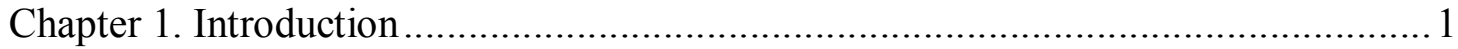

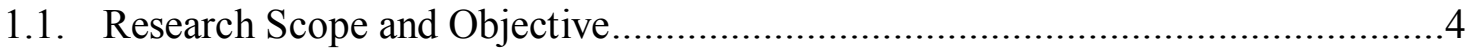

1.1.1. Related Topics and Research Scope .................................................... 4

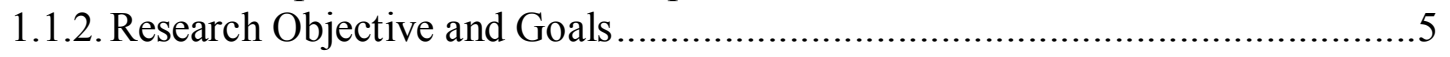

1.2. Research Questions ...........................................................................6

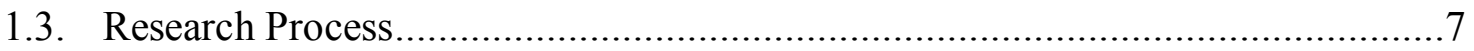

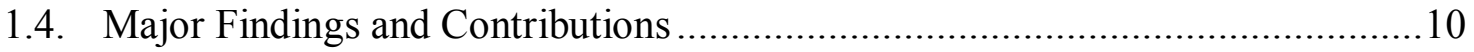

1.4.1. Gap 1: Lack of a study identifying the time-lag effect in licensing .................10

1.4.2. Gap 2 and Gap 3: Difficulties in measuring relative licensing performance, and lack of understanding of changes in licensing performance over time

1.4.3. Gap 4: Lack of understanding the characteristics influencing the performance and practice of licensing ............................................ 13

Chapter 2. Literature Review .......................................................................... 14

2.1. Organizational Characteristics of Universities ........................................... 15

2.1.1. Missions, Goals and Services of Universities ............................................ 15

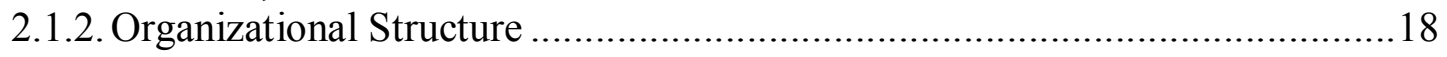

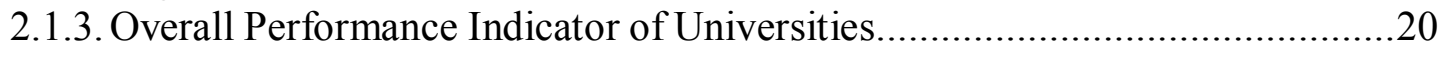

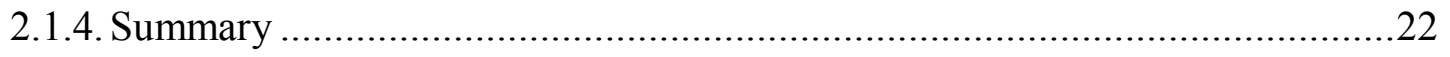

2.2. Technology Commercialization of University Research .................................23

2.2.1. Relationship between Teaching, Research and Technology

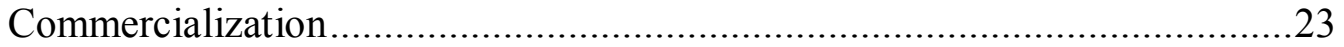

2.2.2. Motivation and Benefit of a University Commercializing a Technology.........23

2.2.3. Technology Transfer Mechanisms ........................................................27

2.2.4. Technology Commercialization Process from University to Industry ..............30

2.2.5. Time-Lag in the Technology Commercialization Process...............................32

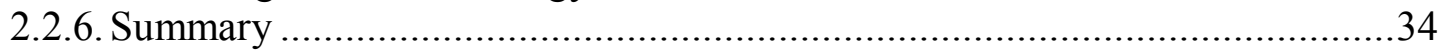

2.3. Assessment of the Performance of University Technology

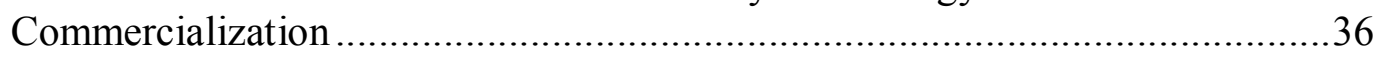

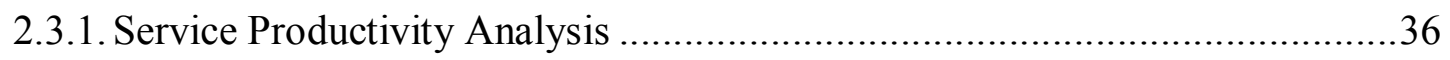


2.3.2. Current Approach to the Evaluation of the Performance of University

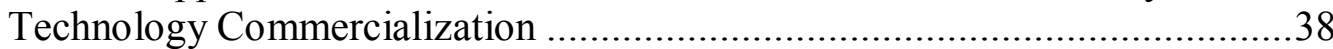

2.3.3. Measuring the effectiveness of university technology commercialization........41

2.3.4. Measuring efficiency of university technology commercialization ..................45

2.3.5. Efficiency Scores of Technology Commercialization of U.S. Universities......47

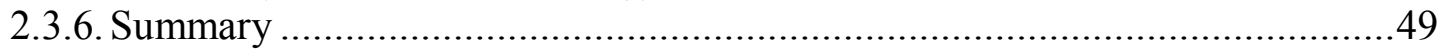

2.4. Characteristics Influencing to Licensing Performance ….................................52

2.4.1. University Characteristics and Technology Commercialization......................52

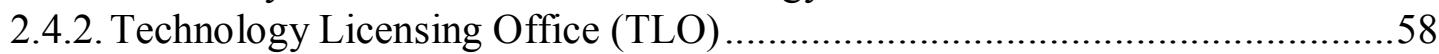

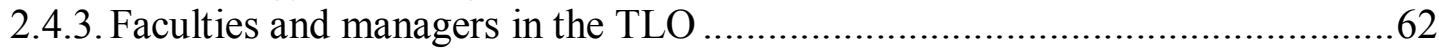

2.4.4. Environmental Characteristics................................................................64

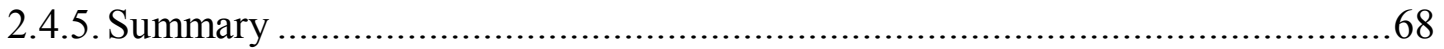

2.5. Process and Influencing Characteristics of Academic Research Institution Technology Commercialization..................................................................72

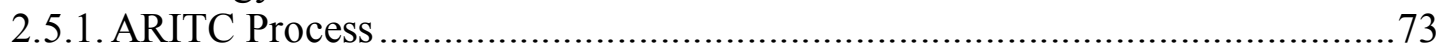

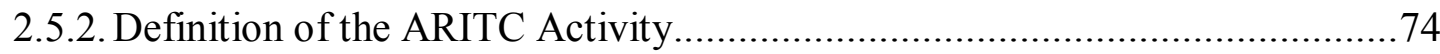

2.5.3. Characteristics influencing the Commercialization Practice ……....................80

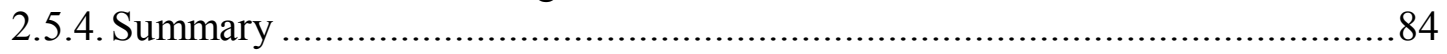

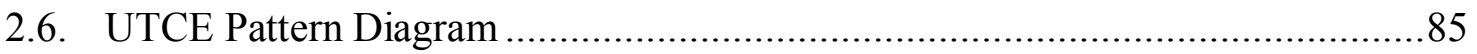

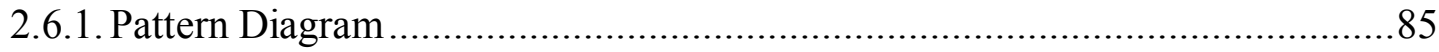

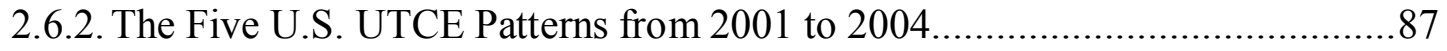

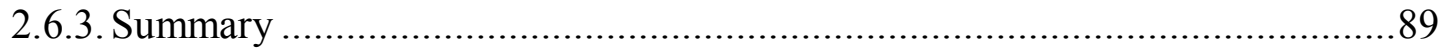

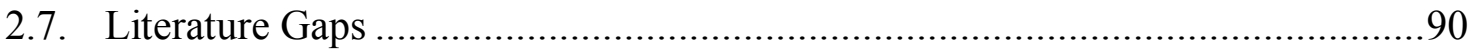

Chapter 3. Research Methodology and Model Development ...................................... 94

3.1. Research Objective, Goals, and Questions .......................................................94

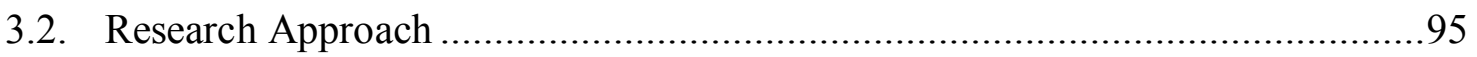

3.3. Developing a Time-Lag Distribution Model (Goal 1) .......................................97

3.3.1. Time Series Models and Their Limitations...................................................99

3.3.2. A Process for Identifying Time-Lag Coefficients ........................................100

3.3.3. Process for Calculating the Aggregate Total Time Lag.................................. 108

3.4. Measuring the Performance of Academic Research Institution Technology

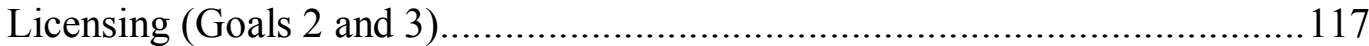

3.4.1. Data Envelopment Analysis ......................................................................117

3.4.2. Infeasibility in the Malmquist Index and the Super-Efficiency Model ...........125

3.4.3. Selecting a Super-Efficiency Model to Resolve Computational

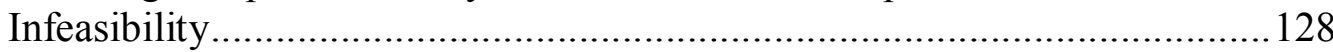

3.4.4. Three-Stage Variable Returns to Scale Super-Efficiency Model...................139

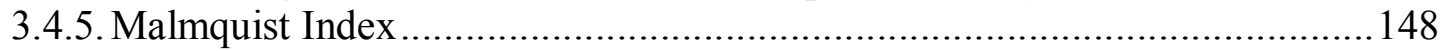

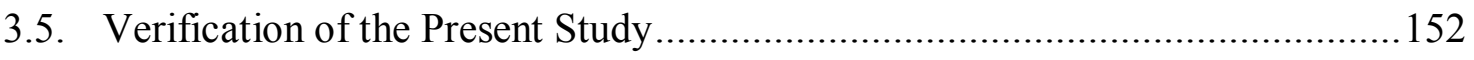


Chapter 4. Verification of the Process Identifying Time-Lag Coefficients Using

Simulated Data........................................................................................... 153

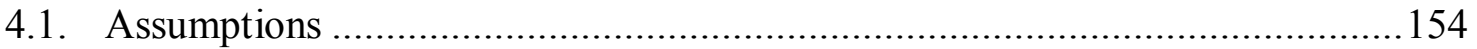

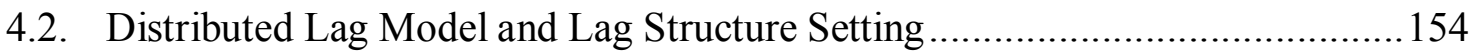

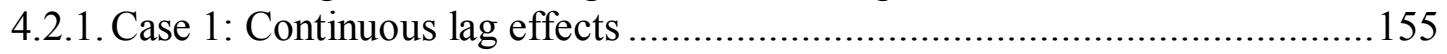

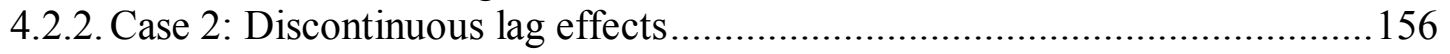

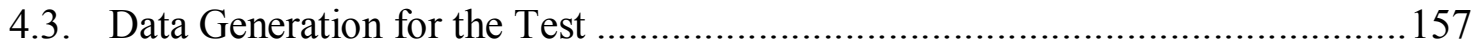

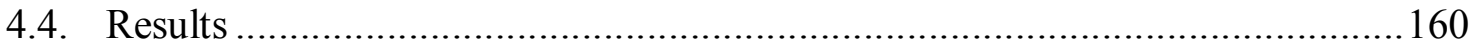

4.4.1. Unit Root Test Using Augmented Dickey-Fuller Test and Data

Transformation ............................................................................... 160

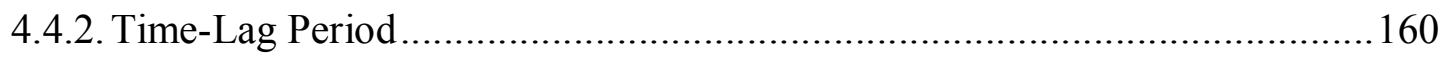

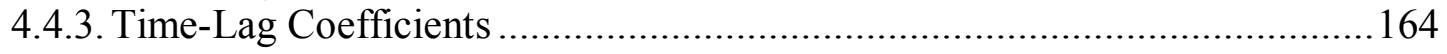

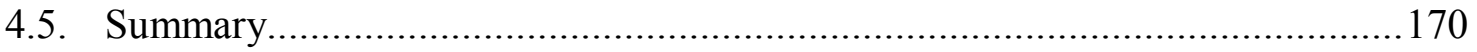

Chapter 5. Time Lags in U.S. Academic Research Institution Licensing Activities . 172

5.1. Forty-Six U.S. Academic Research Institutions and Their Licensing Data .......172

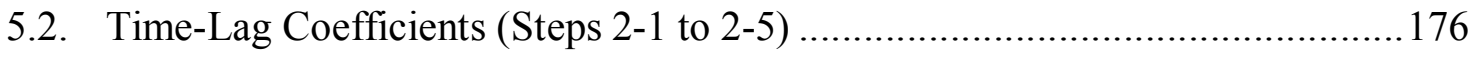

5.2.1. Step 2-1: Stabilize the Time-Series Panel Data........................................176

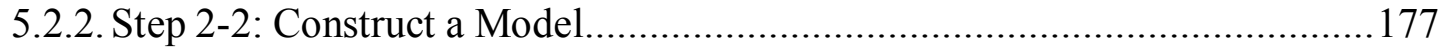

5.2.3. Step 2-3: Identify Potential Lag Period.................................................... 178

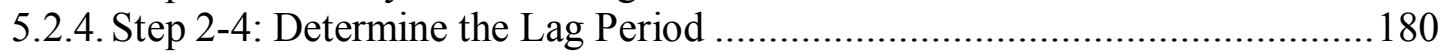

5.2.5. Step 2-5: Estimate Time-Lag Coefficients.......................................... 182

5.3. Aggregated Time-Lag Effects from Licensing Activities to Licensing

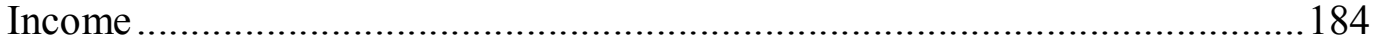

5.3.1. The Paths to Licensing Income ...................................................... 185

5.3.2. The Time-Lag Functions and Aggregated Total Time-Lag Effects ...............187

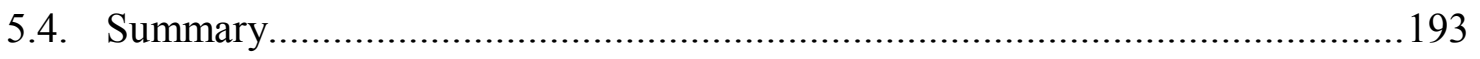

Chapter 6. Licensing Performance of 46 U.S. Academic Research Institutions........ 197

6.1. Input and Output Structure of the Data Envelopment Analysis Model .............197

6.2. Time-Lag Effect Neutralized Input and Output Data ...................................198

6.2.1. Approach to Incorporating Time-Lag Effect Into the Data........................... 198

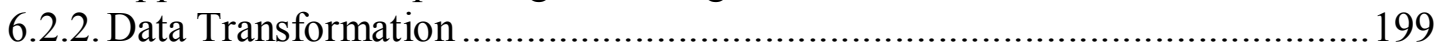

6.3. Verification of the Data Envelopment Analysis Model and Coding ................202

6.4. Super-Efficiency Scores and Malmquist Indexes ........................................204

6.4.1. Step 1: Input Saving and Infeasible Decision-Making Units .......................204

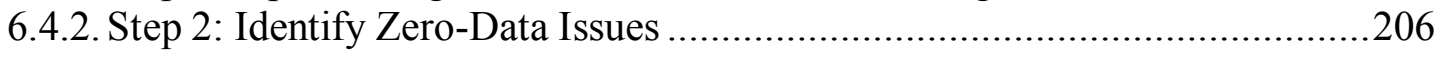

6.4.3. Step 3: Modify $\beta *$ Using the Nonradial Super-Efficiency Model ................208

6.4.4. Step 4: Modified Super-Efficiency Scores Resolving the Zero Data Issue ....209

6.4.5. Malmquist Indexes during the Evaluation Periods ...................................2 210 
6.5. Summary.

Chapter 7. Characteristics of the Efficiency Change Patterns in U.S. Universities'

Technology Commercialization ........................................................... 214

7.1. Licensing Data and Organizational Characteristics .....................................214

7.1.1. Time-lag Effect Neutralized Licensing Data..............................................214

7.1.2. Types of the 46 Academic Research Institutions .....................................216

7.1.3. Characteristic Variables and Data Gathering ..........................................2. 217

7.2. Characteristics of the 46 Academic Research Institutions and Licensing Data. 218

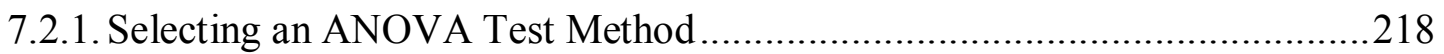

7.2.2. Comparison of Licensing Data from Four Types of Institution ....................219

7.2.3. Comparison of Licensing Data From Two Types of Institution ...................223

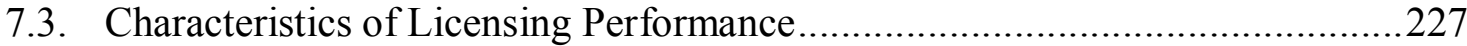

7.3.1. Characteristic Variables by Institutional Type .........................................222

7.3.2. Correlation among Cumulative Licensing and Characteristic Variables........229

7.3.3. Regression of Six Licensing Outcome Variables to the Characteristics

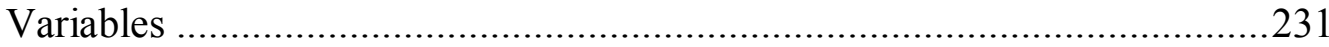

7.3.4. Regression of Efficiency and Efficiency Changes to Characteristic

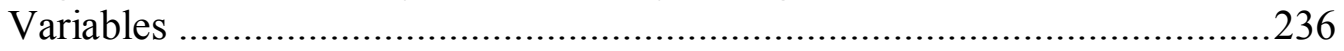

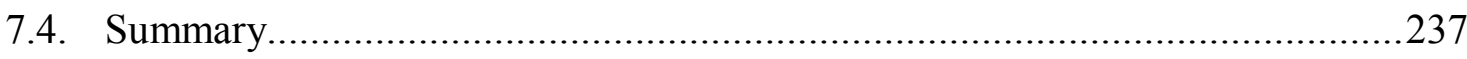

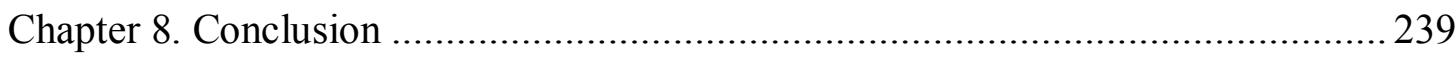

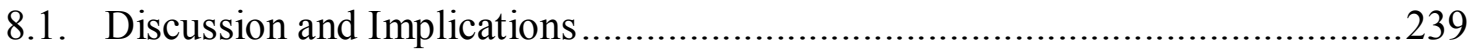

8.1.1. Licensing Time Lags and Licensing Strategy .........................................239

8.1.2. Relative Licensing Performance of Academic Research Institutions.............243

8.1.3. Licensing Practices and Related Characteristics of Academic Research

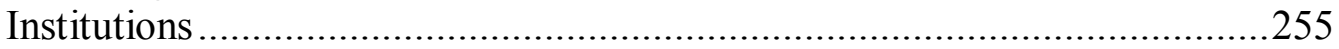

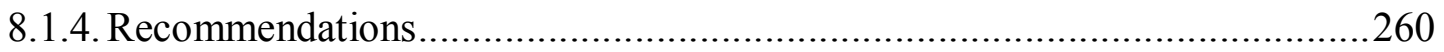

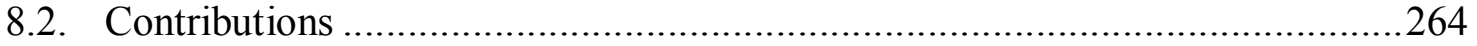

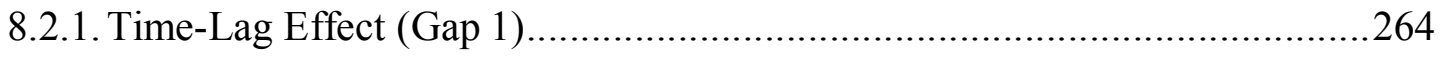

8.2.2. Measurement of Academic Research Institution Technology Commercialization Performance and Influencing Characteristics (Gaps 2,

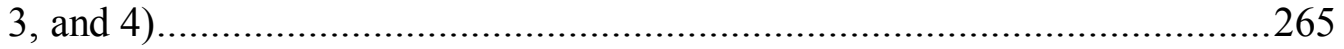

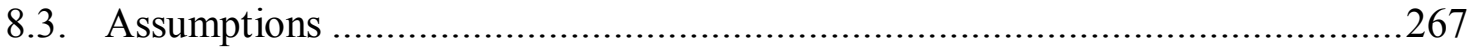

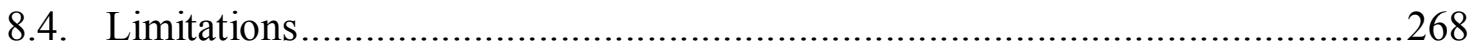

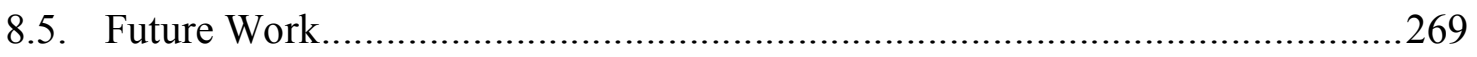

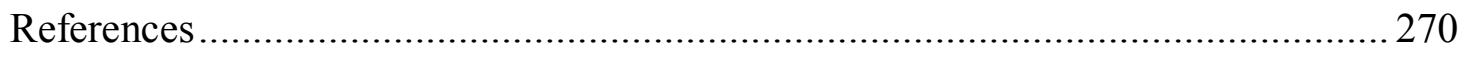

Appendix A. STATA Procedure for the PDL Regression Analysis ....................... 280

Appendix B. Licensing Paths of Each Variable to the Licensing Income.................289 
Appendix C. Xpress Mosel Coding of Modified Super-Efficiency Model 292

Appendix D. Modified Super-Efficiency Score of the 46 Institutions during the

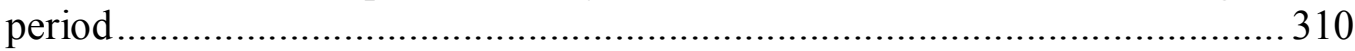

Appendix E. Malmquist Indexes of the 46 Institutions during the Period ..................321

Appendix F. Normality Test of Cumulative Time-Lag Effect Neutralized Licensing

Data by Four Institution Types ................................................................... 333

Appendix G. Normality Test of Cumulative Time-Lag Effect Neutralized Licensing

Data by Two Institution Types …………………………............................ 334 


\section{List of Tables}

Table 1: Links among research objective, goals, questions, and approaches ...................9

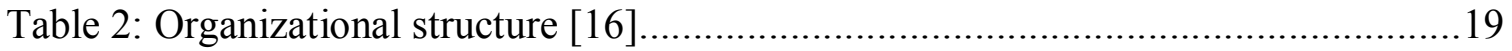

Table 3: University organizational structure and technology transfer activity [16]........20

Table 4: Stakeholders' motivation for technology commercialization [113] ..................24

Table 5: Outcomes of university technology transfer identified by stakeholders

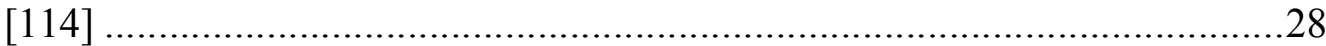

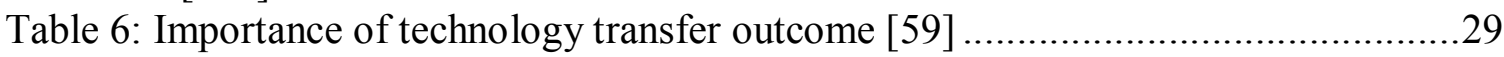

Table 7: Technology transfer mechanisms discussed in the literature ...........................35

Table 8: Techniques for evaluating productivity of service organizations [108] ............37

Table 9: List of efficient U.S. universities identified by different studies......................48

Table 10: Measuring efficiency of university technology commercialization and

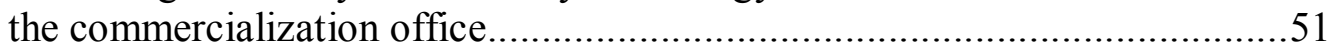

Table 11: Influencing characteristics and university status .......................................55

Table 12: Correlation between TLO structures and licensing strategies [77] ................61

Table 13: External characteristics from the literature ...........................................68

Table 14: Organizational characteristics related to university technology commercialization from the literature .................................................69

Table 15: Organizational characteristics related to university technology commercialization from the literature (continued)....................................70

Table 16: Organizational characteristics related to university technology commercialization from the literature (continued)...............................71

Table 17: Summary of the characteristics influencing licensing performance ................72

Table 18: Linking the identified gaps to the research goals. ......................................91

Table 19: Research goals and corresponding research questions ..............................94

Table 20: General time series models and their limitations........................................ 100

Table 21: Infeasibility of the super-efficiency data envelopment analysis models ........126

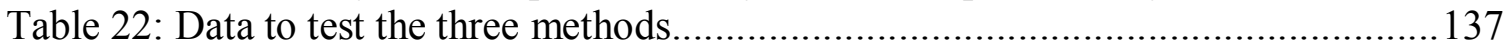

Table 23: Comparisons of the results from the four super-efficiency methods..............138

Table 24: Strengths and limitations of the current super-efficiency models .................139

Table 25: Changes in the location of the institution and frontier from $t$ to $t+1 \ldots \ldots \ldots . .150$

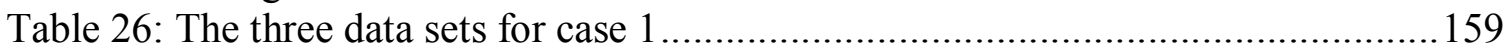

Table 27: Augmented Dickey-Fuller test result for data set 1 .................................. 160

Table 28: Result of Akaike's Information Criterion and Bayesian Information Criterion tests.

Table 29: Correlation between the output variable and time lag of the independent variable.

Table 30: Comparison of selected lag periods and predefined lag periods ................... 162

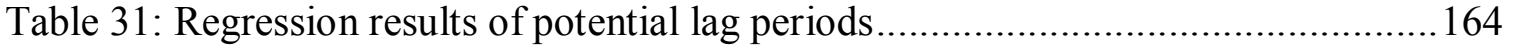

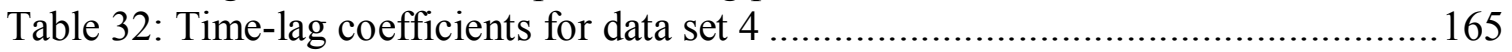

Table 33: Predefined and observed lag structures................................................ 165

Table 34: Results of polynomial distributed lag regression models applied to data set 4 (continuous lags). 
Table 35: Results of polynomial distributed lag regression models applied to

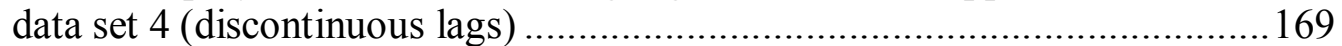

Table 36: The 46 institutions used for the time-lag analysis ...................................... 174

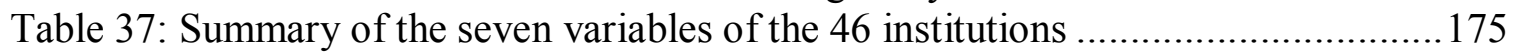

Table 38: Results of the unit root test of licensing data, using the Levin-Lin-Chu

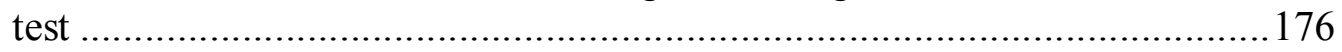

Table 39: Correlation result of the licensing variables.............................................. 179

Table 40: regression result of disclosure and expenditure with potential lag periods ....................................................................................... 180

Table 41: Significant lag periods among the licensing variables ............................. 181

Table 42: Time-lag coefficients of expenditure to disclosure..................................... 182

Table 43: Unstandardized time-lag coefficients of the licensing variables .................... 183

Table 44: Standardized time-lag effects of the licensing variables............................... 184

Table 45: Time-lag functions of patents issued on the patents issued paths ..................188

Table 46: Time-lag aggregator of patent issue....................................................... 190

Table 47: Integration of multiple time-lag aggregators of patents issued on the

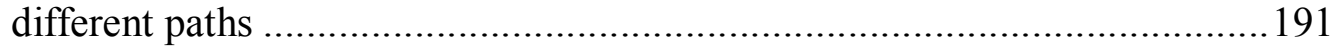

Table 48: Aggregated total time-lag effects of the six licensing variables..................... 192

Table 49: Time-lag coefficients from input to output variables ..................................199

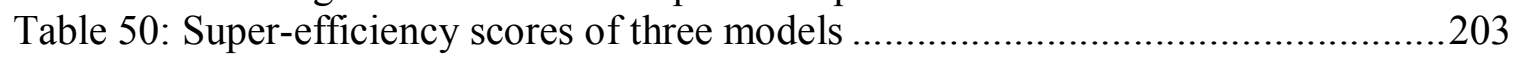

Table 51: Super-efficient and extremely super-efficient institutions ..........................205

Table 52: Input slacks of infeasible institutions in the frontier year $t$ from 1991

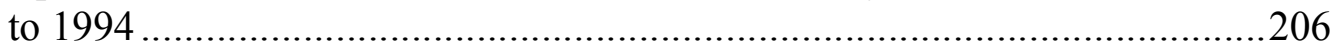

Table 53: Input slacks of infeasible institutions in the frontier year $t$ from 1995

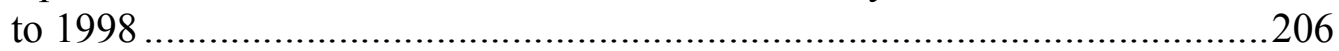

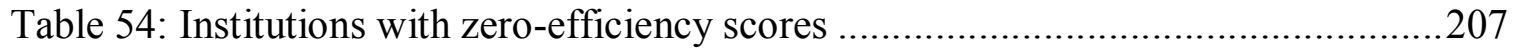

Table 55: Referred institutions causing type 2 zero issue .......................................207

Table 56: Nonradial output super-efficiency scores of institutions with type 2

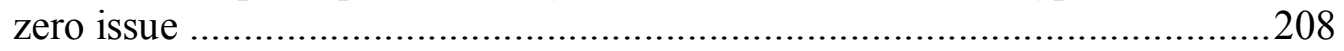

Table 57: Modified super-efficiency scores of 11 institutions (1991-1999).................209

Table 58: Average efficiency change, technical change, and Malmquist Index scores of the 46 institutions ................................................................2 212

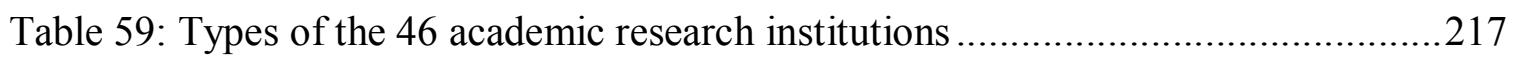

Table 60: Institutional variables and data sources..................................................218

Table 61: Case summaries by four institution types and cumulative time-lag effect neutralized licensing data (1991-1999)......................................2220

Table 62: Kruskal-Wallis test of cumulative licensing data over four institution

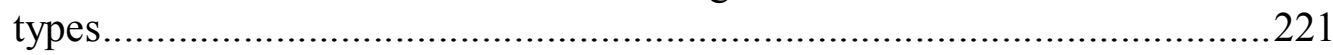

Table 63: Four institution types and six cumulative time-lag effect neutralized licensing output variables per expenditure .........................................222

Table 64: Kruskal-Wallis test of cumulative licensing data per expenditure by four institution types.

Table 65: Two institution types and cumulative time-lag effect neutralized licensing data (1991-1999). 
Table 66: Kruskal-Wallis test of cumulative licensing data from two types of institution

Table 67: Two institution types and cumulative time-lag effect neutralized licensing data per expenditure. .225

Table 68: Kruskal-Wallis test of cumulative licensing data per expenditure by two types of institution 226

Table 69: Journal articles and technology licensing office-related variables by institution type

Table 70: Kruskal-Wallis test of journal papers and technology licensing office variables in four types of institution.

Table 71: Journal articles and technology licensing offices per expenditure by type of institution .228

Table 72: Kruskal-Wallis test of journal papers and technology licensing office variables per expenditure by four types of institution...

Table 73: Correlation matrix of cumulative licensing data and institutional variables 230

Table 74: Correlation among licensing characteristics and universities 231

Table 75: Regression of licensing outcomes to characteristic variables (four institution types excluded)

Table 76: Regression of licensing outcomes to characteristic variables (four institution types).

Table 77: Regression of efficiency and efficiency changes to characteristic variables (four institution types) .................................................236

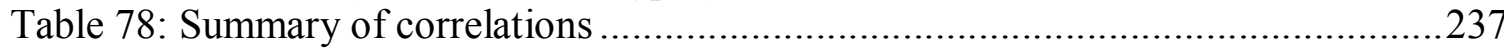

Table 79: Summary of the results of regression of licensing data .............................238

Table 80: Summary of the results of regression of efficiency and efficiency change..... 238

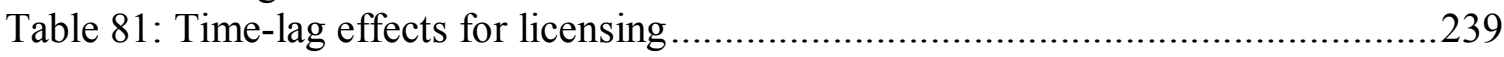

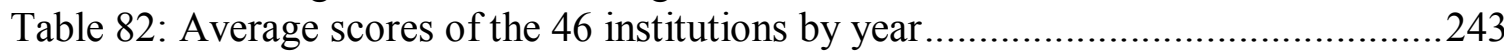

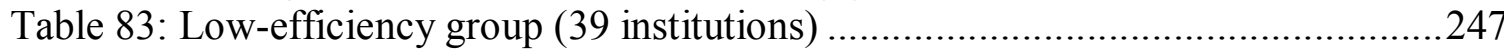

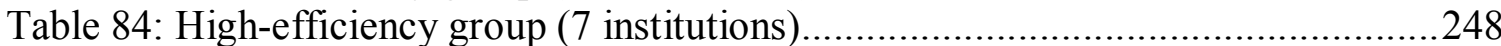

Table 85: Research and licensing activity of top research institutions.........................249

Table 86: Research and licensing activity of research institutions with low school rankings (50 to 100)

Table 87: Effect of the existence of a medical school in a university..... 259 


\section{List of Figures}

Figure 1: Related topics and the scope of the dissertation...........................................5

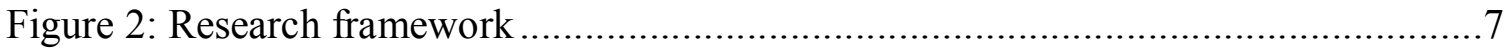

Figure 3 An example of technology commercialization from a university to a firm or entrepreneur (adopted from Siegel, et al. [113]) ..............................31

Figure 4: Technology commercialization process (adopted from Rogers, et al.

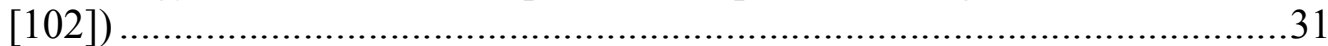

Figure 5: Disclosure and licensing process (adopted from Jensen, et al. [60]) ................32

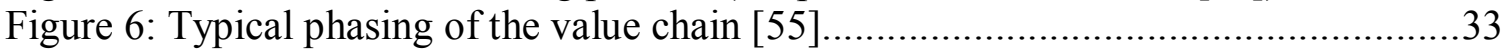

Figure 7: Association between technology stage, commercialization strategy,

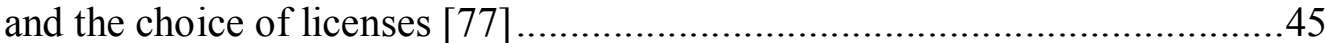

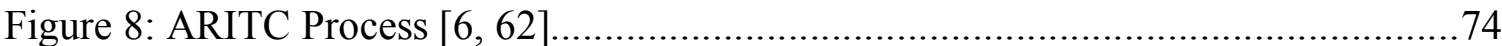

Figure 9: The efficiency pattern diagram of 17 efficient universities from 2001

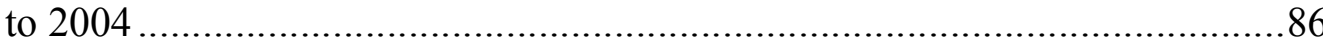

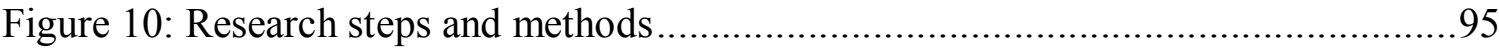

Figure 11: Process to identify time-lag distribution coefficients ..............................101

Figure 12: Coefficient structures of time series models ......................................... 104

Figure 13: Time-lag aggregation process using time-lag coefficients .......................... 109

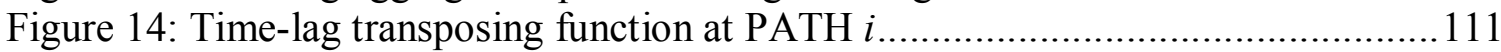

Figure 15: Example of transform function of the time lags...................................... 113

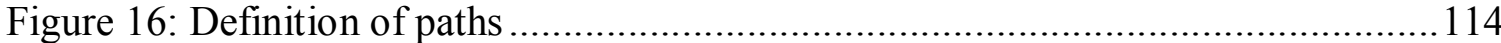

Figure 17: Example of multiple paths from an input to output variable ...................... 115

Figure 18: Super-efficiency of B in the output-oriented super-efficiency variable returns to scale data envelopment analysis model ....................................127

Figure 19: Infeasibility of $A$ in the output oriented super-efficiency variable returns to scale data envelopment analysis model .................................... 128

Figure 20: Modified output-oriented super-efficiency model by Lovell and

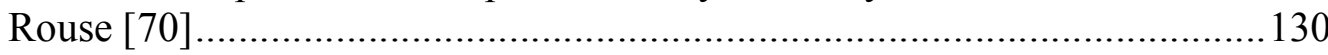

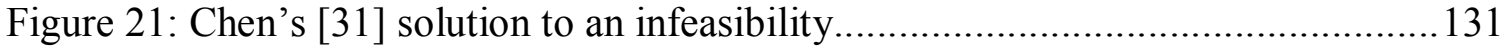

Figure 22: Input saving (or output surplus) in an output-oriented (or inputoriented) model

Figure 23: A new three-stage data envelopment analysis model ................................. 140

Figure 24: A new output-oriented super-efficiency variable returns to scale model

Figure 25: Demonstration of Malmquist Index, efficiency changes, and technical

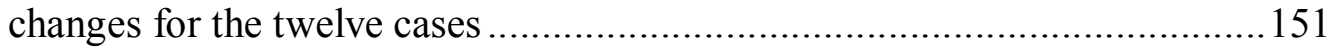

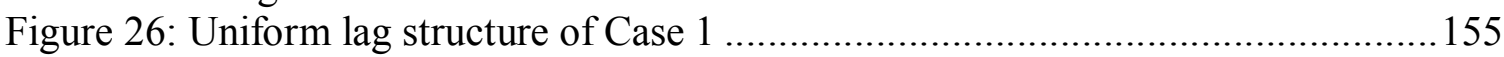

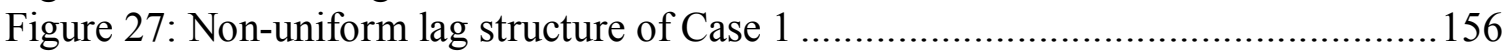

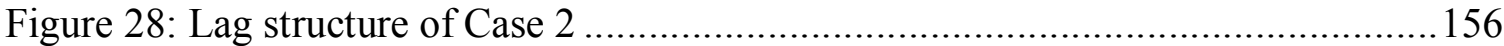

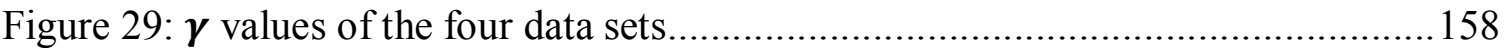

Figure 30: Lag coefficients by polynomial distributed lag regression model with

Data Set 3 (continuous lags) ....................................................... 168 
Figure 31: Lag coefficients by polynomial distributed lag regression model with

Data Set 4 (discontinuous lags) ....................................................... 170

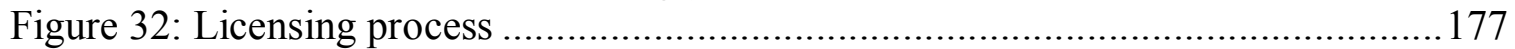

Figure 33: All identified paths from licensing variables to licensing income ................186

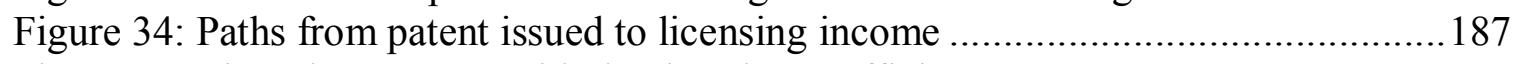

Figure 35: Licensing process with the time-lag coefficients ..................................... 194

Figure 36: Graph of the aggregated total time-lag effects to licensing income of

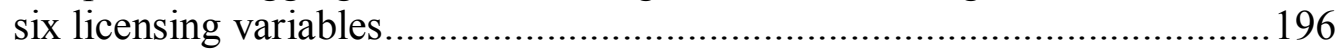

Figure 37: Input and output structure in the data envelopment analysis model ............. 198

Figure 38: Time-lag relationships between input and output variables........................200

Figure 39: Time-lag relationship of transformed data and data envelopment

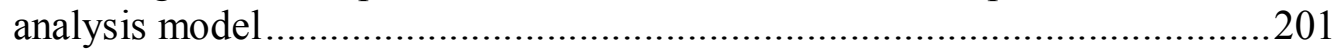

Figure 40: Data transform of the licensing data incorporating time-lag coefficients ............................................................................. 215

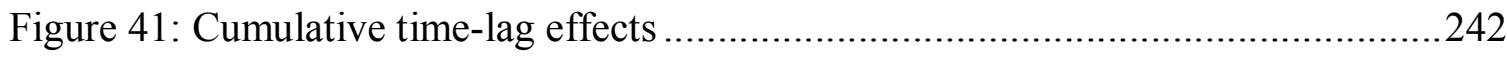

Figure 42: Catch-up and frontier expansion dominating periods...............................244

Figure 43: Average super-efficiency and efficiency change (Malmquist Index)

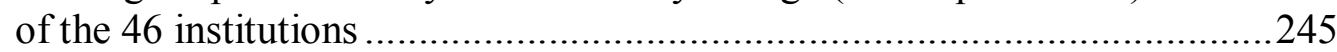

Figure 44: Technology licensing offices' full-time equivalents for slightly efficient and low-efficiency universities 254 
Chapter 1. Introduction

The present study aims to provide a better understanding of technology licensing by academic research institutions. The study assesses the efficiency of academic research institution technology commercialization practices and examines how their efficiency has changed over time and institutional characteristics influencing the performance. This was accomplished using a new approach for identifying time lags in licensing. In addition to the time-lag process, a modified super-efficiency variable returns to scale (VRS) data envelopment analysis (DEA) model was applied to the time lag-neutralized licensing data. This model measured the efficiency of U.S. research institutions' licensing performance over time. To accomplish this, it first was necessary to resolve issues with the super-efficiency DEA model, including mathematical infeasibility and zero-data considerations.

Technology transfer is the movement of technological and technology-related organizational know-how and knowledge to partners in order to enhance the partner's competence and strength [2]. Traditionally, technology transfer was regarded as a method of acquiring new technologies from other companies or as a way to internally transfer products or process technologies throughout a company to improve technological competence and fill technological capacity gaps. In recent years, however, interest has shifted to university research. University research has been an important source of new technologies and products and has contributed significantly to industrial innovation in 
various fields $[16,22,48,56,75,129]$. A university's contribution to the knowledge economy is expected to be increasingly critical in the future [136]. Therefore, universities are shifting from their traditional mission of teaching and are including an emerging mission of contributing to industry with their knowledge [46, 135].

Extensive studies have attempted to understand the research and development (R \& D) of companies and thus to improve their productivity. These studies have provided theoretical and practical advances in the technology management of industry. While the companies were considered the main objective of the studies, in the context of the growth of national science, technology, and economic development, other studies on universities have focused on education and research [90]. Universities need to learn from the development of the business sector to respond to a quickly changing global economy [43].

Universities are service entities providing education, research, and services to the community and local businesses [117]. They transfer knowledge to outside organizations. Applied and basic research, in addition to education, have been universities' primary tasks. However, as the commercialization of university-created knowledge becomes prominent (with federal government support and serving industrial needs), universities are trying to achieve effective technology transfer and to gain financial benefit.

During the past two decades, various university activities have become interesting research areas, and very active and significant studies have focused on universities' 
technology development. Many studies have shown that universities are critical research and innovation centers, accelerating and increasing the national economic growth and technology competencies of a country and its industries $[43,100]$. Therefore, academic studies have attempted to provide a better understanding of the nature of university technology transfer and to outline possible ways to improve technology commercialization. The most popular research topics have focused on finding best practices through benchmarking studies and locating important characteristics that lead to improved university performance.

Performance evaluations require multiple perspectives and must be based on the understanding of complex interests and roles. A framework or model integrating various stakeholder activities and interests, different goals, and different intellectual property portfolios is required to facilitate best practices [80]. 


\subsection{Research Scope and Objective}

\subsubsection{Related Topics and Research Scope}

There are four major paths of technology transfer among organizations: industry to industry, university to industry, government to government, and government to industry [18]. This study examines the commercialization of university technology research for industrial applications. There is a wide range of studies on university-to-industry technology transfer (Figure 1). The top level of topics focuses on the effect of university technology transfer on national economic growth and scientific and technological capacity. The second level focuses on technology transfer at the organizational level. Studies in this area evaluate the performance of university technology commercialization by benchmarking multiple universities, and examine the organizational characteristics that influence performance. The third level examines the commercialization process and the role of technology commercialization offices. Finally, the fourth level focuses on understanding and developing an individual technology commercialization mechanism. This dissertation covers the second and third levels. 


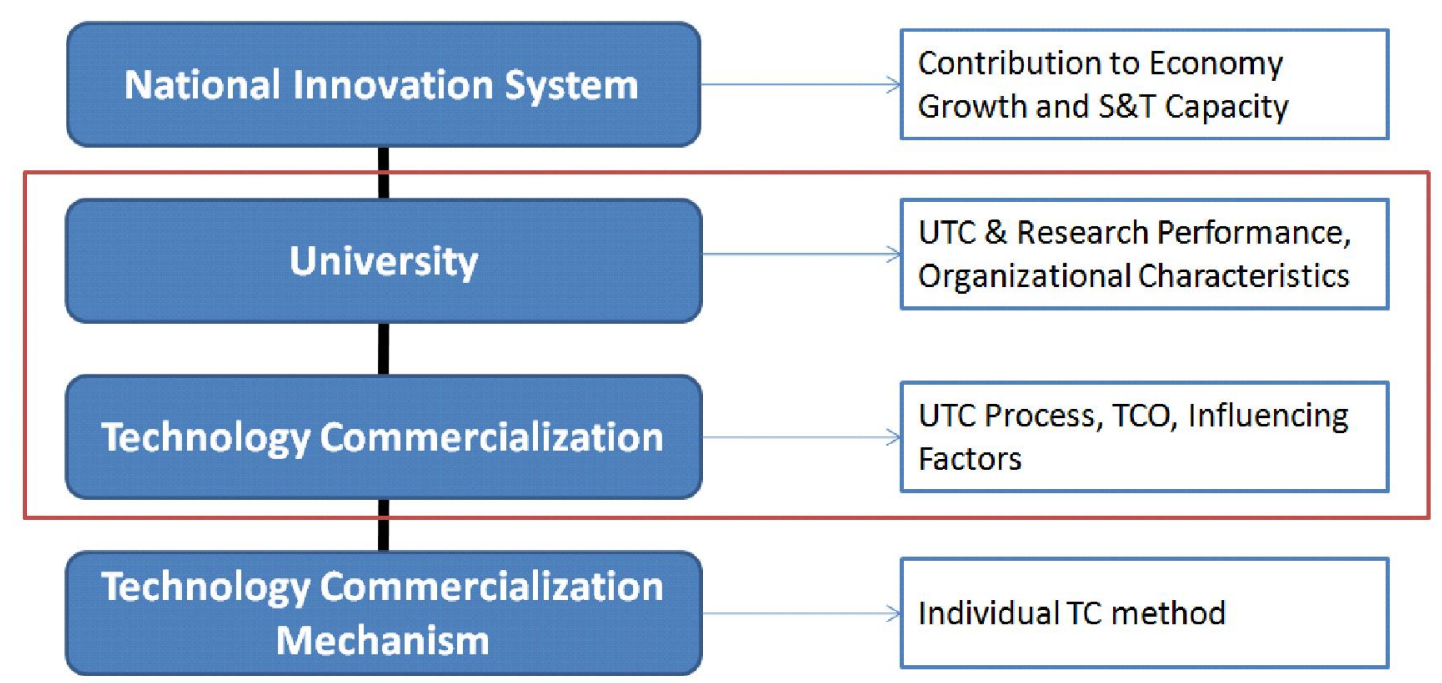

Figure 1: Related topics and the scope of the dissertation

\subsubsection{Research Objective and Goals}

The main objective of this dissertation is to contribute to the understanding of academic research institution technology commercialization (ARITC) activity by evaluating efficiencies and identifying patterns of change over time. Influencing characteristics, identified through the reviewed literature, are explored to understand their effect on performance and to define characteristic patterns. There are four research goals.

- Goal 1: To identify the ARITC process and incorporate the time-lag effect

- Goal 2: To assess U.S. ARITC performance from 1991 to 2007

- Goal 3: To identify changes in ARITC efficiency during the period 1991 to 2007

- Goal 4: To identify the characteristics of ARITC performance 


\subsection{Research Questions}

The following research questions are intended to achieve the research objective and goals.

The research questions corresponding to Goal 1 are as follows:

Research Question 1: What is the process of ARITC?

Research Question 2: What are the input and output structures of ARITC?

Research Question 3: What time lags exist among ARITC inputs and outputs?

Research Question 4: What is the appropriate model to incorporate time-lag effects into the technology commercialization process?

The research question corresponding to Goal 2 is as follows:

Research Question 5: What are the efficiencies of U.S. ARITC from 1991 to 2007 ?

The research question and sub-questions corresponding to Goal 3 are as follows:

Research Question 6: What patterns of change are found in U.S. ARITC efficiencies from 1991 to $2007 ?$

- Research Question 6-1: What trends exist in technology commercialization process inputs and outputs over time?

- Research Question 6-2: What trends exist in the technology commercialization efficiencies of U.S. academic research institutions from 1991 to 2007 ?

The research question corresponding to Goal 4 is as follows: 
Research Question 7: What relationships exist among ARITC characteristics and licensing performance?

\subsection{Research Process}

The present study assesses the relative licensing productivity of academic research institutions. The results will indicate how well a particular institution is licensing its technology, given its resources, relative to other universities. For this purpose, this study develops a research process (Figure 2).

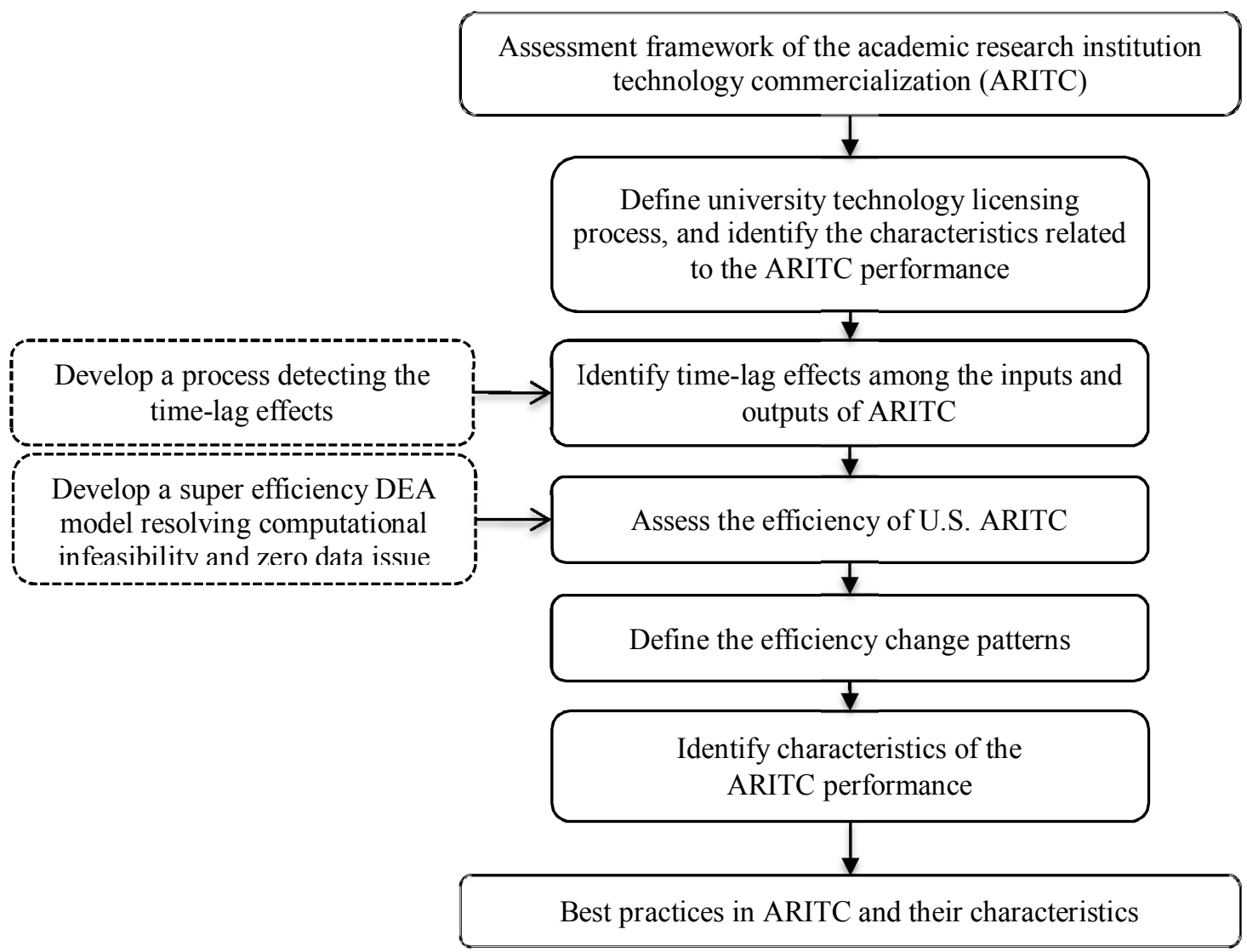

Figure 2: Research framework 
First, the process of ARITC and its input and output structure are defined through a literature review. The characteristics influencing the performance of ARITC are identified.

Second, time-lag coefficients are identified through a suggested time-lag identifying process in order to incorporate into the ARITC efficiency model the duration between input and output variables. For this purpose, time-lag distribution functions and aggregated time-lag effects are defined.

Third, the relative efficiencies of the ARITC are evaluated. The modified superefficiency Banker, Charnes, and Cooper (BCC) [12] DEA model is suggested to assess the technology licensing efficiencies of U.S. academic research institutions from 1991 to 2007. Infeasibility and computation limitation due to zero data of the DEA model are discussed and a solution is provided. Time lag effect neutralized data are used for the analysis.

Fourth, efficiency changes are observed and their patterns are identified.

Finally, the relationships among characteristics and efficiencies and their changes are examined to define characteristic patterns and to understand the technology licensing practices of the observed institutions. 
The links between research goals, questions, and methods are summarized in Table 1.

Table 1: Links among research objective, goals, questions, and approaches

Research Objective:

Contribute to the understanding of academic research institution technology commercialization (ARITC) activity by evaluating efficiencies and identifying patterns of change over time and exploring ARITC characteristics influencing licensing performance.

\begin{tabular}{|c|c|c|c|c|}
\hline Research Goals & & Research Questions & & Research Approaches \\
\hline $\begin{array}{l}\text { G1: Identify the } \\
\text { ARITC process } \\
\text { and incorporate } \\
\text { the time-lag } \\
\text { effect. }\end{array}$ & & $\begin{array}{l}\text { RQ1: What is the process } \\
\text { of ARITC? } \\
\text { RQ2: What is the input and } \\
\text { output structure of ARITC? } \\
\text { RQ3: What time lags exist } \\
\text { among ARITC inputs and } \\
\text { outputs? } \\
\text { RQ4: What is the } \\
\text { appropriate model to } \\
\text { incorporate time-lag effects } \\
\text { into the technology } \\
\text { commercialization process? }\end{array}$ & & $\begin{array}{l}\text { STEP 1: A model of the ARITC } \\
\text { process and its input and output } \\
\text { structure are defined based on } \\
\text { the literature review. } \\
\text { STEP 2: Time lags among input } \\
\text { and output variables are } \\
\text { identified by time-series } \\
\text { analysis. A process identifying } \\
\text { time lags among variables is } \\
\text { developed and then validated by } \\
\text { using simulated ARITC data. }\end{array}$ \\
\hline $\begin{array}{l}\text { G2: Assess U.S. } \\
\text { ARITC } \\
\text { performance } \\
\text { from } 1991 \text { to } \\
2007 .\end{array}$ & & $\begin{array}{l}\text { RQ5: What are the } \\
\text { efficiencies of U.S. ARITC } \\
\text { from } 1991 \text { to } 2007 \text { ? }\end{array}$ & & $\begin{array}{l}\text { STEP 3: Aggregated time-lag } \\
\text { effects of the ARITC are defined } \\
\text { by time-lag functions and } \\
\text { coefficients. } \\
\text { STEP 4: Efficiencies of U.S. } \\
\text { ARITC from } 1991 \text { to } 2007 \text { are } \\
\text { evaluated using a modified } \\
\text { super-efficiency DEA model and } \\
\text { the Malmquist Index. }\end{array}$ \\
\hline $\begin{array}{l}\text { G3: Identify } \\
\text { changes in } \\
\text { ARITC } \\
\text { efficiency during } \\
\text { the period } 1991 \\
\text { to } 2007 .\end{array}$ & & $\begin{array}{l}\text { RQ6: What patterns of } \\
\text { change are found in U.S. } \\
\text { ARITC efficiencies from } \\
1991 \text { to } 2007 ?\end{array}$ & & $\begin{array}{l}\text { STEP 5: Performance } \\
\text { (efficiency) changes are } \\
\text { measured by average efficiency, } \\
\text { efficiency change, and the } \\
\text { Malmquist Index. }\end{array}$ \\
\hline $\begin{array}{l}\text { G4: Identify the } \\
\text { characteristics of } \\
\text { the ARITC } \\
\text { performance. }\end{array}$ & & $\begin{array}{l}\text { RQ7: What relationships } \\
\text { exist among ARITC } \\
\text { characteristics and } \\
\text { licensing performance? }\end{array}$ & - & $\begin{array}{l}\text { STEP6: Explore the } \\
\text { relationships between } \\
\text { performance and characteristics } \\
\text { through statistical analysis. }\end{array}$ \\
\hline
\end{tabular}




\subsection{Major Findings and Contributions}

The present study provides insight into the licensing practices of an academic research institution and presents tools to measure the licensing time lags and the performance of academic researchers and licensing practitioners, thus filling gaps identified in previous research.

\subsubsection{Gap 1: Lack of a study identifying the time-lag effect in licensing}

Licensing is a complicated process involving multiple organizations and time-consuming activities. When discussing licensing performance, existing studies do not identify processes and therefore do not consider time duration. Failure to determine when the actual input was delivered is a significant gap and leads to inappropriate interpretations of licensing output data and their implications.

The limitations arise because licensing is a complicated process associated with the inherently high uncertainty of research and technology transfer activity, and because there is no tool or process to identify licensing time lags in a systematic and scientific way. Therefore, the present study develops a licensing-time-lag identification process based on time series theory and methods widely adopted in econometrics. The process was verified by multiple tests using simulated data that reflect actual licensing behavior, and then was applied to data on 46 U.S. academic research institutions. The process identified statistically significant time-lag effects between two licensing variables. The 
overall time durations identified in the data, from research expenditure to licensing income, range from 2 years to 27 years.

1.4.2. Gap 2 and Gap 3: Difficulties in measuring relative licensing performance, and lack of understanding of changes in licensing performance over time

Government and research institutions have been struggling to understand and define the licensing performance of research institutions, which is necessary to respond to government-facilitated technology transfer policy and institutions' need to contribute to the economy and industry. The conflicting interests and understanding about research licensing as well as a lack of a concrete evaluation framework complicate performance measurement. Existing studies evaluating the relative licensing performances do not satisfy the need because

- they measure the performance of the licensing office rather than the licensing performance of an institution;

- their evaluation models apply different types of variables, such as influencing characteristics and licensing variables, which makes it difficult to interpret and understand the licensing performance;

- they do not measure the different performances of efficient institutions, which is related to the limitation of the DEA method and is associated with computational infeasibility when the variable returns to scale super-efficiency model is applied; and 
- they do not incorporate into their model time lags between the licensing variables.

The present study defines the licensing process and related variables. In order to identify the licensing performance of an organization in a manner that provides clear understanding and avoids conflicting views of the result, the evaluation model used licensing variables associated with intrinsic licensing outcome and licensing quality.

The study also overcomes the methodological limitations of DEA by comparing the strengths and weaknesses of current DEA approaches and by modifying a selected method to resolve the computational infeasibility and zero-data issues. The modified model was applied to the Malmquist Index (MI) to explore efficiency changes from 1991 to 2007 , and the licensing time lags identified in this study were incorporated into the evaluation model. The results show that all 46 research institutions improved their licensing performance during the period. The average annual improvement was $33 \%$. Two distinct periods of licensing performance were identified. Catch-up efforts of the inefficient institutions were dominated in licensing practice associated with research expenditure from 1992 and 1996, whereas the efficient institutions further improved their performance from 1996 to 1998. 


\subsubsection{Gap 4: Lack of understanding the characteristics influencing the}

performance and practice of licensing

The existing studies provide limited understanding of the characteristics influencing licensing performance, which is measured without considering the time-lag effect. As a result, interpretation of identified relationships is limited. In addition, each study analyzes effects on a different type of performance, such as licensing income, average licensing income relative to research expenditure, or efficiency scores, and employs different data sets and institutions. Results therefore vary, depending on the performance types, data, and assumptions used in the studies. This makes it difficult to compare and interpret results.

The present study describes the comprehensive relationships among the selected ARITC characteristics found in the literature review and among different types of licensing performance. The study applied three performance types identified in the literature: licensing income, licensing income relative to expenditure, and DEA efficiency scores. The results provide insight into the current debates about the value, direction, and perceptions of licensing efforts by exploring relationships among academic prestige, research intensity, technology transfer resources, and licensing performance. The study indicates that prior researchers' different findings about the relationships between characteristics and licensing performance were due to the application of different performance metrics: Some measured the amount of licensing income whereas others measured the efficiency of licensing performance. 


\section{Chapter 2. Literature Review}

There are several internal and external stakeholders of universities such as university administrations, faculties, technology commercialization offices, the federal government, and industry. This study will contribute to their understanding of university technology transfer by measuring the relative performances of academic research institution technology commercialization (ARITC) and enlightening the relationships between the performances and the influencing characteristics.

For this purpose, the literature related to these issues has been reviewed in the following sequence.

- The first section of the literature review is done to understand the overall characteristics of universities and motivation for university technology commercialization.

- The second section is focused on studying the nature and process of university research and technology commercialization.

- The current approaches of assessing the performance of technology commercialization are reviewed in section three.

- Section four reviews the influencing characteristics of ARITC and their impact on performance and organizational commercialization practice.

- Section five reviews the pattern diagram identifying ARITC efficiency change patterns. 
- Section six reviews the method of data envelopment analysis (DEA), which is considered as the appropriate method for this study.

- Finally, gaps between the current literature and the goals of this study are discussed in section seven.

\subsection{Organizational Characteristics of Universities}

This section reviews the basic characteristics of a university as they relate to technology commercialization.

\subsubsection{Missions, Goals and Services of Universities}

Universities have evolved from being traditional education centers to knowledge factories and will change to knowledge hubs, according to Youtie and Shapira [135]. As their mission evolves, their roles in industry and the economy are expected to increase.

However, there are conflicts and debates about the missions and goals of universities. One side insists that universities should play a more direct role in assisting industries by commercializing their research, while the other side argues that more involvement with industry will damage the research and teaching done by universities [87, 103].

Since the Bayh-Dole Act of 1980, many universities seem more concerned with introducing their knowledge to industry, and thereby contributing directly to the local economy [88]. Decter, et al. [36] identified the main roles of universities and the 15 
perceived relative importance of them by a survey of 57 U.S. universities. They found that universities regarded teaching, publishing new information and basic research as the most important roles, followed by service to community, technology transfer, applied research, and patenting new technology.

The traditional goal of science and technology colleges in a university is to provide advanced scientific knowledge to the public for various benefits as a service organization. Universities are the source of well-trained technicians, engineers, and managers. These experts support regional and urban economic growth $[48,56]$. Another traditional mission of universities is research. Universities in the U.S. and Europe contribute to the development of knowledge-intensive clusters and play a major role in knowledge creation $[65,115]$.

Hershberg, et al. [56] and Feldman and Desrochers [45] found that not all universities emphasize technology transfer. Florida [46] argued that universities are becoming aggressive at attempting to profit from industry-funded research, and industries are not comfortable with their behavior. He emphasized the importance of the traditional roles of universities: education and research. Some of them try to contribute to the public benefit by opening their licenses.

Kapczynski, et al. [61] gave related examples of providing university technologies for public benefits. Yale University and the University of Washington granted exclusive 
license of high potency compounds to a non-profit drug company, One World Health, in 2003. At the same time, they continued related research as partners. Stanford University also reserves an exclusive licensing agreement for both commercial and non-commercial research. In the case of the University of Wisconsin, licensing is reserved for only noncommercial research.

Different perceptions of technology transfer exist among university scientists, managers in technology licensing offices (TLOs), and industrial counterparts [18, 111]. These conflicts of interest lead universities to select different paths among traditional missions, programs, and their reputations, and the interests of firms seeking profits, growth, and competitive advantages.

Therefore, universities may have different priorities for two different objectives:

- Following the traditional mission of teaching and research

- Gaining a competitive advantage and growing

These objectives influence the following major activities of universities:

- Education and the service to the community

- Applied and basic research

- Commercialization 
Public perception of university technology commercialization is complicated. Therefore, it is worthwhile to establish the right goals, and measure the performance of university technology commercialization in order to obtain public support and improve the activity [118].

\subsubsection{Organizational Structure}

Bercovitz, et al. [16] proposed that technology commercialization activities of processing an invention disclosure, licensing, seeking additional sponsorship of R\&D projects, or a combination of the three, are shaped by the resources, reporting relationship, autonomy, and incentives of the TLO. They adapted organizational structures identified by Chandler [27] to the university structure in order to examine the influences of university organizational structure on technology commercialization performance.

They defined organizational structures in terms of information-processing capacity, coordination capability, and incentive alignment. Four organizational structures are defined: unitary form (U-Form), multidivisional structure (M-Form), holding company (H-Form), and matrix structure (MX-Form). The U-Form has a top-down oriented decision structure and strong vertical control, while the M-Form structure adopts a divisional approach with central control over divisions. H-Form is similar in structure to M-From, but has a less centralized decision process with strong unit level incentives. MX-Form operates with both a functional and product hierarchy in which an individual and subunit are responsible for multidimensional functions. Detailed definitions and 
characteristics of the four forms are provided in Table 2. They found that different university structures have their own effective technology transfer capabilities such as coordination capability, information processing capacity, and incentive alignment.

Table 2: Organizational structure [16]

\begin{tabular}{|c|c|c|c|}
\hline $\begin{array}{l}\text { Organizational } \\
\text { structure }\end{array}$ & $\begin{array}{l}\text { Information- } \\
\text { processing capacity }\end{array}$ & $\begin{array}{c}\text { Coordination } \\
\text { capability (across } \\
\text { units) }\end{array}$ & $\begin{array}{c}\text { Incentive alignment } \\
\text { (across units) }\end{array}$ \\
\hline $\begin{array}{l}\text { U-Form } \\
\text { (Unitary) }\end{array}$ & $\begin{array}{l}0 \\
\text { Limited by HQ size; } \\
\text { the need to funnel } \\
\text { decisions through top } \\
\text { management group } \\
\text { creates a bottleneck }\end{array}$ & $\begin{array}{l}+ \\
\text { Coordination } \\
\text { capabilities among } \\
\text { sequential work units } \\
\text { are relatively strong } \\
\text { given vertical control }\end{array}$ & $\begin{array}{l}+/ 0 \\
\text { Difficult to create } \\
\text { unit-level incentives } \\
\text { compatible across } \\
\text { units and in line with } \\
\text { organizational goals }\end{array}$ \\
\hline $\begin{array}{l}\text { H-Form } \\
\text { (Holding } \\
\text { Company) }\end{array}$ & $\begin{array}{l}++ \\
\text { Decentralized } \\
\text { decision-making } \\
\text { leads to higher overall } \\
\text { information- } \\
\text { processing capacity }\end{array}$ & $\begin{array}{l}+/ 0 \\
\text { Weak central body } \\
\text { allows for limited } \\
\text { top-down } \\
\text { coordination across } \\
\text { units }\end{array}$ & $\begin{array}{l}+/ 0 \\
\text { Strong unit-level } \\
\text { incentives; sub-goal } \\
\text { pursuit often } \\
\text { problematic due to } \\
\text { weak organizational } \\
\text { ties }\end{array}$ \\
\hline $\begin{array}{c}\text { M-Form } \\
\text { (Divisional) }\end{array}$ & $\begin{array}{l}+ \\
\text { Decentralized } \\
\text { decision-making } \\
\text { leads to higher overall } \\
\text { information- } \\
\text { processing capacity } \\
\text { within units }\end{array}$ & $\begin{array}{l}+ \\
\text { Strong central body } \\
\text { allows for moderate } \\
\text { top-down } \\
\text { coordination across } \\
\text { units }\end{array}$ & $\begin{array}{l}+ \\
\text { Strong unit-level } \\
\text { incentives; sub-goal } \\
\text { pursuit problematic } \\
\text { but tempered by } \\
\text { stronger } \\
\text { organizational ties }\end{array}$ \\
\hline $\begin{array}{l}\text { MX-Form } \\
\text { (Matrix) }\end{array}$ & $\begin{array}{l}+ \\
\text { Multiple dimension } \\
\text { responsibilities may } \\
\text { tax information } \\
\text { processing capacity } \\
\text { within units }\end{array}$ & $\begin{array}{l}++ \\
\text { Dual dimension } \\
\text { responsibilities drive } \\
\text { coordinated action }\end{array}$ & $\begin{array}{l}++ \\
\text { Dual incentives: } \\
\text { Functional and } \\
\text { product incentives } \\
\text { are integrated to } \\
\text { reflect organizational } \\
\text { goals }\end{array}$ \\
\hline
\end{tabular}

Note: Impact on Capabilities (0:weak, +: semi strong, ++:strong) 
Bercovitz, et al. analyzed three universities to examine the relationship between technology transfer activity and organizational structures. The coordination capability is measured by customer overlaps (number of transactions); information processing capacity by yield of disclosure, licenses, and sponsored research agreements; and licensing alignment by trade-off between licensing royalty rate and sponsored research dollars. The results are summarized in Table 3: however, they were measured subjectively by the authors, and statistical methods were not applied.

Table 3: University organizational structure and technology transfer activity [16]

\begin{tabular}{|c|c|c|c|c|c|c|c|}
\hline \multirow{2}{*}{ University } & \multirow{2}{*}{ Structure } & \multicolumn{2}{|c|}{$\begin{array}{c}\text { Coordination } \\
\text { Capability }\end{array}$} & \multicolumn{2}{c|}{$\begin{array}{c}\text { Information } \\
\text { Processing } \\
\text { Capacity }\end{array}$} & \multicolumn{2}{c|}{$\begin{array}{c}\text { Licensing } \\
\text { Alignment }\end{array}$} \\
\cline { 3 - 8 } & & Expect & Result & Expect & Result & Expect & Result \\
\hline $\begin{array}{c}\text { Johns Hopkins } \\
\text { Univ. }\end{array}$ & H-Form & Low & Low & High & High & Low & Low \\
\hline Duke Univ. & $\begin{array}{c}\text { MX- } \\
\text { Form }\end{array}$ & High & High & Medium & Medium & High & High \\
\hline $\begin{array}{c}\text { Pennsylvania } \\
\text { State Univ. }\end{array}$ & M-Form & Medium & Medium & High & High & Medium & Medium \\
\hline
\end{tabular}

\subsubsection{Overall Performance Indicator of Universities}

Quality assessment (or performance evaluation) of higher education institutions has been a major concern since the 1980s [49]. There are three quantitative approaches to the assessment of the overall performance of universities: performance indicators, cost function, and non-parametric [49]. Performance indicator (PI) focuses on the performance of teaching (teaching quality assessment, TQA) and research (research assessment exercise, RAE). The UK government, for example, published PIs of higher 
education institutions and highlighted efficiency and PI as tools central to its policies [25]. The cost function is a classic economics tool applying economies of scales, marginal costs and economies of scope. However, this tool requires sufficient and reliable cost data for the individual university. Finally, a non-parametric approach uses a model of the inputs and outputs [49].

Both state and federal governments have tried to assess the performance of higher education institutions to develop and implement their policies $[85,118]$. They developed performance indicators (PI) for universities. PIs assess the areas of general administration, teaching and research. The current studies and practices on the performance index measure combine indicators of mostly teaching and research. The PI components or check-list, which are generally developed by the coordinating body, include the organizational setting of the study program, student input numbers and characteristics, aims and curriculum, assessment methods, teaching and learning environment, study load, student progress, completion rates, student counseling arrangements, number of graduates and employment, educational policy, personnel policy, and internal quality [49].

For example, the Southern Regional Education Board (SREB) adopted legislation to collect and report information on the performance of higher education institutions in the region from the 1980s [118]. The South Carolina Commission on Higher Education (SCH) developed nine categories and 37 indicators of overall performance to assess teaching and research of universities in South Carolina. They applied some of the 37 
indicators every year and used a scoring method to calculate overall PI. The categories consist of mission focus, faculty quality, classroom quality, collaboration, administration efficiency, entrance requirement, graduates' achievements (graduation rate, employment rate, employer feedback, exams, and certificates), the user-friendliness of the institution, and research funding.

Geva-May [49] identified 12 PIs which are related to the universities' policies and goals. They include the increase in the number of graduate students, the increase in the number of students at the universities, drop-out rate, number of years of study, the increase in the number of senior faculty, faculty qualifications, ratio of faculty per number of graduates, number of publications, amount of research grants, budgets and expenditure, physical conditions (built area and related facilities), and answers to social/national needs. Mollis and Marginson [85] in their study assessing overall performance of universities pointed out that university size, age, mission and public or private status should be considered when evaluating universities.

\subsubsection{Summary}

Universities have different research environments and attitudes toward the commercialization of their discoveries than the industry. These differences are inherent in the distinctive missions, roles, and organizational structures. Goals and missions of universities are becoming more complicated as the social need for economic 
contributions of universities increase, along with their traditional services, such as knowledge creation/dissemination and education [17, 42].

\subsection{Technology Commercialization of University Research}

2.2.1. Relationship between Teaching, Research and Technology Commercialization

Generally, universities with high reputations are regarded as having high quality instruction and good research environments in which their faculties can spend less time and effort on teaching. However, studies show that research and teaching are not related $[37,44,120]$.

Universities conduct more than half of the national basic research in the U.S. [61], and their research has served as an important source of scientific and technical knowledge for industrial firms [17]. Mansfield [75] provided evidence that the contribution of university research is considerable, especially in the areas of drugs, instruments and information processing. The author showed that about $10 \%$ of the new products and commercialized processes were based on university research in those areas between 1975 and 1985.

\subsubsection{Motivation and Benefit of a University Commercializing a Technology}

Universities have actively facilitated technology commercialization because of quantitative and qualitative benefits as well as its encouragement by government policy. Some reasons U.S. universities are motivated to transfer their research results are 
contribution to business, royalty income, good publicity for the university, financial support for research, satisfaction of disseminating technologies, and recruitment and retention of staff [36]. Entrepreneurs often finance further research at universities from which they originally spun off [98]. Reinforcement of campus reputations for excellence contributes to the recruitment of the smartest students and the brightest faculty [46]. Siegel, et al. [113] identified stakeholders' primary and secondary motives for technology commercialization as shown in Table 4.

Table 4: Stakeholders' motivation for technology commercialization [113]

\begin{tabular}{|c|c|c|c|}
\hline Stakeholder & Primary motives & Secondary motives & Perspective \\
\hline Scientist & $\begin{array}{c}\text { Recognition within } \\
\text { the scientific } \\
\text { community }\end{array}$ & $\begin{array}{c}\text { Financial gain and a desire } \\
\text { to secure additional } \\
\text { research funding }\end{array}$ & Scientific \\
\hline $\begin{array}{c}\text { Technology } \\
\text { commercialization } \\
\text { office }\end{array}$ & $\begin{array}{c}\text { Protect and market } \\
\text { the university's } \\
\text { intellectual property }\end{array}$ & $\begin{array}{c}\text { Facilitate technological } \\
\text { diffusion and secure } \\
\text { additional research funding }\end{array}$ & Bureaucratic \\
\hline Firm/Entrepreneur & Financial gain & Maintain control of \\
proprietary technologies & $\begin{array}{c}\text { Organic / } \\
\text { entrepreneurial }\end{array}$ \\
\hline
\end{tabular}

McMillan [82] summarized the literature on the role and contribution of university research and public funding from the view of society and industry.

- University research generates scientific publications.

- Public funding of university research provides patents and innovations. 
- University research provides opportunities for spillovers from the public sector to the private sector.

- University technology transfer drives the movement of trained scientific personnel from academia to industry.

Grimaldi and von Tunzelmann [53] summarized the benefits companies receive from university technology commercialization:

- Economies of scale and scope in research

- Reduction of product or process costs

- Acceleration of R\&D

- Avoiding unnecessary duplication of research

- Risk management

- Financial support for costly projects or equipment

- Access to research know-how networks and related technologies

- Technology and knowledge transfer, assimilation and utilization

- Hiring university students or graduates

- Enhancement of reputation

Decter, et al. [36] surveyed the importance of motivations for U.S. universities to transfer technology to business. They can be ranked as follows based on their survey result from highest to lowest.

- Rank 1: satisfaction of disseminating technologies 
- Rank 2: financial support for university research

- Rank 3: recruitment and retention of staff

- Rank 4: good publicity for the university

- Rank 5: royalty payments to university

- Rank 6: royalty payments to the inventors

- Rank 7: legislation

- Rank 8: university support to business

Grimaldi and von Tunzelmann [53] provided a comprehensive view of the benefits that a university could acquire by technology commercialization or university-industry collaborations as the following.

- Greater research output through university publications and patents

- Exploiting intellectual ideas

- Experience of industrial applications to feed into teaching

- Projects, funds and placements for students

- Funding for laboratory equipment

- Access to company equipment, industry know-how and technical advice

- Adoption of new standards

- Establishment of academic spin-off companies

- Entry to international R\&D programs

- Reputation in general 
Jackson [58] in his case study of the India University Advanced Research and Technology Institute provided four reasons for technology commercialization activities.

- Providing additional revenue to the university through licensing activities

- Enhancing university recognition and visibility in the business community

- Providing additional outlets and incentives to attract and retain talented faculty

- Affecting the employment landscape of the community through company and job creation via incubators, joint ventures and licensing activities

In summary, universities transfer their research in order to acquire financial resources, facilitate internal growth, improve teaching and research, and provide service to their community.

\subsubsection{Technology Transfer Mechanisms}

The outputs of the technology transfer mechanisms range from intangible to tangible outcomes. Patenting, licensing and start-ups are the most frequently discussed and important technology transfer methods in the literature, while a few studies emphasized the importance of other methods such as consulting, training, and exchange programs. This is consistent with the survey done by Siegel, et al. [111] about major outputs mostly recognized by the TLO. There are also informal ways to transfer knowledge to industry via meetings, telephone conversations, and conferences [2]. 
Siegel, et al. [114] also surveyed how different stakeholders defined the outcomes of technology transfer. The results are presented in Table 5.

Table 5: Outcomes of university technology transfer identified by stakeholders [114]

\begin{tabular}{|l|c|c|c|}
\hline \multicolumn{1}{|c|}{ Outcomes } & $\begin{array}{c}\text { TLO director } \\
\text { and } \\
\text { administrators* }\end{array}$ & $\begin{array}{c}\text { University } \\
\text { scientists* }\end{array}$ & $\begin{array}{c}\text { Managers and } \\
\text { entrepreneurs* }\end{array}$ \\
\hline Licenses & 86.7 & 25.0 & 75.0 \\
\hline Royalties & 66.7 & 15.0 & 30.0 \\
\hline Patents & 46.7 & 20.0 & 10.0 \\
\hline $\begin{array}{l}\text { Sponsored research } \\
\text { agreements }\end{array}$ & 46.7 & 0.0 & 5.0 \\
\hline Startup companies & 33.3 & 10.0 & 5.0 \\
\hline Invention disclosures & 33.3 & 5.0 & 0.5 \\
\hline Students & 26.7 & 15.0 & 25.0 \\
\hline $\begin{array}{l}\text { Informal transfer of know- } \\
\text { how }\end{array}$ & 20.0 & 20.0 & 70.0 \\
\hline Economic development & 20.0 & 0.0 & 35.0 \\
\hline Product development & 6.7 & 35.0 & 40.0 \\
\hline
\end{tabular}

Note: $*=$ The number is the percentage of respondents who identified each item as on output

Arvanitis, et al. [8] defined the technology transfer mechanisms as a wide range of knowledge and technology transfer including teaching, university research and research contracts with companies. They studied how those mechanisms contribute to innovation in Swiss industries. They found that reading of and referring to publications, attending conferences and workshops, and informal contacts are the most important knowledge and technology transfer activities. However, they didn't consider direct technology transfer modes such as licensing. 
Jensen and Thursby [59] surveyed how differently the technology commercialization office, university administration and faculty recognized the importance of each outcome. Their rankings are presented in Table 6 . This result indicated that both the commercialization offices and university administrators regard the licensing income as the important outcome. On the other hand, faculties preferred sponsored research to licensing revenue.

Table 6: Importance of technology transfer outcome [59]

\begin{tabular}{|l|c|c|c|}
\hline \multicolumn{1}{|c|}{ Outcomes } & $\begin{array}{c}\text { Rank by } \\
\text { commercialization } \\
\text { office* }\end{array}$ & $\begin{array}{c}\text { Rank by } \\
\text { university } \\
\text { administration* }\end{array}$ & Rank by faculty* \\
\hline Revenue & 1 & 1 & 2 \\
\hline Inventions commercialized & 2 & 3 & 3 \\
\hline Licenses executed & 3 & 3 & 5 \\
\hline Sponsored research & 4 & 2 & 1 \\
\hline Patents & 5 & 5 & 5 \\
\hline
\end{tabular}

Note: $*=$ Lower number means greater importance.

In the case of sponsored research, there is an inconsistency in the result of Siegel, et al. [114] and Jensen and Thursby [59]. The survey of the former study showed that faculties didn't consider sponsored research as an outcome of the university technology transfer, while the latter study found that faculties consider it to be the most important outcome. The reason for the difference in perception is due to the nature of the sponsored research as Thursby and Kemp [122] mentioned, "Sponsored research is, in part, an intermediate good as well as a final product." 


\subsubsection{Technology Commercialization Process from University to Industry}

Stakeholders of university technology commercialization are faculty inventors, the technology licensing office (TLO) in a university, and a firm/entrepreneur. Some studies identified their roles in the technology process. Licensing is identified as a major process in technology commercialization.

Siegel, et al. [113] described the licensing process (Figure 3). After a scientific discovery, the faculty or researcher files an invention disclosure with the help of the TLO only if the disclosure has enough value to be transferred. It should be a significant breakthrough, fill market needs, and be mature enough to be used by a company [23]. The TLO evaluates its potential for commercialization and decides patenting strategies, including global or domestic patents. The TLO is in a stronger negotiation position when it seeks to market and commercialize the intellectual property.

Finally, the TLO negotiates a licensing agreement and manages its financial benefits. However, as the authors pointed out, this linear process emphasizes the patent over the whole process. Some companies may prefer to obtain licensing before the technology is patented. 


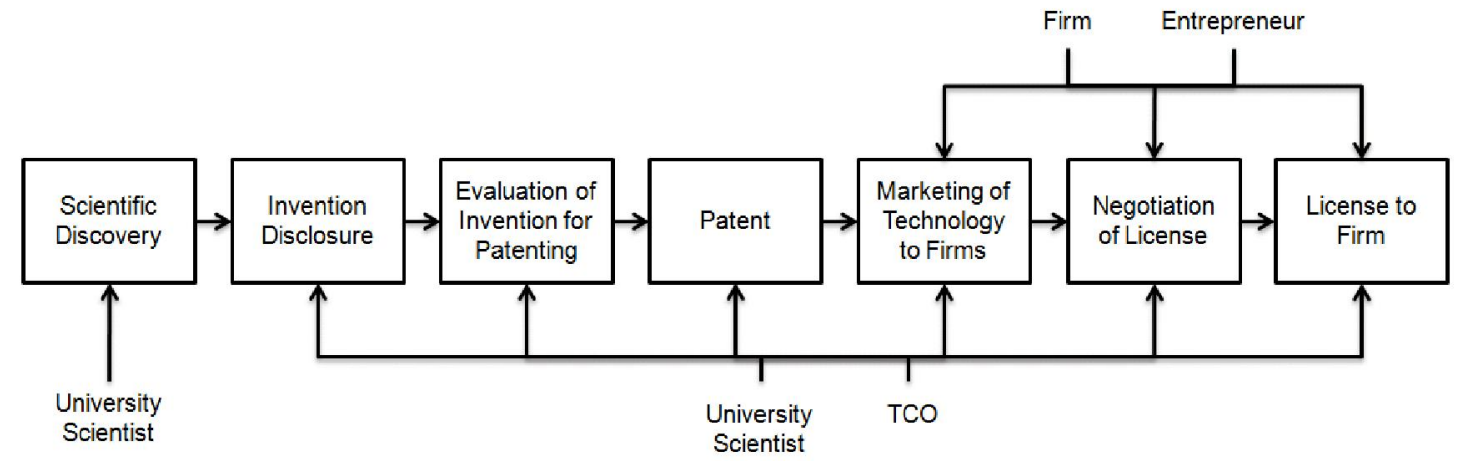

Figure 3 An example of technology commercialization from a university to a firm or entrepreneur (adopted from Siegel, et al. [113])

Rogers, et al. [102] included start-up companies in the technology process. Universities have two options of licensing or forming a venture company once a patent of the discovery is issued (Figure 4).

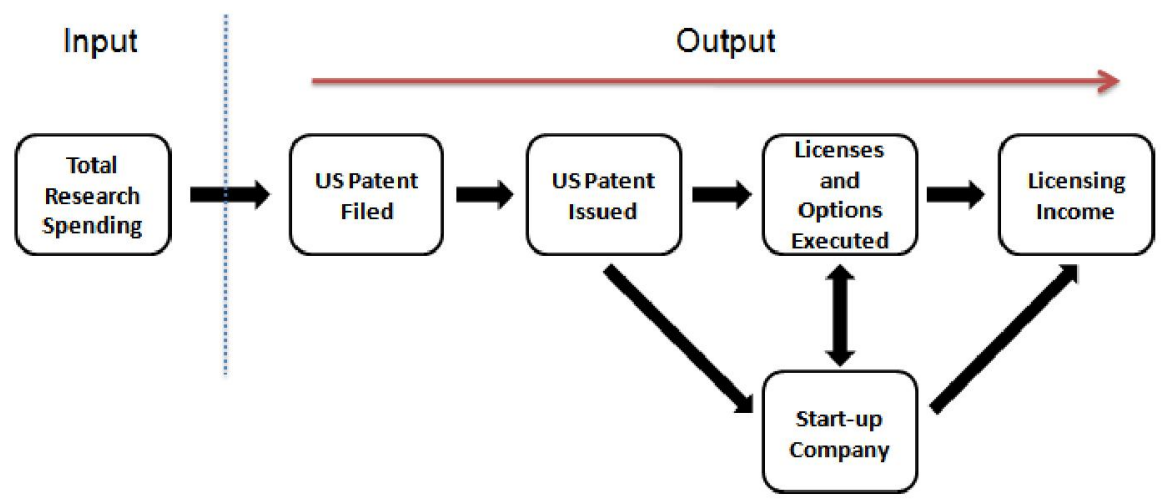

Figure 4: Technology commercialization process (adopted from Rogers, et al. [102])

Jensen, et al. [60] provided an interesting licensing process with the view of a game of three stakeholders: faculty inventor, central administration, and TLO. They defined the TLO as a dual agent serving both the central administration of its university and faculty inventor. According to their model, the central administration decides the contract form 
of commercialization, and the TLO looks for a path to commercialization according to the faculty inventor's decision (Figure 5). They discovered how these three decision makers are working through the different stages of the research result.

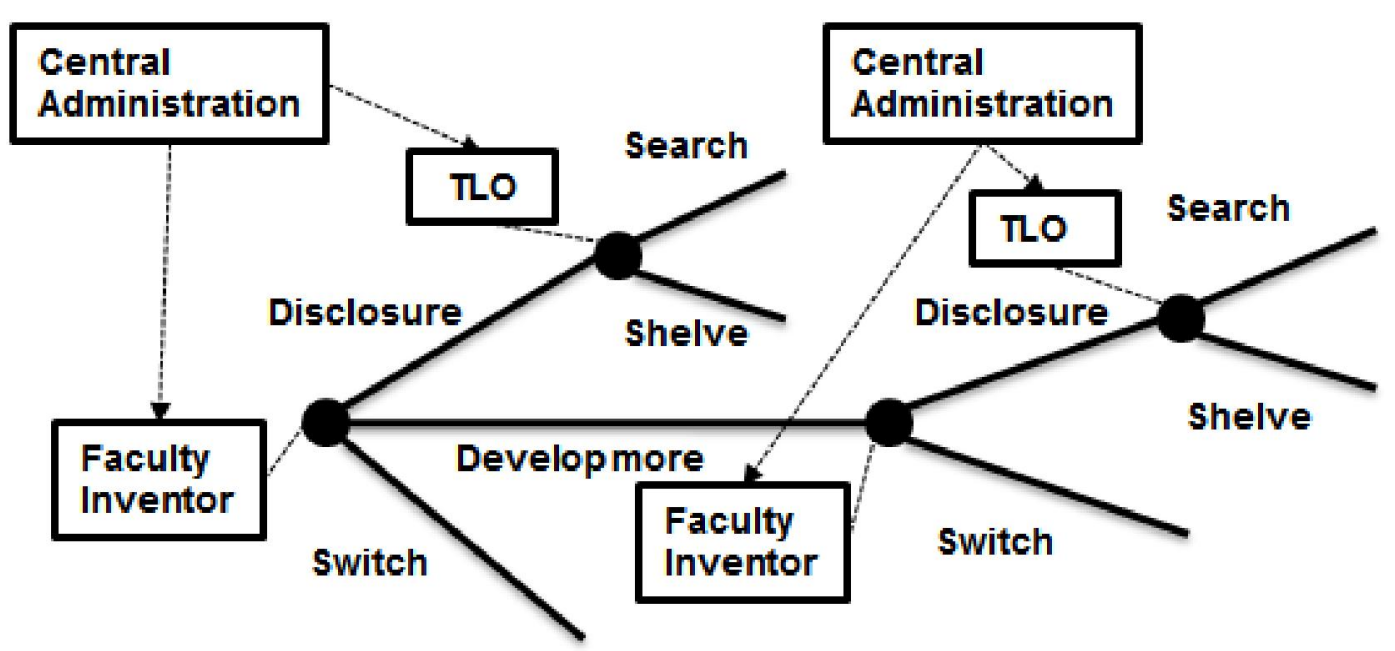

Proof of concept stage Lab-scale prototype stage

Figure 5: Disclosure and licensing process (adopted from Jensen, et al. [60])

\subsubsection{Time-Lag in the Technology Commercialization Process}

The Association of University Technology Managers (AUTM) reported that the Canadian Licensing Survey highlighted time-lags between research expenditure and two outputs of invention disclosures and patent applications using a graphical presentation [10]. They found that the research funding in 2000 is related to the invention disclosure in 2002 and patent in 2004.

Heher [55] suggested typical time-lags among disclosure, license, patent, license income and start-up in Figure 6. 


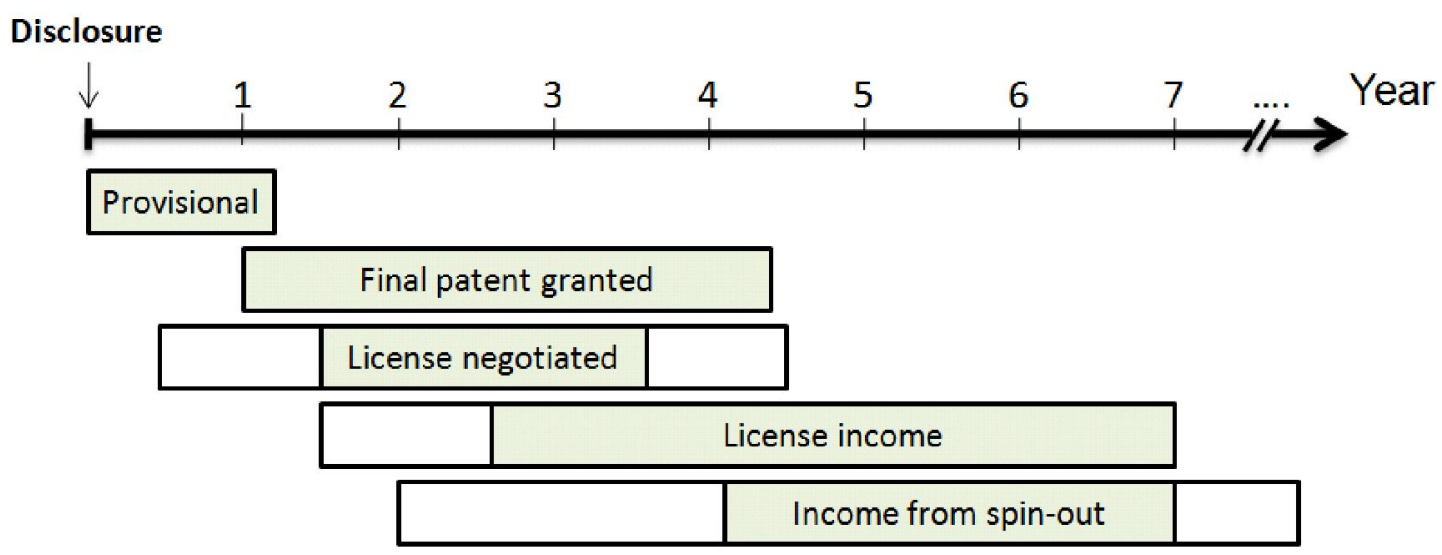

Figure 6: Typical phasing of the value chain [55]

Thursby and Thursby [123] pointed out that more than $20 \%$ of disclosures at Stanford and the University of California System had been patented six years after disclosure. According to their findings, the most difficult part of measuring the time-lag is in licensing revenue. The top five inventions account for $76 \%$ of the license revenue of those universities. But the corresponding inventions were disclosed at least 10 years earlier. So, they excluded the licensing income from their model due to this issue. They found that total factor productivity (TFP) of license executed declined $1.7 \%$ per year. They explained the reason of negative growth could be lack of consideration of time-lags between disclosure and patent application and license agreements.

Thursby and Kemp [122] in their study evaluating licensing performance of U.S. universities by DEA used 6-year average of the AUTM data and suggested that their result needs caution for interpretation because time-lags were not considered. 


\subsubsection{Summary}

A. Conflicted perceptions on the roles and values of the licensing of academic research institutions

There are a few studies discussing the relationships among teaching, research, and technology commercialization of universities. These studies show that there are some disagreements regarding the relationships among the three activities. Technology commercialization activity may have both positive and negative impacts on teaching and research [99]. These complicated relationships and perceptions about the three major activities show that there is not a simple relationship among them. High research performance, for example, doesn't necessarily mean good teaching and better technology commercialization. Some studies argue that one activity could even impede the other. This makes universities focus differently on teaching, research, and technology commercialization. Therefore, university technology commercialization should be incorporated in the university's policies along with its missions and goals.

\section{B. Transfer Mechanism}

All technology transfer mechanisms mentioned by the literature are summarized in Table 7. 
Table 7: Technology transfer mechanisms discussed in the literature

\begin{tabular}{|l|c|c|c|c|c|c|}
\hline \multirow{2}{*}{\multicolumn{1}{|c|}{ Research }} & \multicolumn{5}{c|}{ Technology Transfer Mechanism } \\
\cline { 2 - 7 } & Patent & License & $\begin{array}{c}\text { Start-up / } \\
\text { Spin-off }\end{array}$ & Consulting & Training & $\begin{array}{c}\text { Exchange } \\
\text { Program }\end{array}$ \\
\hline McAdam, et al. [80] & & $\mathrm{X}$ & $\mathrm{X}$ & & & \\
\hline Ndonzuau, et al. [86] & & & $\mathrm{X}$ & & & \\
\hline Lee and Win [67] & & $\mathrm{X}$ & $\mathrm{X}$ & $\mathrm{X}$ & $\mathrm{X}$ & $\mathrm{X}$ \\
\hline Perez and Sanchez [94] & & & $\mathrm{X}$ & & & \\
\hline Lowe [71] & & $\mathrm{X}$ & $\mathrm{X}$ & & & \\
\hline Mazzoleni [79] & $\mathrm{X}$ & $\mathrm{X}$ & & & & \\
\hline Libaers [69] & & & $\mathrm{X}$ & & & \\
\hline Meyer [84] & & & $\mathrm{X}$ & & & \\
\hline Siegel, et al. [28, 109-114] & $\mathrm{X}$ & $\mathrm{X}$ & $\mathrm{X}$ & & & \\
\hline Chapple, et al. [28] & & $\mathrm{X}$ & & & & \\
\hline Anderson, et al. [6] & $\mathrm{X}$ & $\mathrm{X}$ & $\mathrm{X}$ & & & \\
\hline Thursby and Kemp [122] & $\mathrm{X}$ & $\mathrm{X}$ & & & & \\
\hline Markman, et al. [76, 77] & $\mathrm{X}$ & $\mathrm{X}$ & $\mathrm{X}$ & & & \\
\hline Powers [96] & $\mathrm{X}$ & $\mathrm{X}$ & & & & \\
\hline Mazzoleni [79] & $\mathrm{X}$ & $\mathrm{X}$ & & & & \\
\hline Bray and Lee [23] & & $\mathrm{X}$ & $\mathrm{X}$ & & & \\
\hline
\end{tabular}

\section{Time-lags in licensing}

A time lag between university research and the commercialization of the resulting discovery is inevitable and is very important in assessing the performance of technology commercialization. Without considering the time lag, research on technology commercialization could lead to a misunderstanding of the university's performance of the technology commercialization and influencing characteristics. However, there is not a quantitative study measuring the time-lags in licensing. 


\subsection{Assessment of the Performance of University Technology Commercialization}

\subsubsection{Service Productivity Analysis}

Sherman and Zhu [108] surveyed 13 well-known techniques to measure and manage service productivity of the organization based on a literature review in the field of accounting, management control, and operations management. The benefits and limitations of those techniques in evaluating productivity of service are summarized in Table 8 . 
Table 8: Techniques for evaluating productivity of service organizations [108]

\begin{tabular}{|c|c|c|c|c|}
\hline Technique & Strength & Limitation & $\begin{array}{l}\text { Standard } \\
\text { required }\end{array}$ & $\begin{array}{l}\text { Multiple } \\
\text { aspects }\end{array}$ \\
\hline $\begin{array}{l}\text { Standard Cost } \\
\text { Systems }\end{array}$ & $\begin{array}{l}\text { Resolve most productivity } \\
\text { issues with a good standard } \\
\text { cost system. }\end{array}$ & $\begin{array}{l}\text { Focused on manufacturing } \\
\text { rather than the service } \\
\text { environment. Cost itself is } \\
\text { not sufficient for } \\
\text { productivity. }\end{array}$ & Yes & No \\
\hline $\begin{array}{l}\text { Comparative } \\
\text { Efficiency } \\
\text { Analysis } \\
\end{array}$ & $\begin{array}{l}\text { Good when there is no } \\
\text { efficiency standard. }\end{array}$ & $\begin{array}{l}\text { Benchmark based on } \\
\text { judgment, opinion, and past } \\
\text { history. }\end{array}$ & No & Yes \\
\hline Ratio Analysis & $\begin{array}{l}\text { Adopt productive concept of } \\
\text { input and output. }\end{array}$ & $\begin{array}{l}\text { Measures only a certain } \\
\text { aspect of an operation. }\end{array}$ & No & No \\
\hline $\begin{array}{l}\text { Profit and } \\
\text { Return on } \\
\text { Investment } \\
\text { Measures }\end{array}$ & $\begin{array}{l}\text { Good to analyze business } \\
\text { performance. }\end{array}$ & $\begin{array}{l}\text { Measures only capitalized } \\
\text { asset. Cannot evaluate poor } \\
\text { or outstanding productivity. }\end{array}$ & Yes & No \\
\hline $\begin{array}{l}\text { Zero-base } \\
\text { Budgeting }\end{array}$ & $\begin{array}{l}\text { Good when there are no } \\
\text { comprehensive measures of } \\
\text { profitability and no } \\
\text { objective market prices. }\end{array}$ & $\begin{array}{l}\text { Could result in unexpected } \\
\text { dysfunctional results such as } \\
\text { bad service by focusing on } \\
\text { budget. }\end{array}$ & No & No \\
\hline $\begin{array}{l}\text { Program } \\
\text { Budgeting }\end{array}$ & $\begin{array}{l}\text { Consider benefits of } \\
\text { program with budget and } \\
\text { provide a way to enhance } \\
\text { productivity. }\end{array}$ & $\begin{array}{l}\text { Focus is only on budget as a } \\
\text { way to improve productivity. }\end{array}$ & No & No \\
\hline $\begin{array}{l}\text { Best Practice } \\
\text { Analysis or } \\
\text { Reviews }\end{array}$ & $\begin{array}{l}\text { Contribute to build service } \\
\text { standard with various } \\
\text { perspectives. }\end{array}$ & $\begin{array}{l}\text { Should compare similar } \\
\text { units. }\end{array}$ & No & Yes \\
\hline $\begin{array}{l}\text { Data } \\
\text { Envelopment } \\
\text { Analysis }\end{array}$ & $\begin{array}{l}\text { Highly objective and focus } \\
\text { is on technical and scale } \\
\text { efficiency. }\end{array}$ & Excludes qualitative value. & No & Yes \\
\hline Peer Review & $\begin{array}{l}\text { Benefit from the knowledge } \\
\text { of outside professionals. }\end{array}$ & $\begin{array}{l}\text { Subjective and depends on } \\
\text { expert knowledge. }\end{array}$ & No & Yes \\
\hline $\begin{array}{l}\text { Management } \\
\text { Review and } \\
\text { Audit }\end{array}$ & $\begin{array}{l}\text { More comprehensive than } \\
\text { peer review. }\end{array}$ & $\begin{array}{l}\text { Subjective and depends on } \\
\text { expert knowledge. }\end{array}$ & No & Yes \\
\hline $\begin{array}{l}\text { Activity } \\
\text { Analysis }\end{array}$ & $\begin{array}{l}\text { Define changes in job } \\
\text { structure to make all units as } \\
\text { efficient. }\end{array}$ & Focus on employee time. & No & No \\
\hline $\begin{array}{l}\text { Process } \\
\text { Analysis }\end{array}$ & Review details of process. & $\begin{array}{l}\text { Not applicable to } \\
\text { organization whose activity } \\
\text { could not be clearly defined } \\
\text { as a process. }\end{array}$ & No & No \\
\hline Staffing Models & $\begin{array}{l}\text { Quickly assess the need for } \\
\text { resources based on a } \\
\text { projected level of activity }\end{array}$ & $\begin{array}{l}\text { Focus is only on human } \\
\text { resources. }\end{array}$ & Yes & No \\
\hline
\end{tabular}


Generally, service organizations such as banks, hospitals and schools don't have clear standard measurements to evaluate the performance of their operations [34]. Also, multiple perspectives should be considered for the evaluation. A good technique for evaluating productivity of service organizations should meet these criteria. Two review methods, peer review and management review and audit, also fit into this requirement, but they are not available if there are not proper experts. Table 8 shows that benchmarking techniques such as comparative efficiency analysis, best practice analysis or reviews, and DEA satisfy these requirements. Benchmarking is an appropriate and widely used approach to measure the productivity of those organizations.

DEA, developed by Charnes, et al. [29], is a quantitative benchmarking technique applied in various areas. This technique is an excellent tool to measure and improve productivity of service business [108]. Therefore, DEA is used to measure efficiency of university activities.

\subsubsection{Current Approach to the Evaluation of the Performance of University Technology Commercialization}

The literature assessing university technology commercialization can be categorized into five groups according their approaches:

- Ranking the outputs of technology transfer [19],

- Economic contribution and performance [23, 55],

- Efficiency study using stochastic frontier estimation (SFE) [111], 
- Efficiency study using data envelopment analysis (DEA) [6, 122, 123], and

- Multi-stage model using both SFE and DEA [28].

One simple approach to assess the performance of university technology commercialization is to compare the major outputs such as number of patents, licensing income and number of start-ups of each university. Blumenstyk [19] discussed performance by rank of licensing income of U.S. universities based on the data published in the AUTM.

Heher [55] evaluated the economic contribution to a university by using a combination of a university return on investment (ROI) model and a simple economic projection. The result shows that a positive range of return from an investment in research and technology commercialization can be gained in 10 years at the institutional level and 20 years at the national level.

The stochastic frontier efficiency (SFE) is a method developed by Aigner, et al. [4] and Meeusen and Van Den Broeck [83]. The method estimates an efficiency frontier by using the production function and estimates the production function parameters by using regression. The representative study using SFE was done by Sigel, et al. [111]. They evaluated technology commercialization efficiencies of 89 U.S. universities using AUTM 
data from 1991 to 1996 . They used licensing income for the dependent variable and three inputs such as invention disclosures, number of TLO staff, and legal fee for patenting.

While SFE provides some benefits by allowing hypothesis testing and construction of confidence levels, DEA is used by other researchers $[6,122,123]$. The strength of the DEA analysis is that multiple inputs and outputs can be used in the DEA model, and DEA isn't restricted by assumptions such as independence among independent variables [28]. Anderson, et al. [6] evaluated 54 high income universities in 2004. They used research expenditure for the input variable, and licensing income, number of licenses and options executed, number of start-ups, U.S. patents filed and U.S. patents issued for output variables. They also used the weighted value for patents issued over patents filed considering the relative importance of issued patents to filed patents. The result suggested that the total licensing income of 54 universities could be increased by $\$ 659$ million considering efficient universities. Thursby and Kemp [122] used Malmquist indices, a DEA method, in order to trace efficiency change of university technology transfer from 1991 to 1996. Thursby and Thursby [123] applied the three-stage process of the technology commercialization to the DEA model. The three corresponding DEA models for the stages were used to assess which input variables contributed to the growth of the outputs in each stage.

Finally, some studies adopted the benefits of the SFE and DEA approaches [28]. They developed several stages, each applying SFE and DEA. For example, Glass, et al. [50] 
evaluated the relative performance of technology commercialization of UK universities using both SFE and DEA. They developed a two-stage model. In stage one, they used DEA for initial evaluation of efficiency, and in stage two they decomposed efficiency from the first stage into environmental effects, managerial inefficiencies, and statistical noise.

2.3.3. Measuring the effectiveness of university technology commercialization Each university's technology commercialization effectiveness is based on the performance evaluation of technology commercialization activity. Studies related to the effectiveness can be categorized into two groups. One is to analyze the financial benefit from several commercialization mechanisms and contribution to the organization. The second group is to understand and find characteristics related to the technology commercialization performance.

Bozeman [21] suggested a contingent effective technology transfer model to organize the literature of technology transfer. He defined the impacts of technology transfer in terms of who is doing the transfer, how they are doing it, what is being transferred, and to whom. The five effectiveness criteria are out-the-door, market impact, economic development, political reward, and scientific and technical human capital.

Bray and Lee [23] suggested that taking equity in a university's start-up firm can give much higher financial return and reduce the time to get revenue compared to licensing. 
Equity is a proper technology commercialization mechanism when the technology is not adequate for licensing. Also, TLO managers prefer equity since it provides them flexibility in making deals. According to their observations, the total equity value from 16 university spin-offs was $\$ 1.4$ million, while the average annual value of equity was $\$ 63.000$ in 1996.

Trune and Goslin [127] took a more quantitative approach to measure the effectiveness of ARITC by performing a profit and loss analysis. They evaluated 140 universities which received enough revenue from royalty payments to cover costs such as technology commercialization office cost, patent fees, legal expenses, and new research grants. They found that only $48.8 \%$ of these universities operated at a profit. The authors also pointed out that many universities do not operate technology transfer programs with a profit motive, but rather consider them as a necessary administrative function required to support faculty working on a research project with commercial potential.

Another study evaluating the effectiveness of technology commercialization from the perspective of finance was done by Heher [55]. The author developed a forecasting model to estimate economic returns from the commercialization of university research using a combination of an institutional return on investment and an economic projection. He found that a portfolio of patents and licenses are needed to allow a university to receive reasonable probability of positive returns since the performance of a commercialized institution is highly variable and unpredictable. 
Siegel, et al. [114] performed the most comprehensive survey on influencing characteristics in effective commercialization of university discoveries. One of their survey results suggests ways to improve the technology commercialization process as follows:

- Universities and firms should devote more effort to developing a better mutual understanding.

- Universities should align reward systems with UITT goals.

- Universities should devote additional resources to UITT.

- Universities should provide more education and community outreach to overcome informational and cultural barriers.

- Universities should be less aggressive in exercising intellectual property rights.

Markman, et al. [77] suggested a theory of the relationship between technology stage, licensing strategy, and transfer partner. They found that the most dominant licensing strategy was cash by $72 \%$ of investigated universities. Equity and licensing exchange for sponsored research was $17 \%$ and $11 \%$ respectively. The structures included traditional university structure, for-profit private venture extension, and nonprofit research foundation. Their suggested theory built by ground study is presented in Figure 7. They aligned licensing strategy according to the technology stage and type of licensees. For 
example, if a university's discovery is at an early stage of development and has a low degree of technology resolution, a large firm is a good licensee. Sponsored research is proper for the licensing strategy.

A newly disclosed invention has a wide range of technological maturity from its early state to the prototype, which is ready for commercialization. The different degree of maturity affects the licensing strategies of a university. According to the study by Markman, et al. [77], an invention in its early state of maturity is licensed for exchange of sponsored research, while equity is the preferred license strategy for proof of concept. Universities select the royalty as a licensing strategy for a technology in its prototype state.

They also found that licensing strategies can be affected by a university's mission and budget. 


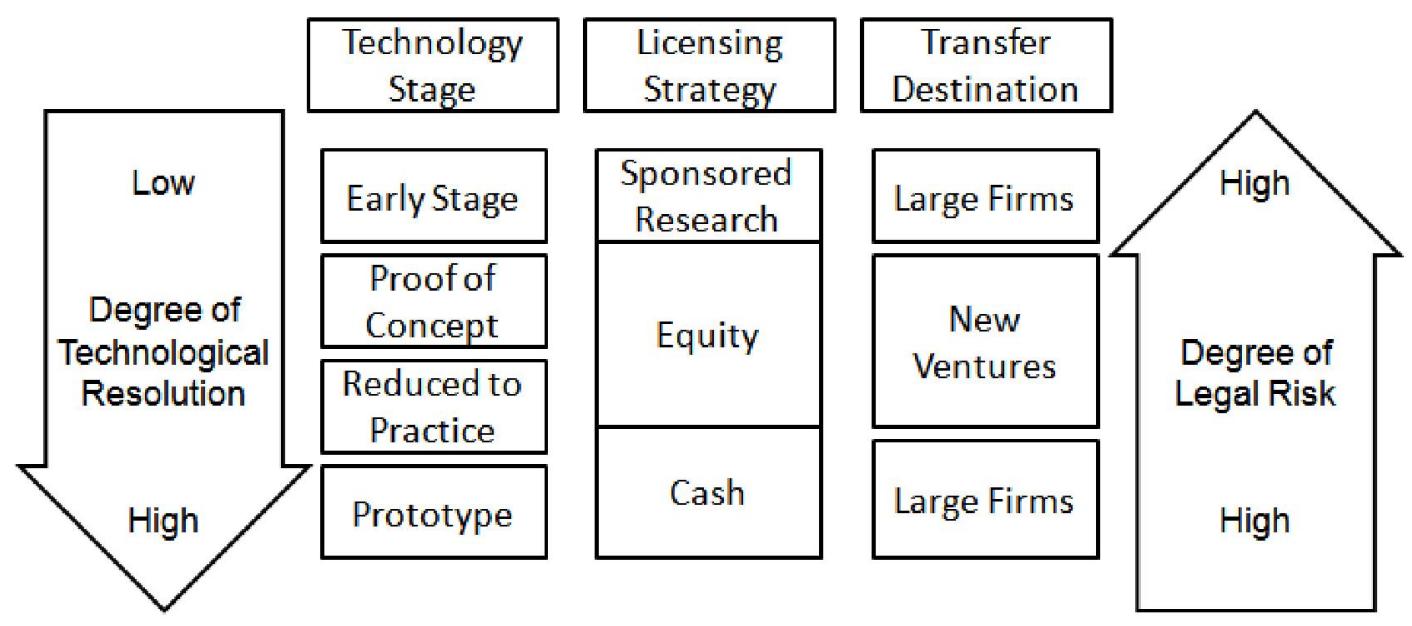

Figure 7: Association between technology stage, commercialization strategy, and the choice of licenses [77]

However, those studies intend to improve the technology process or increase output, but they do not align or assess how the technology commercialization activity of a university fulfills its missions and goals.

\subsubsection{Measuring efficiency of university technology commercialization}

The major difference between the two groups of studies, measuring the efficiency of university technology transfer and the technology licensing office (TLO), is how the variable of disclosure is used in the model. The study by Thursby and Kemp [122] used disclosure as an output variable to assess the efficiency of university technology commercialization, while two other studies, Siegel, et al. [111] and Chapple, et al. [28], defined it as an input variable for measuring the efficiency of the TLO. The reason can be found in the process of disclosing an invention and the role of the TLO. A 
commercialization office can play a role, to some extent, in disclosing an invention, but university faculties have the authority to decide whether an invention will be disclosed or not [60]. Once a scientific discovery is disclosed for the purpose of technology commercialization, the technology licensing office takes over. The TLO's responsibilities are to a) evaluate and valuate the disclosure; b) protect the technologies by patenting; c) sell licensing agreements to industry; and d) collect royalties and enforce contractual agreements with licensees [77]. Therefore, disclosure is an input variable when the objective of the model is to measure efficiency of the commercialization office [111]. On the other hand, disclosure should be considered as an output variable in the model for measuring the efficiency of commercialization activity in a university.

Thursby and Thursby [123] suggested an intermediate input model with a three-stage process for ARITC in their study on whether the productivity of inputs or change in attitude of faculties and administrators toward the technology commercialization drove the increase of licenses. They defined a disclosure as an output at the first stage and used it as an intermediate input at the second stage. The patent application was defined as an output at the second stage and the intermediating input at the third stage. However, they didn't include the licensing income because of the complexity in the time-lag between the licensing income and other input variables.

Variables regarding commercialization offices such as age and size could be considered as input variables for the model measuring the efficiency of a TLO. Both age and size of 
the office are resources representing the experience of the office and effort of the university. Without considering other circumstances, increased age and size would be related to more output of commercialization activity. However, these effects and relationships should be considered as influencing characteristics but not input or output variables if the objective is to measure the UTCE.

\subsubsection{Efficiency Scores of Technology Commercialization of U.S. Universities}

There are three studies $[6,113,122]$ measuring efficiency of technology commercialization of U.S. universities. Two of them $[6,122]$ used DEA to measure the efficiency score of an individual university, while Siegel, et al. [113] applied SFE to study characteristics influencing performance. Therefore, the study with SFE didn't provide individual efficiency scores of observed universities. The efficient U.S. universities identified in two studies are listed in Table 9. However, the table requires a caution: different DEA methods, different years investigated, and absence of high performing universities in either of the two studies result in a significantly different list of efficient universities. 
Table 9: List of efficient U.S. universities identified by different studies

\begin{tabular}{|c|c|c|c|c|c|}
\hline University & $\begin{array}{l}\text { Thursby and } \\
\text { Kemp [122] }\end{array}$ & $\begin{array}{l}\text { Anderson, } \\
\text { et al. }[6]\end{array}$ & University & $\begin{array}{l}\text { Thursby and } \\
\text { Kemp [122] }\end{array}$ & $\begin{array}{l}\text { Anderson, } \\
\text { et al. }[6]\end{array}$ \\
\hline Univ. of Akron & efficient & N/A & Univ. of Kentucky & efficient & $\mathrm{N} / \mathrm{A}$ \\
\hline $\begin{array}{l}\text { Univ. of Alabama } \\
\text { Sys.: Birmingham }\end{array}$ & efficient & N/A & Univ. of Maine Sys. & efficient & N/A \\
\hline Ball State Univ. & efficient & N/A & $\begin{array}{l}\text { Univ. of Maryland Sys.: } \\
\text { Baltimore }\end{array}$ & efficient & N/A \\
\hline Boston Univ. & efficient & N/A & Univ. of Miami & efficient & N/A \\
\hline $\begin{array}{l}\text { Brigham Young } \\
\text { Univ. }\end{array}$ & efficient & efficient & Michigan State Univ. & efficient & inefficient \\
\hline $\begin{array}{l}\text { Univ. of California } \\
\text { Sys. }\end{array}$ & N/A & efficient & $\begin{array}{l}\text { Massachusetts Ins. of } \\
\text { Tech. }\end{array}$ & efficient & efficient \\
\hline $\begin{array}{l}\text { California Inst. of } \\
\text { Tech. }\end{array}$ & efficient & efficient & New Hampshire Univ. & efficient & N/A \\
\hline $\begin{array}{l}\text { Carnegie Mellon } \\
\text { Univ. }\end{array}$ & efficient & inefficient & Univ. of New Orleans & efficient & N/A \\
\hline $\begin{array}{l}\text { Univ. of Central } \\
\text { Florida }\end{array}$ & efficient & N/A & NJ Inst. of Tech. & efficient & N/A \\
\hline Univ. of Chicago & efficient & N/A & $\begin{array}{l}\text { North Carolina State } \\
\text { Univ. }\end{array}$ & efficient & inefficient \\
\hline $\begin{array}{l}\text { Colorado State } \\
\text { Univ. }\end{array}$ & efficient & N/A & $\begin{array}{l}\text { North Dakota State } \\
\text { Univ. }\end{array}$ & efficient & N/A \\
\hline Columbia Univ. & efficient & $\mathrm{N} / \mathrm{A}$ & Northeastern Univ. & efficient & N/A \\
\hline Cornell Univ. & efficient & inefficient & Northern Illinois Univ. & efficient & $\mathrm{N} / \mathrm{A}$ \\
\hline Univ. of Dayton & efficient & $\mathrm{N} / \mathrm{A}$ & New York Univ. & $\mathrm{N} / \mathrm{A}$ & efficient \\
\hline Univ. of Denver & efficient & $\mathrm{N} / \mathrm{A}$ & Ohio Univ. & efficient & inefficient \\
\hline Duke Univ. & efficient & inefficient & Univ. of Oregon & efficient & $\mathrm{N} / \mathrm{A}$ \\
\hline Emory Univ. & efficient & $\mathrm{N} / \mathrm{A}$ & Penn State Univ. & efficient & N/A \\
\hline $\begin{array}{l}\text { Florida Atlantic } \\
\text { Univ. }\end{array}$ & efficient & $\mathrm{N} / \mathrm{A}$ & Princeton Univ. & efficient & N/A \\
\hline Florida State Univ. & efficient & inefficient & Univ. of South Alabama & efficient & N/A \\
\hline Georgetown Univ. & efficient & $\mathrm{N} / \mathrm{A}$ & Univ. of South Florida & efficient & N/A \\
\hline Univ. of Georgia & efficient & inefficient & Stanford Univ. & efficient & inefficient \\
\hline $\begin{array}{l}\text { Georgia Inst. of } \\
\text { Tech. }\end{array}$ & efficient & efficient & Temple Univ. & efficient & N/A \\
\hline Harvard Univ. & efficient & inefficient & Tulane Univ. & efficient & inefficient \\
\hline $\begin{array}{l}\text { Univ. of Illinois } \\
\text { Sys.: Urbana- } \\
\text { Champaign }\end{array}$ & efficient & N/A & Tulsa Univ. & efficient & N/A \\
\hline $\begin{array}{l}\text { Illinois Inst. of } \\
\text { Tech. }\end{array}$ & efficient & N/A & Utah Univ. & efficient & N/A \\
\hline Illinois State Univ. & efficient & N/A & Wake Forest Univ. & efficient & inefficient \\
\hline Indiana Univ. Sys. & efficient & N/A & $\begin{array}{l}\text { Washington Univ. in St. } \\
\text { Louis }\end{array}$ & efficient & inefficient \\
\hline Iowa State Univ. & efficient & $\mathrm{N} / \mathrm{A}$ & \multirow{2}{*}{$\begin{array}{l}\text { Univ. of Wisconsin Sys: } \\
\text { Madison }\end{array}$} & \multirow[b]{2}{*}{ inefficient } & \multirow[b]{2}{*}{ efficient } \\
\hline $\begin{array}{l}\text { Johns Hopkins } \\
\text { Univ. }\end{array}$ & efficient & inefficient & & & \\
\hline
\end{tabular}


Both of the studies used the variable returns-to-scale (VRS) method. Thursby and Kemp [122] identified 54 efficient universities out of 112 , which was $67 \%$, while the Anderson, et al. [6] study found 7 efficient universities out of 54, which was 13\%. Four universities, Brigham Young University, California Institute of Technology, Georgia Institute of Technology, and Massachusetts Institute of Technology, were identified as efficient by both studies.

Thursby and Kemp [122] also examined changes of the efficiencies from 1991 to 1996 using the Malmquist Index. Fifty seven out of 112 universities were analyzed, excluding 55 universities which didn't respond to the survey during some years. The efficiencies of the 57 universities had increased during the period.

\subsubsection{Summary}

A. Current approaches measuring licensing performances

University technology commercialization has been an emerging research area since the mid 1980's, when the Bayh-Dole Act began facilitating interaction between university and industry. Many public and private universities instituted technology licensing offices (TLOs) in their organizations and achieved quantitative growth in commercialization through licensing and founding new firms.

A handful of studies have been conducted figure out how to evaluate this performance and understand the nature of technology commercialization in universities. Majority of 
these studies focused on benchmarking commercialization performance of universities with major outputs such as licensing income, start-ups, and patents using stochastic frontier efficiency (SFE) or data envelopment analysis (DEA). Some of them examined organizational and external characteristics directly or indirectly influencing the performance of technology commercialization. However, relatively fewer studies have been done on how these recently increasing commercialization activities are related to the missions or policies of universities.

\section{B. Licensing performance}

Most studies on performance assessment of ARITC and TLO evaluate their relative performance. Their detailed research methods and findings are summarized in Table 10. The study by Thursby and Kemp [122] used DEA model of eight input and five output variables. Their model defined 54 efficient universities out of 112 , which is about $50 \%$. The number of efficient universities is due to much higher variables (model dimension). Therefore, caution is needed when input and output variables are designed for a DEA model. 
Table 10: Measuring efficiency of university technology commercialization and the commercialization office

\begin{tabular}{|c|c|c|c|c|c|}
\hline Research & University & Method & Input & Output & Finding \\
\hline $\begin{array}{l}\text { Thursby } \\
\text { and Kemp } \\
{[122]^{*}}\end{array}$ & $\begin{array}{l}112 \text { U.S. } \\
\text { universities }\end{array}$ & DEA & $\begin{array}{l}\text { TLO size } \\
\text { Federal support } \\
\text { Bio. faculty } \\
\text { Eng. faculty } \\
\text { Phys. faculty } \\
\text { Bio quality } \\
\text { Eng. quality } \\
\text { Phys. quality }\end{array}$ & $\begin{array}{c}\text { Industry } \\
\text { support } \\
\text { Royalties } \\
\text { Disclosures } \\
\text { New patent } \\
\text { app. } \\
\text { Licenses }\end{array}$ & $\begin{array}{l}\text { Expansion of frontier is } 7.5 \% \\
\text { while catch-up of inefficient } \\
\text { universities is only } 0.4 \% \text {. } \\
\text { Suggesting the expansion of } \\
\text { the frontier stems from a } \\
\text { change in the } \\
\text { commercialization } \\
\text { environment involving a } \\
\text { reallocation of inputs, a change } \\
\text { in market demand TLOs. }\end{array}$ \\
\hline $\begin{array}{l}\text { Anderson, } \\
\text { et al. }[6]^{*}\end{array}$ & $\begin{array}{l}57 \text { U.S. } \\
\text { universities }\end{array}$ & DEA & $\begin{array}{l}\text { Research } \\
\text { expenditure }\end{array}$ & $\begin{array}{l}\text { License } \\
\text { income } \\
\text { Licenses } \\
\text { executed } \\
\text { Start-up } \\
\text { U.S. Patents } \\
\quad \text { filed } \\
\text { U.S. Patent } \\
\quad \text { issued }\end{array}$ & $\begin{array}{l}\text { DEA can effectively be used as } \\
\text { a productivity evaluation tool } \\
\text { to assess ARITC efficiency. } \\
\text { Private universities are more } \\
\text { efficient than their public } \\
\text { counterparts in terms of } \\
\text { technology commercialization. }\end{array}$ \\
\hline $\begin{array}{c}\text { Thursby } \\
\text { and } \\
\text { Thursby } \\
{[123]}\end{array}$ & $\begin{array}{c}64 \text { U.S. } \\
\text { universities }\end{array}$ & $\begin{array}{c}\text { DEA } \\
(3 \text { stages })\end{array}$ & $\begin{array}{c}\text { Stage 1: } \\
\text { Federal and } \\
\text { industry support } \\
\text { TLO personnel } \\
\text { Stage 2: } \\
\text { Disclosures } \\
\text { Faculty quality } \\
\text { Stage 3: } \\
\text { Disclosures } \\
\text { Patent } \\
\text { applications } \\
\end{array}$ & $\begin{array}{c}\text { Stage 1: } \\
\text { Disclosures } \\
\\
\text { Stage 2: } \\
\text { Patent } \\
\text { applications } \\
\\
\text { Stage 3: } \\
\text { License and } \\
\text { option } \\
\text { agreements } \\
\end{array}$ & $\begin{array}{l}\text { The increased positive attitude } \\
\text { of faculty and administrators to } \\
\text { the technology } \\
\text { commercialization increased } \\
\text { the number of licenses. }\end{array}$ \\
\hline $\begin{array}{l}\text { Siegel, et } \\
\text { al. [111]** }\end{array}$ & $\begin{array}{c}80 \text { U.S. } \\
\text { universities }\end{array}$ & SFE & $\begin{array}{l}\text { Disclosures } \\
\text { TLO Size } \\
\text { Legal Fees }\end{array}$ & $\begin{array}{l}\text { License } \\
\text { agreements } \\
\text { Licensing } \\
\text { income }\end{array}$ & $\begin{array}{l}\text { Larger TLO staff is related to } \\
\text { more licensing agreements but } \\
\text { less licensing revenue. }\end{array}$ \\
\hline $\begin{array}{l}\text { Chapple, et } \\
\text { al. }[28]^{* *}\end{array}$ & $\begin{array}{c}98 \mathrm{UK} \\
\text { universities }\end{array}$ & $\begin{array}{l}\text { DEA } \\
\text { SFE }\end{array}$ & $\begin{array}{l}\text { Research } \\
\text { income } \\
\text { Disclosures } \\
\text { TLO Size } \\
\text { Legal Fees }\end{array}$ & $\begin{array}{l}\text { Licensing } \\
\text { income } \\
\text { License } \\
\text { agreements }\end{array}$ & $\begin{array}{l}\text { TLOs exhibit low levels of } \\
\text { absolute efficiency and they } \\
\text { need to be reconfigured into } \\
\text { smaller units. TLOs need to } \\
\text { upgrade the business skills and } \\
\text { capabilities of U.K. TLO } \\
\text { managers and licensing office. }\end{array}$ \\
\hline
\end{tabular}

Note: $*=$ Studies assessing relative performance of the ARITC; $* *=$ Studies assessing the relative performance of the TLO 


\subsection{Characteristics Influencing to Licensing Performance}

\subsubsection{University Characteristics and Technology Commercialization}

A study [95] investigating the effect of university characteristics on faculties' interaction with industry indicated that a certain level of university characteristics affect the behavior of the faculties. For example, more industry R\&D funds increased faculties' interaction with industry, and also recruited more master's students by grants. More funds also decreased the positive effect of affiliation with a university research center on the interaction with industry. The academic qualities of universities were negatively related to the interaction with industry. This study shows that university characteristics indirectly affect the technology commercialization activity.

The results of current studies regarding the effect of university characteristics mostly failed to identify their significant influence, or their results were not consistent. The studies used the characteristics as control variables or independent variables. They failed to understand how those university characteristics influence the performance indirectly. Universities in different organizational situations set their technology transfer organization, licensing policy, and strategy differently, which directly influence the operation of technology commercialization. Therefore, university characteristics such as technology licensing office, licensing policy and strategy are expected to indirectly influence the technology commercialization performance. 


\section{A. Mission and goal of a university}

As technology commercialization activity becomes more intensive, universities seem to have a dilemma between two different goals. Nelson [87] pointed out that the traditional goal of a university is to provide advanced scientific knowledge to the public for various benefits as a service organization, but instead universities began to act like profit organizations, making money from their knowledge. The different views of transferring their knowledge are applied to their missions and goals, which then influence technology commercialization activities. The operations of ARITC depend on the policy and strategy at the highest level of the universities. Their priorities are influenced by other organizational characteristics [24]. Studies on the impact of commercialization activity on the university mission are rare. Most studies on this issue discuss the relationships among university mission, policy and performance of commercialization, or selection of a transfer mechanism $[9,28,77,87,115,132,133]$.

The policy of commercialization is another important organizational characteristic such as the reward system toward faculty's contribution to commercialization, and licensing strategy favorable to university policy. This affects the responsibilities and structure of the TLO. For example, TLOs of most universities have traditional structure, which places the office under the university organization [77]. The responsibilities and roles of the director of a commercialization office in this type of university are limited, and a vice provost or vice president has more responsibilities for commercialization activities. They will establish and operate the office in line with the university's objective [114]. 
Therefore, the university's mission and goal toward the technology commercialization are indirectly related to technology commercialization performance by setting TLO, licensing policy and strategy differently.

\section{B. Public vs. Private Universities}

The public or private status of a university has been an interesting topic to researchers regarding technology commercialization. There are basic differences between the two types of universities in terms of income sources and operational flexibility. The private universities are more dependent on student fees, gifts, and research grants and contracts than public universities [1].

According to Powers [96], the level of state support for public universities influences both public and private universities with unexpected directions. Well-supported public universities do not have as much pressure to find extra revenue sources. Therefore, technology commercialization activities have not been focused as an additional budget source. In regards to the economic condition, Powers explained that increased state support results from a state's good economic situation. Thus, private universities would have the benefits of getting more opportunities of technology commercialization. Also, the demand of students on public universities with good state support was getting high, which resulted in high financial pressure on private universities. Therefore, private universities enforced technology commercialization. 
The study also investigated the effect of industry and federal R\&D support on technology commercialization which influenced only patents, with no significant effect on license agreements and license income. Federal sponsorship was typically granted for basic studies, which had fewer opportunities for industry application and thereby less relevance to licenses.

On the other hand, the study done by Lach and Schankerman [64] is remarkable. They studied the influencing characteristics of university technology commercialization in terms of private vs. public. Their results are summarized in Table 11. Royalty shares of both public and private universities influenced licensing income positively, and the public and private status itself didn't influence licensing income. Private universities were more influenced by TLO age than public. Private universities exploited the local high-tech density more than the public. There was no difference between public and private in the effect of research orientation. Faculty size was positively related to license income in both public and private universities, but there was no difference between the two groups of universities.

Table 11: Influencing characteristics and university status

\begin{tabular}{|l|c|c|c|c|c|c|}
\hline \multirow{3}{*}{ Output } & \multicolumn{6}{|c|}{ Effect of characteristics for public and private } \\
\cline { 2 - 7 } & $\begin{array}{c}\text { Royalty } \\
\text { share }\end{array}$ & TLO size & TLO age & $\begin{array}{c}\text { Local high- } \\
\text { tech density }\end{array}$ & $\begin{array}{c}\text { Technology } \\
\text { fields }\end{array}$ & $\begin{array}{c}\text { Faculty } \\
\text { size }\end{array}$ \\
\hline $\begin{array}{l}\text { Licensing } \\
\text { Income }\end{array}$ & $\begin{array}{c}\text { Public }(+) \\
\text { Private }(+)\end{array}$ & $\begin{array}{c}\text { Public }(N E) \\
\text { Private }(+)\end{array}$ & $\begin{array}{c}\text { Public (NE) } \\
\text { Private }(+)\end{array}$ & $\begin{array}{c}\text { Public }(+) \\
\text { Private }(+)\end{array}$ & $\begin{array}{c}\text { Public }(\text { NE) } \\
\text { Private }(\text { NE) }\end{array}$ & $\begin{array}{c}\text { Public }(+) \\
\text { Private }(+)\end{array}$ \\
\hline
\end{tabular}

Note: $\mathrm{NE}=$ no effect 
Regarding the relationships between public/private status and the performance of university technology commercialization, current studies show two findings. First, there were three studies $[6,111,122]$ that compared public and private universities in terms of technology commercialization efficiencies. All of them indicated a negative relationship between public universities and efficiencies of technology commercialization activities. Therefore, private universities are expected to perform technology commercialization activity more efficiently. Second, other researchers $[76,96,111]$ studying the relationship between commercialization outputs and public or private status showed that private universities had more license agreements and income.

Therefore, the public or private status of a university is expected to indirectly influence the technology commercialization performance depending on other characteristics.

\section{Universities with medical schools}

Trune and Goslin [127] in their 1998 study of financial profitability and loss of university technology commercialization in the U.S. found that only $68(40.5 \%)$ out of 168 institutions (140 universities and 28 hospitals) received enough royalties to make up for the operation costs of their commercialization offices. Baldini, et al. [11] found a weak but positive relationship between medical schools and patents, while Powers's [96] study concluded no relationship. In case of licenses of UK institutions, Chapple, et al. [28] found positive relations with the presence of medical schools. Siegel, et al. [111] and 
Anderson, et al.'s [6] studies showed a negative relationship but statistically insignificant when U.S. universities were explored.

D. Academic prestige

The highly qualified scientists and engineers of universities are important mediums of technology transfer [104]. Hicks, et al. [57] studied the relationship between patents in the area of technology development and the quality of university research. They found that U.S. research papers which are in the top $1 \%$ of cited papers, are much more cited by U.S. patents. They emphasize the importance of excellent science in universities because mediocre research would contribute to neither science nor innovation. While most TLOs have failed to gain a significant income, only the universities with high prestige had received multi-million dollar incomes from their licensing [100].

Therefore, it can be assumed that recognized academic prestige is linked to higher research quality and more research funds. Hence, it indirectly influences the outcomes of technology commercialization.

\section{E. University size}

Studies on the influence of university size are rare. Baldini, et al. [11] studied the impact of university size on technology commercialization outcomes by logistic regression. They 
measured the size by the total budget of a university and found that the size of a university is positively related to the patent but is not statistically significant.

Therefore, the size of a university is expected to be indirectly related to the relative or absolute performance by influencing TLO and IP policy.

\subsubsection{Technology Licensing Office (TLO)}

The technology licensing office (TLO) plays an important role as a facilitator of technology commercialization within a university, as well as an intermediary outside of the organization. The TLO fills the gap among university, industry and government [99]. However, some problems in TLOs and related barriers have also been identified in the literature $[96,110,113,114,136]$.

Among those studies, Yusuf [136] listed three difficulties regarding TLOs. The first barrier is the lack of marketing skills of TLOs. The second is poor links between universities and companies. The third is the difficulty in developing an embryonic technology further and finding the proper market place of the technology. A wellorganized process of technology commercialization could help to overcome these limitations. Thus, the TLO, business incubators, and science parks play important roles in transferring university knowledge to industry $[72,77,107,111,114,115,128]$. 


\section{A. Size and age of TLOs}

There have been some studies examining the effect of experience and intensity of TLOs by looking at their size and age. While all the studies of TLO size $[64,76,96]$ showed a positive effect on the outcomes of technology commercialization, there were inconsistencies in the results of the effect of a TLO's age.

Siegel, et al. [111], Powers [96], and Lach and Schankerman [64] found positive relationships between the age of a TLO and licenses. On the other hand, Markman, et al. [76] found a weak negative effect of the age of a TLO on the number of licensing agreements but a positive effect on the starts-up. Chapple, et al. [28] also found that the increased age of a TLO was related to less licensing activities. However, these studies showing negative relationships were not statistically significant.

A university's effort to enhance technology commercialization activity by increasing a TLO's size could improve the performance of technology commercialization. Most studies showed a positive impact of TLO size on the license activities $[11,64,76]$.

\section{B. TLO structure}

The structure of the TLO is another important characteristic. The functions of the TLOs are limited to IP protection and licensing contracts if they are under the traditional organization structure [77]. Some extended forms of TLOs, as well as public institutions, 
have been instituted to overcome these limitations. These intermediary organizations could facilitate the linkage between a university and industry [63].

A new organization called a proof of concept center established by MIT and UCSD was introduced by Gulbranson and Audretsch [54]. The centers were to facilitate the technology commercialization by funding excellent research in its early state, and promoting a collaboration network for the research. They found that their success depended on the skill and social network structure of the staff. The knowledge integration community (KIC) is also another organization that the Cambridge-MIT institute developed to improve knowledge sharing between universities and industry [3].

Markman, et al. [77] studied how TLOs were housed and how those structures were related to licensing strategies. They studied 128 U.S. universities. The results indicated that $52 \%$ conformed to the traditional structure, $41 \%$ had nonprofit research foundations, and only $7 \%$ were for-profit venture extensions. The result of their correlation analysis between the structures and licensing strategies is presented in Table 12. Sponsored research was positively related only to the traditional structure. The licensing for cash strategy, which was the most preferable commercialization strategy, was negatively related to a for-profit structure. 
Table 12: Correlation between TLO structures and licensing strategies [77]

\begin{tabular}{|l|c|c|c|c|c|}
\hline \multicolumn{1}{|c|}{ TLO structure } & Startups & $\begin{array}{c}\text { Startups in } \\
\text { process }\end{array}$ & $\begin{array}{c}\text { Sponsored } \\
\text { research }\end{array}$ & $\begin{array}{c}\text { License for } \\
\text { cash }\end{array}$ & $\begin{array}{c}\text { License for } \\
\text { equity }\end{array}$ \\
\hline Traditional & $-(\mathrm{SI})$ & $-(\mathrm{SI})$ & + & $+(\mathrm{SI})$ & + \\
\hline Non profit & $+(\mathrm{SI})$ & $+(\mathrm{SI})$ & - & $-(\mathrm{SI})$ & $+(\mathrm{SI})$ \\
\hline For profit extension & + & + & $-(\mathrm{SI})$ & - & + \\
\hline
\end{tabular}

Note: SI = statistically insignificant

Therefore, characteristics regarding a TLO such as size, age, and structure are expected to directly influence the commercialization performance.

\section{Licensing Policy and Strategy}

The mission of a university drives its TLO to pursue different licensing policies and strategies. Based on their literature review, Djokovic and Souitaris [38] suggested that the quantity and quality of start-ups are related to the institutional structure and strategic objectives of universities and TLOs. Gopalakrishnan and Santoro [52] also found that the university supporting systems such as the policy for IPR, patent protection, ownership and licensing facilitate both knowledge and technology commercialization of university research.

Some universities may consider technology commercialization activity and related IP protection as a way to contribute to regional economic growth and knowledge diffusion, while others emphasize licensing revenue from patenting their technologies [130]. Most universities are inclined to grant exclusive licenses and obtain more revenue from them. Stanford University, for example, reserves rights for both commercial and 
noncommercial research so that the university contributes to further research for both other institutions and itself [61].

Three licensing strategies, cash, licensing exchange for sponsored research and equity, are identified. Markman, et al. [77] in their theory of the relationship among technology stage, licensing strategy and transfer partner suggested that licensing strategies should be aligned according to the technology stage and type of licensees. The study also indicated that most universities selected the strategy of licensing for cash more than the other two strategies.

Therefore, licensing policy and strategy will affect the technology commercialization operation and its performance, but they should be understood within the organizational contexts.

\subsubsection{Faculties and managers in the TLO}

Personal skill levels, training and experience are very important characteristics because technology or knowledge transfer is a human-embodied activity [22]. Two major personal players in commercialization activity, university researchers and managers of TLOs, are identified in the literature.

The faculties producing a new invention and the practitioners in the TLO are the main entities for transferring the technology to industry. Faculties have an important role even 
after an invention is disclosed, by conducting further research and development of the invention. Some of them also become the entrepreneur of a venture using the technology. Powers [96] found that better faculty quality influenced more patents, licenses, and licensing income. Lach and Schankerman [64] studied the relationship between the number of faculties and licensing income in public and private universities. Their results showed that in both private and public universities, more faculties were related to more technology commercialization activity.

The faculty's interaction with industry was also identified as an important characteristic in the studies $[95,113,114]$. Faculties with more personal relationships with companies had more opportunities to get sponsored research and cooperate more actively during the commercialization process. Martinelli, et al. [78] studied faculties' relationships with industry through a case study of Sussex University in which a considerable number of researchers were involved in technology commercialization activities despite its late start in commercialization activity. They found that more faculties in life science, science and engineering departments interacted with industry than those in the humanities and social sciences. There were also differences in the way faculties in life sciences and science and engineering interacted with industry. Faculties of life sciences linked to industry though collaborative research, while faculties in science and engineering preferred consultancy agreements. 
Regarding personnel in TLOs, Chapple, et al. [28] and Siegel, et al. [111] found that their business skills were important and needed further improvement. Their marketing skills promote licensing by introducing a new invention to a firm and being able to take a good position in negotiations. More specifically, Colyvas, et al. [32] suggested that an invention which is less attractive to industry requires more active marketing. Industry actively monitors university inventions through networks in the scientific community, and thus acquires promising and interesting academic inventions through those channels rather than the commercialization office.

Faculties and managers in the TLOs are the major stakeholders who facilitate the technology commercialization events. Therefore, their expertise and quality are expected to directly influence the performance of the university technology commercialization.

\subsubsection{Environmental Characteristics}

A few studies identified the relationship between the environmental characteristics and the technology commercialization performance. Those characteristics are categorized as industry and government support in terms of supporting start-up and funding university research, the local economy, and high-tech activity in a state.

A. Venture capital and entrepreneurial climate of a state Powers [96] performed a comprehensive study of the effects of external environmental characteristics on the technology commercialization performance by using regression 
models, which used patents, number of license agreements and license income as dependent variables. He found that venture capitalization of a state was positively related to the number of licenses, but had a negative relationship with the licensing income of the universities. He explained that the strategy of technology commercialization of the universities caused the different relationship. The universities with weak venture capital in the state would try to find opportunities for technology transfer from well-established companies which would contribute to the greatest income in the short term. On the other hand, universities with good venture capital would transfer their technologies to small companies, yielding a small licensing income.

The second external characteristic, the entrepreneurial climate of a state, related positively to the number of license agreements. Powers explained that universities with a healthy entrepreneurial climate, meaning they may have good opportunities for licensing to small companies, got small but better technology transfer opportunities than universities with a weak climate. Finally, the study found that strong state support of higher education was negatively related to licensing income of public universities, but positively related to income of private universities.

B. Industry and government support

More sponsored research could result in more scientific inventions, where the university technology commercialization process begins. Therefore, both in industry and government, sponsored research would be related to the positive performance of 
technology commercialization. However, they are expected to influence the individual outcomes in different ways. Government sponsored research tends to focus on basic research, while companies want to invest in applied science or the development of a mature technology that is ready to commercialize, which helps to solve their technical problems. As a result, the research output of federally sponsored research may tend to stay in the early state of maturity and result in patents. On the other hand, industry sponsored research may have a higher likelihood of producing more license agreements and income. Powers [96] in his empirical study indicated that both of them are positively related to the number of patents, but have no relationship with licenses or income. Boardman and Ponomariov [20] showed that government funded research was also positively related to the more active interaction between university researchers and industry. However, this study didn't show if their interactions actually resulted in any of the technology commercialization outcomes.

Therefore, more organizational characteristics should be considered to find their impact on the technology commercialization performance.

\section{R\&D intensity of a state and local economy}

Wright, et al. [95] studied the technology commercialization of universities located in areas of average R\&D intensity and economic activity in the UK, Belgium, Germany, and Sweden. They suggested that those universities should generate world-class research and critical mass in certain areas of expertise. Chapple, et al. [28] found that the regional 
economy positively influenced the licensing income and number of license agreements, but license agreement was not statistically significant.

In most related studies, the environmental characteristics were considered as control variables in the models because of their exogenous nature in technology commercialization. These variables are not expected to be directly linked to the commercialization performance. However, the situation in which the universities are will influence the performance. Therefore, both direct and indirect relationships should be examined along with university characteristics.

Current studies of the external characteristics are summarized in Table 13. 
Table 13: External characteristics from the literature

\begin{tabular}{|c|c|c|}
\hline Research & Characteristics & Influence \\
\hline \multirow{2}{*}{$\begin{array}{l}\text { Chapple, et } \\
\text { al. } 2005 \\
{[28]^{*}}\end{array}$} & - Regional GDP & $\begin{array}{l}+(\text { SI, LICENSES }) \\
+(\text { INCOME })\end{array}$ \\
\hline & - Regional R\&D intensity of industry firms & $\begin{array}{l}+(\text { LICENSES) } \\
\text {-(SI, INCOME) }\end{array}$ \\
\hline \multirow{4}{*}{$\begin{array}{l}\text { Powers, } \\
2003 \text { [96] }\end{array}$} & - Entrepreneurial climate within a state & $\begin{array}{l}+(\text { SI, LICENSES, } \\
\text { INCOME) } \\
\text {-(SI, patent, INCOME) }\end{array}$ \\
\hline & $\begin{array}{l}\text { - The level of venture capitalization within } \\
\text { a state }\end{array}$ & $\begin{array}{l}\text { - (LICENSES, INCOME) } \\
+ \text { (SI, patent) }\end{array}$ \\
\hline & $\begin{array}{l}\text { - State support for (public) higher } \\
\text { education }\end{array}$ & $\begin{array}{l}\text { - (for public Univ.) } \\
+ \text { (for private Univ.) }\end{array}$ \\
\hline & - Federal and industry R\&D support & $\begin{array}{l}+ \text { (patents) } \\
\text { O(LICENSES, INCOME) }\end{array}$ \\
\hline $\begin{array}{l}\text { Baldini, et } \\
\text { al. }[11]^{* *}\end{array}$ & $\begin{array}{l}\text { - Geographical locations (in terms of } \\
\text { degree of industrialization) }\end{array}$ & $+($ SI, patent $)$ \\
\hline $\begin{array}{l}\text { Lach and } \\
\text { Schankerm } \\
\text { an [64]*** }\end{array}$ & $\begin{array}{l}\text { - Geographical locations (in terms of } \\
\text { degree of high-tech activities, public vs. } \\
\text { private) }\end{array}$ & $\begin{array}{l}+(\text { INCOME, Public }< \\
\text { Private })\end{array}$ \\
\hline
\end{tabular}

Note: $\mathrm{SI}=$ statistically insignificant, $+=$ positive relation, $-=$ negative relation, $\mathrm{M}=$ mentioned as important by the survey, LICENSES $=$ number of license agreements, INCOME $=$ license income

$*=$ U.K. universities were studied.

** = Italian universities were studied.

*** $=$ U.S. and Canadian universities were studied

\subsubsection{Summary}

Internal characteristics and influences on technology commercialization identified by the literature are summarized in Table 14, Table 15, and Table 16. 
Table 14: Organizational characteristics related to university technology commercialization from the literature

\begin{tabular}{|c|c|c|}
\hline Research & Characteristics & Influence on TT \\
\hline \multirow{2}{*}{$\begin{array}{l}\text { Anderson, } \\
\text { et al. [6] }\end{array}$} & - Presence of a medical school & -(SI, efficiency of TT) \\
\hline & - Public (vs. private) & -(efficiency of TT) \\
\hline \multirow{10}{*}{$\begin{array}{l}\text { Siegel, et } \\
\text { al. [111] }\end{array}$} & - Presence of a medical school & $\begin{array}{l}\text {-(SI, LICENSES, SFE) } \\
+(\text { SI, INCOME, SFE) }\end{array}$ \\
\hline & - Public (vs. private) & \begin{tabular}{|l} 
- (SI, LICENSE, SFE) \\
- (SI, INCOME, SFE)
\end{tabular} \\
\hline & - TLO age & $\begin{array}{l}+ \text { (SI, LICENSES, SFE) } \\
+(\text { INCOME, SFE })\end{array}$ \\
\hline & - TLO size & \begin{tabular}{|l}
-(LICENSES, SFE) \\
$+($ SI, INCOME, SFE) \\
\end{tabular} \\
\hline & $\begin{array}{l}\text { - Mutual understanding between university and } \\
\text { corporation }\end{array}$ & $\mathrm{M}$ \\
\hline & - Reward system for researchers & $\mathrm{M}$ \\
\hline & - Skill of TLO & M \\
\hline & - Less aggressive attitude toward intellectual right & $\mathrm{M}$ \\
\hline & $\begin{array}{l}\text { - Low degree of bureaucracy and flexibility of university } \\
\text { administrators }\end{array}$ & M \\
\hline & - Personal relationship between university and company & $\mathrm{M}$ \\
\hline \multirow{6}{*}{$\begin{array}{l}\text { Powers } \\
{[96]}\end{array}$} & - Presence of a medical school & \multirow{2}{*}{$\begin{array}{l}-(\text { SI, patent) } \\
+(\text { SI, LICENSES, INCOME) }\end{array}$} \\
\hline & - Presence of engineering school & \\
\hline & - Public (vs. private) & $\begin{array}{l}+(\text { SI, patent }) \\
\text {-(SI, LICENSES, INCOME) }\end{array}$ \\
\hline & - TLO age & $\begin{array}{l}+ \text { +(patent, LICENSES }) \\
+(\text { SI, INCOME) }\end{array}$ \\
\hline & - TLO size & $\begin{array}{l}+(\text { SI, patent }) \\
+(\text { LICENSES, INCOME) } \\
\end{array}$ \\
\hline & - Quality of faculty & $\begin{array}{l}+(\text { patent, LICENSES, } \\
\text { INCOME) }\end{array}$ \\
\hline \multirow{5}{*}{$\begin{array}{l}\text { Thursby, et } \\
\text { al. [121] }\end{array}$} & $\begin{array}{l}\text { - Early development stage of disclosure (proof of } \\
\text { concept without prototype or with lab scale) }\end{array}$ & $\begin{array}{l}+(\text { INCOME, frequency of } \\
\text { sponsored research })\end{array}$ \\
\hline & - Number of disclosures & $+($ LICENSES, patent $)$ \\
\hline & - Presence of a medical school & $+($ SI, LICENSES) \\
\hline & - TLO size & $+($ LICENSES $)$ \\
\hline & - Licenses & $\begin{array}{l}+(\text { INCOME, sponsored } \\
\text { research tied to license })\end{array}$ \\
\hline \multirow{4}{*}{$\begin{array}{l}\text { Decter, et } \\
\text { al. [36] }\end{array}$} & - Communication and stronger relationship & $\mathrm{M}$ \\
\hline & - Greater availability of experienced personnel in TLOs & M \\
\hline & - Less bureaucracy of university administration & M \\
\hline & - Greater autonomy of TLO & M \\
\hline
\end{tabular}

Note: $\mathrm{SI}=$ statistically insignificant, $+=$ positive relation, $-=$ negative relation, $\mathrm{M}=$ mentioned as important by the survey, LICENSES $=$ number of license agreements, INCOME $=$ license income 
Table 15: Organizational characteristics related to university technology commercialization from the literature (continued)

\begin{tabular}{|c|c|c|}
\hline Research & Characteristics & Influence on TT \\
\hline \multirow{5}{*}{$\begin{array}{l}\text { Markman, et } \\
\text { al. [76] }\end{array}$} & - Public (vs. private) & $\begin{array}{l}\text {-(LICENSES) } \\
\text {-(SI, Start-up) }\end{array}$ \\
\hline & - TLO age & $\begin{array}{l}-(\text { SI, LICENSES }) \\
+(\text { Start-up) }\end{array}$ \\
\hline & - TLO size & $+($ LICENSES, Start-up) \\
\hline & $\begin{array}{l}\text { - TLO structure (traditional within university } \\
\text { structure) }\end{array}$ & -(LICENSES, Start-up) \\
\hline & - TLO structure (for profit) & $\begin{array}{l}\text {-(SI, LICENSES) } \\
+(\text { SI, Start-up) }\end{array}$ \\
\hline \multirow{3}{*}{$\begin{array}{l}\text { Chapple, et } \\
\text { al. }[28]^{*}\end{array}$} & - Presence of a medical school & $\begin{array}{l}+(\text { SI, LICENSES }) \\
-(\text { INCOME) }\end{array}$ \\
\hline & - TLO age & $\begin{array}{l}-(\mathrm{LICENSES}) \\
-(\mathrm{SI}, \mathrm{INCOME})\end{array}$ \\
\hline & - TLO personnel's skill in business & $\mathrm{M}$ \\
\hline \multirow{5}{*}{$\begin{array}{l}\text { Thursby and } \\
\text { Kemp [122] }\end{array}$} & - Faculty quality (bioscience, input variable) & -(efficiency of TT) \\
\hline & - Faculty quality (engineering, input variable) & -(efficiency of TT) \\
\hline & - TLO size (input variable) & -(efficiency of TT) \\
\hline & - Presence of a medical school & -(efficiency of TT) \\
\hline & - Public (vs. private) & -(efficiency of TT) \\
\hline \multirow{2}{*}{$\begin{array}{l}\text { Baldini, et al. } \\
{[11]^{* *}}\end{array}$} & $\begin{array}{l}\text { - University size (measured by the budget; most of } \\
\text { the budget used for salaries) }\end{array}$ & $+(\mathrm{SI}$, patent $)$ \\
\hline & - Presence of a medical school & $+($ SI, patent $)$ \\
\hline \multirow{5}{*}{$\begin{array}{l}\text { Lach and } \\
\text { Schankerman } \\
{[64] * * *}\end{array}$} & - Royalty share to inventors (public vs. private) & $\begin{array}{l}+(\text { private }, \text { Income }) \\
+(\text { SI, public }, \text { Income })\end{array}$ \\
\hline & - Incentive effect (public vs. private) & $+($ Income, both $)$ \\
\hline & - Faculty size (public vs. private) & $+($ Income, public $=$ private $)$ \\
\hline & - Faculty quality & $+(\mathrm{SI}$, Income $)$ \\
\hline & - TLO size and age (public vs. private) & $+($ Income, Public $<$ Private $)$ \\
\hline \multirow{2}{*}{$\begin{array}{l}\text { Friedman } \\
\text { and } \\
\text { Silberman } \\
{[47]}\end{array}$} & - TLO age & $\begin{array}{l}+(\text { License generating } \\
\text { income, Licenses with } \\
\text { equity, Income) } \\
+(\text { Start-up) }\end{array}$ \\
\hline & - Public (vs. private), presence of a medical school & (SI, All) \\
\hline
\end{tabular}

Note: $\mathrm{SI}=$ statistically insignificant,$+=$ positive relation, $-=$ negative relation, $\mathrm{M}=$ mentioned as important by the survey, LICENSES $=$ number of license agreements, INCOME $=$ license income $*=$ U.K. universities were studied.

** = Italian universities were studied.

*** $=$ U.S. and Canadian universities were studied 
Table 16: Organizational characteristics related to university technology commercialization from the literature (continued)

\begin{tabular}{|c|c|c|}
\hline Research & Characteristics & Influence on TT \\
\hline \multirow{4}{*}{$\begin{array}{l}\text { Gopalakrishnan } \\
\text { and Santoro } \\
{[52]}\end{array}$} & - Stable \& direction-oriented culture & $+($ TT activity) \\
\hline & - Flexible \& change-oriented culture & $+($ TT activity) \\
\hline & - Firm's trust of university partner & +(TT activity) \\
\hline & $\begin{array}{l}\text { - Support systems (policy for IPR, patent } \\
\text { protection, ownership and licensing }\end{array}$ & $+($ TT activity) \\
\hline \multirow{5}{*}{$\begin{array}{l}\text { Arvanitis, et al. } \\
{[7]}\end{array}$} & - Applied research & -(LICENSE) \\
\hline & - Engineering & $\begin{array}{l}+(\text { patent }) \\
-(\text { SI, LICENSE) }\end{array}$ \\
\hline & - Natural science & $\begin{array}{l}+ \text { (patent) } \\
-(\text { SI, LICENSE) }\end{array}$ \\
\hline & - Medicine & $\begin{array}{l}+(\text { patent }) \\
-(\text { SI, LICENSE) }\end{array}$ \\
\hline & - Teaching & $\begin{array}{l}\text {-(LICENSE) } \\
+(\text { Start-up) }\end{array}$ \\
\hline
\end{tabular}

Note: $\mathrm{SI}=$ statistically insignificant, $+=$ positive relation, $-=$ negative relation, $\mathrm{M}=$ mentioned as important by the survey, LICENSES $=$ number of license agreements, $\mathrm{INCOME}=$ license income

Characteristics influencing licensing performance identified from literature are summarized by technical, organizational, personal, and external environmental perspectives in Table 17. 
Table 17: Summary of the characteristics influencing licensing performance

\begin{tabular}{|c|c|c|}
\hline Perspective & Category & Characteristics \\
\hline Technical & Disclosure & Development state of discovery \\
\hline \multirow{13}{*}{ Organizational } & \multirow{5}{*}{ University } & Universities mission and goals \\
\hline & & An Institution's Private or Public Status \\
\hline & & The existence of Medical school \\
\hline & & Academic prestige \\
\hline & & University size (budget) \\
\hline & \multirow{3}{*}{ TLO } & Size \\
\hline & & Age \\
\hline & & Structure \\
\hline & \multirow{2}{*}{$\begin{array}{l}\text { Licensing } \\
\text { Policy }\end{array}$} & Non-exclusive \\
\hline & & Exclusive \\
\hline & \multirow{3}{*}{$\begin{array}{l}\text { Licensing } \\
\text { strategy }\end{array}$} & Licensing for cash \\
\hline & & Licensing for equity \\
\hline & & Licensing for sponsored research \\
\hline \multirow{3}{*}{ Personal } & \multirow{3}{*}{ People } & Faculties' relationship with industry \\
\hline & & Faculty quality \\
\hline & & TLO personnel's skill \\
\hline \multirow{4}{*}{$\begin{array}{l}\text { External } \\
\text { Environmental }\end{array}$} & \multirow{2}{*}{ Support } & Federal R\&D support \\
\hline & & Industry R\&D support \\
\hline & Economy & Regional GDP \\
\hline & $\begin{array}{l}\text { High-tech } \\
\text { activity }\end{array}$ & Technical intensity \\
\hline
\end{tabular}

\subsection{Process and Influencing Characteristics of Academic Research Institution} Technology Commercialization

In this section, the academic research institution technology commercialization (ARITC) process and its structure of input and output variables are defined. Characteristics which are suggested to be influencing the ARITC performance in the literature are discussed. 


\subsubsection{ARITC Process}

A number of researchers $[15,91,107,123]$ emphasized that academic research institution technology commercialization (ARITC) should be understood as several distinct stages rather than occasional events of a sequential process. Parker, et al. [91] defined ARITC stages by functions of a technology commercialization office (TLO) contributing to net income: discovery, development, manufacturing, and marketing. They understood a TLO's operation as similar to the process of product development of a manufacturing company.

ARITC is a multi-stage process which should be the defined by the functions of TLO, outcomes of ARITC, and resources and characteristics involved. The multi-stage view of TLO functions can provide deep insight into ARITC practices and, thereby, suggest approaches to improve their processes along with other influencing characteristics. In this study, the ARITC process suggested by Kim, et al. and Anderson, et al. [6, 62] are adopted as shown in Figure 8. The research expenditure is the measure of research activity which yields technologies for the potential licensing. This includes both private and public research funds. The first step of commercialization of the technology is for a faculty or researcher to disclose their invention through the TLO. Then, the TLO proceeds with patenting after evaluating the value of the technology. Licensing can take place at any stage from disclosure by different commercialization methods such as an exclusive or non-exclusive licensing, and start-up. Finally, licensing income is the result of the licensing agreements or equity from a start-up company throughout multiple years. 
These processes include different paths and time-lags among the commercialization stages.

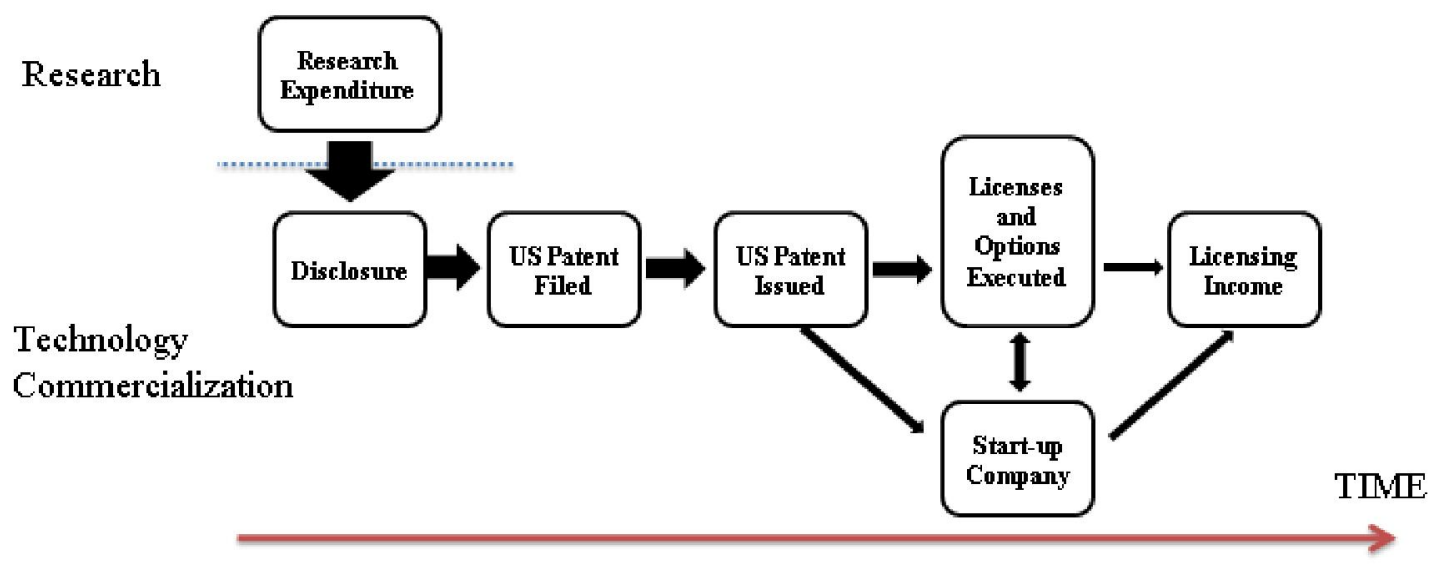

Figure 8: ARITC Process [6, 62]

\subsubsection{Definition of the ARITC Activity}

A. Research expenditure

Research support from government, industry and faculties is an important resource for research which yields inventions (sources of disclosures). Jensen and Thursby [59] indicated that $63 \%$ of inventions were funded by the federal government, $17 \%$ by industry and $20 \%$ unsponsored. Less than half of them were licensed, and only $31 \%$ of licenses were either exclusively or nonexclusively used in the field. Scientific inventions by faculties are important resources of technology commercialization. There is no doubt that more and better quality disclosures about the inventions result in a higher possibility of technology commercialization success. Therefore, research expenditures are inputs of the ARITC process. 


\section{B. Disclosure}

The first step of the commercialization is to evaluate and screen the valuable inventions created by faculties. TLOs actively seek and identify university scientists and their ideas which are potentially marketable. TLOs encourage faculties to disclose their research results if they consider the inventions to be valuable to the market.

TLO size is a resource influencing the performance at this stage. The complexity of the invention and the willingness of the inventor play important roles in helping TLO personnel determine the potential of the invention [91]. TLO personnel's contact with the inventors is important to seek related information and encourage them [115] [91]. Therefore, the bigger the TLO, the more opportunities to find new inventions, and thereby more inventions may be disclosed.

Faculties' relationships with industry and the personalities of entrepreneurs result in more disclosures from their research and higher success of commercialization. They should be understood as characteristics influencing research, disclosures, or any other output variables.

The TLO skills of identifying applications and market potential are important at this stage. Technology commercialization is more challenging if the disclosure is oriented to the basic research. For example, Palmberg [90] found that Finnish university researchers and 
companies had different perceptions of nanotechnology. The problems came from the identification of commercial applications and the low business skills of university researchers for a technology which is immature and uncertain.

Tornquist and Kallsen [126] suggested that universities with more resources, a longer history of applied research, and higher faculty salaries produce results which better fit industrial needs. They also found that higher quality universities with excellent faculties generate more suitable research results for commercialization.

C. Patent

The TLOs yield both patents filed and issued from disclosures. TLOs perform more detailed evaluation of the disclosures for market potential and legal protection, and they submit patent applications. Not all of the disclosures are secured by patents because of the cost of securing IP $[39,115]$. Therefore, TLOs assess the market potential and value for technology commercialization of the disclosures. A more formal and detailed evaluation process focusing on marketability and return on invest is applied at this stage than in the previous stage.

Most universities file patent applications and recover legal fees from license agreements once they recognize the disclosures are worth the investment, while some do not file until they find a licensee [91]. At this stage, TLOs tend to find a potential licensee and investigate market potential in more detail to avoid sunk costs of legal fees. Unreasonable 
transaction costs for holding patents would make an institution unprofitable to transfer the technologies [89]. Therefore, the legal fee paid by a TLO is another input of this stage to understand a TLOs' patenting operations.

Traditionally, there have been two different ways of operating intellectual property in TLOs. One is to maintain in-house legal staff, the other is to contract the service to outside vendors [91]. As the transactions and complexity of university technology commercialization increase, universities institute three types of TLO structures: traditional university structure, non-profit research foundation, and for-profit venture extension [77]. Baldini, et al. [11] found that the patenting activities of the Italian universities with internal IPR regulations have increased almost three times during the 1990s. They also found that larger universities and universities close to industry-intense locations are involved in more patenting activities. Therefore, different resources, legitimacy, and mission of the universities influence patent activity.

D. License \& option executed and start-up

TLOs look for a licensee opportunity inside or outside of their organizations where the technologies are transferred, and negotiate the contract details. Disclosure as well as the patent application are input resources at this stage and are issued because some inventions are licensed before the patent is filed [47, 123]. 
TLO managers must have excellent business skills to obtain a good position in the contract. Also, the goal and mission of the university influence the licensing strategy of TLOs at this stage. The license strategies for university IP include an exclusive or nonexclusive license for the sponsored research, cash, and equity. These are defined as outputs at this stage.

Most disclosures (88\%) were too embryonic to use commercially at the time of licensing. Therefore, they needed further development before they could be used commercially. For this purpose, cooperation between licensees and inventors was suggested as a very important characteristic for successful commercialization [59, 105]. Therefore, interaction between faculty and industry will influence the TLO's operation at this stage.

Universities employ different policies and effort toward licensing, depending on their goals toward public contribution, by distributing the knowledge, securing IP, and obtaining research funds from it $[45,46,56,61]$. These different perceptions of technology commercialization and IP policy affect TLO organizational culture and structure that universities institute [77]. Therefore, TLO structure influences the licensing strategy. 


\section{E. Licensing Income}

TLOs monitor and manage licensing income from various licensing contracts. They optimize the licensing portfolio to both maximize the profits and correspond to the organizational policy.

Considering the scale of licensing income, which is only $2.3 \%$ of research expenditure, the licensing income can be neither a major source of research funding nor by itself contribute to the institution. However, it could be an important source of funding for the technology commercialization transaction costs of licensing, patenting, and maintaining the TLO [24]. Additionally, some universities consider it as an important financial source in addition to other non-monetary benefits $[96,107]$. Universities receive royalty on sales and equity in start-up companies which receive equity of a start-up, royalty, or one time cash from the licensing in compensation for transferring their intellectual property. Depending on the licensing types, the profit occurs for the different range of years.

Intellectual properties of universities are licensed in several different ways: licensing in exchange for sponsored research, licensing for equity, up-front license fees, and royalties on sales [23, 77]. Bray and Lee [23] found that license fees range from $\$ 10,000$ to $\$ 50,000$, and $\$ 250,000$ for a matured technology in a market. Royalties range from $2 \%$ to $5 \%$ on sales. They suggested that equity can provide the TLO flexibility to make more deals and higher returns than royalty. While cash is still the most preferred strategy, the use of equity has increased significantly. 
Finally, TLO structures (traditional university structure, non-profit research foundation, and for-profit venture extension) will influence licensing income by building up different licensing portfolios and management.

\subsubsection{Characteristics influencing the Commercialization Practice}

Powers [96] suggested that ARITC is a process involving various resources such as quality of faculties, the presence of particular programs and infrastructure, the amount of R\&D support, and other characteristics.

The process of the ARIC includes non-serial activities, time-lag, resources and influencing characteristics. The technology commercialization process yields disclosures, patents, license agreements, startups, and licensing income by transferring university knowledge or technology to industry throughout each transferring stage. The TLO is the agency operating and managing this process given the university's resources. The outcomes of each stage will vary according to the quantity and quality of resources and influencing characteristics. In order to understand and evaluate the performance of a TLO through the ARIC process, the related characteristics are identified for further analysis through the literature review. 


\section{A. TLO skills}

Current studies of TLO skills showed inconsistencies in their impact on outcomes. While most researchers expect better business skills to enhance ARITC activity, some studies $[28,76]$ resulted in negative relationships with outcomes. TLO skills are essential and could improve the ARITC activity, but a TLO by itself cannot overcome the limitations which universities may have such as low market attractiveness, low interest of university researchers in commercialization, organizational culture, and policy. It would be difficult to find conclusive relationships between TLO skills and final results such as license and licensing income. Therefore, TLO skills should be understood for how they facilitate the commercialization process and how they influence the result along with other characteristics.

\section{B. TLO size}

TLO size was negatively related only to the licensing income but was not statistically significant in the Siegel, et al. [111] study. Except for that study, TLO size is the only characteristic that almost all surveyed studies concluded had a positive relationship to patent, license agreement, and licensing income. It could be understood in two ways. First, universities need more TLO expertise to deal with increasing numbers of ARITC transactions. Second, universities have invested in the TLO to enhance the ARITC process and, therefore, as a result more outcomes could be acquired. Whichever is correct, it is clear that TLO size is positively related to more outcomes. However, our interest here is to understand how efficiently and effectively universities operate their ARITC 
processes. One interesting finding by Siegel, et al. [111] was that TLO size had constant returns-to-scale to the licensing agreements. They used SFE and F-test to check returnsto-scale, but their result was not statistically significant. However, it would be worth investigating further if TLO size has a certain optimal point for effective ARITC by examining scale efficiency of DEA.

\section{Presence of a medical school}

Presence of a medical school is also another characteristic for which relationships with outcomes such as patent, license agreements, and licensing income varied in several studies $[11,28,96,111]$. There have been conclusive views of the impact of the medical school on the ARITC outcomes. Thursby and Kemp [122] explained that the negative relationship between presence of a medical school and efficiency was due to the heavy service commitments of medical schools. This reduced technology commercialization efficiency even though the university produced significant amounts of licensing for biomedical inventions. Another explanation could be found in the study by Bekkers and Freitas [14] exploring technology transfer channels from university to industry. The study found that technologies in the areas of biomedical and computer sciences were transferred by more collaborative and contract research, while inventions in material sciences and chemical engineering had more licenses and patents. The firms preferred these different channels based on their strategies of innovator or early adopter. Therefore, the existence of a medical school is expected to be related to other characteristics which indirectly influence the technology commercialization performance. 
D. University's public or private status

Private universities were found to be efficient in ARITC and produce relatively more license agreements and income than public universities $[6,76,96,111,122]$. Lach and Schankerman [64] provided better insight regarding the impact of the university status by examining it along with other characteristics. They found that TLO size and age was more positively related to licensing income for private schools than public. However, in order to understand why private schools are more effective in technology commercialization, their influence should be investigated.

\section{E. Institutional prestige}

Academic prestige is related to the university ARITC. An academic institution of high prestige could have an advantage in licensing because a potential buyer easily recognizes its technologies [116]. Academic prestige and quality of faculty influence licensing income. Thursby and Thursby [123] found that the top five inventions yield about $76 \%$ of the total licensing revenue. This implies that only a few valuable inventions by outstanding faculties in high prestigious universities could obtain remarkable success in markets [96] [123]. Sine, et al. [116] provided a comprehensive study of the influence of institutional prestige on the ARITC. Their exploratory study indicated that institutional prestige increases licensing activities, and this positively influences a university's research and disclosures. 


\subsubsection{Summary}

In this section, the licensing process and characteristics influencing characteristics which will be used in the analysis are defined based on literature review.

The licensing process includes:

- Research expenditure,

- Disclosure,

- US patent filed,

- US patent issued,

- License \& option executed,

- Start-up, and

- Licensing income.

The characteristics include:

- TLO skills,

- TLO size,

- Presence of a medical school, and

- Institutional prestige. 


\subsection{UTCE Pattern Diagram}

There have been very active and significant studies done in the area of ARITC. One interesting topic among them was to measure the performance of the ARITC. Data envelopment analysis (DEA) had been regarded as an appropriate approach to measure university technology commercialization efficiency (UTCE). However, current studies only identify efficient and inefficient universities and related output or input variables. On the other hand, Kim, et al. [62] provided an interesting approach to further understanding how the efficient universities are categorized according to their efficiencies and how the efficiencies of the universities change over time. The study [62] suggested the efficiency pattern diagram to identify changing patterns of the technology transfer of 17 efficient universities out of 51 U.S. universities from 2001 to 2004. Five efficiency patterns were identified by this study: "newly emerging," "strengthening," "strong," "weakening," and "declining."

\subsubsection{Pattern Diagram}

In order to get a comprehensive view of efficiency and reference patterns using three measures-change in efficiency, reference frequency, and reference change-a twodimensional diagram was developed. The horizontal axis represents change of efficiency, while the vertical axis explains change in reference. For example, the northeast of the diagram indicates improved efficiency and an increased number of references. On the other hand, a university plotted on the southwest area means declining efficiency and decreased references. A university near the origin was stable in both efficiency and 
reference count. Three sizes of circles were adopted to indicate the degree of frequency of reference. The efficiency diagram was applied to 17 efficient universities as shown in Figure 9.

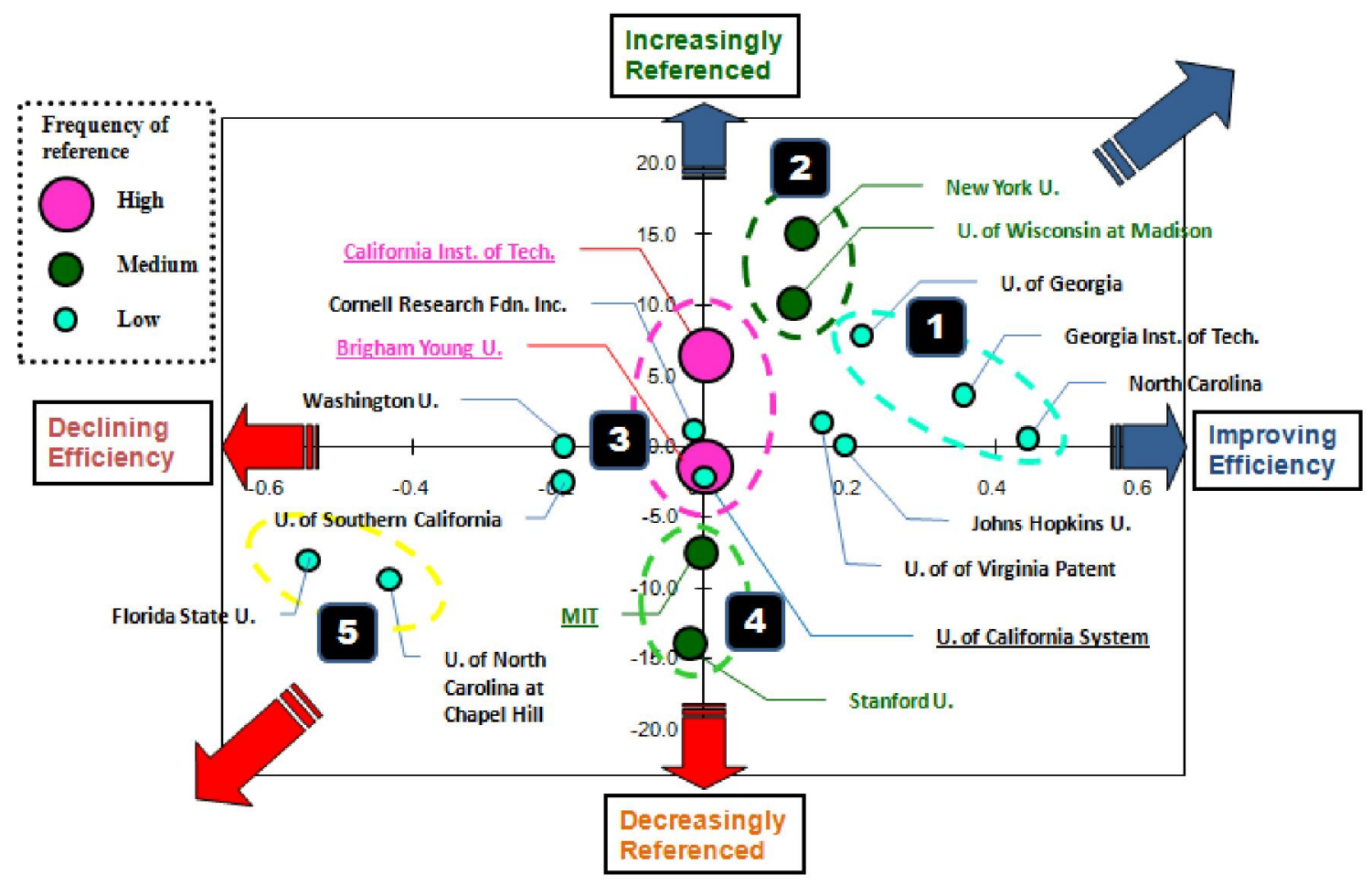

Figure 9: The efficiency pattern diagram of 17 efficient universities from 2001 to 2004

Five groups of the 17 efficient universities were identified based on their locations on the efficiency pattern diagram. Group one and five consist of low reference frequency universities. Universities in the second and fourth group were medium frequency universities. The third group included high frequency universities. There were six universities which don't belong to these groups. They were expected to have different circumstances compared with the universities in the five groups. For example, the University of California System was a strong and stable efficient university. However, its 
incomparably large scales of input and output of technology commercialization prevented inefficient universities from referring to it as a target. The other five universities, including Johns Hopkins University and Washington University, had been efficient just for one or two times during the period. Because of their short history of efficiency, they could not show enough trends to characterize themselves. Therefore, these six universities were regarded as outliers of patterns in the efficiency pattern diagram.

\subsubsection{The Five U.S. UTCE Patterns from 2001 to 2004}

Using the pattern diagram of the 17 efficient universities, five patterns were identified.

\section{A. Pattern 1: Newly Emerging University}

University of Georgia (UG), Georgia Institute of Technology (Georgia Tech), and North Carolina State University (NCSU) were on the northeast of the efficiency diagram. They emerged into the frontier line of the efficiency in 2004. The group was characterized as having a low frequency of references, which is less than 10 times, and increasing reference.

\section{B. Pattern 2: Strengthening University (two universities)}

New York University (NYU) and University of Wisconsin at Madison (UWM) were located in the northeast. They also belonged to the medium frequencies of reference group. Their efficiencies and reference frequencies were increasing. 


\section{Pattern 3: Strong University (two universities)}

Two universities belong to this category: California Institute of Technology (Caltech) and Brigham Young University (BYU). These universities had strong and stable efficiencies during the period. Caltech and BYU were referred to 34 and 31 times during the period, which was the greatest amount. Almost all inefficient universities referenced the two universities as targets.

D. Pattern 4: Weakening University (two universities)

MIT and Stanford University (SU) were in the medium size of reference groups as were NYU and UWM, but MIT and Stanford University were located in the middle-south area on the efficiency diagram. This indicates that their reference frequencies were decreasing. Even though they had been efficient for three and four years respectively, they might not remain efficient in the near future according to the efficiency diagram.

\section{E. Pattern 5: Declining University (two universities)}

Florida State University and University of North Carolina at Chapel Hill were on the southwest corner of the diagram. Their efficiency and number of references decreased during the period. The result showed that most of the outputs of the two universities had decreased. Therefore, the result indicated that their performances were declining and the trend was expected to continue over the next year. 


\subsubsection{Summary}

This study [62] has limitations and therefore indicates important issues which will be studied further in the dissertation.

First, the study used changes in efficiency, reference frequency, and reference change to categorize efficiency changes on the pattern diagram. However, the number of references does not necessarily present a robust trend of efficiency change. Many other characteristics can result in changes in the number of references. Therefore, more reliable measures which could explain efficiency changes should be used.

Second, the model assumes that the potential time-lag from 2001 to 2004 didn't affect the result, so the data of the same year was used. However, more investigation about timelags is required by examining a wider time frame to build a more robust model.

Third, the study suggested a new approach, the pattern diagram, to identify and understand possible patterns of efficiency changes. However, it excluded other inefficient universities. The diagram should include all universities, including inefficient universities, to examine comprehensive patterns of both efficient and inefficient universities. 
Fourth, the study observed data from 2001 to 2004. In order to generalize the patterns, a further study should investigate a wider time frame. This dissertation will investigate about 100 universities from 1996 to 2006.

Finally, the patterns showed how efficiency had changed during the period and which variables drove those changes. However, they didn't explain what organizational characteristics were related to the changes. Therefore, organizational characteristics which were identified by the literature review will be linked to the patterns.

\subsection{Literature Gaps}

The literature was reviewed in the areas of 1) the nature and process of teaching, research, and technology commercialization in higher education, 2) the organizational perspective of licensing of academic research institutions, 3) current approaches to assess the licensing efficiency, 4) characteristics influencing licensing performance, and 5) a new approach, the efficiency pattern diagram.

There are a number of studies evaluating the performance of technology commercialization of academic research institutions. They measured efficiencies of the technology commercialization or the performance of the TLO. However, some limitations of the current studies have been identified. The four major gaps are identified through the literature review as summarized in Table 18. 
Table 18: Linking the identified gaps to the research goals.

\begin{tabular}{|c|c|c|}
\hline Topics & Gaps & Research Goals \\
\hline Time-lag & $\begin{array}{l}\text { GAP 1: Time-lag effect } \\
\text { - Current studies do not properly } \\
\text { incorporate the time-lag effect of } \\
\text { variables on the efficiency model. } \\
\text { - No exploratory studies on identifying } \\
\text { time-lag in licensing exist. }\end{array}$ & $\begin{array}{l}\text { G1: Identify the } \\
\text { ARITC process } \\
\text { incorporating the } \\
\text { time-lag effect }\end{array}$ \\
\hline $\begin{array}{l}\text { Measuring } \\
\text { performance of } \\
\text { academic research } \\
\text { institution } \\
\text { commercialization } \\
\text { (ARITC) }\end{array}$ & $\begin{array}{l}\text { GAP 2: Measurement of ARITC. } \\
\text { - Current study doesn't explain managerial } \\
\text { issue regarding changes of the licensing } \\
\text { performance over time. } \\
\text { - There is not a study providing changing } \\
\text { pattern of the licensing performance. } \\
\text { - Some outcomes of ARITC are excluded } \\
\text { in the efficiency models. } \\
\text { GAP 3: ARITC change pattern } \\
\text { - Unreliable measures were used for the } \\
\text { efficiency changes. } \\
\text { - Organizational characteristics of the } \\
\text { patterns were identified. }\end{array}$ & $\begin{array}{l}\text { G2: Assess the ARITC } \\
\text { from } 1991 \text { to } \\
\\
2007 . \\
\text { G3: Identify the } \\
\text { efficiency and } \\
\text { change patterns } \\
\text { during the period. }\end{array}$ \\
\hline $\begin{array}{l}\text { ARITC and their } \\
\text { Characteristics }\end{array}$ & $\begin{array}{l}\text { GAP 4: Identification of the characteristics } \\
\text { influencing to the performance and efficiency } \\
\text { change of ARITC } \\
\text { - Inconsistencies exist in the effect of the } \\
\text { characteristics throughout the current } \\
\text { studies. } \\
\text { - Lack of comprehensive and systematic } \\
\text { view of the characteristics. }\end{array}$ & $\begin{array}{l}\text { G4: Identify the } \\
\text { relationships } \\
\text { between } \\
\text { characteristics and } \\
\text { the licensing } \\
\text { performances. }\end{array}$ \\
\hline
\end{tabular}

A. Gap 1: Time-lag effect

Current studies on the performance of university technology commercialization do not appropriately incorporate time-lag among output variables in their models. At best, they used averaged value of variables for the purpose. This is due to the lack of an exploratory study to identify the time-lags. Without considering time-lag in the model, the evaluation result could cause misunderstanding of the practices and performance of the ARITC [55]. 
The current method from econometrics doesn't fit to the licensing data and lag behavior (see 3 for detail discussion)

B. GAP 2: Measurement of the technology commercialization efficiency A performance index of the ARITC can provide a yardstick which a commercialization office at an individual institution or policy maker at the national level could use for assessing the status and impact of the ARITC. Therefore, an approach for measuring the performance index will be provided in this study.

There are, however, a few benchmarking studies of the ARITC. They measure the efficiency of the commercialization office or technology commercialization itself. However, most studies, except Anderson, et al. [6], used the characteristics as input or output variables. Therefore, the input and output structure should be built based on the clear and robust process definition of the ARITC.

There are computation limitations, infeasibility and zero data, in super-efficiency VRS DEA model. The current solutions to the infeasibility don't consider the problem in zero data (see 3 for detail discussion). 
C. GAP 3: Efficiency and efficiency change of ARITC

The preliminary study [62] suggesting a pattern diagram used unreliable measures for the efficiency changes. The number of references and their changes which were used as the Y-axis and Z-axis don't necessary represent a certain direction or reasonable reasons for efficiency changes. Therefore, more robust measures should be used to measure the changes of ARITC performance. Second, the study didn't identify meaningful organizational characteristics of the patterns. In order to provide manageable implications to an institution by the patterns, related characteristics and relations to their practices should be provided.

D. GAP 4: Identification of the characteristics influencing the performance and efficiency of ARITC

There are a handful of studies on characteristics influencing the practice of ARITC. Some of them examine relationships between characteristics and efficiency scores of ARITC and others between characteristics and a single output such as patents and licensing income by regression analysis. They find some influencing characteristics, but most of them are statistically insignificant. Indeed, some of their results are inconsistent with others. ARITC involves complex and diverse interests among university administrators, faculties, and relationships with industry. However, current studies focus on only the direct impact of characteristics on a certain output of ARITC. Therefore, a more comprehensive and systematic approach to identifying those direct and indirect impacts of the ARITC performance characteristics is required. 
Chapter 3. Research Methodology and Model Development

\subsection{Research Objective, Goals, and Questions}

The objective of this study is to provide a better understanding of academic research institution technology licensing activity by evaluating both efficiencies and efficiency changes. Seven research questions and corresponding sub-questions designed to achieve the research objective are outlined in Table 19.

Table 19: Research goals and corresponding research questions

\begin{tabular}{|c|c|}
\hline Research Goals & Research Questions \\
\hline $\begin{array}{l}\text { Goal 1: } \\
\text { Identify the academic } \\
\text { research institution } \\
\text { technology } \\
\text { commercialization (ARITC) } \\
\text { process, incorporating the } \\
\text { time-lag effect. }\end{array}$ & $\begin{array}{l}\text { Research Question 1: What is the process of ARITC? } \\
\text { Research Question 2: What is the input and output structure } \\
\text { of ARITC? } \\
\text { Research Question 3: What time lags exist among ARITC } \\
\text { inputs and outputs? } \\
\text { Research Question 4: What is the appropriate model to } \\
\text { incorporate time-lag effects into the technology } \\
\text { commercialization process? }\end{array}$ \\
\hline $\begin{array}{l}\text { Goal 2: } \\
\text { Assess U.S. ARITC from } \\
1991 \text { to } 2007 .\end{array}$ & $\begin{array}{l}\text { Research Question 5: What are the efficiencies of U.S. } \\
\text { ARITC from } 1991 \text { to } 2007 ?\end{array}$ \\
\hline $\begin{array}{l}\text { Goal 3: } \\
\text { Identify the change of ARITC } \\
\text { efficiency during the period } \\
1991 \text { to } 2007 .\end{array}$ & $\begin{array}{l}\text { Research Question 6: What patterns of change are found in } \\
\text { U.S. ARITC efficiencies from } 1991 \text { to } 2007 \text { ? } \\
\text { - Research Question 6-1: What trends exist in technology } \\
\text { commercialization process inputs and outputs over time? } \\
\text { - Research Question 6-2: What trends exist in the } \\
\text { technology commercialization efficiencies of U.S. } \\
\text { academic research institutions from } 1991 \text { to 2007? }\end{array}$ \\
\hline $\begin{array}{l}\text { Goal 4: } \\
\text { Identify the characteristics of } \\
\text { ARITC performance. }\end{array}$ & $\begin{array}{l}\text { Research Question 7: What relationships exist among ARITC } \\
\text { characteristics and efficiency changes? }\end{array}$ \\
\hline
\end{tabular}




\subsection{Research Approach}

The research steps and methods are outlined in Figure 10.

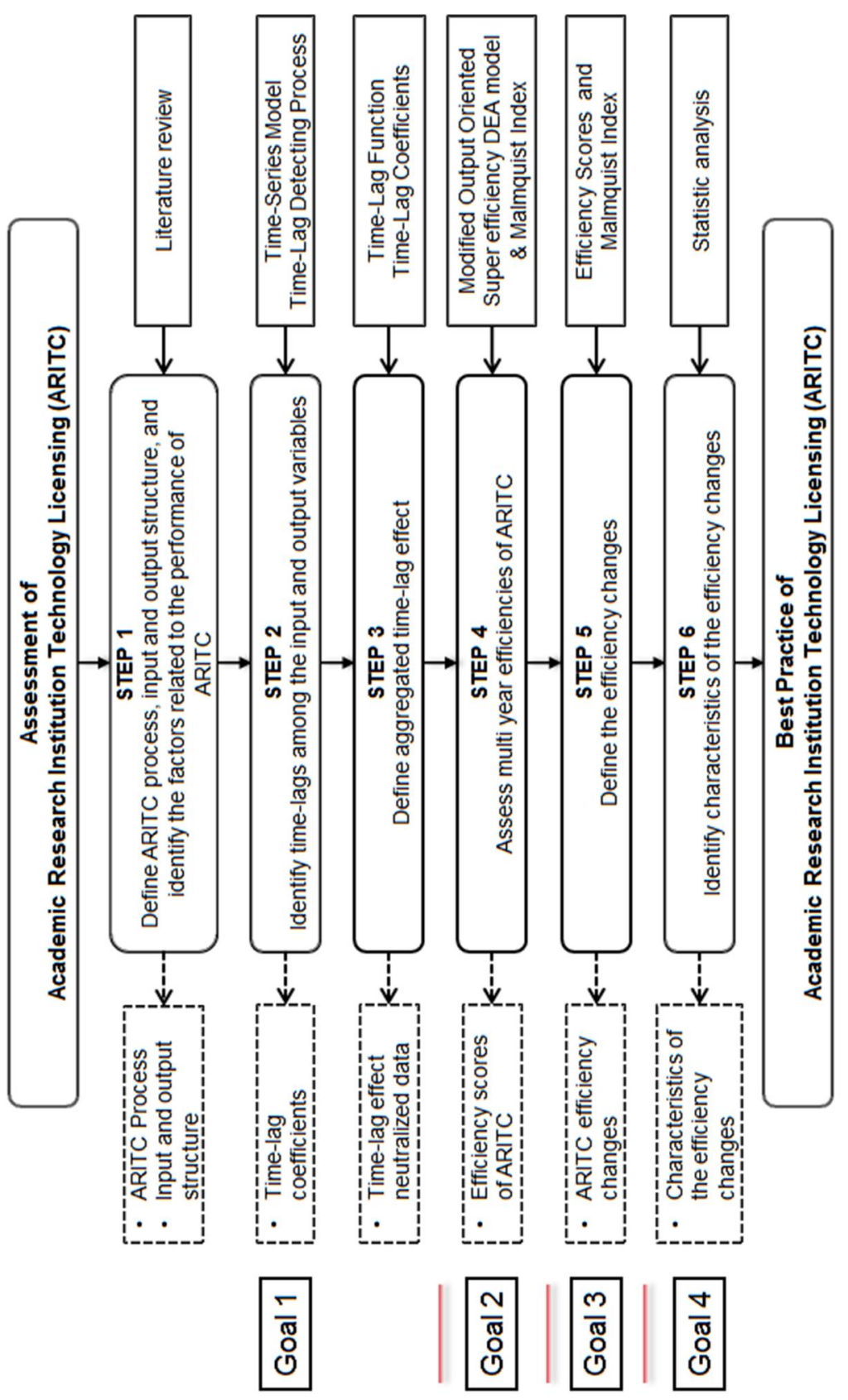

Figure 10: Research steps and methods 
A. Goal 1: To identify the ARITC process and incorporate the time-lag effect

- Step 1: A model of the ARITC process and its input and output structure are defined based on the literature review.

- Step 2: Time lags among input and output variables are identified by time-series analysis. A process identifying time lags among variables is developed and then validated by using simulated ARITC data.

B. Goal 2: To assess U.S. ARITC performance from 1991 to 2007

- Step 3: Aggregated time-lag effects of the ARITC are defined by time-lag functions and coefficients.

- Step 4: Efficiencies of U.S. ARITC from 1991 to 2007 are evaluated using a modified super-efficiency DEA model and the Malmquist Index. A modified output-oriented super-efficiency VRS model is developed to resolve infeasibility and zero-data issues in the VRS DEA model.

C. Goal 3: To identify changes in ARITC efficiency during the period 1991 to 2007

- STEP 5: Performance (efficiency) changes are measured by average efficiency, efficiency change, and the Malmquist Index. 
D. Goal 4: To identify the characteristics of ARITC performance

Step 6: Explore the relationships between performance and characteristics through statistical analysis.

\subsection{Developing a Time-Lag Distribution Model (Goal 1)}

An exploratory study was performed to identify the time lag between the ARITC input and output variables. For this purpose, hypothetical time-lag models of expenditure, disclosure, patent receipt, license agreements, start-up, and license income were built, based on the findings from the literature review. The suggested time-lag regression models were then tested. Finally, a time-lag distribution function for each variable is suggested to incorporate the time lags into the DEA model of ARITC.

The time lag between academic research and disclosure of the invention is difficult to infer because the wide range of academic fields and technical maturity of research complicates the duration variances. Given a government-sponsored research period of 2 to 5 years, the average time lag from research expenditure to disclosure could be 3 years. Payne and Aloysius [93], in their study of the effect of public funding on university research, insisted that there was a gradual effect of research funding on research outputs. They took the average over 3 years to incorporate a 3 -year lag from funding to published articles. 
Heher [55] suggested a typical delay in the technology commercialization process. According to his model, patents generally are filed within 1 year of disclosure and are approved within 4 years. When the TLO appreciates enough commercial value of the invention, they file a patent without delay to protect the invention. Therefore, most disclosed technologies will be filed for patents within 1 year of disclosure. Thereafter, it takes an average of 1.5 to 3 years until the patent is approved and issued [127].

Disclosures are expected to be licensed during the patenting process. Licensing income begins to be collected after about 2 years. A start-up company can be formed after the second year, but this usually happens between 4 and 7 years after disclosure. Markman, et al. [76], in their study of the effect of innovation speed on the outcomes of university technology commercialization, found that the average lag between disclosure and start-up was 4.27 years. Mansfield [74] found that the time lag between academic research findings and the first commercialization based on the research is about 7 years.

Time series analysis in econometrics provides an advanced method of identifying relationships among time series subjects that rarely has been applied to the engineering management field. Sophisticated econometrics methods—-such as a distributed lag model with unrestricted lag, arithmetic lag, polynomial lag, or geometric lag structures—and dynamics model theories enrich the analysis of long-term economic data and their lasting effects. However, observations in the engineering management field, which tends to have highly uncertain time effects and relatively insufficient time series, hinder the application 
and benefits of time-lag analysis, which is very important to understanding the dynamic behavior of subjects in this field. Therefore, this section revisits and compares selected time series approaches and suggests a process for identifying the time-lag coefficients of licensing input and output variables. The verification of this process is performed in Chapter 4, using a simulated data set to represent university technology licensing activities.

In addition to the process used to identify time-lag coefficients, an approach of combining each pair of lag coefficients with the complicated multiple paths from licensing to licensing income is provided.

\subsubsection{Time Series Models and Their Limitations}

The current time-lag identification process in econometrics has several limitations when applied to licensing data. First, the models assume continuous lags over time. Second, their effects are prolonged for a long period and diminish over time. Finally, the lags are assumed to be effective at the beginning of the occurrence of the investigated subject. The models select length of time lags in such a way as to minimize Akaike's information criterion (AIC) or Bayesian information criterion (BIC) statistics. Although the models can measure time-lag effects of subjects in which the coefficients follow a certain pattern, such as linear, polynomial, or geometric change over a long period, these assumptions are not appropriate for licensing data for which discontinuous and short-term time-lag effects exist. 
The current time series models are summarized in Table 20.

Table 20: General time series models and their limitations

\begin{tabular}{|c|c|c|}
\hline Time Series Model & Model Specification & Limitation \\
\hline $\begin{array}{l}\text { Autoregressive (AR) } \\
\text { model }\end{array}$ & $\begin{array}{l}A R(p) \\
y_{t}=\alpha+\beta_{0} y_{t-1}+\beta_{1} y_{t-2}+ \\
\cdots+y_{t-p}+e_{t}\end{array}$ & \multirow[t]{3}{*}{$\begin{array}{l}\text { The concept of self- } \\
\text { growing is not applicable } \\
\text { to licensing theory }\end{array}$} \\
\hline $\begin{array}{l}\text { Autoregressive moving } \\
\text { average } \quad \text { (ARMA) } \\
\text { model }\end{array}$ & $\begin{array}{l}A R M A(p, q) \\
y_{t}=\alpha+\beta_{0} y_{t-1}+\beta_{1} y_{t-2}+ \\
\cdots+y_{t-p}+\sum_{i=1}^{q} \beta_{i} e_{t-i} \\
\text { Where } \beta_{i} \text { is defined by } \\
y_{t}=\alpha+\beta_{1} y_{t-1}+\beta_{2} y_{t-2}+ \\
\cdots+y_{t-q}+e_{t}\end{array}$ & \\
\hline $\begin{array}{l}\text { Autoregressive } \\
\text { integrated moving } \\
\text { average } \\
\text { model }\end{array}$ & $\operatorname{ARIMA}(p, d, q)$ & \\
\hline Distributed lag model & $\begin{array}{l}y_{t}=\alpha+\beta_{0} x_{t}+\beta_{1} x_{t-1}+ \\
\cdots+x_{t-n}+e_{t}\end{array}$ & $\begin{array}{l}\text { Explains the licensing } \\
\text { theory } \\
\text { Selected as licensing lag } \\
\text { model }\end{array}$ \\
\hline
\end{tabular}

\subsubsection{A Process for Identifying Time-Lag Coefficients}

Time lags among the licensing data are examined by using a distributed lag regression model. The distributed regression model, a well-known and widely used time series analysis in economics, estimates causal effects on two subjects. For this purpose, a series of statistical processes has been developed. The five steps for identifying time-lag coefficients are presented in Figure 11. 


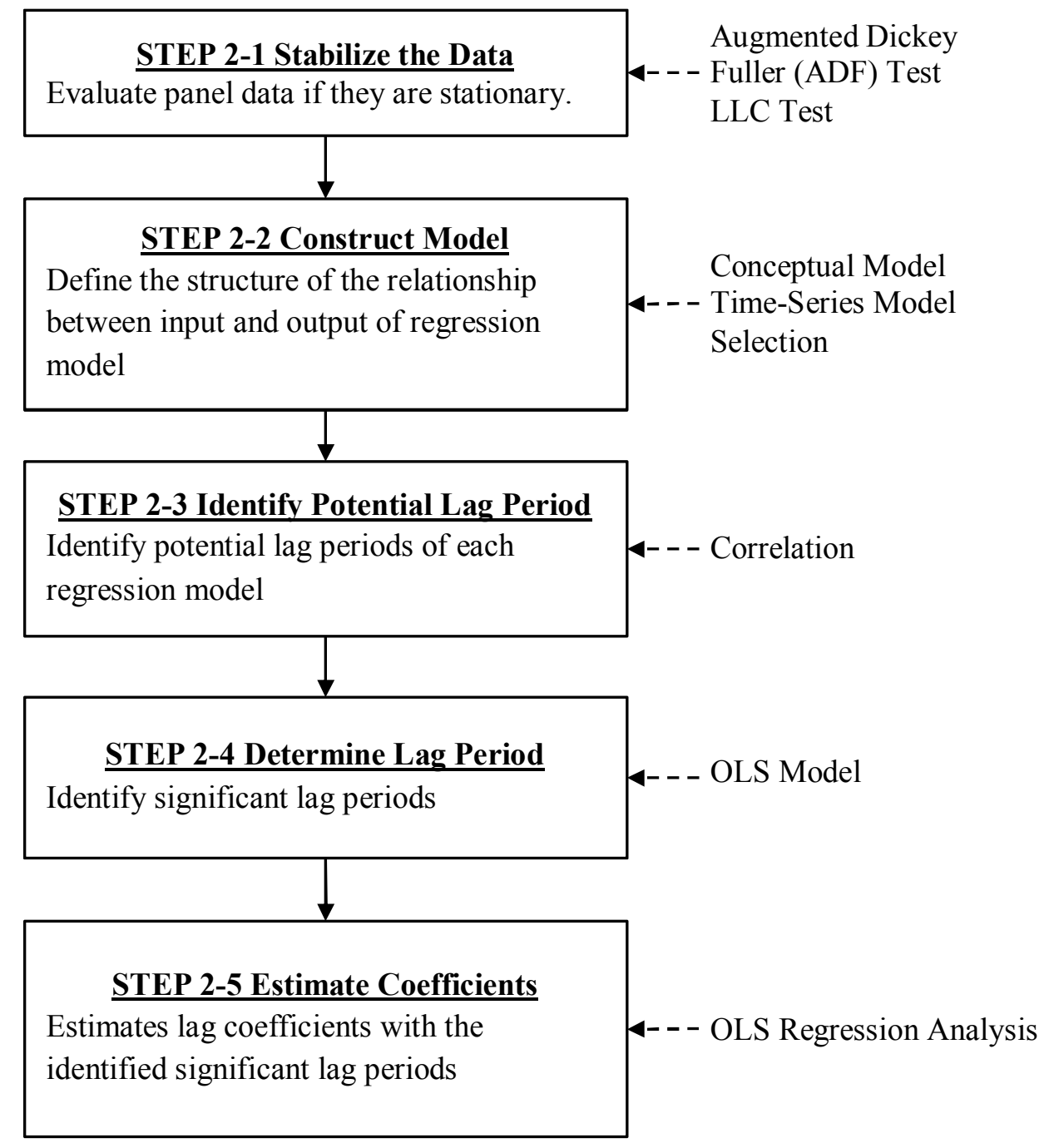

Figure 11: Process to identify time-lag distribution coefficients

\section{A. Step 2-1: Stabilize the Data}

In time series analysis, the data should be stationary in order to create a model that will correctly predict future behavior, means, variances, and correlation with other variables based on the past data $[40,119,131]$. To say that data is stationary means that statistical 
properties such as means and variances are all constant over time. If there is a systematic change, such as a trend, the data should be transformed to eliminate the trend.

For example, consider the first-order autoregressive model $y_{t}=\rho y_{t-1}+\varepsilon_{t}$, where $t=$ $1 \ldots \infty$ and error term $\varepsilon_{t}=N\left(0, \sigma^{2}\right)$. If $\rho=1$ and $y_{0}=0$ are assumed, $y_{t}$ is equal to $y_{0}+\sum_{j=1}^{t} \varepsilon_{t}$ by repeated substitution. Then, the variance of $y_{t}, \operatorname{Var}\left(y_{t}\right)$, becomes $\operatorname{Var}\left(\sum_{j=1}^{t} \varepsilon_{t}\right)=t \sigma^{2}$. As a result, the variance is time dependent and the regression model causes problems in predicting the future. To avoid this problem in this example, therefore, $\rho$ should not be 1 .

The augmented Dickey-Fuller (ADF) test is the most common method to test whether a time series data is stationary. Continuing with the previous example, the ADF tests whether parameter $\rho$ is 1 by testing $\nabla y_{t}=(\rho-1) y_{t-1}+\varepsilon_{t}$, using the Dickey-Fuller table [119]. The Levin-Lin-Chu (LLC) test determines whether cross-sectional panel data is stationary $[68,131]$. The present study used the Stata package to conduct ADF and LLC tests.

If the data is not stationary, the first order difference, $\operatorname{diff}(1)=y_{t}-y_{t-1}$, is applied to the data and then the test is repeated. 


\section{B. Step 2-2: Construct Model}

The time lags are defined by the significant relationship between an output variable at a certain year and corresponding input with intervals of time. The 21 regression models representing the potential relationships among time-lagged input and output licensing variables are tested to find significant relationships.

For this purpose, the distributed lag model is suggested as an appropriate regression model to detect time lags in licensing data. The distributed lag equations present the dependent variable $Y_{t}$ at time $t$ and is the result of a weighted sum of the past value of independent variable $X$ from time $t$ to $t-n[5,13,92]$, as follows:

$Y_{i, t}=\beta_{0} X_{i, t}+\beta_{1} X_{i, t-1}+\beta_{2} X_{i, t-2}+\cdots+\beta_{n} X_{i, t-n}+e_{i, t}$,

where

$Y=$ output technology licensing variable (disclosure, patent application, patent issued, licenses and options executed, start-up, and licensing income);

$X=$ input technology licensing variable (expenditure, disclosure, patent application, patent issued, licenses and options executed, and start-up);

$i=i^{\text {th }}$ institution $(i=1,2, \ldots 46)$;

$t=$ year;

$n=n^{\text {th }}$ year before $t$;

$\beta_{0}, \beta_{1}, \ldots, \beta_{n}=$ coefficients corresponding to input variable $X$ in the current year $\left(X_{i, t}\right)$, the previous year $\left(X_{i, t-1}\right)$, and the $n^{\text {th }}$ year earlier $\left(X_{i, t-n}\right)$; and 
$e_{i, t}=$ residual (error term).

There are four ways to estimate the coefficients of the distributed lag model: through unrestricted lags, through linearly declining lags, through polynomial lags, and through geometrically declining lags. Each method assumes a unique coefficient structure of the lags over time (Figure 12).

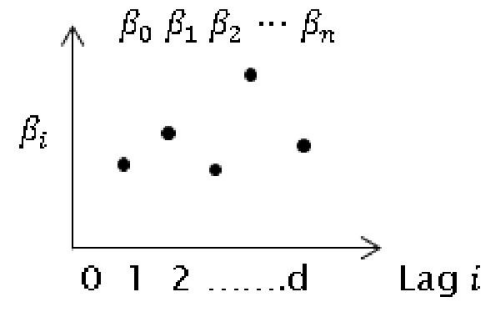

(a) Unrestricted lags

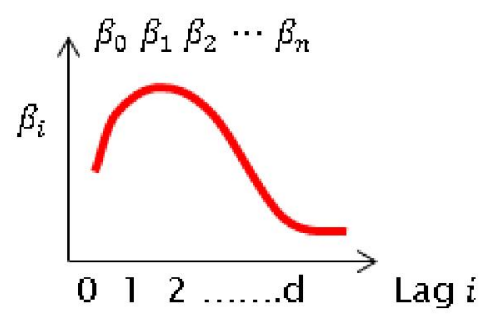

(c) Polynomial lags

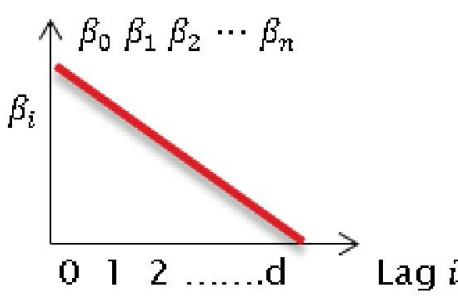

(b) Linearly declining lags

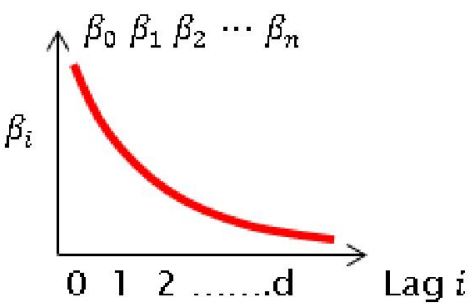

(d) Geometrically declining lags

Figure 12: Coefficient structures of time series models

Unrestricted time-lag coefficients are estimated using ordinary least squares (OLS). The OLS estimation suffers from limitations such as imprecise, large standard errors, but the approach helps when no structure is assumed with finite lags. Arithmetic or linearly declining lags assume that the effect of the independent variable eventually reaches zero and that the effect of each lag is less than the effect of the previous one. The coefficient 
structure follows an arithmetic series, $\beta_{n}=\beta_{1}+\gamma(n-1)$. It benefits from simple estimation of only one parameter and presents a more reliable result than unstructured lag, with straightforward interpretation. However, if the restriction of the lag structure is not true, the estimators will be biased and inconsistent.

Polynomial lag, or Almon lag, requires the assumption of finite effect and zero at the end of the period. The coefficients are dependent on each other, as arithmetic lag, but they don't have a uniform pattern. The coefficient structure is $\beta_{n}=\gamma_{0}+\gamma_{1} n+\gamma_{2} n^{2} \ldots \gamma_{t} n^{t}$. This model has fewer parameters to estimate but is more precise than the unrestricted lag structure.

Geometric lag, or Koyck lag, is used when the lag length is infinite and the lag coefficients follow a geometric pattern. The equation of the coefficient structure is $\beta_{n}=\delta \gamma^{n}$, where $|\gamma|<1$ and $\delta \gamma^{n}>0$. It requires an estimate of only $\delta$ and $\gamma$, but geometric lag transformation is required for the estimation. It doesn't allow a heterogeneous or unsmooth declining lag structure.

Linearly and geometrically declining lag structures are not considered. The models assume that the effect of an independent variable is high at year zero and diminishes as time goes on, but this doesn't represent the nature of licensing variables. Some licensing variables are expected to result from other, independent licensing variables after a certain number of years have passed, and the overall distribution of the lag effects will have a 
convex curve shape. Therefore, unrestricted and polynomial lag structures are considered for the lag structure of the licensing.

The following section describes a test to identify which structure fits better with the licensing data and lag behavior, using a simulated data set. The result shows that the unrestricted lag structure fits the data better than a polynomial structure. Therefore, the unrestricted lag model with OLS estimation is applied in this study.

\section{Step 2-3: Identify Potential Lag Period}

The maximum lag period in the distributed lag regression models is determined by goodness-of-fit statistics. The statistics used for this purpose are mean square error, Akaike's information criterion, and Bayesian information criterion [13, 92, 119]. Both $\mathrm{AIC}$ and BIC measure the trade-off between accuracy and complexity of information in the model by adding more lag periods. If more lag periods or parameters are included in the models, the model's goodness of fit is increased, but it also results in overfitting. The lower value of the two criteria implies fewer independent variables (lag periods) and a better fit. These methods identify the maximum lag period when the independent variables effect continuously over a time period.

In this paper, an exploratory approach is utilized to identify significant lag periods. Based on the findings of the study, the time-lag periods are defined in two steps; identifying potential lag period and define significant lag period. First, the correlations among the 
independent variables (lag periods) and the dependent variables are examined. The lags that have positive correlation with the dependent variable are selected as potential lags. The lags showing negative correlations are excluded because it is assumed that, in licensing, an increase (or decrease) of an independent variable results in an increase (or decrease) of a dependent variable. Therefore, the negative correlation of a lag with a dependent variable indicates that it is not associated with change in the dependent variable, as demonstrated in the test with simulated data. The following describes the second step of defining significant lag period.

\section{Step 2-4: Determine Lag Period}

Second, the lags with positive correlation with the dependent variables could be either true lags, representing actual lags in licensing, or coincident events. Therefore, the distributed time-lag models with the identified potential lags are tested to define which lags are significant. The lags with a statistically significant level of $1 \%$ from the regression analysis are selected as final lag periods for each pair of independent lag variables and the dependent variable of licensing.

\section{E. Step 2-5: Estimate Coefficients}

The final distributed lag models with the lag periods identified in the previous step are tested to observe actual lag effects on a dependent variable. 


\subsubsection{Process for Calculating the Aggregate Total Time Lag}

Performance evolution of universities' licensing practices has received favorable interest in the literature. However, the existing studies implicitly or explicitly state their limitation of ignoring time-lag effects of the licensing variables, such as expenditure, patents, and start-up licensing income. A statistical process to identify the time-lag coefficients of licensing variables with regard to U.S. research institutions provided insight into the time lags of each pair of licensing variables.

The present section employs an approach that incorporates multiple paths in the licensing process, with the time-lag coefficients. The identified time lags include both direct and indirect relationships presenting time duration among licensing activities. As a result, multiple time-lag relations are involved in multiple paths from a licensing activity to another activity. Using the identified time-lag effects for the evaluation of the entire licensing process requires an approach that will connect the lag effects of all other licensing variables to the output variable in the final licensing process. For this purpose, a time-lag transform function is defined and applied to all possible licensing paths, generating total time-lag effect neutralized licensing data. The overall process is presented in Figure 13. 


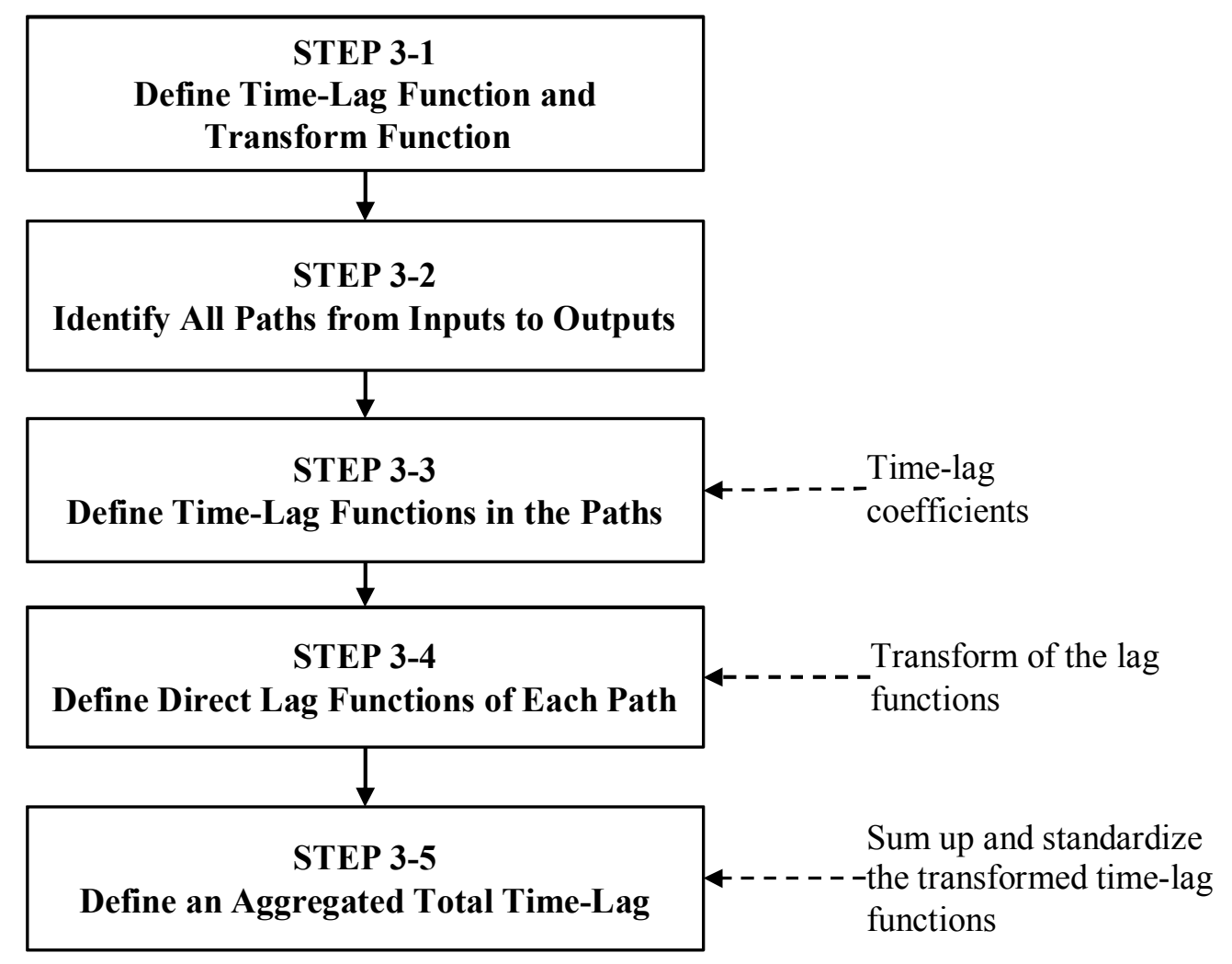

Figure 13: Time-lag aggregation process using time-lag coefficients

A. Step 3-1: Define Time-Lag Function and Transform Function

A transform function combines two paths in order to extract an intermediating variable.

1) Definition of the time-lag function

Let $x_{t}$ and $y_{t}$ denote values of technology commercialization input $x$ and output $y$ at year $t$, and $x_{t-n}$ denote the value of input $x$ prior to $n$ years; time lag $n$. The output $y_{t}$ at year $t$ is defined as a result of the prior inputs of $x_{t-0}, x_{t-1}, x_{t-2}, \ldots, x_{t-n}$, if there are time lags of $0,1, \ldots, n$ years from input $x$ to output $y$. Assuming no other intervening input between $x$ and $y$, the input, $x_{t^{*}}$, represents the time lag aggregated input value of $x$, 
incorporating all the time lags into a single year $t$. The time aggregated input $x_{t^{*}}$ is calculated by time-lag function $f_{x y}$, which is defined as

$x_{t^{*}}=f_{x y}\left(x_{t-0}, x_{t-1}, x_{t-2}, \ldots, x_{t-n}\right)$

$=b_{0} x_{t-0}+b_{1} x_{t-1}+b_{2} x_{t-2}+\ldots+b_{n} x_{t-n}$

$=\sum_{i=0}^{n} b_{i} x_{t-i}$,

where

$f_{x y}=$ time lag function presenting the relationship between output variable $y$ at year $t$ and input variable $x$ at $i^{\text {th }}$ lag, and

$b_{i}=$ standardized time lag coefficients at $i^{\text {th }}$ lag, $b_{0}+b_{1}+b_{2}+, \ldots,+b_{n}=1$.

The time-lag coefficients $b_{0}, b_{1}, b_{2}, \ldots, b_{n}$ are equivalent to the normalized standard coefficients of the multi-regression model by dependent variable $\Delta y_{t}$ and independent variables $\Delta x_{t-0}, \Delta x_{t-1}, \Delta x_{t-2}, \ldots, \Delta x_{t-N}$, where $N$ is the time range considered in the time-lag analysis.

2) Time-lag transform function with a intervening variable

Let $z$ be an intervening variable that is an output from input $x$ and then an input for the next result, $y$. When the prior time lags of $f_{x z}$ between $x$ and $z$, and posterior time lags of $f_{z y}$ between $z$ and $y$ are observed, the time lags from $x$ to $y, f_{x y}$, are defined by transforming time-lag function $f_{x z} \otimes f_{z y}$, as shown in Figure 14 . 


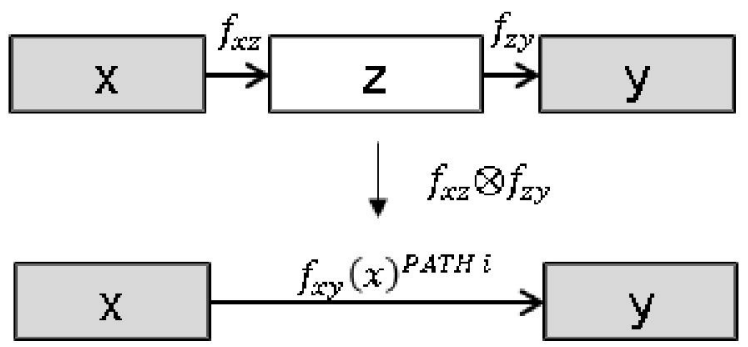

Figure 14: Time-lag transposing function at PATH $i$

The transform function $f_{x z} \otimes f_{z y}$ is defined as follows:

$f_{x y}{ }^{P A T H i}=$ Prior lag function $\otimes$ Posterior lag function $=$

$f_{x z} \otimes \mathrm{f}_{z y}=x_{t^{*}}=f_{x z y}=f_{z y}\left(z^{*}\right)=f_{x y}(x)^{P A T H i}$,

where

$f_{x z}\left(x_{t-(j)}, x_{t-(j+1)}, x_{t-(j+2)}, \ldots, x_{t-(j+n)}\right)=$ prior time-lag function from $x$ to $y$ with lag $j, j+1, \ldots, j+n$,

$f_{z y}\left(z_{t-(k)}, z_{t-(k+1)}, z_{t-(k+2)}, \ldots, z_{t-(k+m)}\right)=$ posterior time-lag function from $z$ to $y$ with lag $k, k+1, \ldots, k+m$,

$f_{x y}{ }^{\text {PATH } i}=$ transform function from $x$ to $y$ through PATH $i$,

PATH $i=i^{\text {th }}$ path from $x$ to $y$ via $z$,

$z=$ an intervening variable between $x$ and $y$, and

$z^{*}=$

$\left\{\begin{array}{c}z^{*}{ }_{t-(k)}=f_{x z}\left(x_{t-(j+k)}, x_{t-(j+1+k)}, x_{t-(j+2+k)}, \ldots, x_{t-(j+n+k)}\right), \\ z^{*}{ }_{t-(k+1)}=f_{x z}\left(x_{t-(j+k+1)}, x_{t-(j+1+k+1)}, x_{t-(j+2+k+1)}, \ldots, x_{t-(j+n+k+1)}\right), \\ \vdots \\ z^{*}{ }_{t-(k+m)}=f_{x z}\left(x_{t-(j+k+m)}, x_{t-(j+1+k+m)}, x_{t-(j+2+k+m)}, \ldots, x_{t-(j+n+k+m)}\right)\end{array}\right\}$ 
Because the time-lag coefficients are the normalized standard regression coefficient, the time-lag aggregated value $x_{t^{*}}$ from $f_{x z}$ is an approximation of the regression model $z_{t}=\beta_{1} x_{t-1}+\beta_{2} x_{t-2}$. The time-lag aggregated value $x_{t^{*}}$ is equal to $\frac{1}{\beta_{1}+\beta_{2}}(=\theta) z_{t}$, and $\theta$ is defined as follows:

Time lag coefficients $b_{1}=\frac{\beta_{1}}{\beta_{1}+\beta_{2}}$ and $b_{1}=\frac{\beta_{2}}{\beta_{1}+\beta_{2}}$

$$
\begin{aligned}
& f_{x z}=x_{t^{*}}=b_{1} x_{t-1}+b_{2} x_{t-2}=\frac{\beta_{1}}{\beta_{1}+\beta_{2}} x_{t-1}+\frac{\beta_{2}}{\beta_{1}+\beta_{2}} x_{t-2} \\
& =\frac{1}{\beta_{1}+\beta_{2}}\left(\beta_{1} x_{t-1}+\beta_{2} x_{t-2}\right)=\frac{1}{\beta_{1}+\beta_{2}}\left(z_{t}\right)=\theta z_{t} \sim z_{t}
\end{aligned}
$$

For example, given time-lag function $f_{x z}\left(x_{t-0}, x_{t-1}, x_{t-2}, \ldots, x_{t-n}\right)=0.2 x_{t-1}+0.8 x_{t-2}$ and $f_{z y}\left(z_{t-0}, z_{t-1}, z_{t-2}, \ldots, z_{t-n}\right)=0.3 z_{t-2}+0.7 z_{t-3}$, the time lag transform function of $f_{x y}$ can be defined as

$f_{x y}=f_{x z} \otimes f_{z y}=f_{x z y}\left(x_{t-1}, x_{t-2}\right)=f_{z y}\left(z^{*}\right)$

The $x_{t^{*}}$ can be substituted for $z_{t}$. Then, $z_{t-2}$ is equivalent to $x_{(t-2)^{*}}=0.2 x_{t-3}+$ $0.8 x_{t-4}$, and $z_{t-3}$ is equivalent to $x_{(t-3)^{*}}=0.2 x_{t-4}+0.8 x_{t-5}$. This transform is summarized as follows:

$$
z^{*}=\left\{\begin{array}{l}
z^{*}{ }_{t-2}=0.2 x_{t-(1+2)}+0.8 x_{t-(2+2)} \\
z^{*}{ }_{t-3}=0.2 x_{t-(1+3)}+0.8 x_{t-(2+3)}
\end{array}\right\}
$$

Finally, the transposed time-lag function $f_{x z y}\left(x_{t-0}, x_{t-1}, x_{t-2}, \ldots, x_{t-n}\right)$ is defined as 


$$
\begin{aligned}
& f_{x z y}\left(x_{t-1}, x_{t-2}\right)=f_{z y}\left(z^{*}\right)=f_{z y}\left(z^{*}{ }_{t-2}, z^{*}{ }_{t-3}\right) \\
& =0.3 z^{*}{ }_{t-2}+0.7 z^{*}{ }_{t-3} \\
& =0.3\left(0.2 x_{t-3}+0.8 x_{t-4}\right)+0.7\left(0.2 x_{t-4}+0.8 x_{t-5}\right) \\
& =0.06 x_{t-3}+0.38 x_{t-4}+0.56 x_{t-5}
\end{aligned}
$$

The transform function combines the prior and posterior time-lag functions in a way that extends the lags to the sum of maximum lag lengths of each lag period and smooths the two lag distributions by multiplying them as illustrated in Figure 15.

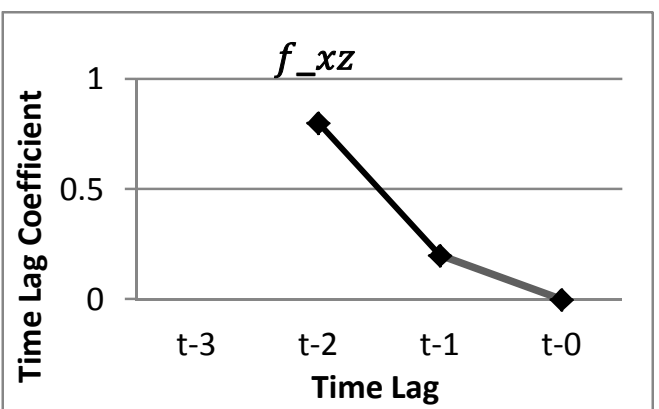

(a) Time lag function: $f_{x z}$

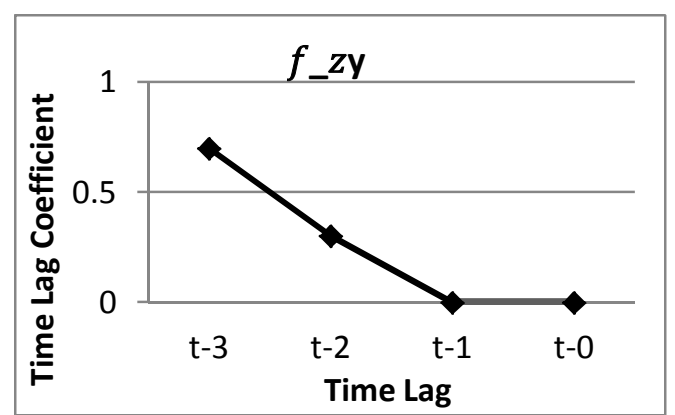

(b) Time lag function: $f_{z y}$

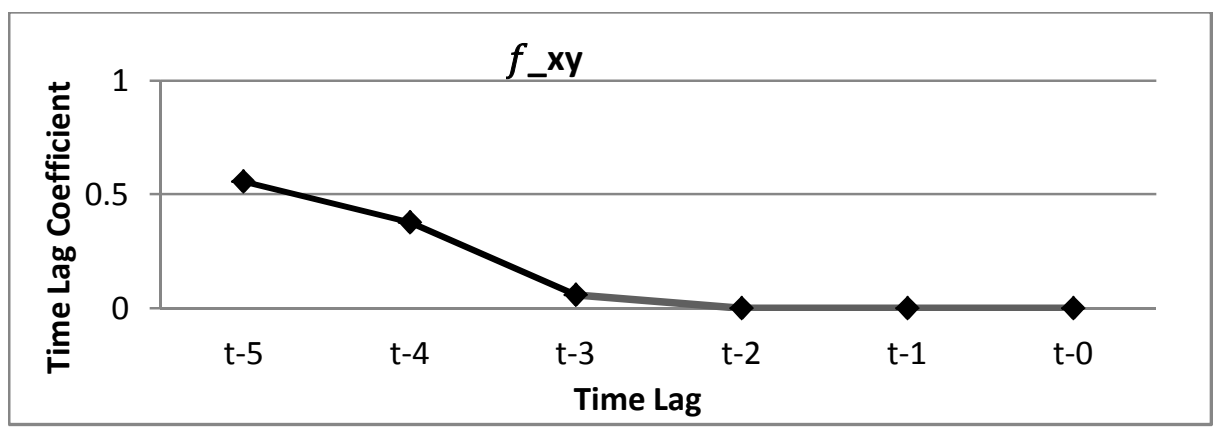

(b) Transposed time lag function: $f_{x y}$

Figure 15: Example of transform function of the time lags 
B. Step 3-2: Identify All Paths from Input to Output

To identify all paths from each input to licensing income, direct and indirect paths are defined as illustrated in Figure 16. The direct path is the first-degree path between two licensing variables. The indirect path is associated with an intermediating variable between the two variables, with multiple distance degrees of more than two. The licensing paths are defined using all possible paths from each variable to the licensing income.

$1^{\text {st }}$ distance degree path (direct path)

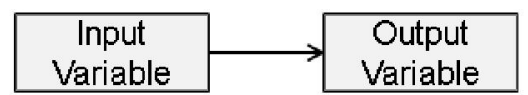

$2^{\text {st }}$ distance degree path (indirect path)

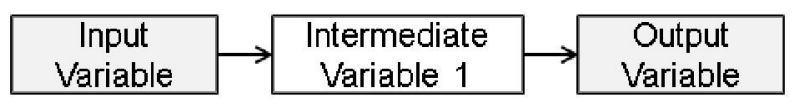

$3^{\text {st }}$ distance degree path (indirect path)

\begin{tabular}{|c|c|c|}
\hline Input \\
Variable
\end{tabular}$\rightarrow \begin{gathered}\text { Intermediate } \\
\text { variable 1 }\end{gathered} \rightarrow \begin{gathered}\text { Intermediate } \\
\text { variable 2 }\end{gathered} \rightarrow$\begin{tabular}{c}
$\begin{array}{c}\text { Output } \\
\text { variable }\end{array}$ \\
\hline
\end{tabular}

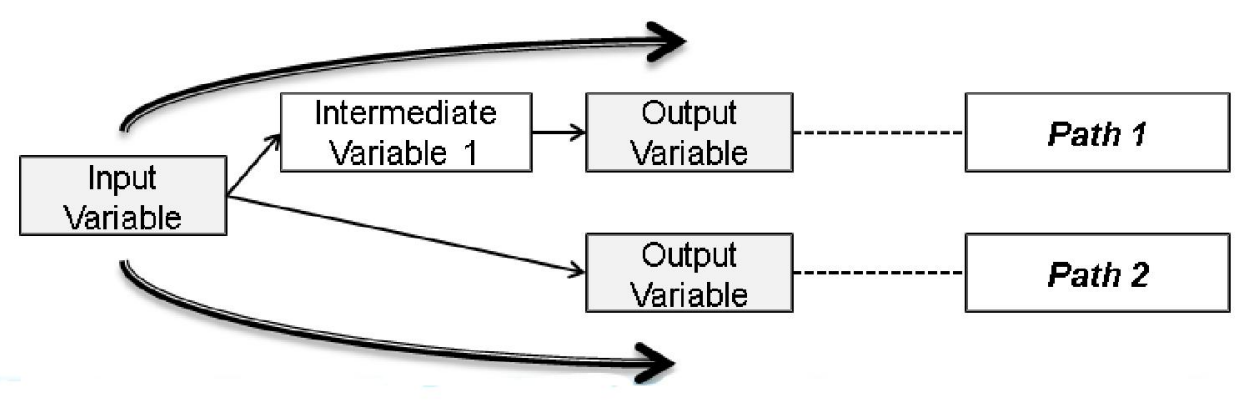

Figure 16: Definition of paths

C. Step 3-3: Define Time-Lag Functions in the Paths

Calculate new time-lag functions between the two licensing entities in the paths, using time-lag coefficients as demonstrated in Step 3-1. 


\section{Step 3-4: Define Direct Lag Functions of Each Path}

Define the direct lag function from each input to licensing income, using the transform function. After transform functions are applied to all paths in the licensing activity, all associated intermediating variables are eliminated and only a direct path from variable of interest to the licensing variable remains.

Figure 19 presents an example of multiple paths from an input variable, $X$, to an output variable, $Y$. Two intermediating variables, $Z 1$ and $Z 2$, are associated in the paths. Therefore, the indirect Path $1\left(f_{X, Y}{ }^{1}\right)$ from $X$ to $Y$ requires two transform functions $\left(f_{X Z 1} \otimes \mathrm{f}_{Z 1 Z 2} \otimes \mathrm{f}_{Z 2} \vartheta\right)$, and the indirect Path $2\left(f_{X, Y}{ }^{2}\right)$ is defined by one transform function $\left(f_{X Z 1} \otimes f_{Z 1 Y}\right)$.

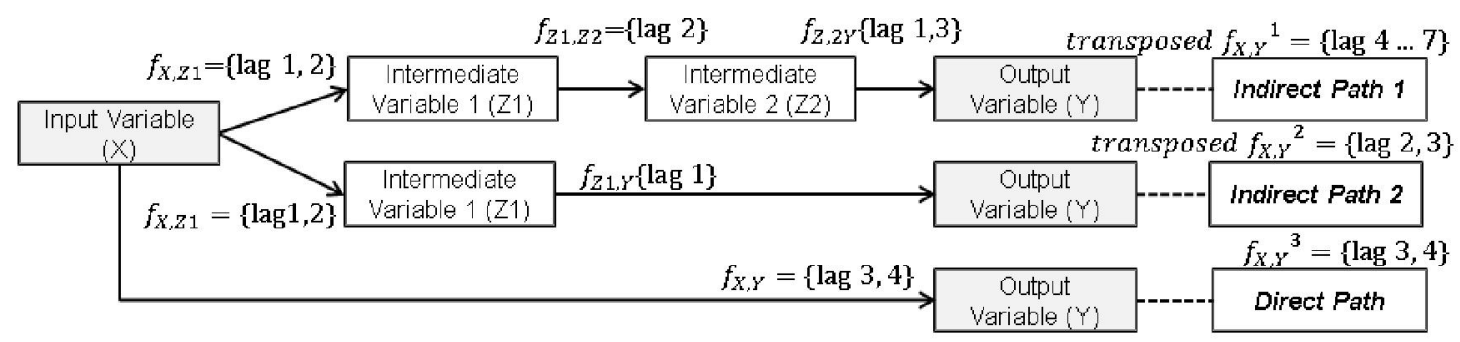

Figure 17: Example of multiple paths from an input to output variable

The direct path indicates either an actual lag effect from $X$ to $Y$ or a virtual effect, presenting overall lag effects of indirect Path 1 and Path 2. For example, patents $(X)$ are licensed for cash $(Y)$, or patents $(X)$ are licensed to a start-up (Z1), and then yield 
licensing income $(Y)$. Lags from expenditure to licensing income could be a virtual effect representing all other ways to be licensed.

\section{E. Step 3-5: Define a Total Aggregated Time-Lag Effect}

Sum up and standardize transformed direct lag functions, incorporating all lag effects from all the paths.

Lag coefficients $\left(f_{X, Y}\right)$ of the direct path, which are observed in the regression model, represent the most significant effect (in case of virtual effect) or the most important effect (in case of actual effect) out of time lags in all paths. In both cases, adding up the three transformed lag functions (first-degree functions) in the paths, $f_{X, Y}{ }^{1}+{f_{X, Y}}^{2}+f_{X, Y}{ }^{3}$, provides a reasonable way to integrate the paths by giving more weight to these important lags. 
3.4. Measuring the Performance of Academic Research Institution Technology Licensing (Goals 2 and 3)

The efficiencies of university technology commercialization show certain patterns over time [62]. Thus, ARITC practices could be better understood by examining those changing patterns and finding characteristics related to the changes. The changes in the efficiency scores could result from either the improvement of the institution or changes in the efficiency frontier. The Malmquist Index, comprising efficiency change (EC) and technical change (TC), provides a way to measure both changes in efficiency and the frontier of best practices over time.

In the present study, the output-oriented super-efficiency model is applied to measure the efficiencies and the Malmquist Index. However, both super-efficiency and the Malmquist Index models have an inherent computational infeasibility when a variable returns to scale is applied. Therefore, the computation limitation and related approaches to the issue are explored. Finally, a new method of resolving the issue for both super-efficiency and the Malmquist Index model is suggested.

\subsubsection{Data Envelopment Analysis}

Data envelopment analysis is a benchmarking technique developed to evaluate the performance of organizations in service sectors [108]. DEA is a mathematical programming tool and model to evaluate the performance of peer units, using multiple 
inputs and outputs [34]. Since it was introduced by Charnes, Cooper, and Rhodes (1978) [29], more than 2,000 related articles have been published [34].

\section{A. Basic Mathematical Model}

DEA is used to find the set of coefficients $\left(u_{r}, v_{i}\right)$ that make the highest possible efficiency ratio $\left(\theta_{\mathrm{o}}\right)$ of input $\left(x_{\mathrm{ij}}\right)$ and outputs $\left(y_{\mathrm{rj}}\right)$ for all decision-making units (DMUs) $\left(\mathrm{DMU}_{\mathrm{j}} ; j=1 \ldots n\right)[108]$. The basic form of DEA is presented in (7).

Maximize $\theta_{o}=\frac{u_{1} y_{1 o}+u_{2} y_{2 o}+\cdots+u_{r} y_{r o}}{v_{1} x_{1 o}+v_{2} x_{2 o}+\cdots+v_{m} x_{m o}}=\frac{\sum_{r=1}^{S} u_{r} y_{r o}}{\sum_{i=1}^{m} v_{i} x_{i o}}$

Subject to $\frac{\sum_{\mathrm{r}=1}^{\mathrm{s}} u_{\mathrm{r}} y_{r j}}{\sum_{\mathrm{i}=1}^{\mathrm{m}} v_{\mathrm{i}} x_{i j}} \leq 1 \quad j=1,2, \ldots, n$

$$
\begin{gathered}
u_{1}, \ldots, u_{s}>0 \\
\mathrm{v}_{1}, \ldots, v_{m} \geq 0
\end{gathered}
$$

This model calculates the relative efficiency ratio $\left(\theta_{0}\right)$ of the $\operatorname{DMU}_{\mathrm{o}}$. If the value of $\theta_{\mathrm{o}}$ is less than $100 \%$, the $\mathrm{DMU}_{\mathrm{o}}$ is inefficient.

\section{B. Multiplier Model}

The general model (7) as presented is nonlinear; therefore, it must be changed to a linear form, multiplier problem, using the following transformation [34]:

$t=\left(\sum_{\mathrm{i}=1}^{\mathrm{m}} v_{\mathrm{i}} x_{\mathrm{io}}\right)^{-1}=1, \mu_{r}=t u_{r}$ 
The transformed input-oriented model is presented in (9).

$\operatorname{Maximize} \sum_{\mathrm{r}=1}^{\mathrm{s}} \mu_{\mathrm{r}} y_{\mathrm{ro}}$

$$
\begin{aligned}
& \begin{array}{lll}
\text { Subject to } & \sum_{\mathrm{r}=1}^{\mathrm{s}} \mu_{\mathrm{r}} y_{\mathrm{rj}}-\sum_{\mathrm{i}=1}^{\mathrm{m}} v_{\mathrm{i}} x_{\mathrm{ij}} \leq 0 & \mathrm{i}=1,2, \ldots, m \\
& \sum_{\mathrm{i}=1}^{\mathrm{m}} v_{\mathrm{i}} x_{\mathrm{io}}=1 & \mathrm{r}=1,2, \ldots, s
\end{array} \\
& \mu_{\mathrm{r}}, v_{\mathrm{i}} \geq 0 \quad \mathrm{j}=1,2, \ldots, n
\end{aligned}
$$

The variables $\mu_{\mathrm{r}}$ and $v_{\mathrm{i}}$ are decision variables and are called output and input multipliers.

\section{Input- and Output-Oriented Models}

There are two approaches in DEA to identify the efficiency frontier line. One is to minimize input (the input-oriented model) and the other is to maximize output (the output-oriented model). The input-oriented multiplier model is presented in (10) by applying the dual linear program to the multiplier model (9).

Minimize $\theta$

$$
\begin{aligned}
& \text { Subject to } \sum_{\mathrm{j}=1}^{\mathrm{n}} \lambda_{\mathrm{j}} \mathrm{x}_{\mathrm{ij}} \leq \theta \mathrm{x}_{\mathrm{io}} \quad i=1,2, \ldots, m \\
& \sum_{\mathrm{j}=1}^{\mathrm{n}} \lambda_{\mathrm{j}} y_{\mathrm{rj}} \geq y_{\mathrm{ro}} \quad r=1,2, \ldots, s \\
& \lambda_{\mathrm{j}} \geq 0 \quad j=1,2, \ldots, n
\end{aligned}
$$

The relative efficiency of the $j^{\text {th }}$ DMU of the input-oriented model is represented by $\theta_{j}$. If the DMU is efficient, the value of $\theta$ is 1 . Otherwise, the value is less than 1 . 
The output-oriented multiplier model is presented in (11).

Maximize $\phi$

\begin{tabular}{|c|c|c|}
\hline Subject to & $\sum_{\mathrm{j}=1}^{\mathrm{n}} \lambda_{\mathrm{j}} x_{\mathrm{ij}} \leq x_{\mathrm{io}}$ & $i=1,2, \ldots, m$ \\
\hline & $\sum_{\mathrm{j}=1}^{\mathrm{n}} \lambda_{\mathrm{j}} y_{\mathrm{rj}} \geq \phi y_{\mathrm{ro}}$ & $r=1,2, \ldots, s$ \\
\hline & $\lambda_{\mathrm{j}} \geq 0$ & $j=1,2, \ldots, n$ \\
\hline
\end{tabular}

The efficiency of the output-oriented model is $\phi$. The value of $\phi$ of an inefficient DMU is greater than 1 .

D. Input and Output Data Envelopment Analysis Slack: Two-Stage Model

DEA slack is defined as the amount of reduction, or the increase of an input or output variable, of an efficient DMU, which is on the efficient frontier facet. This DMU is called a weakly efficient unit [108]. In order to check the DEA slack, the two-stage model is used. In the first stage, efficiency scores are calculated by the input- or output-oriented DEA model. At the second stage, the DEA slack model is applied. The input- and outputoriented second-stage slack models are presented in (12) and (13) holding the efficiency score from the first phase constant, respectively.

3) Input-oriented second-stage slack model

$\operatorname{Maximize} \sum_{i=1}^{m} s_{i}^{-}+\sum_{r=1}^{s} s_{r}^{+}$

Subject to $\sum_{\mathrm{j}=1}^{\mathrm{n}} \lambda_{\mathrm{j}} x_{\mathrm{ij}}+\mathrm{s}_{\mathrm{i}}^{-} \leq \theta^{*} x_{\mathrm{io}} \quad i=1,2, \ldots, m$ 


$$
\begin{array}{ll}
\sum_{\mathrm{j}=1}^{\mathrm{n}} \lambda_{\mathrm{j}} y_{\mathrm{rj}}-\mathrm{s}_{\mathrm{r}}^{+} \geq y_{\text {ro }} & r=1,2, \ldots, s \\
\lambda_{\mathrm{j}}, \mathrm{s}_{\mathrm{i}}^{-}, \mathrm{s}_{\mathrm{r}}^{+} \geq 0 & j=1,2, \ldots, n
\end{array}
$$

4) Output-oriented slack model

Maximize $\sum_{i=1}^{m} s_{i}^{-}+\sum_{r=1}^{s} s_{r}^{+}$

$$
\begin{aligned}
& \text { Subject to } \sum_{\mathrm{j}=1}^{\mathrm{n}} \lambda_{\mathrm{j}} x_{\mathrm{ij}}+\mathrm{s}_{\mathrm{i}}^{-} \leq x_{\mathrm{io}} \quad i=1,2, \ldots, m \\
& \sum_{\mathrm{j}=1}^{\mathrm{n}} \lambda_{\mathrm{j}} y_{\mathrm{rj}}-\mathrm{s}_{\mathrm{r}}^{+} \geq \phi^{*} y_{\mathrm{ro}} \quad r=1,2, \ldots, s \\
& \lambda_{\mathrm{j}}, \mathrm{s}_{\mathrm{i}}^{-}, \mathrm{s}_{\mathrm{r}}^{+} \geq 0 \quad j=1,2, \ldots, n,
\end{aligned}
$$

where $s_{i}^{-}$and $s_{r}^{+}$represent input and output slack, respectively. The optimal solution of each input- and output-oriented DEA, $\theta^{*}$ and $\phi^{*}$, is calculated by the multiplier model $(8$, 9) before slack models are applied.

\section{E. Returns to Scale}

The DEA models discussed above assume that the input and output variables have a constant returns to scale (CRS) relationship. This means that a change in input results in a change in output with a certain linear ratio. For example, if input $x$ increases to $\alpha^{*} x$, then output $y$ also increases $\beta^{*}$, while $\alpha=\beta$ [34]. On the other hand, if $\alpha \neq \beta$, then it has one of two relations: $\alpha>\beta$ or $\alpha<\beta$. Increasing returns to scale is the case of $\alpha<\beta$, if both $\alpha$ and $\beta$ represent increase. Decreasing returns to scale is the case of $\alpha>\beta$, if both $\alpha$ and $\beta$ decrease. Variable returns to scale represents either increase returns to scale or decrease 
returns to scale. To incorporate VRS into the DEA model, one more constraint, $\sum_{\mathrm{j}=1}^{\mathrm{n}} \lambda_{\mathrm{j}}=$ 1 , can be added.

\section{F. Super-Efficiency Model and Infeasibility}

The super-efficiency DEA model excludes from the reference set of the DEA model a DMU under evaluation. The result is that the (output-oriented) score of an efficient DMU is usually greater than $1[34,137]$. The output-oriented BCC super-efficiency DEA model is presented in (14).

Maximize $\phi^{\text {super }}$

$$
\begin{aligned}
& \text { Subject to } \sum_{\substack{\mathrm{j}=1 \\
\mathrm{j} \neq \mathrm{o}}}^{\mathrm{n}} \lambda_{\mathrm{j}} x_{\mathrm{ij}} \leq x_{\mathrm{io}}, \quad i=1,2, \ldots, m \\
& \sum_{\substack{\mathrm{j}=1 \\
\mathrm{j} \neq 0}}^{\mathrm{n}} \lambda_{\mathrm{j}} y_{\mathrm{rj}} \geq \phi^{\text {super }} y_{\mathrm{ro}}, \quad r=1,2, \ldots, s \\
& \sum_{j=1}^{n} \lambda_{j}=1, \\
& \mathrm{j} \neq 0 \\
& \lambda_{\mathrm{j}} \geq 0 \quad j \neq o
\end{aligned}
$$

In the model (14), if the output value of an evaluated DMU is smaller than a convex combination of the other DMUs, the output constraint cannot be satisfied, therefore resulting a computational infeasibility [106] [134] [30] [70] [31] [33, 66]. 


\section{G. Productivity Change}

The Malmquist productivity index was developed in 1953 by Sten Malmquist [73] and has been proven to be a good tool for measuring productivity changes [34]. It measures changes in both the frontier and the efficiencies of DMUs. MI requires two single-period and two mixed-period measures. The input-oriented CRS DEA models are used, for example, in (15-18) [34].

The first CRS DEA model in time period $t=\theta_{o}^{\mathrm{t}}\left(x_{\mathrm{o}}^{\mathrm{t}}, y_{\mathrm{o}}^{\mathrm{t}}\right)$

$\theta_{o}^{\mathrm{t}}\left(x_{\mathrm{o}}^{\mathrm{t}}, y_{\mathrm{o}}^{\mathrm{t}}\right)=$ Minimize $\theta_{o}$

Subject to

$$
\begin{array}{ll}
\sum_{\mathrm{j}=1}^{\mathrm{n}} \lambda_{\mathrm{j}} x_{\mathrm{ij}}^{\mathrm{t}} \leq \theta_{o} x_{\mathrm{io}}^{\mathrm{t}}, & i=1,2, \ldots, m \\
\sum_{\mathrm{j}=1}^{\mathrm{n}} \lambda_{\mathrm{j}} y_{\mathrm{rj}}^{\mathrm{t}} \geq y_{\mathrm{ro}}^{\mathrm{t}}, & r=1,2, \ldots, s \\
\lambda_{\mathrm{j}} \geq 0 & j=1,2, \ldots, n
\end{array}
$$

The second CRS DEA model in time period $t+1=\theta_{o}^{\mathrm{t}+1}\left(x_{\mathrm{o}}^{\mathrm{t}+1}, y_{\mathrm{o}}^{\mathrm{t}+1}\right)$

$$
\theta_{o}^{\mathrm{t}+1}\left(x_{\mathrm{o}}^{\mathrm{t}+1}, y_{\mathrm{o}}^{\mathrm{t}+1}\right)=\text { Minimize } \theta_{o}
$$

$$
\begin{aligned}
& \text { Subject to } \sum_{\mathrm{j}=1}^{\mathrm{n}} \lambda_{\mathrm{j}} x_{\mathrm{ij}}^{\mathrm{t}+1} \leq \theta_{o} x_{\mathrm{io}}^{\mathrm{t}+1}, \quad i=1,2, \ldots, m \\
& \sum_{\mathrm{j}=1}^{\mathrm{n}} \lambda_{\mathrm{j}} y_{\mathrm{rj}}^{\mathrm{t}+1} \geq y_{\mathrm{ro}}^{\mathrm{t}+1}, \quad r=1,2, \ldots, s \\
& \lambda_{\mathrm{j}} \geq 0 \quad j=1,2, \ldots, n
\end{aligned}
$$

The first mixed CRS DEA model is $\theta_{o}^{\mathrm{t}}\left(x_{\mathrm{o}}^{\mathrm{t}+1}, y_{\mathrm{o}}^{\mathrm{t}+1}\right)$ 
$\theta_{o}^{\mathrm{t}}\left(x_{\mathrm{o}}^{\mathrm{t}+1}, y_{\mathrm{o}}^{\mathrm{t}+1}\right)=$ Minimize $\theta_{o}$

$$
\begin{aligned}
& \text { Subject to } \sum_{\mathrm{j}=1}^{\mathrm{n}} \lambda_{\mathrm{j}} x_{\mathrm{ij}}^{\mathrm{t}} \leq \theta_{o} x_{\mathrm{io}}^{\mathrm{t}+1}, \quad i=1,2, \ldots, m \\
& \sum_{\mathrm{j}=1}^{\mathrm{n}} \lambda_{\mathrm{j}} y_{\mathrm{rj}}^{\mathrm{t}} \geq y_{\mathrm{ro}}^{\mathrm{t}+1}, \quad r=1,2, \ldots, s \\
& \lambda_{\mathrm{j}} \geq 0 \quad j=1,2, \ldots, n
\end{aligned}
$$

The second mixed CRS DEA model is $\theta_{0}^{\mathrm{t}+1}\left(x_{0}^{\mathrm{t}}, y_{0}^{\mathrm{t}}\right)$

$$
\theta_{o}^{\mathrm{t}+1}\left(x_{\mathrm{o}}^{\mathrm{t}}, y_{\mathrm{o}}^{\mathrm{t}}\right)=\text { Minimize } \theta_{o}
$$

$$
\begin{aligned}
& \text { Subject to } \sum_{\mathrm{j}=1}^{\mathrm{n}} \lambda_{\mathrm{j}} \mathrm{x}_{\mathrm{ij}}^{\mathrm{t}+1} \leq \theta_{o} x_{\mathrm{io}}^{\mathrm{t}}, \quad i=1,2, \ldots, m \\
& \sum_{\mathrm{j}=1}^{\mathrm{n}} \lambda_{\mathrm{j}} y_{\mathrm{rj}}^{\mathrm{t}+1} \geq y_{\mathrm{ro}}^{\mathrm{t}}, \quad r=1,2, \ldots, s \\
& \lambda_{\mathrm{j}} \geq 0 \quad j=1,2, \ldots, n
\end{aligned}
$$

Finally, the input-oriented MI is defined by the following equation:

$$
\mathrm{M}_{\mathrm{o}}=\left[\frac{\theta_{0}^{\mathrm{t}}\left(\left(_{\mathrm{o}}^{\mathrm{t}}, \mathrm{t}_{\mathrm{o}}^{\mathrm{t}}\right)\right.}{\theta_{o}^{\mathrm{t}}\left(x_{\mathrm{o}}^{\mathrm{t}+1}, y_{\mathrm{o}}^{\mathrm{t}+1}\right)} \times \frac{\theta_{0}^{\mathrm{t}+1}\left(\mathrm{x}_{\mathrm{t}}^{\mathrm{t}}, y_{\mathrm{o}}^{\mathrm{t}}\right)}{\theta_{0}^{\mathrm{t}+1}\left(x_{\mathrm{o}}^{\mathrm{t}}, y_{\mathrm{o}}^{\mathrm{t}+1}\right)}\right]^{\frac{1}{2}}
$$

The index, $M_{\mathrm{o}}$, measures productivity change between $t$ and $t+1$. If $M_{\mathrm{o}}>1$, it means productivity declines. When $M_{\mathrm{o}}=1$, it remains unchanged. MI is also used to calculate the change of efficiency and the movement of the frontier in terms of a specific DMU. For this purpose, $\mathrm{MI}$ is decomposed to the technical efficiency change and the shift in the frontier (technical change) between $t$ and $t+1$ [34]. 
$\mathrm{EC}_{\mathrm{o}}=\frac{\theta_{o}^{\mathrm{t}}\left(x_{\mathrm{o}}^{\mathrm{t}}, y_{\mathrm{o}}^{\mathrm{t}}\right)}{\theta_{o}^{\mathrm{t}+1}\left(x_{\mathrm{o}}^{\mathrm{t}+1}, y_{\mathrm{o}}^{\mathrm{t}+1}\right)}$

If $\mathrm{EC}_{\mathrm{o}}$ is less than 1 , it means that efficiency improves; if it is equal to 1 , it means efficiency is unchanged; if it is greater than 1, it means that efficiency declines.

$\mathrm{TC}_{\mathrm{o}}=\left[\frac{\theta_{0}^{\mathrm{t}+1}\left(x_{\mathrm{o}}^{\mathrm{t}+1}, y_{\mathrm{o}}^{\mathrm{t}+1}\right)}{\theta_{0}^{\mathrm{t}}\left(x_{\mathrm{o}}^{\mathrm{t}+1}, y_{0}^{\mathrm{t}+1}\right)} \times \frac{\theta_{o}^{\mathrm{t}+1}\left(x_{\mathrm{o}}^{\mathrm{t}}, y_{\mathrm{o}}^{\mathrm{t}}\right)}{\theta_{o}^{\mathrm{t}}\left(x_{\mathrm{o}}^{\mathrm{t}}, y_{0}^{\mathrm{t}}\right)}\right]^{\frac{1}{2}}$

If $\mathrm{TC}_{\mathrm{o}}$ is greater than 1 , it means regression in the frontier. The frontier progresses if $\mathrm{TC}_{\mathrm{o}}$ is less than 1.

\subsubsection{Infeasibility in the Malmquist Index and the Super-Efficiency Model}

Seiford and Zhu [106] explored the details of the necessary and sufficient condition of infeasibility in the super-efficiency model. The issue is applicable only to nonconstant returns to scale, such as non-increase, nondecrease, and variable returns to scale. The conditions of infeasibility, along with the types of returns to scale, are summarized in Table 21. 
Table 21: Infeasibility of the super-efficiency data envelopment analysis models

\begin{tabular}{|c|c|c|c|}
\hline \multicolumn{2}{|c|}{$\begin{array}{c}\text { Super-Efficiency DEA } \\
\text { Models }\end{array}$} & Model Specification of the Condition & $\begin{array}{l}\text { Conditions of } \\
\text { Infeasibility }\end{array}$ \\
\hline \multirow{3}{*}{$\begin{array}{l}\text { Output } \\
\text { oriented }\end{array}$} & VRS & $\begin{array}{c}h^{*}=\min h \\
\text { s.t. } \sum_{\substack{j=1 \\
j \neq o}}^{n} \lambda_{j} x_{j} \leq h x_{o} \\
\\
\sum_{\substack{j=1 \\
j \neq o}}^{n} \lambda_{j}=1, \lambda_{j} \geq 0, j \neq o .\end{array}$ & $\begin{array}{l}\text { If and only if } \\
\qquad h^{*}>1\end{array}$ \\
\hline & $\begin{array}{c}\text { NIRS } \\
\text { (DRS or } \\
\text { CRS) }\end{array}$ & \multicolumn{2}{|l|}{ Always feasible } \\
\hline & NDRS & $\begin{array}{c}h^{*}=\min h \\
\text { s.t. } \sum_{\substack{j=1 \\
j \neq o}}^{n} \lambda_{j} x_{j} \leq h x_{o} \\
\sum_{\substack{j=1 \\
j \neq o}}^{n} \lambda_{j}>1, \lambda_{j} \geq 0, j \neq o .\end{array}$ & $\begin{array}{l}\text { If and only if } \\
\qquad h^{*}>1\end{array}$ \\
\hline \multirow{3}{*}{$\begin{array}{l}\text { Input } \\
\text { oriented }\end{array}$} & VRS & $\begin{array}{c}g^{*}=\max g \\
\text { s.t. } \sum_{\substack{j=1 \\
j \neq o}}^{n} \lambda_{j} y_{j} \leq g y_{o} \\
\sum_{\substack{j=1 \\
j \neq o}}^{n} \lambda_{j}=1, \lambda_{j} \geq 0, j \neq o .\end{array}$ & $\begin{array}{l}\text { If and only if } \\
\qquad g^{*}<1\end{array}$ \\
\hline & NIRS & $\begin{array}{c}g^{*}=\max g \\
\text { s.t. } \sum_{\substack{j=1 \\
j \neq o}}^{n} \lambda_{j} y_{j} \leq g y_{o} \\
\sum_{\substack{j=1 \\
j \neq o}}^{n} \lambda_{j}<1, \lambda_{j} \geq 0, j \neq o\end{array}$ & $\begin{array}{l}\text { If and only if } \\
\qquad g^{*}<1\end{array}$ \\
\hline & NDRS & \multicolumn{2}{|l|}{ Always feasible } \\
\hline
\end{tabular}

Source: Adapted from from Seiford and Zhu [106]

Note: $\mathrm{CRS}=$ constant returns to scale; DEA $=$ data envelopment analysis; $\mathrm{DRS}=$ decrease returns to scale; NDRS $=$ non-decrease returns to scale; NIRS $=$ non-increase returns to scale; VRS $=$ variable returns to scale, $*=$ optimal solution

The infeasibility always occurs at an extreme data point where no other decision-making units can be compared. For an illustration of infeasibility, the output-oriented VRS superefficiency model with one input $x$ and one output variable $y$ is used: 
Maximize $\phi^{\text {super }}$

$$
\begin{aligned}
& \text { Subject to } \sum_{\substack{\mathrm{j}=1 \\
\mathrm{j} \neq \mathrm{0}}}^{\mathrm{n}} \lambda_{\mathrm{j}} x_{\mathrm{ij}} \leq x_{\mathrm{io}}, \quad i=1,2, \ldots, m \\
& \sum_{\substack{\mathrm{j}=1 \\
\mathrm{j} \neq \mathrm{o}}}^{\mathrm{n}} \lambda_{\mathrm{j}} y_{\mathrm{rj}} \geq \phi^{\text {super }} y_{\mathrm{ro}}, \quad \quad r=1,2, \ldots, s \\
& \sum_{\substack{j=1 \\
j \neq 0}}^{n} \lambda_{j}=1 \\
& \lambda_{\mathrm{j}} \geq 0, \quad j=1,2, \ldots, n ; j \neq o
\end{aligned}
$$

In Figure 18, if B is the evaluated DMU, the frontier line is formulated as the line from B to $\mathrm{C}$. Then the virtual point, $\mathrm{B}^{*}$, which is an equivalent performance based on the other frontier points, $\mathrm{A}$ and $\mathrm{C}$, is set by the two convex combinations, $\lambda_{\mathrm{A}} x_{A}+\lambda_{C} x_{C} \leq x_{\mathrm{B}}, \mathrm{d}$ $\lambda_{\mathrm{A}} y_{A}+\lambda_{C} y_{C} \leq y_{B^{*}}$ and $\lambda_{\mathrm{A}}+\lambda_{C}=1$, in the model. The super-efficiency of $\mathrm{B}, \phi_{B}{ }^{\text {super }}$, can be defined by the distance between $\mathrm{B}$ and $\mathrm{B}^{*}$.

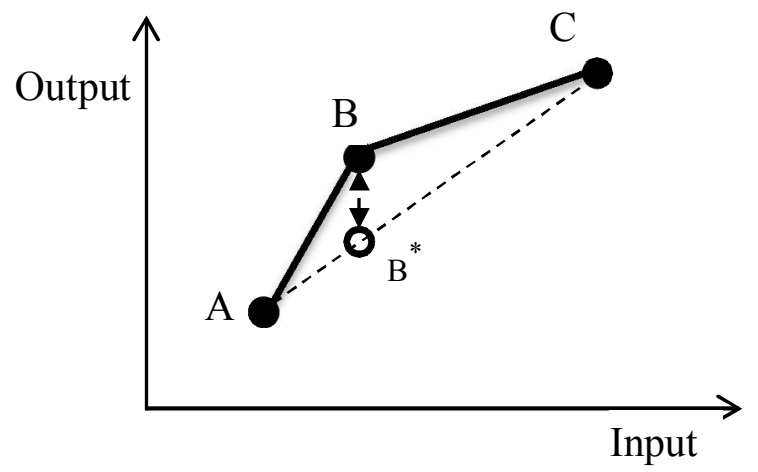

Figure 18: Super-efficiency of $B$ in the output-oriented super-efficiency variable returns to scale data envelopment analysis model

However, when DMU A is evaluated, the frontier line, $\overline{B C}$, forms the feasible boundary, which is defined by the area of points B', B, and C. As a result, the DMU A is located out of the area. The computational error occurs because there is no way to satisfy the 
constraints $\lambda_{B} x_{B}+\lambda_{C} x_{C} \leq x_{A}$ and $\lambda_{B}+\lambda_{C}=1$. In other words, the virtual DMU, $\mathrm{A}^{*}$, which will be compared to A, cannot be defined (Figure 19). In the case of the inputoriented model, the DMU is the extreme point and is infeasible.

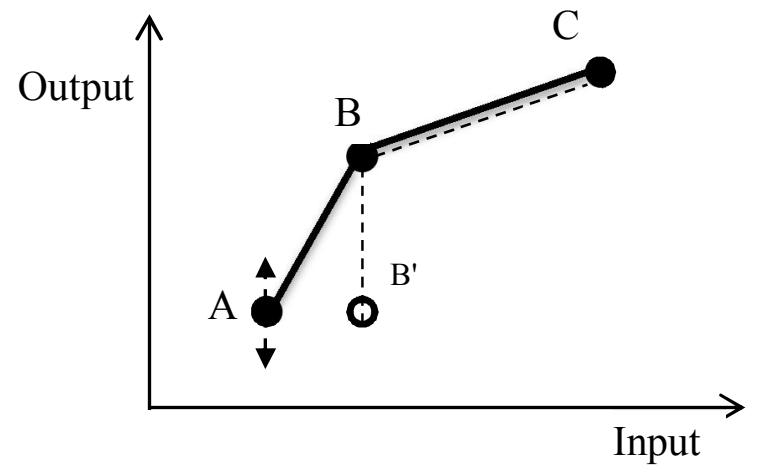

Figure 19: Infeasibility of $A$ in the output oriented super-efficiency variable returns to scale data envelopment analysis model

\subsubsection{Selecting a Super-Efficiency Model to Resolve Computational Infeasibility}

There have been several approaches to resolving the computational infeasibility issue in the Malmquist Index or super-efficiency model when a nonconstant returns to scale is used. One application of the super-efficiency model is to rank the efficient DMUs. The ranking of an infeasible DMU cannot be considered. Xue and Harker [134] suggest an approach to ranking infeasible DMUs by adopting the classification of efficient DMUs by Charnes, et al. [30]. Xue and Harker [134] defined an infeasible DMU as a strongly super-efficient DMU. According to their definition and their finding from the surplus slacks of input (in the output-oriented model) or output (in the input-oriented model) of the infeasible DMU, the efficiency of the strongly super-efficient DMU is superior to that 
of the strongly efficient DMU, which is followed by efficient and weakly efficient DMUs, in order. However, this approach cannot be considered an ultimate solution for infeasibility.

Lovell and Rouse [70] suggested an interesting approach to calculating the superefficiency scores of infeasible DMUs. If a DMU is infeasible in the output-oriented super-efficiency model, a ratio, $\beta$, is applied to the DMU, putting the virtual DMU into the feasible area of the model's constraints.

$\beta=\left\{\max \left(\beta_{1}, \ldots, \beta_{r}\right)\right\}^{-1}$, where $\beta_{r}=\left(\frac{\max y_{r j}}{\min y_{r j}}\right)+1$

Their modified output-oriented super-efficiency model is as follows:

Maximize $\phi^{\prime}$

Subject to $\sum_{\substack{\mathrm{j}=1 \\ \mathrm{j} \neq \mathrm{o}}}^{\mathrm{n}} \lambda_{\mathrm{j}} x_{\mathrm{ij}}+\lambda_{\mathrm{o}} x_{i o} \leq x_{\mathrm{io}}, \quad i=1,2, \ldots, m$

$$
\begin{array}{ll}
\sum_{\substack{\mathrm{j}=1 \\
\mathrm{j} \neq 0}}^{\mathrm{n}} \lambda_{\mathrm{j}} y_{\mathrm{rj}}+\beta \lambda_{o} y_{r o} \geq \beta y_{\mathrm{ro}} \phi^{\prime}, r=1,2, \ldots, s \\
\sum_{\substack{j=1 \\
j \neq o}}^{n} \lambda_{j}+\lambda_{o}=1 \\
\lambda_{\mathrm{j}} \geq 0, & j=1,2, \ldots, n ; j \neq o
\end{array}
$$

The super-efficiency condition in the model is released, and a general efficiency score, $\phi^{\prime}$, is calculated. Then, the original super-efficiency score $\left(\phi^{\text {super*}}\right)$ is equivalent to $\phi^{\prime} * \beta$. 
Figure 20 illustrates how the frontier line is formed using the scale $\beta$. The DMU $\mathrm{A}$ is an infeasible extreme point in the general super-efficiency model. The DMU is projected to $\mathrm{A}^{\prime}$ by multiplying the scale $(\beta)$. Then, the general efficiency model forms a frontier line by the convex combination of $\mathrm{A}^{\prime}, \mathrm{B}$, and $\mathrm{C}$, with the result that the efficiency score of $\mathrm{A}^{\prime}$ is 1. Therefore, the modified super-efficiency score of the DMU A becomes the same value as that of the scale $(\beta)$.

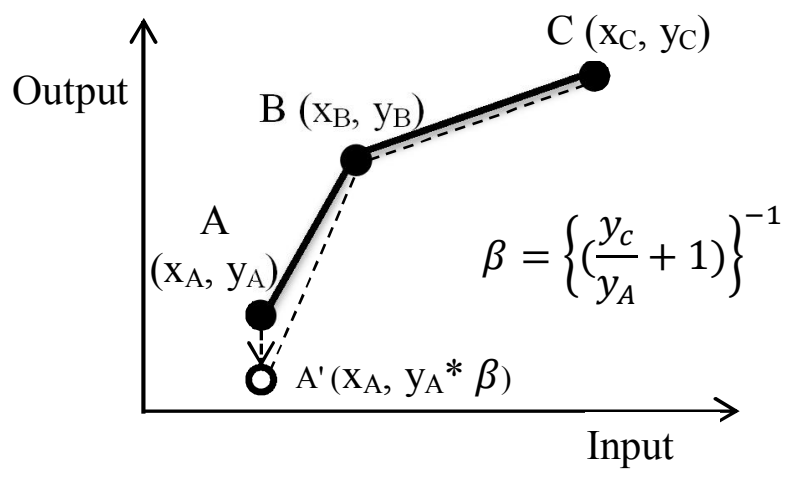

Figure 20: Modified output-oriented super-efficiency model by Lovell and Rouse [70]

This method has two good properties. First, its computation is robust and always feasible because it doesn't use the constraint required for the super-efficiency model. Second, all other feasible DMUs have exactly the same efficiency scores in the super-efficiency model. However, the scale $(\beta)$ Lovell and Rouse [70] defined is arbitrary and results in the same super-efficiency scores when there are multiple infeasible DMUs. In an extreme case where the output variable $\left(\mathrm{y}_{\mathrm{A}}\right)$ is a very small number, less than 1 , the superefficiency score becomes an unrealistically big number because it relies on the ratio of $y_{\mathrm{C}}$ to $y_{\mathrm{A}}$. 
On the other hand, Chen [31] used a different approach to define the super-efficiency scores of the infeasible DMUs. She considered an output surplus of a super-efficient DMU in the output-oriented model, and input saving in the input-oriented model. Consider the DMUs A, B, C, and D in Figure 21. The evaluated DMU, B, is projected to $\mathrm{B}^{* 1}$, which is a convex combination of $\mathrm{A}$ and $\mathrm{C}$ in the output-oriented super-efficiency model. In this case, the super-efficiency $\left(\phi^{\text {super* }}\right)$ of B is defined by the output distance between $B$ and $\mathrm{B}^{* 1}$, which is an output surplus. In the same way, the input-oriented superefficiency $\left(\theta^{\text {super } *}\right)$ represents the input savings between $\mathrm{B}$ and $\mathrm{B}^{* 2}$.

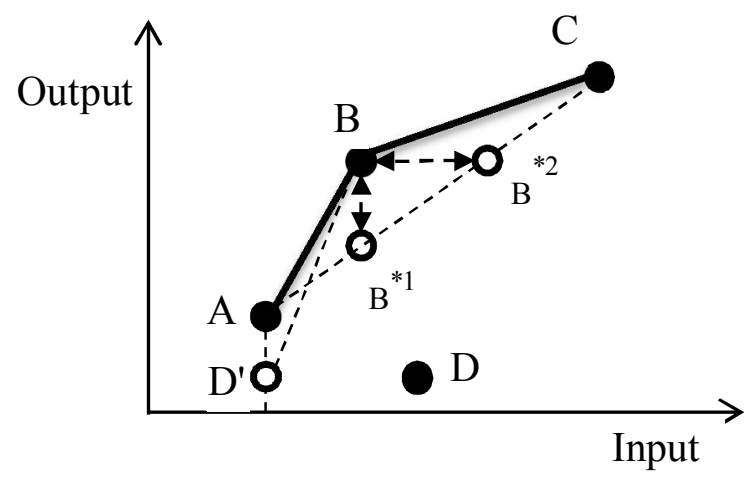

Figure 21: Chen's [31] solution to an infeasibility

However, in the case of the DMU A, no convex combination can be defined for project A when the output-oriented super-efficiency model is applied. Therefore, Chen [31] suggested that the DMU D, which is an efficient DMU, be projected to the same level of input as A, and she defines the super-efficiency of A as the output surplus from A to D'. The inefficient DMUs are projected using the CRS input-oriented (or output-oriented) model in the case of an output-oriented (or input-oriented) super-efficiency model. This 
method is significant in that it provides more reasonable measures of the efficiency of an infeasible DMU using output surplus and input savings, compared with the approach by Lovell and Rouse [70]. However, this method is not applicable if there is no DMU such as DMU D, which is smaller than DMU A. Chen [31] defined the super-efficiency in this case as 1 .

There are two other studies [33, 66] adopting Chen's [31] input savings and output surplus of the infeasible DMUs, but in a different way. Cook, et al. [33] defined the super-efficiencies by moving the evaluated DMU B to both directions of input and output, but with a different priority to project to each direction. In the case of the output-oriented VRS super-efficiency model, an evaluated DMU is projected to the output direction first, until it reaches the frontier line. If the DMU cannot be projected to the frontier line by moving it only to the output direction, it is shifted to the input direction and then again to the output direction.

For example, the DMUs A, B, and C, using an output-oriented VRS super-efficiency model, are illustrated in Figure 22. The evaluated DMUs, A and B, are projected to the frontiers, $\overline{A C}$ (a) and $\overline{B C}$ (b), by moving $1-\gamma$ to the output direction and $1+\delta$ to the input direction. In the case of the DMU B, $\gamma$ is greater than 1 and $\delta$ is zero because there is no need to move to the input direction, as shown in the left graphic (a) of Figure 22. However, the infeasible DMU A should increase both its input and output by $1+\delta$ and $1-\gamma$, respectively. Therefore, $\gamma$ is less than zero and $\delta$ is greater than zero. 


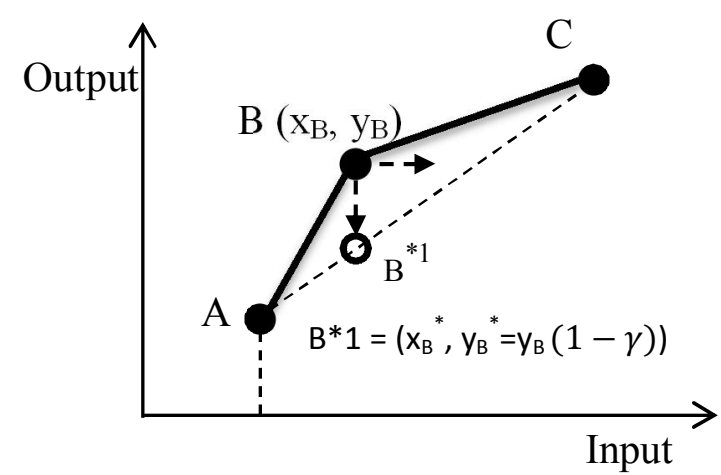

(a) Feasible

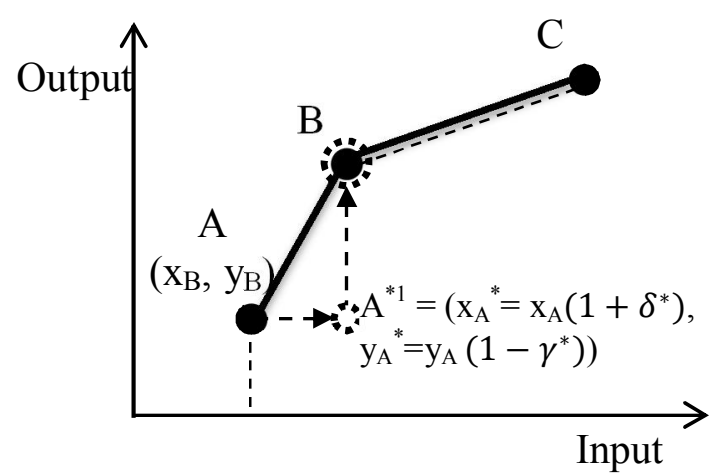

(b) Infeasible

Figure 22: Input saving (or output surplus) in an output-oriented (or input-oriented) model

A user-defined large positive weight, $M$, is used in the model specification of the DEA model in order to incorporate these preferred movements to input and output. The outputoriented modified VRS super-efficiency model is as follows:

Minimize $\gamma+M \times \delta$

Subject to $\sum_{\substack{\mathrm{j}=1 \\ \mathrm{j} \neq \mathrm{o}}}^{\mathrm{n}} \lambda_{\mathrm{j}} x_{\mathrm{ij}} \leq(1+\delta) x_{\mathrm{io}}, \quad i=1,2, \ldots, m$

$$
\begin{array}{ll}
\sum_{\substack{\mathrm{j}=1 \\
\mathrm{j} \neq 0}}^{\mathrm{n}} \lambda_{\mathrm{j}} y_{\mathrm{rj}} \geq(1-\gamma) y_{\mathrm{ro}}, \quad & r=1,2, \ldots, s \\
\sum_{\substack{j=1 \\
j \neq 0}}^{n} \lambda_{j}=1 & \\
\delta \geq 0, \lambda_{\mathrm{j}} \geq 0, & j=1,2, \ldots, n ; j \neq o
\end{array}
$$

In the case of $M=0$, then this is equivalent to the standard output oriented super-efficient model with $\emptyset=1-\gamma^{*}$. On the other hand, as $M$ goes to infinity, the model approaches that of the input oriented super-efficiency model with $\emptyset=1+\delta^{*}$. 
If the model is feasible, the super-efficiency scores are equivalent to $1-\gamma^{*}$. In the infeasible cases, the super-efficiency scores should be modified because the original location of the evaluated DMU is moved by the amount of input saving $\left(1+\delta^{*}\right)$. Cook, et al. [33] defined the modified super-efficiency score of an infeasible DMU as $1+\delta^{*}+1 /\left(1-\gamma^{*}\right)$

Although Cook, et al. [33]'s study provides an advanced approach, applying the concepts of input saving in the output-oriented VRS super-efficiency model and output surplus in the input-oriented model, it suffers another computational limitation because of the arbitrary number of $M$. The results of the model depend on how a user defines the value of $M$.

Lee, et al. [66], adopting Cook, et al. [33], suggested two stages for the modified superefficiency VRS model. At the first stage, the DEA model calculates the input savings (in the output-oriented model) or the output surplus (in the input-oriented model), and at the second stage, the savings and surplus are incorporated into the DEA model, calculating the super-efficiency. The output-oriented model of the input savings at the first stage is

Minimize $\sum_{i=1}^{m} t_{i}$

$$
\begin{gathered}
\text { Subject to } \sum_{\substack{\mathrm{j}=1 \\
\mathrm{j} \neq \mathrm{o}}}^{\mathrm{n}} \lambda_{\mathrm{j}} x_{\mathrm{ij}}-t_{i} x_{i o} \leq x_{\mathrm{io}}, \quad i=1,2, \ldots, m \\
\sum_{\substack{j=1 \\
j \neq o}}^{n} \lambda_{j}=1
\end{gathered}
$$




$$
\begin{array}{ll}
\lambda_{\mathrm{j}} \geq 0, & j=1,2, \ldots, n ; j \neq o \\
t_{i} \geq 0, & i=1,2, \ldots, m,
\end{array}
$$

where $t_{i}$ is the input slack of the $i^{\text {th }}$ input variable of the evaluated DMU.

The second stage determines the distance of the shifted target DMU to the frontier by holding the input savings constant from the first stage using the model

Maximize $\hat{\beta}_{o}$

Subject to $\sum_{\substack{\mathrm{j}=1 \\ \mathrm{j} \neq 0}}^{\mathrm{n}} \lambda_{\mathrm{j}} x_{\mathrm{ij}}-t_{i} x_{i o} \leq x_{\mathrm{io}}, \quad i=1,2, \ldots, m$

$$
\begin{array}{ll}
\sum_{\substack{\mathrm{j}=1 \\
\mathrm{j} \neq 0}}^{\mathrm{n}} \lambda_{\mathrm{j}} y_{\mathrm{rj}} \geq \hat{\beta}_{o} y_{\mathrm{ro}}, & r=1,2, \ldots, s \\
\sum_{\substack{j=1 \\
j \neq o}}^{n} \lambda_{j}=1 & \\
\lambda_{\mathrm{j}} \geq 0, & j=1,2, \ldots, n ; j \neq o .
\end{array}
$$

Finally, the modified super-efficiency score, $\breve{\beta}$, is calculated using

if $I \neq \Phi, \frac{1}{\bar{\beta}_{o}}=\left\{\frac{\sum_{i \in I} \frac{x_{i o}+t_{i}{ }^{*} x_{i o}}{x_{i o}}}{|I|}+\frac{1}{\widehat{\beta}_{o}{ }^{*}}\right.$,

if $I=\Phi, \frac{1}{\widehat{\beta}_{o}}=\frac{1}{\widehat{\beta}_{o}{ }^{*}}$

where $I=\left\{i \mid t_{i}^{*}>0\right\}$. 
If an evaluated DMU is super-efficiency feasible, there is no input savings $\left(t_{i}{ }^{*}=0\right)$ and the efficiency score $\left(\hat{\beta}^{*}\right)$ at the second stage is equivalent to the modified super-efficiency score $(\breve{\beta})$. This method doesn't require a user defined arbitrary number while Cook, et al. [33] used a user defined number $M$.

Another difference between the two methods is in the way they define the modified super-efficiency scores using the input savings and output surplus. In the output-oriented model, for example, Cook, et al. [33] applied the radial input savings and output surplus, which results in a single value of savings and surplus each, whereas Lee, et al. [66] used the nonradial model. The latter method uses the average of multiple savings (in the output-oriented model) or surplus (in the input-oriented model). As a result, the modified super-efficiency scores of an infeasible DMU from Lee, et al.'s [66] method tend to be a little bit higher than the ones from Cook, et al. [33].

For a detailed comparison of the three methods (Lovell and Rouse [70], Cook, et al. [33] and Lee, et al. [66]), the super-efficiency scores are tested using published data from Cook, et al. [33] for both input- and output-oriented models (Table 22). (See [33] for detailed information about the data.) 
Table 22: Data to test the three methods

\begin{tabular}{|c|c|c|c|c|c|c|c|}
\hline \multirow{2}{*}{\multicolumn{2}{|c|}{$\begin{array}{l}\text { Decision- } \\
\text { Making Unit } \\
\text { (City) }\end{array}$}} & \multicolumn{3}{|c|}{ Input Variables } & \multicolumn{3}{|c|}{ Output Variables } \\
\hline & & $\begin{array}{l}\text { House } \\
\text { price }\end{array}$ & Rental & Violent & Income & $\begin{array}{c}\text { Bachelor's } \\
\text { degree }\end{array}$ & Doctorate \\
\hline 1 & Seattle & 586 & 581 & $1,193.06$ & 46,928 & 0.6534 & 9.878 \\
\hline 2 & Denver & 475 & 558 & $1,131.64$ & 42,879 & 0.5529 & 5.301 \\
\hline 3 & Philadelphia & 201 & 600 & 3,468 & 43,576 & 1.135 & 18.2 \\
\hline 4 & Minneapolis & 299 & 609 & $1,340.55$ & 45,673 & 0.729 & 7.209 \\
\hline 5 & Raleigh & 318 & 613 & 634.7 & 40,990 & 0.319 & 4.94 \\
\hline 6 & St. Louis & 265 & 558 & 657.5 & 39,079 & 0.515 & 8.5 \\
\hline 7 & Cincinnati & 467 & 580 & 882.4 & 38,455 & 0.3184 & 4.48 \\
\hline 8 & Washington & 583 & 625 & $3,286.7$ & 54,291 & 1.7158 & 15.41 \\
\hline 9 & Pittsburgh & 347 & 535 & 917.04 & 34,534 & 0.4512 & 8.784 \\
\hline 10 & Dallas & 296 & 650 & $3,714.3$ & 41,984 & 1.2195 & 8.82 \\
\hline 11 & Atlanta & 600 & 740 & $2,963.1$ & 43,249 & 0.9205 & 7.805 \\
\hline 12 & Baltimore & 575 & 775 & $3,240.75$ & 43,291 & 0.5825 & 10.05 \\
\hline 13 & Boston & 351 & 888 & $2,197.12$ & 46,444 & 1.04 & 18.208 \\
\hline 14 & Milwaukee & 283 & 727 & 778.35 & 41,841 & 0.321 & 4.665 \\
\hline 15 & Nashville & 431 & 695 & $1,245.75$ & 40,221 & 0.2365 & 3.575 \\
\hline
\end{tabular}

Source: Cook, et al. (2009) [33]

The super-efficiency scores of the four methods, including the general model, are summarized in Table 23. Three cities, including Philadelphia, Washington, and Boston, are infeasible according to the general super-efficiency model. Lovell and Rouse's [70] super-efficiency scores for the three cities are identical, and the magnitude seems to be unrealistic. The scores from the other two methods (Cook, et al. [33] and Lee, et al. [66]) are very close and present different performances for all the DMUs. The scores from the 
three cities that are infeasible DMUs are higher in Lee, et al. [66] than those in Cook, et al. [33].

Table 23: Comparisons of the results from the four super-efficiency methods

\begin{tabular}{|c|c|c|c|c|c|c|c|c|c|}
\hline \multirow{2}{*}{\multicolumn{2}{|c|}{$\begin{array}{l}\text { Decision- } \\
\text { Making Unit } \\
\text { (City) }\end{array}$}} & \multicolumn{2}{|c|}{ General SE VRS } & \multicolumn{2}{|c|}{$\begin{array}{l}\text { Lovell and Rouse } \\
\text { (2003) }\end{array}$} & \multicolumn{2}{|c|}{$\begin{array}{l}\text { Cook, et al. } \\
\text { (2009) }\end{array}$} & \multicolumn{2}{|c|}{ Lee, et al. (2011) } \\
\hline & & \multirow{2}{*}{$\begin{array}{c}\text { IO SE } \\
\text { (theta) }\end{array}$} & \multirow{2}{*}{\begin{tabular}{|c|}
$\begin{array}{c}\text { OO SE } \\
(1 / \mathrm{phi})\end{array}$ \\
1.09 \\
\end{tabular}} & \multirow{2}{*}{\begin{tabular}{|c|}
$\begin{array}{c}\text { IO SE } \\
\text { (theta) }\end{array}$ \\
1.44 \\
\end{tabular}} & \multirow{2}{*}{$\begin{array}{c}\text { OO SE } \\
(1 / \text { phi })\end{array}$} & \multirow{2}{*}{$\begin{array}{c}\text { IO } \\
\text { SE } \\
\text { (theta) } \\
1.44 \\
\end{array}$} & \multirow{2}{*}{$\begin{array}{c}\text { OO } \\
\text { SE } \\
(1 / \mathrm{phi}) \\
1.09\end{array}$} & \multirow{2}{*}{$\begin{array}{c}\mathrm{IO} \\
\mathrm{SE} \\
\text { (theta) } \\
1.44\end{array}$} & \multirow{2}{*}{$\begin{array}{c}\text { OO } \\
\text { SE } \\
(1 / \mathrm{phi})\end{array}$} \\
\hline 1 & Seattle & & & & & & & & \\
\hline 2 & Denver & 1.02 & 1.05 & 1.02 & 1.05 & 1.02 & 1.05 & 1.02 & 1.05 \\
\hline 3 & Philadelphia & Infeasible & Infeasible & 6.85 & 8.26 & 2.89 & 3.52 & 2.93 & 3.52 \\
\hline 4 & Minneapolis & 1.23 & 1.09 & 1.23 & 1.09 & 1.23 & 1.09 & 1.23 & 1.09 \\
\hline 5 & Raleigh & 1.17 & Infeasible & 1.17 & 8.26 & 1.17 & 2.08 & 1.17 & 2.08 \\
\hline 6 & St. Louis & 1.52 & Infeasible & 1.52 & 8.26 & 1.52 & 2.77 & 1.52 & 2.83 \\
\hline 7 & Cincinnati & 0.95 & 0.90 & 0.95 & 0.90 & 0.95 & 0.90 & 0.95 & 0.90 \\
\hline 8 & Washington & Infeasible & 1.53 & 6.85 & 1.53 & 2.54 & 1.53 & 2.45 & 1.53 \\
\hline 9 & Pittsburgh & 1.05 & Infeasible & 1.05 & 8.26 & 1.05 & 2.08 & 1.05 & 2.08 \\
\hline 10 & Dallas & 0.93 & 0.95 & 0.93 & 0.95 & 0.93 & 0.95 & 0.93 & 0.95 \\
\hline 11 & Atlanta & 0.77 & 0.81 & 0.77 & 0.81 & 0.77 & 0.81 & 0.77 & 0.81 \\
\hline 12 & Baltimore & 0.74 & 0.80 & 0.74 & 0.80 & 0.74 & 0.80 & 0.74 & 0.80 \\
\hline 13 & Boston & Infeasible & 1.32 & 6.85 & 1.32 & 2.59 & 1.32 & 2.60 & 1.32 \\
\hline 14 & Milwaukee & 1.07 & 1.03 & 1.07 & 1.03 & 1.07 & 1.03 & 1.07 & 1.03 \\
\hline 15 & Nashville & 0.80 & 0.87 & 0.80 & 0.87 & 0.80 & 0.87 & 0.80 & 0.87 \\
\hline
\end{tabular}

Note: $\mathrm{IO}=$ input oriented, $\mathrm{OO}=$ output oriented, $\mathrm{SE}=$ super-efficiency; $\mathrm{VRS}=$ variable returns to scale.

In the present study, Lee, et al.'s [66] modified VRS super-efficiency model is adopted because of its computational reliability and the sound logical approach of using the input savings or output surplus of each variable. 


\subsubsection{Three-Stage Variable Returns to Scale Super-Efficiency Model}

The strengths and limitations of the various super-efficiency models are summarized in Table 24 .

Table 24: Strengths and limitations of the current super-efficiency models

\begin{tabular}{|l|l|l|}
\hline \multicolumn{1}{|c|}{ Model } & \multicolumn{1}{|c|}{ Strength } & \multicolumn{1}{c|}{ Limitations } \\
\hline $\begin{array}{l}\text { Lovell and } \\
\text { Rouse } \\
(2003)\end{array}$ & $\begin{array}{l}\text { The model is easy to use and robust } \\
\text { in terms of computation, and } \\
\text { identifies infeasible decision-making } \\
\text { units. }\end{array}$ & $\begin{array}{l}\text { The super-efficiency scores of the } \\
\text { infeasible decision-making units are } \\
\text { not comparable to other super- } \\
\text { efficiency scores because the scores } \\
\text { depend on the ratio of the data. }\end{array}$ \\
\hline $\begin{array}{l}\text { Cook, } \quad \text { (2009) } \\
\text { al }\end{array}$ & $\begin{array}{l}\text { The model generates reasonable } \\
\text { super-efficiency scores for infeasible } \\
\text { decision-making units using both } \\
\text { input savings and output surplus. }\end{array}$ & $\begin{array}{l}\text { The model is not robust and results } \\
\text { can be different depending on how } \\
\text { one defines the arbitrary number in } \\
\text { the objective function. }\end{array}$ \\
\hline $\begin{array}{l}\text { Lee, et al. } \\
(2011)\end{array}$ & $\begin{array}{l}\text { The model produces reasonable } \\
\text { super-efficiency scores for infeasible } \\
\text { decision-making units, using input } \\
\text { savings (in the output-oriented } \\
\text { model) or output surplus (in the } \\
\text { input-oriented model) of all input } \\
\text { variables (in the output-oriented } \\
\text { model) or output variables (in the } \\
\text { input-oriented model). }\end{array}$ & $\begin{array}{l}\text { The model is reliable in } \\
\text { computation but no zero-data issue } \\
\text { is addressed. }\end{array}$ \\
\hline
\end{tabular}

Although each method provides unique benefits in finding the super-efficiency scores, none of them is applicable if zero values are associated with the data. The licensing of the U.S. academic research institution technologies in the early 1990s was not active, and there were several institutions that didn't have experience with start-up companies. If these data are applied to any of the super-efficiency models, it will result in infeasibility or zero-efficiency scores. Therefore, this study employs a three-stage DEA model (Figure 
23) that allows zero values in data and resolves the general infeasibility issue by adopting the nonradial model (Russell measure) of Färe and Lovell [42] and the modified superefficiency model of Lee, et al. [66].

STAGE 1

Identify potential input saving $\left(t_{i} x_{i}^{k}\right)$

$\operatorname{Min} \sum_{i=1}^{m} t_{i}$

s.t. $\sum_{j=1}^{n} \lambda_{j} x_{i}^{j}-t_{i} x_{i}^{k} \leq x_{i}^{k} \quad i=1,2, \ldots, m$ $j \neq k$

$\sum_{j=1}^{n} \lambda_{j}=1$

$t_{i} x_{i}^{k}>0$ if a DMU is super

$j \neq k$

$\lambda_{j} \geq 0, j \neq k$

$t_{i} \geq 0, i=1,2, \ldots, M$

efficient, otherwise zero

STAGE 2

Evaluate non-radial efficiency

$$
\begin{aligned}
& \operatorname{Max} \frac{1}{m} \sum_{i=1}^{m} \hat{\beta}_{r} \\
& \text { s.t. } \sum_{j=1}^{n} \lambda_{j} x_{i}^{j}-t_{i}{ }^{*} x_{i}{ }^{k} \leq x_{i}{ }^{k} \quad i=1,2, \ldots, m \\
& j \neq k \\
& \sum_{j=1}^{n} \lambda_{j} y_{r}{ }^{j} \geq \hat{\beta}_{r} y_{r}{ }^{k} \quad r=1,2, \ldots, s \\
& j \neq k \\
& \sum_{j=1}^{n} \lambda_{j}=1 \\
& j \neq k \\
& \lambda_{j} \geq 0, j \neq k
\end{aligned}
$$

Non-radial efficient $\hat{\beta}_{r}$ for each output $r$

\section{STAGE 3}

Define modified super efficiency

$$
\begin{aligned}
& \frac{1}{\tilde{\beta}}= \begin{cases}\frac{\sum_{i \in I}\left(\frac{x_{i}^{k}+t_{i}^{*} x_{i}^{k}}{x_{i}^{k}}\right)}{|I|}+\frac{1}{\hat{\beta}^{*}}, & \text { if } I \neq \emptyset \\
\frac{1}{\hat{\beta}^{*}}, & \text { if } I=\emptyset\end{cases} \\
& \text { If an input savings exists for } \\
& \text { an evaluated DMU, add } \\
& \text { average of the savings to the }
\end{aligned}
$$

Figure 23: A new three-stage data envelopment analysis model 
A detailed description of the three-stage DEA model process is presented in Figure 24.

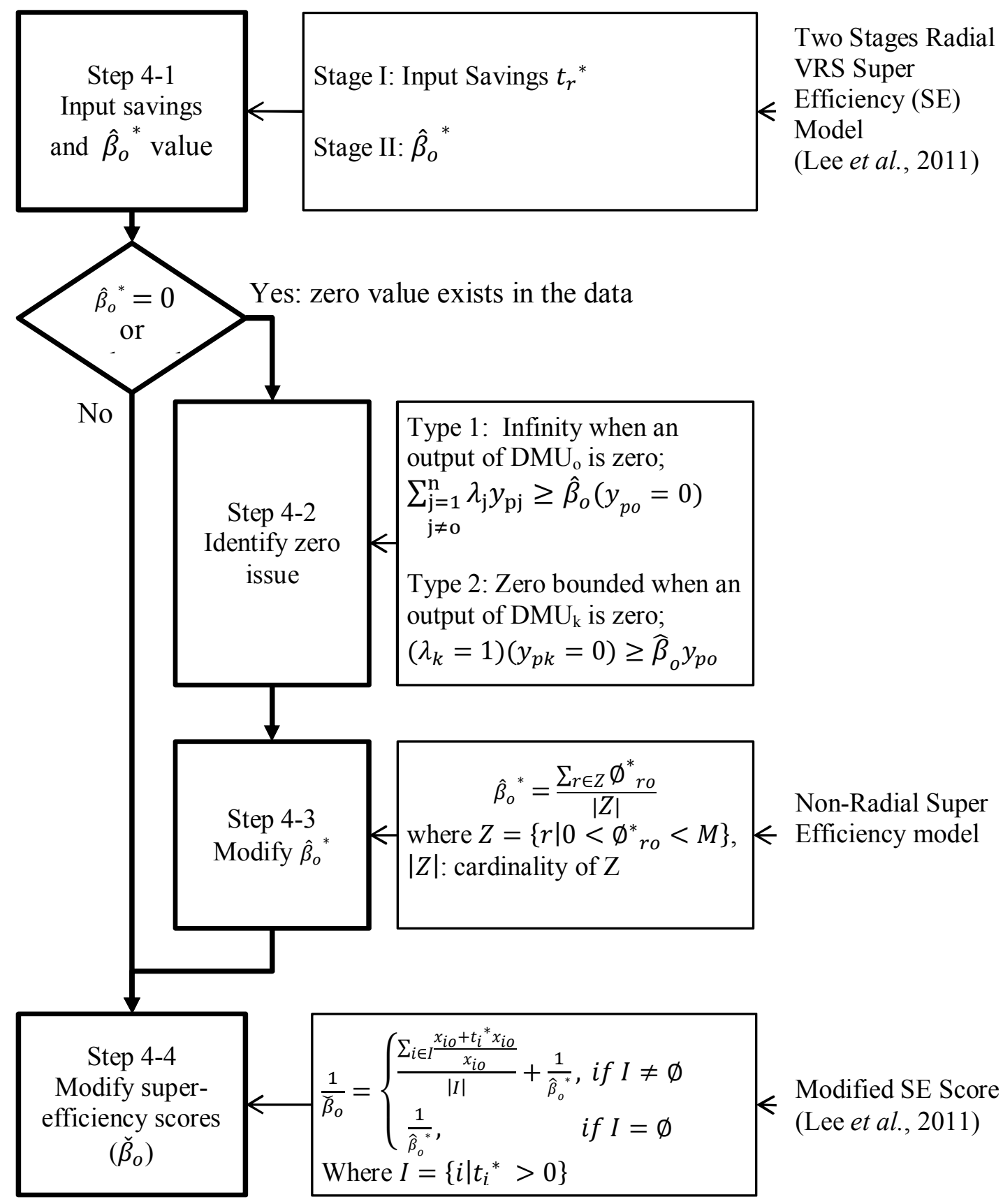

Figure 24: A new output-oriented super-efficiency variable returns to scale model 
A. Step 4-1: Identify infeasibility

Lee, et al.'s [66] output-oriented VRS super-efficiency model is applied to measure the super-efficiency scores of the licensing activities of 46 U.S. academic research institutions. Their two-stage model is as follows.

1) Stage I: input saving $t_{i}^{*}$

Minimize $\sum_{i=1}^{m} t_{i}$

Subject to $\sum_{\substack{\mathrm{j}=1 \\ \mathrm{j} \neq \mathrm{o}}}^{\mathrm{n}} \lambda_{\mathrm{j}} x_{\mathrm{ij}}-t_{i} x_{i o} \leq x_{\mathrm{io}}, \quad i=1,2, \ldots, m$

$\sum_{\substack{j=1 \\ j \neq 0}}^{n} \lambda_{j}=1$

$\lambda_{\mathrm{j}} \geq 0$,

$j=1,2, \ldots, n ; j \neq o$

$t_{i} \geq 0$

$i=1,2, \ldots, m$,

where

$x_{i, j}=$ the $i^{\text {th }}$ input of the $j^{\text {th }}$ university,

$o=$ the institution being evaluated in the iteration,

$\lambda_{j}=$ the coefficient of university $j$ used in creating a performance target for university $o$,

$t_{i}=$ the input saving of $i^{\text {th }}$ input of the $o^{\text {th }}$ university,

$m=$ the number of input variables, and

$n=$ the number of output variables. 
2) Stage II: efficiency $\hat{\beta}_{o}^{*}$

Maximize $\hat{\beta}_{o}$

$$
\begin{aligned}
& \text { Subject to } \sum_{\substack{\mathrm{j}=1 \\
\mathrm{j} \neq \mathrm{o}}}^{\mathrm{n}} \lambda_{\mathrm{j}} x_{\mathrm{ij}}-t_{i}{ }^{*} x_{i o} \leq x_{\mathrm{io}}, \quad i=1,2, \ldots, m \\
& \sum_{\substack{\mathrm{j}=1 \\
\mathrm{j} \neq \mathrm{o}}}^{\mathrm{n}} \lambda_{\mathrm{j}} y_{\mathrm{rj}} \geq \hat{\beta}_{o} y_{\mathrm{ro}}, \quad r=1,2, \ldots, s \\
& \sum_{j=1}^{n} \lambda_{j}=1 \\
& j \neq 0 \\
& \lambda_{\mathrm{j}} \geq 0 \\
& j=1,2, \ldots, n ; j \neq o,
\end{aligned}
$$

where

$t_{i}^{*}=$ the input savings of $i^{\text {th }}$ input of the $o^{\text {th }}$ institution calculated at Stage I,

$y_{r j}=j$ 's output of the institution $j$, and

$s=$ the number of outputs.

B. Step 4-2: Identify zero issue

If $\hat{\beta}^{*}$ of a DMU from Stage I is bounded to zero or infinite, the DMU is associated with zero data in its output variable. The case of zero data in the input variable is excluded from the discussion because there is no research expenditure of zero in the licensing data. The infinite or zero efficiency scores result from the models when the output variable of the evaluated $\mathrm{DMU}_{\mathrm{o}}$ is zero (Type 1) or one of the evaluated $\mathrm{DMU}_{\mathrm{k}}$ has zero data in its output variable (Type 2). 
Type 1: Infinite when the evaluated $\mathrm{DMU}_{\mathrm{o}}$ has a zero for one or more outputs.

$$
\sum_{\substack{\mathrm{j}=1 \\ \mathrm{j} \neq \mathrm{o}}}^{\mathrm{n}} \lambda_{\mathrm{j}} y_{\mathrm{pj}} \geq \hat{\beta}_{o}\left(y_{p o}=0\right)
$$

If the output variable $r$ of the evaluated $\mathrm{DMU}_{\mathrm{o}}$ is zero, $\hat{\beta}_{o}$ increases infinitely to maximize it because the left-hand side of the constraint is always greater than the righthand side.

Type 2: Bounded to zero efficiency when zero is in the referenced $\mathrm{DMU}_{\mathrm{k}}$;

$$
\left(\lambda_{k}=1\right)\left(y_{r k}=0\right) \geq \hat{\beta}_{o} y_{r o}
$$

In cases when the output variable $r$ of the $\mathrm{DMU}_{\mathrm{k}}$ (the only DMU referenced) is zero, $\hat{\beta}_{o}$ is restricted to zero because the left-hand side of the constraint is zero.

C. Step 4-3: Modify $\widehat{\boldsymbol{\beta}}^{*}$ using the nonradial super-efficiency model In his study presenting a slacks-based measure (SBM) of efficiency, Tone [124] identified a similar issue with regard to zero data. He assumed that the DMU may have no function to produce output, or it may have the capability to function but may not be utilized yet. In the first case, the associated slack variable is excluded from the objective function. If the latter case is plausible, a small positive number replaces the zero. This approach allows one to measure an approximate efficiency score of a DMU that doesn't 
have an output value in one or some of the output variables, using the nonradial efficiency of each output variable.

Therefore, this study employs a method to deal with the zero issue by using a nonradial DEA model. The licensing data fits into Tone's [124] second case, the assumption of a DMU with zero data. It cannot be assumed that any institution is prohibited from producing a certain licensing output or doesn't intend to patent or license its technologies at all. In such a case, Tone suggested assigning a small number for the variable. However, this will result in arbitrary efficiency scores. Therefore, the present study excludes the nonradial super-efficiency score of the output variable if it is zero or infinite, and uses the average of other DMU efficiency scores. This approach is similar to the solution Tone adopted for the first case.

For this purpose, a nonradial super-efficiency model is used, adopting both the superefficiency model of Lee, et al. [66] and the output-oriented nonradial slack-based superefficiency model of Cooper, et al. [35].

Cooper, et al. [35] adopted the slack-based model developed by Tone [125] and suggested following the output-oriented nonradial slack-based DEA model as follows:

$$
\begin{aligned}
& \text { Minimize } \frac{1}{\left(\frac{1}{m}\right) \sum_{r=1}^{n} \emptyset_{r o}} \\
& \text { Subject to } \sum_{\substack{\mathrm{j}=1 \\
\mathrm{j} \neq \mathrm{0}}}^{\mathrm{n}} \lambda_{\mathrm{j}} x_{\mathrm{ij}} \leq x_{\mathrm{io}}, \quad i=1,2, \ldots, m
\end{aligned}
$$




$$
\begin{array}{ll}
\sum_{\substack{\mathrm{j}=1 \\
\mathrm{j} \neq 0}}^{\mathrm{n}} \lambda_{\mathrm{j}} y_{\mathrm{rj}} \geq \emptyset_{\text {ro }} y_{\mathrm{ro}}, & r=1,2, \ldots, s \\
\lambda_{\mathrm{j}} \geq 0, & j=1,2, \ldots, n ; j \neq o
\end{array}
$$

Applying nonradial specifications to the model by Lee, et al. [66], the nonradial superefficiency model is as follows:

1) Stage I: input saving $t_{i}^{*}$

Minimize $\sum_{i=1}^{m} t_{i}$

$$
\begin{aligned}
& \text { Subject to } \sum_{\substack{\mathrm{j}=1 \\
\mathrm{j} \neq \mathrm{o}}}^{\mathrm{n}} \lambda_{\mathrm{j}} x_{\mathrm{ij}}-t_{i} x_{i o} \leq x_{\mathrm{io}}, \quad i=1,2, \ldots, m \\
& \sum_{\substack{j=1 \\
j \neq 0}}^{n} \lambda_{j}=1 \\
& \lambda_{\mathrm{j}} \geq 0, \quad j=1,2, \ldots, n ; j ; \neq o \\
& t_{i} \geq 0, \quad i=1,2, \ldots, m
\end{aligned}
$$

2) Stage II: efficiency $\emptyset_{\text {ro }}{ }^{*}$ for a DMU with zero data in output

$$
\begin{aligned}
& \text { Minimize } \frac{1}{\left(\frac{1}{m}\right) \sum_{r=1}^{n} \emptyset_{r o}} \\
& \text { Subject to } \sum_{\substack{\mathrm{j}=1 \\
\mathrm{j} \neq \mathrm{o}}}^{\mathrm{n}} \lambda_{\mathrm{j}} x_{\mathrm{ij}}-t_{i}{ }^{*} x_{i o} \leq x_{\mathrm{io}}, \quad i=1,2, \ldots, m \\
& \sum_{\substack{\mathrm{j}=1 \\
\mathbf{j} \neq 0}}^{\mathrm{n}} \lambda_{\mathrm{j}} y_{\mathrm{rj}} \geq \emptyset_{\text {ro }} y_{\mathrm{ro}}, \quad r=1,2, \ldots, s \\
& 0 \leq \emptyset_{\text {ro }} \leq \mathrm{M} \\
& \sum_{\substack{j=1 \\
j \neq 0}}^{n} \lambda_{j}=1
\end{aligned}
$$




$$
\lambda_{\mathrm{j}} \geq 0, \quad j=1,2, \ldots, n ; j \neq o,
$$

where

$\emptyset_{\text {ro }}=$ the output $r$ efficiency score of a $\mathrm{DMU}_{\mathrm{o}}$, and

$M=$ a user-defined large number to limit unbounded efficiency due to the Type 1 zerodata issue.

The efficiency score $\left(\emptyset_{\text {ro }}\right)$ is allowed from 0 to the large number $M$ in order to represent Type 1 and Type 2 zero data.

The previous super-efficiency score $\left(\hat{\beta}_{o}{ }^{*}\right)$, which is associated with zero data, is replaced by the average nonradial efficiency scores, excluding an efficiency of zero or $M$, using

$\hat{\beta}_{j}^{*}=\frac{\sum_{r \in Z} \emptyset^{*}{ }_{r j}}{|Z|}, j=1,2, \ldots, n ; r=1,2, \ldots, s$,

where

$Z=\left\{r \mid 0<\emptyset^{*}{ }_{r o}<M\right\}$, and

$|Z|=$ cardinality of $Z$.

D. Step 4-4: Modify super-efficiency scores

Finally, the modified super-efficiency scores incorporating both efficiencies from Step 1 and nonradial efficiencies, which are replaced due to the zero issue at Step 3, are calculated using the term defined by Lee, et al. [66]: 
if $I \neq \Phi, \frac{1}{\bar{\beta}_{o}}=\frac{\sum_{i \in I} \frac{x_{i 0}+t_{i}{ }^{*} x_{i o}}{x_{i o}}}{|I|}+\frac{1}{\widehat{\beta}_{o}{ }^{*}}$

if $I=\Phi, \frac{1}{\bar{\beta}_{o}}=\frac{1}{\widehat{\hat{\beta}}_{o}{ }^{*}}$,

where $I=\left\{i \mid t_{i}^{*}>0\right\}$.

\subsubsection{Malmquist Index}

The Malmquist Index measures the difference in the relative distances of a DMU from time $t$ to $t+1$. The index tells us how the technology changes over time. The Malmquist decompositions can explain in detail whether the change is due to the efficiency change or to technical change. The traditional Malmquist Index was suggested by Caves, et al. [26] and Fare, et al. [41], who further developed it to incorporate a variable returns to scale, which became the widely used Malmquist Index.

Fare, et al. [41] suggested two and three decomposition of the Malmquist Index. The former decomposes the Malmquist Index into efficiency change and technical change, whereas the latter decomposes it into EC, TC, and scale efficiency change. Ray and Desli [101] also provided a method for three decompositions. The difference in the two approaches is that Fare, et al.'s (1978) [42] EC and TC are based on variable returns to scale and constant returns to scale, respectively, whereas Ray and Desli's (2000) EC and TC are both based on the VRS model. As a result, their scale efficiency changes have mathematically different forms. In the present study, the original approach of the decomposition by Fare, et al. (1978) is used to measure changes in university technology 
commercialization efficiency. The two and three decompositions of the Malmquist Index by Fare, et al. are as follows:

The two decompositions are:

$$
\begin{aligned}
& M=\frac{D_{v}^{t+1}\left(x^{t+1}, y^{t+1}\right)}{D_{V}^{t}\left(x^{t}, y^{t}\right)} \times\left[\frac{D_{v}^{t}\left(x^{t+1}, y^{t+1}\right)}{D_{v}^{t+1}\left(x^{t+1}, y^{t+1}\right)} \times \frac{D_{v}^{t}\left(x^{t}, y^{t}\right)}{D_{v}^{t+1}\left(x^{t}, y^{t}\right)}\right]^{\frac{1}{2}}=E C_{v} \times C_{v} \\
& \mathrm{EC}_{\mathrm{v}}=\frac{\mathrm{D}_{\mathrm{v}}^{\mathrm{t}+1}(\mathrm{t}+1)}{\mathrm{D}_{\mathrm{v}}^{\mathrm{t}}(\mathrm{t})} \\
& \mathrm{TC}_{\mathrm{v}}=\left[\frac{\mathrm{D}_{\mathrm{V}}^{\mathrm{t}}(\mathrm{t}+1)}{\mathrm{D}_{\mathrm{v}}^{\mathrm{t}+1}(\mathrm{t}+1)} \times \frac{\mathrm{D}_{\mathrm{V}}^{\mathrm{t}}(\mathrm{t})}{\mathrm{D}_{\mathrm{v}}^{\mathrm{t}+1}(\mathrm{t})}\right]^{\frac{1}{2}}
\end{aligned}
$$

The three decompositions are:

$$
\begin{aligned}
& M_{c}\left(x^{t}, y^{t}, x^{t+1}, y^{t+1}\right)=M_{v}\left(x^{t}, y^{t}, x^{t+1}, y^{t+1}\right) \times \varepsilon \\
& =E_{v} \times \frac{S^{t+1}\left(x^{t+1}, y^{t+1}\right)}{S^{t}\left(x^{t}, y^{t}\right)} \times \mathrm{TC}_{v} \times \frac{T_{c}}{T^{t} C_{v}} \\
& =E_{v} \times \mathrm{TC}_{c} \times \frac{S^{t+1}\left(x^{t+1}, y^{t+1}\right)}{S^{t}\left(x^{t}, y^{t}\right)} \\
& S^{t}\left(x^{t}, y^{t}\right)=\frac{D_{v}^{t}\left(x^{t}, y^{t}\right)}{D_{c}^{t}\left(x^{t}, y^{t}\right)}
\end{aligned}
$$

Where

$D=$ efficiency, equivalent to $\emptyset$

$D^{t}\left(x^{t}, y^{t}\right)=D^{t}(t)$ : distance (efficiency) of a technology $\left(x^{t}, y^{t}\right)$ to the frontier at time $t$, $S^{t}\left(x^{t}, y^{t}\right)=$ scale efficiency change of a technology $\left(x^{t}, y^{t}\right)$, EC - efficiency change, 
TC - technical change,

subscript $v=$ DEA model based on VRS (variable returns to scale), and

subscript $c=$ DEA model based on CRS (constant returns to scale).

A simple example of the Malmquist decomposition by Fare, et al. (1994) shows how the index indicates the efficiency changes of an institution (A) (Table 25). The DEA efficiency of the institution is defined by the distance from A to the frontier line (F). Therefore, the efficiency of A could remain the same or could change (increase or decrease), depending on the change in the location of the institution and the change of the frontier in the following year $t+1$. Twelve cases are defined along with the changes of the institution (A) and frontier (F) from $t$ to $t+1$, in the table. To simplify the example, it is assumed that the frontier doesn't retract at $t+1$.

Table 25: Changes in the location of the institution and frontier from $t$ to $t+1$

\begin{tabular}{|c|c|c|c|c|}
\hline & \multicolumn{3}{|c|}{ Changes of the frontier from $t$ to $t+1$} \\
\hline & & No change & Expand & High expand \\
\hline \multirow{4}{*}{$\begin{array}{l}\text { Changes } \\
\text { of the } \\
\text { location of } \\
\text { A from } t \\
\text { to } t+1\end{array}$} & No change & $\begin{aligned} \mathrm{A}^{\mathrm{t}} & =\mathrm{A}^{\mathrm{t}+1} \\
\mathrm{~F}^{\mathrm{t}} & =\mathrm{F}^{\mathrm{t}+1}\end{aligned}$ & $\begin{aligned} \mathrm{A}^{\mathrm{t}} & =\mathrm{A}^{\mathrm{t}+\mathrm{I}} \\
\mathrm{F}^{\mathrm{t}} & <\mathrm{F}^{\mathrm{t}+1}\end{aligned}$ & $\begin{array}{l}A^{t}=A^{t+1} \\
F^{t}<<F^{t+1}\end{array}$ \\
\hline & Close to F & $\begin{array}{c}\mathrm{A}^{\mathrm{t}}<\mathrm{A}^{\mathrm{t}+1} \\
\mathrm{~F}^{\mathrm{t}}=\mathrm{F}^{\mathrm{t}+1}\end{array}$ & $\begin{aligned} \mathrm{A}^{\mathrm{t}} & <\mathrm{A}^{\mathrm{t}+1} \\
\mathrm{~F}^{\mathrm{t}} & <\mathrm{F}^{\mathrm{t}+1}\end{aligned}$ & $\begin{array}{l}\mathrm{A}^{\mathrm{t}}<\mathrm{A}^{\mathrm{t}+\mathrm{I}} \\
\mathrm{F}^{\mathrm{t}}<<\mathrm{F}^{\mathrm{t}+1}\end{array}$ \\
\hline & Very close to $\mathrm{F}$ & $\begin{array}{c}\mathrm{A}^{\mathrm{t}}<<\mathrm{A}^{\mathrm{t}+1} \\
\mathrm{~F}^{\mathrm{t}}=\mathrm{F}^{\mathrm{t}+1}\end{array}$ & $\begin{array}{c}\mathrm{A}^{\mathrm{t}}<<\mathrm{A}^{\mathrm{t}+1} \\
\mathrm{~F}^{\mathrm{t}}<\mathrm{F}^{\mathrm{t}+1}\end{array}$ & $\begin{aligned} \mathrm{A}^{\mathrm{t}} & <\mathrm{A}^{\mathrm{t}+1} \\
\mathrm{~F}^{\mathrm{t}} & <<\mathrm{F}^{\mathrm{t}+1}\end{aligned}$ \\
\hline & Far from $\mathrm{F}$ & $\begin{aligned} \mathrm{A}^{\mathrm{t}} & >\mathrm{A}^{\mathrm{t}+1} \\
\mathrm{~F}^{\mathrm{t}} & =\mathrm{F}^{\mathrm{t}+1}\end{aligned}$ & $\begin{aligned} \mathrm{A}^{\mathrm{t}} & >\mathrm{A}^{\mathrm{t}+1} \\
\mathrm{~F}^{\mathrm{t}} & <\mathrm{F}^{\mathrm{t}+1}\end{aligned}$ & $\begin{array}{l}\mathrm{A}^{\mathrm{t}}>\mathrm{A}^{\mathrm{t}+1} \\
\mathrm{~F}^{\mathrm{t}}<<\mathrm{F}^{\mathrm{t}+1}\end{array}$ \\
\hline
\end{tabular}

Note: $\mathrm{A}=\mathrm{DMU} \mathrm{A}, \mathrm{F}=$ frontier

The distance from the institution (A) of the year $t$ and $t+1$ to the frontier (F) of the year $t$

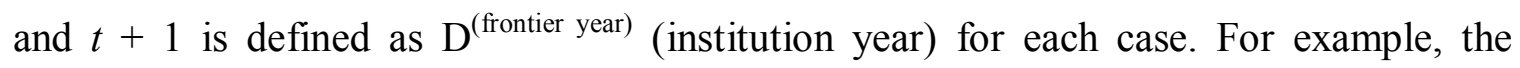
150 
distance from $\mathrm{A}$ at $t+1$ to the frontier at $t$ is $\mathrm{D}^{t}(t+1)$. The values of the efficiency changes, technical changes, and Malmquist Index of the twelve cases are provided in Figure 25 .

Distances of $A^{t}$ and $A^{t+1}$ to the frontiers $F^{t}$ and $F^{t+1}$ along with the different cases

\begin{tabular}{|c|c|c|c|c|c|c|c|c|c|c|c|c|}
\hline \multirow{2}{*}{ Cases } & \multicolumn{4}{|c|}{$\mathrm{F}^{\mathrm{t}}=\mathrm{F}^{\mathrm{t}+1}$} & \multicolumn{4}{c|}{$\mathrm{F}^{\mathrm{t}}<\mathrm{F}^{\mathrm{t}+1}$} & \multicolumn{4}{c|}{$\mathrm{F}^{\mathrm{t}}<\mathrm{F}^{\mathrm{t}+1}$} \\
\cline { 2 - 15 } & $\begin{array}{c}\mathrm{D}^{\mathrm{t}} \\
(\mathrm{t})\end{array}$ & $\begin{array}{c}\mathrm{D}^{\mathrm{t}} \\
(\mathrm{t}+1)\end{array}$ & $\begin{array}{c}\mathrm{D}^{\mathrm{t}+1} \\
(\mathrm{t})\end{array}$ & $\begin{array}{c}\mathrm{D}^{\mathrm{t}+1} \\
(\mathrm{t}+1)\end{array}$ & $\begin{array}{c}\mathrm{D}^{\mathrm{t}} \\
(\mathrm{t})\end{array}$ & $\begin{array}{c}\mathrm{D}^{\mathrm{t}} \\
(\mathrm{t}+1)\end{array}$ & $\begin{array}{c}\mathrm{D}^{\mathrm{t}+1} \\
(\mathrm{t})\end{array}$ & $\begin{array}{c}\mathrm{D}^{\mathrm{t}+1} \\
(\mathrm{t}+1)\end{array}$ & $\begin{array}{c}\mathrm{D}^{\mathrm{t}} \\
(\mathrm{t})\end{array}$ & $\begin{array}{c}\mathrm{D}^{\mathrm{t}} \\
(\mathrm{t}+1)\end{array}$ & $\begin{array}{c}\mathrm{D}^{\mathrm{t}+1} \\
(\mathrm{t})\end{array}$ & $\begin{array}{c}\mathrm{D}^{\mathrm{t}+1} \\
(\mathrm{t}+1)\end{array}$ \\
\hline $\mathrm{A}^{\mathrm{t}}=\mathrm{A}^{\mathrm{t}+1}$ & 4 & 4 & 4 & 4 & 4 & 4 & 8 & 8 & 4 & 4 & 10 & 10 \\
\hline $\mathrm{A}^{\mathrm{t}}<\mathrm{A}^{\mathrm{t}+1}$ & 4 & 2 & 4 & 2 & 4 & 2 & 8 & 6 & 4 & 2 & 10 & 8 \\
\hline $\mathrm{A}^{\mathrm{t}} \ll \mathrm{A}^{\mathrm{t}+1}$ & 4 & 1 & 4 & 1 & 4 & 1 & 8 & 5 & 4 & 1 & 10 & 7 \\
\hline $\mathrm{A}^{\mathrm{t}}>\mathrm{A}^{\mathrm{t}+1}$ & 4 & 6 & 4 & 6 & 4 & 6 & 4 & 10 & 4 & 6 & 4 & 12 \\
\hline
\end{tabular}

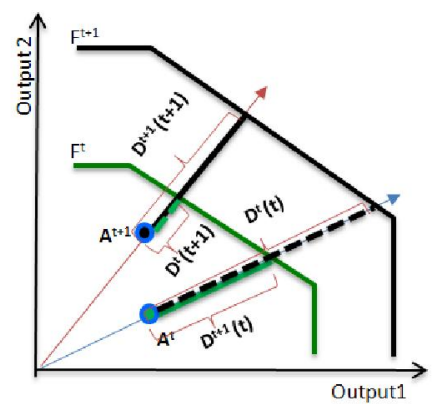

$\mathrm{EC}, \mathrm{TC}$, and $\mathrm{M}$ of each case

\begin{tabular}{|c|c|c|c|c|c|c|c|c|c|c|c|c|c|c|c|}
\hline \multirow{3}{*}{ Cases } & \multicolumn{5}{|c|}{$\mathrm{F}^{\mathrm{t}}=\mathrm{F}^{\mathrm{t}+1}$} & \multicolumn{5}{|c|}{$\mathrm{F}^{\mathrm{t}}<\mathrm{F}^{\mathrm{t}+1}$} & \multicolumn{5}{|c|}{$\mathrm{F}^{\mathrm{t}} \ll<\mathrm{F}^{\mathrm{t}+1}$} \\
\hline & \multirow{2}{*}{ EC } & \multicolumn{3}{|c|}{ TC } & \multirow{2}{*}{$M$} & \multirow{2}{*}{ EC } & \multicolumn{3}{|c|}{ TC } & \multirow{2}{*}{ M } & \multirow{2}{*}{ EC } & \multicolumn{3}{|c|}{$\mathrm{TC}$} & \multirow{2}{*}{ M } \\
\hline & & $\mathbf{a}$ & b & TC & & & a & b & $\mathrm{TC}$ & & & a & b & TC & \\
\hline$A^{t}=A^{t+1}$ & 1 & 1 & 1 & 1 & 1 & 2 & 0.50 & 0.50 & 0.50 & 1 & 2.50 & 0.40 & 0.40 & 0.40 & 1 \\
\hline$A^{t}<A^{t+1}$ & 0.50 & 1 & 1 & 1 & 0.50 & 1.50 & 0.33 & 0.50 & 0.41 & 0.61 & 2 & 0.25 & 0.40 & 0.32 & 0.63 \\
\hline$A^{t} \ll A^{t+1}$ & 0.25 & 1 & 1 & 1 & 0.25 & 1.25 & 0.20 & 0.50 & 0.32 & 0.40 & 1.75 & 0.14 & 0.40 & 0.24 & 0.42 \\
\hline$A^{t}>A^{t+1}$ & 1.50 & 1 & 1 & 1 & 1.50 & 2.50 & 0.60 & 1.00 & 0.77 & 1.94 & 3 & 0.50 & 1.00 & 0.71 & 2.12 \\
\hline
\end{tabular}

Figure 25: Demonstration of Malmquist Index, efficiency changes, and technical changes for the twelve cases

The example shows that the EC is influenced by the TC even though there is no change in outputs of the institution. The DEA efficiency scores in nature present the relative efficiency of institutions, and the changes in the efficiency score of an institution can be influenced by any change in both the evaluated institution and other institutions. For example, even though the institution stays at the same level of outputs as the previous year, the efficiency decreases if the other efficient institutions improve, so the frontier 
expands. Therefore, caution is required when interpreting the result of the EC by itself. On the other hand, the Malmquist Index provides a more reliable indication of the change of an institution by compensating the amount of efficiency change caused by frontier expansion (TC).

\subsection{Verification of the Present Study}

This is an exploratory study identifying relationships between characteristics and licensing efficiency and, through data analysis, evaluating changes in the licensing performance of 46 U.S. academic institutions. For this purpose, two methods have been developed: a time-lag identifying process and a modified VRS super-efficiency DEA model of the Malmquist Index. First, the time-lag method is verified by testing several simulation data sets designed to emulate licensing lag behavior. The current econometrics approach also is compared to the suggested methods to discuss its limitations. Second, the DEA model and coding are verified by testing the published data set and comparing it with current models.

One licensing expert (a technology transfer lawyer) was selected to verify the identified time lags. The expert was asked to review the licensing process defined and the time lags observed in this study. The expert checked whether the identified time lags between each pair of licensing variables reflected real cases, based on his experience and patent law. He confirmed that all the time lags reflect reality. 
Chapter 4. Verification of the Process Identifying Time-Lag Coefficients Using Simulated Data

The current econometric methods identifying lag effects of an event of interest using regression model are not appropriate for licensing in nature, as described in the methodology chapter. In this section, an exploratory approach testing simulated data is applied to understand the behavior of the distributed lag model with two coefficient restriction models, the unstructured and polynomial models, and to verify the suggested time-lag identifying process. Also discussed are the limitations of the lag period determination methods, AIC and BIC, and the polynomial coefficient structure used for the licensing data.

In order to verify the time-lag approach developed in this dissertation, the following additional research questions are explored.

- What does a negative correlation mean in the distributed lag model?

- Does the model correctly reflect the changes of the independent variables at single or multiple periods?

- Which coefficient structure is appropriate for the licensing data, the unstructured model (unrestricted lag) or the polynomial structure (polynomial distributed lag $[\mathrm{PDL}]) ?$ 


\subsection{Assumptions}

Several lag effects patterns in licensing are assumed to generate data sets reflecting the real situation of licensing activities. First, unlike in economics, which is one of the popular applications of the time-lag model, the time-lag effect of licensing activity could be either continuous or discontinuous. Second, there exists a delay between a change in licensing activity and the resulting outcome. The time-lag identifying process should be able to detect these two different lag behaviors correctly.

\subsection{Distributed Lag Model and Lag Structure Setting}

Two cases are explored through the tests to understand how the lag patterns affect regression coefficients. The time-lag relationship between the independent and dependent variables is predefined.

Time $t$ is defined as 1991 to 2007. The distributed lag model is

$y_{t}=\alpha+\beta_{0} x_{t}+\beta_{1} x_{t-1}+\beta_{2} x_{t-2}+\beta_{3} x_{t-3}+\beta_{4} x_{t-4}+e_{t}$,

where $y_{t}$ is the result of licensing activity $x$ at year $t ; x_{t} \ldots x_{t-4}$ are lagged independent variables from $t$ to $t-3 ; \beta_{0} \ldots \beta_{t-4}$ are time-lag coefficients; and $e_{t}$ is a regression error term following an $N(1,0)$ distribution.

Data for both independent variables, from lag 0 to lag 3 of a licensing input, and a dependent variable of licensing outcome from 1991 to 2007 are generated in such a way as to produce the lag behaviors defined below. 


\subsubsection{Case 1: Continuous lag effects}

First, an evenly distributed (uniform) lag effect of $20 \%$ during the lag periods from $t$ (lag 0) to $t$ - 4 (lag 4) are defined as shown in Figure 26.

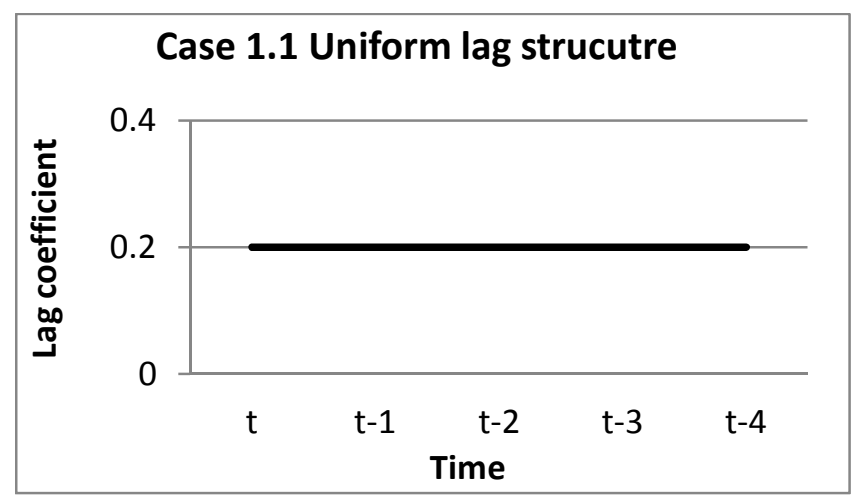

Figure 26: Uniform lag structure of Case 1

Second, an asymmetric lag effect is applied to the continuous case. A dependent variable at year $t, y_{t}$, is a result of $20 \%$ of independent variable $x$ at year $t, 50 \%$ at year $t-1,20 \%$ at year $t-2$, and $10 \%$ at year $t-3$. Therefore, the estimated lag coefficient values of $\beta_{0}$, $\beta_{1}, \beta_{2}$, and $\beta_{3}$ from the time-lag identifying process should be $0.2,0.5,0.2$, and 0.1 , respectively, as shown in Figure 27. 


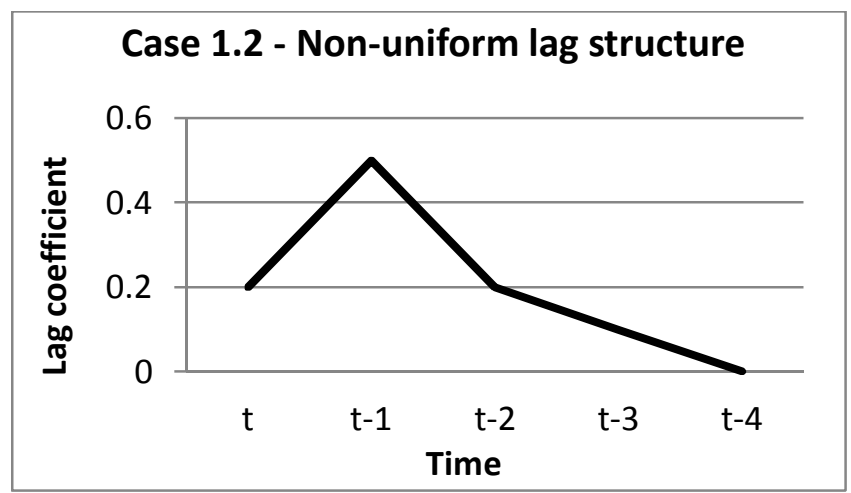

Figure 27: Non-uniform lag structure of Case 1

\subsubsection{Case 2: Discontinuous lag effects}

To test whether the time-lag identifying process using the unrestricted model can identify true lags, discontinuous lag effects are also assumed. Data for Case 2 is generated in such a way that $20 \%$ of the independent variable at year $t-1$ (lag 1$), 50 \%$ at $t-3(\operatorname{lag} 3)$, and $30 \%$ at $t-4$ (lag 4$)$ are associated with the value of the dependent variable at year $t$. The coefficient structure of the second case is illustrated in Figure 28.

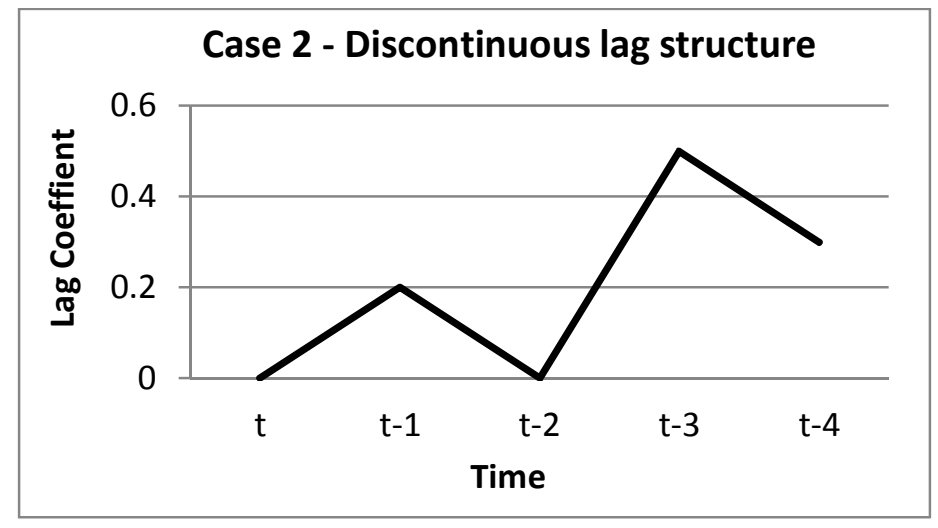

Figure 28: Lag structure of Case 2 


\subsection{Data Generation for the Test}

The data sets for the examination are generated by the relationships between the independent variables with lag coefficients and the dependent variable. In the case of the continuous lag effect, three data sets are generated. The first data set is the basis of the other data sets, which adds variances on the basis for the independent variables. The second data set includes an increase of independent variables at a certain time. The third data set includes two independent variables that have increases at two time periods and are the same in other periods. In addition to these three data sets, the fourth data set is added to analyze the discontinuous case.

The data for the dependent variables are calculated using the equations for the predefined lag relationships. The time period is defined from 1991 to 2007, reflecting actual licensing data from the Association of University Technology Managers, to be analyzed later. The data sets of both independent and dependent variables include random numbers representing error terms with a normal distribution, $N$ (mean, standard deviation). The equations used to generate the data set are as follows:

The simulated data of the independent variables at time $t$ is generated by

$$
x_{t}=N(\gamma, 1)
$$

The simulated data of the dependent variables at time $t$ is generated by

$y_{t}=\beta_{0} x_{t}+\beta_{1} x_{t-1}+\beta_{2} x_{t-2}+\beta_{3} x_{t-3}+\beta_{4} x_{t-4}+N(0,0.01)$ 
The $\gamma$ value and its changes, along with years and data sets, are illustrated in Figure 29.

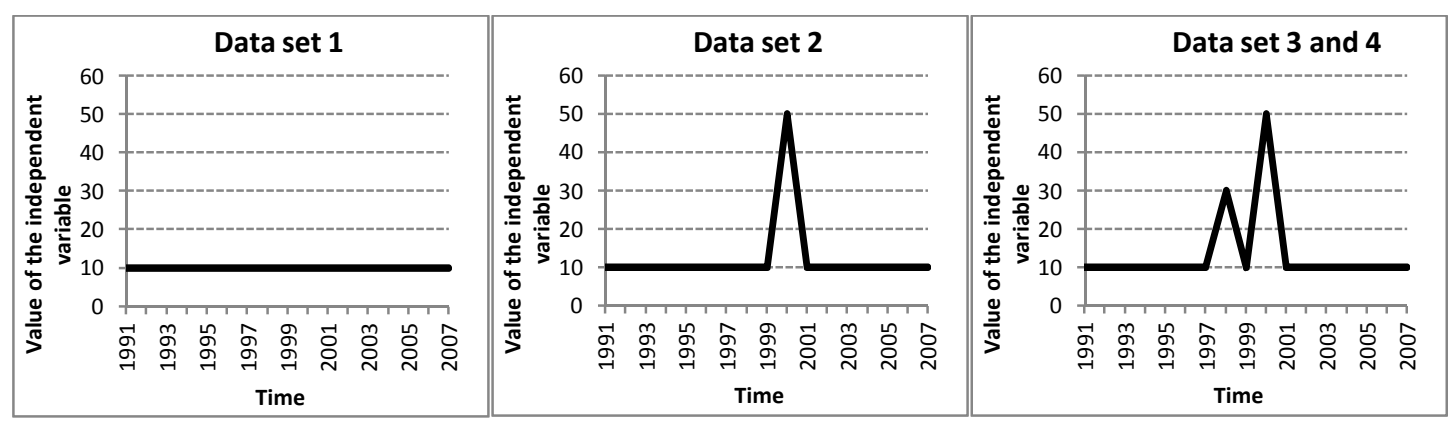

Figure 29: $\gamma$ values of the four data sets

Finally, the simulated data sets used are presented in Table 26. 
Table 26: The three data sets for case 1

\begin{tabular}{|c|c|c|c|c|c|c|c|c|}
\hline \multirow{4}{*}{ Year } & \multicolumn{6}{|c|}{ Case 1: Continuous Lag Effect } & \multirow{2}{*}{\multicolumn{2}{|c|}{$\begin{array}{c}\text { Case 2: Discontinuous } \\
\text { With Non-Uniform Lag } \\
\text { Structure }\end{array}$}} \\
\hline & \multirow{2}{*}{\multicolumn{2}{|c|}{\begin{tabular}{|c}
$\begin{array}{c}\text { Case 1.1: Uniform with } \\
\text { no change }\end{array}$ \\
Data set 1
\end{tabular}}} & \multicolumn{4}{|c|}{ Case 1.2: Non-uniform lag structure } & & \\
\hline & & & \multicolumn{2}{|c|}{ Data set 2} & \multicolumn{2}{|c|}{ Data set 3} & \multicolumn{2}{|c|}{ Data set 4} \\
\hline & $\begin{array}{c}\text { Independent } \\
\text { variable } \\
(x 1)\end{array}$ & $\begin{array}{c}\text { Dependent } \\
\text { variable } \\
(y 1)\end{array}$ & $\begin{array}{l}\text { Independent } \\
\text { variable } \\
(x 2)\end{array}$ & $\begin{array}{l}\text { Dependent } \\
\text { variable } \\
(y 2)\end{array}$ & $\begin{array}{c}\text { Independent } \\
\text { variable } \\
(x 3)\end{array}$ & $\begin{array}{c}\text { Dependent } \\
\text { variable } \\
(y 3)\end{array}$ & $\begin{array}{c}\text { Independent } \\
\text { variable } \\
(x 4)\end{array}$ & $\begin{array}{l}\text { Dependent } \\
\text { variable } \\
(y 4)\end{array}$ \\
\hline 1991 & 9.09 & & 11.01 & & 9.22 & & 7.61 & \\
\hline 1992 & 9.96 & & 10.74 & & 9.69 & & 10.79 & \\
\hline 1993 & 9.72 & & 10.58 & & 8.86 & & 11.08 & \\
\hline 1994 & 9.64 & & 10.01 & & 11.15 & & 10.41 & \\
\hline 1995 & 8.14 & 9.31 & 9.12 & 10.03 & 11.35 & 10.59 & 9.03 & 9.76 \\
\hline 1996 & 8.23 & 9.13 & 11.52 & 9.92 & 8.78 & 10.55 & 9.55 & 10.57 \\
\hline 1997 & 9.68 & 9.09 & 9.73 & 10.55 & 9.97 & 9.77 & 12.35 & 10.44 \\
\hline 1998 & 11.63 & 9.48 & 9.99 & 10.07 & 30.27 & 13.91 & 29.86 & 10.10 \\
\hline 1999 & 9.81 & 9.51 & 11.36 & 10.37 & 10.03 & 19.98 & 9.51 & 13.46 \\
\hline 2000 & 9.68 & 9.82 & 49.10 & 18.48 & 48.67 & 21.80 & 50.02 & 10.94 \\
\hline 2001 & 9.66 & 10.09 & 9.68 & 29.76 & 10.13 & 31.38 & 10.97 & 28.62 \\
\hline 2002 & 8.84 & 9.93 & 10.70 & 17.94 & 9.68 & 17.73 & 8.89 & 15.90 \\
\hline 2003 & 11.43 & 9.89 & 9.02 & 13.99 & 10.83 & 13.91 & 11.76 & 29.65 \\
\hline 2004 & 9.13 & 9.76 & 10.00 & 9.61 & 10.07 & 10.39 & 10.48 & 22.87 \\
\hline 2005 & 9.55 & 9.72 & 11.06 & 10.08 & 10.06 & 10.18 & 9.34 & 9.84 \\
\hline 2006 & 8.21 & 9.44 & 8.62 & 10.15 & 10.31 & 10.17 & 9.89 & 10.42 \\
\hline 2007 & 8.48 & 9.37 & 9.72 & 9.47 & 8.81 & 9.93 & 11.14 & 10.75 \\
\hline
\end{tabular}




\subsection{Results}

\subsubsection{Unit Root Test Using Augmented Dickey-Fuller Test and Data}

Transformation

The ADF test was applied to see whether the simulated data has a unit root. The statistics package Stata was used for the test. The null hypothesis of the test is that the data include a unit root and is therefore nonstationary. The null hypothesis is rejected if the p-value is greater than 0.05 . The result shows that all dependent variables in the four data sets are stationary (Table 27). Because all data follow the stationary process, the data can be used for further time series analysis without taking first-order difference (delta).

Table 27: Augmented Dickey-Fuller test result for data set 1

\begin{tabular}{|c|c|c|c|}
\hline Data Set & Test Statistic, $Z(t)$ & P-Value & Result \\
\hline Data Set 1 $(y 1)$ & -1.17 & 0.67 & Stationary \\
\hline Data Set 2 $(y 2)$ & -1.70 & 0.43 & Stationary \\
\hline Data Set 3 $(y 3)$ & -1.49 & 0.54 & Stationary \\
\hline Data Set 4 $(y 4)$ & -2.42 & 0.14 & Stationary \\
\hline
\end{tabular}

\subsubsection{Time-Lag Period}

The suggested time-lag identifying method, using correlation, is compared with the current method, using AIC and BIC. 


\section{A. Akaike's Information Criterion and Bayesian Information Criterion}

In the model, the two information criteria, AIC and BIC, decline as more lags are added, as summarized in Table 28. If AIC and BIC are used for the lag period, the maximum lag, 6 years, is selected, regardless of which data sets are used because both AIC and BIC are minimum at lag 6. Therefore, both information criteria are not applicable to the licensing data.

Table 28: Result of Akaike's Information Criterion and Bayesian Information Criterion tests

\begin{tabular}{|c|c|c|c|c|c|c|c|c|}
\hline \multirow{2}{*}{\multicolumn{2}{|c|}{ Data Set / Statistics }} & \multicolumn{7}{|c|}{ Model (Independent Variables From Lag 0 to Each Duration) } \\
\hline & & \multirow{2}{*}{$\begin{array}{r}\text { Lag 0 } \\
0.04\end{array}$} & \multirow{2}{*}{$\begin{array}{l}\text { Lag } 1 \\
0.09\end{array}$} & \multirow{2}{*}{$\begin{array}{l}\text { Lag } 2 \\
0.28\end{array}$} & \multirow{2}{*}{\begin{tabular}{|l|}
$\operatorname{Lag} 3$ \\
0.56
\end{tabular}} & \multirow{2}{*}{$\begin{array}{r}\operatorname{Lag} 4 \\
1.00\end{array}$} & \multirow{2}{*}{$\begin{array}{r}\text { Lag } 5 \\
1.00\end{array}$} & \multirow{2}{*}{$\begin{array}{r}\text { Lag } 6 \\
1.00\end{array}$} \\
\hline \multirow{3}{*}{ Data Set 1} & $\begin{array}{l}\text { Adjusted } \\
R^{2}\end{array}$ & & & & & & & \\
\hline & AIC & 8.12 & 8.06 & 5.71 & -0.07 & -85.19 & -75.15 & -81.46 \\
\hline & $\mathrm{BIC}$ & 9.25 & 9.76 & 7.97 & 2.75 & -81.80 & -71.76 & -78.28 \\
\hline \multirow{3}{*}{ Data Set 2} & $\begin{array}{l}\text { Adjusted } \\
R^{2}\end{array}$ & -0.01 & 0.81 & 0.96 & 1.00 & 1.00 & 1.00 & 1.00 \\
\hline & AIC & 85.02 & 63.75 & 45.49 & -78.08 & -76.84 & -68.47 & -59.85 \\
\hline & $\mathrm{BIC}$ & 86.15 & 65.44 & 47.75 & -75.26 & -73.45 & -65.08 & -56.67 \\
\hline \multirow{3}{*}{ Data Set 3} & $\begin{array}{l}\text { Adjusted } \\
R^{2}\end{array}$ & 0.00 & 0.84 & 0.96 & 1.00 & 1.00 & 1.00 & 1.00 \\
\hline & AIC & 87.38 & 64.39 & 46.72 & -71.68 & -72.11 & -64.41 & -58.33 \\
\hline & $\mathrm{BIC}$ & 88.51 & 66.08 & 48.98 & -68.85 & -68.72 & -61.02 & -55.15 \\
\hline \multirow{3}{*}{ Data Set 4} & $\begin{array}{l}\text { Adjusted } \\
R^{2}\end{array}$ & -0.05 & 0.11 & 0.02 & 0.69 & 1.00 & 1.00 & 1.00 \\
\hline & AIC & 90.98 & 89.59 & 91.53 & 77.15 & -84.20 & -78.27 & -70.29 \\
\hline & $\mathrm{BIC}$ & 92.11 & 91.28 & 93.79 & 79.97 & -80.82 & -74.87 & -67.11 \\
\hline
\end{tabular}

Note: $\mathrm{AIC}=$ Akaike's information criterion; $\mathrm{BIC}=$ Bayesian information criterion 


\section{B. Correlation Matrix}

Correlations among the dependent variable and independent variables with time lags from 0 to 6 are summarized in Table 29.

Table 29: Correlation between the output variable and time lag of the independent variable

\begin{tabular}{|l|c|c|c|c|c|c|c|c|}
\hline \multirow{2}{*}{ Data Set } & \multicolumn{7}{|c|}{ Time Lag of Independent Variable $x$} \\
\cline { 2 - 9 } & Lag 0 & Lag 1 & Lag 2 & Lag 3 & Lag 4 & Lag 5 & Lag 6 \\
\hline Data Set 1 & $y 1$ & 0.13 & 0.29 & 0.51 & 0.34 & 0.07 & -0.13 & -0.22 \\
\hline Data Set 2 & $y 2$ & 0.25 & 0.86 & 0.25 & 0.02 & -0.21 & -0.18 & -0.21 \\
\hline Data Set 3 & $y 3$ & 0.26 & 0.83 & 0.25 & 0.29 & -0.17 & -0.27 & -0.32 \\
\hline Data Set 4 & $y 4$ & -0.28 & 0.47 & -0.10 & 0.82 & 0.31 & 0.03 & -0.05 \\
\hline
\end{tabular}

The time-lag variables showing positive correlations with the dependent variable are selected as potential time-lag periods. The results show that the time-lag periods selected by correlation are consistent with the predefined time-lag periods, except in the case of Data Set 4, as shown in Table 30. The results of Data Set 4 include the fault period, lag 5.

Table 30: Comparison of selected lag periods and predefined lag periods

\begin{tabular}{|l|l|l|}
\hline Data Set & $\begin{array}{l}\text { Selected Time-Lag Periods by } \\
\text { Correlation }\end{array}$ & Predefined Time-Lag Periods \\
\hline Data Set 1 & Lag $0-4$ & Lag 0-4 \\
\hline Data Set 2 & Lag $0-3$ & Lag 0-3 \\
\hline Data Set 3 & Lag $0-3$ & Lag $0-3$ \\
\hline Data Set 4 & Lag $1,3,4$, and 5 & Lag 1,3 , and 4 \\
\hline
\end{tabular}




\section{Regression Model to Define Correct Lag Periods}

The following regression model, using only selected potential lag periods for each data set, is tested to identify correct lag periods from among the potential lag periods produced by correlation. The regression model of each data set is as follows:

Model 1 for Data Set 1:

$y 1_{t}=\alpha+\beta_{0} x 1_{t}+\beta_{1} x 1_{t-1}+\beta_{2} x 1_{t-2}+\beta_{3} x 1_{t-3}+\beta_{4} x 1_{t-4}+e_{t}$

Model 2 for Data Set 2:

$y 2_{t}=\alpha+\beta_{0} x 2_{t}+\beta_{1} x 2_{t-1}+\beta_{2} x 2_{t-2}+\beta_{3} x 2_{t-3}+e_{t}$

Model 3 for Data Set 3:

$y 3_{t}=\alpha+\beta_{0} x 3_{t}+\beta_{1} x 3_{t-1}+\beta_{2} x 3_{t-2}+\beta_{3} x 3_{t-3}+e_{t}$

Model 4 for Data Set 4:

$y 4_{t}=\alpha+\beta_{1} x 4_{t-1}+\beta_{3} x 4_{t-3}+\beta_{4} x 4_{t-4}+\beta_{5} x 5_{t-5}+e_{t}$

The results of the regression are summarized in Table 31. All the potential lag periods in data sets 1, 2 and 3 are significant. Therefore, they are defined as actual time lags to be analyzed for lag effects. In these three cases, the regression coefficients of the lags represent actual lag effects because all of the lags are significant. Therefore, no further 
regression is required. However, the regression results for Data Set 4 show that the potential lag 5 is not significant and should be excluded.

Table 31: Regression results of potential lag periods

\begin{tabular}{|c|c|c|c|c|}
\hline \multirow{2}{*}{$\begin{array}{c}\text { Variables / } \\
\text { Statistics }\end{array}$} & \multicolumn{4}{|c|}{ Models } \\
\cline { 2 - 5 } & Data Set 1 & Data Set 2 & Data Set 3 & Data Set 4 \\
\hline \multirow{2}{*}{ Lag 0 } & 0.20 & 0.20 & 0.20 & - \\
& $(0.00)$ & $(0.00)$ & $(0.00)$ & 0.20 \\
\hline \multirow{2}{*}{ Lag 1 } & 0.20 & 0.50 & 0.50 & $(0.00)$ \\
\hline \multirow{2}{*}{ Lag 2 } & $(0.00)$ & $(0.00)$ & $(0.00)$ & - \\
& 0.20 & 0.20 & 0.20 & 0.50 \\
\hline \multirow{2}{*}{ Lag 3 } & $(0.00)$ & $(0.00)$ & $(0.00)$ & $(0.00)$ \\
\hline \multirow{2}{*}{ Lag 4 } & 0.20 & 0.10 & 0.10 & 0.30 \\
& $(0.00)$ & $(0.00)$ & $(0.00)$ & $(0.00)$ \\
\hline Lag 5 & 0.20 & - & - & 0.00 \\
& $(0.00)$ & - & - & $0.22)$ \\
\hline Probability $>F$ & 0.00 & 0.00 & 0.00 & 1.00 \\
\hline Adjusted $R^{2}$ & 1.00 & 1.00 & 1.00 & \\
\hline
\end{tabular}

\subsubsection{Time-Lag Coefficients}

A. Nonstructured Regression Model (Ordinary Least Squares)

The potential lag periods in Data Set 4 include a fake lag period, $t-5$, as shown in the previous regression. Therefore, time-lag coefficients for Data Set 4 are defined using a regression model with lags 1,3 , and 4 only.

Model 5 for Data Set 4:

$y 4_{t}=\alpha+\beta_{1} x 4_{t-1}+\beta_{3} x 4_{t-3}+\beta_{4} x 4_{t-4}+e_{t}$ 
The regression results show that the three lag periods are significant (Table 32).

Table 32: Time-lag coefficients for data set 4

\begin{tabular}{|c|c|c|c|c|}
\hline \multirow{2}{*}{} & \multicolumn{4}{|c|}{ Variables } \\
\cline { 2 - 5 } & Lag 1 & Lag 3 & Lag 4 & Constant \\
\hline \multirow{2}{*}{ Coefficients } & $\begin{array}{c}0.20 \\
(0.00)\end{array}$ & $\begin{array}{c}0.50 \\
(0.00)\end{array}$ & $\begin{array}{c}0.30 \\
(0.00)\end{array}$ & 0.00 \\
\hline Statistics & \multicolumn{4}{|c|}{ Probability $>$ F: $0.00, R^{2}: 1.00$} \\
\hline
\end{tabular}

The time-lag coefficients from Table 31 and Table 32 were compared with the predefined time-lag structure (Table 33). The observed lag structures using the suggested process successfully identified the actual lag periods and their effect.

Table 33: Predefined and observed lag structures

\begin{tabular}{|c|c|c|c|c|c|c|c|c|}
\hline \multirow{2}{*}{ Lag Periods } & \multicolumn{4}{|c|}{ Predefined Lag Structure } & \multicolumn{4}{c|}{ Observed Lag Structure } \\
& \multicolumn{1}{|c|}{$\begin{array}{c}\text { Data } \\
\text { Set 1 }\end{array}$} & $\begin{array}{c}\text { Data } \\
\text { Set 2 }\end{array}$ & $\begin{array}{c}\text { Data } \\
\text { Set 3 }\end{array}$ & $\begin{array}{c}\text { Data } \\
\text { Set 4 }\end{array}$ & $\begin{array}{c}\text { Data } \\
\text { Set 1 }\end{array}$ & $\begin{array}{c}\text { Data } \\
\text { Set 2 }\end{array}$ & $\begin{array}{c}\text { Data } \\
\text { Set 3 }\end{array}$ & $\begin{array}{c}\text { Data } \\
\text { Set 4 }\end{array}$ \\
\hline Lag 0 & 0.20 & 0.20 & 0.20 & - & 0.20 & 0.20 & 0.20 & - \\
\hline Lag 1 & 0.20 & 0.50 & 0.50 & 0.20 & 0.20 & 0.50 & 0.50 & 0.20 \\
\hline Lag 2 & 0.20 & 0.20 & 0.20 & - & 0.20 & 0.20 & 0.20 & - \\
\hline Lag 3 & 0.20 & 0.10 & 0.10 & 0.50 & 0.20 & 0.10 & 0.10 & 0.50 \\
\hline Lag 4 & 0.20 & - & - & 0.30 & 0.20 & - & - & 0.30 \\
\hline Lag 5 & - & - & - & - & - & - & - & - \\
\hline
\end{tabular}

\section{B. Polynomial Distributed Lag Method}

Polynomial lag structure is similar to the behavior of the time-lag effects of the licensing data, as described in Chapter 3. Therefore, the PDL method is tested to determine 
whether it can measure the time-lag effect of licensing, although the data is different from the data in typical applications of the PDL method, such as economic and agriculture data.

Polynomial coefficient of the regression is expressed as follows [81, 92]:

$\beta_{m}=\sum_{k=0}^{d} \eta_{k} m^{k}$

where

$d=$ the degree of the polynomial $(k=0,1, \ldots, d)$,

$m=$ the lag index $(m=0,1, \ldots, n)$, and

$\eta_{k}=$ the new parameters of the PDL model.

If the second degree $(d=2)$ is assumed, then the PDL regression model using the polynomial structure is

$Y_{t}=\alpha+\left(\eta_{0}\right) X_{t}+\left(\eta_{0}+\eta_{1}+\eta_{2}\right) X_{t-1}+$

$\left(\eta_{0}+2 \eta_{1}+4 \eta_{2}\right) X_{t-2}+\cdots+\left(\eta_{0}+n \eta_{1}+n^{2} \eta_{2}\right) X_{t-n}+e_{t}$

McDowell [81] provided a Stata package procedure to estimate the PDL model. This study adopts the script language and estimates the PDL coefficients using data sets 3 (continuous lag) and 4 (discontinuous lag). The script language is provided in Appendix A. Different polynomial degrees and lag periods are applied to test their applicability to the licensing data. 


\section{1) Continuous time-lag effect (Data Set 3)}

The results of the PDL regression models using the continuous lag case of Data Set 3 are provided in Table 34. The PDL model requires at least four lag periods, so lag periods 4 and 5 with second- and third-degree polynomials are applied. None of the models perfectly matches the predefined lag structure, which is 0.2 at lag $0,0.5$ at lag $1,0.2$ at lag 2, and 0.1 at lag 3 , but they are close to the setting. Although the model in the second column ( $n=4$ and $d=3)$ has the highest adjusted $R^{2}$ value, the last model $(n=5$ and $d=$ 3) presents a better fit to the actual lag structures if nonsignificant coefficients are excluded.

Table 34: Results of polynomial distributed lag regression models applied to data set 4 (continuous lags)

\begin{tabular}{|c|c|c|c|c|}
\hline \multirow{2}{*}{$\begin{array}{c}\text { Variables / } \\
\text { Statistics }\end{array}$} & \multicolumn{4}{|c|}{ Polynomial Distributed Lag Model Specification (Lag Period = $n$, Polynomial Degree $=d$ ) } \\
\cline { 2 - 5 } & $n=4, d=2$ & $n=4, d=3$ & $n=5, d=2$ & $n=5, d=3$ \\
\hline \multirow{2}{*}{ Lag 0 } & 0.20 & 0.17 & 0.25 & 0.16 \\
& $(0.01)$ & $(0.00)$ & $(0.00)$ & $(0.01)$ \\
\hline \multirow{2}{*}{ Lag 1 } & 0.32 & 0.45 & 0.27 & 0.41 \\
& $(0.00)$ & $(0.00)$ & $(0.00)$ & $(0.00)$ \\
\hline \multirow{2}{*}{ Lag 2 } & 0.31 & 0.31 & 0.25 & 0.33 \\
& $(0.00)$ & $(0.00)$ & $(0.00)$ & $(0.00)$ \\
\hline \multirow{2}{*}{ Lag 3 } & 0.18 & 0.05 & 0.18 & 0.10 \\
\hline \multirow{2}{*}{ Lag 4 } & $(0.00)$ & $\underline{\mathbf{( 0 . 2 8}}$ & $(0.00)$ & $(0.02)$ \\
\hline Lag 5 & -0.07 & -0.03 & 0.06 & -0.08 \\
& $\underline{\mathbf{( 0 . 3 4 )}}$ & $\underline{\mathbf{( 0 . 5 0 )}}$ & $\underline{\mathbf{( 0 . 2 5}}$ & $\underline{\mathbf{( 0 . 1 1}}$ \\
\hline Probability $>\mathrm{F}$ & - & - & -0.10 & -0.01 \\
\hline Adjusted $R^{2}$ & 0.00 & 0.00 & $\underline{\mathbf{( 0 . 2 8}}$ & $\underline{\mathbf{0 . 9 3}}$ \\
\hline
\end{tabular}


The difference between the predefined time-lag structure (the result of the nonstructured regression model) and the result of the PDL regression model using Data Set 3 is illustrated in Figure 30.

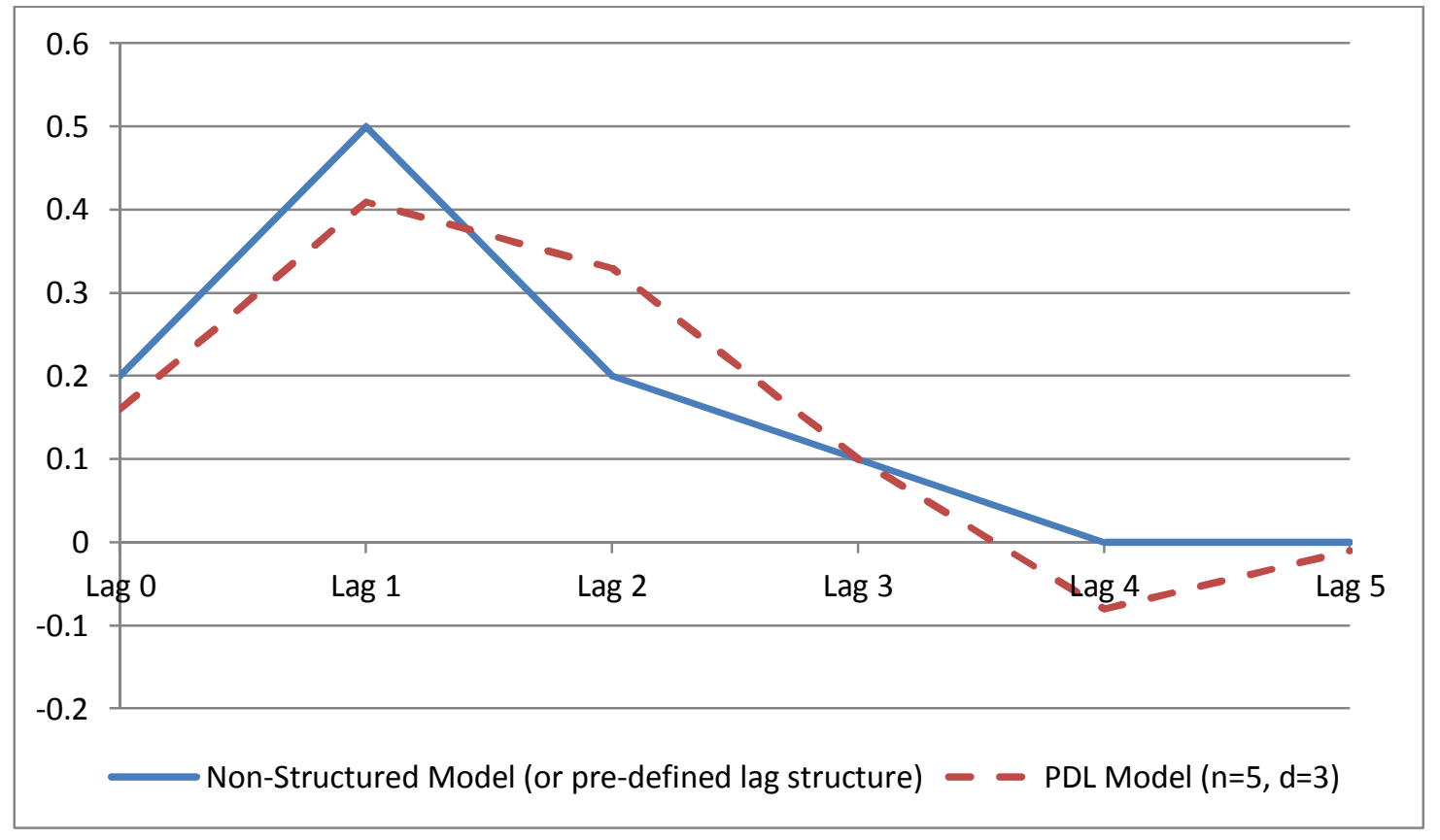

Figure 30: Lag coefficients by polynomial distributed lag regression model with Data Set 3 (continuous lags)

2) Discontinuous time-lag effect

The coefficients resulting from the PDL regression model using the discontinuous timelag case in Data Set 4 are summarized in Table 35. All of the models have the highest coefficient value at lag 5, which is consistent with the predefined lag structure. However, their coefficient values at $t$ (lag 0$)$ are negative, and their overall structure is different from the predefined lag structure. 
Table 35: Results of polynomial distributed lag regression models applied to data set 4 (discontinuous lags)

\begin{tabular}{|c|c|c|c|c|}
\hline \multirow{2}{*}{$\begin{array}{l}\text { Variables / } \\
\text { Statistics }\end{array}$} & \multicolumn{4}{|c|}{$\begin{array}{l}\text { Polynomial Distributed Lag Model Specification }(\text { Lag Period }=n \text {, } \\
\qquad \text { Polynomial Degree }=d)\end{array}$} \\
\hline & $n=4, d=2$ & $n=4, d=3$ & $n=5, d=2$ & $n=5, d=3$ \\
\hline Lag 0 & $\begin{array}{c}-0.08 \\
\mathbf{( 0 . 5 1 )} \\
\end{array}$ & $\begin{array}{l}-0.06 \\
(\mathbf{0 . 6 3}) \\
\end{array}$ & -0.09 & $\begin{array}{c}-0.06 \\
\mathbf{( 0 . 6 9 )} \\
\end{array}$ \\
\hline Lag 1 & $\begin{array}{c}0.14 \\
(0.05)\end{array}$ & $\begin{array}{c}0.07 \\
(\mathbf{0 . 5 3}) \\
\end{array}$ & 0.15 & $\begin{array}{c}0.11 \\
\mathbf{( 0 . 3 4 )} \\
\end{array}$ \\
\hline Lag 2 & $\begin{array}{c}0.27 \\
(0.00)\end{array}$ & $\begin{array}{c}0.27 \\
(0.00)\end{array}$ & 0.28 & $\begin{array}{c}0.25 \\
(0.01)\end{array}$ \\
\hline Lag 3 & $\begin{array}{c}0.31 \\
(0.00) \\
\end{array}$ & $\begin{array}{c}0.37 \\
(0.00) \\
\end{array}$ & 0.30 & $\begin{array}{c}0.33 \\
(0.00) \\
\end{array}$ \\
\hline Lag 4 & $\begin{array}{c}0.26 \\
(0.04)\end{array}$ & $\begin{array}{c}0.24 \\
(\mathbf{0 . 0 6 )} \\
\end{array}$ & 0.23 & $\begin{array}{c}0.27 \\
(0.02)\end{array}$ \\
\hline Lag 5 & - & - & 0.05 & $\begin{array}{c}0.02 \\
(\mathbf{0 . 8 9}) \\
\end{array}$ \\
\hline Probability $>$ F & 0.01 & 0.03 & 0.03 & 0.07 \\
\hline Adjusted $R^{2}$ & 0.57 & 0.54 & $\underline{0.66}$ & 0.49 \\
\hline
\end{tabular}

The best-fitting PDL regression model ( $n=5$ and $d=2)$ is compared to the actual timelag effect (Figure 31). The PDL regression model estimates coefficients using a concave curve and doesn't identify the discontinuous period, lag 2 . 


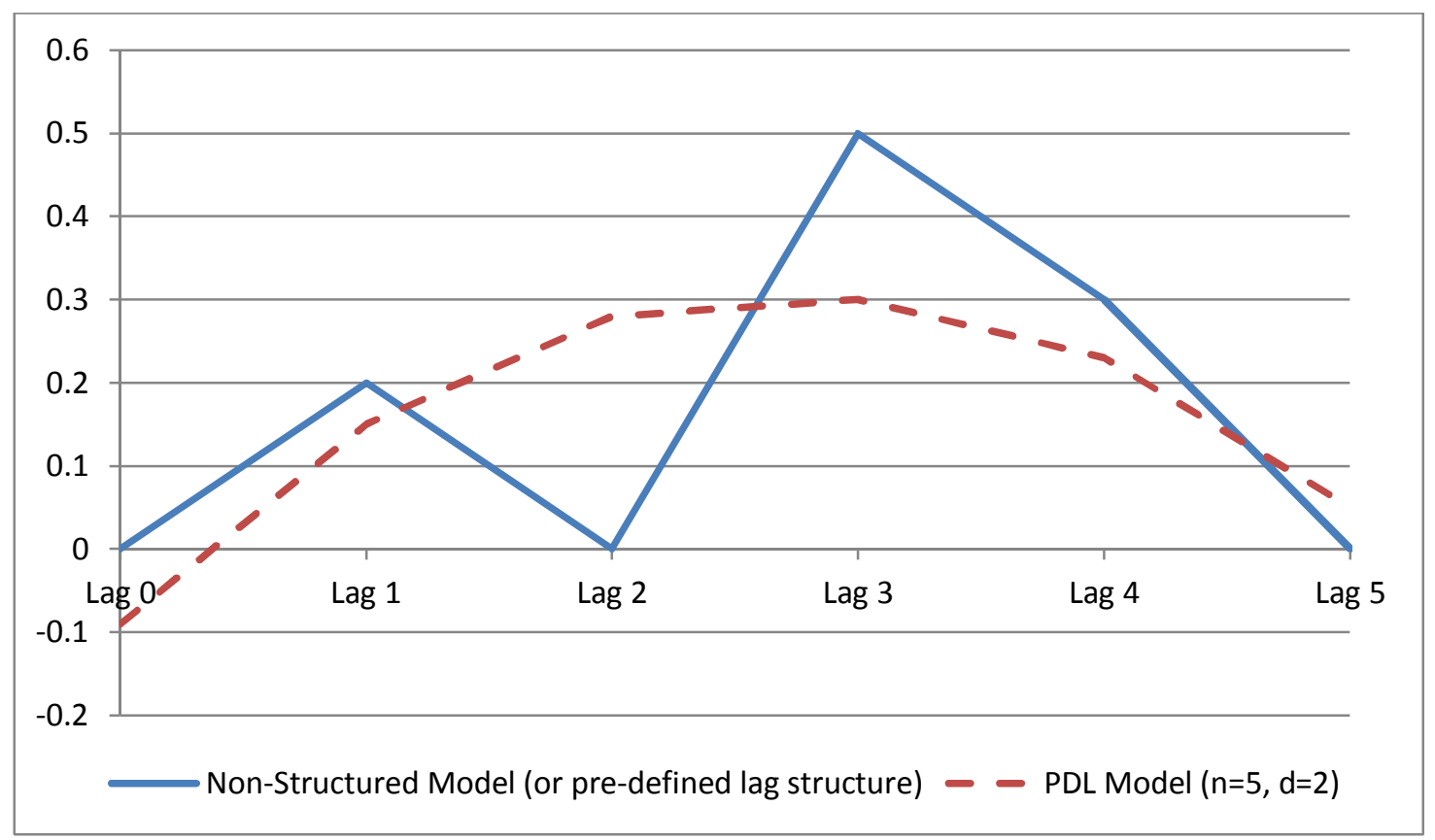

Figure 31: Lag coefficients by polynomial distributed lag regression model with Data Set 4 (discontinuous lags)

\subsection{Summary}

Licensing data is different from data in other areas, such as economics or biology, where long-term and continuous time-lag effects are assumed. Therefore, the well-known econometrics time-series procedures are not well suited to licensing data. The present study suggests a process to identify time-lag effects in licensing data.

This study compared the current approach to estimating time-period and time-lag coefficients with the new procedure, using an unstructured regression model (OLS) on simulated data sets that reflect time-lag behavior in licensing. The results show that the time-lag coefficients of actual lag effects result in positive correlations and present the 
correct continuous or discontinuous periods, whereas AIC and BIC always pick the maximum lag length in the simulated data sets.

The OLS estimates exactly the same coefficients as those that are predefined, whereas the PDL regression model produces approximations. In the case of a discontinuous lag structure, the PDL method cannot identify the discontinuing effect of the licensing due to its inherent polynomial structure. The PDL method would be effective when a relatively long-lasting time-lag effect, without discontinuousness, is assumed.

The simulated test of four time-lag cases supports and validates the suggested time-lag identifying process. The process is robust and successfully detects the correct time-lag coefficients in the unique licensing data. 
Chapter 5. Time Lags in U.S. Academic Research Institution Licensing Activities

\subsection{Forty-Six U.S. Academic Research Institutions and Their Licensing Data}

The time-lag analysis employed data from the Association of University Technology Managers licensing survey of U.S. academic research institutions from 1991 to 2007. Raw data on about 198 institutions was reviewed and refined before being used for the analysis, for several reasons. First, although AUTM licensing surveys employed certain common questionnaires during the period, they also had new questionnaires on specific topics only for certain periods. Another difficulty in using the raw data was due to inconsistency in the names of the variables. In some cases, there also were data missing for certain years, and institutions are excluded from the present study if they didn't have a complete data set for the variables used in the examination of time-lag effect. Only 48 U.S. institutions were identified as having full data for the period under examination.

The seven variables used in the analysis include research expenditure, number of disclosures, number of U.S. patent applications, number of U.S. patents issued, number of licenses and options executed, number of start-ups, and licensing income. Research expenditure and licensing income were inflation-adjusted using the 1990 consumer price index. 
Among the 48 institutions, two outliers were identified. First, Emory University had an extraordinarily high licensing income of $\$ 585.7$ million in 2005 . The university licensed its discovery of the HIV/AIDS drug Emtriva to Gilead Sciences and Royalty Pharma and received from the licensees a lump sum payment of $\$ 525$ million in 2005 . The University of California system also had peculiar incomes, in 2000 and 2006. Given the average licensing income during the period, these data could distort the normal time-lag effect of the licensing and cause a biased result. Therefore, these two universities were defined as outliers and were excluded from the time-lag analysis. The remaining 46 institutions used in the analysis are listed in Table 36. 
Table 36: The 46 institutions used for the time-lag analysis

\begin{tabular}{cl|cl}
\hline $\begin{array}{c}\text { Ranking } \\
\text { (Income, }\end{array}$ & \multicolumn{1}{c}{ University } & $\begin{array}{c}\text { Ranking } \\
\text { (Income, } \\
2007)\end{array}$ & \multicolumn{1}{c}{ University } \\
\hline 1 & City of Hope National Medic & 24 & Univ. of Oregon \\
2 & Northwestern Univ. & 25 & Indiana Univ. (ARTI) \\
3 & Wake Forest Univ. & 26 & Ohio Univ. \\
4 & Univ. of Minnesota & 27 & Fred Hutchinson Cancer Res. \\
5 & Massachusetts Inst. of Tech & 28 & Clemson Univ. \\
6 & Mayo Foundation & 29 & Univ. of Southern California \\
7 & Univ. of Utah & 30 & Dartmouth College \\
8 & Univ. of Iowa Research Fdn. & 31 & St. Jude Children's Res. \\
9 & Univ. of Michigan & 32 & Brigham Young Univ. \\
10 & Harvard Univ. & 33 & Colorado State Univ. \\
11 & Washington Univ. & 34 & Oregon State Univ. \\
12 & Case Western Reserve Univ. & 35 & Georgia Inst. of Technology \\
13 & Baylor College of Medicine & 36 & Penn State Univ. \\
14 & Johns Hopkins Univ. & 37 & Florida State Univ. \\
15 & California Institute of Tech. & 38 & Ohio State Univ. \\
16 & Vanderbilt Univ. & 39 & Univ. of Arizona \\
17 & Brigham \& Women's Hospital, & 40 & Univ. of Maryland, College \\
18 & Inc. & & \\
19 & Rutgers, The State Univ. & 41 & Univ. of Connecticut \\
20 & Univ. of Texas Southwestern & 42 & Univ. of Cincinnati \\
21 & Tulane Univ. & 43 & Univ. of Delaware \\
22 & Mniv. of Akron & 44 & New Jersey Institute of Tech. \\
23 & Univ. of Virginia Patent Fdn. & 46 & Univ. of Dayton \\
\hline & & & \\
\end{tabular}

Data on the 46 institutions is summarized in Table 37. The average research expenditure of the institutions from 1991 to 2007 was $\$ 170$ million, and licensing income was $\$ 4.6$ million. The variances among the institutions in expenditure and number of disclosures are two times higher than the variances in time, whereas institutional variances in the number of start-ups and licensing income are similar to the variances in time. The number of patent applications, patents issued, and licenses and options executed have little variance, other than time. 
Table 37: Summary of the seven variables of the 46 institutions

\begin{tabular}{|c|c|c|c|c|c|c|}
\hline \multicolumn{2}{|c|}{ Variable } & \multirow{2}{*}{$\begin{array}{r}\text { Mean } \\
16.91\end{array}$} & \multirow{2}{*}{$\begin{array}{r}\begin{array}{c}\text { Standard } \\
\text { Deviation }\end{array} \\
15.81 \\
\end{array}$} & \multirow{2}{*}{$\begin{array}{r}\text { Minimum } \\
0.72\end{array}$} & \multirow{2}{*}{$\begin{array}{r}\text { Maximum } \\
113.93 \\
\end{array}$} & \multirow{2}{*}{$\begin{array}{c}\begin{array}{c}\text { Observatio } \\
\text { ns }\end{array} \\
N=782 \\
\end{array}$} \\
\hline EXP & Overall & & & & & \\
\hline million & Between & & 14.96 & 1.36 & 84.52 & $n=46$ \\
\hline $\begin{array}{l}\text { 1n } 1990 \\
\text { dollars) }\end{array}$ & Within & & 5.54 & -11.04 & 46.32 & $T=17$ \\
\hline \multirow{3}{*}{ DIS } & Overall & 94.52 & 96.02 & 0.00 & 661.00 & $N=782$ \\
\hline & Between & & 85.76 & 13.24 & 390.12 & $n=46$ \\
\hline & Within & & 44.90 & -150.77 & 367.23 & $T=17$ \\
\hline \multirow{3}{*}{ PTF } & Overall & 46.12 & 66.46 & 0.00 & 562.00 & $N=782$ \\
\hline & Between & & 49.50 & 6.76 & 209.76 & $n=46$ \\
\hline & Within & & 44.91 & -133.64 & 398.36 & $T=17$ \\
\hline \multirow{3}{*}{ PTI } & Overall & 20.19 & 26.67 & 0.00 & 172.00 & $N=782$ \\
\hline & Between & & 21.62 & 3.76 & 116.35 & $n=46$ \\
\hline & Within & & 15.91 & -96.16 & 108.01 & $T=17$ \\
\hline \multirow{3}{*}{ LOE } & Overall & 25.86 & 26.02 & 0.00 & 163.00 & $N=782$ \\
\hline & Between & & 21.74 & 2.18 & 95.35 & $n=46$ \\
\hline & Within & & 14.63 & -20.14 & 121.33 & $T=17$ \\
\hline \multirow{3}{*}{ STU } & Overall & 2.93 & 5.35 & 0.00 & 64.00 & $N=782$ \\
\hline & Between & & 3.34 & 0.00 & 20.18 & $n=46$ \\
\hline & Within & & 4.20 & -17.24 & 51.81 & $T=17$ \\
\hline \multirow{3}{*}{$\begin{array}{c}\text { LCI } \\
(\$ 0.1 \\
\text { million } \\
\text { in } 1990 \\
\text { dollars) }\end{array}$} & Overall & 46.23 & 85.91 & 0.00 & 743.81 & $N=782$ \\
\hline & Between & & 61.07 & 0.59 & 313.48 & $n=46$ \\
\hline & Within & & 61.05 & -125.82 & 532.36 & $T=17$ \\
\hline
\end{tabular}

Note: Between $=$ institution variance, $\overline{x_{l}}$; Within $=$ time variance, $x_{i t}-\overline{x_{l}}+\overline{\bar{x}}$. DIS $=$ number of disclosures, $\mathrm{EXP}=$ research expenditure, $\mathrm{LCI}=$ licensing income, $\mathrm{LOE}=$ number of licenses and options executed, PTF = number of U.S. patent applications, PTI = number of U.S. patents issued, STU = number of start-ups. 


\subsection{Time-Lag Coefficients (Steps 2-1 to 2-5)}

\subsubsection{Step 2-1: Stabilize the Time-Series Panel Data}

A unit root test of the licensing data was conducted using the LLC test, which is a stationary test method for time series panel data. The study used the "xtunitrrot" function of the Stata package for the test. The two raw data sets, Diff( $(0)=$ variable $_{t}$, and firstorder difference, $\operatorname{Diff}(1)=$ variable $_{t}-$ variable $_{t-1}$, were tested. The result shows that all variables except for the patents issued and license and options executed have a unit root and are not stationary (Table 38). If the first-order difference (delta) is taken for the variables, they become stationary. Therefore, the delta data for each variable is used for the time-lag analysis.

Table 38: Results of the unit root test of licensing data, using the Levin-Lin-Chu test

\begin{tabular}{|c|c|c|}
\hline \multirow{2}{*}{ Variable } & \multicolumn{2}{|c|}{ P-Value From Levin-Lin-Chu Test } \\
\hline & $\begin{array}{l}\text { Raw data, } \\
\operatorname{Diff}(0)\end{array}$ & $\begin{array}{c}\text { First-order difference, } \\
\text { Diff (1) }\end{array}$ \\
\hline Expenditure & $\begin{array}{c}0.27 \\
\text { (Not stationary) }\end{array}$ & $\begin{array}{c}0.00 \\
\text { (Stationary) }\end{array}$ \\
\hline Disclosure & $\begin{array}{c}0.99 \\
\text { (Not stationary) }\end{array}$ & $\begin{array}{c}0.00 \\
\text { (Stationary) }\end{array}$ \\
\hline Patent Filed & $\begin{array}{c}0.25 \\
\text { (Not stationary) }\end{array}$ & $\begin{array}{c}0.00 \\
\text { (Stationary) }\end{array}$ \\
\hline Patent Issued & $\begin{array}{c}0.00 \\
\text { (Stationary) }\end{array}$ & $\begin{array}{c}0.00 \\
\text { (Stationary) }\end{array}$ \\
\hline $\begin{array}{l}\text { License and Option } \\
\text { Executed }\end{array}$ & $\begin{array}{c}0.00 \\
\text { (Stationary) }\end{array}$ & $\begin{array}{c}0.00 \\
\text { (Stationary) }\end{array}$ \\
\hline Start-up & $\begin{array}{c}0.99 \\
\text { (Not stationary) }\end{array}$ & $\begin{array}{c}0.00 \\
\text { (Stationary) }\end{array}$ \\
\hline Licensing Income & $\begin{array}{c}1.00 \\
\text { (Not stationary) }\end{array}$ & $\begin{array}{c}0.00 \\
\text { (Stationary) }\end{array}$ \\
\hline
\end{tabular}




\subsubsection{Step 2-2: Construct a Model}

The time flow of each licensing activity is assumed based on the licensing process, which is identified through the literature (Figure 32). For each activity it is assumed that a licensing activity results or influences the other activities on its right, and that there is no reverse effect. For example, the number of disclosures cannot be a result of patents issued or licensing income.

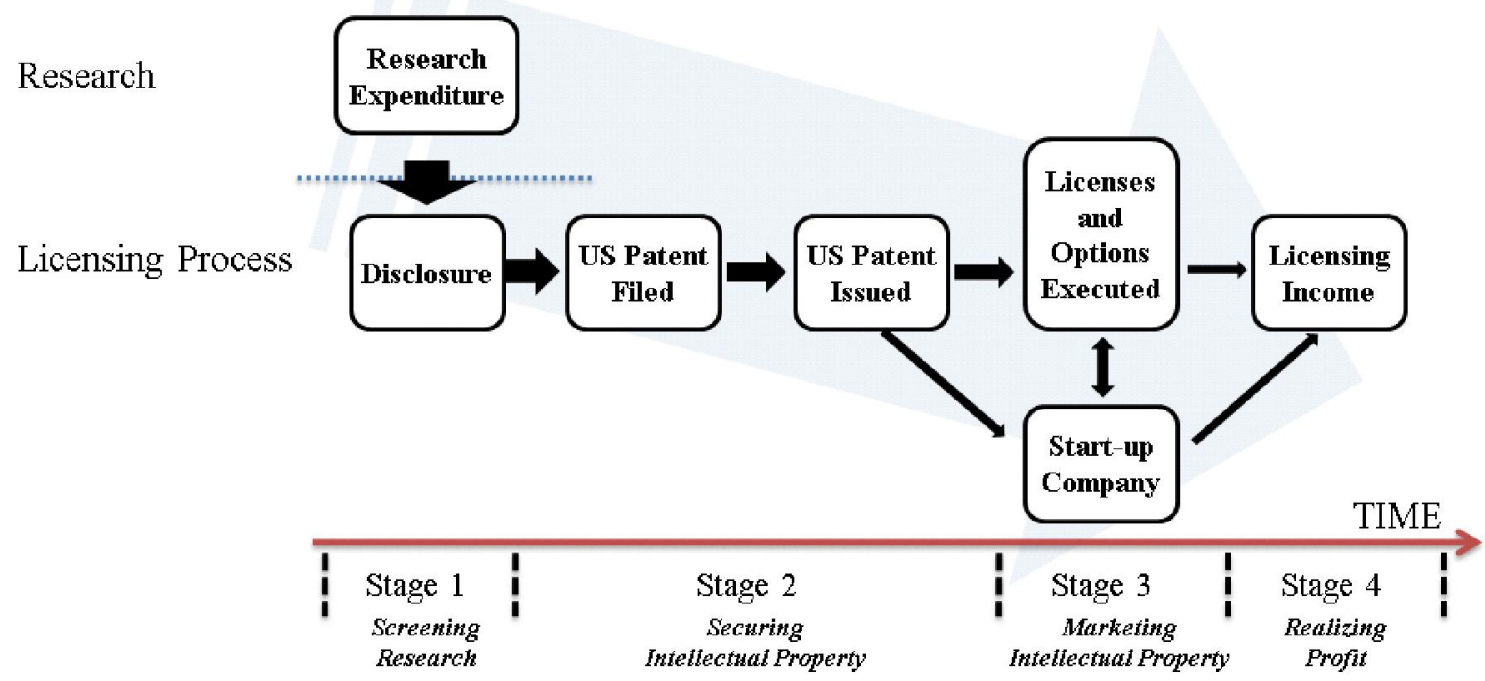

Figure 32: Licensing process

The time-lag effect is defined as the influence of a prior licensing activity on other, posterior activities. Therefore, the time-lag effects of each pair of licensing variables were explored.

The time-lag distributed lag model, using an unstructured lag coefficient, is defined as follows: 
$Y_{i, t}=\beta_{0} X_{i, t}+\beta_{1} X_{i, t-1}+\beta_{2} X_{i, t-2}+\cdots+\beta_{n} X_{i, t-n}+e_{i, t}$

where,

$Y=$ output licensing variables (delta) of disclosure, patent applications, patent issued, licenses and options executed, start-up, and licensing income;

$X=$ input licensing variables (delta) of research expenditure, disclosure, patent applications, patents issued, licenses and options executed, and start-up;

$i=i^{\text {th }}$ institution; $i=1,2, \ldots 46$;

$t=$ year $t$;

$\beta_{0}, \beta_{1}, \ldots, \beta_{n}=$ time-lag coefficients; and

$e_{i, t}=$ error term.

\subsubsection{Step 2-3: Identify Potential Lag Period}

Correlations among each pair of input and output licensing variables, with maximum lag periods of 8 , are summarized at Table 39. The time lags that have a negative correlation to a dependent variable are excluded. For example, the identified potential time lags from research expenditure to disclosure are $0,1,3,5$, and 7 years. 
Table 39: Correlation result of the licensing variables

\begin{tabular}{|c|c|c|c|c|c|c|c|c|c|c|c|}
\hline \multicolumn{2}{|c|}{ Variables } & \multicolumn{9}{|c|}{ Time lags of independent variables } & \multirow{2}{*}{$\begin{array}{c}\text { Selected } \\
\text { Potential } \\
\text { Lags }\end{array}$} \\
\hline $\begin{array}{c}\text { Depen } \\
\text { dent }\end{array}$ & $\begin{array}{c}\text { Indepe } \\
\text { ndent }\end{array}$ & Lag 0 & Lag 1 & Lag 2 & Lag 3 & Lag 4 & Lag 5 & Lag 6 & Lag 7 & Lag 8 & \\
\hline DIS & EXP & 0.145 & .105 & -0.056 & 0.050 & -0.001 & 0.090 & -0.073 & 0.098 & -0.025 & $0,1,3,5,7$ \\
\hline PTF & EXP & 0.116 & -0.098 & -0.008 & -0.053 & 0.147 & 0.120 & 0.034 & -0.044 & 0.062 & $0,4,5,6,8$ \\
\hline PTI & EXP & 0.094 & 0.112 & -0.073 & -0.013 & -0.099 & 0.176 & -0.281 & 0.076 & -0.038 & $0,1,5,7$ \\
\hline LOE & EXP & 0.024 & -0.011 & -0.048 & -0.084 & 0.005 & 0.036 & 0.009 & -0.072 & 0.145 & $0,4,5,6,8$ \\
\hline STU & EXP & 0.044 & .150 & 0.097 & -0.021 & 0.150 & -0.009 & -0.088 & -0.144 & 0.110 & \\
\hline LCI & EXP & -0.001 & -0.108 & 0.044 & 0.060 & 0.014 & 0.203 & -0.221 & 0.015 & 0.025 & $2,3,4$ \\
\hline PTF & DIS & 0.272 & 0.054 & 0.051 & 0.066 & 0.241 & -0.144 & -0.095 & 0.006 & -0.050 & $0,1,2,3,4,7$ \\
\hline PTI & DIS & 0.065 & -0.069 & 0.066 & 0.043 & -0.114 & 0.100 & -0.208 & -0.001 & 0.015 & $0,2,3,5,8$ \\
\hline LOE & DIS & -0.012 & 0.059 & -0.047 & 0.017 & 0.000 & -0.027 & -0.008 & -0.029 & -0.029 & 1,3 \\
\hline STU & DIS & 0.047 & -0.054 & 0.012 & -0.061 & 0.132 & -0.097 & -0.067 & 0.003 & 0.110 & $0,2,4,7,8$ \\
\hline LCI & DIS & 0.023 & -0.074 & 0.031 & -0.056 & 0.001 & 0.104 & -0.118 & 0.023 & 0.056 & $0,2,4,5,7,8$ \\
\hline PTI & PTF & -0.004 & 0.036 & -0.070 & 0.147 & -0.119 & 0.032 & -0.030 & -0.051 & -0.077 & $1,3,5$ \\
\hline LOE & PTF & 0.056 & -0.012 & 0.077 & -0.004 & -0.032 & -0.020 & -0.033 & -0.018 & -0.071 & 0,2 \\
\hline STU & PTF & 0.204 & -0.161 & -0.065 & 0.092 & \begin{tabular}{|l|}
0.049 \\
\end{tabular} & -0.097 & -0.082 & 0.063 & 0.044 & $0,3,4,7,8$ \\
\hline LCI & PTF & -0.016 & -0.069 & -0.052 & 0.119 & & -0.048 & -0.031 & 0.018 & -0.018 & \\
\hline LOE & PTI & 0.093 & -0.004 & -0.096 & 0.057 & 0.012 & 0.064 & -0.090 & 0.082 & -0.050 & $0,3,4,5,7$ \\
\hline STU & PTI & -0.049 & 0.163 & -0.135 & 0.075 & -0.037 & -0.046 & 0.000 & 0.233 & -0.082 & $1,3,7$ \\
\hline LCI & PTI & 0.149 & -0.031 & 0.017 & -0.046 & 0.014 & -0.036 & 0.066 & 0.024 & 0.112 & $0,2,4,6,7,8$ \\
\hline STU & LOE & 0.217 & -0.061 & -0.078 & 0.069 & 0.029 & -0.010 & -0.024 & -0.008 & -0.032 & $0,3,4$ \\
\hline LCI & LOE & 0.066 & -0.038 & -0.056 & 0.085 & -0.031 & -0.007 & -0.023 & 0.046 & -0.063 & $0,3,7$ \\
\hline LCI & STU & 0.141 & 0.051 & -0.054 & -0.005 & 0.025 & -0.121 & -0.085 & 0.043 & 0.176 & $0,1,4,7,8$ \\
\hline
\end{tabular}

Note: $\mathrm{DIS}=$ number of disclosures, $\mathrm{EXP}=$ research expenditure, $\mathrm{LCI}=$ licensing income, $\mathrm{LOE}=$ number of licenses and options executed, PTF = number of U.S. patent applications, PTI = number of U.S. patents issued, $\mathrm{STU}=$ number of start-ups. 


\subsubsection{Step 2-4: Determine the Lag Period}

The total 21 distributed lag models, using the selected potential lags of each model, were tested to identify significant lag periods. For example, the distributed lag regression model of disclosure and expenditure with $0,1,3,5$, and 7 lags is calculated as

$\Delta y_{i, t}^{D I S}=\beta_{0} \Delta x_{i, t}^{E X P}+\beta_{1} \Delta x_{i, t-1}^{E X P}+\beta_{3} \Delta x_{i, t-3}^{E X P}+\beta_{5} \Delta x_{i, t-5}^{E X P}+\beta_{7} \Delta x_{i, t-7}^{E X P}+e_{t}$

The regression result obtained using the Stata package is presented in Table 40. The lag periods 0,1 , and 5 are significant $(\mathrm{p}$-value $<0.1)$. Therefore, these three lag periods are defined as time lags between disclosure and expenditure.

Table 40: regression result of disclosure and expenditure with potential lag periods

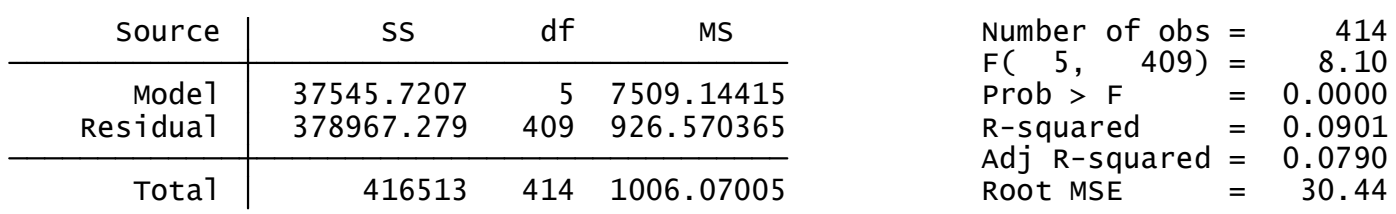

\begin{tabular}{r|rrrrrr}
\hline De1ta_DIS & Coef. & Std. Err. & $\mathrm{t}$ & $\mathrm{P}>|\mathrm{t}|$ & [95\% Conf. Interva1] \\
\hline De1ta_EXP & & & & & & \\
--. & 1.642528 & .5004857 & 3.28 & 0.001 & .6586823 & 2.626373 \\
L1. & 2.109773 & .6970823 & 3.03 & 0.003 & .7394619 & 3.480084 \\
L5. & .4915564 & .5785939 & 0.85 & 0.396 & -.6458325 & 1.628945 \\
L7. & 1.394634 & .5765469 & 2.42 & 0.016 & .2612686 & 2.527998 \\
.9550496 & .6247714 & 1.53 & 0.127 & -.2731142 & 2.183213 \\
\hline
\end{tabular}

The significant time-lag periods from the 21 regression models are summarized in Table 41. As shown in the first column, the significant time lags from expenditure to disclosure are 0,1 , and 5 years; to patent filed, they are 0,4 and 5 years; to patent issue, they are 1 
and 5 years; to licenses and options executed, it is 8 years; to start-up, they are 4 and 8 years; to licensing income, it is 5 years. However, caution is required in interpreting the results. For example, time lags of 0,1 , and 5 years from expenditure to disclosure don't necessarily mean it would not be possible for an institution to have disclosure after 2 or 3 years following their research, which is other than the identified lag periods. Instead, the lag periods shown in the table represent the most plausible time period reflecting the data.

Table 41: Significant lag periods among the licensing variables

\begin{tabular}{|c|c|c|c|c|c|c|}
\hline \multirow[b]{2}{*}{$\begin{array}{l}\text { Dependent } \\
\text { Variables }\end{array}$} & \multicolumn{6}{|c|}{ Significant Lag Periods of the Independent Variables } \\
\hline & Expenditure & Disclosure & Patent filed & $\begin{array}{l}\text { Patent } \\
\text { Issued }\end{array}$ & $\begin{array}{c}\text { Licenses and } \\
\text { Options } \\
\text { Executed }\end{array}$ & Start-up \\
\hline Disclosures & $\operatorname{Lag} 0{ }^{* *}, 1^{* *}, 5^{*}$ & N/A & $\mathrm{N} / \mathrm{A}$ & N/A & N/A & N/A \\
\hline Patent Filed & \begin{tabular}{|c}
$\operatorname{Lag} 0_{* *}^{* *}, 4^{* *}$ \\
5 \\
\end{tabular} & $\begin{array}{c}\operatorname{Lag} 0_{*}^{* *},{ }^{*},{ }^{*}{ }^{*}, \\
3,4\end{array}$ & N/A & N/A & N/A & N/A \\
\hline $\begin{array}{l}\text { Patents } \\
\text { Issued }\end{array}$ & $\operatorname{Lag} 1^{*}, 5^{* *}$ & $\operatorname{Lag} 5^{*}$ & $\operatorname{Lag} 1,3^{* *}$ & $\mathrm{~N} / \mathrm{A}$ & N/A & N/A \\
\hline $\begin{array}{c}\text { Licenses } \\
\text { and Options } \\
\text { Executed }\end{array}$ & $\operatorname{Lag} 8^{* *}$ & $\operatorname{Lag} 1^{* *}$ & $\operatorname{Lag} 0{ }^{* *}, 2^{* *}$ & $\operatorname{Lag} 0{ }^{* *}, 7^{*}$ & N/A & N/A \\
\hline Start-up & $\operatorname{Lag} 4^{* *}, 8^{*}$ & $\operatorname{Lag} 4{ }^{* *}, 8^{* *}$ & $\operatorname{Lag} 0^{* *}$ & $\operatorname{Lag} 1{ }^{* *}, 7^{* *}$ & $\operatorname{Lag} 0^{* *}$ & N/A \\
\hline $\begin{array}{l}\text { Licensing } \\
\text { Income }\end{array}$ & $\operatorname{Lag} 5^{* *}$ & $\operatorname{Lag} 5^{* *}$ & $\operatorname{Lag} 3^{* *}$ & $\operatorname{Lag} 6{ }^{*}, 8^{* *}$ & $\operatorname{Lag} 3^{*}$ & $\operatorname{Lag}_{8^{* *}}^{* *}, 7^{* *}$ \\
\hline
\end{tabular}

Note: ${ }^{*}$-value $<0.1,{ }^{* *}$ p-value $<0.05$

In order to define unobserved time lags, a known lag function or curve should be defined. There is no current study defining the curves or lag behavior of continuous lag effects representing real licensing cases. Therefore, the present study doesn't define or estimate 
time lags if they are not significant in the models, and it assumes discontinuous lag effects.

\subsubsection{Step 2-5: Estimate Time-Lag Coefficients}

The time-lag effects of the identified lag periods among the licensing variables were explored. The 21 regression models were specified by including the significant lags only. For instance, the lag coefficients of expenditure to disclosure are estimated using the model with lag 0,1 , and 5 .

$$
\Delta y_{i, t}^{D I S}=\beta_{0} \Delta x_{i, t}^{E X P}+\beta_{1} \Delta x_{i, t-1}^{E X P}+\beta_{5} \Delta x_{i, t-5}^{E X P}+e_{t}
$$

The result of the model is presented in Table 42. All of the coefficients are significant and have a value of 1.78 for lag $0,1.67$ for lag 1 , and 1.49 for lag 5 . If these coefficient values are normalized, the percentage of expenditure at a certain year relative to the disclosure at year $t$ can be found. In this case, the $36 \%$ of expenditure at year $t, 34 \%$ at $t-$ 1 , and $30 \%$ at $t-5$ are associated with the number of disclosures at $t$.

Table 42: Time-lag coefficients of expenditure to disclosure

\begin{tabular}{|c|c|c|c|c|c|c|c|}
\hline Source & SS & $d f$ & \multicolumn{2}{|c|}{ MS } & & \multirow{3}{*}{$\begin{array}{l}\text { Number of obs }= \\
\text { F( } 3,503)= \\
\text { Prob }>\text { F } \\
\text { R-squared } \\
\text { Adj R-squared } \\
\text { Root MSE }\end{array}$} & \multirow{3}{*}{$\begin{array}{rr}= & 506 \\
= & 13.02 \\
= & 0.0000 \\
= & 0.0720 \\
= & 0.0665 \\
= & 28.64\end{array}$} \\
\hline 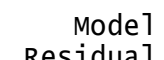 & $\begin{array}{l}32028.8648 \\
412597 \quad 135\end{array}$ & $\begin{array}{r}3 \\
503\end{array}$ & 106 & & & & \\
\hline Tota1 & 444626 & 506 & & 0751 & & & \\
\hline Delta_DIS & Coef. & std. & Err. & $\mathrm{t}$ & $P>|t|$ & [95\% Conf. & Interval] \\
\hline $\begin{array}{r}\text { De1ta_EXP } \\
--. \\
\text { L1. } \\
\text { L5. }\end{array}$ & $\begin{array}{l}1.782722 \\
1.665441 \\
1.490026\end{array}$ & $\begin{array}{l}.4412 \\
.513 \\
.515\end{array}$ & $\begin{array}{l}415 \\
3275 \\
771\end{array}$ & $\begin{array}{l}4.04 \\
3.24 \\
2.89\end{array}$ & $\begin{array}{l}0.000 \\
0.001 \\
0.004\end{array}$ & $\begin{array}{l}.9158181 \\
.6570136 \\
.4766956\end{array}$ & $\begin{array}{l}2.649625 \\
2.673868 \\
2.503357\end{array}$ \\
\hline
\end{tabular}


The unstandardized lag coefficients of 21 regression models are presented in Table 43.

Table 43: Unstandardized time-lag coefficients of the licensing variables

\begin{tabular}{|c|c|c|c|c|c|c|c|c|c|c|}
\hline \multicolumn{7}{|c|}{ Variables } & \multicolumn{7}{|c|}{ Time-lag Coefficients of Independent Variables } \\
\hline $\begin{array}{c}\text { Depen } \\
\text { dent }\end{array}$ & $\begin{array}{c}\text { Indepe } \\
\text { ndent }\end{array}$ & Lag 0 & Lag 1 & Lag 2 & Lag 3 & Lag 4 & Lag 5 & Lag 6 & Lag 7 & Lag 8 \\
\hline DIS & EXP & 1.783 & 1.665 & & & & 1.490 & & & \\
\hline PTF & EXP & 1.320 & & & & 2.101 & 1.987 & & & \\
\hline PTI & EXP & & 0.438 & & & & 0.524 & & & \\
\hline LOE & EXP & & & & & & & & & 0.899 \\
\hline STU & EXP & & & & & 0.143 & & & & 0.112 \\
\hline LCI & EXP & & & & & & 4.252 & & & \\
\hline PTF & DIS & 0.246 & 0.162 & 0.139 & 0.095 & 0.213 & & & & \\
\hline PTI & DIS & & & & & & 0.044 & & & \\
\hline LOE & DIS & & 0.043 & & & & & & & \\
\hline STU & DIS & & & & & 0.014 & & & & 0.016 \\
\hline LCI & DIS & & & & & & 0.260 & & & \\
\hline PTI & PTF & & 0.031 & & 0.059 & & & & & \\
\hline LOE & PTF & 0.047 & & 0.047 & & & & & & \\
\hline STU & PTF & 0.021 & & & & & & & & \\
\hline LCI & PTF & & & & 0.281 & & & & & \\
\hline LOE & PTI & 0.140 & & & & & & & 0.137 & \\
\hline STU & PTI & & 0.026 & & & & & & 0.051 & \\
\hline LCI & PTI & & & & & & & 0.546 & & 0.790 \\
\hline STU & LOE & 0.003 & & & & & & & & \\
\hline LCI & LOE & & & & 0.320 & & & & & \\
\hline LCI & STU & 3.095 & & & & & & & 0.922 & 1.732 \\
\hline
\end{tabular}

Note: $\mathrm{DIS}=$ number of disclosures, $\mathrm{EXP}=$ research expenditure, $\mathrm{LCI}=$ licensing income, $\mathrm{LOE}=$ number of licenses and options executed, PTF $=$ number of U.S. patent applications, PTI $=$ number of U.S. patents issued, STU = number of start-ups.

Finally, the time-lag effects of the licensing variables are defined by normalizing the lag coefficients, as shown in Table 44. 
Table 44: Standardized time-lag effects of the licensing variables

\begin{tabular}{|c|c|c|c|c|c|c|c|c|c|c|}
\hline \multicolumn{7}{|c|}{ Variables } & \multicolumn{7}{|c|}{ Time-Lag Coefficients of Independent Variables } \\
\hline $\begin{array}{c}\text { Depen } \\
\text { dent }\end{array}$ & $\begin{array}{c}\text { Indepe } \\
\text { ndent }\end{array}$ & Lag 0 & Lag 1 & Lag 2 & Lag 3 & Lag 4 & Lag 5 & Lag 6 & Lag 7 & Lag 8 \\
\hline DIS & EXP & 0.361 & 0.337 & & & & 0.302 & & & \\
\hline PTF & EXP & 0.244 & & & & 0.388 & 0.367 & & & \\
\hline PTI & EXP & & 0.455 & & & & 0.545 & & & \\
\hline LOE & EXP & & & & & & & & & 1.000 \\
\hline STU & EXP & & & & & 0.560 & & & & 0.440 \\
\hline LCI & EXP & & & & & & 1.000 & & & \\
\hline PTF & DIS & 0.287 & 0.190 & 0.163 & 0.111 & 0.249 & & & & \\
\hline PTI & DIS & & & & & & 1.000 & & & \\
\hline LOE & DIS & 1.000 & & & & & & & \\
\hline STU & DIS & & & & & 0.463 & & & & 0.537 \\
\hline LCI & DIS & & & & & & 1.000 & & & \\
\hline PTI & PTF & & 0.343 & & 0.657 & & & & & \\
\hline LOE & PTF & 0.498 & & 0.502 & & & & & & \\
\hline STU & PTF & 1.000 & & & & & & & & \\
\hline LCI & PTF & & & & 1.000 & & & & & \\
\hline LOE & PTI & 0.506 & & & & & & & 0.494 & \\
\hline STU & PTI & & 0.342 & & & & & & 0.658 & \\
\hline LCI & PTI & & & & & & & 0.409 & & 0.591 \\
\hline STU & LOE & 1.000 & & & & & & & & \\
\hline LCI & LOE & & & & 1.000 & & & & & \\
\hline LCI & STU & 0.538 & & & & & & & 0.160 & 0.301 \\
\hline
\end{tabular}

Note: DIS $=$ number of disclosures, $\mathrm{EXP}=$ research expenditure, $\mathrm{LCI}=$ licensing income, $\mathrm{LOE}=$ number of licenses and options executed, PTF $=$ number of U.S. patent applications, PTI = number of U.S. patents issued, $\mathrm{STU}=$ number of start-ups.

\subsection{Aggregated Time-Lag Effects from Licensing Activities to Licensing Income}

The aggregated total time-lag effect from each licensing variable to licensing income is developed by incorporating the identified time-lag coefficients between each pair of licensing variables. 


\subsubsection{The Paths to Licensing Income}

A total of 32 paths are involved in the licensing process, as illustrated in Figure 33 . The paths from expenditure on the first node to licensing incomes are associated with all paths from 1 to 32. The paths of all other licensing variables begin from the second node. The paths from disclosure, which is located at the second node after expenditure, to licensing income are defined from paths 1 to 16; the patent application paths are defined from paths 17 to 24; the patent issue paths are defined from paths 25 to 28 ; the license and option paths are defined from paths 29 to 30; and finally, the start-up path to licensing income is associated with path 31. See Appendix B. for individual groups of paths for each licensing variable. 

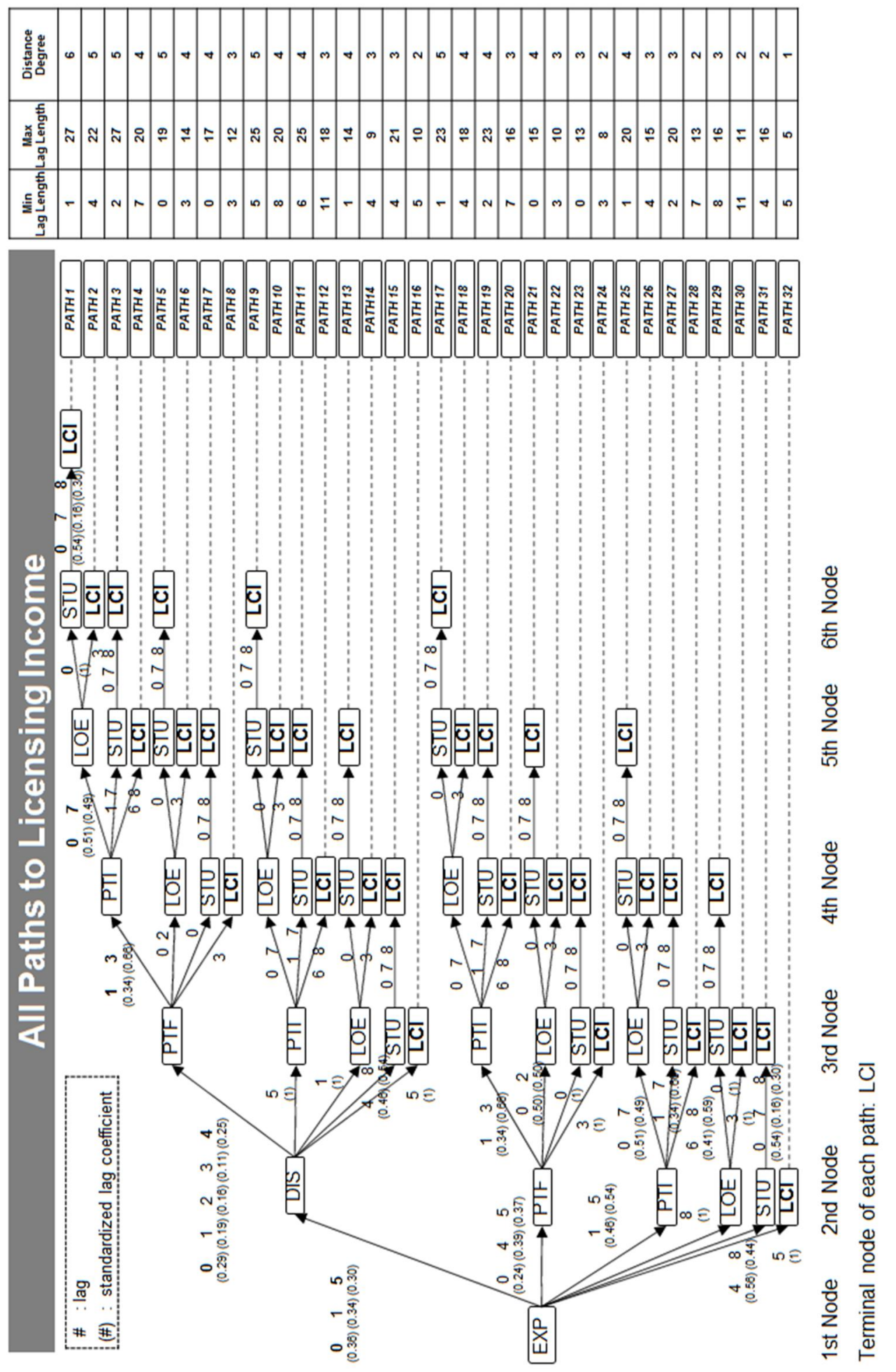

Figure 33: All identified paths from licensing variables to licensing income 


\subsubsection{The Time-Lag Functions and Aggregated Total Time-Lag Effects}

The aggregated total time-lag effects of the six variables incorporating the paths identified (research expenditure, number of disclosures, number of U.S. patent applications, number of U.S. patents issued, number of licenses and options executed, and number of start-ups) are defined by the time-lag functions of each pair of variables and their transformation, as defined in Chapter 3.

For illustration, an example of the time-lag functions and transformation of the patents issued variable is provided. The paths from patents issued to licensing income are presented in Figure 34.

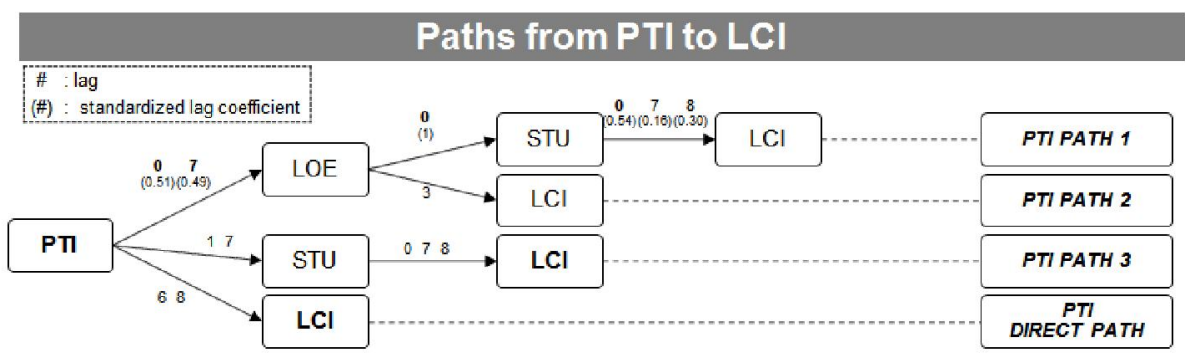

\begin{tabular}{|c|c|c|}
\hline $\begin{array}{c}\text { Min } \\
\text { Lag } \\
\text { Length }\end{array}$ & $\begin{array}{c}\text { Max } \\
\text { Lag }\end{array}$ & $\begin{array}{c}\text { Distance } \\
\text { Degree }\end{array}$ \\
\hline 0 & 15 & 3 \\
\hline 3 & 10 & 2 \\
\hline 1 & 15 & 2 \\
\hline 6 & 8 & 1 \\
\hline
\end{tabular}

Figure 34: Paths from patent issued to licensing income

First, the time-lag functions among the variables from Figure 34 are defined with the lag coefficients. For instance, the time-lag function from patents issued to licenses and options executed, $f_{P T I, L O E}$, is defined as lag 0 and lag 7 of patents issued, with the coefficients of the lags, 0.51 and 0.49 , and is expressed as $f_{P T I, L O E}=0.51 P T I_{t-0}+$ $0.49 P T I_{t-7}$. The functions of each path are defined in this way (Table 45). 
Table 45: Time-lag functions of patents issued on the patents issued paths

\begin{tabular}{|l|l|l|}
\hline Path & Time Lag & Time-Lag Functions Using the Lag Coefficients \\
\hline \multirow{4}{*}{$\begin{array}{l}\text { PTI Path 1 } \\
\text { 6rd degree) }\end{array}$} & PTI to LOE & $f_{P T I, L O E}=0.51 P T I_{t-0}+0.49 P T I_{t-7}$ \\
\cline { 2 - 3 } & LOE to STU & $f_{L O E, S T U}=L O E_{t}$ \\
\cline { 2 - 3 } & STU to LCI & $f_{S T U, L C I}=0.54 S T U_{t}+0.16 S T U_{t-7}+0.30 S T U_{t-8}$ \\
\hline \multirow{2}{*}{$\begin{array}{l}\text { PTI Path 2 } \\
\text { 2nd degree) }\end{array}$} & PTI to LOE & $f_{P T I, L O E}=0.51 P T I_{t-0}+0.49 P T I_{t-7}$ \\
\cline { 2 - 3 } & LOE to LCI & $f_{L O E, L C I}=L O E_{t-3}$ \\
\hline \multirow{2}{*}{$\begin{array}{l}\text { PTI Path 3 } \\
\text { 2nd degree) }\end{array}$} & PTI to STU & $f_{P T I, S T U}=0.34 P T I_{t-1}+0.66 P T I_{t-7}$ \\
\cline { 2 - 3 } & STU to LCI & $f_{S T U, L C I}=0.54 S T U_{t}+0.16 S T U_{t-7}+0.30 S T U_{t-8}$ \\
\hline $\begin{array}{l}\text { PTI Direct } \\
\text { Path }\end{array}$ & PTI to LCI & $f_{P T I, L C I}=0.41 P T I_{t-6}+0.59 P T I_{t-8}$ \\
\hline
\end{tabular}

Note: $\mathrm{LCI}=$ licensing income, $\mathrm{LOE}=$ number of licenses and options executed, PTI $=$ number of U.S. patents issued, STU = number of start-ups.

The next step is to combine all the functions on each path, using the transform function, $\otimes$. The time-lag effect of patent issue, $f_{P T I, L C I}$, on the first path is defined as two transformations of the three time-lag functions, as follows:

$$
\begin{aligned}
& f_{P T I, L C I}=\left(f_{P T I, L O E} \otimes f_{L O E, S T U}\right) \otimes f_{S T U, L C I}=f_{P T I, S T U} \otimes f_{S T U, L C I} \\
& f_{P T I, S T U}=f_{P T I, L O E} \otimes f_{L O E, S T U}=\left(f_{P T I, L O E}\right)_{t}= \\
& \left(0.51 P T I_{t-0}+0.49 P T I_{t-7}\right)_{t-0}= \\
& 0.51 P T I_{t-0+0}+0.49 P T I_{t-7+0}=0.51 P T I_{t}+0.49 P T I_{t-7}
\end{aligned}
$$




$$
\begin{aligned}
& f_{P T I, L C I}^{\text {PTI PATH } 1}=f_{P T I, S T U} \otimes f_{S T U, L C I}= \\
& 0.54\left(f_{P T I, S T U}\right)_{t}+0.16\left(f_{P T I, S T U}\right)_{t-7}+0.30\left(f_{P T I, S T U}\right)_{t-8}= \\
& 0.54\left(0.51 P T I_{t}+0.49 P T I_{t-7}\right)_{t}+0.16\left(0.51 P T I_{t}+0.49 P T I_{t-7}\right)_{t-7}+ \\
& 0.30\left(0.51 P T I_{t}+0.49 P T I_{t-7}\right)_{t-8}= \\
& 0.54 * 0.51 P T I_{t+0}+0.54 * 0.49 P T I_{t-7+0}+0.16 * 0.51 P T I_{t+(-7)}+0.16 * \\
& 0.49 P T I_{t-7+(-7)}+0.30 * 0.51 P T I_{t+(-8)}+0.30 * 0.49 P T I_{t-7+(-8)}= \\
& 0.27 P T I_{t}+0.35 P T I_{t-7}+0.15 P T I_{t-8}+0.08 P T I_{t-14}+0.15 P T I_{t-15}
\end{aligned}
$$

In the same way, $f_{P T I, L C I}{ }^{\text {PTI PATH } 2}$ and $f_{P T I, L C I}{ }^{\text {PTI PATH } 3}$ are transformed, whereas $f_{P T I, L C I}^{P T I \text { DIRECT PATH }}$ is defined by lag coefficients without transformation. Table 46 summarizes the aggregated time-lag effects of patent issue. 
Table 46: Time-lag aggregator of patent issue

\begin{tabular}{|c|c|c|}
\hline Paths & $\begin{array}{l}\text { Transformed } \\
\text { Direct Paths }\end{array}$ & Transformed Direct Time-Lag Functions \\
\hline $\begin{array}{l}\text { PTI Path } 1 \\
\text { (3rd degree) }\end{array}$ & $\begin{array}{c}\text { PTI to LCI } \\
\left(f_{P T I, L C I}^{\text {PTI PATH 1 }}\right)\end{array}$ & $\begin{array}{l}f_{P T I, L C I}=\left(f_{P T I, L O E} \otimes f_{L O E, S T U}\right) \otimes f_{S T U, L C I}= \\
f_{P T I, S T U} \otimes f_{S T U, L C I} \\
f_{P T I, L O E} \otimes f_{L O E I, S T U}=0.51 P T I_{t}+0.49 P T I_{t-7} \\
f_{P T I, L C I}{ }_{P T I P A T H 1}=f_{P T I, S T U} \otimes f_{S T U, L C I}= \\
0.27 \text { PTI I }_{\boldsymbol{t}}+\mathbf{0 . 3 5 P T I _ { t - 7 } + 0 . 1 5 P T I _ { t - 8 }}+ \\
0.08 P T I_{t-14}+0.15 P T I_{t-15}\end{array}$ \\
\hline $\begin{array}{l}\text { PTI Path } 2 \\
\quad(2 \text { nd } \\
\text { degree })\end{array}$ & $\begin{array}{c}\text { PTI to LCI } \\
\left(f_{P T I, L C I}^{P T I P A T H} 2\right)\end{array}$ & $\begin{array}{l}f_{P T I, L C I}^{P T I P A T H 2}=f_{P T I, L O E} \otimes f_{L O E, L C I}= \\
\mathbf{0 . 5 1 P T F}_{\boldsymbol{t}-\mathbf{3}}+\mathbf{0 . 4 9 P T F _ { \boldsymbol { t } - \mathbf { 1 0 } }}\end{array}$ \\
\hline $\begin{array}{l}\text { PTI Path } 3 \\
\text { (2nd } \\
\text { degree) }\end{array}$ & $\begin{array}{c}\text { PTI to LCI } \\
\left(f_{P T I, L C I}^{P T I P A T H 3}\right)\end{array}$ & 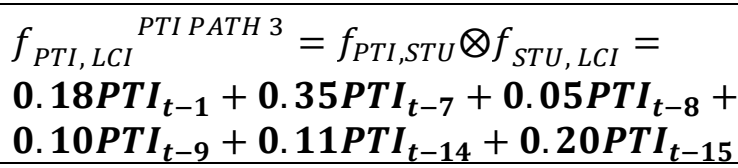 \\
\hline $\begin{array}{l}\text { PTI Direct } \\
\text { Path }\end{array}$ & $\begin{array}{c}\text { PTI to LCI } \\
\left(f_{P T I, L C I}^{\text {DIRECT PATH }}\right) \\
\end{array}$ & $f_{P T I, L C I}=0.41 P T I_{t-6}+0.59 P T I_{t-8}$ \\
\hline
\end{tabular}

Note: $\mathrm{LCI}=$ licensing income, PTI $=$ number of U.S. patents issued.

The multiple time-lag effects under each path are then summed. The aggregated and normalized total time-lag effects of patent issue are summarized in Table 47. 
Table 47: Integration of multiple time-lag aggregators of patents issued on the different paths

\begin{tabular}{|c|l|}
\hline Step & \multicolumn{1}{|c|}{ Result } \\
\hline & \multicolumn{1}{|c|}{$f_{P T F, L C I}$ PTF PATH $1+f_{P T F, L C I}$ PTF PATH $2+$} \\
& $f_{P T F, L C I}{ }^{\prime}+f_{P T F, L C I}$ DIRECT PATH \\
Sum all direct and & $=0.27 P T I_{t}+0.35 P T I_{t-7}+0.15 P T I_{t-8}+0.08 P T I_{t-14}+$ \\
transformed direct time-lag & $0.15 P T I_{t-15}$ \\
functions & $+0.51 P T F_{t-3}+0.49 P T F_{t-10}$ \\
& $+0.18 P T I_{t-1}+0.35 P T I_{t-7}+0.05 P T I_{t-8}+0.10 P T I_{t-9}+$ \\
& $0.11 P T I_{t-14}+0.20 P T I_{t-15}$ \\
& $+0.41 P T I_{t-6}+0.59 P T I_{t-8}$ \\
\hline Total Time-Lag Aggregator & $T F_{P T I, L C I}=0.07 P T I_{t}+0.05 P T I_{t-1}+0.13 P T I_{t-3}+$ \\
of PTI to LCI & $0.10 P T I_{t-6}+0.18 P T I_{t-7}+0.20 P T I_{t-8}+0.03 P T I_{t-9}+$ \\
(Standardized) & $0.12 P T I_{t-10}+0.05 P T I_{t-14}+0.09 P T I_{t-15}$ \\
\hline
\end{tabular}

Note: $\mathrm{LCI}=$ licensing income, PTF $=$ number of U.S. patent applications, PTI $=$ number of U.S. patents issued.

The aggregated and normalized total time-lag effects of the other five variables are calculated and summarized in Table 48. 
Table 48: Aggregated total time-lag effects of the six licensing variables

\begin{tabular}{|c|c|c|}
\hline Variable & Item & Aggregated Total Time-Lag Effect \\
\hline \multirow{2}{*}{ EXP } & Summed Effect & $\begin{array}{l}0.28 E X P_{t}+0.48 E X P_{t-1}+0.50 E X P_{t-2}+0.73 E X P_{t-3}+1.83 E X P_{t-4}+ \\
2.97 E X P_{t-5}+1.42 E X P_{t-6}+1.61 E X P_{t-7}+3.21 E X P_{t-8}+2.17 E X P_{t-9}+ \\
1.54 E X P_{t-10}+2.76 E X P_{t-11}+2.04 E X P_{t-12}+2.34 E X P_{t-13}+ \\
1.36 E X P_{t-14}+1.71 E X P_{t-15}+1.60 E X P_{t-16}+0.73 E X P_{t-17}+ \\
0.64 E X P_{t-18}+0.39 E X P_{t-19}+0.76 E X P_{t-20}+0.33 E X P_{t-21}+ \\
0.22 E X P_{t-22}+0.14 E X P_{t-23}+0.08 E X P_{t-24}+0.13 E X P_{t-25}+ \\
0.02 E X P_{t-26}+0.02 E X P_{t-27}\end{array}$ \\
\hline & $\begin{array}{c}\text { Total Time-Lag } \\
\text { Effect } \\
\left(T F_{E X P, L C I}\right)\end{array}$ & $\begin{array}{l}0.01 E X P_{t}+0.02 E X P_{t-1}+0.02 E X P_{t-2}+0.02 E X P_{t-3}+0.06 E X P_{t-4}+ \\
0.09 E X P_{t-5}+0.04 E X P_{t-6}+0.05 E X P_{t-7}+0.10 E X P_{t-8}+0.07 E X P_{t-9}+ \\
0.05 E X P_{t-10}+0.09 E X P_{t-11}+0.06 E X P_{t-12}+0.07 E X P_{t-13}+ \\
0.04 E X P_{t-14}+0.05 E X P_{t-15}+0.05 E X P_{t-16}+0.02 E X P_{t-17}+ \\
0.02 E X P_{t-18}+0.01 E X P_{t-19}+0.02 E X P_{t-20}+0.01 E X P_{t-21}+ \\
0.01 E X P_{t-22}+0.004 E X P_{t-23}+0.003 E X P_{t-24}+0.004 E X P_{t-25}+ \\
0.001 E X P_{t-26}+0.001 E X P_{t-27}\end{array}$ \\
\hline \multirow[b]{2}{*}{ DIS } & Summed Effect & $\begin{array}{l}0.23 D I S_{t}+0.72 D I S_{t-1}+0.24 D I S_{t-2}+0.65 D I S_{t-3}+1.92 D I S_{t-4}+ \\
1.81 D I S_{t-5}+0.69 D I S_{t-6}+0.70 D I S_{t-7}+1.41 D I S_{t-8}+0.84 D I S_{t-9}+ \\
0.54 D I S_{t-10}+1.08 D I S_{t-11}+1.34 D I S_{t-12}+1.24 D I S_{t-13}+ \\
0.41 D I S_{t-14}+0.83 D I S_{t-15}+0.26 D I S_{t-16}+0.15 D I S_{t-17}+ \\
0.11 D I S_{t-18}+0.28 D I S_{t-19}+0.43 D I S_{t-20}+0.06 D I S_{t-21}+0.06 D I S_{t-22}\end{array}$ \\
\hline & $\begin{array}{l}\text { Total Time-Lag } \\
\text { Effect }\left(T F_{D I S, L C I}\right)\end{array}$ & $\begin{array}{l}0.01 D I S_{t}+0.04 D I S_{t-1}+0.02 D I S_{t-2}+0.04 D I S_{t-3}+0.12 D I S_{t-4}+ \\
0.11 D I S_{t-5}+0.04 D I S_{t-6}+0.04 D I S_{t-7}+0.09 D I S_{t-8}+0.05 D I S_{t-9}+ \\
0.03 D I S_{t-10}+0.07 D I S_{t-11}+0.08 D I S_{t-12}+0.08 D I S_{t-13}+ \\
0.03 D I S_{t-14}+0.05 D I S_{t-15}+0.02 D I S_{t-16}+0.01 D I S_{t-17}+ \\
0.01 D I S_{t-18}+0.02 D I S_{t-19}+0.03 D I S_{t-20}+0.003 D I S_{t-21}+ \\
0.004 D I S_{t-22}\end{array}$ \\
\hline \multirow{2}{*}{ PTF } & Summed Effect & $\begin{array}{l}0.81 P T F_{t}+0.09 P T F_{t-1}+0.33 P T F_{t-2}+1.68 P T F_{t-3}+0.29 P T F_{t-4}+ \\
0.50 P T F_{t-5}+0.33 P T F_{t-6}+0.38 P T F_{t-7}+0.69 P T F_{t-8}+0.62 P T F_{t-9}+ \\
0.65 P T F_{t-10}+0.69 P T F_{t-11}+0.07 P T F_{t-12}+0.32 P T F_{t-13}+ \\
0.06 P T F_{t-15}+0.12 P T F_{t-16}+0.12 P T F_{t-17}+0.23 P T F_{t-18}\end{array}$ \\
\hline & $\begin{array}{l}\text { Total Time-Lag } \\
\text { Effect }\left(T F_{P T F, L C I}\right)\end{array}$ & $\begin{array}{l}0.10 P T F_{t}+0.01 P T F_{t-1}+0.04 P T F_{t-2}+0.21 P T F_{t-3}+0.04 P T F_{t-4}+ \\
0.06 P T F_{t-5}+0.04 P T F_{t-6}+0.05 P T F_{t-7}+0.09 P T F_{t-8}+0.08 P T F_{t-9}+ \\
0.08 P T F_{t-10}+0.09 P T F_{t-11}+0.01 P T F_{t-12}+0.04 P T F_{t-13}+ \\
0.01 P T F_{t-15}+0.01 P T F_{t-16}+0.02 P T F_{t-17}+0.03 P T F_{t-18}\end{array}$ \\
\hline \multirow{2}{*}{ PTI } & Summed Effect & $\begin{array}{l}0.27 P T I_{t}+0.18 P T I_{t-1}+0.51 P T I_{t-3}+0.41 P T I_{t-6}+0.70 P T I_{t-7}+ \\
0.80 P T I_{t-8}+0.10 P T I_{t-9}+0.49 P T I_{t-10}+0.18 P T I_{t-14}+0.35 P T I_{t-15}\end{array}$ \\
\hline & $\begin{array}{l}\text { Total Time-Lag } \\
\text { Effect }\left(T F_{P T I, L C I}\right)\end{array}$ & $\begin{array}{l}0.07 P T I_{t}+0.05 P T I_{t-1}+0.13 P T I_{t-3}+0.10 P T I_{t-6}+0.18 P T I_{t-7}+ \\
0.20 P T I_{t-8}+0.03 P T I_{t-9}+0.12 P T I_{t-10}+0.05 P T I_{t-14}+0.09 P T I_{t-15}\end{array}$ \\
\hline \multirow[b]{2}{*}{ LOE } & Summed Effect & $0.54 L O E_{t}+1.00 L O E_{t-3}+0.16 L O E_{t-7}+0.30 L O E_{t-8}$ \\
\hline & $\begin{array}{l}\text { Total Time-Lag } \\
\text { Effect }\left(T F_{\mathrm{LOE}, L C I}\right)\end{array}$ & $0.27 L O E_{t}+0.50 L O E_{t-3}+0.08 L O E_{t-7}+0.15 L O E_{t-8}$ \\
\hline \multirow[b]{2}{*}{ STU } & Summed Effect & $0.54 S T U_{t}+0.16 S T U_{t-7}+0.30 S T U_{t-8}$ \\
\hline & $\begin{array}{l}\text { Total Time-Lag } \\
\text { Effect }\left(T F_{S T U, L C I}\right)\end{array}$ & $0.54 S T U_{t}+0.16 S T U_{t-7}+0.30 S T U_{t-8}$ \\
\hline
\end{tabular}

Note: DIS = number of disclosures, $\mathrm{EXP}=$ research expenditure, $\mathrm{LCI}=$ licensing income, $\mathrm{LOE}=$ number of licenses and options executed, PTF $=$ number of U.S. patent applications, PTI = number of U.S. patents issued, STU = number of start-ups. 


\subsection{Summary}

The time-lag identifying process, using a distributed lag model with an unstructured coefficient structure, was applied to the data from 46 U.S. academic research institutions. A total of 21 regression models were applied to each step, and they successfully identified the time-lag effect between each pair of the seven licensing variables, including research expenditure, disclosure, patent application, patents issued, licenses and options executed, start-up, and licensing income. The AUTM licensing survey data of the 46 institutions from 1991 to 2007 was used for the analysis.

The standardized time-lag coefficients, along with the licensing process, are illustrated in Figure 35. The shortest time lag in the licensing process, if the durations are added up, is 2 years, and the longest one is 27 years. The time-lag model between disclosure and patent filed has the greatest explanatory power $\left(R^{2}=0.1\right)$ among the 21 regression models, though all of the models have very low $R^{2}$ values. However, because the purpose of the regression models is to identify significant time-lag coefficients rather than to explain a dependent variable by independent variables, the $R^{2}$ values of the regression models are not seriously considered. 


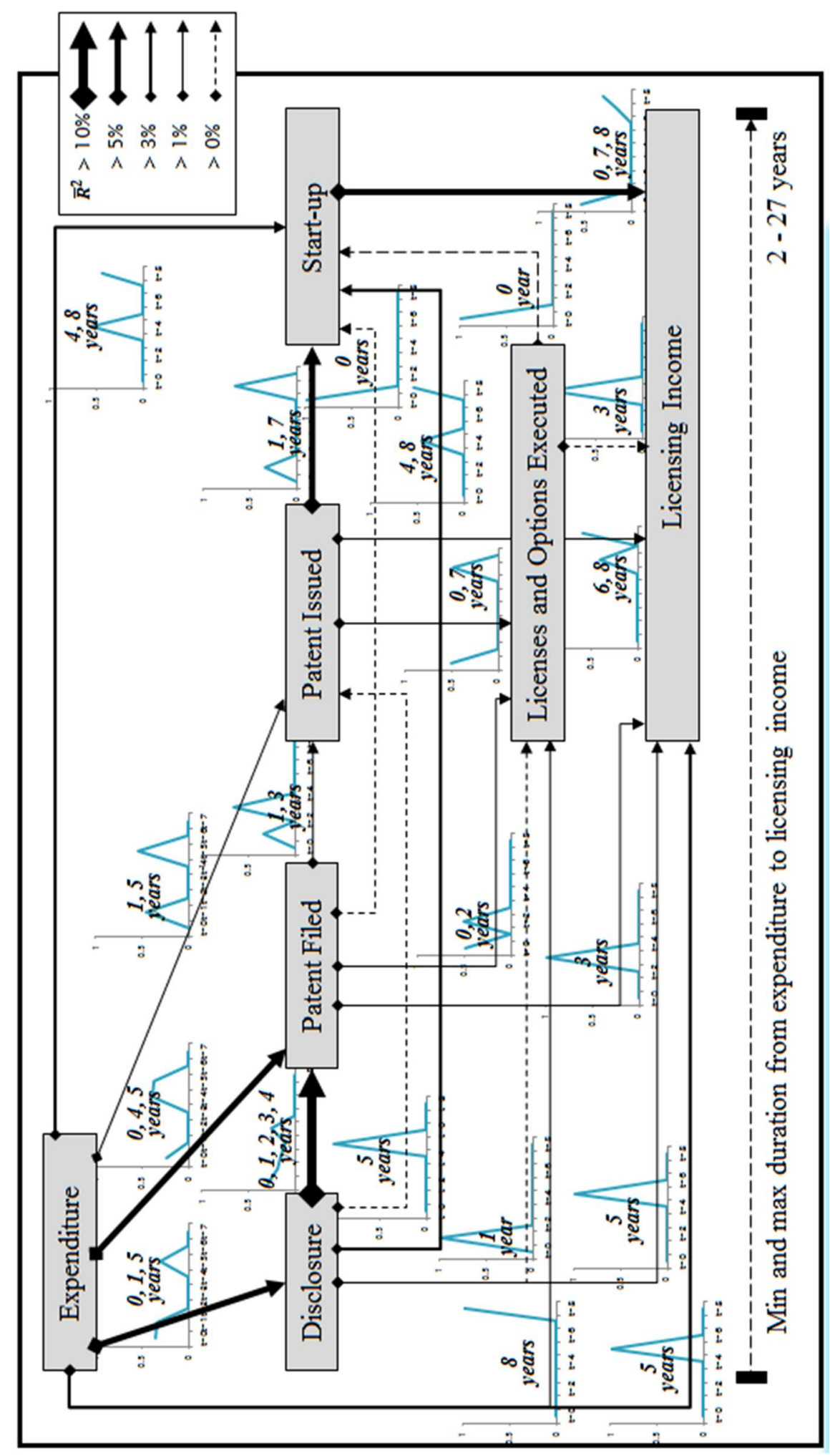

Figure 35: Licensing process with the time-lag coefficients 
The minimum duration from expenditures to licensing is 2 years and the maximum is 27 years. The time lags for which $R^{2}$ values are higher than others are

- from research expenditure to disclosure, patent application, start-up, and licensing income;

- from disclosure to patent application and start-up;

- from patent issued to start-up; and

- from start-up to licensing income.

Although the model identified the continuous time-lag effect of 4 years from disclosure to patent filed, it detected discontinuous lag periods ranging from 1 year to 3 years. This reflects the institutions' licensing practices. After inventions are disclosed through the licensing offices, most of them are filed, thus producing significant distribution across the periods up to 4 years. On the other hand, the lag relationships between a posterior (output) and prior (input) licensing variable depend on the quality and attractiveness of the prior variable in licensing. Therefore, more uncertainty and greater variations of time-lag effects exist in those variables.

The distributions of the total time-lag effects are illustrated in Figure 36. The time-lag effect distributions of expenditure and disclosure show relatively smooth shapes. Over all, the time-lag effects have a higher effect as they get closer to the current year, $t-0$. Unique peak effect values at certain lag periods are observed: $t-8$ for expenditure, $t$ - 4 for disclosure, $t-3$ for patent application, $t-8$ for patent issue, $t-3$ for licenses and options executed, and $t$ - 0 for start-up. 


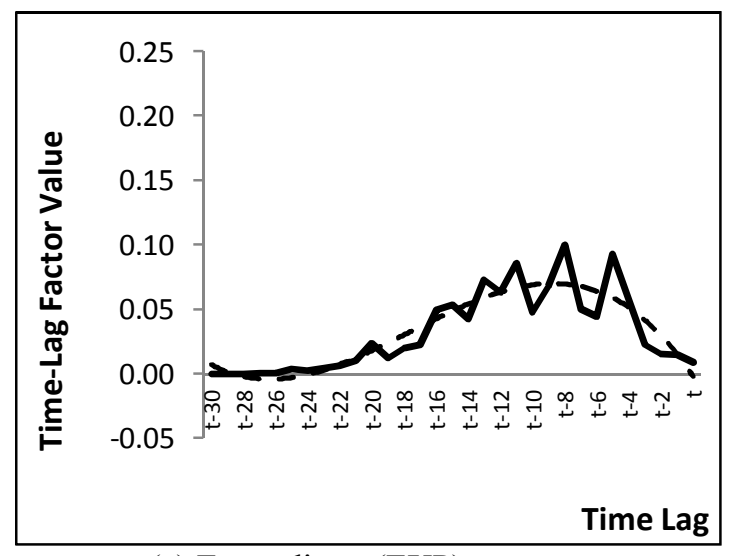

(a) Expenditure (EXP)

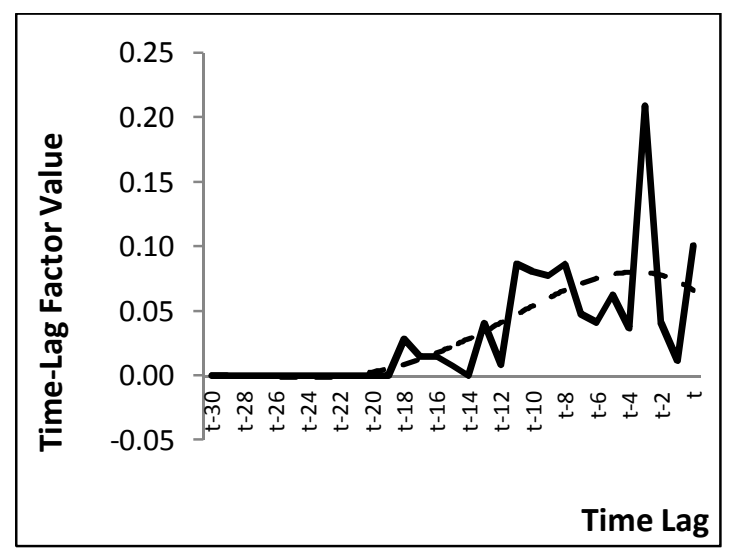

(C) Patent Filed (PTF)

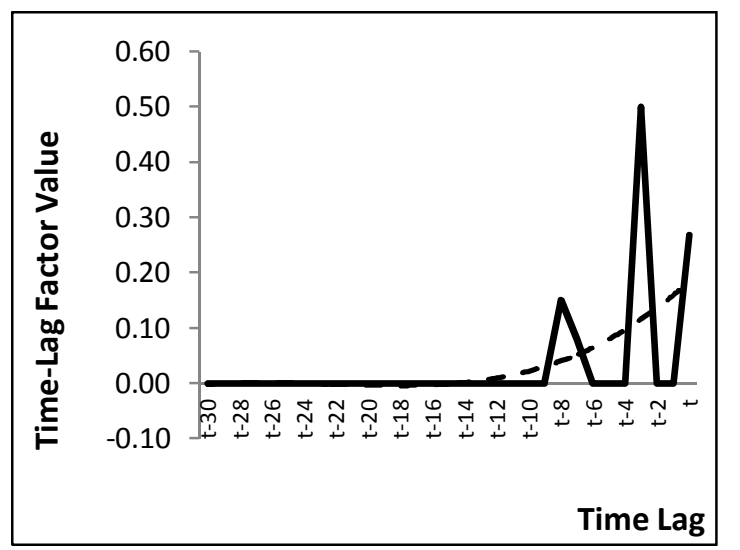

(e) License \& Option Executed (LOE)

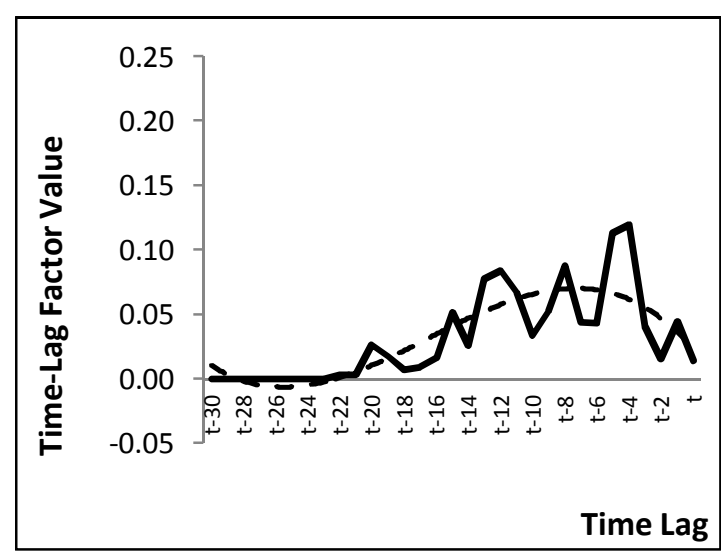

(b) Disclosure (DIS)

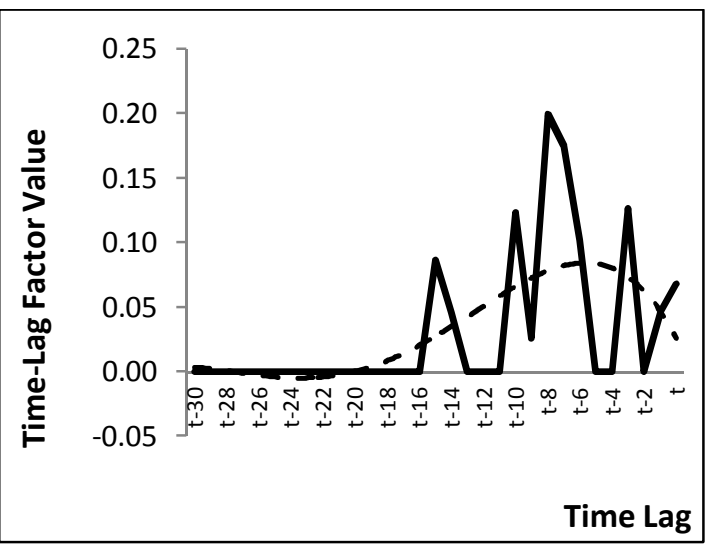

(d) Patent Issued (PTI)

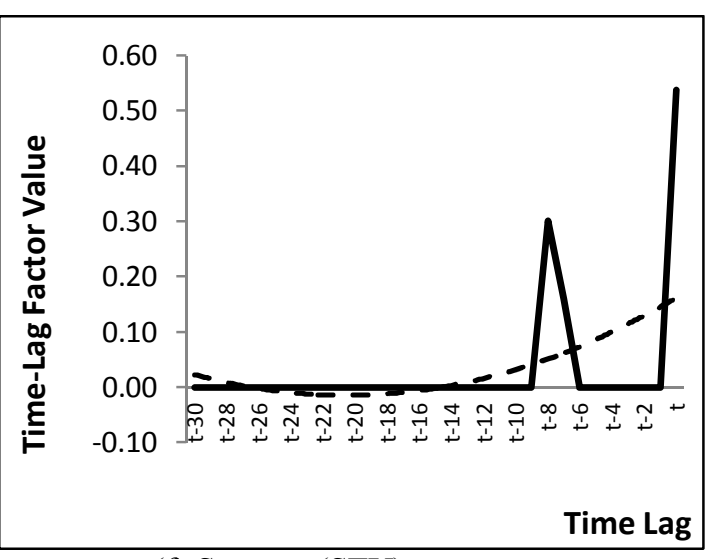

(f) Start-up (STU)

Polynomial trend line of the effect values

Figure 36: Graph of the aggregated total time-lag effects to licensing income of six licensing variables 
Chapter 6. Licensing Performance of 46 U.S. Academic Research Institutions

\subsection{Input and Output Structure of the Data Envelopment Analysis Model}

The input and output structure of the DEA model, exploring efficiencies and changes in U.S. academic research institutions' technology commercialization, is presented in Figure 37. The ARITC process is defined in 3 (see Figure 10). It includes seven variables: research expenditure, number of disclosures, number of U.S. patent applications, number of U.S. patents issued, number of licenses and option executed, number of start-ups, and licensing income. Research expenditure is defined as an input variable for the DEA model. The other six variables can be considered a result of research expenditures on the path of the licensing process.

However, when the performance of the licensing or commercialization effort is discussed, quality of outputs should be considered as well as quantity. In this study, the quality of each invention or license is not measured directly. Instead, the study considers performance quality by excluding output variables that reflect high variance in quality. For this reason, disclosure, patent applications, and licenses and options executed are excluded from the DEA model output. They are intermediating variables that generate final products, patents issued, start-ups, and licensing income. The quantity of the latter 
variables depends on the quality of the intermediating variables. The input and output variables of the DEA model measuring ARITC performance are presented in Figure 37.

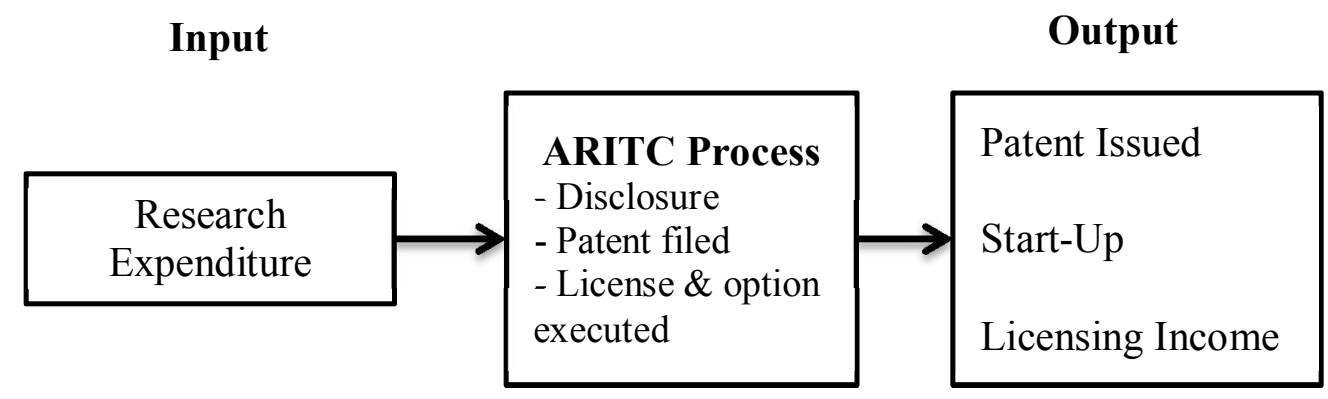

Figure 37: Input and output structure in the data envelopment analysis model

\subsection{Time-Lag Effect Neutralized Input and Output Data}

\subsubsection{Approach to Incorporating Time-Lag Effect Into the Data}

This study evaluates the efficiencies of the licensing performance of 46 U.S. academic research institutions from 1991 to 2007 . The time-lag effects of each variable that leads to licensing income are developed in 5. However, the standard time-lag correlation coefficients among the input and output variables are used to define time lag-effect aggregated data for the DEA analysis.

There are two reasons for using the lag coefficients rather than time-lag effects, including all potential paths to licensing. First, the ranges of the identified time-lag effects are longer than the time period covered in the AUTM data. The time-lag effect from research expenditure to licensing, for example, begins 27 years from the year when licensing income occurs. This would require data from 1980 to 2007. Second, the time-lag effects 
are developed to understand overall time-lag effects from the variables to licensing income by cumulating all possible paths through other variables. Although the finding provides insight into the total distributed effect of the lags over long periods, it doesn't necessarily mean that the actual cases in the data follow the hypothetical paths used in the time-lag effect. Therefore, the time-lag coefficient values derived from the data could reflect more practical lag effects, for the purpose of data transformation.

\subsubsection{Data Transformation}

The time-lag coefficients of the input and output variables identified in 5 are presented in Table 49.

Table 49: Time-lag coefficients from input to output variables

\begin{tabular}{|c|c|c|c|c|c|}
\hline \multirow{2}{*}{$\begin{array}{c}\text { Dependent variable } \\
\text { (PTI, STU, and LCI) }\end{array}$} & \multicolumn{4}{|c|}{ Lag to PTI } & \multicolumn{2}{|c|}{ Lag to STU } & Lag to LCI \\
\cline { 2 - 6 } & Lag 1 & Lag 5 & Lag 4 & Lag 8 & Lag 5 \\
\cline { 2 - 6 } & 0.455 & 0.545 & 0.560 & 0.440 & 1 \\
\hline $\begin{array}{c}\text { Coefficient values of the } \\
\text { lag }\end{array}$ & &
\end{tabular}

Note: $\mathrm{LCI}=$ licensing income, $\mathrm{PTI}=$ number of U.S. patents issued, STU = number of start-ups.

The time-lag coefficients in the distributed lag model are defined as the time duration of expenditure for each output variable at year $t$. This relationship is illustrated in Figure 38. 


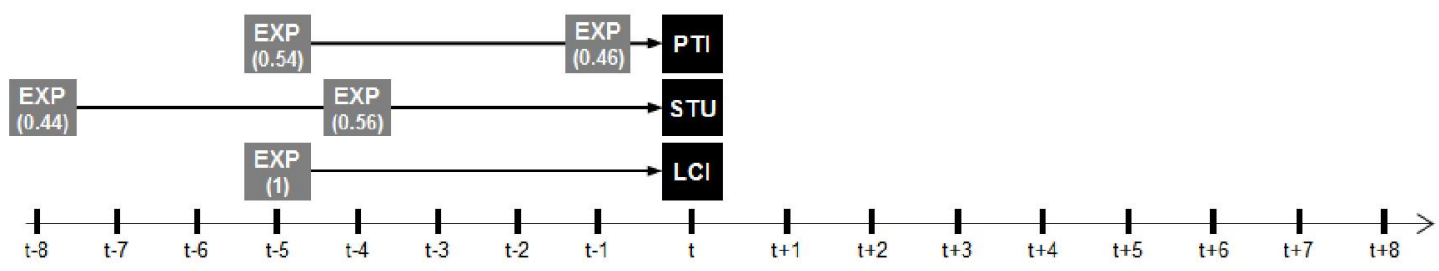

Figure 38: Time-lag relationships between input and output variables

The data is transformed in such a way that the input variable is fixed at year $t$ and the three output variables are forwarded to the same duration as the variables. For this purpose, the time lags defined by lagged years from expenditure to output variables are transformed to the future years of output variables, from the expenditure at year $t$, using the following formulations:

PTI to EXP at $t=$

$E X P_{t}=\frac{1}{0.455} \times P T I_{t+1}+\frac{1}{0.545} \times P T I_{t+5}=$

$2.17 P T I_{t+1}+1.85 P T I_{t+5} \equiv 0.54 P T I_{t+1}+0.46 P T I_{t+5}$

STU to EXP at $\mathrm{t}=$

$E X P_{t}=\frac{1}{0.560} S T U_{t+4}+\frac{1}{0.440} S T U_{t+8}=1.79 S T U_{t+4}+2.27 S T U_{t+8}$

$\equiv 0.44 S T U_{t+4}+0.56 S T U_{t+8}$

LCI to EXP at $\mathrm{t}=$

$E X P_{t}=L C I_{t+5}$ 
The resulting time lag relationships among the transformed data, using the equations above and the data structure for DEA and the Malmquist Index, are presented in Figure 39.

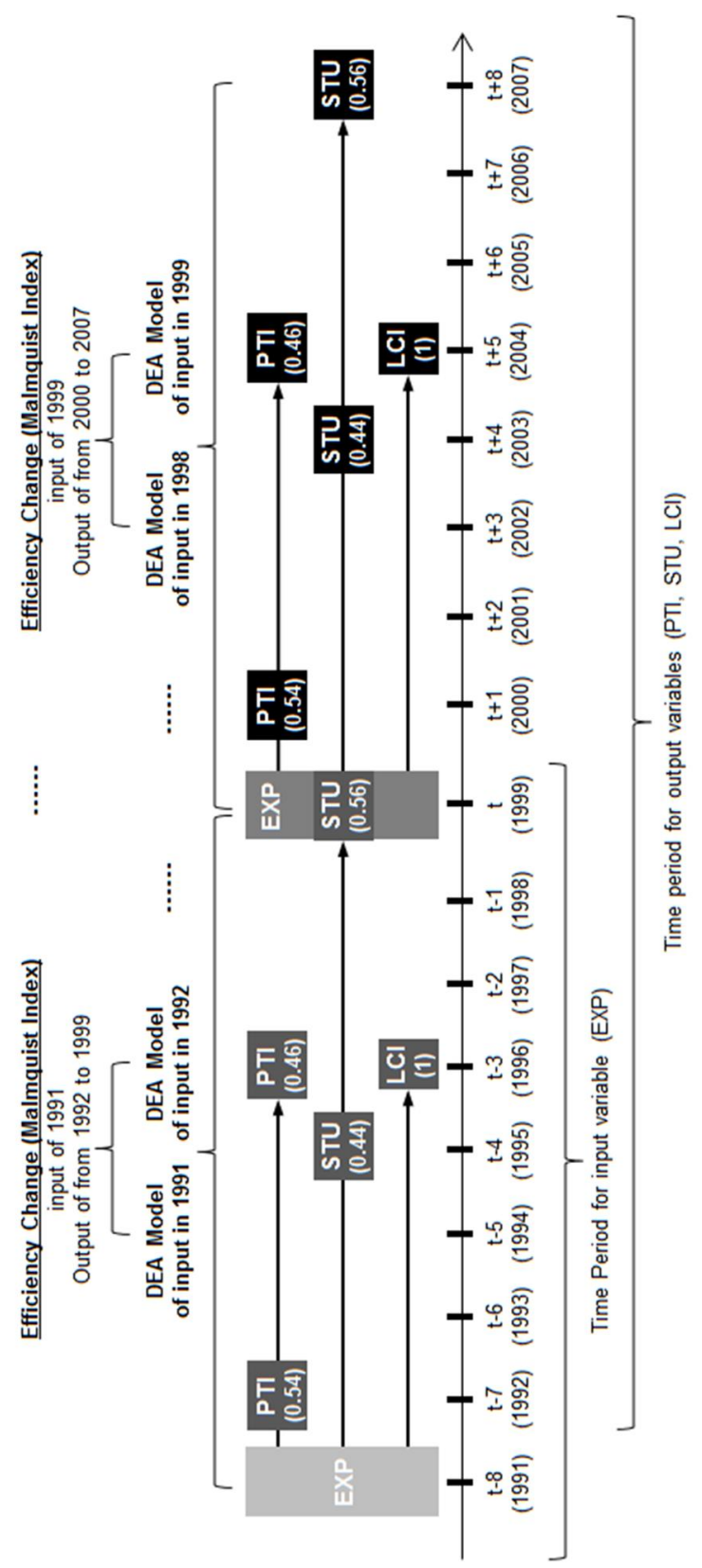

Figure 39: Time-lag relationship of transformed data and data envelopment analysis model 
The amount of expenditure at year $t$ is associated with $54 \%$ of patents issued at $t+1$ and $46 \%$ at $t+5$; with $44 \%$ of start-ups at $t+4$ and $56 \%$ at $t+8$; and with $100 \%$ of licensing income at year $t+5$. The maximum time period for each year of input is 8 years. Therefore, the total input period used in the DEA model ranges from 1991 to 1999 and output variables are from 1992 to 2007 . Malmquist Indexes measuring the efficiency changes using multiyear DEA scores are defined from 1992 (change from 1991 to 1992) to 2000 (change from 1999 to 2000), including output variables from 1992 to 2007.

\subsection{Verification of the Data Envelopment Analysis Model and Coding}

The three super-efficiency models by Cook, et al. [33], Lee, et al. [66], and Lovell and Rouse [70] were applied to the transformed licensing data of the 46 institutions in order to verify the program coding of Xpress-Mosel and to compare those models. For this purpose, expenditure in 1999 and other output variables that incorporate time-lag effect from 2000 to 2007 was used. The results are summarized in Table 50. 
Table 50: Super-efficiency scores of three models

\begin{tabular}{|c|c|c|c|c|c|c|c|}
\hline \multirow{2}{*}{ Institutions } & \multicolumn{3}{|c|}{$\begin{array}{c}\text { Output-Oriented } \\
\text { Super Efficiency } \\
(1 / \text { phi })\end{array}$} & \multirow{2}{*}{ Institutions } & \multicolumn{3}{|c|}{$\begin{array}{c}\text { Output-Oriented } \\
\text { Super Efficiency } \\
(1 / \text { phi })\end{array}$} \\
\hline & $\mid \begin{array}{c}\text { Lovell } \\
\text { and } \\
\text { Rouse } \\
(2003)\end{array}$ & $\begin{array}{c}\text { Cook, } \\
\text { et al. } \\
(2009)\end{array}$ & $\left|\begin{array}{c}\text { Lee, } \text { et } \\
\text { al. } \\
(2011)\end{array}\right|$ & & $\begin{array}{l}\text { Lovell } \\
\text { and } \\
\text { Rouse } \\
(2003)\end{array}$ & $\begin{array}{l}\text { Cook, } \\
\text { et al. } \\
(2009)\end{array}$ & $\begin{array}{l}\text { Lee, } \text { et } \\
\text { al. } \\
(2011)\end{array}$ \\
\hline Baylor College of Medicine & 0.23 & 0.23 & 0.23 & Oregon State Univ. & 0.17 & 0.17 & 0.17 \\
\hline $\begin{array}{l}\text { Brigham \& Women's Hospital, } \\
\text { Inc. }\end{array}$ & 0.37 & 0.37 & 0.37 & Penn State Univ. & 0.32 & 0.32 & 0.32 \\
\hline Brigham Young Univ. & 1.88 & 1.88 & 1.88 & Rutgers, The State Univ. & 0.29 & 0.29 & 0.29 \\
\hline California Institute of Tech. & 3.15 & 3.15 & 3.15 & St. Jude Children's Researc & 0.10 & 0.10 & 0.10 \\
\hline Case Western Reserve Univ. & 0.37 & 0.37 & 0.37 & Tulane Univ. & 0.19 & 0.19 & 0.19 \\
\hline City of Hope National Medic & 1.68 & 1.68 & 1.68 & Univ. of Akron & 865.18 & 3.75 & 3.75 \\
\hline Clemson Univ. & 0.23 & 0.23 & 0.23 & Univ. of Arizona & 0.19 & 0.19 & 0.19 \\
\hline Colorado State Univ. & 0.38 & 0.38 & 0.38 & Univ. of Cincinnati & 0.12 & 0.12 & 0.12 \\
\hline Dartmouth College & 0.19 & 0.19 & 0.19 & Univ. of Connecticut & 0.27 & 0.27 & 0.27 \\
\hline Florida State Univ. & 0.39 & 0.39 & 0.39 & Univ. of Dayton & 0.21 & 0.21 & 0.21 \\
\hline Fred Hutchinson Cancer Res. & 0.08 & 0.08 & 0.08 & Univ. of Delaware & 0.27 & 0.27 & 0.27 \\
\hline Georgia Inst. of Technology & 0.86 & 0.86 & 0.86 & Univ. of Iowa Research Fdn. & 0.35 & 0.35 & 0.35 \\
\hline Harvard Univ. & 0.59 & 0.59 & 0.59 & Univ. of Maryland, College & 0.61 & 0.61 & 0.61 \\
\hline Indiana Univ. (ARTI) & 0.43 & 0.43 & 0.43 & Univ. of Michigan & 0.53 & 0.53 & 0.53 \\
\hline Johns Hopkins Univ. & 0.63 & 0.63 & 0.63 & Univ. of Minnesota & 1.08 & 1.08 & 1.08 \\
\hline Massachusetts Inst. of Tech & 2.04 & 2.04 & 2.04 & Univ. of Oregon & 0.35 & 0.35 & 0.35 \\
\hline Mayo Foundation & 0.57 & 0.57 & 0.57 & Univ. of Southern California & 0.31 & 0.31 & 0.31 \\
\hline Michigan State Univ. & 0.92 & 0.92 & 0.92 & Univ. of Texas Southwestern & 0.42 & 0.42 & 0.42 \\
\hline National Jewish Center & 0.28 & 0.28 & 0.28 & Univ. of Utah & 1.19 & 1.19 & 1.19 \\
\hline New Jersey Institute of Tech. & 0.22 & 0.22 & 0.22 & Univ. of Virginia Patent Fdn. & 0.27 & 0.27 & 0.27 \\
\hline Northwestern Univ. & 0.53 & 0.53 & 0.53 & Vanderbilt Univ. & 0.26 & 0.26 & 0.26 \\
\hline Ohio State Univ. & 0.29 & 0.29 & 0.29 & Wake Forest Univ. & 1.01 & 1.01 & 1.01 \\
\hline Ohio Univ. & 0.45 & 0.45 & 0.45 & Washington Univ. & 0.53 & 0.53 & 0.53 \\
\hline
\end{tabular}

The results confirm that the models have the same super-efficiency scores when decisionmaking units are feasible. The models identify eight institutions as efficient. There is one 
infeasible DMU, the University of Akron. The super-efficiency scores obtained using Cook, et al.'s (2009) and Lee, et al.'s (2011) models are exactly the same because only one input variable is used in the model. On the other hand, Lovell and Rouse's (2003) model generated an unrealistic score: efficiency of $865 \%$. These results verify the coding and theoretical comparisons outlined in 3.

\subsection{Super-Efficiency Scores and Malmquist Indexes}

The suggested output-oriented super-efficiency model is applied to the transformed data using Xpress-Mosel. The coding of both DEA and the Malmquist Index is provided in Appendix C. The results of the steps suggested for the super-efficiency scores (see 3) are presented in this section.

\subsubsection{Step 1: Input Saving and Infeasible Decision-Making Units}

First, Lovell and Rouse's (2003) model was applied to the data of expenditure from 1991 to 1999 to identify super-efficient (efficient and feasible) or extremely super-efficient (efficient but infeasible) institutions. Eleven institutions were found to be efficient for at least 1 year. Three institutions were observed to be infeasible DMUs for at least 1 year: Brigham Young University in 1993, Ohio University in 1991 and 1992, and the University of Akron from 1994 to 1999 (Table 51). 
Table 51: Super-efficient and extremely super-efficient institutions

\begin{tabular}{|l|c|c|c|c|c|c|c|c|c|}
\hline \multirow{2}{*}{\multicolumn{1}{|c|}{ Institution }} & \multicolumn{7}{|c|}{ Year of Expenditure } \\
\cline { 2 - 13 } & 1991 & 1992 & 1993 & 1994 & 1995 & 1996 & 1997 & 1998 & 1999 \\
\hline Brigham Young Univ. & SE & SE & ESE & SE & SE & SE & SE & SE & SE \\
\hline California Institute of Tech. & & SE & SE & SE & SE & SE & SE & SE & SE \\
\hline $\begin{array}{l}\text { City of Hope National } \\
\text { Medic }\end{array}$ & SE & SE & SE & & & SE & SE & SE & SE \\
\hline Dartmouth College & & & & & SE & & & & \\
\hline Florida State Univ. & & & SE & SE & SE & SE & SE & & \\
\hline Massachusetts Inst. of Tech & SE & SE & SE & SE & SE & SE & SE & SE & SE \\
\hline Ohio Univ. & ESE & ESE & & & & & & & \\
\hline Univ. of Akron & SE & & SE & ESE & ESE & ESE & ESE & ESE & ESE \\
\hline Univ. of Minnesota & & & & & & & & & SE \\
\hline Univ. of Utah & & & & & & & & SE & SE \\
\hline Wake Forest Univ. & & & & & & & & & SE \\
\hline
\end{tabular}

Note: $\mathrm{ESE}=$ extremely super-efficient, $\mathrm{SE}=$ super-efficient

Table 52 and Table 53 summarize the infeasible institutions and the input slacks of all DMUs, along with the frontier years of Malmquist Indexes, using Lee, et al.'s (2011) model. Dt(t) stands for super-efficiency scores of an institution in year $t$ when compared with the frontier institutions in year $t$. For example, Ohio University is infeasible when its data for 1991 is compared to other frontier institutions in 1991 and it has input slack of 0.34. The university is also infeasible when its data for 1992 is compared to the frontier of 1991. Its slack value is 0.01 .

The infeasible institutions listed in the tables are consistent with the extremely superefficient institutions identified by the Lovell and Rouse (2003) model. 
Table 52: Input slacks of infeasible institutions in the frontier year $t$ from 1991 to 1994

\begin{tabular}{|c|c|c|c|c|c|c|c|c|c|c|c|c|c|c|c|c|}
\hline \multirow{3}{*}{ Institutions } & \multicolumn{16}{|c|}{ Input Slack Table of Infeasible Decision-Making Units } \\
\hline & \multicolumn{4}{|c|}{ Frontier $t=1991$} & \multicolumn{4}{|c|}{1992} & \multicolumn{4}{|c|}{1993} & \multicolumn{4}{|c|}{1994} \\
\hline & હૅّ & 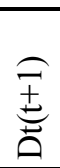 & $\begin{array}{l}\stackrel{E}{E} \\
\underset{ \pm}{ \pm}\end{array}$ & 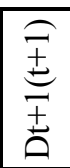 & $\stackrel{\overparen{E}}{\stackrel{\Xi}{0}}$ & 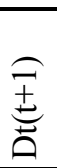 & $\begin{array}{l}\stackrel{E}{E} \\
\underset{+}{ \pm}\end{array}$ & 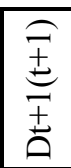 & 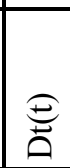 & 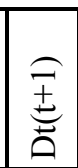 & $\begin{array}{l}\stackrel{E}{E} \\
\underset{+}{ \pm}\end{array}$ & 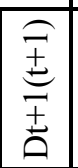 & $\stackrel{E}{E}$ & 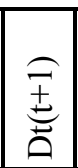 & 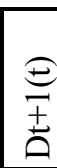 & 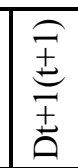 \\
\hline Ohio U. & 0.34 & & 0.01 & 0.31 & 0.31 & & 0.02 & & & & & & & & & \\
\hline Brigham Young U. & & & & & & & & 0.35 & 0.35 & & & & & & & \\
\hline U. of Akron & & & & & & & & & & 0.26 & & 0.28 & 0.28 & 0.03 & & 0.27 \\
\hline
\end{tabular}

Note: $\mathrm{Dt}(\mathrm{t}+1)=\mathrm{DEA}$ efficiency of an institution at time $\mathrm{t}$ compared to the frontier at year $\mathrm{t}+1$.

Table 53: Input slacks of infeasible institutions in the frontier year $t$ from 1995 to 1998

\begin{tabular}{|c|c|c|c|c|c|c|c|c|c|c|c|c|c|c|c|c|}
\hline \multirow{3}{*}{ Institutions } & \multicolumn{16}{|c|}{ Input Slack Table of Infeasible Decision-Making Units } \\
\hline & \multicolumn{4}{|c|}{ Frontier $t=1995$} & \multicolumn{4}{|c|}{1996} & \multicolumn{4}{|c|}{1997} & \multicolumn{4}{|c|}{1998} \\
\hline & $\begin{array}{l}\stackrel{E}{0} \\
\text { D. }\end{array}$ & 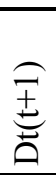 & $\begin{array}{l}\underset{ \pm}{ \pm} \\
\stackrel{ \pm}{ \pm}\end{array}$ & 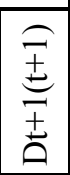 & $\stackrel{\oplus}{\stackrel{E}{0}}$ & 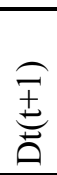 & $\begin{array}{l}\underset{ \pm}{ \pm} \\
\underset{ \pm}{ \pm}\end{array}$ & 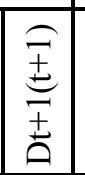 & $\begin{array}{l}E \\
\stackrel{E}{0}\end{array}$ & 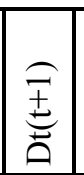 & $\begin{array}{l}\underset{+}{ \pm} \\
\underset{ \pm}{ \pm}\end{array}$ & 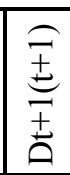 & $\begin{array}{l}\widehat{E} \\
\text { D̆ }\end{array}$ & 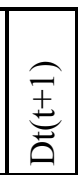 & $\begin{array}{l}\underset{E}{ \pm} \\
\underset{+ \pm}{ \pm}\end{array}$ & $\begin{array}{l}\underset{I}{ \pm} \\
\underset{ \pm}{ \pm} \\
\stackrel{ \pm}{ \pm}\end{array}$ \\
\hline Ohio U. & & & & & & & & & & & & & & & & \\
\hline Brigham Young U & & & & & & & & & & & & & & & & \\
\hline U. of Akron & 0.27 & & 0.03 & 0.38 & 0.38 & & 0.14 & 0.07 & 0.07 & 0.07 & & 0.21 & 0.21 & 0.02 & & 0.49 \\
\hline
\end{tabular}

Note: $\mathrm{Dt}(\mathrm{t}+1)=\mathrm{DEA}$ efficiency of an institution at time $\mathrm{t}$ compared to the frontier at year $\mathrm{t}+1$.

\subsubsection{Step 2: Identify Zero-Data Issues}

Institutions identified as zero efficiency are listed in Table 54. An institution of which efficiency score bounded to zero is associated with the Type 2 zero issue. Zero output of 
the referred DMUs (DMUs on the left hand side of the output constraints in the DEA model) causes the zero efficiency problem.

Table 54: Institutions with zero-efficiency scores

\begin{tabular}{|c|c|c|c|c|c|}
\hline \multirow{2}{*}{ Evaluated Institutions $\left(\boldsymbol{D} \boldsymbol{M U}_{\boldsymbol{k}}\right)$} & \multirow{2}{*}{ Year $\mathrm{t}$} & \multicolumn{4}{|c|}{$\widehat{\boldsymbol{\beta}}_{\boldsymbol{k}}$} \\
\cline { 3 - 6 } & & $\mathrm{Dt}(\mathrm{t})$ & $\mathrm{Dt}(\mathrm{t}+1)$ & $\mathrm{Dt}+1(\mathrm{t})$ & $\mathrm{Dt}+1(\mathrm{t}+1)$ \\
\hline Ohio U. & 1991 & $\mathbf{0 . 0 0}$ & 0.31 & $\mathbf{0 . 0 0}$ & 0.26 \\
\hline U. of Akron & 1995 & 0.26 & 1.41 & 0.71 & $\mathbf{0 . 0 0}$ \\
\hline U. of Akron & 1996 & $\mathbf{0 . 0 0}$ & 0.58 & 1.01 & 0.30 \\
\hline
\end{tabular}

Note: $\mathrm{Dt}(\mathrm{t}+1)=\mathrm{DEA}$ efficiency of an institution at time $\mathrm{t}$ compared to the frontier at year $\mathrm{t}+1$.

Institutions with zero-data in output variables are presented in Table 55. Ohio University in 1991 in the reference set of the evaluated St. Jude Children's Research Center in 1991 has zero start-up (output). Ohio University in 1992 also referred itself in 1991, which also has zero value for start-up. Finally, the zero start-up of Ohio University in 1996 caused the zero efficiency of Ohio University in 1996.

Table 55: Referred institutions causing type 2 zero issue

\begin{tabular}{|c|c|c|c|c|c|}
\hline \multirow{2}{*}{$\begin{array}{l}\text { Referred Institutions }\left(\boldsymbol{D M} \boldsymbol{U}_{\boldsymbol{j}}\right) \\
\qquad\left(\boldsymbol{\lambda}_{\boldsymbol{j}}>\mathbf{0}\right)\end{array}$} & \multirow{2}{*}{$\begin{array}{l}\text { Year of } \\
\boldsymbol{D M U}_{\boldsymbol{j}}\end{array}$} & \multicolumn{4}{|c|}{ Data of Referred Institutions } \\
\hline & & EXP & PTI & STU & LCI \\
\hline $\begin{array}{l}D M U_{k}: \text { Ohio U. D1991(1991) } \\
D M U_{j}: \text { St. Jude Children's Res. Ctr. }\end{array}$ & 1991 & 9.21 & 1.84 & $\underline{\mathbf{0 . 0 0}}$ & 2.68 \\
\hline $\begin{array}{l}D M U_{k}: \text { Ohio U. D1992(1991) } \\
D M U_{j}: \text { Ohio U. }\end{array}$ & 1991 & 0.99 & 7.86 & $\underline{0.00}$ & 0.61 \\
\hline $\begin{array}{l}D M U_{k}: \text { U. of Akron D1996(1996) } \\
D M U_{j}: \text { Ohio U. }\end{array}$ & 1996 & 1.13 & 3.46 & $\underline{0.00}$ & 0.59 \\
\hline
\end{tabular}

Note: $\mathrm{DMU}=$ decision-making unit, EXP = research expenditure, $\mathrm{LCI}=$ licensing income, PTI = number of U.S. patents issued, STU = number of start-ups. 


\subsubsection{Step 3: Modify $\hat{\beta}^{*}$ Using the Nonradial Super-Efficiency Model}

The nonradial super-efficiency model outlined in 3 was applied to the efficiency scores: D1991(1991) and D1992(1991) of Ohio University, and D1996(1996) of the University of Akron. The result is presented in Table 56.

Table 56: Nonradial output super-efficiency scores of institutions with type 2 zero issue

\begin{tabular}{|c|c|c|c|c|c|}
\hline \multirow{2}{*}{$\begin{array}{c}\text { Evaluated Institutions } \\
\left(\boldsymbol{D} \boldsymbol{M U}_{\boldsymbol{k}}\right)\end{array}$} & \multirow{2}{*}{$\begin{array}{c}\text { Year } \\
t\end{array}$} & $\emptyset_{P T I}{ }^{k}$ & $\emptyset_{S T U}{ }^{k}$ & $\emptyset_{L C I}{ }^{k}$ & \begin{tabular}{c} 
Nonradial Efficiency \\
\cline { 3 - 6 } \\
\cline { 3 - 6 }
\end{tabular} \\
\hline Ohio U. Dt(t) & 1991 & 0.80 & 0.00 & 0.37 & 0.59 \\
\hline Ohio U. Dt+1(t) & 1991 & 3.42 & 0.00 & 0.08 & 1.75 \\
\hline U. of Akron Dt(t) & 1996 & 0.37 & 0.00 & 0.29 & 0.33 \\
\hline
\end{tabular}

Note: DMU = decision-making unit, $\mathrm{LCI}=$ licensing income, PTI = number of U.S. patents issued, $\mathrm{STU}=$ number of start-ups.

The nonradial super-efficiency scores of the two institutions that have the Type 2 zero issue show zero efficiency for the output variable (start-up), which caused the zero issue. However, the efficiencies of other output variables (number of U.S. patents issued and licensing income) present non-zero. Therefore, the super-efficiency scores $\left(\hat{\beta}^{*}\right)$ of these institutions are replaced by the average of the other two nonradial output superefficiencies, as presented in the last column of Table 56. 


\subsubsection{Step 4: Modified Super-Efficiency Scores Resolving the Zero Data Issue}

Finally, the modified super-efficiency scores of the 46 institutions were defined using Lee, et al.'s (2011) equation. (Modified super-efficiency scores are provided in Appendix D.) The super-efficiency scores of the 11 super-efficient or extremely super-efficient best practicing institutions during the period are summarized in Table 57.

Table 57: Modified super-efficiency scores of 11 institutions (1991-1999)

\begin{tabular}{|l|c|c|c|c|c|c|c|c|c|}
\hline \multirow{2}{*}{ Institutions } & \multicolumn{7}{|c|}{ Modified Super-Efficience Scores; Dt(t) } \\
\cline { 2 - 11 } & 1991 & 1992 & 1993 & 1994 & 1995 & 1996 & 1997 & 1998 & 1999 \\
\hline Brigham Young Univ. & 2.09 & 1.16 & 17.66 & 3.25 & 1.25 & 1.93 & 2.22 & 2.05 & 1.88 \\
\hline $\begin{array}{l}\text { California Institute of } \\
\text { Tech. }\end{array}$ & & 1.52 & 1.57 & 1.13 & 1.25 & 1.67 & 2.36 & 2.73 & 3.15 \\
\hline $\begin{array}{l}\text { City of Hope National } \\
\text { Medic }\end{array}$ & 5.17 & 2.47 & 1.74 & & & 1.06 & 1.75 & 3.16 & 1.68 \\
\hline Dartmouth College & & & & & 1.59 & & & & \\
\hline Florida State Univ. & & & 1.41 & 2.43 & 1.02 & 1.94 & 1.33 & & \\
\hline $\begin{array}{l}\text { Massachusetts Inst. of } \\
\text { Tech }\end{array}$ & 3.33 & 2.79 & 2.34 & 2.35 & 2.21 & 2.59 & 1.86 & 2.03 & 2.04 \\
\hline Ohio Univ. & $\mathbf{3 . 0 1 *}$ & 5.11 & & & & & & & \\
\hline Univ. of Akron & 2.11 & & 1.47 & 3.04 & 4.78 & $\mathbf{4 . 0 7 *}$ & 4.26 & 2.95 & 4.76 \\
\hline Univ. of Minnesota & & & & & & & & & 1.08 \\
\hline Univ. of Utah & & & & & & & & 1.07 & 1.19 \\
\hline Wake Forest Univ. & & & & & & & & & 1.01 \\
\hline
\end{tabular}

Note: $*$ average of nonradial output super-efficiency scores are applied. 


\subsubsection{Malmquist Indexes during the Evaluation Periods}

Modified super-efficiency scores for the years evaluated ( $t$ and $t+1)$ over each frontier year $(t$ and $t+1)$ are used to calculate Malmquist Indexes. (Efficiency change, technical change, and Malmquist Index scores for the 46 institutions are provided in Appendix E.)

\subsection{Summary}

The licensing or commercialization performance of 46 U.S. research institutions was explored using modified super-efficiency models and the Malmquist Index. The time-lag effect neutralized data for the input of research expenditure from 1991 to 1999 and the outputs of patent applications, start-ups, and licensing income from 1992 to 2007 were used for the analysis.

Brigham Young University and the Massachusetts Institute of Technology are identified as super-efficient universities for all the years. The California Institute of Technology and the University of Akron were super-efficient for most of the years studied, whereas Dartmouth College was efficient only in 1995. Ohio University was efficient in 1991 and 1992, and inefficient since then. On the other hand, three universities became efficient in 1998 or 1999.

Table 58 presents the averages of universities' scores during the periods studied. All of the institutions show improved performance $(\mathrm{MI}>1)$ during the period. All of the institutions also experienced frontier expansion $(\mathrm{TC}>1)$ during the period, which means 
that all other best practicing institutions improved their performance. Also, all but 8 institutions improved efficiency $(\mathrm{EC}>1)$ over the same time period. The efficiency change of an evaluated DMU tends to decline if the frontier of the DMU is expanding (TC $>1)$ in the following year compared to an identical frontier, because the distance between the DMU and frontier becomes larger, as illustrated in 3. Given this, the improved efficiency is significant. This also indicates that performance improvements existed throughout all institutions. 
Table 58: Average efficiency change, technical change, and Malmquist Index scores of the 46 institutions

\begin{tabular}{|c|c|c|c|c|c|c|c|}
\hline \multirow{2}{*}{ Institutions } & \multicolumn{3}{|c|}{$\begin{array}{l}\text { Average over the } \\
\text { periods }\end{array}$} & \multirow{2}{*}{ Institutions } & \multicolumn{3}{|c|}{$\begin{array}{l}\text { Average over the } \\
\text { periods }\end{array}$} \\
\hline & $\mathrm{EC}$ & $\mathrm{TC}$ & MI & & $\mathrm{EC}$ & $\mathrm{TC}$ & MI \\
\hline Baylor College of Medicine & 1.26 & 1.06 & 1.41 & Oregon State Univ. & 1.21 & 1.20 & 1.40 \\
\hline $\begin{array}{l}\text { Brigham \& Women's } \\
\text { Hospital, Inc. }\end{array}$ & 0.98 & 1.22 & 1.16 & Penn State Univ. & 1.08 & 1.08 & 1.13 \\
\hline Brigham Young Univ. & 2.61 & 1.59 & 6.12 & Rutgers, The State Univ. & 0.97 & 1.19 & 1.11 \\
\hline California Institute of Tech. & 1.21 & 1.04 & 1.30 & $\begin{array}{l}\text { St. Jude Children's } \\
\text { Research }\end{array}$ & 1.18 & 1.18 & 1.31 \\
\hline Case Western Reserve Univ. & 1.07 & 1.22 & 1.19 & Tulane Univ. & 0.92 & 1.15 & 1.02 \\
\hline City of Hope National Medic & 1.01 & 1.15 & 1.05 & Univ. of Akron & 1.23 & 1.23 & 1.41 \\
\hline Clemson Univ. & 1.02 & 1.11 & 1.02 & Univ. of Arizona & 1.06 & 1.08 & 1.14 \\
\hline Colorado State Univ. & 1.23 & 1.15 & 1.22 & Univ. of Cincinnati & 0.89 & 1.17 & 1.01 \\
\hline Dartmouth College & 1.50 & 1.20 & 1.77 & Univ. of Connecticut & 1.02 & 1.19 & 1.17 \\
\hline Florida State Univ. & 1.30 & 1.08 & 1.32 & Univ. of Dayton & 0.93 & 1.22 & 1.10 \\
\hline Fred Hutchinson Cancer Res. & 0.99 & 1.18 & 1.18 & Univ. of Delaware & 1.07 & 1.21 & 1.25 \\
\hline Georgia Inst. of Technology & 1.16 & 1.12 & 1.21 & $\begin{array}{l}\text { Univ. of Iowa Research } \\
\text { Fdn. }\end{array}$ & 1.08 & 1.15 & 1.19 \\
\hline Harvard Univ. & 1.07 & 1.10 & 1.19 & $\begin{array}{l}\text { Univ. of Maryland, } \\
\text { College }\end{array}$ & 1.44 & 1.16 & 1.47 \\
\hline Indiana Univ. (ARTI) & 1.19 & 1.17 & 1.29 & Univ. of Michigan & 1.17 & 1.14 & 1.41 \\
\hline Johns Hopkins Univ. & 1.11 & 1.14 & 1.25 & Univ. of Minnesota & 1.12 & 1.06 & 1.19 \\
\hline Massachusetts Inst. of Tech & 0.95 & 1.11 & 1.05 & Univ. of Oregon & 1.06 & 1.17 & 1.13 \\
\hline Mayo Foundation & 1.08 & 1.13 & 1.15 & $\begin{array}{l}\text { Univ. of Southern } \\
\text { California }\end{array}$ & 1.02 & 1.06 & 1.07 \\
\hline Michigan State Univ. & 1.05 & 1.10 & 1.11 & $\begin{array}{l}\text { Univ. of Texas } \\
\text { Southwestern }\end{array}$ & 1.03 & 1.20 & 1.19 \\
\hline National Jewish Center & 1.05 & 1.23 & 1.31 & Univ. of Utah & 1.16 & 1.13 & 1.20 \\
\hline New Jersey Institute of Tech. & 1.33 & 1.26 & 1.75 & $\begin{array}{l}\text { Univ. of Virginia Patent } \\
\text { Fdn. }\end{array}$ & 0.95 & 1.10 & 1.02 \\
\hline Northwestern Univ. & 1.16 & 1.16 & 1.29 & Vanderbilt Univ. & 1.11 & 1.14 & 1.22 \\
\hline Ohio State Univ. & 1.03 & 1.12 & 1.17 & Wake Forest Univ. & 1.33 & 1.16 & 1.39 \\
\hline Ohio Univ. & 1.00 & 1.20 & 1.08 & Washington Univ. & 1.06 & 1.12 & 1.15 \\
\hline
\end{tabular}

Note: $\mathrm{EC}=$ efficiency change, $\mathrm{MI}=$ Malmquist Index, $\mathrm{TC}=$ technical change. 
Brigham Young University received the highest Malmquist Index score among the 46 institutions. The university improved its performance $600 \%$. This is not comparable to other institutions, considering that the next highest score is 1.77 for Dartmouth College. This bias came from Brigham Young's extremely high super-efficiency score, 17.66, in 1993. Excluding Brigham Young University, the average MI of other institutions is 1.23, which means that the institutions improved their performance by $23 \%$ every year. 
Chapter 7. Characteristics of the Efficiency Change Patterns in U.S. Universities' Technology Commercialization

This chapter explores the licensing performance characteristics of 46 U.S. academic research institutions. For this purpose, time-lag effect neutralized licensing data (expenditure, disclosure, patent applications, patents issued, licenses and options executed, number of start-ups, and licensing income) are analyzed, along with institutional types and other licensing-related characteristics identified in 3. Regression analysis and ANOVA tests were used to investigate their relationship of this data with licensing performance. Four types of licensing performance are explored in detail: (a) the cumulative licensing outputs of disclosure, patent applications, patents issued, licenses and options executed, number of start-up, and licensing income; (b) licensing outputs relative to expenditure; (c) super-efficiency scores; and (d) efficiency changes (Malmquist Indexes).

\subsection{Licensing Data and Organizational Characteristics}

\subsubsection{Time-lag Effect Neutralized Licensing Data}

The licensing data were transformed using time-lag coefficients. As shown in 6, time-lag effects of patent applications, number of start-ups, and licensing income were neutralized on the basis of expenditure at year $t$. The same approach was applied to other licensing variables. Figure 40 illustrates the time-lag effect neutralized data of the seven licensing variables. 

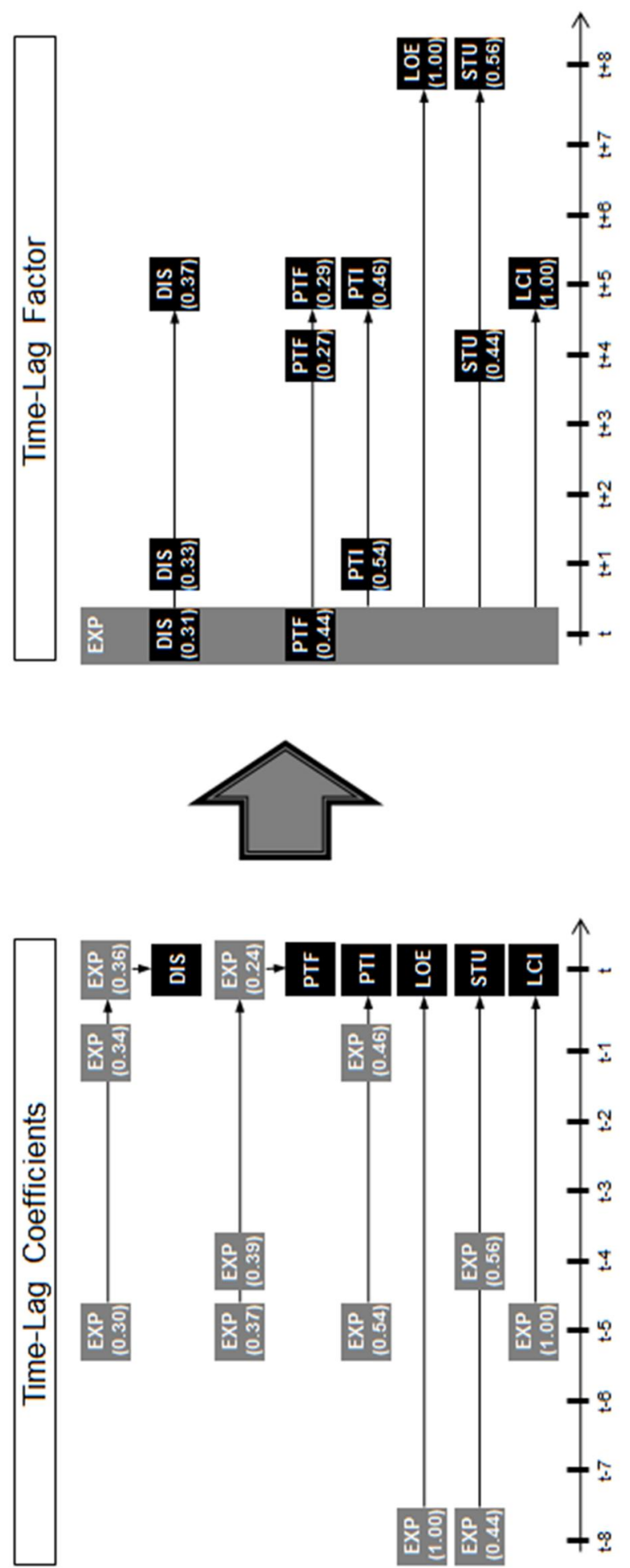

Figure 40: Data transform of the licensing data incorporating time-lag coefficients 


\subsubsection{Types of the 46 Academic Research Institutions}

The 46 academic research institutions are classified by institution type (using definitions from the National Center for Education Statistics), private or public status, and whether the institution includes a medical school (Table 59). The majority (37) of the institutions are 4-year research universities with master's and doctoral degree programs. Twenty-one of the 46 universities are private schools. About $56 \%$ of both the private and public universities include medical schools. The sample includes 9 non-university research institutions, comprising 3 medical research centers, 4 research and teaching institutions specialized in medicine, and 2 teaching and research hospitals. 
Table 59: Types of the 46 academic research institutions

\begin{tabular}{|c|c|c|c|c|}
\hline \multirow{2}{*}{$\begin{array}{l}\text { Institution } \\
\text { Types }\end{array}$} & \multicolumn{2}{|c|}{ Private (21) } & \multicolumn{2}{|c|}{ Public (25) } \\
\hline & $\begin{array}{l}\text { With medical } \\
\text { school (12) }\end{array}$ & $\begin{array}{l}\text { Without medical } \\
\text { school (9) }\end{array}$ & $\begin{array}{l}\text { With medical } \\
\text { school (14) }\end{array}$ & $\begin{array}{l}\text { Without medical } \\
\text { school (11) }\end{array}$ \\
\hline \multicolumn{5}{|l|}{ Universities (37) } \\
\hline $\begin{array}{l}\text { Research } \\
\text { Universities (4 } \\
\text { years, including } \\
\text { master's and } \\
\text { doctoral degree } \\
\text { programs) (37) }\end{array}$ & $\begin{array}{l}\text { - Case Western } \\
\text { Reserve Univ. } \\
\text { - Dartmouth College } \\
\text { - Harvard Univ. } \\
\text { - Johns Hopkins Univ. } \\
\text { - Northwestern Univ. } \\
\text { - Tulane Univ. } \\
\text { - Univ. of Southern } \\
\text { California } \\
\text { - Vanderbilt Univ. } \\
\text { - Wake Forest Univ. } \\
\text { - Washington Univ. in } \\
\text { St. Louis } \\
\text { (10) }\end{array}$ & $\begin{array}{l}\text { - Brigham Young } \\
\text { Univ. } \\
\text { - California Institute of } \\
\text { Tech. } \\
\text { - Massachusetts } \\
\text { Institute of Tech. } \\
\text { - Univ. of Dayton } \\
\text { (4) }\end{array}$ & $\begin{array}{l}\text { - Indiana Univ. at } \\
\text { Indianapolis } \\
\text { - Michigan State Univ. } \\
\text { - Ohio State Univ. } \\
\text { - Ohio Univ. } \\
\text { - Univ. of Arizona } \\
\text { - Univ. of Cincinnati } \\
\text { - Univ. of Connecticut } \\
\text { - Univ. of Iowa } \\
\text { - Univ. of Michigan - } \\
\text { Ann Arbor } \\
\text { - Univ. of Minnesota - } \\
\text { Twin Cities } \\
\text { - Univ. of Utah } \\
\text { - Univ. of Virginia } \\
\text { (12) }\end{array}$ & $\begin{array}{l}\text { - Clemson Univ. } \\
\text { - Colorado State } \\
\text { Univ. } \\
\text { - Florida State Univ. } \\
\text { - Georgia Institute of } \\
\text { Tech. } \\
\text { - New Jersey Institute } \\
\text { of Tech. } \\
\text { - Oregon State Univ. } \\
\text { - Rutgers Univ. } \\
\text { - Univ. of Akron } \\
\text { - Univ. of Delaware } \\
\text { - Univ. of Maryland, } \\
\text { College Park } \\
\text { - Univ. of Oregon } \\
\text { (11) }\end{array}$ \\
\hline \multicolumn{5}{|c|}{ Non-Universities (Hospitals and Research Institutions) (9) } \\
\hline $\begin{array}{l}\text { Medical Research } \\
\text { Centers (3) }\end{array}$ & $\mathrm{n} / \mathrm{a}$ & $\begin{array}{l}\text { - City of Hope } \\
\text { National Med. Ctr. } \\
\text { - Fred Hutchinson } \\
\text { Cancer Res. Ctr. } \\
\text { - National Jewish Med. } \\
\text { and Res. Ctr. } \\
\text { (3) }\end{array}$ & $\mathrm{n} / \mathrm{a}$ & $\mathrm{n} / \mathrm{a}$ \\
\hline $\begin{array}{l}\text { Special-Focus } \\
\text { Institutions - } \\
\text { Medical (4) }\end{array}$ & $\begin{array}{l}\text { - Baylor College of } \\
\text { Medicine } \\
\text { - Mayo Foundation for } \\
\text { Med. Edu. and Res. } \\
\text {-(2) }\end{array}$ & $\mathrm{n} / \mathrm{a}$ & $\begin{array}{l}\text { - Penn State Milton S. } \\
\text { Hershey Med. Ctr. } \\
\text { - Univ. of Texas } \\
\text { Southwestern Med. } \\
\text { Ctr. } \\
\text { - (2) }\end{array}$ & $\mathrm{n} / \mathrm{a}$ \\
\hline $\begin{array}{l}\text { Teaching and } \\
\text { Research Hospitals } \\
\text { (2) }\end{array}$ & $\mathrm{n} / \mathrm{a}$ & $\begin{array}{l}\text { - Brigham and } \\
\text { Women's Hosp. } \\
\text { - St. Jude Children's } \\
\text { Res. Hosp. } \\
\text { (2) }\end{array}$ & $\mathrm{n} / \mathrm{a}$ & $\mathrm{n} / \mathrm{a}$ \\
\hline
\end{tabular}

\subsubsection{Characteristic Variables and Data Gathering}

Institutional characteristics include size, type, research intensity, prestige, and licensing experience and effort of a licensing office. The experience and degree of effort on the part of technology licensing offices is measured by age (2007 - year established), 
licensing, and other full-time equivalents (FTEs). The variables and data sources are summarized in Table 60.

Table 60: Institutional variables and data sources

\begin{tabular}{|c|c|c|c|}
\hline Types & Variables & Definitions & Source \\
\hline \multirow{3}{*}{$\begin{array}{c}\text { Institution } \\
\text { Characteristics }\end{array}$} & Institution Type & Institution types & $\begin{array}{l}\text { AUTM, } \\
\text { NCES }\end{array}$ \\
\hline & Private/Public & Private or public status & $\begin{array}{l}\text { NCES, US } \\
\text { News, } \\
\text { Wikipedia }\end{array}$ \\
\hline & Medical School & The existence of medical school & AUTM \\
\hline \multirow{3}{*}{$\begin{array}{l}\text { Academic } \\
\text { Prestige and } \\
\text { Research }\end{array}$} & $\begin{array}{l}\text { Faculty's } \\
\text { flexible time }\end{array}$ & Number of students per faculty & NCES \\
\hline & $\begin{array}{l}\text { Research } \\
\text { Activity }\end{array}$ & $\begin{array}{l}\text { Total number of journal articles published from } \\
1991 \text { to } 2007 \text { in Compendex and GEOBASE } \\
\text { DB }\end{array}$ & $\begin{array}{l}\text { Engineering } \\
\text { Village DB }\end{array}$ \\
\hline & $\begin{array}{l}\text { Academic } \\
\text { Prestige }\end{array}$ & $\begin{array}{l}\text { Average ranking of "TOP Medical Schools", } \\
\text { "Best Research Ranking of Medical Schools", } \\
\text { "Best Patient Care Ranking of Medical } \\
\text { Schools", "Best Graduate Science School } \\
\text { Ranking", "Best Graduate Engineering School } \\
\text { Ranking"" }\end{array}$ & $\begin{array}{l}\text { US News } \\
\text { Ranking, } \\
2011\end{array}$ \\
\hline \multirow{3}{*}{$\begin{array}{l}\text { Efforts of } \\
\text { Licensing } \\
\text { Office }\end{array}$} & Experience & TTO age (2007- instituted year) & \multirow{3}{*}{ AUTM } \\
\hline & Licensing effort & Licensing FTEs in TLO & \\
\hline & $\begin{array}{l}\text { Licensing } \\
\text { support }\end{array}$ & Other FTEs in TLO & \\
\hline
\end{tabular}

7.2. Characteristics of the 46 Academic Research Institutions and Licensing Data

\subsubsection{Selecting an ANOVA Test Method}

The ANOVA test is used to explore organizational differences. If the dependent variables follow normality, a one-way ANOVA is used; otherwise, the Kruskal-Wallis test is used. (The result of the normality test is presented in Appendix F.) If the p-value of the 
Shapiro-Wilk statistics is greater than 0.05 , the data satisfies normality. The results showed that medical research centers and institutions with a special focus on medicine satisfy normality. However, universities didn't satisfy the normality condition, and teaching and research hospitals were not available for the test because of the small number of cases. Therefore, Kruskal-Wallis, a nonparametric ANOVA test, was used for comparisons of the groups.

\subsubsection{Comparison of Licensing Data from Four Types of Institution}

The cumulative time-lag effect neutralized licensing data of four institutional types is summarized in Table 61. The special-focus medical institutions had the highest expenditure during the period, followed by universities and teaching and research hospitals. However, medical research centers showed higher licensing income than medical institutions. Universities and medical institutions recorded similar licensing income, but medical institutions showed higher values for all outcome variables, excluding licensing income. 
Table 61: Case summaries by four institution types and cumulative time-lag effect neutralized licensing data (1991-1999)

\begin{tabular}{|l|l|c|c|c|c|c|c|c|}
\hline $\begin{array}{l}\text { Institution } \\
\text { Types }\end{array}$ & Statistics & $\begin{array}{c}\text { EXP } \\
\text { from } \\
1991 \text { to } \\
1999\end{array}$ & $\begin{array}{c}\text { DIS } \\
\text { from } \\
1991 \text { to } \\
1999\end{array}$ & $\begin{array}{c}\text { PTF } \\
\text { from } \\
1991 \text { to } \\
1999\end{array}$ & $\begin{array}{c}\text { PTI } \\
\text { from } \\
1992 \text { to } \\
2004\end{array}$ & $\begin{array}{c}\text { LOE } \\
\text { from } \\
1991 \text { to } \\
1999\end{array}$ & $\begin{array}{c}\text { STU } \\
\text { from } \\
1995 \text { to } \\
2007\end{array}$ & $\begin{array}{c}\text { LCI from } \\
1996 \text { to } \\
2004\end{array}$ \\
\hline Universities & $\begin{array}{l}\text { Mean } \\
\text { Standard } \\
\text { Deviation }\end{array}$ & 128 & 777 & 352 & 199 & 291 & 30 & 443 \\
\hline $\begin{array}{l}\text { Medical } \\
\text { Research } \\
\text { Centers }\end{array}$ & Mean & 45 & 179 & 88 & 60 & 97 & 4 & 843 \\
\hline $\begin{array}{l}\text { Teaching } \\
\text { and } \\
\text { Research } \\
\text { Hospitals }\end{array}$ & $\begin{array}{l}\text { Standard } \\
\text { Deviation }\end{array}$ & 32 & 68 & 29 & 19 & 56 & 3 & 1,345 \\
\hline & $\begin{array}{l}\text { Standard } \\
\text { Deviation }\end{array}$ & 52 & 249 & 198 & 119 & 36 & 14 & 240 \\
\hline $\begin{array}{l}\text { Special } \\
\text { Focus } \\
\text { Institution } \\
\text { Medical }\end{array}$ & \begin{tabular}{lllllll} 
Mean \\
\hline
\end{tabular} & 153 & 1,036 & 481 & 206 & 410 & 21 & 442 \\
\hline $\begin{array}{l}\text { Standard } \\
\text { Deviation }\end{array}$ & 70 & 376 & 384 & 64 & 231 & 10 & 230 \\
\hline Mean & 122 & 746 & 339 & 188 & 287 & 27 & 459 \\
\hline Dotal & 114 & 682 & 359 & 197 & 239 & 32 & 626 \\
\hline
\end{tabular}

Note: DIS $=$ number of disclosures, $\mathrm{EXP}=$ research expenditure, $\mathrm{LCI}=$ licensing income, $\mathrm{LOE}=$ number of licenses and options executed, PTF $=$ number of U.S. patent applications, PTI = number of U.S. patents issued, STU = number of start-ups.

The result of the ANOVA test is presented in Table 62. Disclosure is the only statistically significant difference among the institution types. Universities and special focus medical institutions had a higher number of disclosures than the other two groups of institutions. 
Table 62: Kruskal-Wallis test of cumulative licensing data over four institution types

\begin{tabular}{|c|c|c|c|c|c|c|c|}
\hline & $\begin{array}{l}\text { Cumulative } \\
\text { Time } \\
\text { Aggregated } \\
\text { Expenditure } \\
\text { From } 1991 \\
\text { to } 1999\end{array}$ & $\begin{array}{c}\text { Cumulative } \\
\text { Time } \\
\text { Aggregated } \\
\text { Disclosure } \\
\text { From } 1991 \\
\text { to } 1999\end{array}$ & $\begin{array}{l}\text { Cumulative } \\
\text { Time } \\
\text { Aggregated } \\
\text { Patent } \\
\text { Applications } \\
\text { From } 1991 \\
\text { to } 1999\end{array}$ & $\begin{array}{c}\text { Cumulative } \\
\text { Time } \\
\text { Aggregated } \\
\text { Patents } \\
\text { Issued From } \\
1992 \text { to } \\
2004\end{array}$ & $\begin{array}{l}\text { Cumulative } \\
\text { Time } \\
\text { Aggregated } \\
\text { Licenses } \\
\text { and Options } \\
\text { Executed } \\
\text { From } 1991 \\
\text { to } 1999\end{array}$ & $\begin{array}{l}\text { Cumulative } \\
\text { Time } \\
\text { Aggregated } \\
\text { Start-Ups } \\
\text { From } 1995 \text { to } \\
2007 \\
\end{array}$ & $\begin{array}{l}\text { Cumulative } \\
\text { Time } \\
\text { Aggregated } \\
\text { Licensing } \\
\text { Income } \\
\text { From } 1996 \\
\text { to } 2004\end{array}$ \\
\hline $\begin{array}{l}\text { Chi- } \\
\text { square }\end{array}$ & 5.704 & 7.807 & 5.905 & 5.429 & 4.902 & 7.385 & 1.479 \\
\hline $\begin{array}{l}\text { Degrees of } \\
\text { freedom }\end{array}$ & 3 & 3 & 3 & 3 & 3 & 3 & 3 \\
\hline $\begin{array}{l}\text { Asymp. } \\
\text { Sig. }\end{array}$ & . 127 & .050 & .116 & .143 & .179 & .061 & .687 \\
\hline
\end{tabular}

Note: Grouping variable is institution type.

The output variables per expenditure are summarized in Table 63. Medical research centers yielded higher licensing incomes than the total average. Hospitals had a smaller number of start-ups than other groups. The number of start-ups was greater than the total average. However, the ANOVA test (Table 64) showed that the differences among the variables relative to expenditure are not statistically significant for the four institution types. 
Table 63: Four institution types and six cumulative time-lag effect neutralized licensing output variables per expenditure

\begin{tabular}{|c|c|c|c|c|c|c|c|}
\hline \multirow{2}{*}{$\begin{array}{l}\text { Institution } \\
\text { Types }\end{array}$} & \multirow{2}{*}{ Statistics } & \multicolumn{6}{|c|}{ Cumulative Time aggregated Licensing Variables per Expenditur } \\
\hline & & DIS & PTF & PTI & LOE & STU & LCI \\
\hline \multirow[t]{2}{*}{ Universities } & Mean & 8.16 & 3.35 & 1.91 & 2.85 & .32 & 4.72 \\
\hline & $\begin{array}{l}\text { Standard } \\
\text { Deviation }\end{array}$ & 8.42 & 3.05 & 1.74 & 3.11 & .42 & 7.28 \\
\hline \multirow{2}{*}{$\begin{array}{l}\text { Medical } \\
\text { Research } \\
\text { Centers }\end{array}$} & Mean & 4.76 & 2.65 & 1.78 & 2.82 & .12 & 23.62 \\
\hline & $\begin{array}{l}\text { Standard } \\
\text { Deviation }\end{array}$ & 1.70 & 1.44 & .92 & 2.33 & .09 & 38.51 \\
\hline \multirow{2}{*}{$\begin{array}{l}\text { Teaching and } \\
\text { Research } \\
\text { Hospitals }\end{array}$} & Mean & 7.13 & 2.70 & 1.68 & 4.75 & .09 & 2.53 \\
\hline & $\begin{array}{l}\text { Standard } \\
\text { Deviation }\end{array}$ & 1.84 & .85 & .47 & 3.16 & .13 & 1.61 \\
\hline \multirow{2}{*}{$\begin{array}{l}\text { Special-Focus } \\
\text { Institution- } \\
\text { Medical }\end{array}$} & Mean & 7.16 & 2.91 & 1.46 & 3.22 & .14 & 3.67 \\
\hline & $\begin{array}{l}\text { Standard } \\
\text { Deviation }\end{array}$ & 2.51 & 1.10 & .48 & 2.35 & .03 & 2.29 \\
\hline \multirow[t]{2}{*}{ Total } & Mean & 7.81 & 3.24 & 1.85 & 2.96 & .28 & 5.77 \\
\hline & $\begin{array}{l}\text { Standard } \\
\text { Deviation }\end{array}$ & 7.62 & 2.77 & 1.58 & 2.96 & .38 & 11.48 \\
\hline
\end{tabular}

Note: DIS $=$ number of disclosures, LCI $=$ licensing income, LOE $=$ number of licenses and options executed, PTF = number of U.S. patent applications, PTI = number of U.S. patents issued, STU = number of start-ups. 
Table 64: Kruskal-Wallis test of cumulative licensing data per expenditure by four institution types

\begin{tabular}{lrrrrrr}
\hline \hline & $\begin{array}{c}\text { Cumulative } \\
\text { Disclosures per } \\
\text { Expenditure }\end{array}$ & $\begin{array}{c}\text { Cumulative } \\
\text { Patent } \\
\text { Applications } \\
\text { per } \\
\text { Expenditure }\end{array}$ & $\begin{array}{c}\text { Cumulative } \\
\text { Patents Issued } \\
\text { per } \\
\text { Expenditure }\end{array}$ & $\begin{array}{c}\text { Cumulative } \\
\text { Licenses and } \\
\text { Options } \\
\text { Executed per } \\
\text { Expenditure }\end{array}$ & $\begin{array}{c}\text { Cumulative } \\
\text { Start-Ups per } \\
\text { Expenditure }\end{array}$ & $\begin{array}{c}\text { Cumulative } \\
\text { Licensing } \\
\text { Income per } \\
\text { Expenditure }\end{array}$ \\
\hline Chi-Square & 2.114 & .239 & .687 & 2.244 & 6.178 & .632 \\
$\begin{array}{l}\text { Degrees of } \\
\text { freedom }\end{array}$ & 3 & 3 & 3 & 3 & 3 & 3 \\
Asymp. Sig. & .549 & .971 & .876 & .523 & .103 & .889 \\
\hline \hline
\end{tabular}

Note: Grouping variable is institution type.

\subsubsection{Comparison of Licensing Data From Two Types of Institution}

The institutions were regrouped by universities and non-universities, including medical research centers, teaching and research hospitals, and special focus medical institutions, as summarized in Table 65 . The Kruskal-Wallis test indicated no difference between the two groups (Table 66). (See normality test in Appendix G.) 
Table 65: Two institution types and cumulative time-lag effect neutralized licensing data (1991-1999)

\begin{tabular}{|l|l|c|c|c|c|c|c|c|}
\hline $\begin{array}{l}\text { Institution } \\
\text { Types }\end{array}$ & Statistics & $\begin{array}{c}\text { EXP from } \\
1991 \text { to } \\
1999\end{array}$ & $\begin{array}{c}\text { DIS } \\
\text { from } \\
1991 \text { to } \\
1999\end{array}$ & $\begin{array}{c}\text { PTF } \\
\text { from } \\
1991 \text { to } \\
1999\end{array}$ & $\begin{array}{c}\text { PTI from } \\
1992 \text { to } \\
2004\end{array}$ & $\begin{array}{c}\text { LOE } \\
\text { from } \\
1991 \text { to } \\
1999\end{array}$ & $\begin{array}{c}\text { STU } \\
\text { from } \\
1995 \text { to } \\
2007\end{array}$ & $\begin{array}{c}\text { LCI } \\
\text { from } \\
1996 \text { to } \\
2004\end{array}$ \\
\hline $\begin{array}{l}\text { Non- } \\
\text { University }\end{array}$ & Mean & 98 & 616 & 288 & 140 & 267 & 13 & 525 \\
\hline & $\begin{array}{l}\text { Standard } \\
\text { Deviation }\end{array}$ & 73 & 480 & 309 & 89 & 206 & 11 & 739 \\
\hline University & Mean & 128 & 777 & 352 & 199 & 291 & 30 & 443 \\
\hline Total & $\begin{array}{l}\text { Standard } \\
\text { Deviation }\end{array}$ & 122 & 725 & 373 & 214 & 249 & 34 & 606 \\
\hline & $\begin{array}{l}\text { Mean } \\
\text { Standard } \\
\text { Deviation }\end{array}$ & 114 & 682 & 359 & 197 & 239 & 32 & 626 \\
\hline
\end{tabular}

Note: $\mathrm{DIS}=$ number of disclosures, $\mathrm{EXP}=$ research expenditure, $\mathrm{LCI}=$ licensing income, $\mathrm{LOE}=$ number of licenses and options executed, PTF $=$ number of U.S. patent applications, PTI = number of U.S. patents issued, STU = number of start-ups.

Table 66: Kruskal-Wallis test of cumulative licensing data from two types of institution

\begin{tabular}{|c|c|c|c|c|c|c|c|}
\hline & $\begin{array}{l}\text { Cumulative } \\
\text { Time } \\
\text { Aggregated } \\
\text { Expenditure } \\
\text { from } 1991 \\
\text { to } 1999\end{array}$ & $\begin{array}{c}\text { Cumulative } \\
\text { Time } \\
\text { Aggregated } \\
\text { Disclosure } \\
\text { from } 1991 \text { to } \\
1999\end{array}$ & $\begin{array}{l}\text { Cumulative } \\
\text { Time } \\
\text { Aggregated } \\
\text { Patent } \\
\text { Applications } \\
\text { from } 1991 \\
\text { to } 1999\end{array}$ & $\begin{array}{l}\text { Cumulative } \\
\text { Time } \\
\text { Aggregated } \\
\text { Patents } \\
\text { Issued from } \\
1992 \text { to } \\
2004\end{array}$ & $\begin{array}{l}\text { Cumulative } \\
\text { Time } \\
\text { Aggregated } \\
\text { Licenses } \\
\text { and Options } \\
\text { Executed } \\
\text { from } 1991 \\
\text { to } 1999\end{array}$ & $\begin{array}{c}\text { Cumulative } \\
\text { Time } \\
\text { Aggregated } \\
\text { Start-Ups } \\
\text { from } 1995 \text { to } \\
2007\end{array}$ & $\begin{array}{l}\text { Cumulative } \\
\text { Time } \\
\text { Aggregated } \\
\text { Licensing } \\
\text { Income } \\
\text { from } 1996 \\
\text { to } 2004\end{array}$ \\
\hline $\begin{array}{l}\text { Chi- } \\
\text { Square }\end{array}$ & .354 & .184 & .538 & .262 & .000 & 3.043 & .161 \\
\hline $\begin{array}{l}\text { Degrees of } \\
\text { Freedom }\end{array}$ & 1 & 1 & 1 & 1 & 1 & 1 & 1 \\
\hline $\begin{array}{l}\text { Asymp. } \\
\text { Sig. }\end{array}$ & .552 & .668 & .463 & .608 & .989 & .081 & .688 \\
\hline
\end{tabular}

Note: Grouping variable is institution type. 
However, if cumulative variables per expenditure are considered (Table 67), universities had more start-ups than the other institutions (Table 68). Licensing income per expenditure of non-universities was higher than that of universities, but this was not statistically significant.

Table 67: Two institution types and cumulative time-lag effect neutralized licensing data per expenditure

\begin{tabular}{|l|l|c|c|c|c|c|c|}
\hline $\begin{array}{c}\text { Institution } \\
\text { types }\end{array}$ & Statistics & $\begin{array}{c}\text { Cumulative } \\
\text { Disclosures } \\
\text { per } \\
\text { Expenditure }\end{array}$ & $\begin{array}{c}\text { Cumulative } \\
\text { Patent } \\
\text { Applications } \\
\text { per } \\
\text { Expenditure }\end{array}$ & $\begin{array}{c}\text { Cumulative } \\
\text { Patents } \\
\text { Issued per } \\
\text { Expenditure }\end{array}$ & $\begin{array}{c}\text { Cumulative } \\
\text { Licenses } \\
\text { and Options } \\
\text { Executed } \\
\text { per } \\
\text { Expenditure }\end{array}$ & $\begin{array}{c}\text { Cumulative } \\
\text { Start-Ups } \\
\text { per } \\
\text { Expenditure }\end{array}$ & $\begin{array}{c}\text { Cumulative } \\
\text { Licensing } \\
\text { Income per } \\
\text { Expenditure }\end{array}$ \\
\hline $\begin{array}{l}\text { Non- } \\
\text { University }\end{array}$ & Mean & 6.35 & 2.78 & 1.61 & 3.43 & .12 & 10.07 \\
\hline & $\begin{array}{l}\text { Standard } \\
\text { Deviation }\end{array}$ & 2.22 & 1.04 & .59 & 2.29 & .07 & 21.83 \\
\hline University & Mean & 8.16 & 3.35 & 1.91 & 2.85 & .32 & 4.72 \\
\hline Total & $\begin{array}{l}\text { Standard } \\
\text { Deviation }\end{array}$ & 8.42 & 3.05 & 1.74 & 3.11 & .42 & 7.28 \\
\hline & $\begin{array}{l}\text { Mean } \\
\text { Standard } \\
\text { Deviation }\end{array}$ & 7.81 & 3.24 & 1.85 & 2.96 & .28 & 5.77 \\
\hline
\end{tabular}


Table 68: Kruskal-Wallis test of cumulative licensing data per expenditure by two types of institution

\begin{tabular}{|c|c|c|c|c|c|c|}
\hline & $\begin{array}{l}\text { Cumulative } \\
\text { Disclosures } \\
\text { per } \\
\text { Expenditure }\end{array}$ & $\begin{array}{c}\text { Cumulative } \\
\text { Patent } \\
\text { Applications } \\
\text { per } \\
\text { Expenditure }\end{array}$ & $\begin{array}{l}\text { Cumulative } \\
\text { Patents } \\
\text { Issued per } \\
\text { Expenditure }\end{array}$ & $\begin{array}{c}\text { Cumulative } \\
\text { Licenses and } \\
\text { Options } \\
\text { Executed per } \\
\text { Expenditure } \\
\end{array}$ & $\begin{array}{l}\text { Cumulative } \\
\text { Start-Ups per } \\
\text { Expenditure }\end{array}$ & $\begin{array}{l}\text { Cumulative } \\
\text { Licensing } \\
\text { Income per } \\
\text { Expenditure }\end{array}$ \\
\hline $\begin{array}{l}\text { Chi- } \\
\text { Square } \\
\text { Degrees }\end{array}$ & .209 & .069 & .161 & 1.021 & 6.142 & .538 \\
\hline $\begin{array}{l}\text { of } \\
\text { Freedom }\end{array}$ & 1 & 1 & 1 & 1 & 1 & 1 \\
\hline $\begin{array}{l}\text { Asymp. } \\
\text { Sig. }\end{array}$ & .648 & .793 & .688 & .312 & .013 & .463 \\
\hline
\end{tabular}

Note: Grouping variable is institution type - universities or non-universities (hospital research institutions) 


\subsection{Characteristics of Licensing Performance}

\subsubsection{Characteristic Variables by Institutional Type}

The total number of journal articles from 1991 to 2007, and three technology licensing office-related variables, were sorted by institution type (Table 69). Universities had a much higher number of papers published in journals, and this is statistically significant (Table 70). No other significant difference was found. Each variable per expenditure shows the same result (Table 71 and Table 72).

Table 69: Journal articles and technology licensing office-related variables by institution type

\begin{tabular}{|c|c|c|c|c|c|}
\hline Institution Type & Statistics & $\begin{array}{l}\text { Total Number of } \\
\text { Journal Articles from } \\
1991 \text { to } 2007 \\
\text { (Compendex and } \\
\text { GEOBASE) }\end{array}$ & $\begin{array}{c}\text { Age of } \\
\text { Technology } \\
\text { Licensing } \\
\text { Office (2007 - } \\
\text { Year } \\
\text { Instituted) }\end{array}$ & $\begin{array}{c}\text { Licensing } \\
\text { Full-Time } \\
\text { Equivalents } \\
\text { in } \\
\text { Technology } \\
\text { Licensing } \\
\text { Offices }\end{array}$ & $\begin{array}{l}\text { Other Full- } \\
\text { Time } \\
\text { Equivalents } \\
\text { in } \\
\text { Technology } \\
\text { Licensing } \\
\text { Offices }\end{array}$ \\
\hline \multirow[b]{2}{*}{ Universities } & Mean & 7,764 & 24 & 6 & 6 \\
\hline & \begin{tabular}{|l|} 
Standard \\
Deviation
\end{tabular} & 4,521 & 11 & 5 & 6 \\
\hline \multirow{2}{*}{$\begin{array}{l}\text { Medical Research } \\
\text { Centers }\end{array}$} & Mean & 301 & 18 & 3 & 2 \\
\hline & \begin{tabular}{|l|} 
Standard \\
Deviation
\end{tabular} & 133 & 4 & 1 & 1 \\
\hline \multirow{2}{*}{$\begin{array}{l}\text { Teaching and } \\
\text { Research Hospitals }\end{array}$} & Mean & 894 & 17 & 6 & 6 \\
\hline & \begin{tabular}{|l|} 
Standard \\
Deviation
\end{tabular} & 986 & 6 & 4 & 5 \\
\hline \multirow{2}{*}{$\begin{array}{l}\text { Special-Focus } \\
\text { Institution- } \\
\text { Medical }\end{array}$} & Mean & 1,071 & 20 & 8 & 9 \\
\hline & \begin{tabular}{|l|} 
Standard \\
Deviation
\end{tabular} & 638 & 3 & 3 & 5 \\
\hline \multirow[b]{2}{*}{ Total } & Mean & 6,396 & 23 & 6 & 6 \\
\hline & \begin{tabular}{|l|} 
Standard \\
Deviation
\end{tabular} & 4,928 & 10 & 4 & 6 \\
\hline
\end{tabular}


Table 70: Kruskal-Wallis test of journal papers and technology licensing office variables in four types of institution

\begin{tabular}{lrrrr}
\hline \hline & $\begin{array}{c}\text { Total Number of } \\
\text { Journal Articles } \\
\text { from 1991 to 2007 } \\
\text { in Compendex } \\
\text { and GEOBASE }\end{array}$ & $\begin{array}{c}\text { Age of } \\
\text { Technology } \\
\text { Licensing Office } \\
\text { (2007 - Year } \\
\text { Instituted })\end{array}$ & $\begin{array}{c}\text { Licensing Full- } \\
\text { Time } \\
\text { Equivalents in } \\
\text { Technology } \\
\text { Licensing Office }\end{array}$ & $\begin{array}{c}\text { Other Full- } \\
\text { Time } \\
\text { Equivalents in } \\
\text { Technology } \\
\text { Licensing } \\
\text { Office }\end{array}$ \\
\hline $\begin{array}{l}\text { Chi-Square } \\
\text { Degrees of } \\
\text { freedom }\end{array}$ & 19.354 & 2.678 & 3.511 & 4.895 \\
Asymp. Sig. & 3 & 3 & 3 & 3 \\
\hline \hline
\end{tabular}

Note: Grouping variable is institution type

Table 71: Journal articles and technology licensing offices per expenditure by type of institution

\begin{tabular}{|l|l|c|c|c|c|}
\hline \multicolumn{1}{|c|}{ Institution Types } & Statistics & $\begin{array}{c}\text { Journal } \\
\text { Articles per } \\
\text { Expenditure }\end{array}$ & $\begin{array}{c}\text { Age of } \\
\text { Technology } \\
\text { Licensing } \\
\text { Office per } \\
\text { Expenditure }\end{array}$ & $\begin{array}{c}\text { Technology } \\
\text { Licensing } \\
\text { Office } \\
\text { Licensing Full- } \\
\text { Time } \\
\text { Equivalents per } \\
\text { Expenditure }\end{array}$ & $\begin{array}{c}\text { Technology } \\
\text { Licensing } \\
\text { Office Other } \\
\text { Full-Time } \\
\text { Equivalents per } \\
\text { Expenditure }\end{array}$ \\
\hline \multirow{2}{*}{ Universities } & Mean & 118.15 & 0.37 & 0.07 & 0.06 \\
\cline { 2 - 6 } & $\begin{array}{l}\text { Standard } \\
\text { Deviation }\end{array}$ & 201.93 & 0.41 & 0.07 & 0.06 \\
\hline $\begin{array}{l}\text { Medical Research } \\
\text { Centers }\end{array}$ & Mean & 7.94 & 0.51 & 0.09 & 0.04 \\
\cline { 2 - 7 } & $\begin{array}{l}\text { Standard } \\
\text { Deviation }\end{array}$ & 3.05 & 0.25 & 0.06 & 0.02 \\
\hline $\begin{array}{l}\text { Teaching and Research } \\
\text { Hospitals }\end{array}$ & Mean & 10.88 & 0.30 & 0.09 & 0.08 \\
\cline { 2 - 7 } & $\begin{array}{l}\text { Standard } \\
\text { Deviation }\end{array}$ & 6.22 & 0.14 & 0.01 & 0.02 \\
\hline $\begin{array}{l}\text { Special-Focus } \\
\text { Institution-Medical }\end{array}$ & Mean & 9.06 & 0.15 & 0.06 & 0.08 \\
\cline { 2 - 7 } & $\begin{array}{l}\text { Standard } \\
\text { Deviation }\end{array}$ & 6.05 & 0.05 & 0.04 & 0.06 \\
\hline Total & Mean & 96.82 & 0.36 & .07 & 0.06 \\
\cline { 2 - 7 } & $\begin{array}{l}\text { Standard } \\
\text { Deviation }\end{array}$ & 185.84 & 0.38 & 0.06 & 0.05 \\
\hline
\end{tabular}


Table 72: Kruskal-Wallis test of journal papers and technology licensing office variables per expenditure by four types of institution

\begin{tabular}{|c|c|c|c|c|}
\hline & $\begin{array}{l}\text { Total Number of } \\
\text { Journal Articles } \\
\text { per Expenditure } \\
\text { from } 1991 \text { to } 2007\end{array}$ & $\begin{array}{c}\text { Age of } \\
\text { Technology } \\
\text { Licensing Office } \\
(2007-\text { Year } \\
\text { Instituted) per } \\
\text { Expenditure }\end{array}$ & $\begin{array}{l}\text { Licensing Full- } \\
\text { Time } \\
\text { Equivalents in } \\
\text { Technology } \\
\text { Licensing } \\
\text { Offices per } \\
\text { Expenditure } \\
\end{array}$ & $\begin{array}{l}\text { Other Full- } \\
\text { Time } \\
\text { Equivalents in } \\
\text { Technology } \\
\text { Licensing } \\
\text { Offices per } \\
\text { Expenditure }\end{array}$ \\
\hline Chi-Square & 19.354 & 2.678 & 3.511 & 4.895 \\
\hline $\begin{array}{l}\text { Degrees of } \\
\text { Freedom }\end{array}$ & 3 & 3 & 3 & 3 \\
\hline Asymp. Sig. & . 000 & .444 & .319 & .180 \\
\hline
\end{tabular}

Note: Grouping variable is institution type

\subsubsection{Correlation among Cumulative Licensing and Characteristic Variables}

Table 73 summarizes the correlation between cumulative time aggregated variables and institutional characteristic variables. Private institutions showed a positive correlation with all licensing variables, but these correlations were not statistically significant. Universities with medical schools were positively correlated with expenditure. All licensing variables, except for licensing income, had positive relationships with three TLO variables. The average ranking of the institutions was positively related to all licensing variables, except for expenditure and licensing income. In the case of journal articles, all licensing variables showed a positive correlation, except for licenses and options executed and licensing income. 
Table 73: Correlation matrix of cumulative licensing data and institutional variables

\begin{tabular}{|c|c|c|c|c|c|c|c|c|c|}
\hline \multirow{2}{*}{$\begin{array}{l}\text { Cumulative } \\
\text { Time } \\
\text { aggregated } \\
\text { Licensing } \\
\text { Variables }\end{array}$} & \multicolumn{2}{|c|}{$\begin{array}{c}\text { Institution } \\
\text { Type }\end{array}$} & \multirow{2}{*}{$\begin{array}{c}\text { Private } \\
\text { or Public } \\
\text { Status }\end{array}$} & \multirow[b]{2}{*}{$\begin{array}{c}\text { Medical } \\
\text { School }\end{array}$} & \multirow{2}{*}{$\begin{array}{l}\text { Age of } \\
\text { Technolo } \\
\text { gy } \\
\text { Licensing } \\
\text { Office }\end{array}$} & \multirow{2}{*}{\begin{tabular}{|c|} 
Licensing \\
Full-Time \\
Equivalents in \\
Technology \\
Licensing \\
Office
\end{tabular}} & \multirow{2}{*}{\begin{tabular}{|c|} 
Other Full- \\
Time \\
Equivalents in \\
Technology \\
Licensing \\
Offices
\end{tabular}} & \multirow[b]{2}{*}{$\begin{array}{l}\text { Average } \\
\text { Ranking }\end{array}$} & \multirow[b]{2}{*}{$\begin{array}{l}\text { Journal } \\
\text { Articles }\end{array}$} \\
\hline & (a) & (b) & & & & & & & \\
\hline EXP & -0.02 & 0.11 & 0.10 & $\mathbf{0 . 3 3}^{*}$ & $0.54^{* *}$ & $0.51^{* *}$ & $0.69^{* *}$ & 0.18 & $0.30^{*}$ \\
\hline DIS & 0.02 & 0.09 & 0.11 & 0.13 & $0.68^{* * *}$ & $0.62^{* * *}$ & $0.63^{* * *}$ & $0.36^{* *}$ & $0.38^{* * *}$ \\
\hline PTF & 0.03 & 0.07 & 0.15 & 0.12 & $0.59^{* * *}$ & $0.49^{* * *}$ & $0.61^{* *}$ & $0.33^{*}$ & $0.31^{*}$ \\
\hline PTI & -0.05 & 0.12 & 0.16 & 0.09 & $0.69^{* *}$ & $0.60^{* * *}$ & $0.63^{* *}$ & $0.48^{* *}$ & $0.32^{*}$ \\
\hline LOE & 0.07 & 0.04 & 0.20 & 0.28 & $0.68^{* *}$ & $0.71^{* *}$ & $0.75^{* *}$ & $0.29^{*}$ & 0.27 \\
\hline STU & -0.16 & 0.22 & 0.08 & -0.02 & $0.75^{* *}$ & $0.58^{* * *}$ & $0.50^{* *}$ & $0.51^{* *}$ & $0.40^{* * *}$ \\
\hline LCI & 0.00 & -0.05 & 0.15 & -0.04 & 0.28 & 0.27 & 0.24 & 0.18 & 0.00 \\
\hline
\end{tabular}

Note: ${ }^{*}$-value $<0.1,{ }^{* *}$-value $<0.05$

(a) = Universities, medical research centers, teaching and research hospitals, or special focus institutionmedical

(b) = Universities or non-universities

$\mathrm{DIS}=$ number of disclosures, $\mathrm{EXP}=$ research expenditure, $\mathrm{LCI}=$ licensing income, $\mathrm{LOE}=$ number of licenses and options executed, PTF $=$ number of U.S. patent applications, PTI = number of U.S. patents issued, STU = number of start-ups.

Table 74 summarizes the correlations among the variables related to research performance, institutions' size or human research capacity, licensing offices, and licensing performance. 
Table 74: Correlation among licensing characteristics and universities

\begin{tabular}{|c|c|c|c|c|c|c|}
\hline \multicolumn{2}{|c|}{ Other Characteristics } & \multicolumn{3}{|c|}{$\begin{array}{c}\text { Technology Licensing Office } \\
\text { (TLO) }\end{array}$} & \multicolumn{2}{|c|}{ Licensing Performance } \\
\hline Category & Characteristics & TLO Age & $\begin{array}{l}\text { Licensing } \\
\text { Full-Time } \\
\text { Equivalen } \\
\text { ts in TLO }\end{array}$ & \begin{tabular}{|c|} 
Other \\
Full-Time \\
Equivalent \\
s in TLO
\end{tabular} & $\begin{array}{l}\text { Average } \\
\text { Efficiency }\end{array}$ & $\begin{array}{l}\text { Average } \\
\text { Malmquist } \\
\text { Index }\end{array}$ \\
\hline \multirow{3}{*}{$\begin{array}{c}\text { Research } \\
\text { Performance }\end{array}$} & $\begin{array}{l}\text { Science and technology } \\
\text { journal articles }\end{array}$ & $0.29 *$ & 0.22 & 0.28 & 0.02 & -0.16 \\
\hline & $\begin{array}{c}\text { Best graduate engineering } \\
\text { school ranking (higher is } \\
\text { better) }\end{array}$ & $0.65 * *$ & $0.45 * *$ & 0.29 & $0.35^{*}$ & -0.09 \\
\hline & $\begin{array}{l}\text { Best graduate science school } \\
\text { ranking (higher is better) }\end{array}$ & $0.67 * *$ & $0.44 * *$ & $0.37 *$ & $0.38^{*}$ & -0.08 \\
\hline \multirow{3}{*}{$\begin{array}{l}\text { Institutions' } \\
\text { size and } \\
\text { research } \\
\text { capacity } \\
\text { (universities) }\end{array}$} & $\begin{array}{l}\text { Number of students per } \\
\text { faculty }\end{array}$ & -0.18 & -0.13 & $-0.35^{*}$ & 0.16 & 0.24 \\
\hline & $\begin{array}{l}\text { Total enrolled students in } \\
\text { fall } 2009\end{array}$ & 0.07 & 0.20 & 0.10 & 0.05 & 0.09 \\
\hline & $\begin{array}{l}\text { Total enrolled graduate } \\
\text { students in fall } 2009\end{array}$ & $0.35^{*}$ & $0.43 * *$ & $0.43 * *$ & -0.15 & -0.16 \\
\hline
\end{tabular}

Note: $*$ p-value $<0.1, * *$ p-value $<0.05$

The age of a technology licensing office was positively related to research performance and total number graduate students. Similarly, institutions with better performance in research had larger TLO staffs. Average licensing efficiency was positively related to the two research performance variables. On the other hand, significant relationships among licensing performance changes, the Malmquist Index, and other research- and size-related variables were not observed.

\subsubsection{Regression of Six Licensing Outcome Variables to the Characteristics Variables}

The six licensing outcome variables were regressed to expenditure and characteristics variables, including journal articles, average rankings (higher is better), private status, 
and presence of a medical school. The second model includes TLO variables such as TLO age, licensing FTEs in TLOs, and other FTEs in TLOs (Table 75). Private or public status and existence of a medical school were not significant, throughout all models. The journal articles were positively related to disclosure and start-up. The average ranking of an institution was related only to number of patents issued. More licensing FTEs were related to more licenses and options executed. On the other hand, older TLOs were related to more start-ups. 
Table 75: Regression of licensing outcomes to characteristic variables (four institution types excluded)

\begin{tabular}{|c|c|c|c|c|c|c|c|c|c|c|c|}
\hline \multirow{3}{*}{ Variables } & \multicolumn{11}{|c|}{ Cumulative Licensing Outcomes } \\
\hline & \multicolumn{2}{|c|}{ Disclosure } & \multicolumn{2}{|c|}{$\begin{array}{c}\text { Patent } \\
\text { Applications }\end{array}$} & \multicolumn{2}{|c|}{ Patents Issued } & $\begin{array}{c}\text { Licenses anc } \\
\text { Options } \\
\text { Executed }\end{array}$ & \multicolumn{2}{|c|}{ Start-Ups } & \multicolumn{2}{|c|}{$\begin{array}{l}\text { Licensing } \\
\text { Income }\end{array}$} \\
\hline & $\begin{array}{c}\text { Model } \\
1\end{array}$ & $\begin{array}{c}\text { Model } \\
2\end{array}$ & $\begin{array}{c}\text { Model } \\
1\end{array}$ & $\begin{array}{c}\text { Model } \\
2\end{array}$ & $\begin{array}{c}\text { Model } \\
1\end{array}$ & $\begin{array}{c}\text { Model } \\
2\end{array}$ & $\begin{array}{c}\text { Model } \\
1\end{array}$ & $\begin{array}{c}\text { Model } \\
2\end{array}$ & $\begin{array}{c}\text { Model } \\
1\end{array}$ & $\begin{array}{c}\text { Model } \\
2\end{array}$ & $\begin{array}{c}\text { Model } \\
1 \& 2\end{array}$ \\
\hline Expenditure & $0.65 * *$ & $0.40 * *$ & $0.82 * *$ & $0.71 * *$ & $0.66 * *$ & $0.41 * *$ & $0.71 * *$ & $0.38 * *$ & $0.46 * *$ & 0.19 & - \\
\hline $\begin{array}{l}\text { Journal } \\
\text { Articles }\end{array}$ & $0.26 *$ & 0.22 & 0.13 & 0.10 & 0.21 & 0.15 & 0.13 & 0.10 & $0.36 * *$ & $0.26^{*}$ & - \\
\hline $\begin{array}{l}\text { Average } \\
\text { Ranking }\end{array}$ & 0.13 & 0.05 & 0.05 & 0.01 & $0.24 *$ & 0.16 & 0.10 & 0.00 & $0.31^{*}$ & 0.20 & - \\
\hline $\begin{array}{l}\text { Private } \\
\text { Status }\end{array}$ & 0.11 & 0.10 & 0.10 & 0.09 & 0.10 & 0.09 & 0.15 & 0.17 & 0.07 & 0.03 & - \\
\hline $\begin{array}{l}\text { Medical } \\
\text { School }\end{array}$ & -0.08 & -0.16 & -0.15 & -0.17 & -0.08 & -0.14 & 0.06 & -0.06 & -0.12 & -0.17 & - \\
\hline $\begin{array}{l}\text { Technology } \\
\text { Licensing } \\
\text { Office Age }\end{array}$ & & 0.18 & & 0.14 & & 0.23 & & 0.08 & & $0.43 * *$ & - \\
\hline $\begin{array}{l}\text { Licensing } \\
\text { Full-Time } \\
\text { Equivalents } \\
\text { in } \\
\text { Technology } \\
\text { Licensing } \\
\text { Office }\end{array}$ & & 0.23 & & 0.02 & & 0.14 & & $0.32 * *$ & & 0.14 & - \\
\hline $\begin{array}{l}\text { Other Full- } \\
\text { Time } \\
\text { Equivalents } \\
\text { in } \\
\text { Technology } \\
\text { Licensing } \\
\text { Offices }\end{array}$ & & 0.12 & & 0.05 & & 0.14 & & 0.26 & & 0.05 & - \\
\hline $\begin{array}{l}\text { Adjuste } \\
\mathrm{d} R^{2}\end{array}$ & $0.56^{* *}$ & $0.72 * *$ & $0.69 * *$ & $0.74 * *$ & $0.60 * *$ & $0.68 * *$ & $0.62 * *$ & $0.79 * *$ & $0.48 * *$ & $0.67 * *$ & - \\
\hline
\end{tabular}

Note: ${ }^{*}$ p-value $<0.1,{ }^{* *}$ p-value $<0.05$

The four institution types were added to the regression models above, as summarized in Table 76. Most results were similar to those of the previous regression models, except for the effect of existence of a medical school and average ranking. The existence of a 
medical school was negatively related to disclosure and patent applications. An additional significant effect of average ranking to patents issued was observed when institution types were considered. The presence of a special-focus medical institution showed a positive effect on disclosure, whereas effects of other types were not significant. Other licensing FTE was also positively related to licenses and options executed. No significant relationship with licensing income was observed. 
Table 76: Regression of licensing outcomes to characteristic variables (four institution types)

\begin{tabular}{|c|c|c|c|c|c|c|c|c|c|c|c|}
\hline \multirow{3}{*}{ Variables } & \multicolumn{11}{|c|}{ Cumulative Licensing Outcomes } \\
\hline & \multicolumn{2}{|c|}{ Disclosure } & \multicolumn{2}{|c|}{$\begin{array}{c}\text { Patent } \\
\text { Applications }\end{array}$} & \multicolumn{2}{|c|}{ Patents Issued } & $\begin{array}{c}\text { Licenses and } \\
\text { Options } \\
\text { Executed }\end{array}$ & \multicolumn{2}{|c|}{ Start-Ups } & \multicolumn{2}{|c|}{$\begin{array}{l}\text { Licensing } \\
\text { Income }\end{array}$} \\
\hline & $\begin{array}{c}\text { Model } \\
1\end{array}$ & $\begin{array}{c}\text { Model } \\
2\end{array}$ & $\begin{array}{c}\text { Model } \\
1\end{array}$ & $\begin{array}{c}\text { Model } \\
2\end{array}$ & $\begin{array}{c}\text { Model } \\
1\end{array}$ & $\begin{array}{c}\text { Model } \\
2\end{array}$ & $\begin{array}{c}\text { Model } \\
1\end{array}$ & $\begin{array}{c}\text { Model } \\
2\end{array}$ & $\begin{array}{c}\text { Model } \\
1\end{array}$ & $\begin{array}{l}\text { Model } \\
2\end{array}$ & $\begin{array}{c}\text { Model } \\
1 \& 2\end{array}$ \\
\hline Expenditure & $0.55 * *$ & $0.37 * *$ & $0.75^{* *}$ & $0.69 * *$ & $0.57 * *$ & $0.37 * *$ & $0.63 * *$ & $0.36 * *$ & $0.35 * *$ & 0.14 & - \\
\hline $\begin{array}{l}\text { Journal } \\
\text { Articles }\end{array}$ & $0.32 \%$ & $0.30 *$ & 0.18 & 0.16 & 0.18 & 0.14 & 0.18 & 0.14 & $0.28 *$ & $0.25 *$ & - \\
\hline $\begin{array}{l}\text { Average } \\
\text { Ranking }\end{array}$ & $0.32 *$ & 0.17 & 0.17 & 0.11 & $0.16 * *$ & $0.34 * *$ & 0.24 & 0.09 & $0.60 * *$ & $0.12 * *$ & - \\
\hline Private Status & 0.18 & 0.17 & 0.15 & 0.13 & 0.15 & 0.14 & 0.19 & $0.21 *$ & 0.14 & 0.09 & - \\
\hline Medical School & -0.17 & $-0.23 *$ & $-0.21 *$ & $-0 . .22 *$ & -0.12 & -0.18 & 0.01 & -0.10 & -0.18 & $-0.23 *$ & - \\
\hline Universities & 0.15 & 0.14 & 0.12 & 0.08 & 0.17 & 0.17 & 0.00 & 0.09 & 0.32 & 0.24 & - \\
\hline $\begin{array}{l}\text { Medical } \\
\text { Research } \\
\text { Centers }\end{array}$ & -0.21 & -0.11 & -0.12 & -0.10 & -0.27 & -0.18 & -0.23 & -0.08 & -0.31 & -0.21 & - \\
\hline $\begin{array}{l}\text { Special-Focus } \\
\text { Institutions } \\
\text { (Medical) }\end{array}$ & $0.34 *$ & $0.34 *$ & 0.26 & 0.24 & 0.20 & 0.19 & 0.17 & 0.19 & 0.29 & 0.25 & - \\
\hline $\begin{array}{l}\text { Technology } \\
\text { Licensing } \\
\text { Office Age }\end{array}$ & & 0.17 & & 0.14 & & 0.16 & & 0.06 & & $0.35 *$ & \\
\hline $\begin{array}{l}\text { Licensing Full- } \\
\text { Time } \\
\text { Equivalents in } \\
\text { Technology } \\
\text { Licensing } \\
\text { Office }\end{array}$ & & 0.21 & & 0.01 & & 0.13 & & $0.31 * *$ & & 0.13 & \\
\hline $\begin{array}{l}\text { Other Full- } \\
\text { Time } \\
\text { Equivalents in } \\
\text { Technology } \\
\text { Licensing } \\
\text { Office }\end{array}$ & & 0.08 & & 0.02 & & 0.15 & & $0.24 *$ & & 0.05 & \\
\hline Adjusted $R^{2}$ & $0.64 * *$ & $0.74 * *$ & $0.72 * *$ & $0.71 * *$ & $0.66^{* *}$ & $0.71 * *$ & $0.65 * *$ & $0.80 * *$ & $0.60 * *$ & $0.73 * *$ & - \\
\hline
\end{tabular}

Note: ${ }^{*}$ p-value $<0.1, * *$ p-value $<0.05$

Values are standard coefficients. 


\subsubsection{Regression of Efficiency and Efficiency Changes to Characteristic Variables}

The average efficiency and Malmquist Index scores were regressed to the characteristic variables (Table 77). The existence of a medical school had a negative effect on average efficiency. TLO licensing-related FTE per expenditure was positively related to both efficiency and efficiency change. Other FTE per expenditure was related to higher efficiency. Private institutions showed positive effects on average efficiency change.

Table 77: Regression of efficiency and efficiency changes to characteristic variables (four institution types)

\begin{tabular}{lcc}
\hline \multirow{2}{*}{ Independent Variables } & \multicolumn{2}{c}{ Dependent Variable } \\
\cline { 2 - 3 } & Average Efficiency & Average Malmquist Index \\
\hline Total Number of Journal Articles From & 0.13 & 0.04 \\
1991 to 2007 & -0.12 & -0.11 \\
Average of Hospital, Medical, Science, & 0.21 & $\mathbf{0 . 2 7 *}$ \\
and Engineering Ranking & $\mathbf{- 0 . 3 4 * *}$ & -0.18 \\
Private or Public Status & 0.42 & 0.36 \\
Existence of a Medical School & 0.30 & 0.07 \\
Universities & 0.28 & 0.25 \\
Medical Research Centers & 0.21 & -0.02 \\
Special-Focus Institutions (Medical) & $\mathbf{0 . 3 4 *}$ & $\mathbf{0 . 6 1 * *}$ \\
Technology Licensing Office Age (2007 & & 0.16 \\
- year instituted) & $\mathbf{0 . 4 1 * *}$ & $0.54^{* *}$ \\
Technology Licensing Office Licensing & $0.55^{* *}$ & \\
Full-Time Equivalents per Expenditure & & \\
Technology Licensing Office Other & Full-Time Equivalents per Expenditure &
\end{tabular}

Note: ${ }^{*}$-value $<0.1,{ }^{* *}$-value $<0.05$

Values are standard coefficients. 


\subsection{Summary}

The significant correlations among the characteristics and licensing data are summarized in Table 78. All licensing data, except for licensing income, was positively related to TLO and research performance.

Table 78: Summary of correlations

\begin{tabular}{|c|c|c|c|c|c|c|}
\hline $\begin{array}{c}\text { Cumulative Time } \\
\text { Effect Neutralized } \\
\text { Licensing Variables } \\
\text { by Aggregated } \\
\text { Time-Lag }\end{array}$ & $\begin{array}{c}\text { Medical } \\
\text { School }\end{array}$ & $\begin{array}{c}\text { Technolog } \\
\text { y Licensing } \\
\text { Office Age }\end{array}$ & $\begin{array}{c}\text { Licensing Full- } \\
\text { Time Equivalents } \\
\text { in Technology } \\
\text { Licensing Office }\end{array}$ & $\begin{array}{c}\text { Other Full-Time } \\
\text { Equivalents in } \\
\text { Technology } \\
\text { Licensing Offices }\end{array}$ & $\begin{array}{c}\text { Average } \\
\text { Ranking }\end{array}$ & $\begin{array}{c}\text { Journal } \\
\text { Articles }\end{array}$ \\
\hline EXP & Positive & Positive & Positive & Positive & & Positive \\
\hline DIS & & Positive & Positive & Positive & Positive & Positive \\
\hline PTF & Positive & Positive & Positive & Positive & Positive \\
\hline PTI & Positive & Positive & Positive & Positive & Positive \\
\hline LOE & Positive & Positive & Positive & Positive & \\
\hline STU & & Positive & Positive & Positive & Positive & Positive \\
\hline LCI & & & & & & \\
\hline
\end{tabular}

Note: DIS $=$ number of disclosures, EXP $=$ research expenditure, $\mathrm{LCI}=$ licensing income, $\mathrm{LOE}=$ number

of licenses and options executed, PTF = number of U.S. patent applications, PTI = number of U.S. patents issued, STU = number of start-ups.

Results of regression of licensing data on research expenditure and other characteristics are summarized in Table 79. 
Table 79: Summary of the results of regression of licensing data

\begin{tabular}{|c|c|c|c|c|c|c|c|c|}
\hline $\begin{array}{l}\text { Cumulative } \\
\text { Time Effect } \\
\text { Neutralized } \\
\text { Licensing } \\
\text { Variables by } \\
\text { Aggregated } \\
\text { Time-Lag } \\
\text { (Dependent) }\end{array}$ & EXP & $\begin{array}{l}\text { Private } \\
\text { Status }\end{array}$ & $\begin{array}{l}\text { Medical } \\
\text { School }\end{array}$ & $\begin{array}{l}\text { Technology } \\
\text { Licensing } \\
\text { Office Age }\end{array}$ & $\begin{array}{l}\text { Licensing Full- } \\
\text { Time } \\
\text { Equivalents in } \\
\text { Technology } \\
\text { Licensing } \\
\text { Office }\end{array}$ & $\begin{array}{l}\text { Other Full- } \\
\text { Time } \\
\text { Equivalents } \\
\text { in } \\
\text { Technology } \\
\text { Licensing } \\
\text { Offices }\end{array}$ & $\begin{array}{l}\text { Average } \\
\text { Ranking }\end{array}$ & $\begin{array}{l}\text { Journal } \\
\text { Articles }\end{array}$ \\
\hline DIS & Positive & & Negative & & & & Positive & Positive \\
\hline PTF & Positive & & Negative & & & & & \\
\hline PTI & Positive & & & & & & Positive & \\
\hline LOE & Positive & & & & Positive & Positive & & \\
\hline STU & Positive & & Negative & Positive & & & Positive & Positive \\
\hline LCI & & & & & & & & \\
\hline
\end{tabular}

Note: $\mathrm{DIS}=$ number of disclosures, $\mathrm{EXP}=$ research expenditure, $\mathrm{LCI}=$ licensing income, $\mathrm{LOE}=$ number of licenses and options executed, PTF = number of U.S. patent applications, PTI = number of U.S. patents issued, STU $=$ number of start-ups.

Regression results of efficiency scores on characteristics are summarized in Table 80.

Table 80: Summary of the results of regression of efficiency and efficiency change

\begin{tabular}{|c|l|l|l|l|l|l|l|}
\hline $\begin{array}{c}\text { Cumulative Time } \\
\text { Effect Neutralized } \\
\text { Licensing } \\
\begin{array}{c}\text { Variables by } \\
\text { Aggregated Time- } \\
\text { Lag (Dependent) }\end{array}\end{array}$ & $\begin{array}{c}\text { Private } \\
\text { Status }\end{array}$ & $\begin{array}{c}\text { Medical } \\
\text { School }\end{array}$ & $\begin{array}{c}\text { Technology } \\
\text { Licensing } \\
\text { Office Age }\end{array}$ & $\begin{array}{c}\text { Licensing Full- } \\
\text { Time } \\
\text { Equivalents per } \\
\text { Expenditure }\end{array}$ & $\begin{array}{c}\text { Other Full- } \\
\text { Time } \\
\text { Equivalents } \\
\text { per } \\
\text { Expenditure }\end{array}$ & $\begin{array}{c}\text { Average } \\
\text { Ranking }\end{array}$ & $\begin{array}{c}\text { Journal } \\
\text { Articles }\end{array}$ \\
\hline $\begin{array}{c}\text { Average } \\
\text { Efficiency }\end{array}$ & & Negative & & Positive & Positive & Positive & Positive \\
\hline $\begin{array}{c}\text { Average } \\
\text { Malmquist Index }\end{array}$ & Positive & & & Positive & & & \\
\hline
\end{tabular}




\section{Chapter 8. Conclusion}

\subsection{Discussion and Implications}

The implications of this study are discussed in this section.

\subsubsection{Licensing Time Lags and Licensing Strategy}

The individual time-lag relationships between two licensing variables are extended to multipath lag effects on licensing income as a final result of licensing activities. A summary of the time-lag effects is presented in Table 81.

Table 81: Time-lag effects for licensing

\begin{tabular}{|l|c|c|c|c|c|c|}
\hline & Expenditure & Disclosure & $\begin{array}{c}\text { Patent } \\
\text { Application }\end{array}$ & $\begin{array}{c}\text { Patent } \\
\text { Issued }\end{array}$ & $\begin{array}{c}\text { Licenses and } \\
\text { Options } \\
\text { Executed }\end{array}$ & Start-Up \\
\hline $\begin{array}{l}\text { Weighted average lag } \\
\text { duration } \\
\begin{array}{l}\text { Aggregated time lag } \\
\text { effect X time lag) }\end{array}\end{array}$ & 10.3 years & 8.8 & 6.7 & 7.3 & 3.3 & 3.5 \\
\hline $\begin{array}{l}\text { Lag durations with } \\
\text { high aggregated } \\
\text { coefficient value }\end{array}$ & $\begin{array}{c}5(0.09), \\
8(0.10)\end{array}$ & $\begin{array}{c}4(0.12), \\
5(0.11)\end{array}$ & $\begin{array}{c}3(0.21), \\
11(0.09)\end{array}$ & $\begin{array}{c}7(0.18), \\
8(0.20)\end{array}$ & $\begin{array}{c}3(0.50), \\
8(0.15)\end{array}$ & $\begin{array}{c}0(0.54), \\
8(0.30)\end{array}$ \\
\hline
\end{tabular}

The average lag from expenditure to licensing income throughout all possible paths is 10.3 years, and the most plausible lags, which have higher standard lag coefficient values, are $5(9 \%)$ and $8(10 \%)$ years. The overall lags range from 0 to 27 years. Time lags between disclosure and licensing income range from zero to 22 years, with an average of 
8.8 years. The time lag periods which have the highest effect from the disclosure to licensing income are $4(12 \%)$ and $5(11 \%)$ years.

Patent applications and patents issued have similar average lags -6.7 and 7.3 years, respectively. Licenses and options executed and start-up also have similar average lag periods -3.3 and 3.5 years, respectively. The average lags of the two licensing activities are smaller than any other lags. This is a reasonable result because these two variables represent actual licensing practice, which has a high correlation to licensing income.

Interesting observations can be made when the two time lags of the highest aggregated coefficients are selected for each licensing variable, as shown in Table 81. Although disclosure and patents issued have consecutive lags, two time lags of all others are far from each other. This might reflect different licensing paths among them.

The first path is a very attractive invention or technology for which a licensing opportunity is identified at an early stage of the licensing process. The three short lag periods of 5-year lags from expenditure, 3 years from patent, and 3 years from licenses and options exercised could be related to this pattern. The second pattern is a delayed or shelved invention [60]. There could be many reasons for delay. For example, a technology or disclosure may need further breakthrough, market needs may not be clear enough, faculty inventors may not be actively involved in licensing, or an academic institution may be conservative in licensing and negotiation [36, 51, 111]. 
The longer lags, such as 8 years from expenditure, 11 years from patent application, and 8 years from licenses and options exercised, could be associated with the second pattern. Start-up at $t-0$ has the highest effect on licensing. This is consistent with findings from other researchers $[23,55,114,121]$. Generally, universities prefer a short-term cash reward from a spin-off, rather than long-term royalty or equity.

The cumulative total time-lag effects are illustrated in Figure 41. The cumulative lags of start-up reflect two distinct license royalty strategies of spin-offs. The first $50 \%$ of start up is associated with long periods of 7 and 8 years, and the other half is related to zero or one year duration until royalties are collected. The longer period results from annual royalty or equity, which adds years before a new start-up generates revenues. In interviews with university licensing managers, Bray and Lee [23] found that it is not uncommon for a spin-off to take 8 years until it starts to generate revenue; it can take 10 years after licensing is negotiated, if the invention requires clinical trials. The shorter time lags represent the lump sum cash payment option, which occurs within a year or two. 


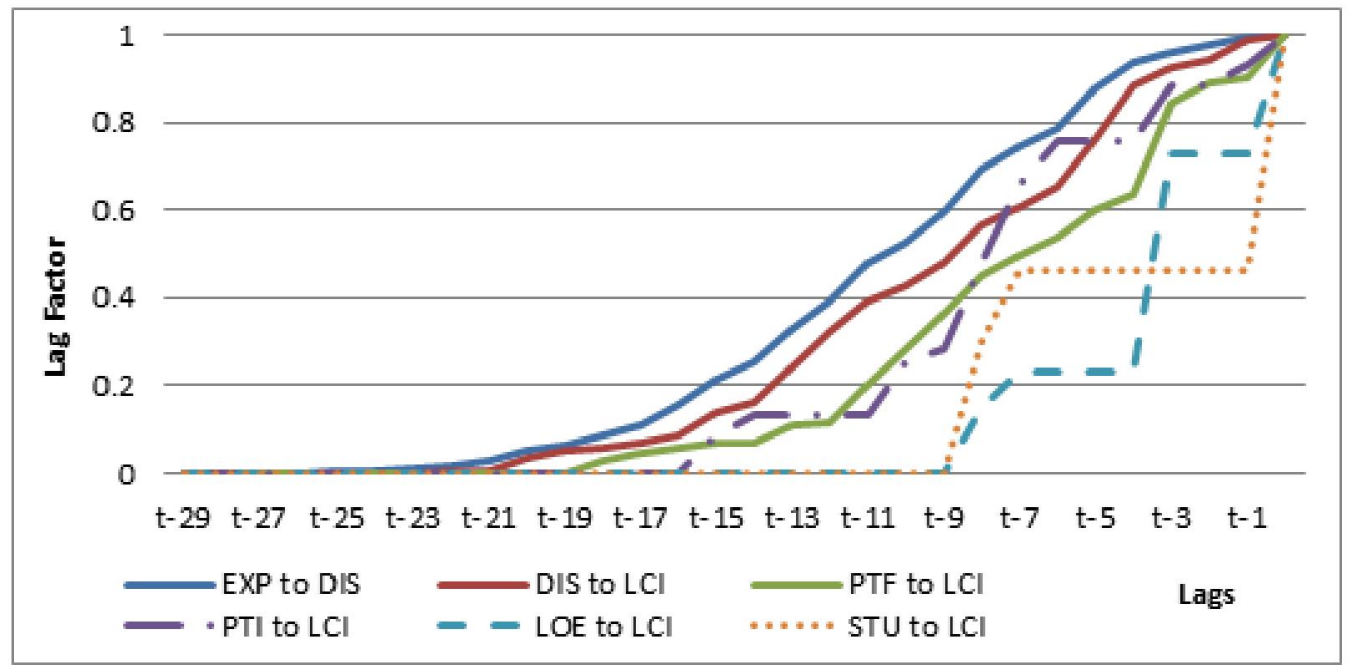

Figure 41: Cumulative time-lag effects

Three distinctive lag periods for licensing and options executed were observed: long term ( 8 to 7 years), medium term (3 to 4 years), and short term (up to 1 year). These lag periods are related to the royalty types that an institution receives from the license, such as equity, running royalty, and lump sum by an auction and up-front payment $[23,121]$.

In summary, research institution licensing offices should consider the time lags in licensing and incorporate these lags into their licensing strategy. Depending on the policy and financial goal of the university's licensing, the licensing office can develop a licensing portfolio for an invention so that the desirable cash flow of multiple licensing negotiations is achieved. This also suggests that university administrators and stakeholders outside of the university must understand that licensing is a time-consuming process. Therefore, they should not enforce a certain licensing format or apply a faculty reward system with a short time frame. 


\subsubsection{Relative Licensing Performance of Academic Research Institutions}

The overall licensing performance of the 46 universities examined is presented in Table 82. The average efficiency of all institutions during the period investigated is $0.65(\mathrm{SE})$, and they improved 33\% (MI) annually over the period. Although most scores show a small change every year, MI in 1992 and SE in 1993 show relatively higher scores because of the extremely high super-efficiency scores of Brigham Young University in 1993.

Table 82: Average scores of the 46 institutions by year

\begin{tabular}{|c|c|c|c|c|}
\hline $\begin{array}{c}\text { Year of } \\
\text { Expenditure }(t)\end{array}$ & $\begin{array}{c}\text { Average Super- } \\
\text { Efficiency at } t\end{array}$ & $\begin{array}{c}\text { Average } \\
\text { Efficiency } \\
\text { Change (From } t \\
\text { to } t+1 \text { ) }\end{array}$ & $\begin{array}{c}\text { Average } \\
\text { Technical } \\
\text { Change } \\
\text { (From } t \text { to } t+1 \text { ) }\end{array}$ & $\begin{array}{c}\text { Average } \\
\text { Malmquist Index } \\
\text { (From } t \text { to } t+1 \text { ) }\end{array}$ \\
\hline 1991 & 0.70 & 1.02 & 1.70 & 1.69 \\
\hline 1992 & 0.61 & 1.41 & 1.23 & 2.20 \\
\hline 1993 & 0.86 & 1.10 & 0.97 & 1.01 \\
\hline 1994 & 0.59 & 1.19 & 1.11 & 1.25 \\
\hline 1995 & 0.59 & 1.21 & 0.98 & 1.13 \\
\hline 1996 & 0.64 & 0.97 & 1.23 & 1.18 \\
\hline 1997 & 0.63 & 0.99 & 1.14 & 1.08 \\
\hline 1998 & 0.60 & 1.23 & 0.92 & 1.12 \\
\hline 1999 & 0.66 & - & - & - \\
\hline Average & 0.65 & 1.14 & 1.16 & 1.33 \\
\hline
\end{tabular}

Note: $t=$ time

Two distinct periods of performance change were observed, as illustrated in Figure 42. The average efficiency change scores of the 46 institutions were higher than the technical change scores from 1992 to 1995. This is the period dominated by the licensing 
performance of institutions that were catching up. During this period, inefficient institutions improved their performance significantly. On the other hand, the prominent performance improvements of the best practicing institutions occurred after this period.

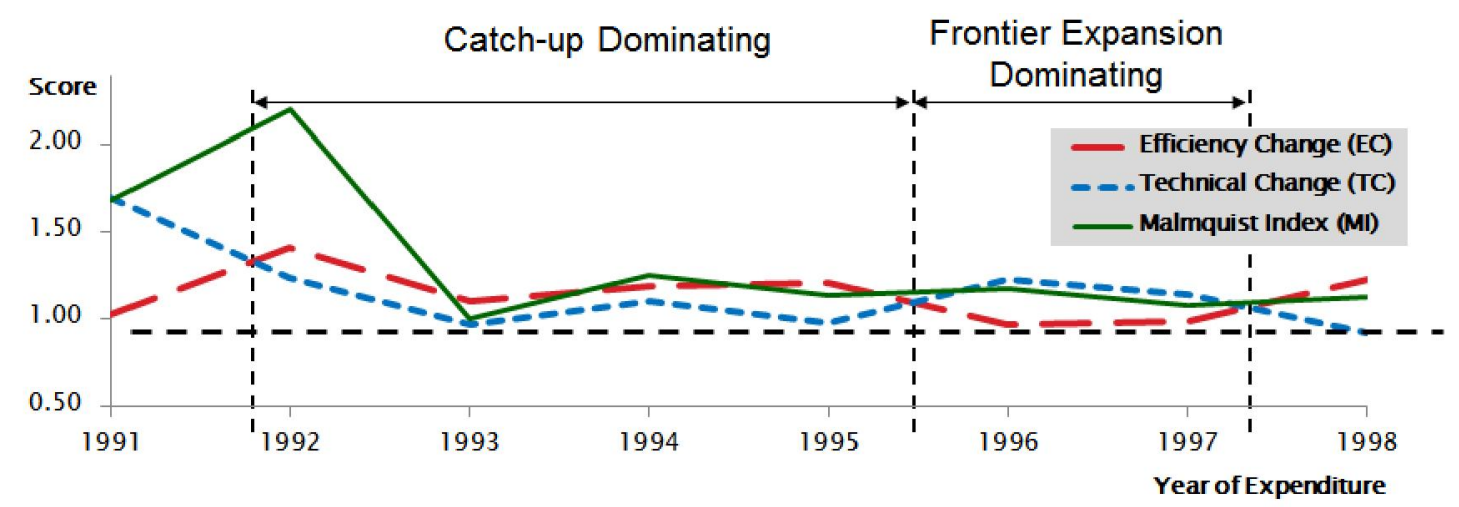

Figure 42: Catch-up and frontier expansion dominating periods

Figure 43 shows the location of the super-efficient $(\mathrm{SE} \geq 1)$ and inefficient $(\mathrm{SE}<1)$ institutions along the two dimensions of average super-efficiency scores and Malmquist Indexes. There were 7 super-efficient institutions, including (in the order of efficiency scores) Brigham Young University, the University of Akron, the Massachusetts Institute of Technology, City of Hope National Medical Center, California Institute of Technology, and Florida State University. The result is consistent with the best practicing universities identified by Thursby and Kemp [122], except for City of Hope, which is a research hospital.

These institutions have similar performance changes, although Brigham Young University improved significantly because the university had an extreme score in 1993. 
The licensing performances of Brigham Young University, the University of Akron, the Massachusetts Institute of Technology, and City of Hope were more than two times higher than that of other low-performance (inefficient) institutions.

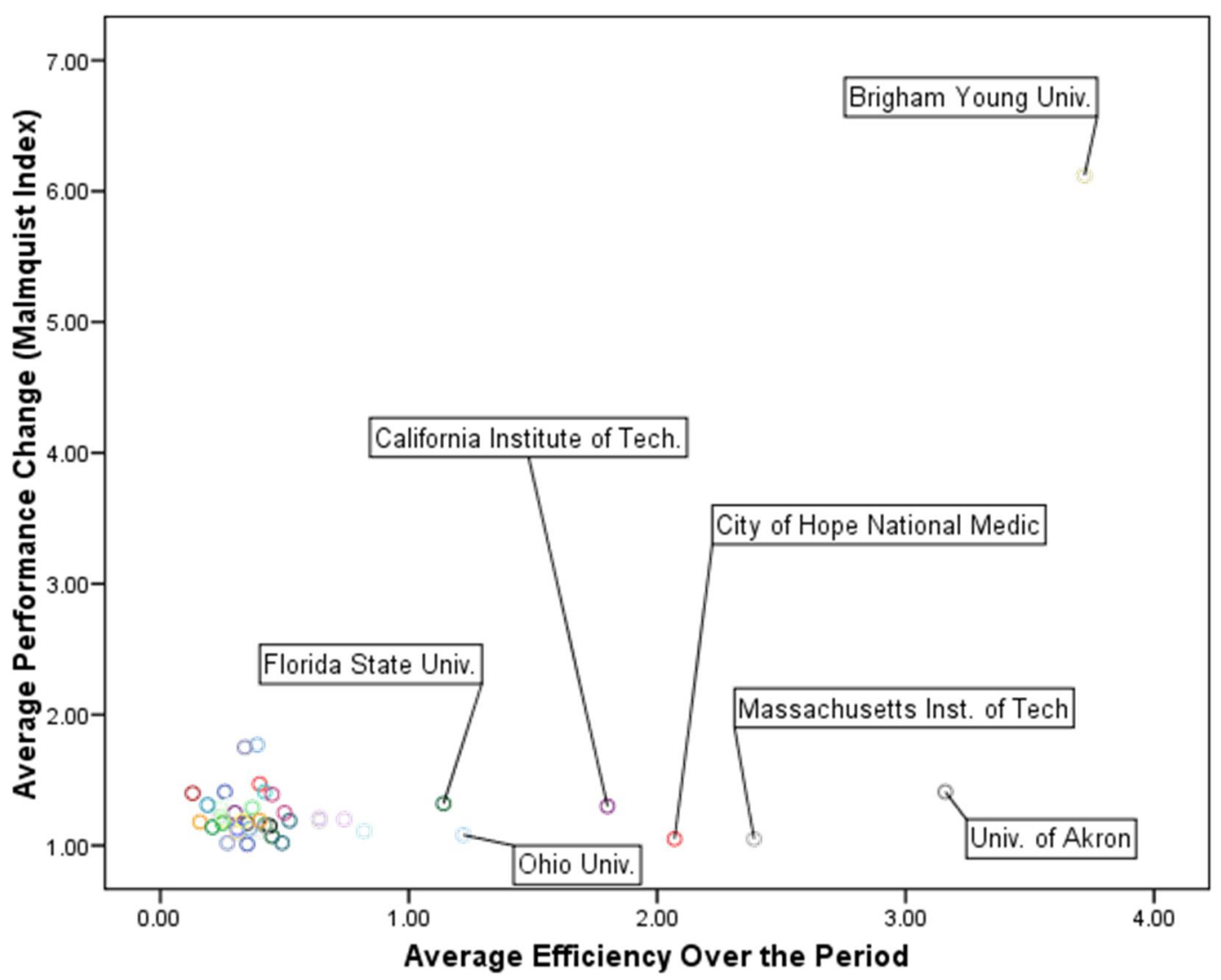

Figure 43: Average super-efficiency and efficiency change (Malmquist Index) of the 46 institutions

The Massachusetts Institute of Technology and the California Institute of Technology are prominent engineering schools that have very intensive research activity because of their higher research funding. Other studies $[6,62,122]$ also identified these schools as the best-performing universities in commercialization. City of Hope is a private teaching and 
research hospital, ranked number 17 in the area of cancer treatment in a 2010 national hospital ranking by US News. The hospital, established in 1913, is famous for its contribution to the development of synthetic human insulin in 1978 as well as for its dedicated comprehensive cancer center. In 2007, the institution had the highest licensing income of the 46 institutions, $\$ 118$ million. However, its average expenditure during the period was relatively low, $\$ 77$ million, which ranked 38 out of 46 . This is a good example of the licensing and commercialization effect of the medical and biotechnology areas. Florida State University is similar to City of Hope. The average expenditure of the university is low, ranked 30th, but its licensing income is high, ranked 4th.

On the other hand, three universities that had both low expenditure and low licensing income were identified as best-practicing institutions. The University of Akron, Ohio University and Brigham Young University had the lowest average research expenditures, ranked 44, 45, and 46, respectively. Their licensing income rankings are 39,37 , and 26 , respectively.

The 46 institutions are grouped by average super-efficiency scores and Malmquist Indexes, as presented in Table 83 and Table 84. 
Table 83: Low-efficiency group (39 institutions)

\begin{tabular}{|c|c|c|c|c|}
\hline \multirow[b]{2}{*}{$\begin{array}{l}\text { Malmquist } \\
\text { Index }\end{array}$} & \multicolumn{4}{|c|}{ Super-efficiency score } \\
\hline & $\begin{array}{c}<30 \% \\
\text { Exceptionally } \\
\text { Low Efficiency }\end{array}$ & $\begin{array}{l}<50 \% \\
\text { Very Low } \\
\text { Efficiency } \\
\end{array}$ & $\begin{array}{c}<70 \% \\
\text { Low Efficiency }\end{array}$ & $\begin{array}{c}<<9 \% \\
\text { Slightly Low } \\
\text { Efficiency }\end{array}$ \\
\hline $\begin{array}{c}<110 \% \\
\text { Low } \\
\text { Improvement }\end{array}$ & $\begin{array}{l}\text {-Clemson Univ. } \\
\text {-Tulane Univ. } \\
\text { (2) }\end{array}$ & $\begin{array}{l}\text { - Univ. of Cincinnati } \\
\text { - Univ. of Dayton } \\
\text { - Univ. of Southern } \\
\text { California } \\
\text { - Univ. of Virginia } \\
\text { Patent Fdn. } \\
\text { (4) }\end{array}$ & & \\
\hline $\begin{array}{c}<130 \% \\
\text { Medium } \\
\text { Improvement }\end{array}$ & $\begin{array}{l}\text { - Case Western } \\
\text { Reserve Univ. } \\
\text { - Colorado State } \\
\text { Univ. } \\
\text { - Fred Hutchinson } \\
\text { Cancer Res. } \\
\text { - Indiana Univ. } \\
\text { (ARTI) } \\
\text {-Univ. of Arizona } \\
\text { - Univ. of } \\
\text { Connecticut } \\
\text { Vanderbilt Univ. } \\
\text { (7) }\end{array}$ & $\begin{array}{l}\text { - Brigham \& } \\
\text { Women's Hospital, } \\
\text { Inc. } \\
\text { - Mayo Foundation } \\
\text { - Northwestern Univ. } \\
\text { - Ohio State Univ. } \\
\text { - Penn State Univ. } \\
\text { - Rutgers, The State } \\
\text { Univ. } \\
\text {-Univ. of Delaware } \\
\text {-Univ. of Iowa } \\
\text { Research Fdn. } \\
\text {-Univ. of Oregon } \\
\text {-Univ. of Texas } \\
\text { Southwestern } \\
\text { - Washington Univ. } \\
\text { (11) }\end{array}$ & $\begin{array}{l}\text { - Georgia Inst. of } \\
\text { Technology } \\
\text { - Harvard Univ. } \\
\text { - Johns Hopkins } \\
\text { Univ. } \\
\text {-Univ. of Minnesota } \\
\text { (4) }\end{array}$ & $\begin{array}{l}\text { - Michigan State } \\
\text { Univ. } \\
\text {-Univ. of Utah } \\
\text { (2) }\end{array}$ \\
\hline $\begin{array}{c}<150 \% \\
\text { High } \\
\text { Improvement }\end{array}$ & $\begin{array}{l}\text { - Baylor College of } \\
\text { Medicine } \\
\text { - National Jewish } \\
\text { Center } \\
\text { - Oregon State Univ. } \\
\text { - St. Jude Children's } \\
\text { Researc } \\
\text { (4) }\end{array}$ & $\begin{array}{l}\text {-Univ. of Maryland, } \\
\text { College } \\
\text {-Univ. of Michigan } \\
\text { - Wake Forest Univ. } \\
\text { (3) }\end{array}$ & & \\
\hline $\begin{array}{l}<200 \% \\
\text { Very High } \\
\text { Improvement }\end{array}$ & & $\begin{array}{l}\text { - Dartmouth College } \\
\text { - New Jersey } \\
\text { Institute of Tech. } \\
\text { (2) }\end{array}$ & & \\
\hline $\begin{array}{c}>200 \% \\
\text { Exceptional }\end{array}$ & & & & \\
\hline
\end{tabular}


Table 84: High-efficiency group (7 institutions)

\begin{tabular}{|c|c|c|c|c|}
\hline \multirow[b]{2}{*}{$\begin{array}{l}\text { Malmquist } \\
\text { Index }\end{array}$} & \multicolumn{4}{|c|}{ Super-efficiency score } \\
\hline & $\begin{array}{c}<100 \% \\
\text { Good } \\
\text { Efficiency }\end{array}$ & $\begin{array}{c}<200 \% \\
\text { Super-Efficiency }\end{array}$ & $\begin{array}{c}<300 \% \\
\text { Very High } \\
\text { Super-Efficiency }\end{array}$ & $\begin{array}{r}\qquad>300 \% \\
\text { Exceptionally } \\
\text { High Super- } \\
\text { Efficiency }\end{array}$ \\
\hline $\begin{array}{c}<110 \% \\
\text { Low } \\
\text { Improvement }\end{array}$ & & $\begin{array}{l}\text {-Ohio Univ. } \\
\text { (1) }\end{array}$ & $\begin{array}{l}\text { - City of Hope } \\
\text { National Medic } \\
\text { - Massachusetts Inst. } \\
\text { of Tech } \\
\text { (2) }\end{array}$ & \\
\hline $\begin{array}{l}<130 \% \\
\text { Medium } \\
\text { Improvement }\end{array}$ & & $\begin{array}{l}\text {-California Institute } \\
\text { of Tech. } \\
\text { (1) }\end{array}$ & & \\
\hline $\begin{array}{c}<150 \% \\
\text { High } \\
\text { Improvement }\end{array}$ & & $\begin{array}{l}\text {-Florida State Univ. } \\
\text { (1) }\end{array}$ & & $\begin{array}{l}\text {-Univ. of Akron } \\
\text { (1) }\end{array}$ \\
\hline $\begin{array}{l}<200 \% \\
\text { Very High } \\
\text { Improvement }\end{array}$ & & & & \\
\hline $\begin{array}{r}>200 \% \\
\text { Exceptional }\end{array}$ & & & & $\begin{array}{l}\text { - Brigham Young } \\
\text { Univ. } \\
\text { (1) }\end{array}$ \\
\hline
\end{tabular}

\section{A. Top Research Institutions with Low Licensing Performance}

The research intensity and licensing performance of prestigious research universities are compared to explore the reasons for the differences in licensing performance. For this purpose, research intensity is defined as a ratio of publications per unit of expenditure to number of students per faculty. Generally, the ratio of students to faculty is used as an indicator of available time and effort that a faculty may use to focus on his or her research. Journal publications relative to research expenditure are used as an approximation of research performance. The research intensity of the six universities and their licensing activity are compared in Table 84. 
Table 85: Research and licensing activity of top research institutions

\begin{tabular}{|c|c|c|c|c|c|c|c|}
\hline \multirow{2}{*}{\multicolumn{2}{|c|}{ Institutions }} & \multicolumn{3}{|c|}{ Research Activity } & \multicolumn{3}{|c|}{ Licensing Activity } \\
\hline & & \multirow{2}{*}{$\begin{array}{c}\text { Number of } \\
\text { students per } \\
\text { faculty (a) }\end{array}$} & \multirow{2}{*}{$\begin{array}{c}\begin{array}{c}\text { Journal } \\
\text { publications } \\
\text { per unit of } \\
\text { research } \\
\text { expenditure } \\
\text { (b) }\end{array} \\
132.80\end{array}$} & \multirow{2}{*}{$\begin{array}{c}\begin{array}{c}\text { Research } \\
\text { Intensity } \\
\text { (b)/(a) }\end{array} \\
44.27\end{array}$} & \multirow{2}{*}{\begin{tabular}{|c|} 
Technolog \\
y licensing \\
office age \\
(2007 - \\
year \\
instituted) \\
\\
29 \\
\end{tabular}} & \multirow{2}{*}{\begin{tabular}{|c}
$\begin{array}{c}\text { Licensing } \\
\text { full-time } \\
\text { equivalents } \\
\text { per unit of } \\
\text { expenditur } \\
\text { e }\end{array}$ \\
0.05
\end{tabular}} & \multirow{2}{*}{$\begin{array}{c}\begin{array}{c}\text { Licensing } \\
\text { full-time } \\
\text { equivalents } \\
\text { per total } \\
\text { disclosure* }\end{array} \\
1.80\end{array}$} \\
\hline $\begin{array}{l}\text { Super-Efficient } \\
\text { and Excellent } \\
\text { Research }\end{array}$ & $\begin{array}{l}\text { California } \\
\text { Institute of } \\
\text { Technology }\end{array}$ & & & & & & \\
\hline $\begin{array}{l}\text { Performance } \\
\text { Institutions } \\
(100 \% \leq \\
\text { Super- }\end{array}$ & $\begin{array}{c}\text { Massachuset } \\
\text { ts Institute } \\
\text { of } \\
\text { Technology }\end{array}$ & 8 & 23.04 & 2.88 & 67 & 0.05 & 5.60 \\
\hline Efficiency) & Average & 5.50 & 77.92 & 14.17 & 48.00 & 0.05 & 3.70 \\
\hline \multirow{5}{*}{$\begin{array}{l}\text { Inefficient but } \\
\text { Good Research } \\
\text { Performance } \\
\text { Institutions } \\
(50 \% \leq \text { Super- } \\
\text { Efficiency }< \\
70 \%)\end{array}$} & $\begin{array}{c}\text { Georgia } \\
\text { Inst. of Tech }\end{array}$ & 18 & 86.29 & 4.79 & 17 & 0.05 & 5.70 \\
\hline & $\begin{array}{c}\text { Harvard } \\
\text { Univ. }\end{array}$ & 7 & 44.37 & 6.34 & 30 & 0.02 & 5.90 \\
\hline & $\begin{array}{l}\text { Johns } \\
\text { Hopkins } \\
\text { Univ. }\end{array}$ & 11 & 11.27 & 1.02 & 34 & 0.01 & 4.10 \\
\hline & $\begin{array}{l}\text { Univ. of } \\
\text { Minnesota }\end{array}$ & 21 & 40.12 & 1.91 & 50 & 0.12 & 16.30 \\
\hline & Average & 11.33 & 56.31 & 4.97 & 37.83 & 0.05 & 8.00 \\
\hline
\end{tabular}

Note: $*=$ The number of the licensing full-time equivalents per total disclosure $=1,000 \mathrm{~s}$

Four institutions have potential to improve their licensing performance: the Georgia Institute of Technology, Harvard University, Johns Hopkins University, and the University of Minnesota. With high research expenditures (among the top 10 for expenditure out of the 46 institutions) and excellent academic reputations, these institutions are located in the same group of low efficiency (efficiency scores between 50\% and $70 \%$ ) and medium improvement (Malmquist Indexes between $110 \%$ and $130 \%$ ), whereas some other research universities, including the California Institute of 
Technology and the Massachusetts Institute of Technology, which also have excellent academic reputations, demonstrate super-efficient licensing performance.

The California Institute of Technology has outstanding research intensity and licensing performance. The superiority of its licensing performance is a result of its research performance in science and engineering, which advances technologies for commercial purposes. The other super-efficient licensing university, the Massachusetts Institute of Technology, has a research intensity similar to that of inefficient universities Johns Hopkins University and the University of Minnesota. The research expenditure of Johns Hopkins is the highest among the 46 institutions.

Although the 2011 medical school rankings place Johns Hopkins University first and Harvard University third, their engineering school rankings are 26th (Johns Hopkins) and 18th (Harvard). The reason for the lagging licensing performance of the two universities is their focus on medical and life sciences rather than engineering. This is supported by the finding that a university with a medical school has lower licensing performance than a university without a medical school. The licensing FTEs per expenditure of Harvard University and Johns Hopkins University are relatively smaller than that of the superefficient universities but similar to the level of licensing FTEs per disclosure of the Massachusetts Institute of Technology. This implies that the licensing offices of the two inefficient universities have the capability to deal with the disclosure for licensing, but not enough licensing experts, given their research scale. Therefore, more licensing 
professionals in the medical and life sciences area would significantly improve their licensing performance.

The Georgia Institute of Technology shows no difference from the Massachusetts Institute of Technology in either research activity or licensing efforts, except for the age of the licensing office. The licensing office of Georgia Tech has the shortest history among the six universities listed in Table 85, and its age is lower than the average age, 23 years, among all 46 institutions. Thus, it can be inferred that, for a long period, the university did not have a strong policy supporting licensing, even after the U.S. government emphasized technology transfer from universities with the Bayh-Dole Act of 1980. The lower annual efficiency change of $21 \%$, which is less than the average of $33 \%$ for the 46 institutions, shows that their licensing practice did not improve significantly compared with other institutions, even though they had a similar levels of TLO staff. Therefore, the inefficient licensing performance is related to their lack of experience and past lack of strong policies supporting licensing, rather than to insufficient research performance or licensing staff.

On the other hand, the University of Minnesota has a greater number of licensing staff but lower licensing performance. The research intensity of the university is similar to that of Johns Hopkins University and the Massachusetts Institute of Technology, but the number of students per faculty is very high compared with the others. Lach and Schankerman [64] found that university faculty size is positively related to license 
income. This implies that, although the research performance of the University of Minnesota is not low, its faculty is suffering from a lack of time to actively engage in licensing activity. Therefore, university support to secure faculty time to collaborate with industry and the licensing office, as well as a reward system for faculty contributions to commercialization, are recommended [114].

The licensing gaps between the two groups cannot be reduced without significant improvement in the licensing practices universities support, even though the inefficient universities have high potential based on excellent research performance.

\section{B. Medium-Level Research Institutions with Low Licensing Performance}

Michigan State University and the University of Utah, which are ranked 17 and 22 in research expenditure, respectively, are located in the same position of slightly low efficiency scores and medium licensing improvement. Dartmouth College and the New Jersey Institute of Technology, which have very low research expenditure as numbers 35 and 42 out of the 46 institutions, improved licensing performance significantly while still having very low efficiency. Their best engineering school rankings in 2011 are between 50 and 100. Although according to their rankings they are similar in terms of academic prestige, their licensing performances are quite different (Table 86). 
Table 86: Research and licensing activity of research institutions with low school rankings (50 to 100)

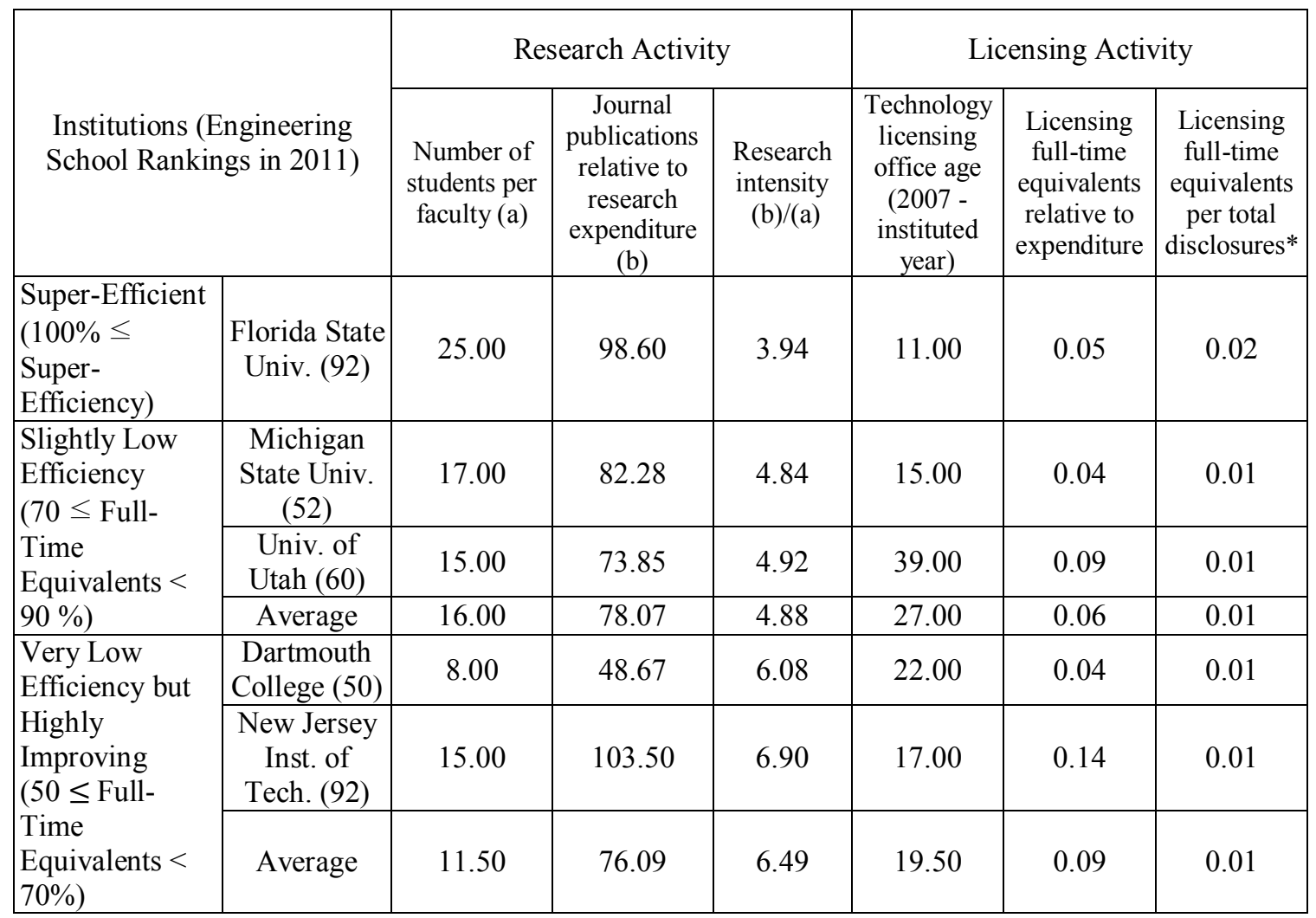

Note: $*=$ The number of the licensing full-time equivalents per total disclosure $=1,000 \mathrm{~s}$

The differences between the slightly low-efficient and very low-efficient groups in research and licensing activity are not clear. However, if the annual changes in licensing FTEs are considered, the difference becomes obvious (Figure 44). The slightly lowefficient universities have increased their licensing staffs significantly so that they are similar to or greater than the average of the 46 institutions. On the other hand, the licensing FTEs of the very low-efficient universities have stayed at a similar level over the years. This implies that the University of Utah and Michigan State University have continuous support for licensing and have emphasized licensing activity. 


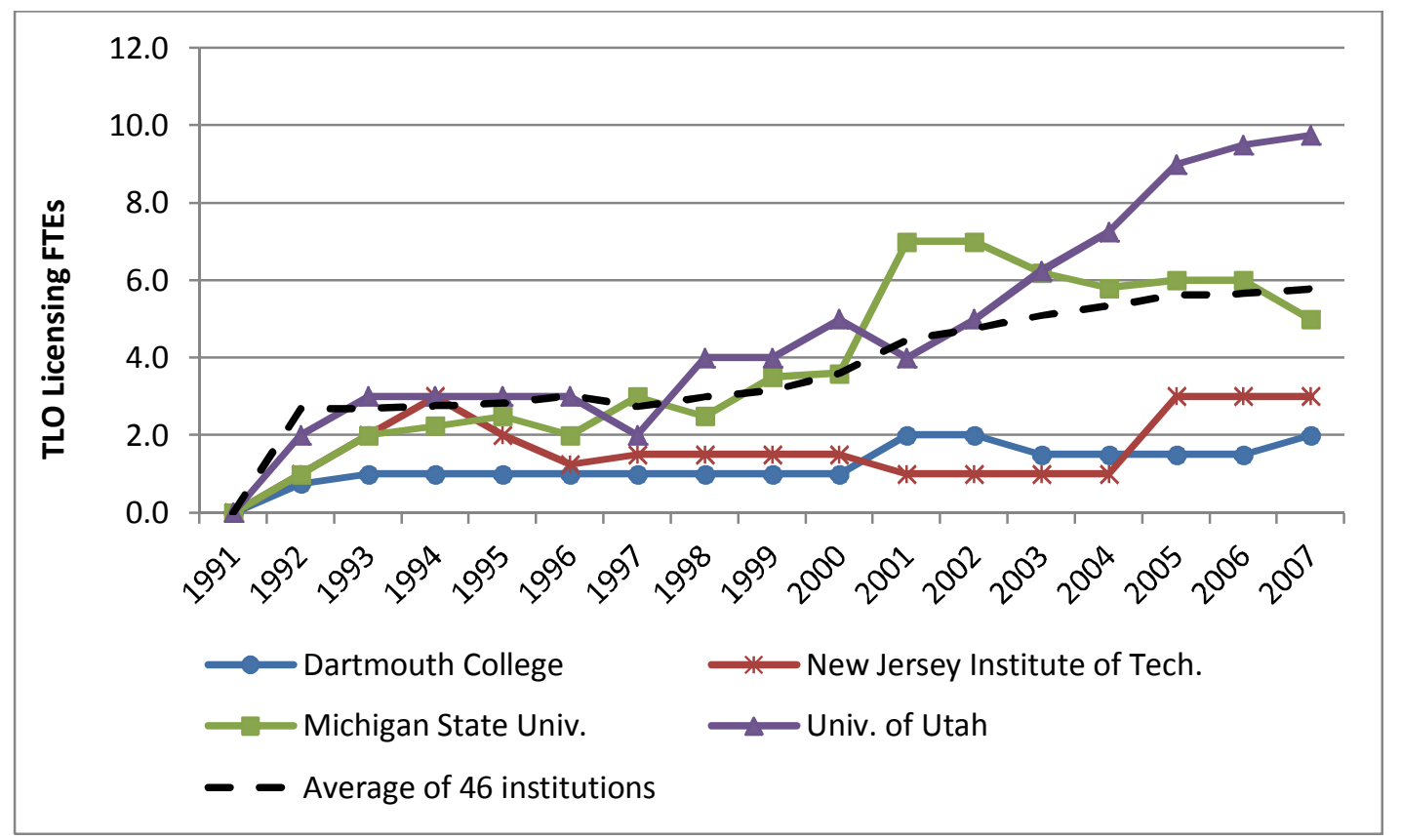

Figure 44: Technology licensing offices' full-time equivalents for slightly efficient and lowefficiency universities

The Malmquist Index shows that the very low-efficiency group, Dartmouth College and the New Jersey Institute of Technology, have greatly improved their licensing performance. However, their effort was not superior to the other two universities with a similar level of academic prestige. Considering the shorter history of licensing offices at the very low-efficiency universities, the significant improvement reflects their late engagement in licensing. Therefore, even though the efficiency changes of the two universities demonstrate their improvement, more significant catch-up to the other, superior universities would not be possible without further investment through their licensing offices. 


\section{Low-Level Research Institutions with Very Low Licensing Performance}

This study also found that a less prestigious university with small research expenditure can achieve significant licensing outcomes. The engineering schools of Ohio University, the University of Akron, and Brigham Young University are ranked 138, 125, and 107, respectively, but they are identified as a super-efficient licensing group. This suggests that a university with a prestigious reputation or low research expenditure can improve its licensing performance.

\subsubsection{Licensing Practices and Related Characteristics of Academic Research Institutions}

\section{A. Institution Types and Licensing}

Only certain differences in licensing data are observed among the institution types. Universities and special-focus medical institutions have more disclosures than others. When universities and non-universities are compared, universities have more start-ups than non-universities. This might be due to universities' greater human resources in the form of students and faculty. Universities, in particular, encourage student entrepreneurs to create spin-offs and involve faculty in new start-ups.

However, caution is needed when these results are associated with institution types, because only a small number of cases ( 9 out of 46) are involved with non-university institutions. 


\section{B. Research Performance, Academic Prestige, and Licensing Performance}

Siegel, et al. [113] suggested that a trade-off exists between university technology commercialization and research performance. On the other hand, some other studies found that higher-quality faculty members, who may bring better-quality research, tend to be reluctant to spend their time in the commercialization of their findings [60]. If faculties get involved in commercialization activity, they may spend less effort or time on their primary duties of teaching and research [96].

The present study found that licensing variables have a positive correlation with TLO variables, ranking, and journal articles. Journal articles and average ranking indirectly reflect research intensity and its quality. The results show that an institution with high research performance has more disclosures and start-ups. Moreover, a better-thanaverage ranking is significantly related to more patents issued. This shows that patents issued (though not patent applications) reflect the quality of inventions. The effect of the existence of a medical school on disclosure, patent applications, and start-up is negative. This shows that, although a medical school spends more research funds, the quantity of new inventions is relatively small, resulting in fewer start-ups.

One surprising result is that academic prestige, as measured by academic ranking, is negatively related to both licensing efficiency and efficiency change. However, the study also found that not only highly prestigious instructions such as the California Institute of Technology and the Massachusetts Institute of Technology but also less prestigious ones 
with lower research expenditure presented high licensing performance. Considering that most of the super-efficient institutions are prestigious ones, the result does not strongly prove that less-prestigious institutions have better licensing performance. Instead, it can be understood that not all prestigious institutions emphasize licensing, and therefore they could improve their performance significantly. Another possible interpretation is that the negative relationships reflect the dominant catch-up efforts of less-efficient institutions, which was observed in 6. Baldini, et al.'s [11] study found that institution size relative to total budget does not have a statistically significant relationship with patents. Therefore, an effective licensing process and organizational support are very important to achieving better licensing performance.

C. Effort, Age, and Licensing Performance of Technology Licensing Offices

The results of the present study support the findings of other studies [111] [96] [121] [76] [64] [47]. Although the effect of a TLO's age on efficiency and efficiency change is not statistically significant, TLO licensing FTEs and other FTEs relative to expenditure contribute to better licensing performance. The study also confirms that TLO age is associated with the number of start-ups. TLO age represents the history of a TLO and therefore its experience. A more experienced TLO with a long history presents good support for start-ups. However, more human resources (licensing and other FTEs), rather than experience (TLO age), are related to more licenses and options executed. This supports the idea that TLO size is important to an institution's successful licensing negotiation. 


\section{Institutions' Private or Public Status and Licensing Performance}

The results also show that private institutions are more active than public institutions in licensing and that their performance is therefore significantly higher.

\section{E. Existence of Medical School and Licensing Performance}

The results of the existing empirical studies of U.S. institutions on the effect of the presence of a medical school conflict with each other. Powers [96] and Thursby, et al. [121] found a positive but statistically insignificant relationship when licensing income was regressed. Anderson, et al. [6] and Thursby and Kemp [122] found that the existence of a medical school exerted a negative effect on licensing efficiency, whereas Siegel, et al.'s [111] study found the opposite effect on efficiency.

However, if these results and methods are compared carefully, as summarized in Table 87, it appears that the differences come from the methods employed. Powers [96] and Thursby, et al.'s [121] results are consistent in that the effect of a medical school on the quantity of licensing income is positive. However, the two other studies [6, 122], using

the same DEA method, both present a negative effect. These results show that a university with a medical school benefits from a greater amount of research funding and licensing income. Universities with medical schools also demonstrated the greatest range in profitability $[28,127]$. On the other hand, their relative licensing performances were 
not better than that of universities without a medical school. Regarding the insignificant effect of a medical school, Powers [96] mentioned, "While this result may seem counterintuitive, it is also true that many of the advances in the life sciences do not emerge from medical schools but rather from within arts and sciences units" (p. 40).

Table 87: Effect of the existence of a medical school in a university

\begin{tabular}{|c|c|c|c|c|}
\hline \multirow{2}{*}{ Literature } & \multicolumn{2}{|c|}{ Effect on Licensing Income } & \multicolumn{2}{|c|}{ Effect on Licensing Efficiency } \\
\hline & Result & Method & Result & Method \\
\hline Anderson, et al. [6] & & & $\begin{array}{l}\text { Negative } \\
\text { (insignificant) }\end{array}$ & $\begin{array}{l}\text { Data } \\
\text { envelopment } \\
\text { analysis }\end{array}$ \\
\hline Siegel, et al. [111] & & & $\begin{array}{l}\text { Positive } \\
\text { (insignificant) }\end{array}$ & $\begin{array}{l}\text { Stochastic } \\
\text { frontier } \\
\text { efficiency }\end{array}$ \\
\hline Powers [96] & $\begin{array}{l}\text { Positive } \\
\text { (insignificant) }\end{array}$ & Regression & & \\
\hline Thursby, et al. [121] & $\begin{array}{l}\text { Positive } \\
\text { (insignificant) }\end{array}$ & Regression & & \\
\hline $\begin{array}{l}\text { Thursby and Kemp } \\
{[122]}\end{array}$ & & & $\begin{array}{l}\text { Negative } \\
\text { (significant) }\end{array}$ & $\begin{array}{l}\text { Data } \\
\text { envelopment } \\
\text { analysis }\end{array}$ \\
\hline
\end{tabular}

The results show that an institution with a medical school obtains more research funding, which has a statistically significant and negative effect on efficiency scores. Also, an institution with a medical school showed less improvement in efficiency scores during the period examined, but this result was not statistically significant. 


\subsubsection{Recommendations}

This section summarizes the finding and implications, presenting recommendations for licensing managers, university administrators, and governments as well as researchers interested in measuring the licensing performance of research institutions.

A. A university with a medical school

Many studies, including the present study, identified that a university with a medical school has lower licensing performance because it has relatively fewer licensing outcomes relative to its significant amount of research funding in the medical area. The lower licensing productivity of a medical school arises from several facts [97]:

1) Research in bioscience is difficult to license in the market, due to high manufacturing costs and production complexity.

2) Bioscience technologies require huge research and development investment and commercialization expenditures.

3) The technologies require government regulatory approval, which takes long a time and many resources, with no guarantee of approval.

4) Physicians and medical researchers are not motivated to engage in the commercialization process.

Therefore, a licensing office must develop a specific screening and marketing process for a bioscience technology. A well-structured assessment and screening process in the early stage of commercialization will reduce the risk inherent in the study of bioscience 
technology and will promote funding opportunities for the further investment required for commercialization. A licensing staff specialized in the medical area is essential to the success of the process.

Although it is necessary for a licensing office to improve its process of commercializing bioscience technologies, the nature of R \& D in a medical school should be considered when its licensing performance is evaluated. Considering the uniqueness of the licensing practice in a medical school, the licensing performance of a medical school should be separated from that of other science and engineering departments when a benchmarking study is done for multiple universities.

B. Public and private status of an institution and its licensing practice The study indicates that a private university has better licensing than a public one. As Powers [96] described in detail, a private university has more flexibility in terms of organization structure and operations in its budget, which enables the university to adapt itself to a new policy and environment. Although a private university is financially more independent from state government, it relies more on student tuitions and other revenue to secure its budget. As a result, technology licensing and commercialization have been considered important financial resources since the Bayh-Dole Act of 1980 allowed universities to obtain benefit from licensing. The changes of private institutions' licensing efficiency observed in this this study justify their motivation and effort. 
On the other hand, public schools are limited in the ways they may secure and manage their budget for their own purposes while also getting support from a state government. The allocation and management of their revenue are controlled heavily by the government. This financial dependency, an insufficient reward system, and a rigid organizational structure make it difficult to motivate faculties to actively engage in licensing practice. Without significant changes in policies and budget operations on the part of both universities and government, licensing practice will to some extent be limited.

\section{Organizational environment encouraging faculty engagement}

This study reveals that, given the same level of research and licensing activity, some institutions had higher licensing productivity than others. One characteristic is faculty time for research, observed by looking at the number of students per faculty member. Although this study is limited in identifying detailed organizational and personal aspects relative to licensing practice, other studies have provided evidence and insight on these topics. Based on the findings from this and other research [114], the following organizational and personal policies to promote licensing activity are recommended:

1) An appropriate reward system should be applied to motivate and compensate an inventor for his or her engagement.

2) Depending on an institution's goals and commercialization preferences, an inventor should be allowed to devote his or her time to licensing activity.

3) An institution should not be too aggressive in exercising intellectual property rights. However, there is a trade-off between aggressive and flexible exercise of 
rights. Aggressive practice reduces the number of licensing agreements but increases revenue from the agreements [111]. Therefore, the potential value of the technology should be considered along with institutional direction for the use of intellectual property.

4) Institutions' perception of licensing should be changed. A licensing exercise should not be considered a trade-off between teaching and research. Also, there still exists a common misunderstanding that capitalizing on technology that was funded by the public limits the public good.

D. Appropriate licensing office skills and resources

Results indicate that licensing offices' history and staff are related to better licensing performance. Given the same research performance and inventor involvement, the success of commercialization relies on the staff's available time, expertise in the technology area, and marketing and negotiation skills. 


\subsection{Contributions}

The present study outlines an approach for assessing the licensing performance of academic research institutions over time and explores these performances with regard to related institutional characteristics. For this purpose, the study developed two new methods: a time-lag identifying process using a distributed lag model and an unstructured regression coefficient structure, and a three-stage modified super-efficiency DEA model resolving computational infeasibility and zero-data issues. The results provide stakeholders in government agencies, companies, research organizations, and other universities with a better understanding of licensing practices, filling in the gaps identified by the literature review.

\subsubsection{Time-Lag Effect (Gap 1)}

Time duration exists in licensing activity and outcomes because of the inherent processing time of the activities. Although most researchers acknowledge the time lag of variables in studies identifying the relationships between characteristics and outcomes (performance) of licensing, they don't apply time lags among the variables in their analysis. Some studies ignore the effect of the time lag and others use the average of the variables during the investigated period to mitigate the effect. However, if time lags are not incorporated into a model, caution is needed when interpreting the results [55]. With regard to their study measuring commercialization efficiencies of 112 U.S. universities, for example, Thursby and Kemp [122] commented, "We are mixing inputs and outputs from different points in time. To the extent that there are lags involved, our result must be 
considered with caution" (p. 114). To understand the practices and performance of academic research institution technology commercialization, time lags should be considered in the analysis.

The time-lag identifying process developed this study provides a better approach to measuring the possible time lags in licensing or commercialization. The time lags identified by the approach also could enable researchers to build a more elaborate and realistic model for evaluating academic research institution technology licensing.

\subsubsection{Measurement of Academic Research Institution Technology}

Commercialization Performance and Influencing Characteristics (Gaps 2, 3, and 4)

ARITC involves various ambiguous aspects. The perceptions, goals, policies, and regulations of an institution concerning technology commercialization could vary, along with the organizational specification. Indeed, different stakeholders, such as university administrators, faculty, and TLO managers, have different perceptions of the importance of commercialization outcomes. The heterogeneous characteristics surrounding ARITCs make it difficult to measure performance. Therefore, benchmarking studies are a widespread method in this area and can provide insights into the relative performance of ARITC practices.

Although the efficiency of a benchmarking study identifies best practitioners and inefficient institutions, there exists a limitation in implementing the results in the real 
world and in understanding the rational reasons for low or high efficiency. Therefore, additional analysis, such as regression, has been performed to explain the characteristics influencing efficiency. However, because the efficiency score created by stochastic frontier estimation or data envelopment analysis puts all unknown specifications of an institution into a single number, the identified relationships between the efficiency score and organizational characteristics also includes aspects that are ambiguous for interpretation and application in the real world.

The approach outlined in this study could overcome those limitations by exploring organizational characteristics and various aspects of efficiency (average efficiency, efficiency changes, technical changes, and Malmquist Index) over time. The approach provides insight into organizational practice and related polices and characteristics by examining their relationships with the efficiency and patterns of ARITC.

For this purpose, this study developed a three-stage super-efficiency VRS model, which overcomes the current limitations in DEA theory. First, the study resolves computational infeasibility caused by an extreme data point when variable returns to scale is applied. For this purpose, the strengths and limitations of the three current approaches $[33,66,70]$ have been discussed and the models have been tested using published data. Second, a nonradial model has been applied to deal with zero-data issues. 


\subsection{Assumptions}

Two types of assumptions have been made in this research: an assumption about the expert and an assumption about measurements and the models.

First, it is assumed that the expert is capable of identifying and understanding all technology licensing mechanisms and related licensing contracts and laws, and that one expert's perceptions and knowledge of the assigned area can represent the related activities of other institutions.

The second group of assumptions is made when developing the model and selecting variables. Such assumptions include the following:

1. The relative performance of technology licensing reflects different levels of practice and policy.

2. The selected outputs and inputs for the DEA models are broad enough to include all possible outcomes and resources.

3. Licensing efficiency could be different, and different performances can be understood in the context of efficiency changes and selected institutional variables.

4. The time-lag coefficients identified in this study represent lag effects common to all institutions. 


\subsection{Limitations}

Although this research sheds light on the efficiency and importance of ARITC, there also are inherent limitations, such as the following:

1. Institutions' policies for technology commercialization are not observed and measured, yet such policies and other related characteristics are expected to influence licensing efficiencies. Therefore, it is worth examining the overall relationship between efficiency and effectiveness, and identifying the organizational characteristics that influence them.

2. The time lags identified in this study are general and common differences observed from the data for the time period. The approach of the study is reasonable enough to observe general trends in commercialization and the performance of ARITC. However, some unique technology commercialization time lags cannot be explained.

3. The quality of the disclosures is related to faculty quality [60]. After the inventions are disclosed, faculty quality also will positively influence patents, licensing, and licensing income $[47,96]$. However, productive faculties inventing valuable technology, which has high potential in the market, are not always positively related to the more or better disclosure [60]. For instance, prominent faculty members may be reluctant to be involved in technology commercialization activity through disclosure and patenting of their inventions because they prefer 
conducting research and publishing their findings in journals $[60,96]$. The present study does not consider those characteristics.

\subsection{Future Work}

The following areas are suggested for future work.

1. Case studies of academic research institutions' technology commercialization practices could help increase model reliability and improve understanding of certain unique institutional situations that could not be observed in this study.

2. The licensing time lags identified in the study need to be explored further by using case studies of several academic research institutions.

3. This study explores a limited number of institutional characteristics that influence licensing performance. A dedicated survey could help to identify other characteristics that explain time lags and licensing performance. 


\section{References}

[1] Abbott W. F., "Prestige and goals in American universities," Social Forces, vol. 52 (3), pp. 401-407, 1974

[2] Abramson H. N., J. Encarnacao, P. P. Reid, and U. Schmoch, "Technology Transfer Systems in the United States and Germany." Washington, D.C.: National Academy Press, 1997.

[3] Acworth E. B., "University-industry engagement: The formation of the Knowledge Integration Community (KIC) model at the Cambridge-MIT Institute," Research Policy, vol. 37 (8), pp. 1241-1254, 2008

[4] Aigner D., C. A. K. Lovell, and P. Schmidt, "Formulation and estimation of stochastic frontier production function models," Journal of Econometrics, vol. 6 (1), pp. 21-37, 1977

[5] Almon S., "The Distributed Lag Between Capital Appropriations and Expenditures," Econometrica, vol. 33 (1), pp. 178-196, 1965

[6] Anderson T. R., T. U. Daim, and F. F. Lavoie, "Measuring the efficiency of university technology transfer," Technovation, vol. 27 (5), pp. 306-318 2007

[7] Arvanitis S., U. Kubli, and M. Woerter, "University-industry knowledge and technology transfer in Switzerland: What university scientists think about cooperation with private enterprises," Research Policy, vol. 37 (10), pp. 1865-1883, 2008

[8] Arvanitis S., N. Sydow, and M. Woerter, "Do specific forms of universityindustry knowledge transfer have different impacts on the performance of private enterprises? An empirical analysis based on Swiss firm data," The Journal of Technology Transfer, vol. 33 (5), pp. 504-533, 2008

[9] Audretsch D. B. and E. E. Lehmann, "Do university policies make a difference?," Research Policy, vol. 34 (3), pp. 343-347, 2005

[10] AUTM, "AUTM US and Canadian licensing survey, FY2006 survey summary," Association of University Technology Managers, 2007.

[11] Baldini N., R. Grimaldi, and M. Sobrero, "Institutional changes and the commercialization of academic knowledge: A study of Italian universities' patenting activities between 1965 and 2002," Research Policy, vol. 35 (4), pp. 518-532, 2006

[12] Banker R. D., A. Charnes, and W. W. Cooper, "Some models for estimating technical and scale inefficiencies in data envelopment analysis," Management Science, vol. 30 (9), pp. 1078-1092, 1984

[13] Batten D. S. and D. L. Thornton, "Polynomial Distributed Lags and the Estimation of the St. Louis Equation," Federal Reserve Bank of St. Louis Review, pp. 13-25, 1983 
[14] Bekkers R. and I. M. Bodas Freitas, "Analysing knowledge transfer channels between universities and industry: To what degree do sectors also matter?," Research Policy, vol. 37 (10), pp. 1837-1853, 2008

[15] Benneworth P., "Academic entrepreneurship and long-term business relationships: Understanding 'commercialization' activities," Enterprise \& Innovation Management Studies, vol. 2 (3), pp. 225-237, 2001

[16] Bercovitz J., M. Feldman, I. Feller, and R. Burton, "Organizational structure as a determinant of academic patent and licensing behavior: An exploratory study of duke, Johns Hopkins, and Pennsylvania State Universities " The Journal of Technology Transfer, vol. 26 (1), pp. 21-35, 2001

[17] Bercovitz J. E. L. and M. P. Feldman, "Fishing upstream: Firm innovation strategy and university research alliances," Research Policy, vol. 36 (7), pp. 930948, 2007

[18] Bird B. J., D. J. Hayward, and D. N. Allen, "Conflicts in the commercialization of knowledge: perspectives from science and entrepreneurship," Entrepreneurship: Theory \& Practice, vol. 17 (4), pp. 57-77, 1993

[19] Blumenstyk G., "Colleges cash in on commercial activity," Chronicle of Higher Education, vol. 52 (15), pp. A25-A26, 2005

[20] Boardman C. P. and B. L. Ponomariov, "University researchers working with private companies," Technovation, vol. In Press, Corrected Proof, 2008

[21] Bozeman B., "Technology transfer and public policy: a review of research and theory," Research Policy, vol. 29 (4-5), pp. 627-655, 2000

[22] Bramwell A. and D. A. Wolfe, "Universities and regional economic development: The entrepreneurial University of Waterloo," Research Policy, vol. 37 (8), pp. 1175-1187, 2008

[23] Bray M. J. and J. N. Lee, "University revenues from technology transfer: Licensing fees vs. equity positions," Journal of Business Venturing, vol. 15 (5-6), pp. 385-392, 2000

[24] Carlsson B. and A.-C. Fridh, "Technology transfer in United States universities," Journal of Evolutionary Economics, vol. 12 (1/2), pp. 199-199, 2002

[25] Casu B. and E. Thanassoulis, "Evaluating cost efficiency in central administrative services in UK universities," Omega, vol. 34 (5), pp. 417-426, 2006

[26] Caves D. W., L. R. Christensen, and W. E. Diewert, "The Economic Theory of Index Numbers and the Measurement of Input, Output, and Productivity," Econometrica, vol. 50 (6), pp. 1393-1414, 1982

[27] Chandler A., Strategy and Structure: Chapters in the History of the American Industrial Enterprise, Cambridge, MA: The M.I.T Press, 1962.

[28] Chapple W., A. Lockett, D. Siegel, and M. Wright, "Assessing the relative performance of U.K. university technology transfer offices: parametric and nonparametric evidence," Research Policy, vol. 34 (3), pp. 369-384, 2005

[29] Charnes A., W. W. Cooper, and E. Rhodes, "Measuring the efficiency of decision making units," European Journal of Operational Research, vol. 2 (6), pp. 429444, 1978 
[30] Charnes A., W. W. Cooper, and R. M. Thrall, "Classifying and characterizing efficiencies and inefficiencies in data development analysis," Operations Research Letters, vol. 5 (3), pp. 105-110, 1986

[31] Chen Y., "Measuring super-efficiency in DEA in the presence of infeasibility," European Journal of Operational Research, vol. 161 (2), pp. 545-551, 2005

[32] Colyvas J., M. Crow, A. Gelijns, R. Mazzoleni, R. R. Nelson, N. Rosenberg, and B. N. Sampat, "How do university inventions get into practice?," Management Science, vol. 48 (1), pp. 61-72, 2002

[33] Cook W. D., L. Liang, Y. Zha, and J. Zhu, "A modified super-efficiency DEA model for infeasibility," Journal of the Operational Research Society, vol. 60 (2), pp. 276-281, 2009

[34] Cook W. D. and J. Zhu, Data Envelopment Analysis: Modeling Operational Processes and Measuring Productivity, U.S.: CreateSpace, 2008.

[35] Cooper W. W., L. M. Seiford, and Z. Joe, "Handbook on data envelopment analysis." Boston: Kluwer Avademic Publishers, 2004.

[36] Decter M., D. Bennett, and M. Leseure, "University to business technology transfer--UK and USA comparisons," Technovation, vol. 27 (3), pp. 145-155, 2007

[37] Dill D. and M. Soo, "Academic quality, league tables, and public policy: A crossnational analysis of university ranking systems," Higher Education, vol. 49 (4), pp. 495-533, 2005

[38] Djokovic D. and V. Souitaris, "Spinouts from academic institutions: a literature review with suggestions for further research," The Journal of Technology Transfer, vol. 33 (3), pp. 225-247, 2008

[39] Elfenbein D. W., "Publications, patents, and the market for university inventions," Journal of Economic Behavior \& Organization, vol. 63 (4), pp. 688-715, 2007

[40] Enders W., Applied econometric time series, 2nd ed., Hoboken NJ: J. Wiley, 2004.

[41] Färe R., S. Grosskopf, M. Norris, and Z. Zhongyang, "Productivity Growth, Technical Progress, and Efficiency Change in Industrialized Countries. (cover story)," American Economic Review, vol. 84 (1), pp. 66-83, 1994

[42] Färe R. and C. A. K. Lovell, "Measuring the technical efficiency of production," Journal of Economic Theory vol. 19, pp. 150-162, 1978

[43] Farnham D., "Managing Universities and Regulating Academic Labour Markets," in Managing academic staff in changing university systems: international trends and comparisons, D. Farnham, Ed. Buckingham, PA: Society for Research into Higher Education \& Open University Press, 1999, pp. 15-43.

[44] Feldman K. A., "Research productivity and scholarly accomplishment of college teachers as related to their instructional effectiveness: A review and exploration," Research in Higher Education, vol. 26 (3), pp. 227-298, 1987

[45] Feldman M. P. and P. Desrochers, "Truth for its own sake: Academic culture and technology transfer at Johns Hopkins University," Minerva: A Review of Science, Learning \& Policy, vol. 42 (2), pp. 105-126, 2004

[46] Florida R., "The role of the university: Leveraging talent, not technology," Issues in Science and Technology, vol. 15 (4), pp. 67-73, 1999 
[47] Friedman J. and J. Silberman, "University Technology Transfer: Do Incentives, Management, and Location Matter?," The Journal of Technology Transfer, vol. 28 (1), pp. 17-30, 2003

[48] Geiger R. and C. Sa, "Beyond technology transfer: US state policies to harness university research for economic development," Minerva: A Review of Science, Learning \& Policy, vol. 43 (1), pp. 1-21, 2005

[49] Geva-May I., "Higher education and attainment of policy goals: Interpretations for efficiency indicators in Israel," Higher Education, vol. 42 (3), pp. 265-305, 2001

[50] Glass J. C., G. McCallion, D. G. McKillop, and K. Stringer, "A technically level playing-field' profit efficiency analysis of enforced competition between publicly funded institutions," European Economic Review, vol. 50 (6), pp. 1601-1626, 2006

[51] Goldfarb B. and M. Henrekson, "Bottom-up versus top-down policies towards the commercialization of university intellectual property," Research Policy, vol. 32 (4), pp. 639-658, 2003

[52] Gopalakrishnan S. and M. D. Santoro, "Distinguishing between knowledge transfer and technology transfer activities: The role of key organizational factors," IEEE Transactions on Engineering Management, vol. 51 (1), February, pp. 57-69, 2004

[53] Grimaldi R. and N. von Tunzelmann, "Assessing collaborative, pre-competitive R\&D projects: the case of the UK LINK scheme," $R \& D$ Management, vol. 32 (2), March, pp. 165-173, 2002

[54] Gulbranson C. and D. Audretsch, "Proof of concept centers: accelerating the commercialization of university innovation," The Journal of Technology Transfer, vol. 33 (3), pp. 249-258, 2008

[55] Heher A., "Return on Investment in Innovation: Implications for Institutions and National Agencies*," The Journal of Technology Transfer, vol. 31 (4), pp. 403414, 2006

[56] Hershberg E., K. Nabeshima, and S. Yusuf, "Opening the ivory tower to business: University-industry linkages and the development of knowledge-intensive clusters in Asian cities," World Development, vol. 35 (6), pp. 931-940, 2007

[57] Hicks D., A. Breitzman, K. Hamilton, and F. Narin, "Research excellence and patented innovation," Science and Public Policy, vol. 27 (5), pp. 310-320, 2000

[58] Jackson S. and D. B. Audretsch, "The Indiana university advanced research and technology institute: A case Study," The Journal of Technology Transfer, vol. 29 (2), pp. 119-124, 2004

[59] Jensen R. and M. Thursby, "Proofs and prototypes for sale: The licensing of university inventions," American Economic Review, vol. 91 (1), pp. 240-259, 2001

[60] Jensen R. A., J. G. Thursby, and M. C. Thursby, "Disclosure and licensing of University inventions: 'The best we can do with the $\mathrm{s}^{* *} \mathrm{t}$ we get to work with'," International Journal of Industrial Organization, vol. 21 (9), pp. 1271-1300, 2003 
[61] Kapczynski A., S. Chaifetz, Z. Katz, and Y. Benkler, "Addressing global health inequities: an open licensing approach for university innovations," Berkeley Technology Law Journal, vol. 20 (2), pp. 1031-1114, 2005

[62] Kim J., T. Anderson, and T. Daim, "Assessing university technology transfer: a measure of efficiency patterns," International Journal of Innovation and Technology Management, vol. 5 (4), pp. 495-526, 2008

[63] Kodama T., "The role of intermediation and absorptive capacity in facilitating university-industry linkages--An empirical study of TAMA in Japan," Research Policy, vol. 37 (8), pp. 1224-1240, 2008

[64] Lach S. and M. Schankerman, "Incentives and invention in universities," RAND Journal of Economics (Blackwell), vol. 39 (2), pp. 403-433, 2008

[65] Lecuyer C., "What do universities really owe industry? The case of solid state electronics at Stanford," Minerva: A Review of Science, Learning \& Policy, vol. 43 (1), pp. 51-71, 2005

[66] Lee H.-S., C.-W. Chu, and J. Zhu, "Super-efficiency DEA in the presence of infeasibility," European Journal of Operational Research, vol. 212 (1), pp. 141147,2011

[67] Lee J. and H. N. Win, "Technology transfer between university research centers and industry in Singapore," Technovation, vol. 24 (5), pp. 433-442, 2004

[68] Levin A., A. Chien-Fu Lin, and C.-S. J. Chu, "Unit root tests in panel data: asymptotic and finite-sample properties," Journal of Econometrics, vol. 108 (1), pp. 1-24, 2002

[69] Libaers D., M. Meyer, and A. Geuna, "The role of university spinout companies in an emerging technology: The case of nanotechnology," The Journal of Technology Transfer, vol. 31 (4), pp. 443-450, 2006

[70] Lovell C. A. K. and A. P. B. Rouse, "Equivalent standard DEA models to provide super-efficiency scores," Journal of the Operational Research Society, vol. 54 (1), pp. 101, 2003

[71] Lowe R., "Who develops a university invention? The impact of tacit knowledge and licensing policies," The Journal of Technology Transfer, vol. 31 (4), pp. 415429, 2006

[72] Macho-Stadler I., D. Perez-Castrillo, and R. Veugelers, "Licensing of university inventions: The role of a technology transfer office," International Journal of Industrial Organization, vol. In Press, Corrected Proof,

[73] Malmquist S., "Index Numbers and indifference surfaces"," Trabajos de Estatistica, vol. 4, pp. 209-242, 1953

[74] Mansfield E., "Academic research and industrial innovation," Research Policy, vol. 20 (1), pp. 1-12, 1991

[75] Mansfield E., "Academic research and industrial innovation: An update of empirical findings," Research Policy, vol. 26 (7-8), pp. 773-776, 1998

[76] Markman G. D., P. T. Gianiodis, P. H. Phan, and D. B. Balkin, "Innovation speed: Transferring university technology to market," Research Policy, vol. 34 (7), pp. $1058-1075,2005$ 
[77] Markman G. D., P. H. Phan, D. B. Balkin, and P. T. Gianiodis, "Entrepreneurship and university-based technology transfer," Journal of Business Venturing, vol. 20 (2), pp. 241-263, 2005

[78] Martinelli A., M. Meyer, and N. von Tunzelmann, "Becoming an entrepreneurial university? A case study of knowledge exchange relationships and faculty attitudes in a medium-sized, research-oriented university," The Journal of Technology Transfer, vol. 33 (3), pp. 259-283, 2008

[79] Mazzoleni R., "The effects of university patenting and licensing on downstream $\mathrm{R} \& \mathrm{D}$ investment and social welfare," The Journal of Technology Transfer, vol. 31 (4), pp. 431-441, 2006

[80] McAdam R., W. Keogh, B. Galbraith, and D. Laurie, "Defining and improving technology transfer business and management processes in university innovation centres," Technovation, vol. 25 (12), pp. 1418-1429, 2005

[81] McDowell A., "From the help desk: Polynomial distributed lag models," The Stata Journal, vol. 4 (2), pp. 180-189, 2004

[82] McMillan G. S. and R. D. Hamilton, III, "The impact of publicly funded basic research: an integrative extension of Martin and Salter," IEEE Transactions on Engineering Management, vol. 50 (2), pp. 184-191, 2003

[83] Meeusen W. and J. Van Den Broeck, "Efficiency estimation from cobb-douglas production functions with composed error," International Economic Review, vol. 18 (2), pp. 435, 1977

[84] Meyer M., "Academic inventiveness and entrepreneurship: On the importance of start-up companies in commercializing academic patents," The Journal of Technology Transfer, vol. 31 (4), pp. 501-510, 2006

[85] Mollis M. and S. Marginson, "The assessment of universities in Argentina and Australia: Between autonomy and heteronomy," Higher Education, vol. 43 (3), pp. 311-330, 2002

[86] Ndonzuau F. N., F. Pirnay, and B. Surlemont, "A stage model of academic spinoff creation," Technovation, vol. 22 (5), pp. 281-289, 2002

[87] Nelson R. R., "Observations on the Post-Bayh-Dole rise of patenting at American universities," The Journal of Technology Transfer, vol. 26 (1), pp. 13-19, 2001

[88] Owen-smith J., "Trends and transitions in the institutional environment for public and private science," Higher Education, vol. 49 (1/2), pp. 91-117, 2005

[89] Pakes A., "Patents as Options: Some Estimates of the Value of Holding European Patent Stocks," Econometrica, vol. 54 (4), pp. 755-784, 1986

[90] Palmberg C., "The transfer and commercialisation of nanotechnology: a comparative analysis of university and company researchers," The Journal of Technology Transfer, vol. 33 (6), pp. 631-652, 2008

[91] Parker D. D., D. Zilberman, and F. Castillo, "Offices of technology transfer," Choices: The Magazine of Food, Farm \& Resource Issues, vol. 13 (1), pp. 19-23, 1998 
[92] Paul P. A., P. E. Lipps, E. De Wolf, G. Shaner, G. Buechley, T. Adhikari, S. Ali, J. Stein, L. Osborne, and L. V. Madden, "A Distributed Lag Analysis of the Relationship Between Gibberella zeae Inoculum Density on Wheat Spikes and Weather Variables," Phytopathology, vol. 97 (12), pp. 1608-1624, 2007

[93] Payne A. and S. Aloysius, "Does federal research funding increase university research output?," Advances in Economic Analysis \& Policy, vol. 3 (1), pp. 10181018, 2003

[94] Perez Perez M. and A. M. Sanchez, "The development of university spin-offs: early dynamics of technology transfer and networking," Technovation, vol. 23 (10), pp. 823-831, 2003

[95] Ponomariov B., "Effects of university characteristics on scientists? interactions with the private sector: an exploratory assessment," The Journal of Technology Transfer, vol. 33 (5), pp. 485-503, 2008

[96] Powers J. B., "Commercializing academic research: Resource effects on performance of university technology transfer," Journal of Higher Education, vol. 74 (1), pp. 26-50, 2003

[97] Price C., R. Huston, and A. D. Meyers, "A new approach to improve technology commercialisation in university medical schools," Journal of Commercial Biotechnology, vol. 14 (2), pp. 96-102, 2008

[98] Quintas P. and K. Guy, "Collaborative, pre-competitive R\&D and the firm," Research Policy, vol. 24 (3), pp. 325-348, 1995

[99] Rasmussen E., "Government instruments to support the commercialization of university research: Lessons from Canada," Technovation, vol. 28 (8), pp. 506517,2008

[100] Rasmussen E., O. Moen, and M. Gulbrandsen, "Initiatives to promote commercialization of university knowledge," Technovation, vol. 26 (4), pp. 518533, 2006

[101] Ray S. C. and E. Desli, "Productivity Growth, Technical Progress, and Efficiency Change in Industrialized Countries: Comment," American Economic Review, vol. 87 (5), pp. 1033-1039, 1997

[102] Rogers E. M., Y. Yin, and J. Hoffmann, "Assessing the effectiveness of technology transfer offices at U.S. research universities," The Journal of the Association of University Technology Managers, vol. 12, pp. 47-80, 2000

[103] Rosenberg N. and R. R. Nelson, "American universities and technical advance in industry," Research Policy, vol. 23 (3), pp. 323-348, 1994

[104] Salter A. J. and B. R. Martin, "The economic benefits of publicly funded basic research: a critical review," Research Policy, vol. 30 (3), pp. 509-532, 2001

[105] Sampat B. N., "Patenting and US academic research in the 20th century: The world before and after Bayh-Dole," Research Policy, vol. 35 (6), pp. 772-789, 2006

[106] Seiford L. M. and J. Zhu, "Infeasibility of super-efficiency data envelopment analysis models," INFOR, vol. 37 (2), pp. 174-187, 1999 
[107] Sharma M., U. Kumar, and L. Lalande, "Role of university technology transfer offices in university technology commercialization: case study of the Carleton University foundry program," Journal of Services Research, vol. 6 (Special Issue), July, pp. 109-139, 2006

[108] Sherman D. H. and J. Zhu, Service productivity management improving service performance using Data Envelopment Analysis (DEA), New York, NY: Springer, 2006.

[109] Siegel D. S. and P. H. Phan, "Analyzing the Effectiveness of University Technology Transfer: Implications for Entrepreneurship Education," Rensselaer Working Papers in Economics with number 0426, Rensselaer Polytechnic Institute, Dec 2004, 2004

[110] Siegel D. S., J. G. Thursby, M. C. Thursby, and A. A. Ziedonis, "Organizational issues in university-industry technology transfer: An overview of the symposium issue," The Journal of Technology Transfer, vol. 26 (1), pp. 5-11, 2004

[111] Siegel D. S., D. Waldman, and A. Link, "Assessing the impact of organizational practices on the relative productivity of university technology transfer offices: an exploratory study," Research Policy, vol. 32 (1), pp. 27-48, 2003

[112] Siegel D. S., D. A. Waldman, L. E. Atwater, and A. N. Link, "Improving the effectiveness of commercial knowledge transfers from universities to firms," Journal of High Technology Management Research, vol. forthcoming, 2002

[113] Siegel D. S., D. A. Waldman, L. E. Atwater, and A. N. Link, "Commercial knowledge transfers from universities to firms: improving the effectiveness of university-industry collaboration," The Journal of High Technology Management Research, vol. 14 (1), pp. 111-133, 2003

[114] Siegel D. S., D. A. Waldman, L. E. Atwater, and A. N. Link, "Toward a model of the effective transfer of scientific knowledge from academicians to practitioners: qualitative evidence from the commercialization of university technologies," Journal of Engineering and Technology Management, vol. 21 (1-2), pp. 115-142, 2004

[115] Siegel D. S., P. Westhead, and M. Wright, "Assessing the impact of university science parks on research productivity: exploratory firm-level evidence from the United Kingdom," International Journal of Industrial Organization, vol. 21 (9), pp. 1357-1369, 2003

[116] Sine W. D., S. Shane, and D. Di Gregorio, "The Halo Effect and Technology Licensing: The Influence of Institutional Prestige on the Licensing of University Inventions," Management Science, vol. 49 (4), pp. 478-496, 2003

[117] Sorensen J. and D. Chambers, "Evaluating academic technology transfer performance by how well access to knowledge is facilitated? Defining an access metric," The Journal of Technology Transfer, vol. 33 (5), pp. 534-547, 2008

[118] SREB, "Linking higher education performance indicators to goals," Southern Regional Educaiton Board (SREG), Atlanta, GA, Feb, 2000.

[119] Stock J. H. and M. W. Watson, Introduction to Econometrics, New York: Addison Wesley, 2003. 
[120] Terenzini P. T. and E. T. Pascarella, "Living with myths," Change, vol. 26 (1), pp. 28,1994

[121] Thursby J. G., R. Jensen, and M. C. Thursby, "Objectives, characteristics and outcomes of university licensing: A survey of major U.S. universities," The Journal of Technology Transfer, vol. 26 (1), pp. 59-72, 2001

[122] Thursby J. G. and S. Kemp, "Growth and productive efficiency of university intellectual property licensing," Research Policy, vol. 31 (1), pp. 109-124, 2002

[123] Thursby J. G. and M. C. Thursby, "Who is selling the ivory tower? Sources of growth in university licensing," Management Science, vol. 48 (1), pp. 90-104, 2002

[124] Tone K., "A slacks-based measure of efficiency in data envelopment analysis," European Journal of Operational Research, vol. 130 (3), pp. 498-509, 2001

[125] Tone K., "A slacks-based measure of super-efficiency in data envelopment analysis," European Journal of Operational Research, vol. 143 (1), pp. 32-41, 2002

[126] Tornquist K. M. and L. A. Kallsen, "Out of the Ivory Tower," Journal of Higher Education, vol. 65 (5), pp. 523-539, 1994

[127] Trune D. R. and L. N. Goslin, "University technology transfer programs: A profit/loss analysis," Technological Forecasting and Social Change, vol. 57 (3), pp. 197-204, 1998

[128] Vaidyanathan G., "Technology parks in a developing country: the case of India," The Journal of Technology Transfer, vol. 33 (3), pp. 285-299, 2008

[129] Ventriss C. and M. Gurdon, "Emerging issues in economic development policy and technology incubators: The Vermont center for emerging technologies experience," Comparative Technology Transfer and Society, vol. 4 (1), pp. 22-52, 2006

[130] Welsh R., L. Glenna, W. Lacy, and D. Biscotti, "Close enough but not too far: Assessing the effects of university-industry research relationships and the rise of academic capitalism," Research Policy, vol. 37 (10), pp. 1854-1864, 2008

[131] Westerlund J., "Some Cautions on the Use of the LLC Panel Unit Root Test," Maastricht Research School of Economics of Technology and Organization, Research Memoranda 055, 2006, pp. 1-28.

[132] Wong P.-K., Y.-P. Ho, and A. Singh, "Towards an "entrepreneurial university" model to support knowledge-based economic development: The Case of the National University of Singapore," World Development, vol. 35 (6), pp. 941-958, 2007

[133] Woolgar L., "New institutional policies for university-industry links in Japan," Research Policy, vol. 36 (8), pp. 1261-1274, 2007

[134] Xue M. and P. T. Harker, "Note: Ranking DMUs with Infeasible Super-Efficiency DEA Models," Management Science, vol. 48 (5), pp. 705-710, 2002

[135] Youtie J. and P. Shapira, "Building an innovation hub: A case study of the transformation of university roles in regional technological and economic development," Research Policy, vol. 37 (8), pp. 1188-1204, 2008 
[136] Yusuf S., "Intermediating knowledge exchange between universities and businesses," Research Policy, vol. 37 (8), pp. 1167-1174, 2008

[137] Zhu J., Quantitative models for performance evaluation and benchmarking: data envelopment analysis with spreadsheets and DEA Excel Solver, Norwell, MA: Kluwer Academic Publishers, 2003. 
* Document: http://www.statajournal.com/sjpdf.html?articlenum=st0065

* generate the $\mathrm{pdl}(12,4)$ data $\mathrm{pdl}(\mathrm{p}=\mathrm{lag}, \mathrm{q}=$ degree $)$

* sim_arma $x, \operatorname{ar}(.9) \operatorname{spin}(10000) \operatorname{nobs}(300)$

* data should $\mathrm{x} \_\mathrm{t} \mathrm{y}$

$*$ lag $=3$ degree $=2$

* tsset year

/* Program Start */

program pdlconstraints

version 8.2

args $\mathrm{p} \mathrm{q}$ matname

local $\mathrm{r}=$ ' $\mathrm{p}$ ' - 'q'

local $m=' \mathrm{q}^{\prime}+1$

matrix 'matname' $=\mathrm{J}\left(\mathrm{rr}^{\prime}, \mathrm{p}^{\prime}+3,0\right)$

forvalues $\mathrm{i}=1 / \mathrm{r}^{\prime}$ '

local $\mathrm{x}={ }^{\prime} \mathrm{i}{ }^{\prime}+$ ' $^{\prime}+1$

local $\mathrm{k}=-1$

local $\mathrm{d}=1$

forvalues $\mathrm{j}=\mathrm{x}^{\prime}(-1)^{\prime} \mathrm{i}$ ' \{

local $\mathrm{k}={ }^{\prime} \mathrm{k} \mathrm{k}^{\prime}+1$

matrix `matname'['i','j'] = 'd'*comb('m', 'k')

local $\mathrm{d}=-1^{*}{ }^{\prime} \mathrm{d}$ '

\}

\}

end

program vandermonde

version 8.2

syntax name, Numlist(numlist)

local p: word count 'numlist'

tokenize 'numlist'

matrix 'namelist' $=\mathrm{J}\left(\mathrm{p}^{\prime}, \mathrm{p}^{\prime}, 0\right)$

forvalues $\mathrm{c}=1 / \mathrm{p}^{\mathrm{p}}$ \{ 


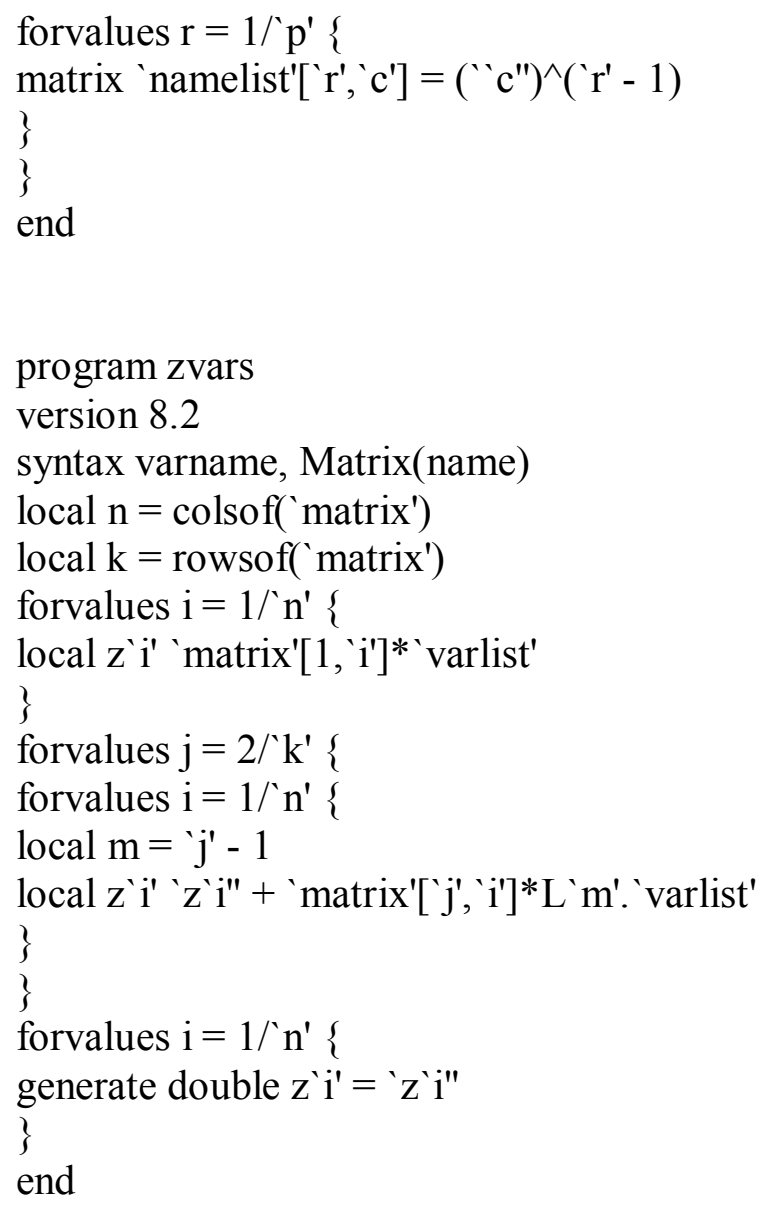









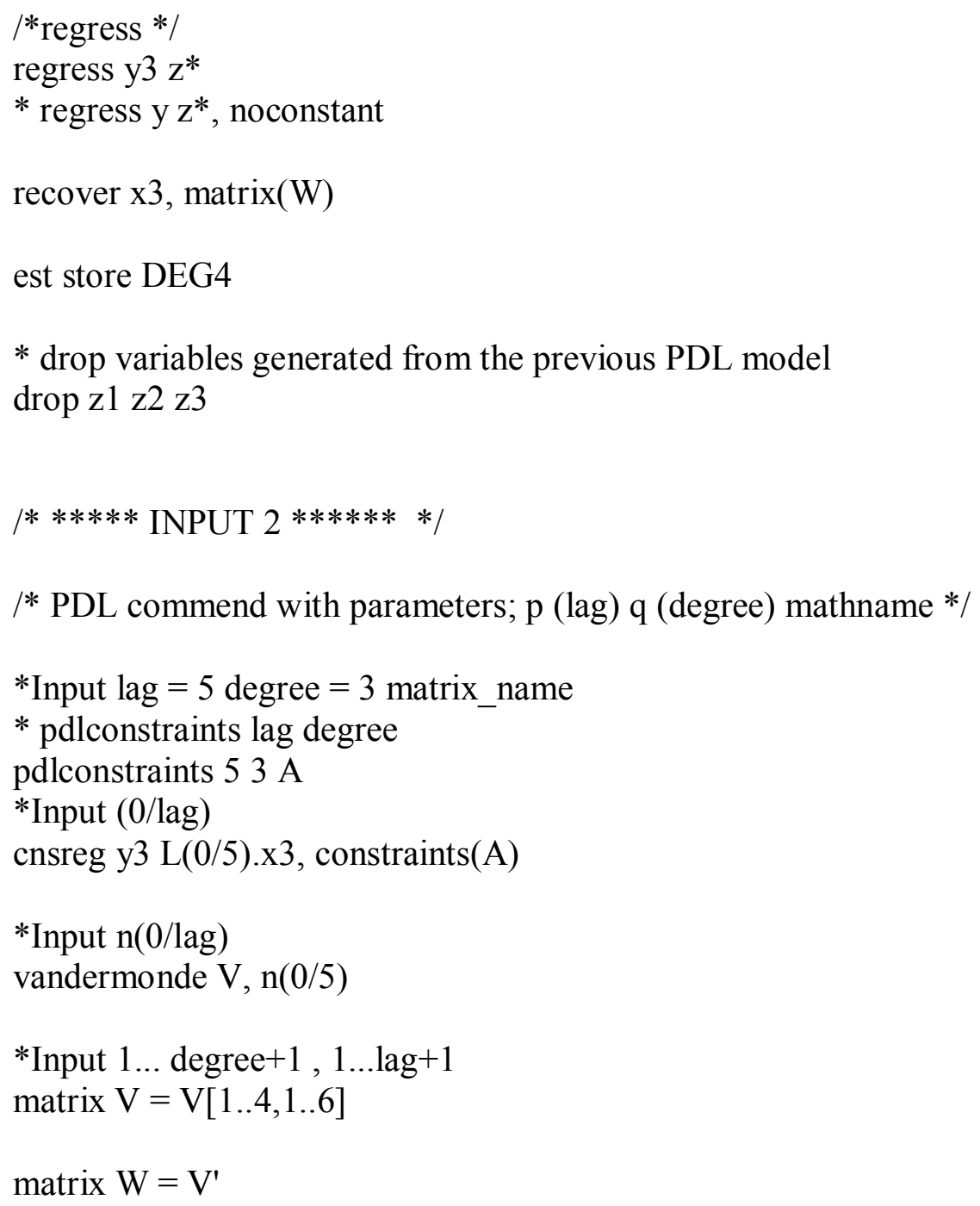




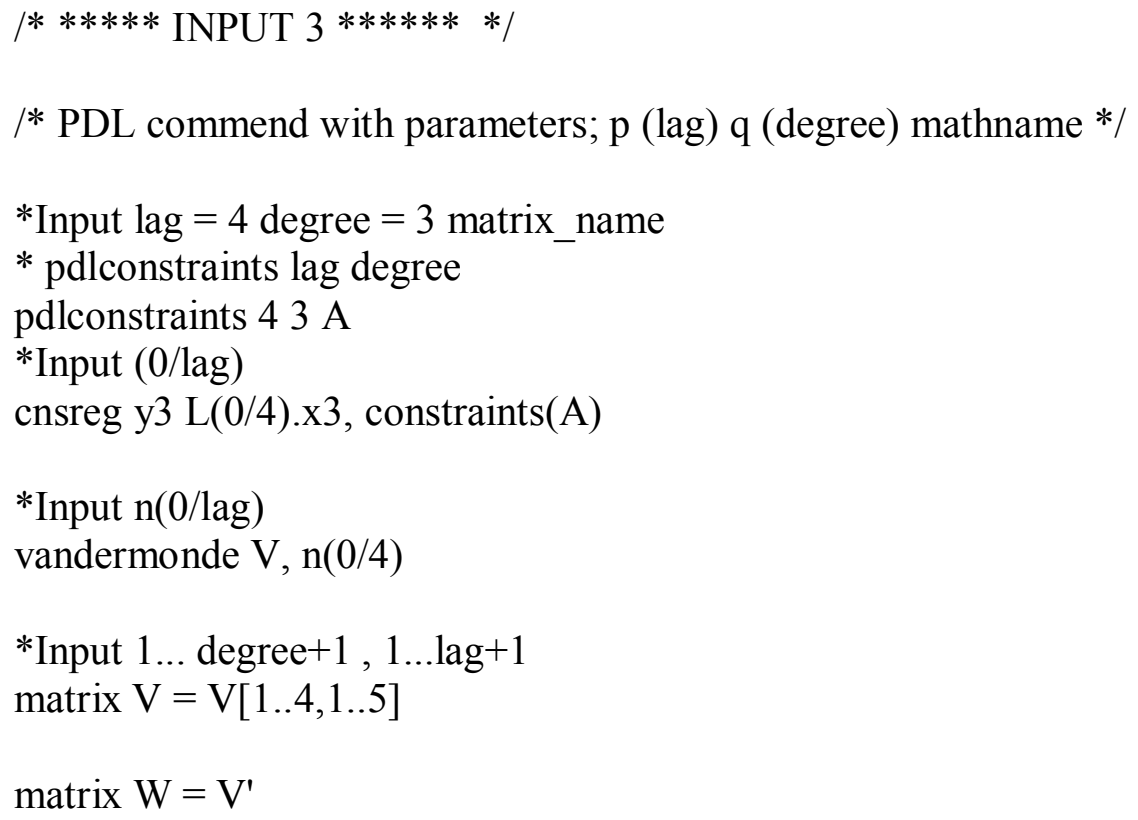


cnsreg y3 L(0/4).x3, constraints(A)

*Input $\mathrm{n}(0 / \mathrm{lag})$

vandermonde $\mathrm{V}, \mathrm{n}(0 / 4)$

*Input $1 \ldots$ degree $+1,1 \ldots$ lag +1

matrix $\mathrm{V}=\mathrm{V}[1 . .3,1 . .5]$

matrix $\mathrm{W}=\mathrm{V}^{\prime}$

zvars $\mathrm{x} 3$, matrix $(\mathrm{W})$

/*regress */

regress $\mathrm{y} 3 \mathrm{z}^{*}$

* regress y z*, noconstant

recover $\mathrm{x} 3$, matrix $(\mathrm{W})$

est store DEG4

* drop variables generated from the previous PDL model drop z1 z2 z3

****** Data set $4(\mathrm{x} 4$ and $\mathrm{y} 4)$

/****** INPUT $1 * * * * * * *$ /

/* PDL commend with parameters; p (lag) q (degree) mathname */

*Input lag $=5$ degree $=2$ matrix_name

$*$ pdlconstraints lag degree

pdlconstraints $52 \mathrm{~A}$

*Input $(0 / \mathrm{lag})$

cnsreg y4 L(0/5).x4, constraints(A)

*xtgls y4 L(0/8).x4, noconstant panels(hetero)

$/ * \operatorname{PDL}($ lag $=8$, degree $=4) * /$

*Input $\mathrm{n}(0 / \mathrm{lag})$

vandermonde $\mathrm{V}, \mathrm{n}(0 / 5)$

*Input $1 \ldots$ degree $+1,1 \ldots$ lag +1

matrix $\mathrm{V}=\mathrm{V}[1 . .3,1 . .6]$ 
matrix $\mathrm{W}=\mathrm{V}^{\prime}$

zvars $\mathrm{x} 4$, matrix (W)

/*regress */

regress $\mathrm{y} 4 \mathrm{z}^{*}$

$*$ regress y $z^{*}$, noconstant

recover $\mathrm{x} 4$, matrix $(\mathrm{W})$

est store DEG4

* drop variables generated from the previous PDL model drop z1 z2 z3

$/ * * * * * * \operatorname{INPUT} 2 * * * * * * * /$

/* PDL commend with parameters; p (lag) q (degree) mathname */

$*$ Input lag $=5$ degree $=3$ matrix_name

* pdlconstraints lag degree

pdlconstraints $53 \mathrm{~A}$

*Input (0/lag)

cnsreg y4 L(0/5).x4, constraints(A)

*Input n(0/lag)

vandermonde $\mathrm{V}, \mathrm{n}(0 / 5)$

*Input $1 \ldots$ degree $+1,1 \ldots$ lag +1

matrix $\mathrm{V}=\mathrm{V}[1 . .4,1 . .6]$

matrix $\mathrm{W}=\mathrm{V}^{\prime}$

zvars x4, matrix(W)

/*regress */

regress y $4 \mathrm{z}^{*}$

$*$ regress y $z^{*}$, noconstant

recover $x 4$, matrix $(W)$ 
est store DEG4

* drop variables generated from the previous PDL model drop z1 z2 z3 z4

$/ * * * * * * \operatorname{INPUT} 3 * * * * * * * /$

/* PDL commend with parameters; p (lag) q (degree) mathname */

$*$ Input lag $=4$ degree $=3$ matrix_name

* pdlconstraints lag degree

pdlconstraints $43 \mathrm{~A}$

*Input $(0 /$ lag $)$

cnsreg y4 L(0/4).x4, constraints(A)

*Input $\mathrm{n}(0 / \mathrm{lag})$

vandermonde $\mathrm{V}, \mathrm{n}(0 / 4)$

*Input $1 \ldots$ degree $+1,1 \ldots$ lag +1

matrix $\mathrm{V}=\mathrm{V}[1 . .4,1 . .5]$

matrix $\mathrm{W}=\mathrm{V}^{\prime}$

zvars $\mathrm{x} 4$, matrix $(\mathrm{W})$

$/ *$ regress */

regress y4 $\mathrm{z}^{*}$

$*$ regress y $z^{*}$, noconstant

recover $\mathrm{x} 4$, matrix $(\mathrm{W})$

est store DEG4

* drop variables generated from the previous PDL model drop z1 z2 z3 z4

$/ * * * * * * \operatorname{INPUT} 4 * * * * * * * /$ 
/* PDL commend with parameters; p (lag) q (degree) mathname */

*Input lag $=4$ degree $=2$ matrix_name

* pdlconstraints lag degree

pdlconstraints $42 \mathrm{~A}$

*Input (0/lag)

cnsreg y4 L(0/4).x4, constraints(A)

*Input $\mathrm{n}(0 / \mathrm{lag})$

vandermonde $\mathrm{V}, \mathrm{n}(0 / 4)$

*Input $1 \ldots$ degree $+1,1 \ldots$ lag +1

matrix $\mathrm{V}=\mathrm{V}[1 . .3,1 . .5]$

matrix $\mathrm{W}=\mathrm{V}^{\prime}$

zvars $\mathrm{x} 4$, matrix $(\mathrm{W})$

$/ *$ regress $* /$

regress $\mathrm{y} 4 \mathrm{z}^{*}$

* regress $\mathrm{y} \mathrm{z}^{*}$, noconstant

recover $\mathrm{x} 4$, matrix $(\mathrm{W})$

est store DEG4

* drop variables generated from the previous PDL model

drop z1 z2 z3 
Appendix B. Licensing Paths of Each Variable to the Licensing Income
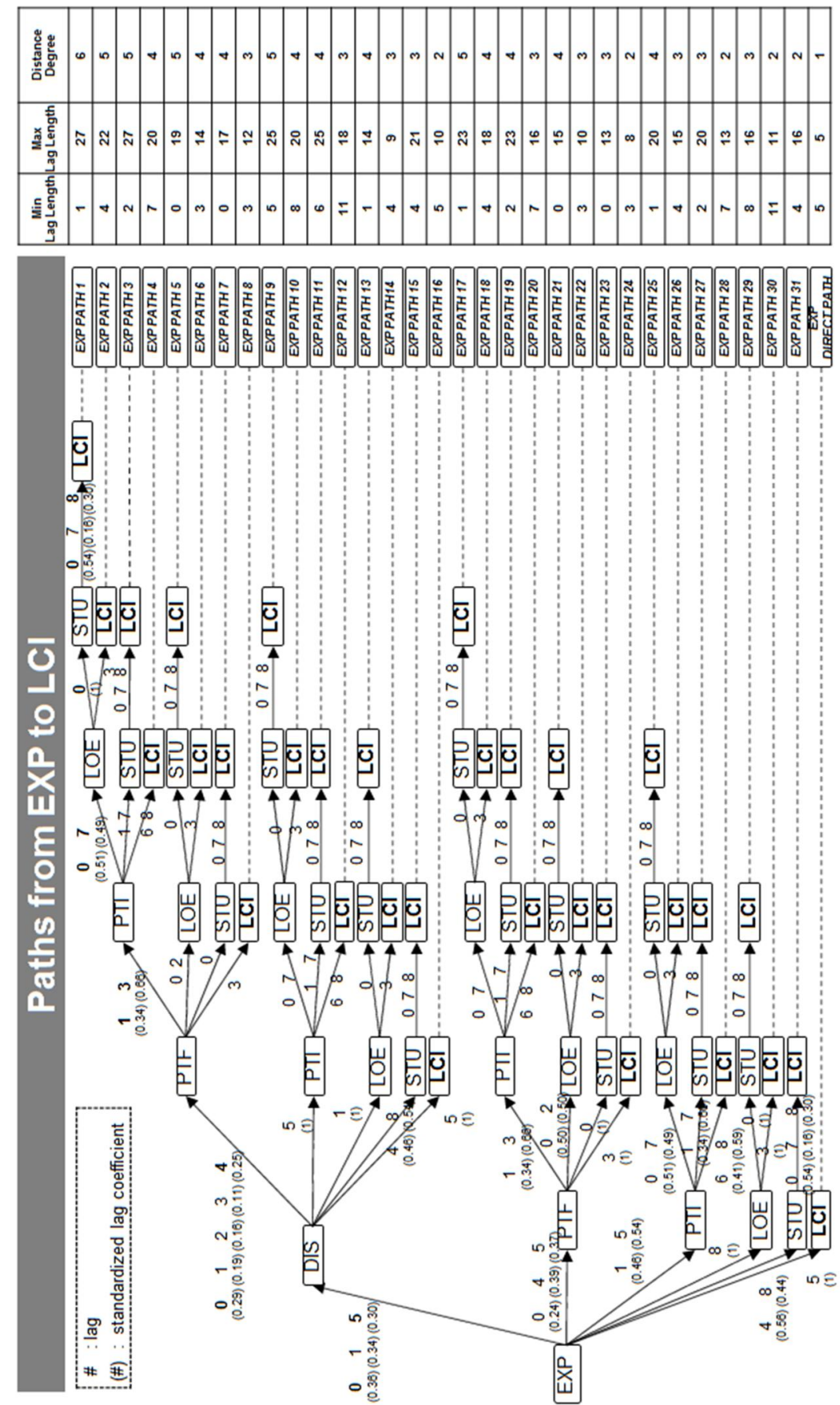

Figure B1: Licensing paths to the licensing income from the expenditure 


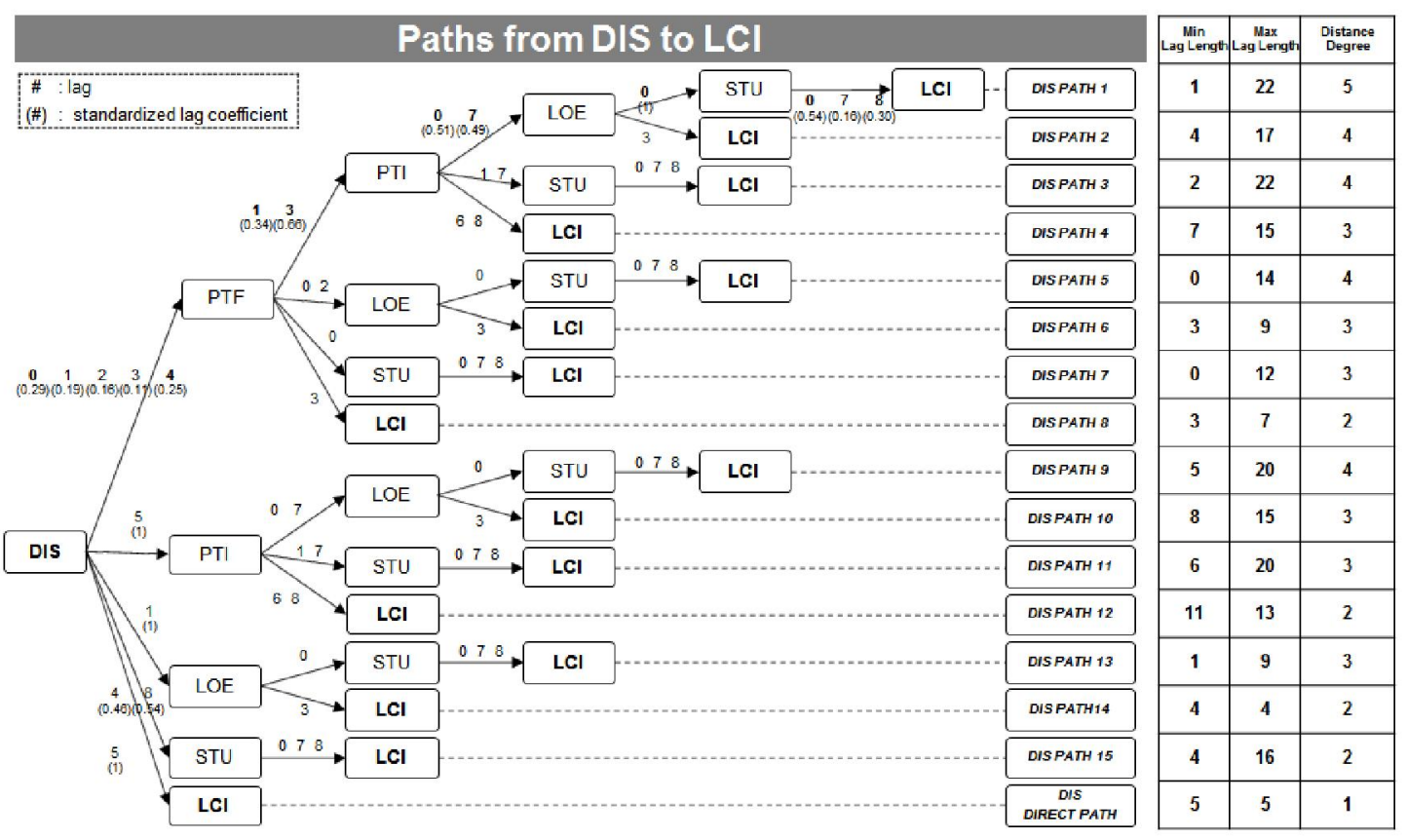

Figure B2: Licensing paths to the licensing income from the disclosure

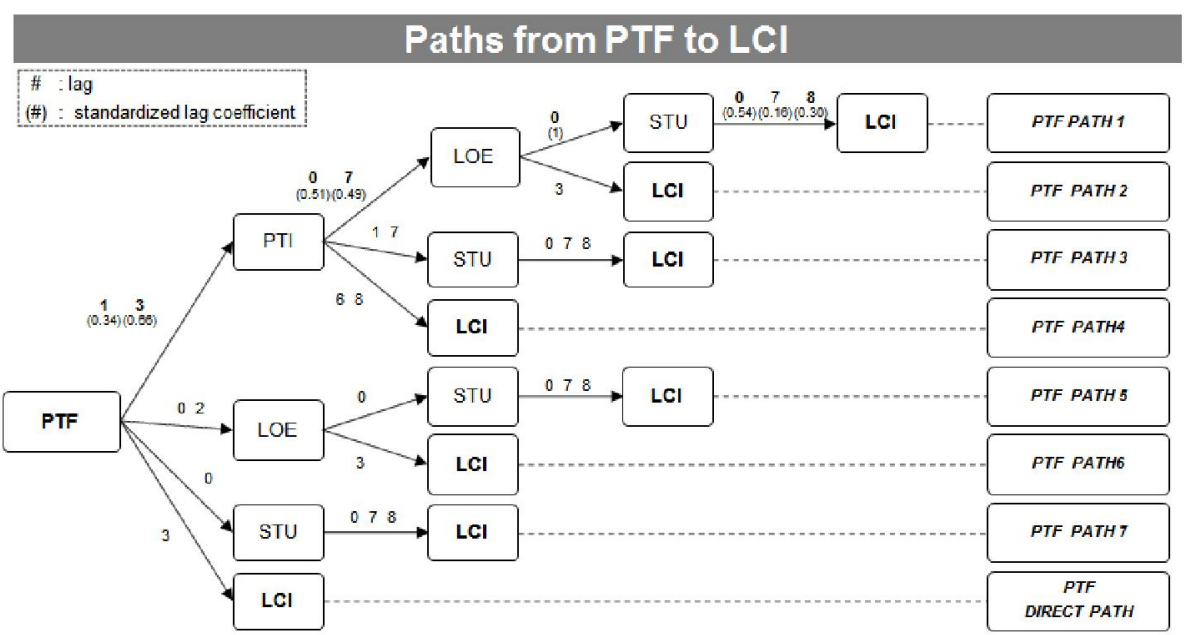

\begin{tabular}{|c|c|c|}
\hline $\begin{array}{c}\text { Min } \\
\text { Lag } \\
\text { Length }\end{array}$ & $\begin{array}{c}\text { Max } \\
\text { Length } \\
\text { Lenth }\end{array}$ & $\begin{array}{c}\text { Distance } \\
\text { Degree }\end{array}$ \\
\hline 1 & 18 & 4 \\
\hline 4 & 13 & 3 \\
\hline 2 & 18 & 3 \\
\hline 7 & 11 & 2 \\
\hline 0 & 10 & 3 \\
\hline 3 & 5 & 2 \\
\hline 0 & 8 & 2 \\
\hline 3 & 3 & 1 \\
\hline
\end{tabular}

Figure B3: Licensing paths to the licensing income from the patent filed

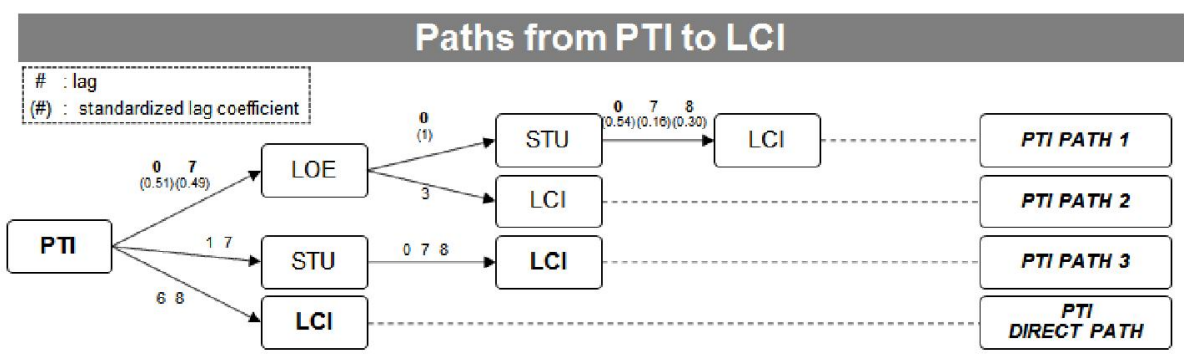

\begin{tabular}{|c|c|c|}
\hline $\begin{array}{c}\text { Min } \\
\text { Lag } \\
\text { Length }\end{array}$ & $\begin{array}{c}\text { Max } \\
\text { Leng } \\
\text { Length }\end{array}$ & $\begin{array}{c}\text { Distance } \\
\text { Degree }\end{array}$ \\
\hline 0 & 15 & 3 \\
\hline 3 & 10 & 2 \\
\hline 1 & 15 & 2 \\
\hline 6 & 8 & 1 \\
\hline
\end{tabular}

Figure B4: Licensing paths to the licensing income from the patent issued 


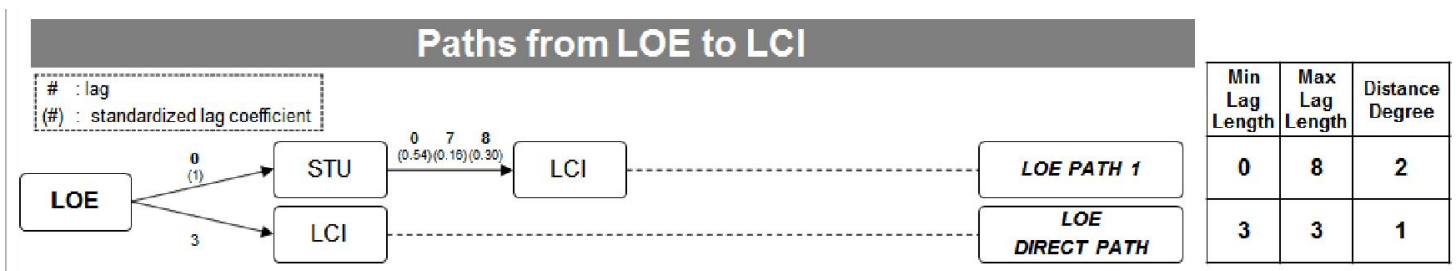

Figure B5: Licensing paths to the licensing income from the license and option executed

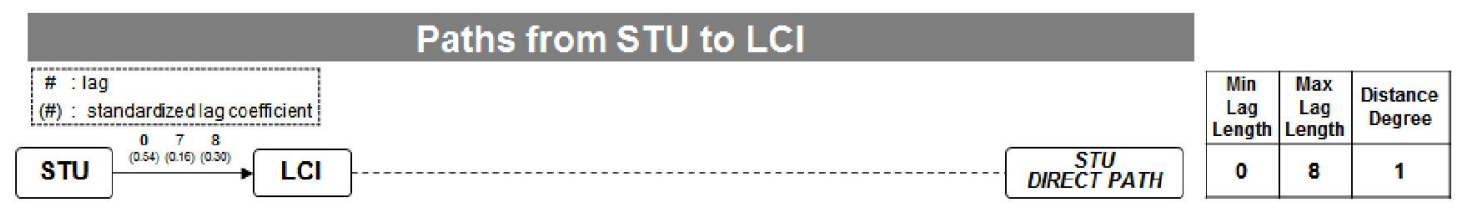

Figure B6: Licensing paths to the licensing income from the start-up 
Appendix C. Xpress Mosel Coding of Modified Super-Efficiency Model

\section{Radial VRS SE Malmquist Model}

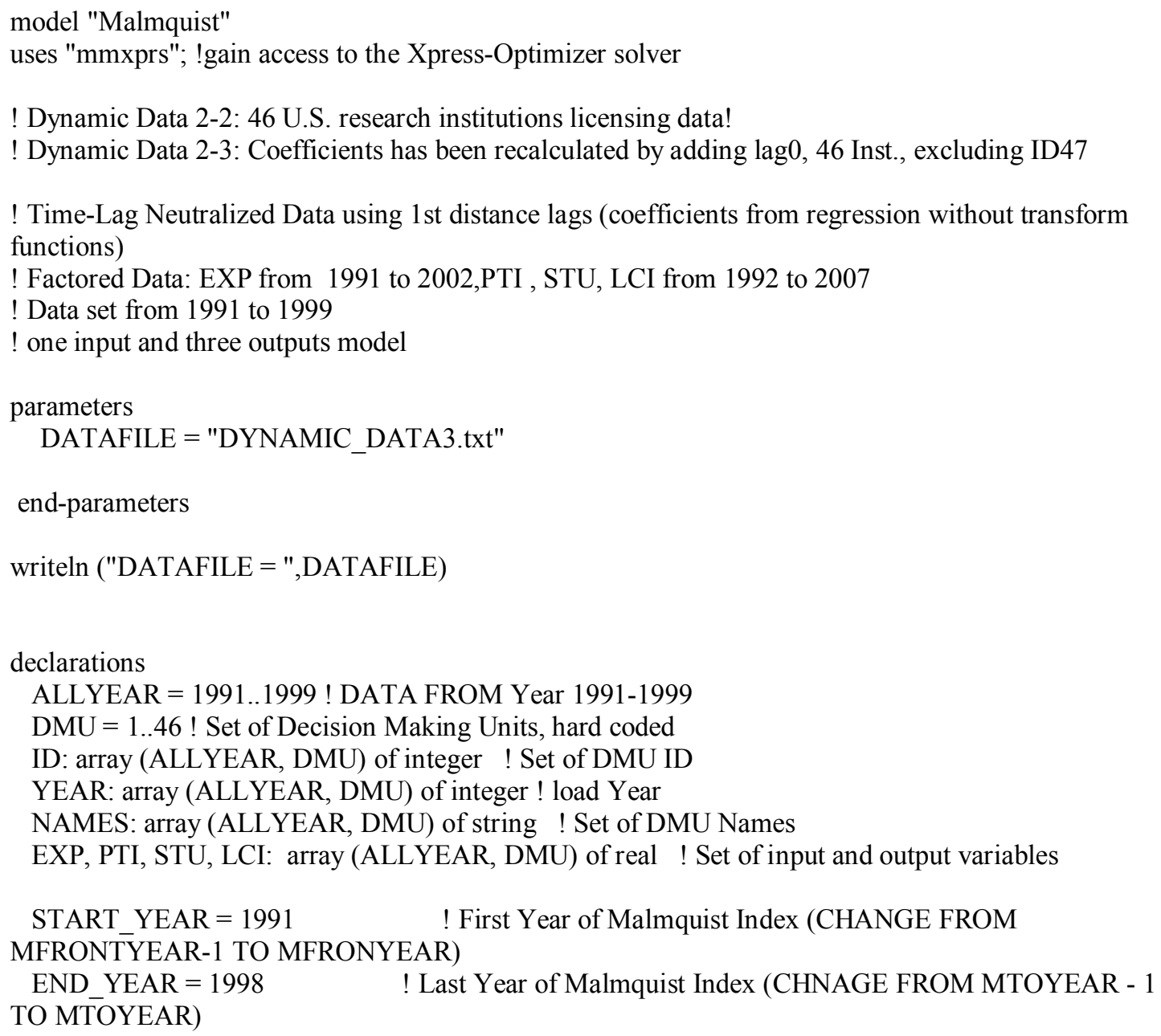




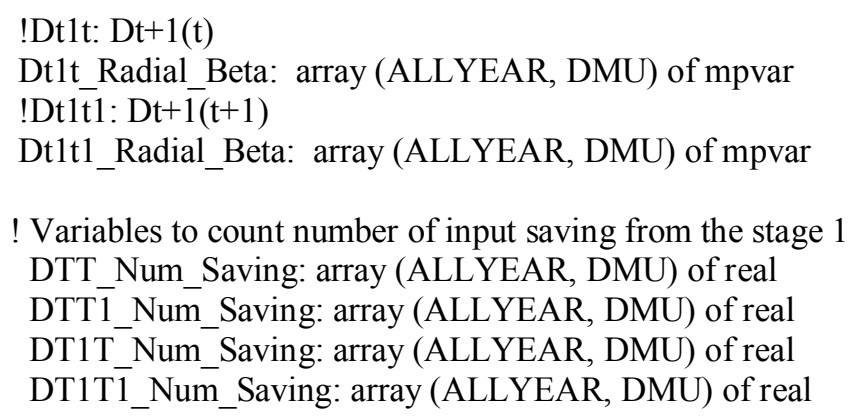

Stage2_Dtt_Lambda: array (ALLYEAR, DMU,DMU) of mpvar ! Array of lambda Stage2_Dtt1_Lambda: array (ALLYEAR, DMU,DMU) of mpvar ! Array of lambda Stage2_Dt1t_Lambda: array (ALLYEAR, DMU,DMU) of mpvar! Array of lambda Stage2_Dt1t1_Lambda: array (ALLYEAR, DMU,DMU) of mpvar ! Array of lambda

! Variables to store input saving from the stage 1 DTT_EXP_STAGE1_SAVING: array (ALLYEAR, DMU) of real DTT1_EXP_STAGE1_SAVING: array (ALLYEAR, DMU) of real DT1T_EXP_STAGE1_SAVING: array (ALLYEAR, DMU) of real DT1T1_EXP_STAGE1_SAVING: array (ALLYEAR, DMU) of real

! Variables to store beta from the stage 2

!Dtt: Dt(t)

DTT_RADIAL_BETA_VALUE: array (ALLYEAR, DMU) of real !Dtt1: Dt $(\mathrm{t}+1)$

DTT1_RADIAL_BETA_VALUE: array (ALLYEAR, DMU) of real !Dt1t: Dt+1(t)

DT1T_RADIAL_BETA_VALUE: array (ALLYEAR, DMU) of real !Dt1t1: Dt+1(t+1)

DT1T1_RADIAL_BETA_VALUE: array (ALLYEAR, DMU) of real

! Final super efficiency phi

!Dtt: $\operatorname{Dt}(\mathrm{t})$

DTT SE phi: array (ALLYEAR, DMU) of real

!Dtt1: $\mathrm{Dt}(\mathrm{t}+1)$

DTT1_SE_phi: array (ALLYEAR, DMU) of real

!Dt1t: $\mathrm{Dt}+1(\mathrm{t})$

DT1T_SE_phi: array (ALLYEAR, DMU) of real

!Dt1t1: Dt+1(t+1)

DT1T1_SE_phi: array (ALLYEAR, DMU) of real

! Final super efficiency SE $(>1$; efficinecy $)=$ SAME WITH_SE_Phi

!Dtt: Dt(t)

DTT_SE: array (ALLYEAR, DMU) of real

!Dtt1: Dt $(\mathrm{t}+1)$ 
DTT1_SE: array (ALLYEAR, DMU) of real

!Dt1t: Dt+1(t)

DT1T_SE: array (ALLYEAR, DMU) of real

!Dt1t1: Dt+1(t+1)

DT1T1_SE: array (ALLYEAR, DMU) of real

end-declarations

initializations from DATAFILE

ID NAMES YEAR EXP PTI STU LCI ! Reads the data from the above file end-initializations

! \#\#\# Stage 1: Calculate input saving. If it is not zero, the DMU is an infeasible case. \#\#\#

forall (dmu_year in ALLYEAR $\mid$ START_YEAR $<=$ dmu_year AND dmu_year $<=$ END_YEAR) do

forall(k in DMU) do

!Dtt: $\operatorname{Dt}(\mathrm{t})$

sum $(\mathrm{j}$ in DMU $\mid \mathrm{j} \diamond \mathrm{k})$ Stage1_Dtt_Lambda $\left(\mathrm{dmu} \_\right.$year, $\left.\mathrm{j}, \mathrm{k}\right)=1 \quad$ ! Variable returns to Scale

Stage1_Dtt_Lambda $\left(\mathrm{dmu} \_\right.$year, $\left.\mathrm{k}, \mathrm{k}\right)=0$

sum $(\mathrm{j}$ in DMU $\mid \mathrm{j} \diamond>\mathrm{k})$ Stage1_Dtt_Lambda $\left(\mathrm{dmu} \_\right.$year,j,k)*EXP(dmu_year, $\left.\mathrm{j}\right)$ - Dtt_Exp_Saving

$\left(\mathrm{dmu} \_\right.$year, $\left.\mathrm{k}\right)<=\operatorname{EXP}\left(\mathrm{dmu} \_\right.$year, $\left.\mathrm{k}\right) \quad$ !input, EXP, constraint

!Dtt1: Dt(t+1)

sum ( $\mathrm{j}$ in DMU) Stage1_Dtt1_Lambda(dmu_year,j,k)=1 ! Variable returns to Scale

sum (j in DMU) Stage1_Dtt1_Lambda(dmu_year,j,k)*EXP(dmu_year, j) - Dtt1_Exp_Saving

$\left(\mathrm{dmu} \_\right.$year, $\left.\mathrm{k}\right)<=\operatorname{EXP}\left(\mathrm{dmu} \_\right.$year $\left.+1, \mathrm{k}\right)$ ! input, $\mathrm{EXP}$, constraint

!Dt1t: $\mathrm{Dt}+1(\mathrm{t})$

sum ( $\mathrm{j}$ in DMU) Stage1_Dt1t_Lambda $(\mathrm{dmu}$ year,j,k)=1 ! Variable returns to Scale

sum (j in DMU) Stage1_Dt1t_Lambda(dmu_year,j,k)*EXP(dmu_year+1, j) - Dt1t_Exp_Saving

$\left(\mathrm{dmu} \_\right.$year, $\left.\mathrm{k}\right)<=\operatorname{EXP}\left(\mathrm{dmu} \_\right.$year, $\left.\mathrm{k}\right) \quad$ !input, EXP, constraint

!Dt1t1: Dt+1(t+1)

sum $(\mathrm{j}$ in DMU $\mid \mathrm{j} \diamond \mathrm{k})$ Stage1_Dt1t1_Lambda $\left(\mathrm{dmu} \_\right.$year,j,k)=1 !Variable returns to Scale

Stage1_Dt1t1_Lambda $\left(\mathrm{dmu} \_\right.$year,k,k) $=0$

$\operatorname{sum}(\mathrm{j}$ in DMU $\mid \mathrm{j} \diamond \mathrm{k})$ Stage1_Dt1t1_Lambda(dmu_year,j,k)*EXP(dmu_year $+1, \mathrm{j})$ -

Dt1t1_Exp_Saving $\left(\mathrm{dmu} \_\right.$year, $\left.\mathrm{k}\right)<=\operatorname{EXP}\left(\overline{\mathrm{dm}} \_\right.$_year $\left.+1, \mathrm{k}\right)$ ! input, EXP, constraint

end-do ! evalute all DMUs

end-do ! Stage1 DEA loop, evaluate all years (from start year to end year)

minimize (sum ( $\mathrm{k}$ in DMU, dmu_year in ALLYEAR | START_YEAR $<=$ dmu_year AND dmu_year $<=$ END_YEAR)

(Dtt_Exp_Saving (dmu_year, $\mathrm{k})+$ Dtt1_Exp_Saving $(\mathrm{dmu}$ _year, $\mathrm{k})+\mathrm{Dt1t}$ _Exp_Saving $(\mathrm{dmu}$ _year, $\mathrm{k})+$ Dt1t1_Exp_Saving (dmu_year, $\mathrm{k})))$ !object function: minimize input saving

! count number of saving

forall (dmu_year in ALLYEAR $\mid$ START_YEAR $<=$ dmu_year AND dmu_year $<=$ END_YEAR) do

forall(k in DMU) do 
!Dtt: $\mathrm{Dt}(\mathrm{t})$

if getsol(Dtt_Exp_Saving $\left(\mathrm{dmu} \_\right.$year, $\left.\left.\mathrm{k}\right)\right)>0$ then DTT_Num_Saving $(\mathrm{dmu}$ year,k) $:=1$ end-if

!Dtt1: Dt(t)

if getsol(Dtt1_Exp_Saving $\left(\mathrm{dmu} \_\right.$year, $\left.\left.\mathrm{k}\right)\right)>0$ then DTT1_Num_Saving $\left(\mathrm{dmu} \_\right.$year,k) $:=1$

end-if

!Dt1t: Dt(t)

if getsol(Dt1t_Exp_Saving $\left(\mathrm{dmu} \_\right.$year, $\left.\left.\mathrm{k}\right)\right)>0$ then DT1T_Num_Saving $(\mathrm{dmu}$ year,k) $:=1$

end-if

!Dt1t1: Dt(t)

if getsol(Dt1t1_Exp_Saving $\left(\mathrm{dmu} \_\right.$year, $\left.\left.\mathrm{k}\right)\right)>0$ then DT1T1_Num_Saving $\left(\mathrm{dmu} \_\right.$year,k) $:=1$

end-if

end-do

end-do

! Print input saving table

writeln("")

writeln("Input Saving Table")

writeln("==================")

writeln("ID", " ","INST NAME"," ", "YEAR"," ", "INPUT SAVING")

writeln(" Dtt Dtt1 Dt1t Dt1t1")

writeln("------------------------------------------")

do

forall (dmu_year in ALLYEAR $\mid$ START_YEAR $<=$ dmu_year AND dmu_year $<=$ END_YEAR)

forall(k in DMU) do

writeln(ID(dmu year,k), "\t",NAMES(dmu year,k),"ไt",

dmu_year,"|t",getsol(Dtt_Exp_Saving (dmu_year, k)),"|t",getsol(Dtt1_Exp_Saving (dmu_year,

k)),"ไt",getsol(Dt1t_Exp_Saving (dmu_year, k)),"ไt",getsol(Dt1t1_Exp_Saving (dmu_year, k)) ) end-do

end-do

writeln("-

! Store input savings to the variables for the stage2

forall (dmu_year in ALLYEAR $\mid$ START_YEAR $<=$ dmu_year AND dmu_year $<=$ END_YEAR) do forall(k in DMU) do

DTT_EXP_STAGE1_SAVING(dmu_year, $\mathrm{k}):=$ getsol(Dtt_Exp_Saving $(\mathrm{dmu}$ year, $\mathrm{k}))$

DTT1_EXP_STAGE1_SAVING(dmu_year, $\mathrm{k}):=$ getsol(Dtt1_Exp_Saving $(\mathrm{dmu}$ - year, $\mathrm{k}))$

DT1T_EXP_STAGE1_SAVING(dmu_year, $\mathrm{k}):=$ getsol(Dt1t_Exp_Saving $(\mathrm{dmu}$-year, $\mathrm{k})$ )

DT1T1_EXP_STAGE1_SAVING(dmu_year, $\mathrm{k}):=\operatorname{getsol}(\mathrm{Dt} \mathrm{t} 1 \mathrm{t} 1$ Exp_Saving $(\mathrm{dmu}$ - year, $\mathrm{k}))$ end-do

end-do

! \#\#\#\# End of Stage 1 \#\#\#

! \#\#\# Stage 2: Using the input savings from the stage 1 evalute super efficiency of the DMUs for all years \#\#\#

forall (dmu_year in ALLYEAR $\mid$ START_YEAR $<=$ dmu_year AND dmu_year $<=$ END_YEAR) do forall(k in DMU) do 
!! Input constraints

!Dtt: Dt(t)

sum ( $\mathrm{j}$ in DMU $\mid \mathrm{j} \diamond \mathrm{k}$ ) Stage2_Dtt_Lambda $(\mathrm{dmu}$ _year, $\mathrm{j}, \mathrm{k})=1 \quad$ ! Variable returns to Scale Stage 2 Dtt Lambda $(\mathrm{dmu}$ year, $\mathrm{k}, \mathrm{k})=0$ sum $(\mathrm{j}$ in DMU $\mid \mathrm{j} \diamond \mathrm{k})$ Stage2_Dtt_Lambda $(\mathrm{dmu}$ year, $\mathrm{j}, \mathrm{k}) * \operatorname{EXP}(\mathrm{dmu}$ year, $\mathrm{j})$ -

DTT_EXP_STAGE1_SAVING $\left(\mathrm{dmu} \_\right.$year, $\left.\mathrm{k}\right)<=\mathrm{EXP}\left(\mathrm{dmu} \_\right.$year,k) $\quad$ !input, EXP, constraint

!Dtt1: Dt(t+1)

sum ( $\mathrm{j}$ in DMU) Stage2 Dtt1 Lambda $(\mathrm{dmu}$ year,j,k)=1 ! Variable returns to Scale sum (j in DMU) Stage2_Dtt1_Lambda(dmu_year,j,k)*EXP(dmu_year, j) -

DTT1_EXP_STAGE1_SAVING $(\mathrm{dmu}$ _year, $\mathrm{k})<=\mathrm{EXP}(\mathrm{dmu}$-year+1,k) !input, EXP, constraint

!Dt1t: Dt+1(t)

sum ( $\mathrm{j}$ in DMU) Stage2_Dt1t_Lambda $\left(\mathrm{dmu} \_\right.$year, $\left.\mathrm{j}, \mathrm{k}\right)=1 \quad$ ! Variable returns to Scale

sum (j in DMU) Stage2_Dt1t_Lambda (dmu_year,j,k)*EXP(dmu_year $+1, \mathrm{j})$ -

DT1T_EXP_STAGE1_SAVING $(\overline{\mathrm{dmu}}$ _year, $\mathrm{k})<=\mathrm{EXP}(\mathrm{dmu}$-year,k) !input, EXP, constraint

!Dt1t1: Dt+1(t+1)

sum $(\mathrm{j}$ in DMU $\mid \mathrm{j} \diamond \mathrm{k})$ Stage2_Dt1t1_Lambda $\left(\mathrm{dmu} \_\right.$year, $\left.\mathrm{j}, \mathrm{k}\right)=1 \quad$ ! Variable returns to Scale Stage2_Dt1t1_Lambda $($ dmu_year, $\mathrm{k}, \overline{\mathrm{k}})=0$

sum ( $\mathrm{j}$ in DMU $\mid \mathrm{j} \diamond \mathrm{k})$ Stage2 Dt1t1 Lambda $(\mathrm{dmu}$ year, $\mathrm{j}, \mathrm{k}) * \operatorname{EXP}(\mathrm{dmu}$ year $+1, \mathrm{j})$ -

DT1T1_EXP_STAGE1_SAVING $(\overline{\mathrm{d} m u}$ year, $\mathrm{k})<=\operatorname{EXP}(\mathrm{dmu}$ year $+1, \mathrm{k})$ ! input, EXP, constraint

!! Output Constraints

!Dtt: Dt(t)

$\operatorname{sum}(\mathrm{j}$ in DMU $\mid \mathrm{j} \diamond \mathrm{k})$ Stage2_Dtt_Lambda(dmu_year,j,k)*PTI(dmu_year, $\mathrm{j})>=$ PTI(dmu_year,

k)*Dtt_Radial_Beta(dmu year, k) !output PTI constraint sum ( $\mathrm{j}$ in DMU $\mid \mathrm{j}<\mathrm{k})$ Stage2_Dtt_Lambda $\left(d m u \_\right.$year,j,k)*STU(dmu_year, $\left.\mathrm{j}\right)>=$

STU(dmu_year, k)*Dtt_Radial_Beta(dmu_year, k) !output STU constraint sum $(\mathrm{j}$ in DMU $\mid \bar{j} \diamond \mathrm{k})$ Stage2_Dtt_Lambda $(\mathrm{dmu}$ year, $\mathrm{j}, \mathrm{k}) * \mathrm{LCI}(\mathrm{dmu}$ year, $\mathrm{j})>=\mathrm{LCI}(\mathrm{dmu}$ year,

k)*Dtt_Radial_Beta(dmu_year, k) !output LCI constraint

!Dtt1: Dt(t+1)

sum (j in DMU) Stage2_Dtt1_Lambda(dmu_year,j,k)*PTI(dmu_year, $\mathrm{j})>=$ PTI $(\mathrm{dmu}$ year +1 ,

k)*Dtt1_Radial_Beta(dmu_year, $\mathrm{k})$ ! output PTI constraint sum ( $\mathrm{j}$ in DMU) Stage2 Dtt1 Lambda (dmu year,j,k)*STU(dmu year, $\mathrm{j})>=\operatorname{STU}(\mathrm{dmu}$ year +1 ,

k)*Dtt1_Radial_Beta(dmu_year, k) !output STU constraint sum (j in DMU) Stage2_Dtt1_Lambda $\left(d m u \_y e a r, j, k\right) * L C I\left(d m u \_y e a r, j\right)>=L C I\left(d m u \_y e a r+1\right.$,

k)*Dtt1_Radial_Beta(dmu_year, k) !output LCI constraint

!Dt1t: Dt+1(t)

sum (j in DMU) Stage2_Dt1t_Lambda (dmu_year,j,k)*PTI $\left(d m u \_y e a r+1, j\right)>=$ PTI $\left(d m u \_y e a r\right.$,

k)*Dt1t_Radial_Beta(dmu_year, k) !output PTI constraint sum (j in DMU) Stage2_Dt1t_Lambda (dmu_year,j,k)*STU(dmu_year $+1, \mathrm{j})>=S T U\left(d m u \_y e a r\right.$,

k)*Dt1t_Radial_Beta(dmu_year, k) !output STU constraint sum (j in DMU) Stage2_Dt1t_Lambda $\left(d m u \_y e a r, j, k\right) * \operatorname{LCI}\left(d m u \_y e a r+1, j\right)>=\operatorname{LCI}\left(d m u \_y e a r\right.$,

k)*Dt1t_Radial_Beta(dmu_year, k) ${ }^{-}$!output LCI constraint

!Dt1t1: Dt+1(t+1)

sum (j in DMU $\mid \mathrm{j} \diamond \mathrm{k})$ Stage2_Dt1t1_Lambda $\left(\mathrm{dmu} \_\right.$year,j,k)*PTI $\left(\mathrm{dmu} \_\right.$year+1, j) $>=$

PTI(dmu_year+1, k)*Dt1t1_Radial_Beta(dmu_year, k) !output PTI constraint $\operatorname{sum}(\mathrm{j}$ in DMU $\mid \mathrm{j} \diamond \overline{\mathrm{k}})$ Stage 2 _Dt1t1_Lambda $\left(\mathrm{dmu} \_\right.$year,j,k)*STU(dmu_year+1, $\left.\mathrm{j}\right)>=$

STU $\left(d m u \_y e a r+1, k\right) * D t 1 t 1 \_R a d i a l \_B e t a(\overline{d m u}$ year, $\mathrm{k})$ ! output STU constraint 
$\operatorname{sum}(\mathrm{j}$ in DMU $\mid \mathrm{j}>\mathrm{k})$ Stage2_Dt1t1_Lambda(dmu_year,j,k)*LCI $(\mathrm{dmu}$ year $+1, \mathrm{j})>=$ LCI(dmu_year+1, k)*Dt1t1_Radial_Beta(dmu_year, k) !output LCI constraint

end-do ! evalute all DMUs

end-do ! Stage 2 DEA loop, evaluate all years (from start year to end year)

forall (dmu_year in ALLYEAR $\mid$ START_YEAR $<=$ dmu_year AND dmu_year $<=$ END_YEAR) do forall(k in DMU) do

Dtt_Radial_Beta $($ dmu_year, $\mathrm{k})<=1000$

Dtt1_Radial_Beta $($ dmu_year, $\mathrm{k})<=1000$

Dt1t_Radial_Beta $($ dmu_year, $\mathrm{k})<=1000$

end-do

Dt1t1_Radial_Beta(dmu_year, $\mathrm{k})<=1000$

end-do

maximize (sum $(\mathrm{k}$ in DMU, dmu_year in ALLYEAR $\mid$ START_YEAR $<=$ dmu_year AND dmu_year $<=$ END_YEAR)

$($ Dtt_Radial_Beta(dmu_year, $\mathrm{k})+$ Dtt1_Radial_Beta(dmu_year, k)+Dt1t_Radial_Beta(dmu_year,

$\mathrm{k})+\overline{\mathrm{D}} \mathrm{t} 1 \mathrm{t} 1 \_$Radial_Beta(dmu_year, $\left.\left.\mathrm{k}\right)\right) \overline{)}$

! Save beta to the static variables for the post evalution

! if beta $=1000$ Type 1 (infinitive case) $->1$

! if beta $=0$ Type 2 (bounded to zero case) $->(1 /$ the output) of the evaluted DMU

forall (dmu_year in ALLYEAR $\mid$ START_YEAR $<=$ dmu_year AND dmu_year $<=$ END_YEAR) do forall(k in DMU) do

!Dtt: Dt(t)

DTT_RADIAL_BETA_VALUE(dmu_year, k):=getsol(Dtt_Radial_Beta(dmu_year,k))

!Dtt1: Dt $(\mathrm{t}+1)$

DTT1_RADIAL_BETA_VALUE(dmu_year, k):=getsol(Dtt1_Radial_Beta(dmu_year,k))

!Dt1t: Dt+1(t)

DT1T_RADIAL_BETA_VALUE(dmu_year, k):=getsol(Dt1t_Radial_Beta(dmu_year,k))

!Dt1t1: Dt+1(t+1)

DT1T1_RADIAL_BETA_VALUE(dmu_year, k):=getsol(Dt1t1_Radial_Beta(dmu_year,k)) end-do

end-do

!!zero-efficinecy is replaced by the average of the non-radial efficiencies

! Average of non zero non-radial efficiencies

!DTT_RADIAL_BETA_VALUE(1991, 23):=0.59

!DT1T_RADIAL_BETA_ VALUE $(1991,23):=1.75$

!DTT RADIAL BETA_VALUE $(1996,29):=0.33$

!DT1T1_RADIĀL_BETA_VALUE $(1995,29):=0.33$

! Min of non zero non-radial efficiencies

DTT_RADIAL_BETA_VALUE $(1991,23):=0.37$ 







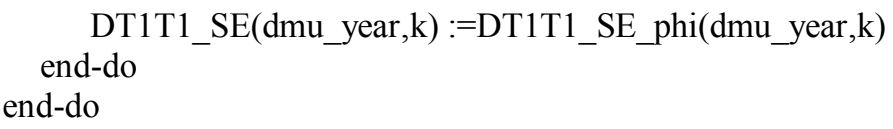




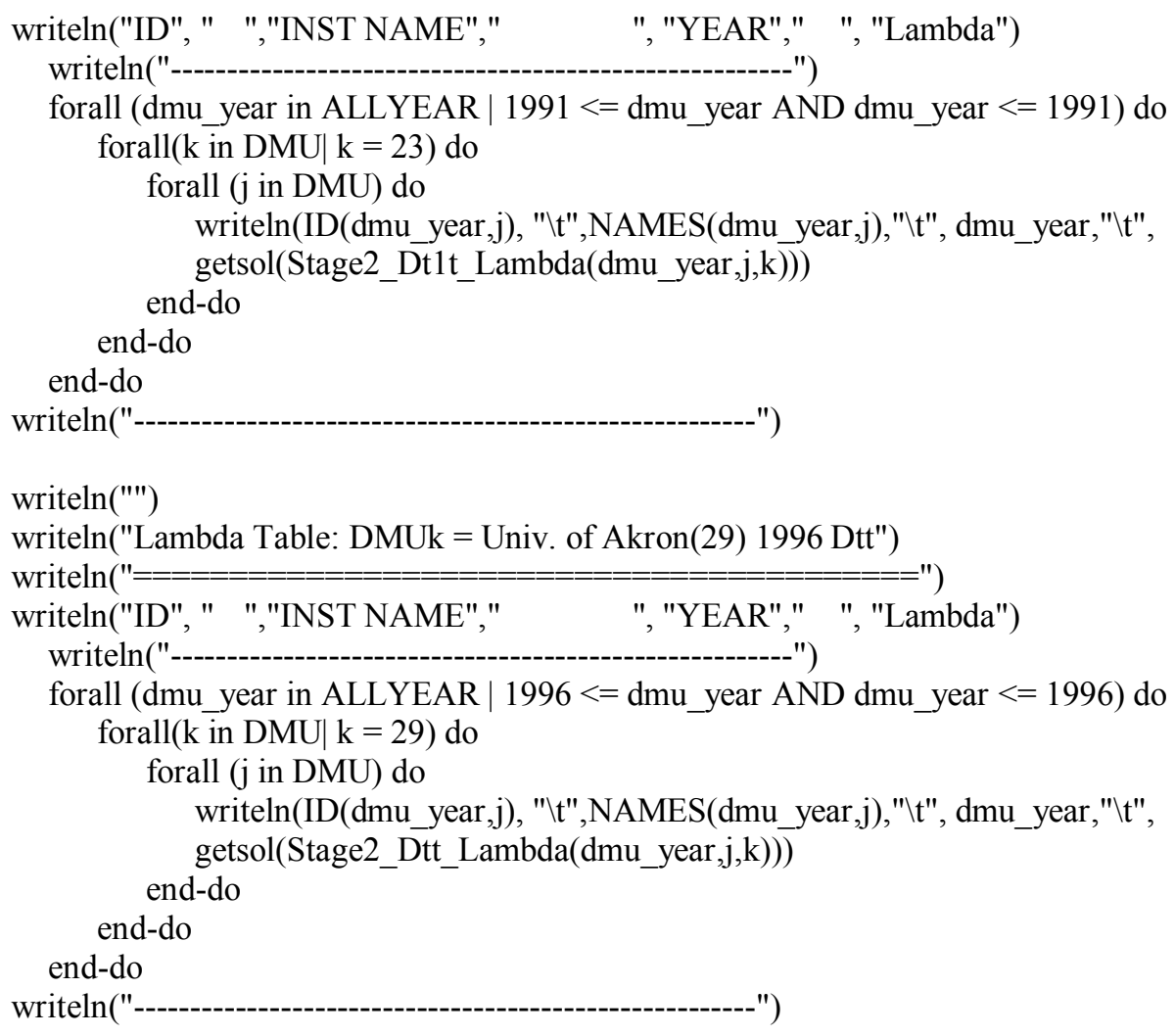

!Print Modified SE

writeln("')

writeln("Modified SE Table")

writeln $("=================="$ )

writeln("ID", " ","INST NAME"," ", "YEAR"," ", "Modified SE")

writeln(" Dtt_SE Dtt1_SE Dt1t_SE Dt1t1_SE")

writeln("---------------------------------------")

forall (dmu_year in ALLYEAR $\mid$ START_YEAR $<=$ dmu_year AND dmu_year $<=$ END_YEAR) do

forall(k in DMU) do

writeln(ID(dmu_year,k), "\t",NAMES(dmu_year,k),"ไt", dmu_year,"ไt",

DTT_SE(dmu_year,k),"ไt",DTT1_SE(dmu_year,k),"ไt",DT1T_SE(dmu_year,k),"|t",DT1T1_SE(dm u_year,k) ) end-do

end-do

writeln("-

!Print Final MI

writeln("')

writeln("MI Table")

writeln("====================") 


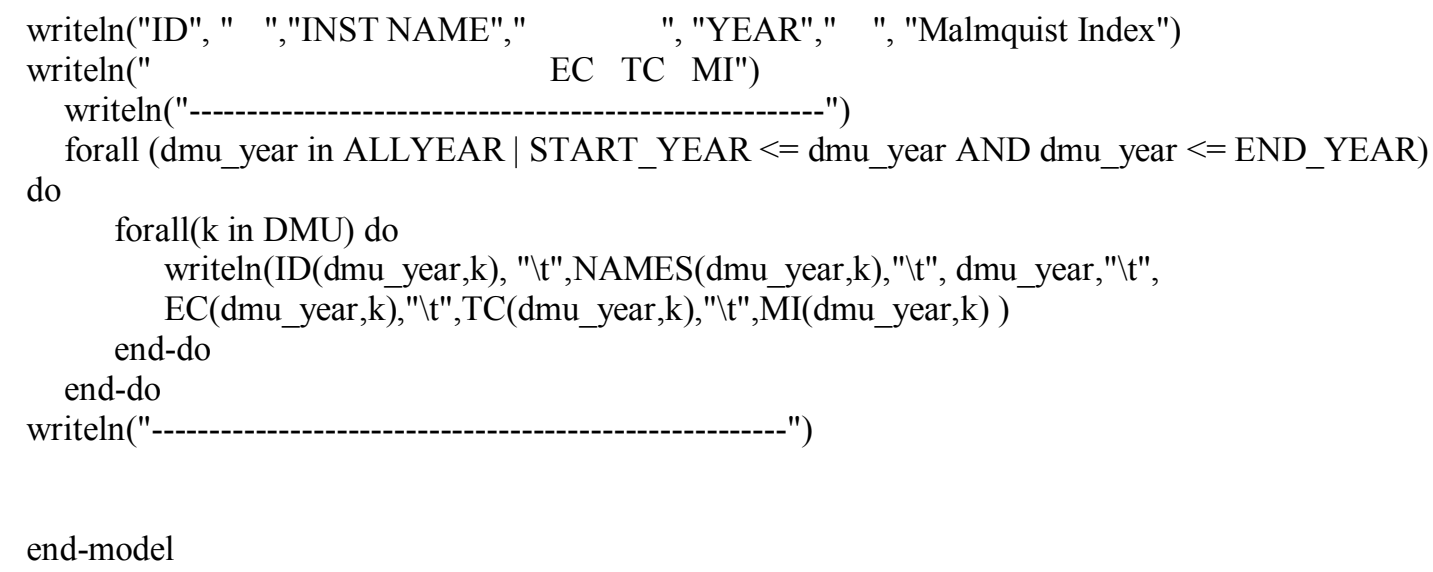

\section{Non-radial VRS SE Malmquist Model}

model "Malmquist"

uses "mmxprs"; !gain access to the Xpress-Optimizer solver

! Dynamic Data 2-1: 47 U.S. research institutions licensing data

! Dynamic Data 2-2: 46 U.S. research institutions licensing data EXCLUDING ID47. Woods Hole

Oceanographic Inst.

! Dynamic Data 2-3: Coefficients has been recalculated by adding lag0, 46 Inst., excluding ID47

! ID47. Woods Hole Oceanographic Inst. has so many zero data point result in unrealistic result in DEA

and Malmquist

! Time-Lag Factored Data using 1st distance lags (coefficients from regression without transform functions)

! Factored Data: EXP from 1991 to 2002,PTI , STU, LCI from 1992 to 2007

! Data set from 1991 to 1999

! one input and three outputs model

parameters

DATAFILE = "DYNAMIC_DATA3.txt"

end-parameters

writeln ("DATAFILE = ",DATAFILE)

declarations

ALLYEAR = 1991..1999 ! DATA FROM Year 1991-1999

$\mathrm{DMU}=1 . .46$ ! Set of Decision Making Units, hard coded

ID: array (ALLYEAR, DMU) of integer ! Set of DMU ID

YEAR: array (ALLYEAR, DMU) of integer ! load Year

NAMES: array (ALLYEAR, DMU) of string ! Set of DMU Names

EXP, PTI, STU, LCI: array (ALLYEAR, DMU) of real ! Set of input and output variables 


START_YEAR $=1991 \quad$ ! First Year of Malmquist Index (CHANGE FROM
MFRONTYEAR-1 TO MFRONYEAR)
$\begin{array}{ll}\text { END_YEAR }=1998 & \text { ! Last Year of Malmquist Index (CHNAGE FROM MTOYEAR - } 1 \text { TO } \\ \text { MTOYEAR) } & \end{array}$

$$
\mathrm{M}=20
$$

! Dtt_TC: array(ALLYEAR, DMU) of real ! Technical Change of Malmquist

! Dtt_TC1: array(ALLYEAR, DMU) of real ! $\mathrm{Dt}(\mathrm{t}+1) / \mathrm{Dt}+1(\mathrm{t}+1)$ in TC

! Dtt TC2: array(ALLYEAR, DMU) of real ! $\mathrm{Dt}(\mathrm{t}) / \mathrm{Dt}+1(\mathrm{t})$ in TC

! Dtt_EC: array(ALLYEAR, DMU) of real ! Efficinecy Change of Malmquist

! Dtt_MALMQUIST: array(ALLYEAR, DMU) of real! Malmquist indices of all 47 DMUs

! Definition of decision variables

Dtt_Exp_Saving: array (ALLYEAR, DMU) of mpvar

Dtt1_Exp_Saving: array (ALLYEAR, DMU) of mpvar

Dt1t_Exp_Saving: array (ALLYEAR, DMU) of mpvar

Dt1t1_Exp_Saving: array (ALLYEAR, DMU) of mpvar

!Dtt: $\overline{\mathrm{D}} \mathrm{t}(\mathrm{t})$

Dtt_PTI_Beta: array (ALLYEAR, DMU) of mpvar

Dtt_STU_Beta: array (ALLYEAR, DMU) of mpvar

Dtt_LCI_Beta: array (ALLYEAR, DMU) of mpvar

!Dtt1: Dt $(\mathrm{t}+1)$

Dtt1_PTI_Beta: array (ALLYEAR, DMU) of mpvar

Dtt1_STU_Beta: array (ALLYEAR, DMU) of mpvar

Dtt1_LCI_Beta: array (ALLYEAR, DMU) of mpvar

!Dt1t: Dt+1(t)

Dt1t PTI Beta: array (ALLYEAR, DMU) of mpvar

Dt1t_STU_Beta: array (ALLYEAR, DMU) of mpvar

Dt1t_LCI_Beta: array (ALLYEAR, DMU) of mpvar

!Dt1t1: Dt+1(t+1)

Dt1t1_PTI_Beta: array (ALLYEAR, DMU) of mpvar

Dt1t1_STU_Beta: array (ALLYEAR, DMU) of mpvar

Dt1t1_LCI_Beta: array (ALLYEAR, DMU) of mpvar

Stage1_Dtt_Lambda: array (ALLYEAR, DMU,DMU) of mpvar ! Array of lambda Stage1_Dtt1_Lambda: array (ALLYEAR, DMU,DMU) of mpvar! Array of lambda Stage1_Dt1t_Lambda: array (ALLYEAR, DMU,DMU) of mpvar! Array of lambda Stage1_Dt1t1_Lambda: array (ALLYEAR, DMU,DMU) of mpvar ! Array of lambda

Stage2_Dtt_Lambda: array (ALLYEAR, DMU,DMU) of mpvar ! Array of lambda Stage2_Dtt1_Lambda: array (ALLYEAR, DMU,DMU) of mpvar! Array of lambda Stage2_Dt1t_Lambda: array (ALLYEAR, DMU,DMU) of mpvar! Array of lambda Stage2_Dt1t1_Lambda: array (ALLYEAR, DMU,DMU) of mpvar ! Array of lambda

! Variables to store input saving from the stage 1

DTT_EXP_STAGE1_SAVING: array (ALLYEAR, DMU) of real DTT1_EXP_STAGE1_SAVING: array (ALLYEAR, DMU) of real DT1T_EXP_STAGE1_SAVING: array (ALLYEAR, DMU) of real DT1T1_EXP_STAGE1_SAVING: array (ALLYEAR, DMU) of real 


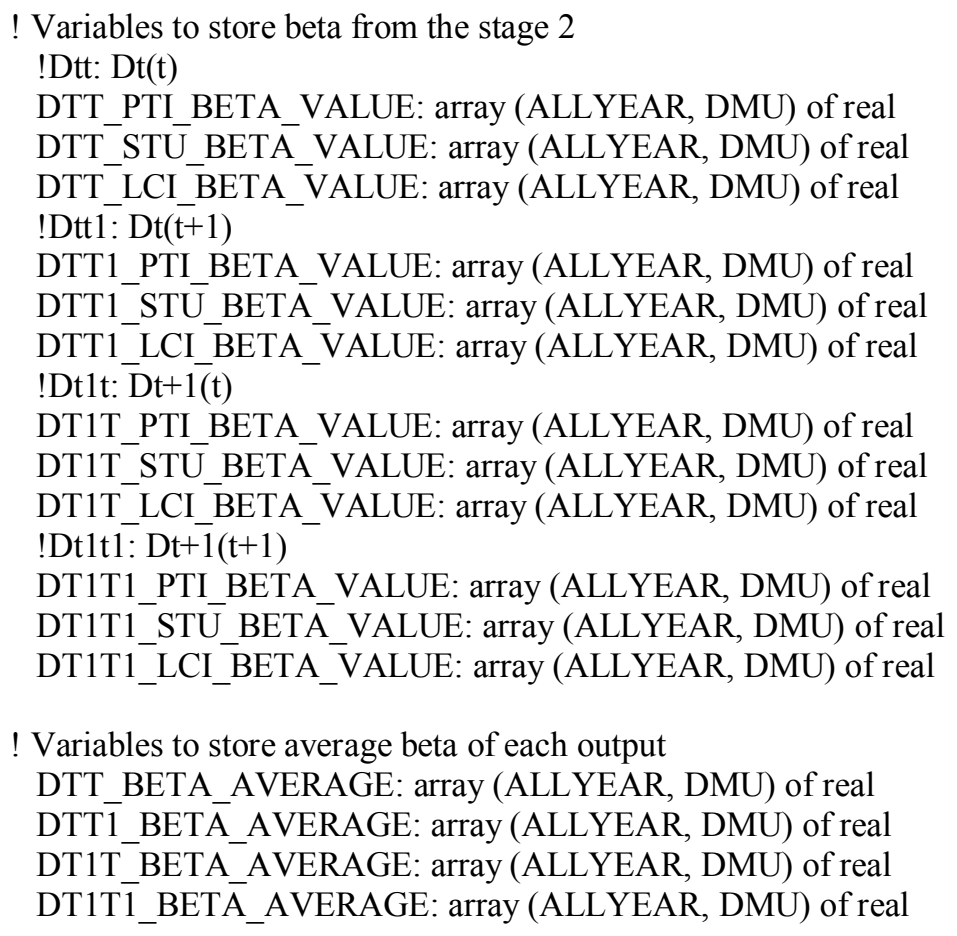

! Variables to store average beta of each output DTT_BETA_AVERAGE: array (ALLYEAR, DMU) of real DTT1_BETA_AVERAGE: array (ALLYEAR, DMU) of real DT1T_BETA_AVERAGE: array (ALLYEAR, DMU) of real DT1T1_BETA_AVERAGE: array (ALLYEAR, DMU) of real

end-declarations

initializations from DATAFILE

ID NAMES YEAR EXP PTI STU LCI ! Reads the data from the above file end-initializations

! \#\#\# Stage 1: Calculate input saving. If it is not zero, the DMU is an infeasible case. \#\#\#

forall (dmu_year in ALLYEAR $\mid$ START_YEAR $<=$ dmu_year AND dmu_year $<=$ END_YEAR) do

forall(k in DMU) do

!Dtt: $\mathrm{Dt}(\mathrm{t})$

sum (j in DMU $\mid \mathrm{j}>\mathrm{k})$ Stage1_Dtt_Lambda $\left(\mathrm{dmu} \_\right.$year, $\left.\mathrm{j}, \mathrm{k}\right)=1 \quad$ ! Variable returns to Scale Stage1_Dtt_Lambda $\left(\mathrm{dmu} \_\right.$year, $\left.\mathrm{k}, \overline{\mathrm{k}}\right)=0$

sum (j in DMU $\mid \mathrm{j} \diamond \mathrm{k})$ Stage1_Dtt_Lambda $\left(\mathrm{dmu} \_\right.$year,j,k)*EXP(dmu_year, j) - Dtt_Exp_Saving

$\left(\mathrm{dmu} \_\right.$year, $\left.\mathrm{k}\right)<=\mathrm{EXP}\left(\mathrm{dmu} \_\right.$year,k)!input, EXP, constraint

!Dtt1: Dt(t+1)

sum (j in DMU) Stage1_Dtt1_Lambda $\left(d m u \_y e a r, j, k\right)=1 \quad$ ! Variable returns to Scale

sum (j in DMU) Stage1_Dtt1_Lambda(dmu_year,j,k)*EXP(dmu_year, j) - Dtt1_Exp_Saving

$\left(\mathrm{dmu} \_\right.$year, $\left.\mathrm{k}\right)<=\mathrm{EXP}\left(\mathrm{dmu} \_\right.$year $\left.+1, \mathrm{k}\right)$ ! input, EXP, constraint

!Dt1t: Dt+1(t)

sum (j in DMU) Stage1_Dt1t_Lambda $\left(\mathrm{dmu} \_\right.$year, $\left.\mathrm{j}, \mathrm{k}\right)=1 \quad$ ! Variable returns to Scale sum (j in DMU) Stage1_Dt1t_Lambda (dmu_year,j,k)*EXP(dmu_year+1, j) - Dt1t_Exp_Saving $\left(\mathrm{dmu} \_\right.$year, $\left.\mathrm{k}\right)<=\mathrm{EXP}\left(\mathrm{dmu} \_\right.$year, $\left.\mathrm{k}\right)$ ! input, EXP, constraint 
!Dt1t1: Dt+1(t+1)

sum ( $\mathrm{j}$ in DMU $\mid \mathrm{j}<>\mathrm{k})$ Stage1_Dt1t1_Lambda $\left(\mathrm{dmu} \_\right.$year,j,k)=1 ! Variable returns to Scale

Stage1_Dt1t1_Lambda $\left(\mathrm{dmu} \_\right.$year, $\left.\mathrm{k}, \overline{\mathrm{k}}\right)=0$

sum $(\mathrm{j}$ in DMU $\mid \mathrm{j}<>\mathrm{k})$ Stage1_Dt1t1_Lambda $(\mathrm{dmu}$ year, $\mathrm{j}, \mathrm{k}) * \operatorname{EXP}(\mathrm{dmu}$ year $+1, \mathrm{j})$ -

Dt1t1_Exp_Saving $\left(\mathrm{dmu} \_\right.$year, $\left.\mathrm{k}\right)<=\overline{\mathrm{EXP}}\left(\mathrm{dm} u \_y e a r+1, \mathrm{k}\right)$ ! input, EXP, constraint

end-do ! evalute all DMUs

end-do ! Stage1 DEA loop, evaluate all years (from start year to end year)

minimize (sum ( $\mathrm{k}$ in DMU, dmu year in ALLYEAR | START_YEAR $<=$ dmu_year AND dmu_year $<=$ END_YEAR)

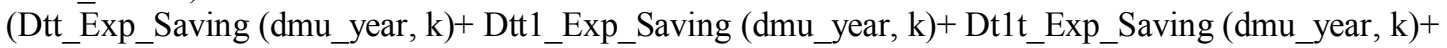

Dt1t1_Exp_Saving $\left(\mathrm{dmu} \_\right.$year, $\left.\left.\left.\mathrm{k}\right)\right)\right)$ ! object function: minimize input saving

! Print input saving table

writeln("'")

writeln("Input Saving Table")

writeln("==================")

writeln("ID", " ","INST NAME"," ", "YEAR"," ", "INPUT SAVING")

writeln(" Dtt Dtt1 Dt1t Dt1t1")

writeln("--------------------o")

forall (dmu_year in ALLYEAR $\mid$ START_YEAR $<=$ dmu_year AND dmu_year $<=$ END_YEAR) do forall(k in DMU) do

writeln(ID(dmu_year,k), "\t",NAMES(dmu_year,k),"ไt", dmu_year,"ไt",getsol(Dtt_Exp_Saving

$(\mathrm{dmu}$ year, $\mathrm{k})), " \backslash \mathrm{t}$, getsol(Dtt1_Exp_Saving $(\mathrm{dmu}$ _year, $\mathrm{k})), " \backslash \mathrm{t} "$,getsol(Dt1t_Exp_Saving (dmu_year,

k)),"ไt",getsol(Dt1t1_Exp_Saving (dmu_year, k)) ) end-do

end-do

writeln("------------------------------------------------")

! Store input savings to the variables for the stage2

forall (dmu year in ALLYEAR $\mid$ START_YEAR $<=$ dmu_year AND dmu_year $<=$ END_YEAR) do forall(k in DMU) do

DTT_EXP_STAGE1_SAVING(dmu_year, $\mathrm{k}):=$ getsol(Dtt_Exp_Saving $(\mathrm{dmu}$ year, $\mathrm{k}))$

DTT1_EXP_STAGE1_SAVING(dmu_year, $\mathrm{k}):=\operatorname{getsol}(\mathrm{Dtt} 1$ Exp_Saving $(\mathrm{dmu}$-year, $\mathrm{k})$ )

DT1T_EXP_STAGE1_SAVING(dmu_year, $\mathrm{k}):=$ getsol(Dt1t_Exp_Saving $($ dmu_year, $\mathrm{k}))$

DT1T1_EXP_STAGE1_SAVING(dmu_year, $\mathrm{k}):=\operatorname{getsol}(\mathrm{Dt} 1 \mathrm{t} 1$ _Exp_Saving $(\mathrm{dmu}$ _year, $\mathrm{k}))$ end-do

end-do

! \#\#\#\# End of Stage 1 \#\#\#\#

! \#\#\# Stage 2: Using the input savings from the stage 1 evalute super efficiency of the DMUs for all years \#\#\#

forall (dmu_year in ALLYEAR $\mid$ START_YEAR $<=$ dmu_year AND dmu_year $<=$ END_YEAR) do

forall(k in DMU) do

!! Input constraints

!Dtt: Dt(t) 
sum ( $\mathrm{j}$ in DMU $\mid \mathrm{j} \diamond \mathrm{k})$ Stage2_Dtt_Lambda $\left(\mathrm{dmu} \_\right.$year, $\left.\mathrm{j}, \mathrm{k}\right)=1 \quad$ ! Variable returns to Scale Stage2_Dtt_Lambda $\left(\mathrm{dmu} \_\right.$year, $\left.\mathrm{k}, \mathrm{k}\right)=0$ sum ( $\mathrm{j}$ in DMU $\mid \mathrm{j}<\mathrm{k}$ ) Stage2_Dtt_Lambda(dmu year,j,k)*EXP(dmu year, $\mathrm{j})$ -

DTT_EXP_STAGE1_SAVING $(\mathrm{dmu}$ _year, $\mathrm{k})<=\operatorname{EXP}\left(\mathrm{dmu} \_\right.$year,k) !input, EXP, constraint

!Dtt1: Dt(t+1)

sum ( $\mathrm{j}$ in DMU) Stage2_Dtt1_Lambda $\left(\mathrm{dmu} \_\right.$year, $\left.\mathrm{j}, \mathrm{k}\right)=1$ ! Variable returns to Scale sum ( $\mathrm{j}$ in DMU) Stage2 Dtt1_Lambda(dmu year, $\mathrm{j}, \mathrm{k})^{*} \mathrm{EXP}(\mathrm{dmu}$ year, $\mathrm{j})$ -

DTT1_EXP_STAGE1_SAVING $(\mathrm{dmu}$ _year, $\mathrm{k})<=\overline{\operatorname{EXP}}\left(\mathrm{dmu} \_\right.$year $\left.+1, \mathrm{k}\right) \quad$ !input, EXP, constraint

!Dt1t: Dt+1(t)

sum ( $\mathrm{j}$ in DMU) Stage2_Dt1t_Lambda $\left(\mathrm{dmu} \_\right.$year, $\left.\mathrm{j}, \mathrm{k}\right)=1$ ! Variable returns to Scale $\operatorname{sum}(\mathrm{j}$ in DMU) Stage2_Dt1t_Lambda(dmu_year,j,k)*EXP(dmu_year $+1, \mathrm{j})$ -

DT1T_EXP_STAGE1_SAVING $(\mathrm{dmu}$ _year, $\mathrm{k})<=\overline{\operatorname{EXP}}(\mathrm{dmu}$ _year,k) !input, EXP, constraint

!Dt1t1: Dt+1(t+1)

sum $(\mathrm{j}$ in DMU $\mid \mathrm{j}<>\mathrm{k})$ Stage2_Dt1t1_Lambda $(\mathrm{dmu}$ _year, $\mathrm{j}, \mathrm{k})=1 \quad$ ! Variable returns to Scale Stage2_Dt1t1_Lambda $($ dmu year, $\mathrm{k}, \mathrm{k})=0$ sum (j in DMU $\mid \mathrm{j}<>\mathrm{k})$ Stage2_Dt1t1_Lambda $\left(d m u \_y e a r, j, k\right) * \operatorname{EXP}\left(d m u \_y e a r+1, j\right)$ -

DT1T1_EXP_STAGE1_SAVING $(\mathrm{dmu}$ _year, $\mathrm{k})<=\mathrm{EXP}\left(\mathrm{dmu} \_\right.$year+1,k) !input, EXP, constraint

!! Output Constraints

!Dtt: $\mathrm{Dt}(\mathrm{t})$

sum $(\mathrm{j}$ in DMU $\mid \mathrm{j} \diamond \mathrm{k})$ Stage2_Dtt_Lambda $\left(\mathrm{dmu} \_\right.$year,j,k)*PTI(dmu year, $\left.\mathrm{j}\right)>=$ PTI $(\mathrm{dmu}$ year,

k)*Dtt_PTI_Beta(dmu_year, k) !output PTI constraint sum $(\mathrm{j}$ in DMU $\mid \mathrm{j}<>\mathrm{k})$ Stage2_Dtt_Lambda $\left(\mathrm{dmu} \_\right.$year,j,k)*STU$\left(\mathrm{dmu} \_\right.$year, $\left.\mathrm{j}\right)>=\mathrm{STU}\left(\mathrm{dmu} \_\right.$year,

k)*Dtt_STU_Beta(dmu_year, k) !output STU constraint sum $(\bar{j}$ in DMU $\mid j<>k)$ Stage2_Dtt_Lambda(dmu_year,j,k)*LCI $\left(d m u \_y e a r, j\right)>=L C I\left(d m u \_y e a r\right.$,

k)*Dtt_LCI_Beta(dmu_year, k) !output LCI constraint

!Dtt1: Dt(t+1)

sum (j in DMU) Stage2_Dtt1_Lambda $\left(d m u \_y e a r, j, k\right) * P T I\left(d m u \_y e a r, j\right)>=P T I\left(d m u \_\right.$year +1 ,

k)*Dtt1_PTI_Beta(dmu year, $\bar{k}) \quad$ !output PTI constraint sum (j in DMU) Stage2_Dtt1_Lambda(dmu_year,j,k)*STU(dmu year, j) $>=S T U\left(d m u \_y e a r+1\right.$,

k)*Dtt1_STU Beta(dmu year, $\mathrm{k})$ !output STU constraint sum (j in DMU) Stage2 Dtt1 Lambda (dmu year,j,k)*LCI (dmu year, $\mathrm{j})>=\operatorname{LCI}(\mathrm{dmu}$ year +1 ,

k)*Dtt1_LCI_Beta(dmu_year, $\mathrm{k}) \quad$ !output LCI constraint

!Dt1t: Dt+1(t)

sum ( $\mathrm{j}$ in DMU) Stage2_Dt1t_Lambda(dmu_year,j,k)*PTI (dmu_year $+1, \mathrm{j})>=$ PTI $\left(\mathrm{dmu} \_\right.$year,

k)*Dt1t_PTI_Beta(dmu year, $\overline{\mathrm{k}})$ !output PTI constraint sum (j in DMU) Stage2_Dt1t_Lambda(dmu_year,j,k)*STU(dmu_year $+1, \mathrm{j})>=\mathrm{STU}(\mathrm{dmu}$ year,

k)*Dt1t_STU_Beta(dmu_year, k) !output STU constraint sum (j in DMU) Stage2_Dt1t_Lambda(dmu_year,j,k)*LCI (dmu_year+1, j $)>=$ LCI (dmu_year,

$\mathrm{k}) *$ Dt1t_LCI_Beta(dmu_year, $\mathrm{k})$ !output LCI constraint

!Dt1t1: Dt+1(t+1) sum (j in DMU $\mid \mathrm{j}<>\mathrm{k})$ Stage2_Dt1t1_Lambda $\left(\mathrm{dmu} \_\right.$year,j,k)*PTI $\left(\mathrm{dmu} \_\right.$year $\left.+1, \mathrm{j}\right)>=$

PTI $(\text { dmu_year }+1, \mathrm{k})^{*}$ Dt1t1_PTI Beta $(\mathrm{dmu}$ year, $\mathrm{k})$ !output PTI constraint sum $(\mathrm{j}$ in DMU $\mid \mathrm{j}>\mathrm{k})$ Stage2_Dt1t1_Lambda $(\mathrm{dmu}$ year,j,k)*STU$(\mathrm{dmu}$ year $+1, \mathrm{j})>=$

STU(dmu_year+1, k)*Dt1t1_STU_Beta(dmu_year, k) !output STU constraint sum $(\mathrm{j}$ in DMU $\mid \mathrm{j}<>\mathrm{k})$ Stage2_Dt1t1_Lambda $\left(\mathrm{dmu} \_\right.$year, $\left.\mathrm{j}, \mathrm{k}\right) * \mathrm{LCI}(\mathrm{dmu}$ year+1, $\mathrm{j})>=$

LCI $($ dmu_year $+1, \mathrm{k}) *$ Dt1t1_LCI_Beta(dmu_year, $\mathrm{k})$ ! output LCI constraint 
end-do ! evalute all DMUs

end-do ! Stage 2 DEA loop, evaluate all years (from start year to end year)

forall (dmu_year in ALLYEAR $\mid$ START_YEAR $<=$ dmu_year AND dmu_year $<=$ END_YEAR) do

forall( $\mathrm{k}$ in DMU) do

Dtt_PTI_Beta $($ dmu_year, $\mathrm{k})<=\mathrm{M}$

Dtt_STU__Beta $($ dmu_year, $\mathrm{k})<=\mathrm{M}$

Dtt_LCI_Beta(dmu_year, $\mathrm{k})<=\mathrm{M}$

Dtt1_PTI_Beta(dmu_year, $\mathrm{k})<=\mathrm{M}$

Dtt1_STU_Beta $($ dmu_year, $\mathrm{k})<=\mathrm{M}$

Dtt1_LCI_Beta $($ dmu_year, $\mathrm{k})<=\mathrm{M}$

Dt1t_PTI_Beta(dmu_year, $\mathrm{k})<=\mathrm{M}$

Dt1t_STU_Beta $($ dmu_year, $\mathrm{k})<=\mathrm{M}$

Dt1t_LCI_Beta $($ dmu_year, $\mathrm{k})<=\mathrm{M}$

Dt1t1_PTI_Beta(dmu_year, $\mathrm{k})<=\mathrm{M}$

Dt1t1_STU_Beta $($ dmu_year, $\mathrm{k})<=\mathrm{M}$

end-do

Dt1t1_LCI_Beta $($ dmu_year, $\mathrm{k})<=\mathrm{M}$

end-do

maximize (sum $(\mathrm{k}$ in DMU, dmu_year in ALLYEAR $\mid$ START_YEAR $<=$ dmu_year AND dmu_year $<=$ END_YEAR)

$($ Dtt_PTI_Beta $($ dmu_year, $\mathrm{k})+$ Dtt1_PTI_Beta(dmu_year, k)+Dt1t_PTI_Beta(dmu_year,

$\mathrm{k})+\overline{\mathrm{D}} \mathrm{t} 1 \mathrm{t} 1 \_$PTI_Beta(dmu_year, $\left.\mathrm{k}\right)+$

Dtt_STU_Beta(dmu_year, k)+Dtt1_STU_Beta(dmu_year, k)+Dt1t_STU_Beta(dmu_year,

$\mathrm{k})+\overline{\mathrm{D}} \mathrm{t} 1 \mathrm{t} 1$ STU_Beta $(\mathrm{dmu} \text { year, } \mathrm{k})^{-}{ }^{-}$

Dtt_LCI_Beta $(\overline{\mathrm{d}} m u$ year, $\overline{\mathrm{k}})+\mathrm{Dtt1}$ LCI_Beta(dmu_year, k)+Dt1t_LCI_Beta(dmu_year,

$\mathrm{k})+\overline{\mathrm{D}} \mathrm{t} 1 \mathrm{t} 1 \_$LCI_Beta(dmu_year, $\left.\left.\mathrm{k}\right)\right) \overline{)}$

! Save beta to the static variables for the post evalution

forall (dmu_year in ALLYEAR $\mid$ START_YEAR $<=$ dmu_year AND dmu_year $<=$ END_YEAR) do forall(k in DMU) do

!Dtt: Dt(t)

if getsol(Dtt_PTI_Beta $($ dmu_year,k) $)=1000$ or getsol(Dtt_PTI_Beta $($ dmu_year,k $))=0$ then

DTT_PTI_BETA_VALUE $(\mathrm{dmu}$ _year,k):=1

else DTT_PTI_BETA_VALUE(dmu_year,k):=getsol(Dtt_PTI_Beta(dmu_year,k))

end-if

if getsol(Dtt_STU_Beta $($ dmu_year,k) $)=1000$ or getsol(Dtt_STU_Beta $($ dmu_year,k $))=0$ then

DTT_STU_BETA_VALUEE $(\mathrm{dmu}$ _year,k):=1

else DTT_STU_BETA_VALUE(dmu_year,k):= getsol(Dtt_STU_Beta(dmu_year,k))

end-if 
if getsol(Dtt_LCI_Beta(dmu_year,k))=1000 or getsol(Dtt_LCI_Beta(dmu_year,k)) $=0$ then DTT_LCI_BETA_VALUE(dmu year,k):=1

else DTT_LCI_BETA_VALUE(dmu_year,k):=getsol(Dtt_LCI_Beta(dmu_year,k))

end-if

!Dtt1: Dt(t+1)

if getsol(Dtt1_PTI_Beta $($ dmu_year,k) $)=1000$ or getsol(Dtt1_PTI_Beta $($ dmu_year,k $))=0$ then

DTT1_PTI_BETA_V̄ALÜE(dmu_year,k):=1

else DTT1_PTI_BETA_VALUE(dmu_year,k):= getsol(Dtt1_PTI_Beta(dmu_year,k))

end-if

if getsol(Dtt1_STU_Beta(dmu_year,k)) $=1000$ or getsol(Dtt1_STU_Beta(dmu_year,k)) $=0$ then

DTT1_STU_BETA_VALÜE(dmu_year,k):=1

else DTT1_STU_BETA_VALLUE(dmu_year,k):=getsol(Dtt1_STU_Beta(dmu_year,k))

end-if

if getsol(Dtt1_LCI_Beta(dmu_year,k))=1000 or getsol(Dtt1_LCI_Beta(dmu_year,k)) 0 then

DTT1_LCI_BETA_VALUE $(\mathrm{dmu}$ year,k):= 1

else DTT1_LCI_BETA_VÁLUE(dmu_year,k):=getsol(Dtt1_LCI_Beta(dmu_year,k))

end-if

!Dt1t: Dt+1(t)

if getsol(Dt1t_PTI_Beta $\left(\mathrm{dmu} \_\right.$year,k) $)=1000$ or getsol(Dt1t_PTI_Beta $(\mathrm{dmu}$ year,k) $)=0$ then

DT1T_PTI_BETA_VALUEE(dmu_year,k):=1

else DT1T_PTI_BETA_VALUE(dmu_year,k):=getsol(Dt1t_PTI_Beta(dmu_year,k))

end-if

if getsol(Dt1t_STU_Beta(dmu_year,k) $)=1000$ or getsol(Dt1t_STU_Beta(dmu_year,k $))=0$ then

DT1T_STU_BETA_VALŪE(dmu_year,k):=1

else DT1T_STU_BETA_VALUE(dmu_year,k):=getsol(Dt1t_STU_Beta(dmu_year,k))

end-if

if getsol(Dt1t_LCI_Beta(dmu_year,k))=1000 or getsol(Dt1t_LCI_Beta(dmu_year,k))=0 then

DT1T_LCI_BETA_V_ALÜE(dmu_year,k):=1

else DT1T_LCI_BETA_VALUE(dmu_year,k):=getsol(Dt1t_LCI_Beta(dmu_year,k))

end-if

!Dt1t1: Dt+1(t+1)

if getsol(Dt1t1_PTI_Beta(dmu_year,k) $)=1000$ or getsol(Dt1t1_PTI_Beta(dmu_year,k $))=0$ then

DT1T1_PTI_BETA_V VALUE $(\mathrm{dmu}$ year,k):=1

else DT1T1_PTI_BETA_VALUE(dmu_year,k):=getsol(Dt1t1_PTI_Beta(dmu_year,k))

end-if

if getsol(Dt1t1_STU_Beta $\left(\mathrm{dmu} \_\right.$year,k) $)=1000$ or getsol(Dt1t1_STU_Beta $($ dmu_year,k $\left.)\right)=0$ then

DT1T1_STU_BETA_VALUE $(\mathrm{dmu}$ _year,k):=1

else DT1T1_STU_BETA_VALUE(dmu_year,k):=getsol(Dt1t1_STU_Beta(dmu_year,k))

end-if

if getsol(Dt1t1_LCI_Beta(dmu_year,k))=1000 or getsol(Dt1t1_LCI_Beta(dmu_year,k) $=0$ then

DT1T1_LCI_BETA_VALUE(dmu_year,k):=1

else DT1T1_LCI_BETA_VALUE(dmu_year,k):=getsol(Dt1t1_LCI_Beta(dmu_year,k))

end-if 
end-do

end-do

! Calcualte Average Beta of the Three Ouptut Betas

forall (dmu year in ALLYEAR $\mid$ START_YEAR $<=$ dmu year AND dmu_year $<=$ END_YEAR) do forall(k in DMU) do

DTT_BETA_AVERAGE $(\mathrm{dmu}$ year,k):=

(DTT_PTI_BETA_VALUE(dmu_year,k)+DTT_STU_BETA_VALUE(dmu_year,k)+DTT_LCI_BETA_V

$\operatorname{ALUE}(\mathrm{dmu}$ year, $\overline{\mathrm{k}})) / 3$

DTT1_BETA_AVERAGE(dmu_year,k):=

(DTT1_PTI_BETA_VALUE(dmu_year,k)+DTT1_STU_BETA_VALUE(dmu_year,k)+DTT1_LCI_BET

A_VALUE $($ dmu_year,k) $) / 3$

DT1T_BETA_AVERAGE(dmu year,k):=

(DT1T_PTI_BETA_VALUE(dmu_year,k)+DT1T_STU_BETA_VALUE(dmu_year,k)+DT1T_LCI_BET

A_VAL̄UE $(\overline{d m u}$ year,k) $) / 3$

DT1T1_BETA_AVERAGE(dmu_year,k):=

(DT1T1_PTI_BETA_VALUE(dmu_year,k)+DT1T1_STU_BETA_VALUE(dmu_year,k)+DT1T1_LCI_B

ETA_VALUE(dmu_year,k))/3 end-do

end-do

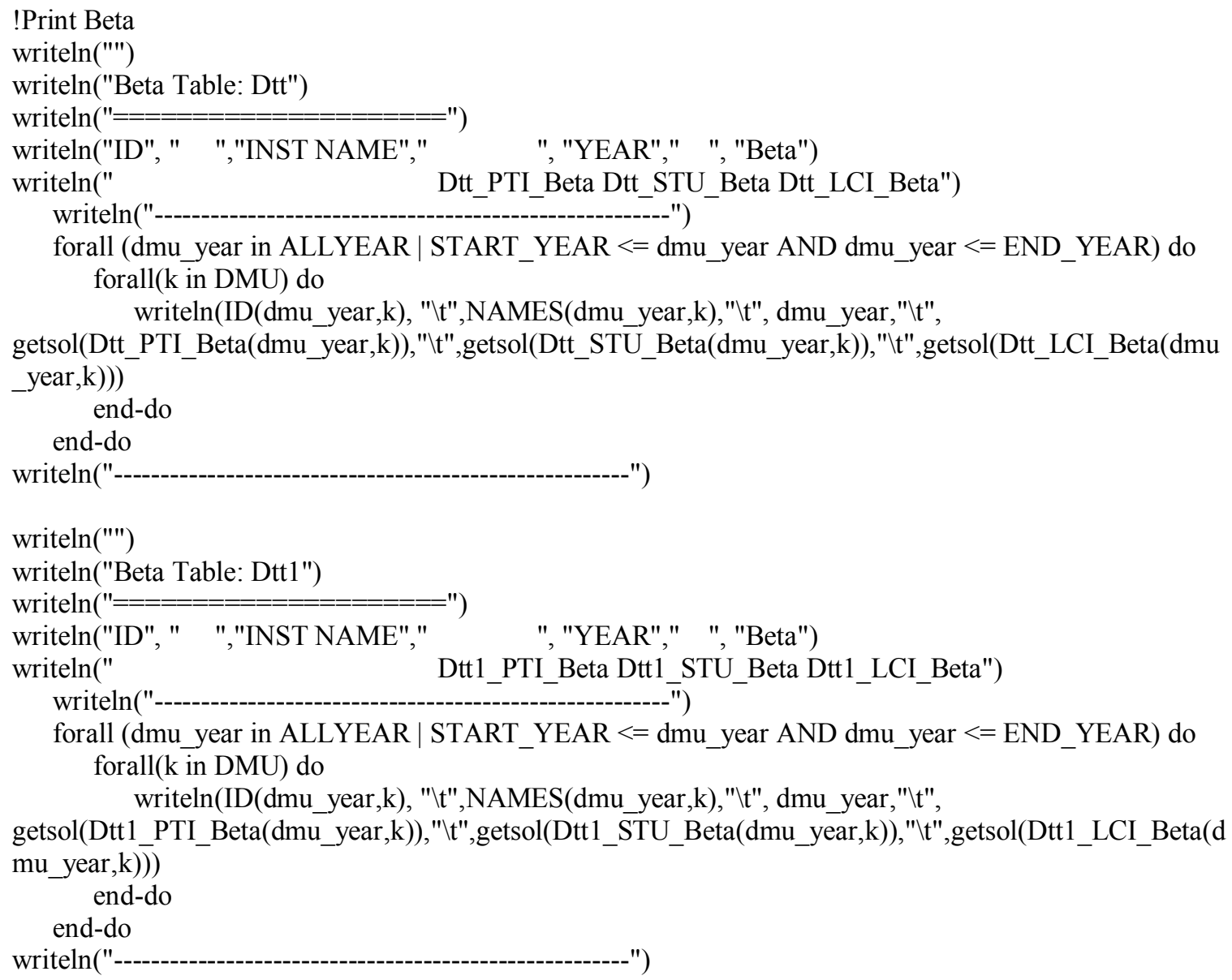




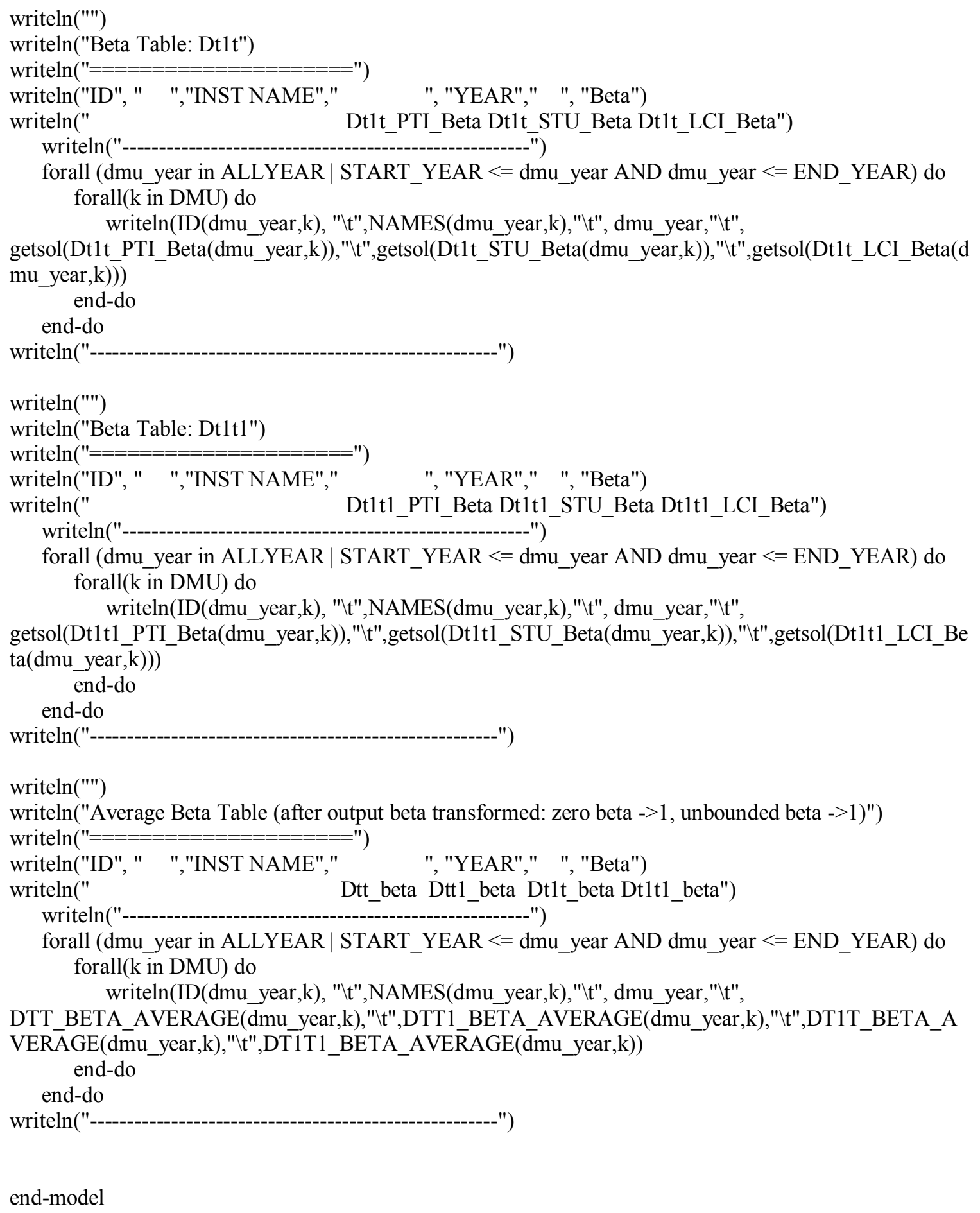

end-model 
Appendix D. Modified Super-Efficiency Score of the 46 Institutions during the period

Table D1: Modified Super-Efficiency Score of the 46 U.S. Institutions

\begin{tabular}{|c|c|c|c|c|c|c|}
\hline $\begin{array}{c}\text { DMU } \\
\text { ID }\end{array}$ & Institutions & Year & $\operatorname{Dt}(\mathbf{t})$ & $\operatorname{Dt}(\mathbf{t}+1)$ & $D t+1(t)$ & $D t+1(t+1)$ \\
\hline 1 & Baylor College of Medicine & 1991 & 0.10 & 0.48 & 0.08 & 0.27 \\
\hline 2 & Brigham \& Women's Hospital, Inc. & 1991 & 0.56 & 1.20 & 0.32 & 0.61 \\
\hline 3 & Brigham Young Univ. & 1991 & 2.09 & 1.08 & 2.50 & 1.16 \\
\hline 4 & California Institute of Tech. & 1991 & 0.87 & 1.97 & 0.49 & 1.52 \\
\hline 5 & Case Western Reserve Univ. & 1991 & 0.35 & 0.31 & 0.18 & 0.15 \\
\hline 6 & City of Hope National Medic & 1991 & 5.17 & 1.49 & 0.99 & 2.47 \\
\hline 7 & Clemson Univ. & 1991 & 0.54 & 0.74 & 0.44 & 0.40 \\
\hline 8 & Colorado State Univ. & 1991 & 0.42 & 0.34 & 0.22 & 0.19 \\
\hline 9 & Dartmouth College & 1991 & 0.21 & 0.55 & 0.12 & 0.34 \\
\hline 10 & Florida State Univ. & 1991 & 0.32 & 0.99 & 0.22 & 0.96 \\
\hline 11 & Fred Hutchinson Cancer Res. & 1991 & 0.21 & 0.22 & 0.12 & 0.11 \\
\hline 12 & Georgia Inst. of Technology & 1991 & 0.44 & 0.73 & 0.24 & 0.39 \\
\hline 13 & Harvard Univ. & 1991 & 0.41 & 0.89 & 0.29 & 0.60 \\
\hline 14 & Indiana Univ. (ARTI) & 1991 & 0.18 & 0.29 & 0.09 & 0.14 \\
\hline 15 & Johns Hopkins Univ. & 1991 & 0.31 & 0.74 & 0.24 & 0.35 \\
\hline 16 & Massachusetts Inst. of Tech & 1991 & 3.33 & 2.16 & 0.76 & 2.79 \\
\hline 17 & Mayo Foundation & 1991 & 0.61 & 0.97 & 0.35 & 0.52 \\
\hline 18 & Michigan State Univ. & 1991 & 0.77 & 0.99 & 0.60 & 0.64 \\
\hline 19 & National Jewish Center & 1991 & 0.37 & 0.22 & 0.25 & 0.15 \\
\hline 20 & New Jersey Institute of Tech. & 1991 & 0.14 & 0.89 & 0.10 & 0.55 \\
\hline 21 & Northwestern Univ. & 1991 & 0.28 & 0.53 & 0.14 & 0.26 \\
\hline 22 & Ohio State Univ. & 1991 & 0.32 & 0.77 & 0.16 & 0.37 \\
\hline 23 & Ohio Univ. & 1991 & 3.01 & 3.27 & 1.56 & 5.11 \\
\hline 24 & Oregon State Univ. & 1991 & 0.13 & 0.24 & 0.07 & 0.13 \\
\hline 25 & Penn State Univ. & 1991 & 0.25 & 0.28 & 0.18 & 0.18 \\
\hline 26 & Rutgers, The State Univ. & 1991 & 0.48 & 0.90 & 0.28 & 0.45 \\
\hline 27 & St. Jude Children's Researc & 1991 & 0.34 & 0.10 & 0.21 & 0.06 \\
\hline 28 & Tulane Univ. & 1991 & 0.45 & 0.55 & 0.28 & 0.33 \\
\hline 29 & Univ. of Akron & 1991 & 2.11 & 1.42 & 1.11 & 0.97 \\
\hline 30 & Univ. of Arizona & 1991 & 0.16 & 0.34 & 0.10 & 0.16 \\
\hline 31 & Univ. of Cincinnati & 1991 & 0.56 & 0.59 & 0.34 & 0.34 \\
\hline 32 & Univ. of Connecticut & 1991 & 0.40 & 0.65 & 0.22 & 0.34 \\
\hline 33 & Univ. of Dayton & 1991 & 0.49 & 0.58 & 0.30 & 0.33 \\
\hline
\end{tabular}


Table D1: Modified Super-Efficiency Score of the 46 U.S. Institutions (continued)

\begin{tabular}{|c|c|c|c|c|c|c|}
\hline $\begin{array}{c}\text { DMU } \\
\text { ID }\end{array}$ & Institutions & Year & $\operatorname{Dt}(\mathbf{t})$ & $\operatorname{Dt}(\mathbf{t}+1)$ & $D t+1(t)$ & $D t+1(t+1)$ \\
\hline 34 & Univ. of Delaware & 1991 & 0.45 & 0.61 & 0.32 & 0.34 \\
\hline 35 & Univ. of Iowa Research Fdn. & 1991 & 0.27 & 0.46 & 0.14 & 0.22 \\
\hline 36 & Univ. of Maryland, College & 1991 & 0.35 & 0.53 & 0.20 & 0.26 \\
\hline 37 & Univ. of Michigan & 1991 & 0.20 & 0.58 & 0.10 & 0.40 \\
\hline 38 & Univ. of Minnesota & 1991 & 0.45 & 1.08 & 0.32 & 0.51 \\
\hline 39 & Univ. of Oregon & 1991 & 0.70 & 0.70 & 0.42 & 0.39 \\
\hline 40 & Univ. of Southern California & 1991 & 0.36 & 0.57 & 0.23 & 0.32 \\
\hline 41 & Univ. of Texas Southwestern & 1991 & 0.41 & 0.84 & 0.23 & 0.42 \\
\hline 42 & Univ. of Utah & 1991 & 0.86 & 1.32 & 0.45 & 0.74 \\
\hline 43 & Univ. of Virginia Patent Fdn. & 1991 & 0.66 & 1.07 & 0.37 & 0.56 \\
\hline 44 & Vanderbilt Univ. & 1991 & 0.18 & 0.21 & 0.10 & 0.12 \\
\hline 45 & Wake Forest Univ. & 1991 & 0.40 & 0.59 & 0.24 & 0.34 \\
\hline 46 & Washington Univ. & 1991 & 0.41 & 0.53 & 0.34 & 0.26 \\
\hline 1 & Baylor College of Medicine & 1992 & 0.27 & 0.27 & 0.28 & 0.25 \\
\hline 2 & Brigham \& Women's Hospital, Inc. & 1992 & 0.61 & 0.48 & 0.44 & 0.37 \\
\hline 3 & Brigham Young Univ. & 1992 & 1.16 & 72.50 & 0.60 & 17.66 \\
\hline 4 & California Institute of Tech. & 1992 & 1.52 & 1.44 & 1.15 & 1.57 \\
\hline 5 & Case Western Reserve Univ. & 1992 & 0.15 & 0.20 & 0.11 & 0.15 \\
\hline 6 & City of Hope National Medic & 1992 & 2.47 & 1.04 & 1.15 & 1.74 \\
\hline 7 & Clemson Univ. & 1992 & 0.40 & 0.20 & 0.32 & 0.17 \\
\hline 8 & Colorado State Univ. & 1992 & 0.19 & 0.11 & 0.19 & 0.12 \\
\hline 9 & Dartmouth College & 1992 & 0.34 & 0.25 & 0.32 & 0.17 \\
\hline 10 & Florida State Univ. & 1992 & 0.96 & 1.46 & 0.79 & 1.41 \\
\hline 11 & Fred Hutchinson Cancer Res. & 1992 & 0.11 & 0.35 & 0.08 & 0.27 \\
\hline 12 & Georgia Inst. of Technology & 1992 & 0.39 & 0.33 & 0.32 & 0.32 \\
\hline 13 & Harvard Univ. & 1992 & 0.60 & 0.47 & 0.50 & 0.43 \\
\hline 14 & Indiana Univ. (ARTI) & 1992 & 0.14 & 0.24 & 0.12 & 0.20 \\
\hline 15 & Johns Hopkins Univ. & 1992 & 0.35 & 0.47 & 0.34 & 0.47 \\
\hline 16 & Massachusetts Inst. of Tech & 1992 & 2.79 & 1.19 & 1.15 & 2.34 \\
\hline 17 & Mayo Foundation & 1992 & 0.52 & 0.29 & 0.40 & 0.26 \\
\hline 18 & Michigan State Univ. & 1992 & 0.64 & 0.85 & 0.56 & 0.86 \\
\hline 19 & National Jewish Center & 1992 & 0.15 & 0.51 & 0.13 & 0.21 \\
\hline 20 & New Jersey Institute of Tech. & 1992 & 0.55 & 1.65 & 0.46 & 0.61 \\
\hline 21 & Northwestern Univ. & 1992 & 0.26 & 0.54 & 0.20 & 0.38 \\
\hline
\end{tabular}


Table D1: Modified Super-Efficiency Score of the 46 U.S. Institutions (continued)

\begin{tabular}{|c|c|c|c|c|c|c|}
\hline $\begin{array}{c}\text { DMU } \\
\text { ID }\end{array}$ & Institutions & Year & $\operatorname{Dt}(\mathbf{t})$ & $\operatorname{Dt}(t+1)$ & $D t+1(t)$ & $D t+1(t+1)$ \\
\hline 22 & Ohio State Univ. & 1992 & 0.37 & 0.40 & 0.32 & 0.44 \\
\hline 23 & Ohio Univ. & 1992 & 5.11 & 0.85 & 2.35 & 0.46 \\
\hline 24 & Oregon State Univ. & 1992 & 0.13 & 0.29 & 0.10 & 0.21 \\
\hline 25 & Penn State Univ. & 1992 & 0.18 & 0.32 & 0.18 & 0.31 \\
\hline 26 & Rutgers, The State Univ. & 1992 & 0.45 & 0.49 & 0.38 & 0.44 \\
\hline 27 & St. Jude Children's Researc & 1992 & 0.06 & 0.27 & 0.06 & 0.21 \\
\hline 28 & Tulane Univ. & 1992 & 0.33 & 0.32 & 0.31 & 0.28 \\
\hline 29 & Univ. of Akron & 1992 & 0.97 & 1.32 & 0.77 & 1.47 \\
\hline 30 & Univ. of Arizona & 1992 & 0.16 & 0.14 & 0.15 & 0.15 \\
\hline 31 & Univ. of Cincinnati & 1992 & 0.34 & 0.41 & 0.27 & 0.33 \\
\hline 32 & Univ. of Connecticut & 1992 & 0.34 & 0.22 & 0.24 & 0.16 \\
\hline 33 & Univ. of Dayton & 1992 & 0.33 & 0.46 & 0.25 & 0.34 \\
\hline 34 & Univ. of Delaware & 1992 & 0.34 & 0.42 & 0.25 & 0.35 \\
\hline 35 & Univ. of Iowa Research Fdn. & 1992 & 0.22 & 0.25 & 0.19 & 0.22 \\
\hline 36 & Univ. of Maryland, College & 1992 & 0.26 & 0.38 & 0.19 & 0.30 \\
\hline 37 & Univ. of Michigan & 1992 & 0.40 & 0.47 & 0.34 & 0.39 \\
\hline 38 & Univ. of Minnesota & 1992 & 0.51 & 0.48 & 0.52 & 0.48 \\
\hline 39 & Univ. of Oregon & 1992 & 0.39 & 0.34 & 0.29 & 0.27 \\
\hline 40 & Univ. of Southern California & 1992 & 0.32 & 0.48 & 0.33 & 0.52 \\
\hline 41 & Univ. of Texas Southwestern & 1992 & 0.42 & 0.48 & 0.32 & 0.37 \\
\hline 42 & Univ. of Utah & 1992 & 0.74 & 0.57 & 0.76 & 0.44 \\
\hline 43 & Univ. of Virginia Patent Fdn. & 1992 & 0.56 & 0.47 & 0.63 & 0.47 \\
\hline 44 & Vanderbilt Univ. & 1992 & 0.12 & 0.31 & 0.13 & 0.22 \\
\hline 45 & Wake Forest Univ. & 1992 & 0.34 & 0.31 & 0.34 & 0.24 \\
\hline 46 & Washington Univ. & 1992 & 0.26 & 0.38 & 0.27 & 0.37 \\
\hline 1 & Baylor College of Medicine & 1993 & 0.25 & 0.36 & 0.25 & 0.36 \\
\hline 2 & Brigham \& Women's Hospital, Inc. & 1993 & 0.37 & 0.31 & 0.46 & 0.39 \\
\hline 3 & Brigham Young Univ. & 1993 & 17.66 & 2.23 & 0.87 & 3.25 \\
\hline 4 & California Institute of Tech. & 1993 & 1.57 & 0.91 & 1.34 & 1.13 \\
\hline 5 & Case Western Reserve Univ. & 1993 & 0.15 & 0.18 & 0.19 & 0.23 \\
\hline 6 & City of Hope National Medic & 1993 & 1.74 & 0.73 & 1.51 & 0.97 \\
\hline 7 & Clemson Univ. & 1993 & 0.17 & 0.19 & 0.22 & 0.23 \\
\hline 8 & Colorado State Univ. & 1993 & 0.12 & 0.11 & 0.14 & 0.14 \\
\hline 9 & Dartmouth College & 1993 & 0.17 & 0.28 & 0.21 & 0.36 \\
\hline
\end{tabular}


Table D1: Modified Super-Efficiency Score of the 46 U.S. Institutions (continued)

\begin{tabular}{|c|c|c|c|c|c|c|}
\hline $\begin{array}{c}\text { DMU } \\
\text { ID }\end{array}$ & Institutions & Year & $\operatorname{Dt}(\mathbf{t})$ & $\operatorname{Dt}(t+1)$ & $D t+1(t)$ & $D t+1(t+1)$ \\
\hline 10 & Florida State Univ. & 1993 & 1.41 & 1.21 & 1.08 & 2.43 \\
\hline 11 & Fred Hutchinson Cancer Res. & 1993 & 0.27 & 0.17 & 0.34 & 0.22 \\
\hline 12 & Georgia Inst. of Technology & 1993 & 0.32 & 0.58 & 0.36 & 0.64 \\
\hline 13 & Harvard Univ. & 1993 & 0.43 & 0.50 & 0.41 & 0.48 \\
\hline 14 & Indiana Univ. (ARTI) & 1993 & 0.20 & 0.17 & 0.23 & 0.19 \\
\hline 15 & Johns Hopkins Univ. & 1993 & 0.47 & 0.60 & 0.43 & 0.57 \\
\hline 16 & Massachusetts Inst. of Tech & 1993 & 2.34 & 1.12 & 1.12 & 2.35 \\
\hline 17 & Mayo Foundation & 1993 & 0.26 & 0.31 & 0.30 & 0.36 \\
\hline 18 & Michigan State Univ. & 1993 & 0.86 & 0.82 & 0.92 & 0.88 \\
\hline 19 & National Jewish Center & 1993 & 0.21 & 0.22 & 0.21 & 0.23 \\
\hline 20 & New Jersey Institute of Tech. & 1993 & 0.61 & 0.88 & 0.37 & 0.51 \\
\hline 21 & Northwestern Univ. & 1993 & 0.38 & 0.40 & 0.51 & 0.49 \\
\hline 22 & Ohio State Univ. & 1993 & 0.44 & 0.30 & 0.49 & 0.33 \\
\hline 23 & Ohio Univ. & 1993 & 0.46 & 0.50 & 0.47 & 0.50 \\
\hline 24 & Oregon State Univ. & 1993 & 0.21 & 0.11 & 0.28 & 0.15 \\
\hline 25 & Penn State Univ. & 1993 & 0.31 & 0.30 & 0.34 & 0.28 \\
\hline 26 & Rutgers, The State Univ. & 1993 & 0.44 & 0.39 & 0.48 & 0.45 \\
\hline 27 & St. Jude Children's Researc & 1993 & 0.21 & 0.15 & 0.25 & 0.18 \\
\hline 28 & Tulane Univ. & 1993 & 0.28 & 0.23 & 0.36 & 0.27 \\
\hline 29 & Univ. of Akron & 1993 & 1.47 & 2.36 & 1.09 & 3.04 \\
\hline 30 & Univ. of Arizona & 1993 & 0.15 & 0.22 & 0.15 & 0.24 \\
\hline 31 & Univ. of Cincinnati & 1993 & 0.33 & 0.21 & 0.37 & 0.27 \\
\hline 32 & Univ. of Connecticut & 1993 & 0.16 & 0.12 & 0.20 & 0.16 \\
\hline 33 & Univ. of Dayton & 1993 & 0.34 & 0.29 & 0.42 & 0.36 \\
\hline 34 & Univ. of Delaware & 1993 & 0.35 & 0.18 & 0.31 & 0.22 \\
\hline 35 & Univ. of Iowa Research Fdn. & 1993 & 0.22 & 0.37 & 0.25 & 0.44 \\
\hline 36 & Univ. of Maryland, College & 1993 & 0.30 & 0.18 & 0.34 & 0.19 \\
\hline 37 & Univ. of Michigan & 1993 & 0.39 & 0.39 & 0.44 & 0.36 \\
\hline 38 & Univ. of Minnesota & 1993 & 0.48 & 0.48 & 0.52 & 0.49 \\
\hline 39 & Univ. of Oregon & 1993 & 0.27 & 0.22 & 0.27 & 0.23 \\
\hline 40 & Univ. of Southern California & 1993 & 0.52 & 0.42 & 0.57 & 0.46 \\
\hline 41 & Univ. of Texas Southwestern & 1993 & 0.37 & 0.38 & 0.47 & 0.45 \\
\hline 42 & Univ. of Utah & 1993 & 0.44 & 0.51 & 0.55 & 0.59 \\
\hline 43 & Univ. of Virginia Patent Fdn. & 1993 & 0.47 & 0.26 & 0.52 & 0.30 \\
\hline
\end{tabular}


Table D1: Modified Super-Efficiency Score of the 46 U.S. Institutions (continued)

\begin{tabular}{|c|c|c|c|c|c|c|}
\hline $\begin{array}{c}\text { DMU } \\
\text { ID }\end{array}$ & Institutions & Year & $\operatorname{Dt}(\mathbf{t})$ & $\operatorname{Dt}(\mathbf{t}+1)$ & $D t+1(t)$ & $D t+1(t+1)$ \\
\hline 44 & Vanderbilt Univ. & 1993 & 0.22 & 0.20 & 0.29 & 0.26 \\
\hline 45 & Wake Forest Univ. & 1993 & 0.24 & 0.15 & 0.30 & 0.19 \\
\hline 46 & Washington Univ. & 1993 & 0.37 & 0.41 & 0.40 & 0.42 \\
\hline 1 & Baylor College of Medicine & 1994 & 0.36 & 0.24 & 0.41 & 0.19 \\
\hline 2 & Brigham \& Women's Hospital, Inc. & 1994 & 0.39 & 0.50 & 0.31 & 0.37 \\
\hline 3 & Brigham Young Univ. & 1994 & 3.25 & 1.43 & 2.51 & 1.25 \\
\hline 4 & California Institute of Tech. & 1994 & 1.13 & 1.41 & 1.50 & 1.25 \\
\hline 5 & Case Western Reserve Univ. & 1994 & 0.23 & 0.25 & 0.18 & 0.31 \\
\hline 6 & City of Hope National Medic & 1994 & 0.97 & 1.02 & 0.59 & 0.62 \\
\hline 7 & Clemson Univ. & 1994 & 0.23 & 0.19 & 0.16 & 0.13 \\
\hline 8 & Colorado State Univ. & 1994 & 0.14 & 0.23 & 0.11 & 0.34 \\
\hline 9 & Dartmouth College & 1994 & 0.36 & 1.68 & 0.28 & 1.59 \\
\hline 10 & Florida State Univ. & 1994 & 2.43 & 1.18 & 0.95 & 1.02 \\
\hline 11 & Fred Hutchinson Cancer Res. & 1994 & 0.22 & 0.12 & 0.19 & 0.16 \\
\hline 12 & Georgia Inst. of Technology & 1994 & 0.64 & 0.69 & 0.90 & 0.99 \\
\hline 13 & Harvard Univ. & 1994 & 0.48 & 0.51 & 0.38 & 0.41 \\
\hline 14 & Indiana Univ. (ARTI) & 1994 & 0.19 & 0.23 & 0.24 & 0.32 \\
\hline 15 & Johns Hopkins Univ. & 1994 & 0.57 & 0.60 & 0.51 & 0.47 \\
\hline 16 & Massachusetts Inst. of Tech & 1994 & 2.35 & 1.27 & 1.34 & 2.21 \\
\hline 17 & Mayo Foundation & 1994 & 0.36 & 0.32 & 0.35 & 0.24 \\
\hline 18 & Michigan State Univ. & 1994 & 0.88 & 1.02 & 0.64 & 0.74 \\
\hline 19 & National Jewish Center & 1994 & 0.23 & 0.63 & 0.24 & 0.44 \\
\hline 20 & New Jersey Institute of Tech. & 1994 & 0.51 & 0.35 & 1.12 & 0.25 \\
\hline 21 & Northwestern Univ. & 1994 & 0.49 & 0.26 & 0.45 & 0.21 \\
\hline 22 & Ohio State Univ. & 1994 & 0.33 & 0.32 & 0.47 & 0.28 \\
\hline 23 & Ohio Univ. & 1994 & 0.50 & 0.59 & 0.32 & 0.39 \\
\hline 24 & Oregon State Univ. & 1994 & 0.15 & 0.12 & 0.15 & 0.09 \\
\hline 25 & Penn State Univ. & 1994 & 0.28 & 0.30 & 0.31 & 0.28 \\
\hline 26 & Rutgers, The State Univ. & 1994 & 0.45 & 0.46 & 0.53 & 0.35 \\
\hline 27 & St. Jude Children's Researc & 1994 & 0.18 & 0.25 & 0.12 & 0.18 \\
\hline 28 & Tulane Univ. & 1994 & 0.27 & 0.28 & 0.18 & 0.19 \\
\hline 29 & Univ. of Akron & 1994 & 3.04 & 2.32 & 0.71 & 4.78 \\
\hline 30 & Univ. of Arizona & 1994 & 0.24 & 0.16 & 0.33 & 0.23 \\
\hline 31 & Univ. of Cincinnati & 1994 & 0.27 & 0.39 & 0.25 & 0.42 \\
\hline
\end{tabular}


Table D1: Modified Super-Efficiency Score of the 46 U.S. Institutions (continued)

\begin{tabular}{|c|c|c|c|c|c|c|}
\hline $\begin{array}{c}\text { DMU } \\
\text { ID }\end{array}$ & Institutions & Year & $\operatorname{Dt}(\mathbf{t})$ & $\operatorname{Dt}(\mathbf{t}+1)$ & $D t+1(t)$ & $D t+1(t+1)$ \\
\hline 32 & Univ. of Connecticut & 1994 & 0.16 & 0.35 & 0.17 & 0.28 \\
\hline 33 & Univ. of Dayton & 1994 & 0.36 & 0.31 & 0.27 & 0.32 \\
\hline 34 & Univ. of Delaware & 1994 & 0.22 & 0.22 & 0.16 & 0.28 \\
\hline 35 & Univ. of Iowa Research Fdn. & 1994 & 0.44 & 0.54 & 0.46 & 0.41 \\
\hline 36 & Univ. of Maryland, College & 1994 & 0.19 & 0.50 & 0.27 & 0.74 \\
\hline 37 & Univ. of Michigan & 1994 & 0.36 & 0.39 & 0.33 & 0.37 \\
\hline 38 & Univ. of Minnesota & 1994 & 0.49 & 0.64 & 0.65 & 0.52 \\
\hline 39 & Univ. of Oregon & 1994 & 0.23 & 0.61 & 0.33 & 0.45 \\
\hline 40 & Univ. of Southern California & 1994 & 0.46 & 0.37 & 0.64 & 0.53 \\
\hline 41 & Univ. of Texas Southwestern & 1994 & 0.45 & 0.49 & 0.34 & 0.35 \\
\hline 42 & Univ. of Utah & 1994 & 0.59 & 0.51 & 0.84 & 0.73 \\
\hline 43 & Univ. of Virginia Patent Fdn. & 1994 & 0.30 & 0.39 & 0.36 & 0.59 \\
\hline 44 & Vanderbilt Univ. & 1994 & 0.26 & 0.34 & 0.29 & 0.27 \\
\hline 45 & Wake Forest Univ. & 1994 & 0.19 & 0.34 & 0.13 & 0.26 \\
\hline 46 & Washington Univ. & 1994 & 0.42 & 0.48 & 0.34 & 0.41 \\
\hline 1 & Baylor College of Medicine & 1995 & 0.19 & 0.40 & 0.23 & 0.36 \\
\hline 2 & Brigham \& Women's Hospital, Inc. & 1995 & 0.37 & 0.47 & 0.47 & 0.45 \\
\hline 3 & Brigham Young Univ. & 1995 & 1.25 & 1.53 & 2.34 & 1.93 \\
\hline 4 & California Institute of Tech. & 1995 & 1.25 & 1.42 & 1.32 & 1.67 \\
\hline 5 & Case Western Reserve Univ. & 1995 & 0.31 & 0.39 & 0.23 & 0.28 \\
\hline 6 & City of Hope National Medic & 1995 & 0.62 & 0.67 & 1.00 & 1.06 \\
\hline 7 & Clemson Univ. & 1995 & 0.13 & 0.21 & 0.17 & 0.28 \\
\hline 8 & Colorado State Univ. & 1995 & 0.34 & 0.29 & 0.24 & 0.21 \\
\hline 9 & Dartmouth College & 1995 & 1.59 & 0.25 & 1.80 & 0.18 \\
\hline 10 & Florida State Univ. & 1995 & 1.02 & 0.89 & 1.19 & 1.94 \\
\hline 11 & Fred Hutchinson Cancer Res. & 1995 & 0.16 & 0.11 & 0.12 & 0.13 \\
\hline 12 & Georgia Inst. of Technology & 1995 & 0.99 & 1.24 & 0.70 & 0.87 \\
\hline 13 & Harvard Univ. & 1995 & 0.41 & 0.50 & 0.44 & 0.48 \\
\hline 14 & Indiana Univ. (ARTI) & 1995 & 0.32 & 0.25 & 0.23 & 0.25 \\
\hline 15 & Johns Hopkins Univ. & 1995 & 0.47 & 0.49 & 0.42 & 0.43 \\
\hline 16 & Massachusetts Inst. of Tech & 1995 & 2.21 & 1.92 & 1.27 & 2.59 \\
\hline 17 & Mayo Foundation & 1995 & 0.24 & 0.38 & 0.30 & 0.46 \\
\hline 18 & Michigan State Univ. & 1995 & 0.74 & 0.76 & 0.95 & 0.99 \\
\hline 19 & National Jewish Center & 1995 & 0.44 & 0.26 & 0.58 & 0.27 \\
\hline
\end{tabular}


Table D1: Modified Super-Efficiency Score of the 46 U.S. Institutions (continued)

\begin{tabular}{|c|c|c|c|c|c|c|}
\hline $\begin{array}{c}\text { DMU } \\
\text { ID }\end{array}$ & Institutions & Year & $\operatorname{Dt}(\mathbf{t})$ & $\operatorname{Dt}(\mathbf{t}+1)$ & $D t+1(t)$ & $D t+1(t+1)$ \\
\hline 20 & New Jersey Institute of Tech. & 1995 & 0.25 & 0.33 & 0.33 & 0.42 \\
\hline 21 & Northwestern Univ. & 1995 & 0.21 & 0.35 & 0.24 & 0.39 \\
\hline 22 & Ohio State Univ. & 1995 & 0.28 & 0.45 & 0.29 & 0.32 \\
\hline 23 & Ohio Univ. & 1995 & 0.39 & 0.23 & 0.54 & 0.32 \\
\hline 24 & Oregon State Univ. & 1995 & 0.09 & 0.07 & 0.11 & 0.09 \\
\hline 25 & Penn State Univ. & 1995 & 0.28 & 0.33 & 0.34 & 0.40 \\
\hline 26 & Rutgers, The State Univ. & 1995 & 0.35 & 0.44 & 0.43 & 0.51 \\
\hline 27 & St. Jude Children's Researc & 1995 & 0.18 & 0.20 & 0.23 & 0.25 \\
\hline 28 & Tulane Univ. & 1995 & 0.19 & 0.18 & 0.26 & 0.24 \\
\hline 29 & Univ. of Akron & 1995 & 4.78 & 0.71 & 2.15 & 4.07 \\
\hline 30 & Univ. of Arizona & 1995 & 0.23 & 0.26 & 0.17 & 0.21 \\
\hline 31 & Univ. of Cincinnati & 1995 & 0.42 & 0.49 & 0.39 & 0.51 \\
\hline 32 & Univ. of Connecticut & 1995 & 0.28 & 0.19 & 0.34 & 0.21 \\
\hline 33 & Univ. of Dayton & 1995 & 0.32 & 0.37 & 0.29 & 0.30 \\
\hline 34 & Univ. of Delaware & 1995 & 0.28 & 0.65 & 0.22 & 0.45 \\
\hline 35 & Univ. of Iowa Research Fdn. & 1995 & 0.41 & 0.34 & 0.51 & 0.38 \\
\hline 36 & Univ. of Maryland, College & 1995 & 0.74 & 0.53 & 0.53 & 0.38 \\
\hline 37 & Univ. of Michigan & 1995 & 0.37 & 0.68 & 0.44 & 0.57 \\
\hline 38 & Univ. of Minnesota & 1995 & 0.52 & 0.60 & 0.58 & 0.67 \\
\hline 39 & Univ. of Oregon & 1995 & 0.45 & 0.51 & 0.57 & 0.44 \\
\hline 40 & Univ. of Southern California & 1995 & 0.53 & 0.69 & 0.37 & 0.50 \\
\hline 41 & Univ. of Texas Southwestern & 1995 & 0.35 & 0.33 & 0.46 & 0.43 \\
\hline 42 & Univ. of Utah & 1995 & 0.73 & 0.78 & 0.52 & 0.63 \\
\hline 43 & Univ. of Virginia Patent Fdn. & 1995 & 0.59 & 0.89 & 0.43 & 0.64 \\
\hline 44 & Vanderbilt Univ. & 1995 & 0.27 & 0.31 & 0.32 & 0.30 \\
\hline 45 & Wake Forest Univ. & 1995 & 0.26 & 0.60 & 0.32 & 0.67 \\
\hline 46 & Washington Univ. & 1995 & 0.41 & 0.47 & 0.46 & 0.52 \\
\hline 1 & Baylor College of Medicine & 1996 & 0.36 & 0.29 & 0.32 & 0.29 \\
\hline 2 & Brigham \& Women's Hospital, Inc. & 1996 & 0.45 & 0.49 & 0.33 & 0.38 \\
\hline 3 & Brigham Young Univ. & 1996 & 1.93 & 1.81 & 0.93 & 2.22 \\
\hline 4 & California Institute of Tech. & 1996 & 1.67 & 1.52 & 0.93 & 2.36 \\
\hline 5 & Case Western Reserve Univ. & 1996 & 0.28 & 0.35 & 0.20 & 0.24 \\
\hline 6 & City of Hope National Medic & 1996 & 1.06 & 1.50 & 0.73 & 1.75 \\
\hline 7 & Clemson Univ. & 1996 & 0.28 & 0.22 & 0.19 & 0.18 \\
\hline
\end{tabular}


Table D1: Modified Super-Efficiency Score of the 46 U.S. Institutions (continued)

\begin{tabular}{|c|c|c|c|c|c|c|}
\hline $\begin{array}{c}\text { DMU } \\
\text { ID }\end{array}$ & Institutions & Year & $\operatorname{Dt}(\mathbf{t})$ & $\operatorname{Dt}(\mathbf{t}+1)$ & $D t+1(t)$ & $D t+1(t+1)$ \\
\hline 8 & Colorado State Univ. & 1996 & 0.21 & 0.15 & 0.15 & 0.10 \\
\hline 9 & Dartmouth College & 1996 & 0.18 & 0.26 & 0.14 & 0.20 \\
\hline 10 & Florida State Univ. & 1996 & 1.94 & 1.01 & 1.21 & 1.33 \\
\hline 11 & Fred Hutchinson Cancer Res. & 1996 & 0.13 & 0.22 & 0.09 & 0.15 \\
\hline 12 & Georgia Inst. of Technology & 1996 & 0.87 & 0.75 & 0.74 & 0.59 \\
\hline 13 & Harvard Univ. & 1996 & 0.48 & 0.52 & 0.60 & 0.61 \\
\hline 14 & Indiana Univ. (ARTI) & 1996 & 0.25 & 0.37 & 0.20 & 0.29 \\
\hline 15 & Johns Hopkins Univ. & 1996 & 0.43 & 0.55 & 0.49 & 0.62 \\
\hline 16 & Massachusetts Inst. of Tech & 1996 & 2.59 & 0.98 & 1.96 & 1.86 \\
\hline 17 & Mayo Foundation & 1996 & 0.46 & 0.50 & 0.44 & 0.42 \\
\hline 18 & Michigan State Univ. & 1996 & 0.99 & 1.11 & 0.87 & 0.96 \\
\hline 19 & National Jewish Center & 1996 & 0.27 & 0.39 & 0.23 & 0.28 \\
\hline 20 & New Jersey Institute of Tech. & 1996 & 0.42 & 0.27 & 0.34 & 0.20 \\
\hline 21 & Northwestern Univ. & 1996 & 0.39 & 0.44 & 0.29 & 0.35 \\
\hline 22 & Ohio State Univ. & 1996 & 0.32 & 0.36 & 0.28 & 0.31 \\
\hline 23 & Ohio Univ. & 1996 & 0.32 & 0.46 & 0.31 & 0.45 \\
\hline 24 & Oregon State Univ. & 1996 & 0.09 & 0.17 & 0.06 & 0.11 \\
\hline 25 & Penn State Univ. & 1996 & 0.40 & 0.42 & 0.39 & 0.40 \\
\hline 26 & Rutgers, The State Univ. & 1996 & 0.51 & 0.45 & 0.35 & 0.31 \\
\hline 27 & St. Jude Children's Researc & 1996 & 0.25 & 0.39 & 0.19 & 0.28 \\
\hline 28 & Tulane Univ. & 1996 & 0.24 & 0.36 & 0.17 & 0.29 \\
\hline 29 & Univ. of Akron & 1996 & 4.07 & 1.71 & 1.85 & 4.26 \\
\hline 30 & Univ. of Arizona & 1996 & 0.21 & 0.26 & 0.19 & 0.25 \\
\hline 31 & Univ. of Cincinnati & 1996 & 0.51 & 0.60 & 0.36 & 0.43 \\
\hline 32 & Univ. of Connecticut & 1996 & 0.21 & 0.26 & 0.14 & 0.18 \\
\hline 33 & Univ. of Dayton & 1996 & 0.30 & 0.33 & 0.21 & 0.24 \\
\hline 34 & Univ. of Delaware & 1996 & 0.45 & 0.32 & 0.35 & 0.22 \\
\hline 35 & Univ. of Iowa Research Fdn. & 1996 & 0.38 & 0.36 & 0.31 & 0.34 \\
\hline 36 & Univ. of Maryland, College & 1996 & 0.38 & 0.73 & 0.27 & 0.53 \\
\hline 37 & Univ. of Michigan & 1996 & 0.57 & 0.52 & 0.56 & 0.53 \\
\hline 38 & Univ. of Minnesota & 1996 & 0.67 & 0.64 & 0.68 & 0.71 \\
\hline 39 & Univ. of Oregon & 1996 & 0.44 & 0.34 & 0.32 & 0.27 \\
\hline 40 & Univ. of Southern California & 1996 & 0.50 & 0.55 & 0.45 & 0.50 \\
\hline 41 & Univ. of Texas Southwestern & 1996 & 0.43 & 0.65 & 0.35 & 0.47 \\
\hline
\end{tabular}


Table D1: Modified Super-Efficiency Score of the 46 U.S. Institutions (continued)

\begin{tabular}{|c|c|c|c|c|c|c|}
\hline $\begin{array}{c}\text { DMU } \\
\text { ID }\end{array}$ & Institutions & Year & $\operatorname{Dt}(\mathbf{t})$ & $\operatorname{Dt}(\mathbf{t}+1)$ & $D t+1(t)$ & $D t+1(t+1)$ \\
\hline 42 & Univ. of Utah & 1996 & 0.63 & 0.60 & 0.44 & 0.41 \\
\hline 43 & Univ. of Virginia Patent Fdn. & 1996 & 0.64 & 0.76 & 0.52 & 0.55 \\
\hline 44 & Vanderbilt Univ. & 1996 & 0.30 & 0.51 & 0.20 & 0.41 \\
\hline 45 & Wake Forest Univ. & 1996 & 0.67 & 0.78 & 0.47 & 0.55 \\
\hline 46 & Washington Univ. & 1996 & 0.52 & 0.46 & 0.48 & 0.42 \\
\hline 1 & Baylor College of Medicine & 1997 & 0.29 & 0.31 & 0.26 & 0.28 \\
\hline 2 & Brigham \& Women's Hospital, Inc. & 1997 & 0.38 & 0.35 & 0.29 & 0.25 \\
\hline 3 & Brigham Young Univ. & 1997 & 2.22 & 1.96 & 0.97 & 2.05 \\
\hline 4 & California Institute of Tech. & 1997 & 2.36 & 1.42 & 1.30 & 2.73 \\
\hline 5 & Case Western Reserve Univ. & 1997 & 0.24 & 0.31 & 0.24 & 0.30 \\
\hline 6 & City of Hope National Medic & 1997 & 1.75 & 1.36 & 0.85 & 3.16 \\
\hline 7 & Clemson Univ. & 1997 & 0.18 & 0.25 & 0.17 & 0.27 \\
\hline 8 & Colorado State Univ. & 1997 & 0.10 & 0.22 & 0.11 & 0.27 \\
\hline 9 & Dartmouth College & 1997 & 0.20 & 0.37 & 0.20 & 0.29 \\
\hline 10 & Florida State Univ. & 1997 & 1.33 & 0.49 & 0.99 & 0.45 \\
\hline 11 & Fred Hutchinson Cancer Res. & 1997 & 0.15 & 0.14 & 0.17 & 0.11 \\
\hline 12 & Georgia Inst. of Technology & 1997 & 0.59 & 0.52 & 0.72 & 0.63 \\
\hline 13 & Harvard Univ. & 1997 & 0.61 & 0.78 & 0.54 & 0.68 \\
\hline 14 & Indiana Univ. (ARTI) & 1997 & 0.29 & 0.26 & 0.23 & 0.21 \\
\hline 15 & Johns Hopkins Univ. & 1997 & 0.62 & 0.80 & 0.53 & 0.68 \\
\hline 16 & Massachusetts Inst. of Tech & 1997 & 1.86 & 1.18 & 1.08 & 2.03 \\
\hline 17 & Mayo Foundation & 1997 & 0.42 & 0.58 & 0.30 & 0.53 \\
\hline 18 & Michigan State Univ. & 1997 & 0.96 & 0.82 & 0.77 & 0.66 \\
\hline 19 & National Jewish Center & 1997 & 0.28 & 0.36 & 0.24 & 0.28 \\
\hline 20 & New Jersey Institute of Tech. & 1997 & 0.20 & 0.18 & 0.16 & 0.16 \\
\hline 21 & Northwestern Univ. & 1997 & 0.35 & 0.36 & 0.43 & 0.45 \\
\hline 22 & Ohio State Univ. & 1997 & 0.31 & 0.42 & 0.37 & 0.50 \\
\hline 23 & Ohio Univ. & 1997 & 0.45 & 0.43 & 0.35 & 0.33 \\
\hline 24 & Oregon State Univ. & 1997 & 0.11 & 0.08 & 0.09 & 0.06 \\
\hline 25 & Penn State Univ. & 1997 & 0.40 & 0.49 & 0.33 & 0.41 \\
\hline 26 & Rutgers, The State Univ. & 1997 & 0.31 & 0.39 & 0.24 & 0.30 \\
\hline 27 & St. Jude Children's Researc & 1997 & 0.28 & 0.18 & 0.22 & 0.14 \\
\hline 28 & Tulane Univ. & 1997 & 0.29 & 0.26 & 0.24 & 0.21 \\
\hline 29 & Univ. of Akron & 1997 & 4.26 & 2.83 & 0.87 & 2.95 \\
\hline
\end{tabular}


Table D1: Modified Super-Efficiency Score of the 46 U.S. Institutions (continued)

\begin{tabular}{|c|c|c|c|c|c|c|}
\hline $\begin{array}{c}\text { DMU } \\
\text { ID }\end{array}$ & Institutions & Year & $\operatorname{Dt}(\mathbf{t})$ & $\operatorname{Dt}(\mathbf{t}+1)$ & $D t+1(t)$ & $D t+1(t+1)$ \\
\hline 30 & Univ. of Arizona & 1997 & 0.25 & 0.23 & 0.29 & 0.27 \\
\hline 31 & Univ. of Cincinnati & 1997 & 0.43 & 0.20 & 0.33 & 0.20 \\
\hline 32 & Univ. of Connecticut & 1997 & 0.18 & 0.27 & 0.21 & 0.21 \\
\hline 33 & Univ. of Dayton & 1997 & 0.24 & 0.20 & 0.20 & 0.16 \\
\hline 34 & Univ. of Delaware & 1997 & 0.22 & 0.16 & 0.19 & 0.12 \\
\hline 35 & Univ. of Iowa Research Fdn. & 1997 & 0.34 & 0.38 & 0.27 & 0.31 \\
\hline 36 & Univ. of Maryland, College & 1997 & 0.53 & 0.17 & 0.65 & 0.22 \\
\hline 37 & Univ. of Michigan & 1997 & 0.53 & 0.53 & 0.53 & 0.44 \\
\hline 38 & Univ. of Minnesota & 1997 & 0.71 & 0.88 & 0.65 & 0.84 \\
\hline 39 & Univ. of Oregon & 1997 & 0.27 & 0.20 & 0.24 & 0.15 \\
\hline 40 & Univ. of Southern California & 1997 & 0.50 & 0.45 & 0.59 & 0.53 \\
\hline 41 & Univ. of Texas Southwestern & 1997 & 0.47 & 0.38 & 0.35 & 0.30 \\
\hline 42 & Univ. of Utah & 1997 & 0.41 & 0.83 & 0.42 & 1.07 \\
\hline 43 & Univ. of Virginia Patent Fdn. & 1997 & 0.55 & 0.33 & 0.68 & 0.37 \\
\hline 44 & Vanderbilt Univ. & 1997 & 0.41 & 0.31 & 0.32 & 0.26 \\
\hline 45 & Wake Forest Univ. & 1997 & 0.55 & 0.46 & 0.46 & 0.35 \\
\hline 46 & Washington Univ. & 1997 & 0.42 & 0.55 & 0.34 & 0.43 \\
\hline 1 & Baylor College of Medicine & 1998 & 0.28 & 0.21 & 0.34 & 0.23 \\
\hline 2 & Brigham \& Women's Hospital, Inc. & 1998 & 0.25 & 0.31 & 0.30 & 0.37 \\
\hline 3 & Brigham Young Univ. & 1998 & 2.05 & 0.80 & 1.85 & 1.88 \\
\hline 4 & California Institute of Tech. & 1998 & 2.73 & 1.14 & 1.33 & 3.15 \\
\hline 5 & Case Western Reserve Univ. & 1998 & 0.30 & 0.31 & 0.36 & 0.37 \\
\hline 6 & City of Hope National Medic & 1998 & 3.16 & 0.85 & 1.54 & 1.68 \\
\hline 7 & Clemson Univ. & 1998 & 0.27 & 0.19 & 0.30 & 0.23 \\
\hline 8 & Colorado State Univ. & 1998 & 0.27 & 0.36 & 0.29 & 0.38 \\
\hline 9 & Dartmouth College & 1998 & 0.29 & 0.21 & 0.26 & 0.19 \\
\hline 10 & Florida State Univ. & 1998 & 0.45 & 0.33 & 0.53 & 0.39 \\
\hline 11 & Fred Hutchinson Cancer Res. & 1998 & 0.11 & 0.06 & 0.10 & 0.08 \\
\hline 12 & Georgia Inst. of Technology & 1998 & 0.63 & 0.81 & 0.67 & 0.86 \\
\hline 13 & Harvard Univ. & 1998 & 0.68 & 0.56 & 0.72 & 0.59 \\
\hline 14 & Indiana Univ. (ARTI) & 1998 & 0.21 & 0.38 & 0.27 & 0.43 \\
\hline 15 & Johns Hopkins Univ. & 1998 & 0.68 & 0.64 & 0.67 & 0.63 \\
\hline 16 & Massachusetts Inst. of Tech & 1998 & 2.03 & 1.06 & 1.15 & 2.04 \\
\hline
\end{tabular}


Table D1: Modified Super-Efficiency Score of the 46 U.S. Institutions (continued)

\begin{tabular}{|c|c|c|c|c|c|c|}
\hline $\begin{array}{c}\text { DMU } \\
\text { ID }\end{array}$ & Institutions & Year & $\operatorname{Dt}(\mathbf{t})$ & $\operatorname{Dt}(\mathrm{t}+1)$ & $D t+1(t)$ & $D t+1(t+1)$ \\
\hline 17 & Mayo Foundation & 1998 & 0.53 & 0.51 & 0.63 & 0.57 \\
\hline 18 & Michigan State Univ. & 1998 & 0.66 & 0.81 & 0.77 & 0.92 \\
\hline 19 & National Jewish Center & 1998 & 0.28 & 0.30 & 0.26 & 0.28 \\
\hline 20 & New Jersey Institute of Tech. & 1998 & 0.16 & 0.24 & 0.17 & 0.22 \\
\hline 21 & Northwestern Univ. & 1998 & 0.45 & 0.50 & 0.48 & 0.53 \\
\hline 22 & Ohio State Univ. & 1998 & 0.50 & 0.27 & 0.53 & 0.29 \\
\hline 23 & Ohio Univ. & 1998 & 0.33 & 0.40 & 0.33 & 0.45 \\
\hline 24 & Oregon State Univ. & 1998 & 0.06 & 0.16 & 0.07 & 0.17 \\
\hline 25 & Penn State Univ. & 1998 & 0.41 & 0.35 & 0.38 & 0.32 \\
\hline 26 & Rutgers, The State Univ. & 1998 & 0.30 & 0.27 & 0.31 & 0.29 \\
\hline 27 & St. Jude Children's Researc & 1998 & 0.14 & 0.10 & 0.14 & 0.10 \\
\hline 28 & Tulane Univ. & 1998 & 0.21 & 0.17 & 0.26 & 0.19 \\
\hline 29 & Univ. of Akron & 1998 & 2.95 & 1.78 & 1.23 & 4.76 \\
\hline 30 & Univ. of Arizona & 1998 & 0.27 & 0.18 & 0.29 & 0.19 \\
\hline 31 & Univ. of Cincinnati & 1998 & 0.20 & 0.14 & 0.23 & 0.12 \\
\hline 32 & Univ. of Connecticut & 1998 & 0.21 & 0.24 & 0.19 & 0.27 \\
\hline 33 & Univ. of Dayton & 1998 & 0.16 & 0.20 & 0.14 & 0.21 \\
\hline 34 & Univ. of Delaware & 1998 & 0.12 & 0.23 & 0.11 & 0.27 \\
\hline 35 & Univ. of Iowa Research Fdn. & 1998 & 0.31 & 0.31 & 0.39 & 0.35 \\
\hline 36 & Univ. of Maryland, College & 1998 & 0.22 & 0.58 & 0.23 & 0.61 \\
\hline 37 & Univ. of Michigan & 1998 & 0.44 & 0.56 & 0.45 & 0.53 \\
\hline 38 & Univ. of Minnesota & 1998 & 0.84 & 0.96 & 0.88 & 1.08 \\
\hline 39 & Univ. of Oregon & 1998 & 0.15 & 0.30 & 0.17 & 0.35 \\
\hline 40 & Univ. of Southern California & 1998 & 0.53 & 0.29 & 0.56 & 0.31 \\
\hline 41 & Univ. of Texas Southwestern & 1998 & 0.30 & 0.36 & 0.35 & 0.42 \\
\hline 42 & Univ. of Utah & 1998 & 1.07 & 0.97 & 1.06 & 1.19 \\
\hline 43 & Univ. of Virginia Patent Fdn. & 1998 & 0.37 & 0.23 & 0.41 & 0.27 \\
\hline 44 & Vanderbilt Univ. & 1998 & 0.26 & 0.21 & 0.32 & 0.26 \\
\hline 45 & Wake Forest Univ. & 1998 & 0.35 & 0.84 & 0.49 & 1.01 \\
\hline 46 & Washington Univ. & 1998 & 0.43 & 0.55 & 0.48 & 0.53 \\
\hline
\end{tabular}


Appendix E. Malmquist Indexes of the 46 Institutions during the Period

Table E1: Malmquist Index Scores of the 46 Institutions

\begin{tabular}{|c|c|c|c|c|c|}
\hline $\begin{array}{l}\text { DMU } \\
\text { ID }\end{array}$ & Institutions & Year & EC & TC & MI \\
\hline 1 & Baylor College of Medicine & 1991 & 2.65 & 1.48 & 3.91 \\
\hline 2 & $\begin{array}{l}\text { Brigham \& Women's Hospital, } \\
\text { Inc. }\end{array}$ & 1991 & 1.07 & 1.87 & 2.00 \\
\hline 3 & Brigham Young Univ. & 1991 & 0.56 & 0.88 & 0.49 \\
\hline 4 & California Institute of Tech. & 1991 & 1.75 & 1.52 & 2.66 \\
\hline 5 & Case Western Reserve Univ. & 1991 & 0.43 & 2.00 & 0.86 \\
\hline 6 & City of Hope National Medic & 1991 & 0.48 & 1.78 & 0.85 \\
\hline 7 & Clemson Univ. & 1991 & 0.74 & 1.50 & 1.11 \\
\hline 8 & Colorado State Univ. & 1991 & 0.44 & 1.85 & 0.82 \\
\hline 9 & Dartmouth College & 1991 & 1.64 & 1.68 & 2.75 \\
\hline 10 & Florida State Univ. & 1991 & 2.98 & 1.24 & 3.69 \\
\hline 11 & Fred Hutchinson Cancer Res. & 1991 & 0.52 & 1.91 & 0.99 \\
\hline 12 & Georgia Inst. of Technology & 1991 & 0.89 & 1.87 & 1.66 \\
\hline 13 & Harvard Univ. & 1991 & 1.47 & 1.46 & 2.14 \\
\hline 14 & Indiana Univ. (ARTI) & 1991 & 0.79 & 2.03 & 1.60 \\
\hline 15 & Johns Hopkins Univ. & 1991 & 1.10 & 1.68 & 1.85 \\
\hline 16 & Massachusetts Inst. of Tech & 1991 & 0.84 & 1.84 & 1.54 \\
\hline 17 & Mayo Foundation & 1991 & 0.85 & 1.81 & 1.54 \\
\hline 18 & Michigan State Univ. & 1991 & 0.82 & 1.42 & 1.17 \\
\hline 19 & National Jewish Center & 1991 & 0.41 & 1.48 & 0.61 \\
\hline 20 & New Jersey Institute of Tech. & 1991 & 3.88 & 1.54 & 5.98 \\
\hline 21 & Northwestern Univ. & 1991 & 0.92 & 2.06 & 1.89 \\
\hline 22 & Ohio State Univ. & 1991 & 1.14 & 2.09 & 2.39 \\
\hline 23 & Ohio Univ. & 1991 & 1.70 & 1.11 & 1.89 \\
\hline 24 & Oregon State Univ. & 1991 & 1.00 & 1.86 & 1.86 \\
\hline 25 & Penn State Univ. & 1991 & 0.73 & 1.48 & 1.07 \\
\hline 26 & Rutgers, The State Univ. & 1991 & 0.93 & 1.86 & 1.73 \\
\hline 27 & St. Jude Children's Researc & 1991 & 0.17 & 1.66 & 0.28 \\
\hline 28 & Tulane Univ. & 1991 & 0.73 & 1.66 & 1.20 \\
\hline
\end{tabular}


Table E1: Malmquist Index Scores of the 46 Institutions (continued)

\begin{tabular}{|c|c|c|c|c|c|}
\hline $\begin{array}{l}\text { DMU } \\
\text { ID }\end{array}$ & Institutions & Year & EC & TC & MI \\
\hline 29 & Univ. of Akron & 1991 & 0.46 & 1.66 & 0.77 \\
\hline 30 & Univ. of Arizona & 1991 & 1.02 & 1.77 & 1.82 \\
\hline 31 & Univ. of Cincinnati & 1991 & 0.60 & 1.69 & 1.02 \\
\hline 32 & Univ. of Connecticut & 1991 & 0.85 & 1.84 & 1.57 \\
\hline 33 & Univ. of Dayton & 1991 & 0.67 & 1.69 & 1.13 \\
\hline 34 & Univ. of Delaware & 1991 & 0.75 & 1.57 & 1.19 \\
\hline 35 & Univ. of Iowa Research Fdn. & 1991 & 0.83 & 1.99 & 1.65 \\
\hline 36 & Univ. of Maryland, College & 1991 & 0.73 & 1.88 & 1.37 \\
\hline 37 & Univ. of Michigan & 1991 & 1.97 & 1.77 & 3.48 \\
\hline 38 & Univ. of Minnesota & 1991 & 1.14 & 1.74 & 1.98 \\
\hline 39 & Univ. of Oregon & 1991 & 0.56 & 1.73 & 0.96 \\
\hline 40 & Univ. of Southern California & 1991 & 0.90 & 1.66 & 1.50 \\
\hline 41 & Univ. of Texas Southwestern & 1991 & 1.03 & 1.89 & 1.94 \\
\hline 42 & Univ. of Utah & 1991 & 0.86 & 1.84 & 1.58 \\
\hline 43 & Univ. of Virginia Patent Fdn. & 1991 & 0.85 & 1.84 & 1.56 \\
\hline 44 & Vanderbilt Univ. & 1991 & 0.66 & 1.81 & 1.19 \\
\hline 45 & Wake Forest Univ. & 1991 & 0.86 & 1.68 & 1.45 \\
\hline 46 & Washington Univ. & 1991 & 0.62 & 1.59 & 0.99 \\
\hline 1 & Baylor College of Medicine & 1992 & 0.93 & 1.02 & 0.95 \\
\hline 2 & $\begin{array}{l}\text { Brigham \& Women's Hospital, } \\
\text { Inc. }\end{array}$ & 1992 & 0.61 & 1.34 & 0.82 \\
\hline 3 & Brigham Young Univ. & 1992 & 15.18 & 2.82 & 42.80 \\
\hline 4 & California Institute of Tech. & 1992 & 1.03 & 1.10 & 1.14 \\
\hline 5 & Case Western Reserve Univ. & 1992 & 1.02 & 1.35 & 1.38 \\
\hline 6 & City of Hope National Medic & 1992 & 0.71 & 1.13 & 0.80 \\
\hline 7 & Clemson Univ. & 1992 & 0.43 & 1.18 & 0.51 \\
\hline 8 & Colorado State Univ. & 1992 & 0.66 & 0.94 & 0.62 \\
\hline 9 & Dartmouth College & 1992 & 0.50 & 1.23 & 0.62 \\
\hline 10 & Florida State Univ. & 1992 & 1.48 & 1.12 & 1.66 \\
\hline 11 & Fred Hutchinson Cancer Res. & 1992 & 2.45 & 1.30 & 3.20 \\
\hline 12 & Georgia Inst. of Technology & 1992 & 0.83 & 1.11 & 0.93 \\
\hline 13 & Harvard Univ. & 1992 & 0.73 & 1.14 & 0.83 \\
\hline 14 & Indiana Univ. (ARTI) & 1992 & 1.40 & 1.17 & 1.64 \\
\hline
\end{tabular}


Table E1: Malmquist Index Scores of the 46 Institutions (continued)

\begin{tabular}{|c|c|c|c|c|c|}
\hline $\begin{array}{c}\text { DMU } \\
\text { ID }\end{array}$ & Institutions & Year & EC & TC & MI \\
\hline 15 & Johns Hopkins Univ. & 1992 & 1.34 & 1.01 & 1.35 \\
\hline 16 & Massachusetts Inst. of Tech & 1992 & 0.84 & 1.11 & 0.93 \\
\hline 17 & Mayo Foundation & 1992 & 0.50 & 1.20 & 0.59 \\
\hline 18 & Michigan State Univ. & 1992 & 1.35 & 1.06 & 1.43 \\
\hline 19 & National Jewish Center & 1992 & 1.38 & 1.72 & 2.38 \\
\hline 20 & New Jersey Institute of Tech. & 1992 & 1.11 & 1.78 & 1.99 \\
\hline 21 & Northwestern Univ. & 1992 & 1.47 & 1.34 & 1.97 \\
\hline 22 & Ohio State Univ. & 1992 & 1.18 & 1.03 & 1.21 \\
\hline 23 & Ohio Univ. & 1992 & 0.09 & 2.01 & 0.18 \\
\hline 24 & Oregon State Univ. & 1992 & 1.62 & 1.35 & 2.19 \\
\hline 25 & Penn State Univ. & 1992 & 1.72 & 1.02 & 1.76 \\
\hline 26 & Rutgers, The State Univ. & 1992 & 0.99 & 1.14 & 1.13 \\
\hline 27 & St. Jude Children's Researc & 1992 & 3.71 & 1.10 & 4.06 \\
\hline 28 & Tulane Univ. & 1992 & 0.85 & 1.11 & 0.94 \\
\hline 29 & Univ. of Akron & 1992 & 1.51 & 1.06 & 1.61 \\
\hline 30 & Univ. of Arizona & 1992 & 0.90 & 1.02 & 0.91 \\
\hline 31 & Univ. of Cincinnati & 1992 & 0.98 & 1.25 & 1.22 \\
\hline 32 & Univ. of Connecticut & 1992 & 0.47 & 1.39 & 0.65 \\
\hline 33 & Univ. of Dayton & 1992 & 1.03 & 1.33 & 1.38 \\
\hline 34 & Univ. of Delaware & 1992 & 1.03 & 1.27 & 1.31 \\
\hline 35 & Univ. of Iowa Research Fdn. & 1992 & 0.97 & 1.18 & 1.15 \\
\hline 36 & Univ. of Maryland, College & 1992 & 1.17 & 1.30 & 1.51 \\
\hline 37 & Univ. of Michigan & 1992 & 0.99 & 1.18 & 1.16 \\
\hline 38 & Univ. of Minnesota & 1992 & 0.94 & 0.99 & 0.93 \\
\hline 39 & Univ. of Oregon & 1992 & 0.69 & 1.30 & 0.90 \\
\hline 40 & Univ. of Southern California & 1992 & 1.61 & 0.95 & 1.53 \\
\hline 41 & Univ. of Texas Southwestern & 1992 & 0.87 & 1.32 & 1.15 \\
\hline 42 & Univ. of Utah & 1992 & 0.59 & 1.13 & 0.67 \\
\hline 43 & Univ. of Virginia Patent Fdn. & 1992 & 0.84 & 0.94 & 0.79 \\
\hline 44 & Vanderbilt Univ. & 1992 & 1.90 & 1.12 & 2.12 \\
\hline 45 & Wake Forest Univ. & 1992 & 0.69 & 1.16 & 0.80 \\
\hline 46 & Washington Univ. & 1992 & 1.45 & 0.98 & 1.43 \\
\hline
\end{tabular}


Table E1: Malmquist Index Scores of the 46 Institutions (continued)

\begin{tabular}{|c|c|c|c|c|c|}
\hline $\begin{array}{l}\text { DMU } \\
\text { ID }\end{array}$ & Institutions & Year & EC & TC & MI \\
\hline 1 & Baylor College of Medicine & 1993 & 1.45 & 0.99 & 1.44 \\
\hline 2 & $\begin{array}{l}\text { Brigham \& Women's Hospital, } \\
\text { Inc. }\end{array}$ & 1993 & 1.06 & 0.80 & 0.85 \\
\hline 3 & Brigham Young Univ. & 1993 & 0.18 & 3.73 & 0.69 \\
\hline 4 & California Institute of Tech. & 1993 & 0.72 & 0.97 & 0.70 \\
\hline 5 & Case Western Reserve Univ. & 1993 & 1.46 & 0.80 & 1.17 \\
\hline 6 & City of Hope National Medic & 1993 & 0.55 & 0.94 & 0.52 \\
\hline 7 & Clemson Univ. & 1993 & 1.33 & 0.80 & 1.07 \\
\hline 8 & Colorado State Univ. & 1993 & 1.16 & 0.83 & 0.96 \\
\hline 9 & Dartmouth College & 1993 & 2.13 & 0.80 & 1.70 \\
\hline 10 & Florida State Univ. & 1993 & 1.72 & 0.80 & 1.38 \\
\hline 11 & Fred Hutchinson Cancer Res. & 1993 & 0.83 & 0.77 & 0.64 \\
\hline 12 & Georgia Inst. of Technology & 1993 & 1.98 & 0.91 & 1.79 \\
\hline 13 & Harvard Univ. & 1993 & 1.10 & 1.06 & 1.16 \\
\hline 14 & Indiana Univ. (ARTI) & 1993 & 0.96 & 0.87 & 0.83 \\
\hline 15 & Johns Hopkins Univ. & 1993 & 1.22 & 1.08 & 1.31 \\
\hline 16 & Massachusetts Inst. of Tech & 1993 & 1.00 & 1.00 & 1.00 \\
\hline 17 & Mayo Foundation & 1993 & 1.42 & 0.86 & 1.22 \\
\hline 18 & Michigan State Univ. & 1993 & 1.02 & 0.93 & 0.95 \\
\hline 19 & National Jewish Center & 1993 & 1.10 & 0.97 & 1.07 \\
\hline 20 & New Jersey Institute of Tech. & 1993 & 0.83 & 1.68 & 1.40 \\
\hline 21 & Northwestern Univ. & 1993 & 1.28 & 0.78 & 1.00 \\
\hline 22 & Ohio State Univ. & 1993 & 0.76 & 0.90 & 0.69 \\
\hline 23 & Ohio Univ. & 1993 & 1.08 & 1.00 & 1.08 \\
\hline 24 & Oregon State Univ. & 1993 & 0.71 & 0.76 & 0.54 \\
\hline 25 & Penn State Univ. & 1993 & 0.91 & 0.99 & 0.91 \\
\hline 26 & Rutgers, The State Univ. & 1993 & 1.02 & 0.89 & 0.91 \\
\hline 27 & St. Jude Children's Researc & 1993 & 0.85 & 0.85 & 0.72 \\
\hline 28 & Tulane Univ. & 1993 & 0.99 & 0.81 & 0.80 \\
\hline 29 & Univ. of Akron & 1993 & 2.07 & 1.02 & 2.11 \\
\hline 30 & Univ. of Arizona & 1993 & 1.68 & 0.95 & 1.59 \\
\hline 31 & Univ. of Cincinnati & 1993 & 0.83 & 0.83 & 0.69 \\
\hline 32 & Univ. of Connecticut & 1993 & 1.03 & 0.77 & 0.80 \\
\hline
\end{tabular}


Table E1: Malmquist Index Scores of the 46 Institutions (continued)

\begin{tabular}{|c|c|c|c|c|c|}
\hline $\begin{array}{l}\text { DMU } \\
\text { ID }\end{array}$ & Institutions & Year & EC & TC & MI \\
\hline 33 & Univ. of Dayton & 1993 & 1.06 & 0.80 & 0.85 \\
\hline 34 & Univ. of Delaware & 1993 & 0.62 & 0.97 & 0.60 \\
\hline 35 & Univ. of Iowa Research Fdn. & 1993 & 2.03 & 0.86 & 1.74 \\
\hline 36 & Univ. of Maryland, College & 1993 & 0.65 & 0.90 & 0.58 \\
\hline 37 & Univ. of Michigan & 1993 & 0.90 & 0.99 & 0.89 \\
\hline 38 & Univ. of Minnesota & 1993 & 1.03 & 0.94 & 0.97 \\
\hline 39 & Univ. of Oregon & 1993 & 0.84 & 1.00 & 0.84 \\
\hline 40 & Univ. of Southern California & 1993 & 0.89 & 0.91 & 0.80 \\
\hline 41 & Univ. of Texas Southwestern & 1993 & 1.21 & 0.81 & 0.98 \\
\hline 42 & Univ. of Utah & 1993 & 1.35 & 0.83 & 1.12 \\
\hline 43 & Univ. of Virginia Patent Fdn. & 1993 & 0.64 & 0.89 & 0.57 \\
\hline 44 & Vanderbilt Univ. & 1993 & 1.16 & 0.76 & 0.88 \\
\hline 45 & Wake Forest Univ. & 1993 & 0.81 & 0.78 & 0.63 \\
\hline 46 & Washington Univ. & 1993 & 1.12 & 0.96 & 1.07 \\
\hline 1 & Baylor College of Medicine & 1994 & 0.51 & 1.05 & 0.54 \\
\hline 2 & $\begin{array}{l}\text { Brigham \& Women's Hospital, } \\
\text { Inc. }\end{array}$ & 1994 & 0.94 & 1.32 & 1.24 \\
\hline 3 & Brigham Young Univ. & 1994 & 0.38 & 1.22 & 0.47 \\
\hline 4 & California Institute of Tech. & 1994 & 1.11 & 0.92 & 1.02 \\
\hline 5 & Case Western Reserve Univ. & 1994 & 1.38 & 1.00 & 1.38 \\
\hline 6 & City of Hope National Medic & 1994 & 0.64 & 1.64 & 1.05 \\
\hline 7 & Clemson Univ. & 1994 & 0.56 & 1.44 & 0.81 \\
\hline 8 & Colorado State Univ. & 1994 & 2.38 & 0.92 & 2.18 \\
\hline 9 & Dartmouth College & 1994 & 4.36 & 1.17 & 5.11 \\
\hline 10 & Florida State Univ. & 1994 & 0.42 & 1.72 & 0.72 \\
\hline 11 & Fred Hutchinson Cancer Res. & 1994 & 0.71 & 0.95 & 0.68 \\
\hline 12 & Georgia Inst. of Technology & 1994 & 1.55 & 0.70 & 1.09 \\
\hline 13 & Harvard Univ. & 1994 & 0.85 & 1.25 & 1.07 \\
\hline 14 & Indiana Univ. (ARTI) & 1994 & 1.72 & 0.75 & 1.28 \\
\hline 15 & Johns Hopkins Univ. & 1994 & 0.83 & 1.18 & 0.98 \\
\hline 16 & Massachusetts Inst. of Tech & 1994 & 0.94 & 1.01 & 0.95 \\
\hline 17 & Mayo Foundation & 1994 & 0.65 & 1.18 & 0.77 \\
\hline 18 & Michigan State Univ. & 1994 & 0.85 & 1.37 & 1.16 \\
\hline
\end{tabular}


Table E1: Malmquist Index Scores of the 46 Institutions (continued)

\begin{tabular}{|c|c|c|c|c|c|}
\hline $\begin{array}{l}\text { DMU } \\
\text { ID }\end{array}$ & Institutions & Year & EC & TC & MI \\
\hline 19 & National Jewish Center & 1994 & 1.91 & 1.18 & 2.25 \\
\hline 20 & New Jersey Institute of Tech. & 1994 & 0.50 & 0.80 & 0.40 \\
\hline 21 & Northwestern Univ. & 1994 & 0.44 & 1.15 & 0.50 \\
\hline 22 & Ohio State Univ. & 1994 & 0.82 & 0.91 & 0.75 \\
\hline 23 & Ohio Univ. & 1994 & 0.79 & 1.53 & 1.21 \\
\hline 24 & Oregon State Univ. & 1994 & 0.63 & 1.12 & 0.70 \\
\hline 25 & Penn State Univ. & 1994 & 0.98 & 0.99 & 0.97 \\
\hline 26 & Rutgers, The State Univ. & 1994 & 0.78 & 1.06 & 0.83 \\
\hline 27 & St. Jude Children's Researc & 1994 & 1.02 & 1.41 & 1.44 \\
\hline 28 & Tulane Univ. & 1994 & 0.69 & 1.48 & 1.02 \\
\hline 29 & Univ. of Akron & 1994 & 1.58 & 1.44 & 2.27 \\
\hline 30 & Univ. of Arizona & 1994 & 0.93 & 0.73 & 0.68 \\
\hline 31 & Univ. of Cincinnati & 1994 & 1.54 & 1.01 & 1.56 \\
\hline 32 & Univ. of Connecticut & 1994 & 1.72 & 1.10 & 1.89 \\
\hline 33 & Univ. of Dayton & 1994 & 0.88 & 1.15 & 1.01 \\
\hline 34 & Univ. of Delaware & 1994 & 1.27 & 1.02 & 1.30 \\
\hline 35 & Univ. of Iowa Research Fdn. & 1994 & 0.93 & 1.13 & 1.05 \\
\hline 36 & Univ. of Maryland, College & 1994 & 3.83 & 0.70 & 2.69 \\
\hline 37 & Univ. of Michigan & 1994 & 1.05 & 1.06 & 1.11 \\
\hline 38 & Univ. of Minnesota & 1994 & 1.05 & 0.96 & 1.02 \\
\hline 39 & Univ. of Oregon & 1994 & 1.97 & 0.97 & 1.91 \\
\hline 40 & Univ. of Southern California & 1994 & 1.14 & 0.71 & 0.82 \\
\hline 41 & Univ. of Texas Southwestern & 1994 & 0.78 & 1.36 & 1.06 \\
\hline 42 & Univ. of Utah & 1994 & 1.25 & 0.70 & 0.87 \\
\hline 43 & Univ. of Virginia Patent Fdn. & 1994 & 1.94 & 0.75 & 1.45 \\
\hline 44 & Vanderbilt Univ. & 1994 & 1.04 & 1.05 & 1.10 \\
\hline 45 & Wake Forest Univ. & 1994 & 1.36 & 1.38 & 1.88 \\
\hline 46 & Washington Univ. & 1994 & 0.97 & 1.21 & 1.18 \\
\hline 1 & Baylor College of Medicine & 1995 & 1.92 & 0.95 & 1.83 \\
\hline 2 & $\begin{array}{l}\text { Brigham \& Women's Hospital, } \\
\text { Inc. }\end{array}$ & 1995 & 1.23 & 0.90 & 1.11 \\
\hline 3 & Brigham Young Univ. & 1995 & 1.54 & 0.65 & 1.00 \\
\hline 4 & California Institute of Tech. & 1995 & 1.34 & 0.90 & 1.20 \\
\hline
\end{tabular}


Table E1: Malmquist Index Scores of the 46 Institutions (continued)

\begin{tabular}{|c|c|c|c|c|c|}
\hline $\begin{array}{c}\text { DMU } \\
\text { ID }\end{array}$ & Institutions & Year & EC & TC & MI \\
\hline 5 & Case Western Reserve Univ. & 1995 & 0.88 & 1.36 & 1.21 \\
\hline 6 & City of Hope National Medic & 1995 & 1.71 & 0.63 & 1.07 \\
\hline 7 & Clemson Univ. & 1995 & 2.15 & 0.74 & 1.59 \\
\hline 8 & Colorado State Univ. & 1995 & 0.62 & 1.40 & 0.87 \\
\hline 9 & Dartmouth College & 1995 & 0.11 & 1.12 & 0.12 \\
\hline 10 & Florida State Univ. & 1995 & 1.90 & 0.63 & 1.19 \\
\hline 11 & Fred Hutchinson Cancer Res. & 1995 & 0.84 & 1.04 & 0.87 \\
\hline 12 & Georgia Inst. of Technology & 1995 & 0.88 & 1.41 & 1.25 \\
\hline 13 & Harvard Univ. & 1995 & 1.18 & 0.98 & 1.16 \\
\hline 14 & Indiana Univ. (ARTI) & 1995 & 0.78 & 1.18 & 0.92 \\
\hline 15 & Johns Hopkins Univ. & 1995 & 0.92 & 1.13 & 1.03 \\
\hline 16 & Massachusetts Inst. of Tech & 1995 & 1.17 & 1.14 & 1.33 \\
\hline 17 & Mayo Foundation & 1995 & 1.96 & 0.81 & 1.58 \\
\hline 18 & Michigan State Univ. & 1995 & 1.32 & 0.78 & 1.03 \\
\hline 19 & National Jewish Center & 1995 & 0.61 & 0.85 & 0.52 \\
\hline 20 & New Jersey Institute of Tech. & 1995 & 1.65 & 0.77 & 1.28 \\
\hline 21 & Northwestern Univ. & 1995 & 1.83 & 0.89 & 1.63 \\
\hline 22 & Ohio State Univ. & 1995 & 1.14 & 1.16 & 1.32 \\
\hline 23 & Ohio Univ. & 1995 & 0.81 & 0.72 & 0.59 \\
\hline 24 & Oregon State Univ. & 1995 & 0.98 & 0.82 & 0.81 \\
\hline 25 & Penn State Univ. & 1995 & 1.46 & 0.81 & 1.18 \\
\hline 26 & Rutgers, The State Univ. & 1995 & 1.44 & 0.83 & 1.21 \\
\hline 27 & St. Jude Children's Researc & 1995 & 1.36 & 0.79 & 1.07 \\
\hline 28 & Tulane Univ. & 1995 & 1.27 & 0.73 & 0.93 \\
\hline 29 & Univ. of Akron & 1995 & 0.85 & 0.62 & 0.53 \\
\hline 30 & Univ. of Arizona & 1995 & 0.91 & 1.31 & 1.20 \\
\hline 31 & Univ. of Cincinnati & 1995 & 1.22 & 1.02 & 1.25 \\
\hline 32 & Univ. of Connecticut & 1995 & 0.75 & 0.88 & 0.65 \\
\hline 33 & Univ. of Dayton & 1995 & 0.96 & 1.15 & 1.10 \\
\hline 34 & Univ. of Delaware & 1995 & 1.61 & 1.34 & 2.16 \\
\hline 35 & Univ. of Iowa Research Fdn. & 1995 & 0.92 & 0.85 & 0.78 \\
\hline 36 & Univ. of Maryland, College & 1995 & 0.51 & 1.40 & 0.72 \\
\hline 37 & Univ. of Michigan & 1995 & 1.53 & 1.01 & 1.54 \\
\hline
\end{tabular}


Table E1: Malmquist Index Scores of the 46 Institutions (continued)

\begin{tabular}{|c|c|c|c|c|c|}
\hline $\begin{array}{l}\text { DMU } \\
\text { ID }\end{array}$ & Institutions & Year & EC & TC & MI \\
\hline 38 & Univ. of Minnesota & 1995 & 1.30 & 0.89 & 1.16 \\
\hline 39 & Univ. of Oregon & 1995 & 0.98 & 0.96 & 0.94 \\
\hline 40 & Univ. of Southern California & 1995 & 0.94 & 1.41 & 1.33 \\
\hline 41 & Univ. of Texas Southwestern & 1995 & 1.22 & 0.77 & 0.94 \\
\hline 42 & Univ. of Utah & 1995 & 0.85 & 1.32 & 1.13 \\
\hline 43 & Univ. of Virginia Patent Fdn. & 1995 & 1.09 & 1.38 & 1.50 \\
\hline 44 & Vanderbilt Univ. & 1995 & 1.11 & 0.93 & 1.03 \\
\hline 45 & Wake Forest Univ. & 1995 & 2.55 & 0.86 & 2.18 \\
\hline 46 & Washington Univ. & 1995 & 1.29 & 0.89 & 1.16 \\
\hline 1 & Baylor College of Medicine & 1996 & 0.80 & 1.06 & 0.85 \\
\hline 2 & $\begin{array}{l}\text { Brigham \& Women's Hospital, } \\
\text { Inc. }\end{array}$ & 1996 & 0.85 & 1.33 & 1.13 \\
\hline 3 & Brigham Young Univ. & 1996 & 1.15 & 1.30 & 1.50 \\
\hline 4 & California Institute of Tech. & 1996 & 1.41 & 1.08 & 1.52 \\
\hline 5 & Case Western Reserve Univ. & 1996 & 0.88 & 1.42 & 1.25 \\
\hline 6 & City of Hope National Medic & 1996 & 1.65 & 1.12 & 1.84 \\
\hline 7 & Clemson Univ. & 1996 & 0.64 & 1.34 & 0.87 \\
\hline 8 & Colorado State Univ. & 1996 & 0.48 & 1.45 & 0.69 \\
\hline 9 & Dartmouth College & 1996 & 1.15 & 1.30 & 1.49 \\
\hline 10 & Florida State Univ. & 1996 & 0.69 & 1.10 & 0.76 \\
\hline 11 & Fred Hutchinson Cancer Res. & 1996 & 1.12 & 1.46 & 1.63 \\
\hline 12 & Georgia Inst. of Technology & 1996 & 0.67 & 1.23 & 0.83 \\
\hline 13 & Harvard Univ. & 1996 & 1.27 & 0.82 & 1.04 \\
\hline 14 & Indiana Univ. (ARTI) & 1996 & 1.15 & 1.26 & 1.45 \\
\hline 15 & Johns Hopkins Univ. & 1996 & 1.44 & 0.88 & 1.27 \\
\hline 16 & Massachusetts Inst. of Tech & 1996 & 0.72 & 0.83 & 0.60 \\
\hline 17 & Mayo Foundation & 1996 & 0.90 & 1.12 & 1.01 \\
\hline 18 & Michigan State Univ. & 1996 & 0.97 & 1.15 & 1.11 \\
\hline 19 & National Jewish Center & 1996 & 1.06 & 1.28 & 1.35 \\
\hline 20 & New Jersey Institute of Tech. & 1996 & 0.48 & 1.30 & 0.62 \\
\hline 21 & Northwestern Univ. & 1996 & 0.88 & 1.31 & 1.16 \\
\hline 22 & Ohio State Univ. & 1996 & 0.97 & 1.15 & 1.11 \\
\hline
\end{tabular}


Table E1: Malmquist Index Scores of the 46 Institutions (continued)

\begin{tabular}{|c|c|c|c|c|c|}
\hline $\begin{array}{l}\text { DMU } \\
\text { ID }\end{array}$ & Institutions & Year & EC & TC & MI \\
\hline 23 & Ohio Univ. & 1996 & 1.41 & 1.02 & 1.43 \\
\hline 24 & Oregon State Univ. & 1996 & 1.26 & 1.49 & 1.88 \\
\hline 25 & Penn State Univ. & 1996 & 0.99 & 1.04 & 1.04 \\
\hline 26 & Rutgers, The State Univ. & 1996 & 0.60 & 1.46 & 0.87 \\
\hline 27 & St. Jude Children's Researc & 1996 & 1.13 & 1.36 & 1.53 \\
\hline 28 & Tulane Univ. & 1996 & 1.21 & 1.33 & 1.61 \\
\hline 29 & Univ. of Akron & 1996 & 1.05 & 0.94 & 0.99 \\
\hline 30 & Univ. of Arizona & 1996 & 1.19 & 1.08 & 1.29 \\
\hline 31 & Univ. of Cincinnati & 1996 & 0.84 & 1.41 & 1.18 \\
\hline 32 & Univ. of Connecticut & 1996 & 0.88 & 1.46 & 1.28 \\
\hline 33 & Univ. of Dayton & 1996 & 0.81 & 1.41 & 1.14 \\
\hline 34 & Univ. of Delaware & 1996 & 0.50 & 1.35 & 0.68 \\
\hline 35 & Univ. of Iowa Research Fdn. & 1996 & 0.91 & 1.13 & 1.02 \\
\hline 36 & Univ. of Maryland, College & 1996 & 1.39 & 1.38 & 1.92 \\
\hline 37 & Univ. of Michigan & 1996 & 0.92 & 1.01 & 0.93 \\
\hline 38 & Univ. of Minnesota & 1996 & 1.05 & 0.95 & 0.99 \\
\hline 39 & Univ. of Oregon & 1996 & 0.61 & 1.33 & 0.81 \\
\hline 40 & Univ. of Southern California & 1996 & 1.01 & 1.10 & 1.11 \\
\hline 41 & Univ. of Texas Southwestern & 1996 & 1.10 & 1.29 & 1.42 \\
\hline 42 & Univ. of Utah & 1996 & 0.65 & 1.45 & 0.94 \\
\hline 43 & Univ. of Virginia Patent Fdn. & 1996 & 0.85 & 1.30 & 1.11 \\
\hline 44 & Vanderbilt Univ. & 1996 & 1.36 & 1.38 & 1.87 \\
\hline 45 & Wake Forest Univ. & 1996 & 0.83 & 1.42 & 1.17 \\
\hline 46 & Washington Univ. & 1996 & 0.80 & 1.09 & 0.87 \\
\hline 1 & Baylor College of Medicine & 1997 & 0.98 & 1.10 & 1.07 \\
\hline 2 & $\begin{array}{l}\text { Brigham \& Women's Hospital, } \\
\text { Inc. }\end{array}$ & 1997 & 0.66 & 1.36 & 0.89 \\
\hline 3 & Brigham Young Univ. & 1997 & 0.93 & 1.47 & 1.37 \\
\hline 4 & California Institute of Tech. & 1997 & 1.15 & 0.97 & 1.12 \\
\hline 5 & Case Western Reserve Univ. & 1997 & 1.25 & 1.01 & 1.26 \\
\hline 6 & City of Hope National Medic & 1997 & 1.81 & 0.94 & 1.70 \\
\hline 7 & Clemson Univ. & 1997 & 1.49 & 1.01 & 1.50 \\
\hline 8 & Colorado State Univ. & 1997 & 2.70 & 0.85 & 2.30 \\
\hline
\end{tabular}


Table E1: Malmquist Index Scores of the 46 Institutions (continued)

\begin{tabular}{|c|c|c|c|c|c|}
\hline $\begin{array}{c}\text { DMU } \\
\text { ID }\end{array}$ & Institutions & Year & EC & TC & MI \\
\hline 9 & Dartmouth College & 1997 & 1.43 & 1.14 & 1.63 \\
\hline 10 & Florida State Univ. & 1997 & 0.34 & 1.21 & 0.41 \\
\hline 11 & Fred Hutchinson Cancer Res. & 1997 & 0.73 & 1.07 & 0.77 \\
\hline 12 & Georgia Inst. of Technology & 1997 & 1.07 & 0.82 & 0.88 \\
\hline 13 & Harvard Univ. & 1997 & 1.11 & 1.14 & 1.27 \\
\hline 14 & Indiana Univ. (ARTI) & 1997 & 0.74 & 1.24 & 0.91 \\
\hline 15 & Johns Hopkins Univ. & 1997 & 1.09 & 1.18 & 1.29 \\
\hline 16 & Massachusetts Inst. of Tech & 1997 & 1.09 & 1.00 & 1.09 \\
\hline 17 & Mayo Foundation & 1997 & 1.26 & 1.23 & 1.56 \\
\hline 18 & Michigan State Univ. & 1997 & 0.70 & 1.24 & 0.86 \\
\hline 19 & National Jewish Center & 1997 & 1.00 & 1.24 & 1.24 \\
\hline 20 & New Jersey Institute of Tech. & 1997 & 0.77 & 1.21 & 0.93 \\
\hline 21 & Northwestern Univ. & 1997 & 1.29 & 0.81 & 1.04 \\
\hline 22 & Ohio State Univ. & 1997 & 1.63 & 0.83 & 1.35 \\
\hline 23 & Ohio Univ. & 1997 & 0.75 & 1.29 & 0.96 \\
\hline 24 & Oregon State Univ. & 1997 & 0.52 & 1.31 & 0.67 \\
\hline 25 & Penn State Univ. & 1997 & 1.01 & 1.21 & 1.23 \\
\hline 26 & Rutgers, The State Univ. & 1997 & 0.98 & 1.30 & 1.27 \\
\hline 27 & St. Jude Children's Researc & 1997 & 0.49 & 1.31 & 0.65 \\
\hline 28 & Tulane Univ. & 1997 & 0.74 & 1.23 & 0.91 \\
\hline 29 & Univ. of Akron & 1997 & 0.69 & 2.16 & 1.50 \\
\hline 30 & Univ. of Arizona & 1997 & 1.09 & 0.86 & 0.94 \\
\hline 31 & Univ. of Cincinnati & 1997 & 0.46 & 1.15 & 0.53 \\
\hline 32 & Univ. of Connecticut & 1997 & 1.16 & 1.05 & 1.21 \\
\hline 33 & Univ. of Dayton & 1997 & 0.64 & 1.25 & 0.79 \\
\hline 34 & Univ. of Delaware & 1997 & 0.55 & 1.22 & 0.66 \\
\hline 35 & Univ. of Iowa Research Fdn. & 1997 & 0.92 & 1.24 & 1.14 \\
\hline 36 & Univ. of Maryland, College & 1997 & 0.41 & 0.81 & 0.33 \\
\hline 37 & Univ. of Michigan & 1997 & 0.84 & 1.09 & 0.91 \\
\hline 38 & Univ. of Minnesota & 1997 & 1.20 & 1.06 & 1.27 \\
\hline 39 & Univ. of Oregon & 1997 & 0.58 & 1.22 & 0.70 \\
\hline 40 & Univ. of Southern California & 1997 & 1.05 & 0.85 & 0.89 \\
\hline 41 & Univ. of Texas Southwestern & 1997 & 0.63 & 1.31 & 0.83 \\
\hline
\end{tabular}


Table E1: Malmquist Index Scores of the 46 Institutions (continued)

\begin{tabular}{|c|c|c|c|c|c|}
\hline $\begin{array}{l}\text { DMU } \\
\text { ID }\end{array}$ & Institutions & Year & EC & TC & MI \\
\hline 42 & Univ. of Utah & 1997 & 2.63 & 0.86 & 2.27 \\
\hline 43 & Univ. of Virginia Patent Fdn. & 1997 & 0.67 & 0.86 & 0.57 \\
\hline 44 & Vanderbilt Univ. & 1997 & 0.64 & 1.23 & 0.79 \\
\hline 45 & Wake Forest Univ. & 1997 & 0.64 & 1.25 & 0.80 \\
\hline 46 & Washington Univ. & 1997 & 1.02 & 1.26 & 1.29 \\
\hline 1 & Baylor College of Medicine & 1998 & 0.83 & 0.85 & 0.71 \\
\hline 2 & $\begin{array}{l}\text { Brigham \& Women's Hospital, } \\
\text { Inc. }\end{array}$ & 1998 & 1.46 & 0.85 & 1.24 \\
\hline 3 & Brigham Young Univ. & 1998 & 0.92 & 0.68 & 0.63 \\
\hline 4 & California Institute of Tech. & 1998 & 1.15 & 0.86 & 1.00 \\
\hline 5 & Case Western Reserve Univ. & 1998 & 1.24 & 0.82 & 1.02 \\
\hline 6 & City of Hope National Medic & 1998 & 0.53 & 1.02 & 0.54 \\
\hline 7 & Clemson Univ. & 1998 & 0.85 & 0.86 & 0.74 \\
\hline 8 & Colorado State Univ. & 1998 & 1.43 & 0.93 & 1.33 \\
\hline 9 & Dartmouth College & 1998 & 0.66 & 1.13 & 0.74 \\
\hline 10 & Florida State Univ. & 1998 & 0.86 & 0.85 & 0.73 \\
\hline 11 & Fred Hutchinson Cancer Res. & 1998 & 0.70 & 0.97 & 0.68 \\
\hline 12 & Georgia Inst. of Technology & 1998 & 1.37 & 0.94 & 1.28 \\
\hline 13 & Harvard Univ. & 1998 & 0.87 & 0.95 & 0.82 \\
\hline 14 & Indiana Univ. (ARTI) & 1998 & 2.00 & 0.84 & 1.69 \\
\hline 15 & Johns Hopkins Univ. & 1998 & 0.93 & 1.01 & 0.95 \\
\hline 16 & Massachusetts Inst. of Tech & 1998 & 1.01 & 0.96 & 0.96 \\
\hline 17 & Mayo Foundation & 1998 & 1.08 & 0.87 & 0.94 \\
\hline 18 & Michigan State Univ. & 1998 & 1.38 & 0.87 & 1.21 \\
\hline 19 & National Jewish Center & 1998 & 0.97 & 1.09 & 1.06 \\
\hline 20 & New Jersey Institute of Tech. & 1998 & 1.42 & 1.00 & 1.42 \\
\hline 21 & Northwestern Univ. & 1998 & 1.18 & 0.93 & 1.10 \\
\hline 22 & Ohio State Univ. & 1998 & 0.58 & 0.93 & 0.54 \\
\hline 23 & Ohio Univ. & 1998 & 1.35 & 0.95 & 1.28 \\
\hline 24 & Oregon State Univ. & 1998 & 2.98 & 0.87 & 2.58 \\
\hline 25 & Penn State Univ. & 1998 & 0.80 & 1.08 & 0.86 \\
\hline 26 & Rutgers, The State Univ. & 1998 & 0.98 & 0.93 & 0.92 \\
\hline 27 & St. Jude Children's Researc & 1998 & 0.71 & 1.01 & 0.71 \\
\hline 28 & Tulane Univ. & 1998 & 0.90 & 0.86 & 0.77 \\
\hline
\end{tabular}


Table E1: Malmquist Index Scores of the 46 Institutions (continued)

\begin{tabular}{|l|l|c|c|c|c|}
\hline $\begin{array}{c}\text { DMU } \\
\text { ID }\end{array}$ & \multicolumn{1}{|c|}{ Institutions } & Year & EC & TC & MI \\
\hline 29 & Univ. of Akron & 1998 & 1.61 & 0.95 & 1.53 \\
\hline 30 & Univ. of Arizona & 1998 & 0.71 & 0.93 & 0.66 \\
\hline 31 & Univ. of Cincinnati & 1998 & 0.61 & 0.98 & 0.60 \\
\hline 32 & Univ. of Connecticut & 1998 & 1.29 & 0.99 & 1.28 \\
\hline 33 & Univ. of Dayton & 1998 & 1.37 & 1.01 & 1.38 \\
\hline 34 & Univ. of Delaware & 1998 & 2.19 & 0.97 & 2.13 \\
\hline 35 & Univ. of Iowa Research Fdn. & 1998 & 1.12 & 0.85 & 0.96 \\
\hline 36 & Univ. of Maryland, College & 1998 & 2.83 & 0.94 & 2.65 \\
\hline 37 & Univ. of Michigan & 1998 & 1.19 & 1.02 & 1.22 \\
\hline 38 & Univ. of Minnesota & 1998 & 1.28 & 0.92 & 1.18 \\
\hline 39 & Univ. of Oregon & 1998 & 2.29 & 0.87 & 2.00 \\
\hline 40 & Univ. of Southern California & 1998 & 0.59 & 0.93 & 0.55 \\
\hline 41 & Univ. of Texas Southwestern & 1998 & 1.42 & 0.85 & 1.22 \\
\hline 42 & Univ. of Utah & 1998 & 1.11 & 0.91 & 1.01 \\
\hline 43 & Univ. of Virginia Patent Fdn. & 1998 & 0.74 & 0.88 & 0.65 \\
\hline 44 & Vanderbilt Univ. & 1998 & 0.99 & 0.81 & 0.80 \\
\hline 45 & Wake Forest Univ. & 1998 & 2.87 & 0.77 & 2.21 \\
\hline 46 & Washington Univ. & 1998 & 1.23 & 0.97 & 1.19 \\
\hline
\end{tabular}




\section{Appendix F. Normality Test of Cumulative Time-Lag Effect Neutralized Licensing}

Data by Four Institution Types

\begin{tabular}{|c|c|c|c|c|c|c|c|}
\hline \multirow{2}{*}{ Variables } & \multirow{2}{*}{ Institution Types } & \multicolumn{3}{|c|}{ Kolmogorov-Smirnov(a) } & \multicolumn{3}{|c|}{ Shapiro-Wilk } \\
\hline & & Statistic & $\mathrm{df}$ & Sig. & Statistic & df & Sig. \\
\hline \multirow{5}{*}{$\begin{array}{l}\text { Cumulative Time } \\
\text { Aggregated } \\
\text { Expenditure from } \\
1991 \text { to } 1999\end{array}$} & Universities & .229 & 37 & .000 & .739 & 37 & .000 \\
\hline & Medical Research & .283 & 3 & (2) & .934 & 3 & .503 \\
\hline & Centers & & & & & & \\
\hline & $\begin{array}{l}\text { Teaching and Research } \\
\text { Hospitals }\end{array}$ & .260 & 2 & . & & & \\
\hline & $\begin{array}{l}\text { Special Focus } \\
\text { Institution - Medical }\end{array}$ & .321 & 4 & . & .813 & 4 & .127 \\
\hline \multirow{4}{*}{$\begin{array}{l}\text { Cumulative Time } \\
\text { Aggregated } \\
\text { Disclosure from } \\
1991 \text { to } 1999\end{array}$} & Universities & .185 & 37 & .003 & .779 & 37 & .000 \\
\hline & $\begin{array}{l}\text { Medical Research } \\
\text { Centers }\end{array}$ & .338 & 3 & . & .852 & 3 & .245 \\
\hline & $\begin{array}{l}\text { Teaching and Research } \\
\text { Hospitals }\end{array}$ & .260 & 2 & . & & & \\
\hline & $\begin{array}{l}\text { Special Focus } \\
\text { Institution - Medical }\end{array}$ & .237 & 4 & . & .932 & 4 & .604 \\
\hline \multirow{4}{*}{$\begin{array}{l}\text { Cumulative Time } \\
\text { Aggregated Patents } \\
\text { Filed from } 1991 \text { to } \\
1999\end{array}$} & Universities & .211 & 37 & .000 & .717 & 37 & .000 \\
\hline & $\begin{array}{l}\text { Medical Research } \\
\text { Centers }\end{array}$ & .289 & 3 & . & .928 & 3 & .480 \\
\hline & $\begin{array}{l}\text { Teaching and Research } \\
\text { Hospitals }\end{array}$ & .260 & 2 & . & & & \\
\hline & $\begin{array}{l}\text { Special Focus } \\
\text { Institution - Medical }\end{array}$ & .327 & 4 & . & .788 & 4 & .082 \\
\hline \multirow{4}{*}{$\begin{array}{l}\text { Cumulative Time } \\
\text { Aggregated Patents } \\
\text { Issued from } 1992 \text { to } \\
2004\end{array}$} & Universities & .227 & 37 & .000 & .700 & 37 & .000 \\
\hline & $\begin{array}{l}\text { Medical Research } \\
\text { Centers }\end{array}$ & .222 & 3 & . & .985 & 3 & .768 \\
\hline & $\begin{array}{l}\text { Teaching and Research } \\
\text { Hospitals }\end{array}$ & .260 & 2 & . & & & \\
\hline & $\begin{array}{l}\text { Special Focus } \\
\text { Institution - Medical }\end{array}$ & .283 & 4 & . & .937 & 4 & .637 \\
\hline \multirow{4}{*}{$\begin{array}{l}\text { Cumulative Time } \\
\text { Aggregated } \\
\text { Licenses and } \\
\text { Options Executed } \\
\text { from } 1991 \text { to } 1999\end{array}$} & Universities & .161 & 37 & .017 & .878 & 37 & .001 \\
\hline & $\begin{array}{l}\text { Medical Research } \\
\text { Centers }\end{array}$ & .195 & 3 & . & .996 & 3 & .882 \\
\hline & $\begin{array}{l}\text { Teaching and Research } \\
\text { Hospitals }\end{array}$ & .260 & 2 & . & & & \\
\hline & $\begin{array}{l}\text { Special Focus } \\
\text { Institution - Medical }\end{array}$ & .246 & 4 & . & .873 & 4 & .308 \\
\hline \multirow{4}{*}{$\begin{array}{l}\text { Cumulative Time } \\
\text { Aggregated Start- } \\
\text { Ups from } 1995 \text { to } \\
2007\end{array}$} & Universities & .211 & 37 & .000 & 679 & 37 & .000 \\
\hline & $\begin{array}{l}\text { Medical Research } \\
\text { Centers }\end{array}$ & .182 & 3 & . & .999 & 3 & .935 \\
\hline & $\begin{array}{l}\text { Teaching and Research } \\
\text { Hospitals }\end{array}$ & .260 & 2 & . & & & \\
\hline & $\begin{array}{l}\text { Special Focus } \\
\text { Institution - Medical }\end{array}$ & .302 & 4 & . & .923 & 4 & .554 \\
\hline \multirow{4}{*}{$\begin{array}{l}\text { Cumulative Time- } \\
\text { Aggregated } \\
\text { Licensing Income } \\
\text { from } 1996 \text { to } 2004\end{array}$} & Universities & .241 & 37 & .000 & .691 & 37 & .000 \\
\hline & $\begin{array}{l}\text { Medical Research } \\
\text { Centers }\end{array}$ & .375 & 3 & . & .775 & 3 & .057 \\
\hline & $\begin{array}{l}\text { Teaching and Research } \\
\text { Hospitals }\end{array}$ & .260 & 2 & . & & & \\
\hline & $\begin{array}{l}\text { Special Focus } \\
\text { Institution - Medical }\end{array}$ & .348 & 4 & . & .841 & 4 & .198 \\
\hline
\end{tabular}

a Lilliefors Significance Correction 
Appendix G. Normality Test of Cumulative Time-Lag Effect Neutralized Licensing

Data by Two Institution Types

\begin{tabular}{|c|c|c|c|c|c|c|c|}
\hline & \multirow[t]{2}{*}{ Universities } & \multicolumn{3}{|c|}{ Kolmogorov-Smirnov(a) } & \multicolumn{3}{|c|}{ Shapiro-Wilk } \\
\hline & & Statistic & $\mathrm{df}$ & Sig. & Statistic & $\mathrm{df}$ & Sig. \\
\hline \multirow{2}{*}{$\begin{array}{l}\text { Cumulative Time } \\
\text { Aggregated } \\
\text { Expenditure from } 1991 \\
\text { to } 1999\end{array}$} & $\begin{array}{l}\text { Non- } \\
\text { university }\end{array}$ & .194 & 9 & $.200(*)$ & .885 & 9 & .176 \\
\hline & University & .229 & 37 & .000 & .739 & 37 & .000 \\
\hline \multirow{2}{*}{$\begin{array}{l}\text { Cumulative Time } \\
\text { Aggregated Disclosure } \\
\text { from } 1991 \text { to } 1999\end{array}$} & $\begin{array}{l}\text { Non- } \\
\text { university }\end{array}$ & .219 & 9 & $.200(*)$ & .894 & 9 & .219 \\
\hline & University & .185 & 37 & .003 & .779 & 37 & .000 \\
\hline \multirow{2}{*}{$\begin{array}{l}\text { Cumulative Time } \\
\text { Aggregated Patents } \\
\text { Filed from } 1991 \text { to } \\
1999\end{array}$} & $\begin{array}{l}\text { Non- } \\
\text { university }\end{array}$ & .240 & 9 & .142 & .739 & 9 & .004 \\
\hline & University & .211 & 37 & .000 & .717 & 37 & .000 \\
\hline \multirow{2}{*}{$\begin{array}{l}\text { Cumulative Time } \\
\text { Aggregated Patents } \\
\text { Issued from } 1992 \text { to } \\
2004\end{array}$} & $\begin{array}{l}\text { Non- } \\
\text { university }\end{array}$ & .194 & 9 & $.200(*)$ & .900 & 9 & .254 \\
\hline & University & .227 & 37 & .000 & .700 & 37 & .000 \\
\hline \multirow{2}{*}{$\begin{array}{l}\text { Cumulative Time } \\
\text { Aggregated Licenses } \\
\text { and Options Executed } \\
\text { from } 1991 \text { to } 1999\end{array}$} & $\begin{array}{l}\text { Non- } \\
\text { university }\end{array}$ & .288 & 9 & .030 & .858 & 9 & .091 \\
\hline & University & .161 & 37 & .017 & .878 & 37 & .001 \\
\hline \multirow{2}{*}{$\begin{array}{l}\text { Cumulative Time } \\
\text { Aggregated Start-Ups } \\
\text { from } 1995 \text { to } 2007\end{array}$} & $\begin{array}{l}\text { Non- } \\
\text { university }\end{array}$ & .164 & 9 & $.200(*)$ & .916 & 9 & .362 \\
\hline & University & .211 & 37 & .000 & .679 & 37 & .000 \\
\hline \multirow{2}{*}{$\begin{array}{l}\text { Cumulative Time- } \\
\text { Aggregated Licensing } \\
\text { Income from } 1996 \text { to } \\
2004\end{array}$} & $\begin{array}{l}\text { Non- } \\
\text { university }\end{array}$ & .331 & 9 & .005 & .668 & 9 & .001 \\
\hline & University & .241 & 37 & .000 & .691 & 37 & .000 \\
\hline
\end{tabular}

* This is a lower bound of the true significance.

a Lilliefors Significance Correction 